\title{
TÜRKISCH-RUSSISCHE ZENTRALASIENPOLITIK
}

GEOPOLITISCHE RIVALITÄT ODER STRATEGISCHE PARTNERSCHAFT?

\author{
Inauguraldissertation \\ zur Erlangung des Grades einer \\ Doktorin der Philosophie \\ im Fachbereich Gesellschaftswissenschaften \\ im Fach Politikwissenschaft der \\ Johann-Wolfgang-Goethe-Universität \\ zu Frankfurt am Main
}

vorgelegt von

Fatma Varli-Schwarz

aus

Kemah

2020

Erstgutachter: Prof. Dr. Joachim Hirsch

Zweitgutachterin: Prof. Dr. Heike Holbig

Tag der mündlichen Prüfung: 30.09.2021 
Für Felix $\Upsilon$. 


\section{INHALTSVERZEICHNIS}

$\underline{\text { Abkürzungsverzeichnis }}$

Abbildungs- und Tabellenverzeichnis

1 EINLEITUNG

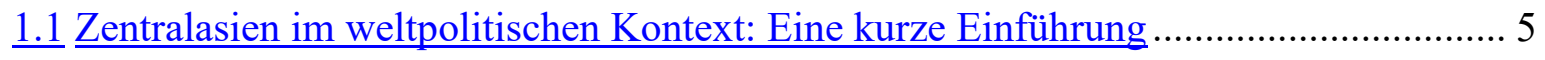

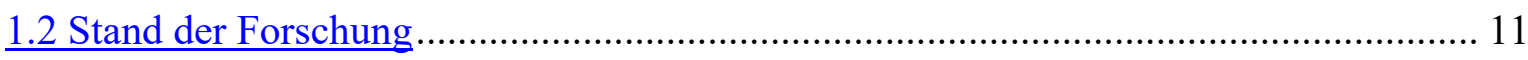

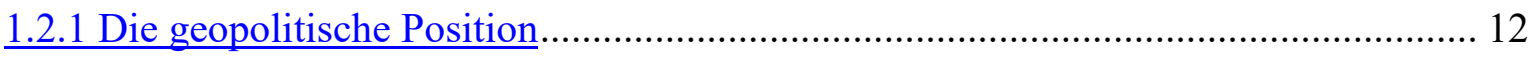

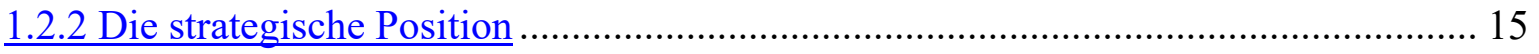

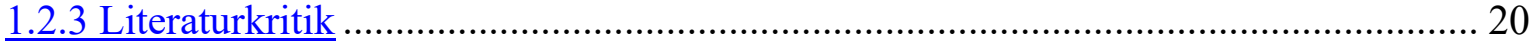

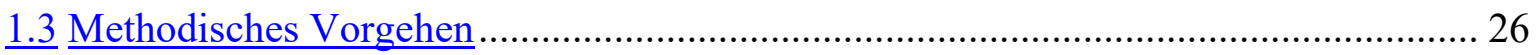

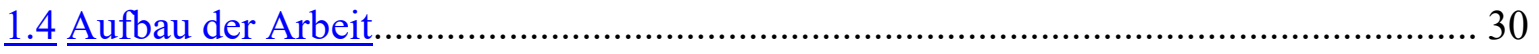

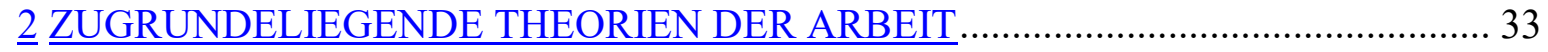

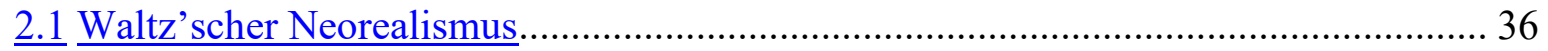

Wichtige Annahmen des Neorealismus im Überblick .................................................. 43

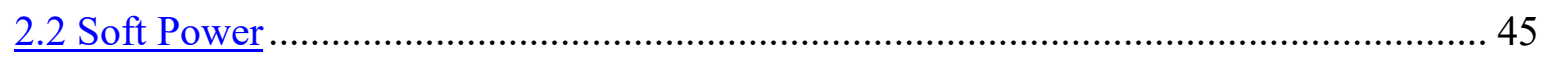

Wichtige Annahmen des Soft-Power-Konzeptes im Überblick....................................... 51

3 TÜRKISCH-RUSSISCHE ZENTRALASIENPOLITIK VON IHREM ANFANG BIS

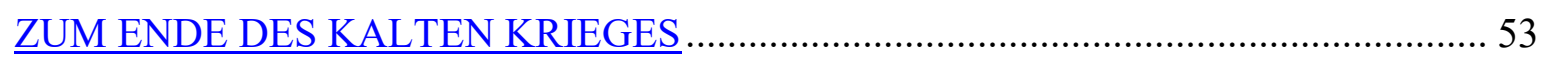

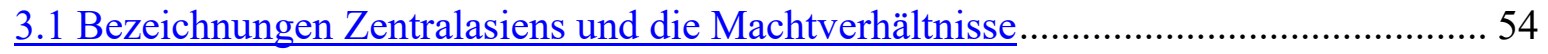

Transoxanien

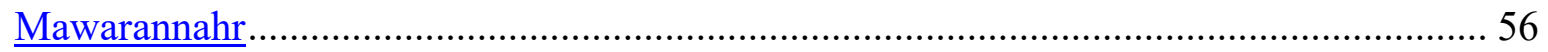

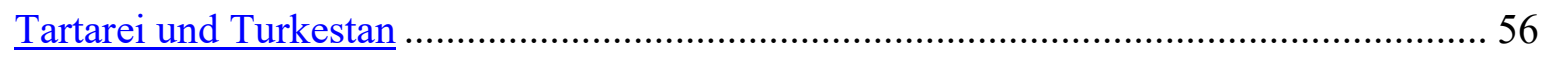

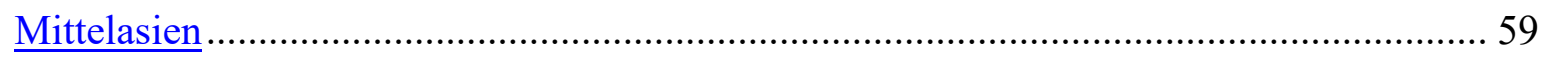

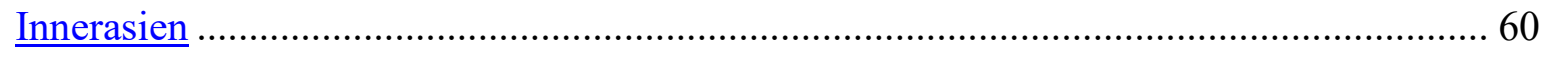

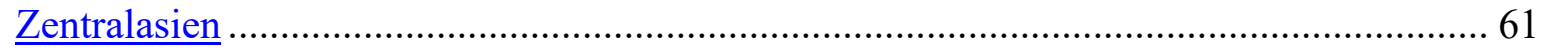

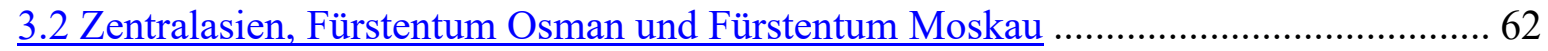

3.3 Zentralasien, das Osmanische Reich und das Zarenreich ............................................ 65

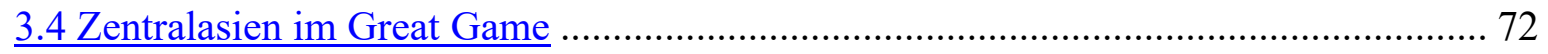

3.5 Zentralasien, Panslawismus und Pantürkismus....................................................... 75

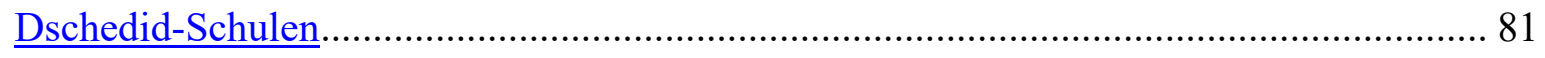


4 TÜRKISCH-RUSSISCHE KULTUR- UND BILDUNGSPOLITIK IN

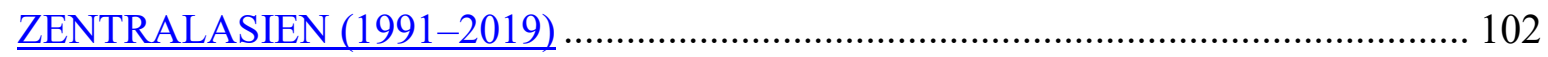

4.1 Türkische Kultur- und Bildungspolitik in Zentralasien .......................................... 103

4.1.1 Der Pantürkismus und Islam in der türkischen Zentralasienpolitik ........................ 105

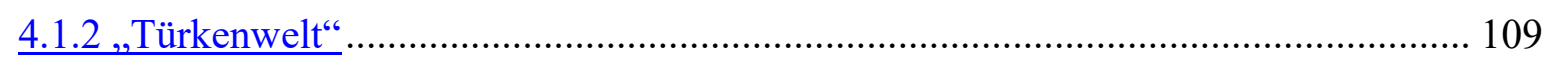

4.1.2.1 Türkische Soft-Power-Mittel in Zentralasien.................................................... 113

4.1.2.2 Die Gülen-Bewegung: Ein gemeinsames Soft-Power-Instrument der Türkei und

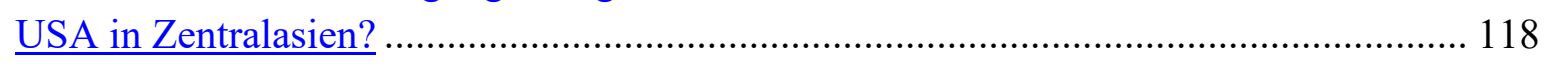

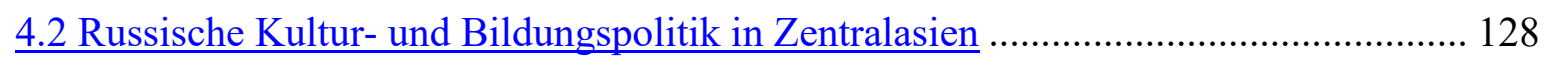

4.2.1 „Nahes Ausland“ in russischen nationalen Dokumenten ....................................... 128

4.2.2 Russische Diaspora und Russisch als russische Soft-Power-Mittel........................ 134

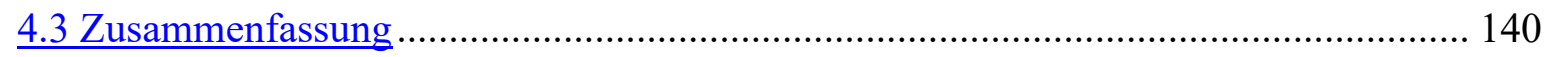

5 TÜRKISCH-RUSSISCHE WIRTSCHAFTSPOLITIK IN ZENTRALASIEN (1991-

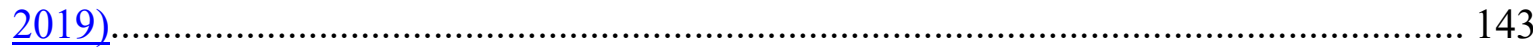

5.1 Energiepolitische Rivalität zwischen der Türkei und Russland um das kaspische Erdöl

$\underline{5.2 \text { Energiepolitische Rivalität zwischen der Türkei und Russland um das kaspische Erdgas }}$ 150

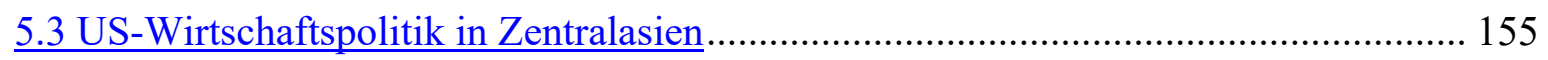

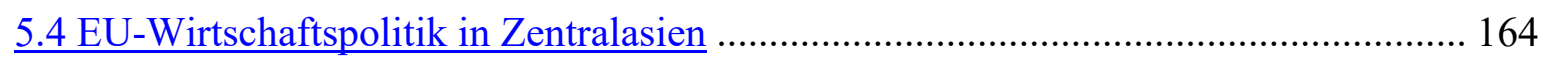

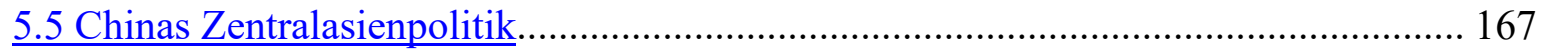

5.6 Russlands Eurasische Wirtschaftsunion gegen die türkischen Initiativen in Zentralasien

5.7 Ist eine türkisch-russische strategische Wirtschaftspolitik im Rahmen der EAWU

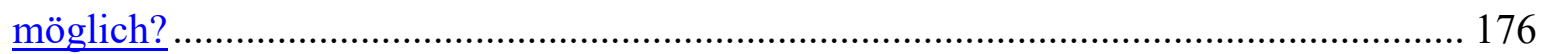

$\underline{5.8 \text { Wirtschaftliche Beziehungen der zentralasiatischen Staaten mit der Türkei und }}$

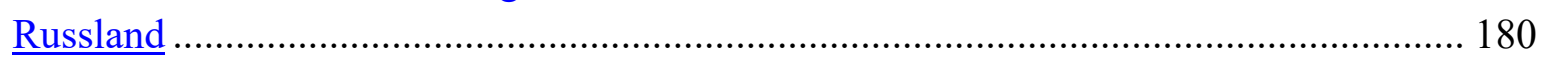

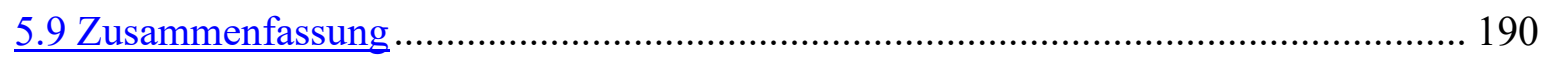


6.1 (Sicherheits)Politische Probleme der zentralasiatischen Staaten .............................. 197

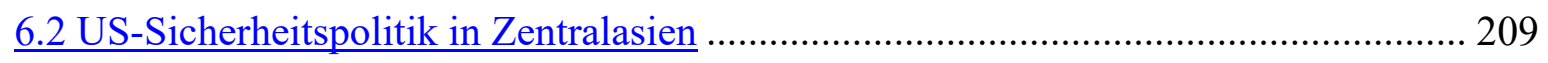

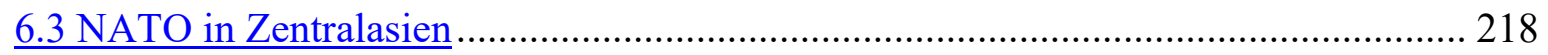

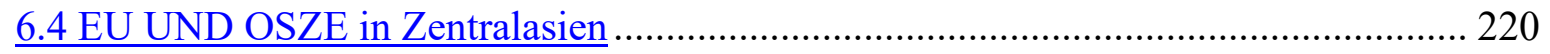

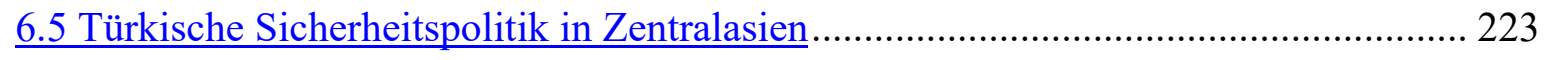

6.6 Russische Sicherheitspolitik in Zentralasien......................................................... 227

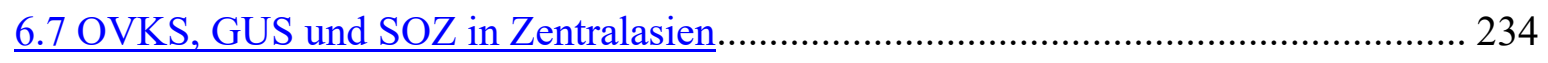

6.8 Die sicherheitspolitische Rivalität zwischen der Türkei und Russland um postsowjetische Staaten am Beispiel des Berg-Karabach-Konfliktes und der Krimfrage: ,Türkenwelt“ gegen das „Nahe Ausland“ “................................................................... 240

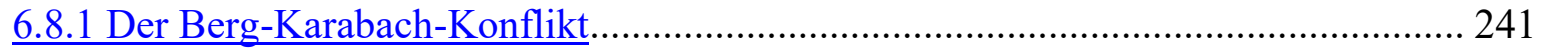

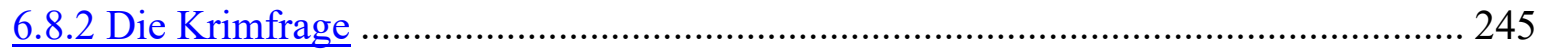

6.9 Ist eine türkisch-russische strategische Sicherheitspolitik in Zentralasien möglich? . 248

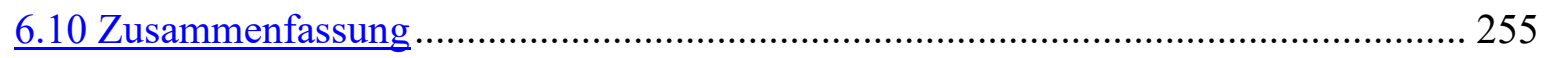

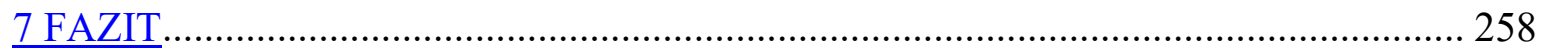

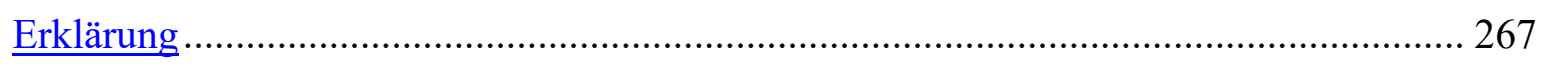

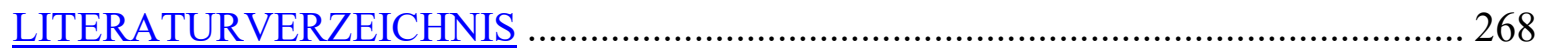




\section{Abkürzungsverzeichnis}

ABM-Vertrag

AIOC

AKP oder AK Parti

ASAM

ASSR

BILGESAM

BIP

BOMCA

BSREC

BTC

BTE

C5+1

CAC

CACO

CADAP

CAPG

CAU

CENTCOM

CIA

CICA

CPC

DCI

EAPC/EAPR

EAWG

EAWU

ECO
Anti-Ballistic Missiles Treaty

Azerbaijan International Operating Company

Adalet ve Kalkınma Partisi (Partei für Gerechtigkeit und Entwicklung

Avrasya Stratejik Arastirmalar Merkezi (Zentrum für Strategische Studien für Eurasien)

Autonome Sozialistische Sowjetrepublik

Bilge Adamlar Stratejik Araştırmalar Merkezi

(Strategisches Forschungszentrum der Weisen)

Bruttoinlandsprodukt

Border Management Programme in Central Asia

Black Sea Regional Energy Center

Baku-Tiflis-Ceyhan Pipeline

Baku-Tiflis-Erzurum Pipeline

U.S.-Central Asia (C5+1) Joint Projects

Central Asia Center Pipeline

Central Asian Cooperation Organisation

Central Asia Drug Action Programme

Central Asia Gas Pipeline

Central Asian Union

The United States Central Command

Central Intelligence Agency

Conference on Interaction and Confidence Building Measures in Asia

Caspian Pipeline Consortium

Development Cooperation Instrument

Euro-Atlantic Partnership Council/Euro-atlantischer Partnerschaftsrat

Eurasische Wirtschaftsgemeinschaft

Eurasische Wirtschaftsunion

Economic Cooperation Organization 
EPKA

ESPO

EU

EWG

FSB

GIZ

GKS

GUAM

GUS

GUUAM

IMF

INOGATE

IS

ISAF

KSZE

LGTBI

LNG

MHP

NATO

NGO

ODIHR

OIC

OPEC

OSZE

OVKS

PfP
Erweitertes Partnerschafts- und

Kooperationsabkommen

Eastern Siberia Pacific Ocean

Europäische Union

Europäische Wirtschaftsgemeinschaft

Federalnaja sluschba besopasnosti Rossijskoi

Federazii (Föderaler Dienst für Sicherheit der

Russischen Föderation)

Deutsche Gesellschaft für Internationale

Zusammenarbeit

Russisches Statistikamt Rosstat

Georgien, Ukraine, Aserbaidschan und Moldavien

Gemeinschaft Unabhängiger Staaten

Georgien, Ukraine, Usbekistan, Aserbaidschan und Moldavien

International Monetary Fund

Interstate Oil and Gas Transport to Europe

Islamischer Staat

International Security Assistance Force

Konferenz für Sicherheit und Zusammenarbeit in Europa

Lesbian, Gay, Bisexual, Transgender, Intersex

Liquified Natural Gas

Milliyetçi Hareket Partisi (Partei der Nationalistischen Bewegung)

North Atlantic Treaty Organization

Non-Governmental Organization

Office for Democratic Institutions and Human Rights

Organisation of Islamic Cooperation

Organization of the Petroleum Exporting Countries

Organisation für Sicherheit und Zusammenarbeit in Europa

Organisation des Vertrags über Kollektive Sicherheit

Partnership for Peace 
PKA

PKK

PNAC

PYD

RSFSR

RU

RUTAM

SIPRI

SOZ

TACIS

TAKM

TANAP

TAP

TAP(I)

TASAM

TBMM

TDAV

TDIK

TIKA

TR

TRACECA

TUIK
Partnerschafts- und Kooperationsabkommen

Partiya Karkeren Kurdistan (Arbeiterpartei

Kurdistans)

Project for the New American Century

Partiya Yekitiya Demokrat (Partei der

Demokratischen Union)

Die Russische Sozialistische Föderative

Sowjetrepublik

Russland

Rus-Türk Arastirmalari Merkezi (Russisch-Türkisches Forschungszentrum)

Stockholm International Peace Research Institute

Shanghaier Organisation für Zusammenarbeit

Technical Assistance to the Commonwealth of Independent States

Avrasya Askeri Statülü Kolluk Kuvvetleri Teşkilatı, Vereinigung der eurasischen Strafverfolgungskräfte mit militärischem Status oder „Türkenarmee“

Transanatolische Pipeline

Transadriatische Pipeline

Turkmenistan, Afghanistan, Pakistan, Indien Pipeline

Türk Asya Stratejik Araştırmalar Merkezi (TürkischAsiatisches Zentrum für strategische Studien)

Türkiye Büyük Millet Meclisi (Die Große

Nationalversammlung der Türkei)

Türk Dünyasi Arastirmalari Vakfi (Stiftung für die Erforschung der türkischen Welt)

Türk Dili Konusan Ülkeler Isbirligi Konseyi (Der Kooperationsrat der türksprachigen Staaten)

Türk İşbirliği ve Koordinasyon Ajansı Başkanlığı (Präsidentschaft der türkischen Kooperation und Entwicklungsagentur)

Türkei

The Europe-Caucasus-Asia Transport Corridor

Türkiye İstatistik Kurumu (Das Statistikinstitut der Türkei) 
TÜRKPA

TÜRKSOY

Übers. d. d. Verfasserin

ÜDİK

UdSSR

$\mathrm{UN} / \mathrm{UNO}$

UNAIDS

UNODC

USA

USAID

USAK

YPG

ZA

ZAP
Türk Dili Konuşan Ülkeler Parlamenter Asamblesi (Die internationale Mission der Assemblee der türksprachigen Länder)

Uluslararasi Türk Kültürü Teskilati (Internationale Organisation für Türkkulturen)

Übersetzt durch die Verfasserin

Üst Düzey İşbirliği Konseyi (Hoher Kooperationsrat)

Union der Sozialistischen Sowjetrepubliken

United Nations/United Nations Organization

Joint United Nations Programme on HIV/AIDS

United Nations Office on Drugs and Crime

United States of America

United States Agency for International Development

Uluslararası Stratejik Araştırma Kurumu

(Internationale Strategische Forschungsorganisation)

Yekineyen Parastina Gel (Die

Volksverteidigungseinheiten)

Zentralasien

Zentralasienpolitik 


\section{Abbildungs- und Tabellenverzeichnis}

Abbildungen:

Seite

Abb. 1: Zentralasien 2

Abb. 2: Russische Expansion in Zentralasien 53

Abb. 3: Amu Darja und Syr Darja 55

Abb. 4: Turkestan um $1900 \quad 58$

Abb. 5: Tian Shan und Altai Gebirge $\quad 61$

Abb. 6: Khanate Kazan, Astrachan, Krim 67

$\begin{array}{ll}\text { Abb. 7: Strategische Ellipse } & 157\end{array}$

$\begin{array}{ll}\text { Abb. 8: Ölpreisentwicklung } & 161\end{array}$

Abb. 9: Lage Afghanistans, Pakistans und der zentralasiatischen Staaten 215

$\begin{array}{ll}\text { Abb. 10: Berg-Karabach } & 241\end{array}$

Abb. 11: Schwarzmeerflotte auf der Krim 245

\section{Tabellen:}

Tabelle 1: Anteile der wichtigsten 3 Handelspartner an den 188

Exporten zentralasiatischen Staaten 2016

Tabelle 2: Anteile der 3 wichtigsten Handelspartner an den Importen der zentralasiatischen Staaten 2016

Tabelle 3: Die Mitgliedschaften zentralasiatischen Staaten 


\section{EINLEITUNG}

Das Thema dieser empirisch-analytisch vergleichenden Dissertation ist die „TürkischRussische Zentralasienpolitik. Geopolitische Rivalität oder Strategische Partnerschaft?". Wie aus dem Titel hervorgeht, konzentriert sich diese Arbeit auf die türkisch-russische Zentralasienpolitik (ZAP), ${ }^{1}$ bzw. darauf, wie die Türkei (TR) und Russland (RU) auf ihre gegenseitige ZAP reagieren, ob sie in Zentralasien (ZA) geopolitisch rivalisieren oder strategisch kooperieren (siehe Forschungsfragen und -Hypothesen unten). Andere Beziehungen zwischen den beiden Staaten werden nur berücksichtigt, falls sie für die Erklärung dieses Themas relevant erscheinen.

Unter ZA² werden die nach dem Zerfall der Sowjetunion 1991 unabhängig gewordenen ehemaligen asiatischen Sowjetrepubliken Kasachstan, Kirgisistan, Tadschikistan, Turkmenistan und Usbekistan (siehe Abbildung 1 und Kap. 3.1) verstanden. ${ }^{3}$ ZA umfasst eine Fläche von 4 Mio. km² (Aynural/Kesici 2005: 1212), ein Gebiet, in dem 2019 etwa 73 Mio. Menschen leben (United Nations, Department of Economic and Social Affairs, Population Division 2019). ${ }^{4}$ Die Bevölkerung der zentralasiatischen Staaten besteht überwiegend aus sunnitischen Muslimen; außer Tadschikistan (persophon) sind alle Staaten turksprachig geprägt. Aufgrund ihrer gleichen Sprachfamilie werden die turksprachigen postsowjetischen Staaten auch als Turkstaaten bezeichnet. Die Region grenzt im Westen an das Kaspische Meer, im Osten an China, im Norden an die Russische Föderation und im Süden an Afghanistan und den Iran (siehe Abbildung 1). ${ }^{5}$

\footnotetext{
1 Aus Übersichtlichkeits- und Platzgründen werden in dieser Arbeit die häufig wiederkehrenden Begriffe „Zentralasienpolitik, Zentralasien, Türkei, Russland“ nach ihrer erstmaligen Nennung abgekürzt verwendet (ZAP, ZA, TR, RU). „Russland“ ist gleichbedeutend mit „Russischen bzw. Russländischen Föderation“ (RF). ${ }^{2}$ Die Bezeichnung der Region als ZA geht auf die geographische Definition von Alexander von Humboldt zurück, die dieser bei seiner Asienexpedition 1829 festlegte. In sowjetischer Zeit verwendete RU die Bezeichnung ZA (russisch: Central'naja Aziya) in Anlehnung an Humboldts Definition für den westlichen Teil Chinas, Xinjiang; das heute als ZA bezeichnete Gebiet wurde dagegen „Mittelasien und Kasachstan“ (russisch: Sredn'jaja Aziya i Kazakhstan) genannt. Nach der Unabhängigkeit der zentralasiatischen Staaten 1991 wurde die englische Bezeichnung der Region „Central Asia“ (ZA) übernommen. Die zentralasiatischen Staaten wollten nach ihrer Unabhängigkeit 1991 die sowjetische Bezeichnung durch „Zentralasien“ ersetzen und forderten die Weltgemeinschaft auf einer Pressekonferenz am 4. Januar 1993 dazu auf, ihre Region zukünftig einheitlich als ZA zu bezeichnen (Özdamar 2010) (siehe hierzu Kap. 3.1).

3 Kirgisistan erklärte am 31. August, Usbekistan am 1. September, Tadschikistan am 9. September, Turkmenistan am 27. Oktober und Kasachstan am 16. Dezember 1991 seine Unabhängigkeit.

${ }^{4} 2019$ leben in Usbekistan etwa 33 Mio., in Kasachstan 18,5 Mio., in Tadschikistan 9,3 Mio., in Kirgisistan 6,4 Mio. und in Turkmenistan 5,9 Mio. Menschen (United Nations, Department of Economic and Social Affairs, Population Division 2019).

5 Keiner der zentralasiatischen Staaten hat einen Zugang zum Meer, es handelt sich um Binnenstaaten (landlocked countries). Die Landschaft der Region ist unterschiedlich: Der Norden ist durch Steppen geprägt,
} 


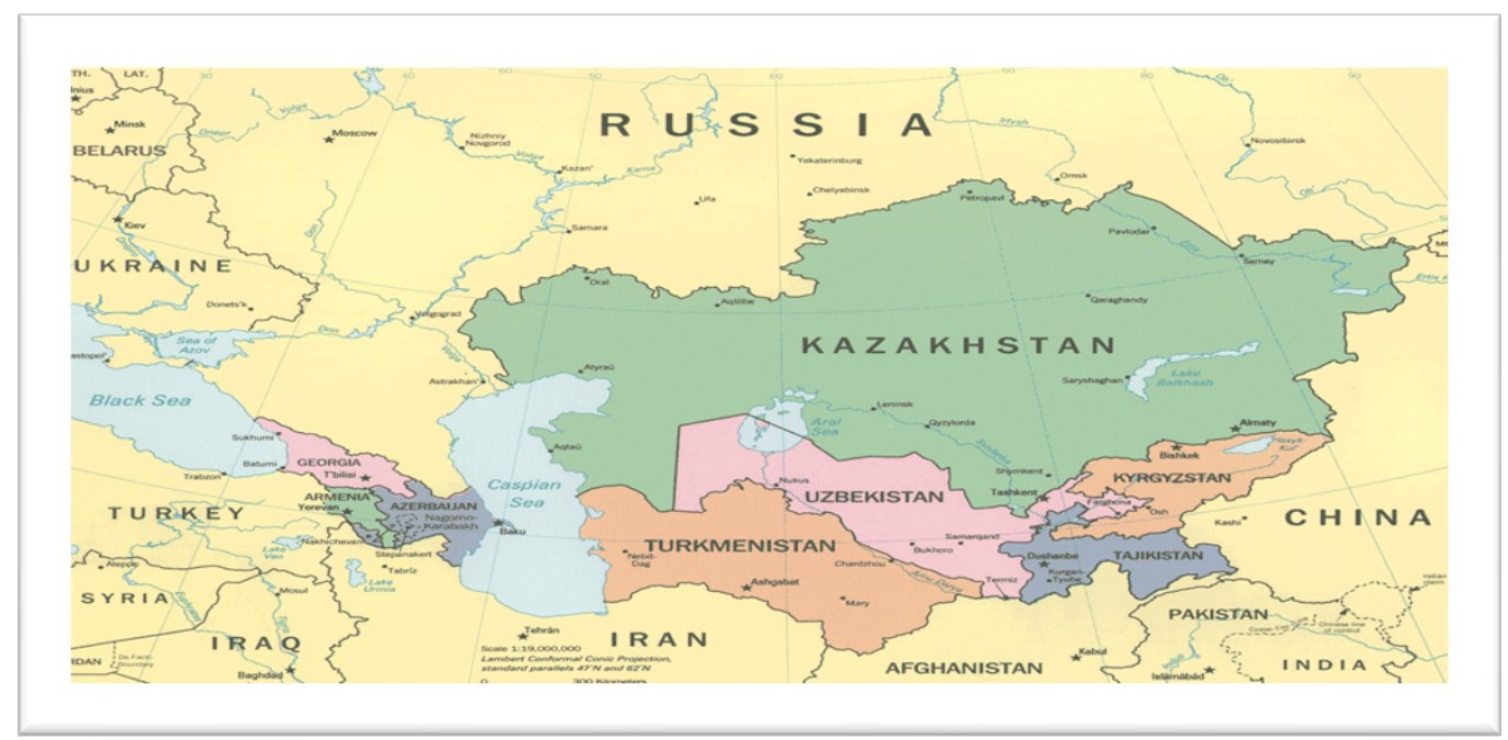

Quelle: Blogspot o. J. ${ }^{6}$

Der Untersuchungszeitraum der Arbeit erstreckt sich vom Anfang der türkisch-russischen ZAP 1552, bzw. $1554^{7}$ bis zum Ende 2019. Ich habe mich für eine Langzeituntersuchung entschieden - einerseits, um die aktuellen Perzeptionen der Hauptakteure (TR, RU, zentralasiatische Länder) zu verstehen, da sie sehr wesentlich durch die historischen Ereignisse bestimmt sind. Andererseits begründen die TR und RU ihre hegemonialen Ansprüche auf ZA nicht zuletzt mit „,historischen Gemeinsamkeiten“, bzw. „historischen Tatsachen“. Für die TR ist ZA ein Teil ihrer pantürkistischen „,Türkenwelt“ ${ }^{8}$ für RU dagegen ein Teil seines „Nahen Auslands“ (russisch: blizhneye zarubezhye). ${ }^{9}$ Des Weiteren sind die historischen Vorkenntnisse von Vorteil, um z. B. die Inhalte der Daten (wie Reden, Texte, Statistiken usw.) in ihren Kausalzusammenhängen besser zu verstehen, bzw. auszuwerten.

der Süden eher durch Wüsten. Die östliche Seite der Region ist bergig, das Zentrum ist durch Oasen und Flusstäler geprägt. Wichtige Gewässer sind die Flüsse Ural, Emba, Amu Darja, Syr Darja sowie das Kaspische Meer und der Aralsee (Akiner 1994: 4).

${ }^{6}$ O. J.: Ohne Jahr

${ }^{7}$ Als Anfang der türkisch-russischen geopolitischen Rivalität gelten die russischen Eroberungen der Khanate Kasan 1552 und Astrachan 1554. Dies führte zum ersten türkisch-russischen Krieg (Astrachan-Krieg, 15681570). In einigen Quellen steht das Datum 1556 für die Eroberung des Khanats Astrachan.

${ }^{8}$ Ich verwende in dieser Arbeit anstelle des in Deutschland gängigen Begriffes Panturkismus den Begriff Pantürkismus. Der Panturkismus geht von der Idee der „Vereinigung aller Turkvölker“ aus; der Pantürkismus hingegen zielt auf die Vereinigung und Türkisierung der Turkvölker unter türkischer Führung ab. Nach dem Pantürkismus sind alle Turkvölker ,türkischsprachige Türken“. Bis heute (2019) werden auf der Homepage des türkischen Außenministeriums der Begriff „Türkenwelt“ (türkisch: Türk Dünyasi) für die Turkstaaten und die Begriffe „türkische Sprache, bzw. Türkensprache oder Türksprache“ (türkisch: Türk Dili) für die Turksprachen verwendet (Türkiye Cumhuriyeti Disisleri Bakanligi o. J. a). Allerdings sind die Einwohner der Turkstaaten weder Türken, noch sprechen sie Türkisch, wie im Kapitel 4 gründlich dargestellt wird. Eine sprachliche Kommunikation zwischen einem Sprecher, einer Sprecherin des Türkischen und einem Sprecher, einer Sprecherin einer zentralasiatischen Turksprache ist nicht möglich.

${ }^{9}$ Mit dem Begriff „Nahes Ausland“ meint RU die postsowjetischen Länder. 
Weiterhin ist eine Langzeituntersuchung deshalb sinnvoll, weil dadurch die möglichen Gesetzmäßigkeiten erkannt, bzw. verallgemeinerbare Aussagen getroffen, neue Erkenntnisse gewonnen sowie die Kontinuitäten oder Wandel der türkisch-russischen ZAP festgestellt werden können.

Im Allgemeinen mangelt es an wissenschaftlichen Arbeiten über die Türkisch-Russische ZAP; zudem ist die vorhandene Literatur meist lückenhaft. Es fehlt an Arbeiten, die die türkisch-russische ZAP in allen Bereichen (bildungs- und kulturpolitisch, wirtschaftlich und sicherheitspolitisch), bzw. in ihren Kausalzusammenhängen vergleichend erklären (siehe Kap. 1.2). Das ist die größte wissenschaftliche Lücke bei diesem Thema. Des Weiteren ist das Thema besonders durch die TR-stämmigen oder RU-stämmigen Wissenschaftler*innen politisch belastet (siehe Kap. 1.2.4). Beispielsweise sieht der größte Teil der türkischen Wissenschaftler*innen die Bevölkerung der zentralasiatischen Turkstaaten als „türkischsprachige Türken“ an. Sie definiert sie in den entsprechenden Arbeiten z. B. die Kasachen als „kasachische Türken“ (türkisch: Kazak Türkleri) und ihre Sprache Kasachisch als „kasachisches Türkisch“ (türkisch: Kazak Türkcesi). Die pantürkistische türkische ZAP wird aus dieser Sichtweise heraus als „selbstverständlich“ gesehen. Diese pantürkistische Sichtweise ist zum Teil auch in der deutschsprachigen und der englischsprachigen Literatur $\mathrm{zu}$ finden (siehe Kap. 1.2.4). In RU hingegen wird ZA als ,selbstverständliches Hegemoniegebiet" ${ }^{\text {10 }}$ RUs, als sein „Nahes Ausland“ betrachtet. Eine weitere Lücke ist, dass in keiner mir bekannten wissenschaftlichen Arbeit die Zusammenhänge zwischen der türkischen Sicherheitspolitik und ihrer ZAP sowie ihrer Russlandpolitik erläutert werden (siehe Kap. 1.2.4 und Kap. 6.9). Die Schließung dieser Lücken ist das Ziel dieser Arbeit.

Die Literatur (siehe Kap. 1.2) über die türkisch-russischen Beziehungen sowie über ihre vergleichende ZAP ist durch zwei Strömungen geprägt: Die Wissenschaftler*innen der „geopolitischen Position“ vertreten die Meinung, dass die türkisch-russischen Beziehungen sowohl bilateral als auch in Hinblick auf ZA durch geopolitische Rivalität geprägt sind (siehe Kap. 1.2.1). Die Wissenschaftler*innen der „strategischen Position“ hingegen bezeichnen

\footnotetext{
${ }^{10}$ Der Begriff Hegemonie stammt aus dem Griechischen (Hegemonia) und bedeutet „Heerführung“. In der Politikwissenschaft wird der Begriff für die Vorherrschaft eines Staates über einen anderen Staat, bzw., die anderen Staaten gebraucht. Die führende (politisch, militärisch, wirtschaftlich usw. überlegene) Macht, bzw. der Hegemon gibt den von ihm geführten Staaten die Richtung vor. Nach dem Historiker Perry Anderson muss es dem Hegemonen gelingen, den beherrschten Staaten den Eindruck zu vermitteln, ,die Vorteile ihrer Fügsamkeit überstiegen deren Nachteile“" (Mangold 2018).
} 
die türkisch-russischen bilateralen Beziehungen als strategische Partnerschaft und/oder „multilaterale Partnerschaft“ (Büyükakinci 2012, Aras 2009b) (siehe Kap. 1.2.2). Zwar fasst auch die strategische Strömung die aktuelle türkisch-russische ZAP als geopolitische Rivalität auf. Sie hält allerdings aufgrund der „strategisch-bilateralen Beziehungen und Interessen" zwischen der TR und RU eine türkisch-russische strategische Partnerschaft in ZA in Zukunft für möglich. Beide Positionen sind sich also über die folgende These einig: Die aktuelle türkisch-russische ZAP ist durch geopolitische Rivalität geprägt. Diese Erkenntnis übernehme ich als 1. Hypothese meiner Arbeit wie folgt:

Hypothese 1: Die Türkei und Russland rivalisieren in Zentralasien geopolitisch in kultur- und bildungspolitischen, wirtschaftlichen und sicherheitspolitischen Bereichen.

Weil es bis heute zu keiner strategischen Partnerschaft zwischen der TR und RU in ZA kam und meiner Meinung nach eine solche Partnerschaft unter den heutigen Umständen auch in Zukunft nicht zu erwarten ist, positioniere ich mich mit meiner 2. Hypothese gegen die „strategische Position“:

Hypothese 2: Eine türkisch-russische „strategische Partnerschaft“ in Zentralasien ist unter den heutigen Umständen nicht möglich.

Meine Forschungsfragen zielen in erster Linie auf die Verifizierung dieser Hypothesen sowie die Schließung der Wissenslücken über dieses Thema ab. Sie lauten folgendermaßen:

Forschungsfrage 1: Warum rivalisieren die Türkei und Russland in Zentralasien geopolitisch?

Forschungsfrage 2: Ist eine türkisch-russische „strategische Partnerschaft“ in Zentralasien möglich?

Die Antwort auf die 1. Forschungsfrage macht den wesentlichen Inhalt dieser Arbeit aus. Dabei soll die türkisch-russische ZAP zwischen den Jahren 1552 und 2019 in den kulturund bildungspolitischen, wirtschaftlichen und sicherheitspolitischen Bereichen vergleichend erklärt werden. Die Antwort auf die 2. Forschungsfrage hingegen baut auf der Beantwortung der 1. Forschungsfrage auf und zeigt, warum eine türkisch-russische strategische Partnerschaft in ZA nicht möglich ist. Bei der Beantwortung der Forschungsfragen beziehe ich mich auf die dieser Arbeit zugrunde liegenden theoretischen Ansätze, den Neorealismus von Kenneth Waltz und den Soft-Power-Ansatz von Joseph Nye (siehe Kap. 2). 
Ich bevorzuge für diese Dissertation Primärliteratur (siehe Kap. 1.3). Für die Auswertung der Literatur verwende ich qualitative Inhaltsanalyse (siehe Kap. 1.3). Bevor die Einführung in das Thema im folgenden Teil vertieft wird, sollten zunächst zwei wichtige Begriffe dieser Arbeit geklärt werden: Geopolitische Rivalität und Strategische Partnerschaft.

Geopolitik kann als hegemoniale Strategien eines Staates für die Macht- und Einflusserweiterung verstanden werden. Zur Strategieentwicklung werden die Machtmittel - die geographische Lage, die Bevölkerungszahl, das militärische Potenzial, die wirtschaftliche Lage usw. - des eigenen Staates und des Zielobjekts berücksichtigt. Die entwickelten Strategien werden mit diplomatischen Techniken gerechtfertigt. D. h. die Geopolitik und Diplomatie hängen eng zusammen. Geopolitik ist ein Null-Summen-Spiel ${ }^{11}$ und zielt bei der Rivalität auf Gewinne auf Kosten des Gegners ab. Weil der Schwerpunkt der Geopolitik auf der Macht- und Einflusserweiterung eines Staates liegt, kann sie der realistischen Denkrichtung zugeordnet werden.

Eine Strategische Partnerschaft hingegen kann als Gegenteil von Geopolitischer Rivalität verstanden werden. Damit von einer „strategischen Partnerschaft“ die Rede sein kann, müssen die zwischenstaatlichen Beziehungen einige Kriterien erfüllen. Die wichtigsten Merkmale einer strategischen Partnerschaft sind laut Lang (2004: 7) eine gemeinsame Agenda im Hinblick auf die gemeinsamen Vorteile, die konstruktive bilaterale Geschichtsverarbeitung und die Absicht einer langfristigen gemeinsamen, institutionell verankerten kultur-, wirtschafts- und sicherheitspolitischen Zusammenarbeit. Bis jetzt ist die türkisch-russische ZAP durch geopolitische Rivalität geprägt und weit entfernt von einer strategischen Partnerschaft.

\subsection{Zentralasien im weltpolitischen Kontext: Eine kurze Einführung}

ZA ist nach den archäologischen Funden von Teschik Tasch ein mindestens 70.000 Jahre altes Siedlungsgebiet (Stadelbauer 2004a: 26). Die Region wurde im Laufe der Zeit sowohl von den „Türken“ als auch von den Russen beheimatet und geprägt. Die TR sieht ihre

\footnotetext{
${ }^{11}$ In einem Nullsummenspiel versuchen die Akteure, ihre Gewinne zu maximieren und ihre Gegner zu schwächen oder, falls möglich, zu beseitigen.
} 
Wurzeln in $\mathrm{ZA}^{12}$ und betrachtet die großen Herrscher der Region, wie den hunnischen Oghus Khan (209-174 v. Chr.), den Hunnenkönig Attila (395-453) und den usbekischen Herrscher Timur (1336-1405), als ihre Vorfahren, bzw. ethnischen Verwandten. Laut der Geschichte kamen die Vorfahren der Türken 1071 aus ZA nach Anatolien, bzw. in die heutige TR. Daher werden die turkophonen Zentralasiaten in der TR als ethnische und historisch-kulturelle (sprachlich und religiöse) Verwandte der Türken angesehen. Die Attila-Ära ist für die Weltgeschichte wegen der von den zentralasiatischen Hunnen ausgelösten Völkerwanderung (375-568) relevant. Des Weiteren ist ZA im Zusammenhang mit der historischen Seidenstraße berühmt, die in der Antike und im Mittelalter (von 200 v. Chr. bis etwa zum 15. Jahrhundert) der wichtigste Handelsweg von China entlang des südlichen ZAs nach Europa war. Durch diesen Handelsweg wurden nicht nur Waren, Kulturen und Wissen ausgetauscht; sondern auch Religionen und Krankheiten verbreitet.

Politikwissenschaftlich wird ZA mit dem (New) Great Game ${ }^{13}$ genannten geopolitischen Null-Summen-Spiel in Verbindung gebracht. Die Region gewann ab dem 19. Jahrhundert im geopolitischen Machtkampf zwischen dem Britischen Imperium und dem Zarenreich ${ }^{14}$ an geostrategischer Relevanz. Die Eroberungen des Zarenreichs in ZA sowie dessen Einmarsch in Persien im Jahre 1828 lösten im Britischen Imperium Ängste um seine Kolonie Indien aus. Deshalb glaubte es Afghanistan besetzen zu müssen, um die mögliche russische Expansion Richtung Indien stoppen zu können. Um dieses Ziel zu erreichen, führte das Britische Imperium Kriege gegen Afghanistan. ${ }^{15}$ Laut Ucarol (2000: 268) markiert der erste Afghanistan-Einsatz (1838) den Anfang des Great Game.

\footnotetext{
${ }^{12}$ Laut dem renommierten türkischen Historiker Halil Inalcik (O. V. 2009: Kayi Soyu Teorisi Siyasi ...) ist die türkische Verwandtschaft mit den Zentralasiaten eine von der TR infolge der Niederlage im Ankara-Krieg 1402 selbsterfundene Geschichte (siehe hierzu Kap. 3.2).

O. V.: Ohne Verfasser

13 „The Great Game“ wurde bereits seit der Mitte des 19. Jahrhunderts in der Geschichtswissenschaft und Politik als Terminus für das Null-Summen-Spiel zwischen RU und England verwendet. Als Erster gebrauchte sie der englische Kapitän Arthur Conolly 1842 in Buchara (hierzu Hopkirk 2001: 1). Populär wurde die Bezeichnung erst mit Rudyard Kiplings Roman „Kim“ (ebd.).

${ }^{14}$ Das Zarenreich bezeichnete sich von 1721 (Ära Peters I., 1682-1725) bis zur Ausrufung der „Russischen Sowjetrepublik“ 1917 offiziell als „,Russisches Kaiserreich“. „Zarenreich“ war von 1547 bis 1721 die offizielle Bezeichnung gewesen; davor hieß das Reich „Fürstentum Moskau“. In Europa wurde durchgehend die Bezeichnung Zarenreich verwendet.

${ }^{15}$ Im ersten Anglo-Afghanischen-Krieg (1838-1842) versuchte das Britische Imperium, den afghanischen Thron auszuwechseln und dadurch Einfluss in der Region zu gewinnen. Der Krieg endete mit einer Niederlage der Briten. Im Zweiten Anglo-Afghanischen-Krieg (1878-1879) griffen die Briten Afghanistan wegen der Annäherung des afghanischen Königs Scher Ali an RU an. Afghanistan wurde nach der Niederlage ein halbautonomes Protektorat. Im Dritten Anglo-Afghanischen-Krieg (Mai-August 1919) erklärten die Afghanen den Briten den Krieg. Nach dem Sieg wurde Afghanistan am 8. August 1919 unabhängig (Baberowski 2007: 26-27).
} 
Das Zarenreich eroberte bis 1895 das gesamte ZA. Die Region war strategisch gesehen eine Pufferzone gegen das Britische Imperium. Weil die Region unter der russischen Herrschaft stand, wurde es für das Osmanische Reich ${ }^{16}$ zunehmend schwieriger, in ZA trotz des Zarenreiches eine aktive Außenpolitik zu verfolgen. Zu dieser Zeit war wegen der schlechten politischen, militärischen und wirtschaftlichen Lage des Osmanischen Reiches ohnehin eine aktive türkische ZAP möglich. Aufgrund dieser Bedingungen, d. h. der russischen Überlegenheit und der mangelnden osmanischen Kapazitäten, versuchte das Osmanische Reich, seine Ziele für, bzw. in ZA mit Soft-Power-Mitteln (siehe Kap. 2.2) zu verfolgen. Diese Mittel reichten von der Verbreitung des Korans in ZA bis zur Unterstützung der pantürkistischen Aktivitäten der Dschedid-Schulen, wie im Kapitel 3 ausführlich dargestellt wird.

Wirtschaftlich war ZA für das Zarenreich zunächst für seine Baumwollproduktion von großer Relevanz. Baumwolle wurde infolge des amerikanischen Bürgerkrieges (1861-1865) knapper und deshalb verteuert. Um die Bedürfnisse der Textilbranche zu decken, wurde in ZA der Baumwollanbau gefördert. Das russische Ziel war eine vollständige Unabhängigkeit von Baumwollimporten. 1865 machten die Baumwollexporte nach Moskau 74,1 \% des gesamten zentralasiatischen Baumwollexports aus. $\mathrm{Zu}$ dieser Zeit waren die fossilen Brennstoffe der zentralasiatischen Staaten noch nicht entdeckt worden. Im rohstoffreichen Kasachstan wird Erdöl erst seit etwa 100 Jahren gefördert. Erste Erdölvorkommen wurden 1899 in Karagüngül entdeckt (Ismayilov/Budak 2015: 1-2). Die erste zentralasiatische Erdgaspipeline hingegen wurde erst 1967 gebaut (von Usbekistan via Turkmenistan und Kasachstan nach RU). Sie wurde bis 1985 ausgebaut (Kisacik 2012).

Nach der Unabhängigkeit der zentralasiatischen Staaten 1991 begann ein energiepolitischer Wettbewerb um die Ausbeutung der fossilen Brennstoffe, den die Literatur New Great Game nennt. In diesem neuen Spiel blieb RU alter Hauptakteur des Great Game. Sein Gegner war nun nicht mehr England; sondern die „United States of America“(USA) mit ihren westlichen Partnern (westliche Achse). Wie das alte ist auch das neue Great Game ein Null-SummenSpiel. Die TR als Mitglied der „North Atlantic Treaty Organization“ (NATO) ist Bestandteil der westlichen Achse und handelt gegen RU. Das westliche Ziel des New Great Game am Kaspischen Meer war und bleibt die Ausbeutung der fossilen Brennstoffe dieser Region

\footnotetext{
${ }^{16}$ Der Vorgängerstaat der TR, das Osmanische Reich, bezeichnete sich nicht als solches; sondern als Diyar-i Rum (Land der Römer), Devlet-i Aliyye (erhabener Staat) oder Devlet-i Aliyye-i Osmaniyye (erhabener osmanischer Staat) usw. Die Bezeichnung „Osmanisches Reich“ ist europäisch geprägt.
} 
unter Umgehung RUs (und Irans) in die TR und via die TR nach Europa (siehe Kap. 5). Die Erdölpipeline Baku-Tiflis-Ceyhan (BTC) und die Erdgaspipeline Baku-Tiflis-Erzurum (BTE) aus der aserbaidschanischen Hauptstadt in die TR wurden erfolgreich realisiert. Seit 2008 transportiert Kasachstan mit Öltankern Erdöl nach Aserbaidschan, das dort in die BTC eingespeist wird oder von dort aus mit dem $\mathrm{Zug}$ zu dem georgischen Hafen Batumi transportiert wird. Seit November 2007 liefert die BTE im Rahmen des Projekts der Europäischen Union (EU) „Interstate Oil and Gas Transport to Europe“ (INOGATE) Erdgas nach Griechenland (Türkiye Cumhuriyeti Disisleri Bakanligi o. J. b). Obwohl die TR mit RU um die kaspischen fossilen Brennstoffe energiepolitisch rivalisiert, besteht eine enge bilaterale Kooperation mit RU auf energiepolitischer Ebene. Die TR importiert etwa 60 \% ihres Erdgases und 23 \% ihres Erdöls aus RU (O. V. 2016: 2015 Ekim Döneminde Petrol ...). RU ist also der größte Energiepartner der TR.

Mit dem Afghanistan-Einsatz der USA/NATO im Oktober $2001^{17}$ gewann Afghanistan, wie schon im Great Game, auch im New Great Game an der sicherheitspolitischen Relevanz. Die USA/NATO erwarben in ZA für ihren Krieg im Afghanistan Militärbasen. ZA wurde dadurch die Region, in der sich die gegnerischen Militärbündnisse trafen: die amerikanisch geprägte NATO, die russisch geprägte „Organisation des Vertrags über Kollektive Sicherheit“ (OVKS) und die chinesisch geprägte „Shanghaier Organisation für Zusammenarbeit“ (SOZ). Dieser Zustand erhöhte die geostrategische Relevanz ZAs. Die Nationale Verteidigungsstrategie (National Defense Strategy) der USA von 2018 erweiterte die geostrategische Relevanz der Region weiter, indem die Nachbarstaaten ZAs - RU, China und der Iran - als größte sicherheitspolitische Gefahren (United States Department of Defense 2018: 2-2) definiert wurden. Der islamistische Terrorismus, den die USA/NATO bis dahin als größte sicherheitspolitische Gefahr sahen und zu dessen Bekämpfung sie z. B. in Afghanistan einmarschierten, wurde somit auf den 2. Platz verdrängt. Als langfristige Hauptpriorität des US-Verteidigungsministeriums wurde der strategische Wettbewerb mit China und Russland genannt (ebd.: 2-3). Neben politischen und militärischen Druck ergriffen die USA auch wirtschaftliche Maßnahmen gegen RU, China und den Iran. Alle diese Staaten werden von den USA sanktioniert. Des Weiteren sind die USA gegen das

\footnotetext{
${ }^{17}$ Die NATO beschloss am 4. Oktober 2001 zum ersten Mal in ihrer Geschichte den Bündnisfall und begann nach drei Tagen, am 7. Oktober, mit dem Afghanistan-Krieg.
} 
russische (Eurasische ${ }^{18}$ Wirtschaftsunion, EAWU) und das chinesische Bündnisprojekt (Seidenstraße-Wirtschaftsgürtel). Beide Projekte schließen ZA ein (siehe Kap. 5). ${ }^{19}$

RU hingegen definiert in seinen aktuellen nationalen Dokumenten (Nationale Sicherheitsstrategie 2015, Militärdoktrin 2014 und Außenpolitikkonzept 2016) neben dem Islamismus $^{20}$ die NATO und die amerikanischen Aktivitäten, wie Raketenabwehrsysteme, als sicherheitspolitische Gefahr für seine territoriale Integrität und Souveränität. Dem Westen wirft das Land in seiner „Nationalen Sicherheitsstrategie von 2015“ den Regierungswechsel der legitim gewählten Regierungen z. B. durch die sogenannten

\footnotetext{
${ }^{18}$ Im Allgemeinen werden unter Eurasien die beiden Kontinente Europa und Asien verstanden. Die TR und RU haben ein eigenes Eurasienverständnis. Der Eurasismus als Ideologie wurde in den 1920er-Jahren von russischen Denkern entwickelt, die nach der Oktoberrevolution 1917 in den Westen (Prag, Berlin, Paris) emigriert waren. Der bekannteste eurasistische Denker der damaligen Zeit war Nikolaj Sergejevic Trubetzkoy (1890-1938). Er lehnte die romano-germanische Kultur Europas ab und sah den „europäischen“ Chauvinismus und Kosmopolitismus als Ideologien zur „Versklavung der restlichen Welt mit europäischen Werten“ an (Maas 2018). Nach dem Kalten Krieg wurde der Eurasismus als Neo-Eurasismus bezeichnet; sein bekanntester Vertreter ist Alexandr Dugin (geb. 1962). Er ist Berater des russischen Präsidenten Wladimir Putin (vom Mai 2000 bis heute mit Unterbrechung (1999 bis Mai 2000 und von 2008-2012 Ministerpräsident) Präsident). Dugin ist antiamerikanisch und gegen die NATO eingestellt. Er lehnt die Alleinherrschaft der USA ab (Dugin 2007: 89) und befürwortet eine führende Rolle RUs in der Weltpolitik (Bassin 2011: 136-138) (siehe Kap. 1.2.2). Der türkische Eurasismus hingegen hat laut Kireyev (ebd.: 202) im Vergleich zum Russischen eine kurze Geschichte; er entstand erst nach der Auflösung der Sowjetunion. Die Eurasisten in der TR sind im Allgemeinen unter dem Namen „Ulusalcilar“ ((Ultra)Nationalisten) bekannt. Das türkische Eurasismus zielt auf die Einheit der ethnisch-kulturell-sprachlichen Gemeinschaft der Turkvölker ab, dessen marginale Form der Pantürkismus ist (ebd.: 203-211). In der TR wird der Begriff von den Eurasisten anstelle der Begriffe „Türk Dünyasi“ (Türkische Welt) oder „Turan“ (Großes Reich der Turkvölker) gebraucht, da er „weicher“ und politisch wenig belastet ist (Kolobov/Kornilov/Özbay 2006: 295-296). Allerdings sieht Dugin die „Türkenwelt“ der TR als russisches Hegemoniegebiet an. Nach Dugin (2007: 95) würde RU die TR energieund geopolitisch unterstützen, wenn diese im Gegenzug die Eurasienpolitik RUs im Kaukasus und in ZA unterstützen würde. Dies würde jedoch bedeuten, dass die TR die postsowjetischen Turkstaaten als russisches Hegemoniegebiet anerkennen und auf ihren Pantürkismus, bzw. Eurasismus in diesen Gebieten verzichten müsste (siehe Kap. 1.2.2). Für Dugin (ebd.: 95) kann RU der sicherheitspolitische Garant der TR werden, wenn sie mit ihm kooperieren würde. Ansonsten wird sie von den USA mit Hilfe ihrer Zypern- und Kurdenprobleme aufgeteilt (ebd.: 96).

19 Aktuell (2019) sind von den zentralasiatischen Staaten nur Kasachstan und Kirgisistan Mitglieder der EAWU. Tadschikistan hat erklärt, dass das Land die Möglichkeit einer Mitgliedschaft prüfen werde. Usbekistan war von 2005 bis 2012 Mitglied. Turkmenistan als „neutrales Land“ hält sich vor den Mitgliedschaften in Bündnissen zurück. Bezüglich des Seidenstraße-Wirtschaftsgürtels sind einige Handelsrouten in ZA schon in Betrieb, weitere werden noch gebaut. Wenn die Infrastruktur komplett ist, wird die gesamte Region als wirtschaftliches Bindeglied den europäischen mit dem asiatischen Kontinent durch Handelswege verbinden. Davon werden alle beteiligten Staaten politisch und wirtschaftlich profitieren.

${ }^{20}$ Das „Bundesamt für Verfassungsschutz“ definiert Islamismus folgendermaßen: “Der Islamismus basiert auf der Überzeugung, dass der Islam nicht nur eine persönliche, private Angelegenheit ist, sondern auch das gesellschaftliche Leben und die politische Ordnung bestimmt oder zumindest teilweise regelt. Der Islamismus postuliert die Existenz einer gottgewollten und daher ,wahren“ und absoluten Ordnung, die über den von Menschen gemachten Ordnungen steht. Mit ihrer Auslegung des Islam stehen Islamisten im Widerspruch insbesondere zu den im Grundgesetz verankerten Grundsätzen der Volkssouveränität, der Trennung von Staat und Religion, der freien Meinungsäußerung und der allgemeinen Gleichberechtigung. Ein wesentliches ideologisches Element des Islamismus ist außerdem der Antisemitismus“. Nach dieser Definition sind die Staaten islamistisch, die mit islamischen Recht regiert werden, wie Saudi-Arabien und der Iran, weil der Verfassungsschutz im Grunde genommen unter dem Begriff Islamismus das islamische Recht „Scharia“ definiert. Ein Islamist ist dementsprechend auch derjenige, der die Scharia anstrebt.
} 
Farbenrevolutionen und die Unterstützung der innenpolitischen Instabilität und der Konflikte im postsowjetischen Raum vor (ebd., Artikel 18) sowie Stärkung der islamistischen Organisationen infolge seiner Angriffe, bzw. Aktivitäten (wie z. B. in Irak und Syrien) vor (ebd.) (siehe Kap. 4.2.1 und 6.6).

Die größte sicherheitspolitische Sorge RUs ist die Zerstörung seiner territorialen Integrität und Souveränität. Z. B. die Tschetschenen und Tataren wollten sich von RU loslösen (siehe Fußnote 66), konnten allerdings bis jetzt dieses Ziel nicht erreichen. Eine weitere Gefahr ist die Verbreitung des Pantürkismus und Islamismus (u. a. durch die Spill-Over-Effekte aus ZA und/oder Afghanistan oder aus Kaukasus) in der Russischen Föderation, in der etwas über 20 Mio. turksprachige (14\% der Gesamtbevölkerung RUs) ${ }^{21}$ und/oder 30 Mio. Muslime (21\% der Gesamtbevölkerung RUs) leben (O. V. 2018: Rusya'da Müslüman Nüfus Problemi). Wenn diese Minderheiten sich in den pantürkistisch und/oder islamistisch motivierten Gruppierungen organisieren, radikalisieren und gegen RU erheben würden, würden sie mit sehr großer Wahrscheinlichkeit auch Unterstützung von anderen muslimischen Ländern erhalten; aus dem angrenzenden muslimischen ZA, aus Afghanistan oder aus der TR und Saudi-Arabien usw. Im Falle eines solchen Ereignisses könnte die territoriale Integrität und Souveränität $R U s$ zerstört werden. In der Vergangenheit gab es einen pantürkisch-islamistischen Aufstand gegen RU, namens Basmatschi-Aufstands (1918-1924), dessen bekanntesten Leiter die türkischen Pantürkisten waren (siehe hierzu Kap. 3.1, Kap. 3.5 und Kap. 3.6).

RU betrachtet die TR als Teil der NATO, bzw. als verlängerten Arm der USA im Kaukasus und ZA als sicherheitspolitische Gefahr (Basaran 2013: 154; Kazgan 2003: 172-173). Nach dem russischen Politikwissenschaftler Nikolai Nartov (Erol 2012: 7) verfolgt die TR in ZA einerseits ihre Interessen mit Unterstützung der USA; andererseits versucht sie die Rahmenbedingungen für die US-Zentralasienpolitik zu schaffen. Außerdem warf RU der TR die Unterstützung des Islamismus, wie in Syrien, vor. Die TR vereint aus russischer Sicht also die beiden größten sicherheitspolitischen Gefahren in sich: NATO-Mitgliedschaft und Islamismus. Die Loslösung der TR vom „Westen“ wäre in diesem Zusammenhang ein großer sicherheitspolitischer Gewinn. Daher lud RU die Türkei im November 2011 ein, anstelle der EU der EAWU beizutreten. Eine ähnliche Einladung erhielt die TR vom

\footnotetext{
${ }^{21}$ Tataren, Baschkiren, Jakuten, Tschuwaschen, Tuwinen, Altaier, Nogaier usw. Tataren sind mit ca. 5,7 Mio. Menschen das größte Turkvolk der Russischen Föderation.
} 
zentralasiatischen EAWU-Mitglied Kasachstan im Oktober 2013 (Dügen 2013). Der ehemalige kasachische Präsident Nursultan Nasarbajew (1991-2019) erklärte, der türkische Präsident Recep Tayyip Erdogan (2014 - im Amt) habe Interesse für den EAWU-Beitritt der TR und fragte ihn nach der Aufnahmemöglichkeiten seines Landes in die EAWU (O. V. 2013: Erdogan Birlige Girmek ...). ${ }^{22}$ In der TR wird der EAWU-Beitritt bis heute als Alternative zu einem EU-Beitritt bzw. zum Westen dargestellt. 2017 erklärte der damalige Wirtschaftsminister der TR, Nihat Zeybekci (2013-2015 und 2016-2018), die TR wolle auch der EAWU-Zollunion beitreten und diskutiert dieses Ziel mit RU aus (O. V. 2017: Alternatif Avrasya Gümrük ...) (siehe hierzu Kap. 5.7). Allerdings werde ich in dieser Arbeit nachweisen, dass eine türkisch-russische strategische Partnerschaft unter heutigen Umständen nicht möglich ist.

\subsection{Stand der Forschung}

Wie in der Einleitung bereits erwähnt wurde, mangelt es an wissenschaftlichen Arbeiten über die türkisch-russische ZAP. Das Thema wird meistens nur im Rahmen der türkischen und russischen Außenpolitik oder der türkisch-russischen bilateralen Beziehungen sowie der Arbeiten über ihre ZA behandelt, und auch dort nur am Rande. Über die Frühgeschichte ZAs sind die Arbeiten von Svat Soucek, Marion Linska et al., Paul Jürgen und Jörg Stadelbauer von großer Bedeutung. Die Arbeiten von Haluk Gürsel, Baymirza Hayit, M. Nekrasov, Nimet Akdes Kurat, Halil Inalcik, Ilber Ortayli, Ibrahim Koncak, Ahat Andican, Ismet Bozdag, Zehra Önder usw. konzentrieren sich auf die türkisch-russischen Beziehungen bis zum Beginn des Kalten Krieges. Alle diese Experten bezeichnen die türkisch-russische ZAP im genannten Zeitraum als geopolitische Rivalität. Während des Kalten Krieges konnte die TR wegen der Blockkonfrontation mit der Sowjetunion keine Beziehungen $\mathrm{zu}$ den zentralasiatischen sowjetischen Staaten aufnehmen. Dies geschah erst durch die Unabhängigkeit der zentralasiatischen Staaten 1991. Daher wurden auch vergleichende Arbeiten über die türkisch-russische ZAP erst ab diesem Datum wieder möglich. ${ }^{23}$

\footnotetext{
22 Nasarbajew: "Türkiye Başbakanı Recep Tayyip Erdoğan beni aradı. Türkiye'nin Gümrük Birliği'ne alınmasının mümkün olup olmadığını sordu.” (O. V. 2013: Erdogan Birlige Girmek Istiyor).

${ }^{23} \mathrm{Im}$ Unterkapitel 1.2.1 und 1.2.2 werde ich die Literaturangaben vollständig machen, weil es sich in diesen Teilen explizit um die Literaturbewertung handelt.
} 


\subsubsection{Die geopolitische Position}

Im deutschsprachigen Raum fand das Thema dieser Arbeit bisher kaum Beachtung, obwohl Deutschland das letzte NATO-Land ist, das bis Ende 2015 über eine Militärbasis in ZA verfügte und in der Region weiterhin wirtschaftlich aktiv ist. Die deutschsprachige Literatur ist sich darüber einig, dass die TR und RU in ZA geopolitisch rivalisieren. Heinz Kramer (1996), ${ }^{24}$ Faruk Sen (2001: 70), ${ }^{25}$ Uwe Halbach o. J., ${ }^{26}$ Martin Malek (2002: 10), ${ }^{27}$ Efe Caman (2005: 378, 411), ${ }^{28}$ Udo Steinbach (2007: 81, 84-85), ${ }^{29}$ Rauf Dschafarow (2009: 95) ${ }^{30}$ und August Pradetto (2012: 124) ${ }^{31}$ nennen die ,energiepolitischen Interessen “ der TR und RU in ZA als Hauptgrund ihrer geopolitischen Rivalität um diese Region. Von diesen Experten erwähnen Sen (2001: 67), Dschafarow (2009: 95), Malek (2002: 10), Caman (2005: 378, 410) sowie Savas Genc (2006: 195-197) ${ }^{32}$, außerdem die „ZAWahrnehmungen“ beider Staaten und die „NATO-Aktivitäten“ in der Region als weitere Gründe für ihre Rivalität. Sergey Golunov (2004: 201) ${ }^{33}$ und Martin Malek (2003: 31-32) ${ }^{34}$ hingegen betonen eher die sicherheitspolitischen Interessen RUs als Rivalitätsgrund. Steinbach (2007: 79-85) hebt neben der energiepolitischen Rivalität auch die politische und

\footnotetext{
${ }^{24}$ Kramer, Heinz (1996): Will Central Asia become Turkey's sphere of influence. In: SAM, Center for Strategic Research, Perceptions, March-May 1996, http://sam.gov.tr/wp-content/uploads/2012/01/8.-WILLCENTRAL-ASIA-BECOME-TURKEYS-SPHERE-OF-INFLUENCE.pdf (Letzter Zugriff: 09.12.2013)

${ }^{25}$ Sen, Faruk (2001): Kaukasus und Mittelasien: neue gemeinsame Interessenssphären für die Länder der Europäischen Union und der Türkei. In: Sen, Faruk/ Hill, Bernhard (Hrsg.): Kaukasus, Mittelasien, Nahost Gemeinsame Interessen von EU und Türkei, München: Hans Seidel Stiftung. S. 64-72.

26 Halbach, Uwe (o. J.): Der Kaspische Raum - Zwischen „Great Game“ und „Seidenstraße“. http://www.blz.bayern.de/blz/web/old 100111/halbach.htm (Letzter Zugriff: 20.04.2014)

27 Malek, Martin (2002): Aktuelle Aspekte der Außenpolitik Russlands. In: Bundesheer, Oktober 2002, http://www.bmlv.gv.at/wissen-forschung/publikationen/beitrag.php?id=1396 (Letzter Zugriff: 07.09.2013)

${ }^{28}$ Caman, M. Efe (2005): Türkische Außenpolitik nach dem Ende des Ost-West-Konflikts. Außenpolitische Kontinuität und Neuorientierungen zwischen der EU-Integration und neuer Regionalpolitik, Diss., Universität Augsburg. Vorgelegt in 2004, Datum der Freischaltung in OPUS: 22.07.2005, https://opus.bibliothek.uniaugsburg.de/opus4/frontdoor/deliver/index/docId/72/file/Dissertation_Efe_CAMAN.pdf_(Letzter Zugriff: 06.06.2011)

${ }^{29}$ Steinbach, Udo (2007 [2000]): Geschichte der Türkei. München: C.H. Beck. 4., durchgesehene und aktualisierte Auflage.

${ }^{30}$ Dschafarow, Rauf (2009): Die Politik der Groß- und Regionalmächte im Südkaukasus und in Zentralasien. Frankfurt am Main: Lang.

${ }^{31}$ Pradetto, August (2012): Zentralasien und die Weltmächte, oder Great Game Boys auf Reisen. Frankfurt am Main: Lang.

${ }^{32}$ Genc, Savas (2006): Das neue „Great Game“ in Zentralasien um das Erdöl. Eine Region im Fadenkreuz der internationalen Interessen, Diss., Ruprecht-Karl-Universität, Heidelberg.

${ }^{33}$ Golunov, Sergey (2004): The Role of Russia in Central Asia: Realities and Stereotypes. In: Seidelmann, Reimund/ Giese, Ernst (Hrsg.): Cooperation and Conflict Management in Central Asia. Frankfurt am Main, Berlin, Bern: Peter Lang (Studien zur Internationalen Entwicklungs- und Unweltforschung, hrsg. vom Zentrum für internationale Entwicklungs- und Unweltforschung der Justus-Liebig-Universität Gießen, Band 10), S. 189-201.

${ }^{34}$ Malek, Martin (2003): Die NATO und Russland zwischen Kooperation und Konfrontation. Studien und Berichte zur Sicherheitspolitik 3/2003, in: Bundesheer,. Juli 2003, http://www.bmlv.gv.at/wissenforschung/publikationen/beitrag.php?id=44 (Letzter Zugriff: 19.04.2014)
} 
sicherheitspolitische Rivalität zwischen den beiden Staaten hervor. Nach Halbach o. J., Pradetto (2012: 122) und Genc (2006: 197) entscheiden die zentralasiatischen Staaten selbst darüber, mit welchem Staat sie kooperieren wollen. Die Autoren betonen also auch die Akteursebene als bestimmenden Faktor in der türkisch-russischen ZAP. Nach Kramer (1996), Caman (2005: 410-412) und Mischa Gabowitsch (2005) ${ }^{35}$ sind die Versuche kultureller Einflussnahme beider Staaten in ZA ein weiterer Grund für ihre geopolitische Rivalität in ZA.

In der englischsprachigen Literatur herrscht eine ähnliche Meinung vor wie in der deutschsprachigen. Graham Fuller (1992: 59-60) ${ }^{36}$ vertritt die These, dass der Grund der türkisch-russischen Rivalität in ZA ihre Einflussnahmeversuche in der Region ist. Auch Gareth M. Winrow (1996: 128-129) ${ }^{37}$ vertritt die gleiche These wie Fuller. Winrow (ebd.) zufolge wirkt die geographische Entfernung zwischen der TR und den zentralasiatischen Staaten auf die türkische ZAP negativ aus. In einer anderen Studie vertritt Fuller (1993: $76)^{38}$ die These, dass der türkische Pantürkismus und Fundamentalismus in ZA den russischen sicherheitspolitischen Interessen entgegensteht und die beiden Staaten deshalb rivalisieren. Ryskeldi Satke, Casey Michel und Sertaç Korkmaz (2014) ${ }^{39}$ unterstreichen die negative Wahrnehmung der TR und RU voneinander als Grund ihrer Rivalität.

Nach Philip Robins (1993: 609-610) ${ }^{40}$ konnte die TR wegen ihrer mangelnden Kapazitäten keine Erfolge in ZA erzielen. Daher bevorzugen die zentralasiatischen Staaten eher die Beziehungen mit RU (ebd.). Patricia M. Carley (1995: 192) ${ }^{41}$ vertritt die These, dass die

\footnotetext{
${ }^{35}$ Gabowitsch, Mischa (2005): „Türkei und Russland- eurasische Rivalen“. In: Le Monde diplomatique, Dezember, http://www.monde-diplomatique.de/pm/.dossier/tuerkei artikel.id,20051209a0008 (Letzter Zugriff: 12.09.2012)

${ }^{36}$ Fuller, Graham E. (1992): Turkey faces East: new orientations toward the Middle East and the old Soviet Union. Santa Monica: RAND, (R-4232-AF/A).

${ }^{37}$ Winrow, Gareth M. (1996): Turkey`s relations with the Transcaucasus and the Central Asian Republics. In: SAM, Center for Strategic Research, Perceptions, March May 1996, http://sam.gov.tr/wpcontent/uploads/2012/01/11.-TURKEYS-RELATIONS-WITH-THE-TRANSCAUCASUS.pdf ） (Letzter Zugriff: 21.02.2012)

${ }^{38}$ Fuller, Graham E. (1993): Turkey’s New Eastern Orientation. In: Fuller, Graham E./Lesser, Ian O./Henze, Paul u. a. (1993): Turkey's new geopolitics: from the Balkans to Western China. Boulder; San Francisco; Oxford: Westview Press, S. 37-97.

${ }^{39}$ Satke, Ryskeldi/Michel, Casey/Korkmaz, Sertaç (2014): Turkey in Central Asia: Turkic Togetherness? In: The Diplomat, 28 November 2014, http://thediplomat.com/2014/11/turkey-in-central-asia-turkic-togetherness/ (Letzter Zugriff: 21.12.2014)

${ }^{40}$ Robins, Philip (1993): Between sentiment and self-interest: Turkey`s policy toward Azerbaijan and the Central Asian States. In: Middle East Journal, vol. 47, No: 4, S. 593-610.

${ }^{41}$ Carley, Patricia M. (1995): Turkey and Central Asia. Reality Comes Calling, In: In: Rubinstein, Alvin Z./Smolansky, Oles M. (Hrsg.): Regional Power Rivalries in the New Eurasia. Russia, Turkey, and Iran, Armonk, New York, London: M. E. Sharpe, S. 169-197.
} 
prorussischen zentralasiatischen Entscheidungsträger die Garantie für den russischen Einfluss und Erfolg in ZA sind. In einer späteren Arbeit betont Graham Fuller $(2008)^{42}$ die pro-russischen Wahrnehmungen der zentralistischen Entscheidungsträger bei ihren außenpolitischen Entscheidungen. Nach Svante E. Cornell (1999) ${ }^{43}$ ist das wirtschaftliche Interesse der TR an RU viel größer als ihr Interesse am gesamten ZA, weshalb sie sich eher auf ihre Beziehungen zu RU konzentriert. George S. Harris (1995: 22-23) ${ }^{44}$ zufolge rivalisieren beide Staaten auf sicherheitspolitischer, energiepolitischer und kulturpolitischer Ebene. Dimitri Trenin $(1997)^{45}$ zufolge mangelt es der TR und RU an Ressourcen für die Herrschaft in ZA, weshalb für sie eher die EU eine gewisse Anziehungskraft besitzt.

Türkische und russische Wissenschaftler*innen legen auf das Thema dieser Arbeit mehr Wert. Die russische Wissenschaftlerin Natalya Ulcenko $(2003)^{46}$ sieht den Grund der Rivalität zwischen der TR und RU im energiepolitischen Bereich; eine besondere Rolle spiele dabei das turkmenische Erdgas. In einem anderen Aufsatz von 2003 (hier wird die englische Schreibweise ihres Namens, Natalia Oultchenko, verwendet) ${ }^{47}$ schreibt die Autorin, dass die Energieabhängigkeit der TR von RU als Garant ihrer politischen Loyalität zu RU angesehen werden kann. Auch Saban Kardas (2009) $)^{48}$ betont die Energieabhängigkeit der TR von RU. Laut Kardas (ebd.) begrenzt die asymmetrische Abhängigkeit der TR von RU ihre Entscheidungsfähigkeit, was etwa im Georgien Krieg 2008 offenbar wurde (siehe hierzu Kap. 6.9).

\footnotetext{
${ }^{42}$ Fuller, Graham E. (2008): Yeni Türkiye Cumhuriyeti. Istanbul: Timas.

${ }^{43}$ Cornell, Svante E. (1999): Geopolitics and Strategic Alignments in the Caucasus and Central Asia. In: Perceptions, June - August 1999 Volume IV - Number 2, http://sam.gov.tr/wpcontent/uploads/2012/01/SVANTE-E.-CORNELL.pdf (Letzter Zugriff: 03.10.2012)

${ }^{44}$ Harris, George (1995): The Russian Federation and Turkey. S. 3-25. In: Rubinstein, Alvin Z./Smolansky, Oles M. (Hrsg.): Regional Power Rivalries in the New Eurasia. Russia, Turkey, and Iran, Armonk, New York, London: M. E. Sharpe.

${ }^{45}$ Trenin, Dmitri (1997): Russia and Turkey: A Cure for Schizophrenia. In: SAM, Center for Strategic Research, Perceptions, June-August 1997, http://sam.gov.tr/tr/wp-content/uploads/2012/01/DMITRI-TRENIN.pdf (Letzter Zugriff: 25.06.2012).

${ }^{46}$ Ulcenko, Natalya Y. (2003): Rusya ve Türkiye`nin Stratejik Güvenliginin Saglanmasinda Enerji Hammaddeleri Ihracaat ve Ithalatinin Rolü. In: Ulcenko, Natalya Y./Kazgan, Gülten (Hrsg.): Dünden Bugüne Türkiye Rusya: Politik, Ekonomik ve Kültürel Iliskiler. Kasim 2003, Istanbul: Istanbul Bilgi Üniversitesi Yayinlari 45, S. 183-197.

${ }^{47}$ Oultchenko, Natalia (2003): Turkey's Strategic Future: A Russian View. Mai 2003, Center for European Policy Studies (CEPS), International Institute for Strategic Studies (IISS), http://www.isn.ethz.ch/DigitalLibrary/Publications/Detail/?ots591=0c54e3b3-1e9c-be1e-2c24-a6a8c7060233\&lng=en\&id=22401 (Letzter Zugriff: 13.12.2014)

${ }^{48}$ Kardas, Saban (2009): Turkey and Russia Developing a New Economic and Strategic Partnership. In: Eurasia Daily Monitor Volume: 6 Issue: 31, February 17, $2009 \quad 02: 49 \quad$ PM, http://www.jamestown.org/single/?no_cache=1\&tx_ttnews[tt_news]=34515 (Letzter Zugriff: 23.08.2013)
} 
Hakan Kantarci (2006: 175) ${ }^{49}$ zufolge besteht in ZA zwischen der TR und RU neben der energiepolitischen Rivalität auch eine politische und kulturelle Rivalität. Mit USUnterstützung kann die TR laut Kantarci (ebd.) eine erfolgreiche ZAP betreiben. Die türkische Wissenschaftlerin Gülten Kazgan (2003: 172-177) $)^{50}$ sieht auch die energiepolitische Rivalität als Grund der russisch-türkischen Rivalität um das Kaspische Meer an. Als weiteren wichtigen Grund nennt sie die negative TR-Wahrnehmung RUs. Nach Kazgan (ebd.) betrachtet RU die TR als verlängerten Arm der USA im kaspischen Raum. Nach Efe Caman und Kenan Dagci (2013) ${ }^{51}$ sieht RU die TR wegen ihrer „Türkrepublikenpolitik“ (ebd.: 66) und die USA/NATO als Gefahr für seine territoriale Integrität an (ebd.: 70). Um seinen Einfluss und Vorteile in seinem „Nahen Ausland“ nicht zu verlieren, versuche RU, diese postsowjetischen Regionen in eine Zollunion zu integrieren (ebd.: 66). Ilyas Kamalov (2011: 66) ${ }^{52}$ betont in seiner Arbeit die Entscheidungen der zentralasiatischen Staaten als entscheidender Faktor für den Erfolg der türkischen und russischen ZAP. Kamalov zufolge bevorzugen die zentralasiatischen Staaten eher die Zusammenarbeit mit RU. Er prognostiziert, dass ZA weiterhin russisches Hegemoniegebiet, bzw. RUs „Nahes Ausland“ bleiben wird - mit anderen Worten: ein Gebiet der Rivalität zwischen der TR und RU.

\subsubsection{Die strategische Position}

Die Bezeichnung „Strategische Partnerschaft“ für die türkisch-russischen Beziehungen entstand nach dem Kalten Krieg und wird meistens von eurasistischen Wissenschaftler*innen benutzt. Der aktuell bekannteste russische (Neo-)Eurasist ist Aleksandr Dugin (siehe hierzu Kap. 1, Einleitung). Nach Dugin ist eine türkisch-russische strategische Partnerschaft in Kaukasus und ZA nur möglich, wenn die TR diese postsowjetischen Gebiete weiterhin als russische Einflussgebiete, bzw. sein „Nahes Ausland“ ansehen und hier die russische Herrschaft akzeptieren würde (Dugin 2007: 95-96).

\footnotetext{
${ }^{49}$ Kantarci, Hakan (2006): Kiskactaki Bölge Kafkasya. Istanbul: IQ Kültür Sanat Yayincilik.

${ }^{50}$ Kazgan, Gülten (2003): Bati ile iliskilerin Gölgesinde Türkiye-Rusya Iliskileri. In: Ulcenko, Natalya Y. I Kazgan, Gülten (Hrsg.): Dünden Bugüne Türkiye Rusya: Politik, Ekonomik ve Kültürel Iliskiler. Kasim 2003, Istanbul: Istanbul Bilgi Üniversitesi Yayinlari 45, S. 145-181

${ }^{51}$ Caman, Efe/Dagci, Kenan (2013): Rusya Federasyonu'nun Sovyet Ardili Bölgeleri Algilayişi: Avrasyacilik Stratejisi Ve Rus Diş Politikasi. In: Turan, Yıldırım / Yalçinkaya, Alâeddin / Efegil, Ertan (Hrsg.): Siyaset, Ekonomi Ve Toplum Üzerine 3. Uluslararasi Mavi Karadeniz Kongresi: Uyuşmazlik Çözümü, İşbirliği Ve Demokratikleşme, Gündoğan Yayınları: Istanbul, S. 63-73.

52 Kamalov, Ilyas (2011): Rusya'nın Orta Asya Politikaları. Rapor, Yayin No: 2, Ankara: Hoca Ahmet Yesevi Uluslararası Türk-Kazak Üniversitesi.
} 
Als Gegenleistung würde RU die TR wirtschaftlich, strategisch und sicherheitspolitisch unterstützen (ebd.). D. h., Dugin sieht eine türkisch-russische Zusammenarbeit auf der gleichen Augenhöhe in ZA nicht vor.

Der Eurasismus beeinflusst die russische Innen- und Außenpolitik seit der russischen Rückkehr (siehe hierzu Kap. 4.2.1 und Kap. 5.6) zu seinem „Nahen Ausland“, also seit etwa 1993 und machte sich in der Primakow-Ära (1996-1999) in der russischen Außenpolitik sichtbarer. In dieser Ära konzentrierte sich das Land neben dem Westen auch auf den Süden: auf die TR, den Iran, sowie China. In RU gelten u. a. die Zeitung „Zavtra“ und die Zeitschrift „Elementi“, Dugin`s Eurasienpartei, die renommierten Journalisten Alexander Prochanow, Anatolii Glivakovski, der Journalist und Politiker Shamil Sultanow, der Historiker und Politiker Alexander Fomenko, der Parteivorsitzende der Kommunistischen Partei der Russischen Föderation Gennady Zuganov als eurasistisch.

In der TR hingegen ist der Eurasismus eine neue Ideologie und ist erst nach dem Kalten Krieg entstanden (siehe hierzu Kap. 1, Einleitung). 2003 gründete Dugin die „Internationale Eurasien Bewegung“, in dessen Vorstand u. a. auch der türkische Politiker und Parteivorsitzende der „Vatan Partisi“ (Vaterlandspartei), Dogu Perincek, gewählt wurde. 2004 wurde in der TR die RUTAM (türkisch: Rus-Türk Arastirmalari Merkezi, RussischTürkisches Forschungszentrum) gegründet. Die bekanntesten türkischen Eurasisten sind neben Dogu Perincek u. a. der Wissenschaftler Anil Cecen, der Politikwissenschaftler Erel Tellal, der pensionierte Generalstabschef Tuncer Kilinc, der pensionierte Oberst Tahir Tamer Kumkale und der pensionierte Generalkonsul und ehemalige Abgeordnete Onur Öymen. In der TR vertreten die Vereine „Ahmed Yesevi Vakfi“ und „ASAM“ (türkisch: Avrasya Stratejik Arastirmalar Merkezi, Zentrum für Strategische Studien für Eurasien), die „Dialog Avrasya Platformu“ (Dialog-Plattform für Eurasien) sowie die Zeitschriften „Aydinlik“ und „Yarin“ eurasistische Ideen. Sie fordern eine „strategische Partnerschaft“ zwischen der TR und RU und sind anti-westlich eingestellt.

Offiziell wurde die Bezeichnung „Strategische Partnerschaft“ erstmals vom ehemaligen russischen Ministerpräsidenten Wiktor Tschernomyrdin 1997 bei seiner Türkei-Reise benutzt. Tschernomyrdin sprach von der bevorstehenden „strategischen Partnerschaft“ zwischen den beiden Staaten im Falle einer erfolgreichen wirtschaftlichen Zusammenarbeit. 
Nach Aleksey Bogaturov (2010) ${ }^{53}$ sieht RU die TR als „strategischen Partner“ und beabsichtigt, die wirtschaftlichen und politischen Beziehungen mit der TR um eine sicherheitspolitische und kulturelle Dimension zu erweitern. Als Beginn der Strategischen Partnerschaft werden drei unterschiedliche Daten angesehen: das Datum der Unterzeichnung des Aktionsplans von 2001, die Regierungszeiten Erdogans (ab 2002) und Putins (ab 1999) oder die Gründung des „Hohen Kooperationsrats“ (türkisch: Üst Düzey İşbirliği Konseyi (ÜDİK)) im Jahre 2010.

Der habilitierte Politikwissenschaftler, ehemalige Chefberater Erdogans (2002-2009), Außenminister (2009-2014) und Premierminister (2014-2016) der Türkei, Ahmet Davutoglu, erörterte 2001 in seiner Monographie „Stratejik Derinlik“ (,Strategische Tiefe“ $)^{54}$ die Möglichkeit einer vertieften Zusammenarbeit zwischen der TR und RU. Nach Davutoglu (2011: 497-498) benötigt die TR für eine erfolgreiche ZAP, d. h. für die politische Einflussnahme und die Ausbeutung der kaspischen Energieressourcen, eine Landverbindung zu der Region: Diese ist entweder durch den Iran oder durch RU möglich. Davutoglu prognostiziert, dass infolge der EU-Osterweiterung die TR und RU näher zusammenrücken werden, da beide Staaten von der EU diskriminiert würden (ebd.: 240). Laut Erhan Büyükakinci (2012: 814-815) ${ }^{55}$ verfolgt die TR seit 2000 - und besonders seit 2002, als die AKP (AK Parti oder Adalet ve Kalkinma Partisi, Partei für die Gerechtigkeit und Entwicklung) an die Macht kam - das von Davutoglu entwickelte Konzept „Gevşek Avrasyacıl1k“ (,lockerer Eurasismus“) und weicht somit von ihrer westlich geprägten Außenpolitik seit dem 2. Weltkrieg ab. Büyükakinci betont in seiner Analyse die Akteursebene und erklärt das Außenpolitikverhalten und die „Transformation der türkischrussischen Beziehungen“ mit der Machtübernahme Erdogans und Putins. Nach ihm (ebd.: 784) entwickelten sich die türkisch-russischen Beziehungen seit deren Regierungsantritt in eine „multidimensionale Partnerschaft“. Auch Bülent Aras (2009a: 1) ${ }^{56}$ ist der Ansicht, dass

\footnotetext{
${ }^{53}$ Bogaturov, Aleksey (2010): Türkiye, Rusya'nın yeni stratejik ortağ 1 [Die Türkei ist Russlands neuer strategischer Partner]. In: Zaman, 10 May1s 2010, Pazartesi 11:55, http://www.zaman.com.tr/dunya turkiyerusyanin-yeni-stratejik-ortagi 982396.html (Letzter Zugriff: 15.02.2014)

${ }^{54}$ Ich benutze in dieser Arbeit die 61. Auflage Davutoglu, Ahmet (2011 [2001]): Stratejik Derinlik. Türkiye'nin Uluslararasi Konumu [Strategische Tiefe. Die Internationale Lage der Türkei], 61. Aufl., Istanbul: Küre Yayinlari.

${ }^{55}$ Büyükakinci, Erhan (2012): Türk-Rus İlişkilerinin Değerlendirilmesi: Güvenlik Sorunsalından Çok Boyutlu Derinliğe Geçiş [Bewertung der türkisch-russischen Beziehungen: Übergang von Sicherheitsproblemen in mehrdimensionale Tiefe]. In: http://www.erhanbuyukakinci.com/dosya/Turk-Rus-iliskilerininDegerlendirilmesi.pdf (Letzter Zugriff: 17.07.2015)

${ }^{56}$ Aras, Bülent (2009a) Turkey And The Russian Federation: An Emerging Multidimensional Partnership. August 2009, Brief No: 35, In: SETA, Policy Brief, letzter Zugriff: 1. April 2010, http://arsiv.setav.org/Ups/dosya/7776.pdf (Letzter Zugriff: 01.08.2010)
} 
sich die türkisch-russischen Beziehungen seit dem Ende der 1990er-Jahre in eine „,multidimensionale Partnerschaft" transformiert haben, auch wenn weiterhin Konflikte zwischen den beiden Staaten bestehen, beispielsweise in ZA. Sie könnten ihre Beziehungen jedoch in Zukunft weiter vertiefen, wenn sie ,gemeinsame Interessen“ entwickeln (ebd.).

Für Mehmet Seyfettin Erol (2013: 50-51) ${ }^{57}$ ist die Unterzeichnung des Aktionsplans der Beginn der türkisch-russischen Annäherung. Erol zufolge (ebd.) versuchen die beiden Staaten seitdem, ihre Beziehungen in eine „mehrdimensionale Zusammenarbeit“ zu transformieren. Sie könnten nach Erol (ebd.: 54-55) erfolgreich zusammenarbeiten, wenn sie sich in einer gemeinsamen Organisation, die mit einer Ideologie wie etwa dem Eurasismus verbunden ist, zusammenfänden. Aufgrund der türkisch-russischen Rivalität jedoch, wie z. B. in ZA, bezeichnet Erol ihre Beziehungen als „Mischung aus Kooperation und Wettbewerb“ (ebd.: 51). Oleg Kolobov, Aleksandr A. Kornilov und Fatih Özbay (2006: $322,325)^{58}$ sehen den Aktionsplan von 2001 als ersten Schritt zu der Vertiefung der türkischrussischen wirtschaftlichen Partnerschaft an. Laut den Autoren (ebd.: 283, 327) erreichten ihre Beziehungen wegen der türkischen NATO-Mitgliedschaft und ihres EUBeitrittsprozesses allerdings nicht das Niveau einer strategischen Partnerschaft. Die Bedingung für eine strategische Partnerschaft sehen sie dementsprechend in der strategischen Zusammenarbeit in Eurasien. In einem späteren Artikel schreibt Fatih Özbay (2011: 35), ${ }^{59}$ die bilateralen türkisch-russischen Beziehungen hätten im Handel und im energiepolitischen Bereich schon eine „strategische Dimension“ ${ }^{“ 60}$ erreicht. Weil es aber in ZA weiterhin Konflikte zwischen den beiden Staaten gibt, bezeichnet er wie Erol (2013) die

\footnotetext{
${ }^{57}$ Erol, Mehmet Seyfettin (2013): Yeni Büyük Oyun'da "bati'nin iki ötekisi” olarak Türkiye ve Rusya'nin Avrasya'da İşbirliği arayişlari. In: Turan, Yıldırım / Yalçinkaya, Alaeddin / Efegil, Ertan (Hrsg.): Siyaset, Ekonomi Ve Toplum Üzerine 3. Uluslararasi Mavi Karadeniz Kongresi: Uyuşmazlik Çözümü, İşbirliği Ve Demokratikleşme, Gündoğan Yayınları: Istanbul, S. 49-62.

${ }^{58}$ Kolobov, Oleg A./Kornilov, Aleksandr A./Özbay, Fatih (2006): Cagdas Türk-Rus Iliskileri. Sorunlar ve Isbirligi Alanlari (1992-2005), Istanbul: Tasam Yayinlari (Uluslararasi Iliskiler Serisi: 10).

${ }^{59}$ Özbay, Fatih (2011): Soguk Savas Sonrasi Türkiye-Rusya Iliskileri: 1992-2010. In: Bilge Strateji, Cilt 2, Say1 4, Bahar 2011, S. 35-77.

${ }^{60}$ Von den Wissenschaftlern, die die strategische Position vertreten, werden die türkisch-russischen energiepolitischen Beziehungen und der Handel meistens als Beweis für ihre strategische Partnerschaft angeführt. Die TR importierte 2015 etwa 60 \% ihres Erdgases und 23 \% ihres Erdöls aus RU (O. V. 2016: 2015 Ekim Döneminde Petrol ve Doğalgaz İthal ...). Dieser Anteil ist bis heute ähnlich hoch geblieben. Die russischen Exporte in die TR beliefen sich 2017 auf 19,5 Milliarden US-Dollar, das entspricht 8,3\% der türkischen Gesamtimporte. 58,7 \% davon machten die fossilen Brennstoffe sowie deren Erzeugnisse aus (Trade Map 2018: Bilateral trade between Turkey and Russian Federation: Imports ...). Im selben Jahr exportierte die TR Waren im Wert von 2,7 Milliarden US-Dollar nach RU, 1,74 \% ihrer gesamten Exporte (Trade Map 2018: Bilateral trade between Turkey and Russian Federation: Exports ...). Wie aus diesen Zahlen zu ersehen ist, fällt das Handelsdefizit zu Ungunsten der TR aus. Die energiepolitische Abhängigkeit der TR von RU wird mit der Inbetriebnahme der TurkStream Ende 2019 noch größer. Die energiepolitische Beziehung beider Staaten ist weniger eine strategische Partnerschaft, sondern kann eher als energiepolitische Abhängigkeit bezeichnet werden.
} 
türkisch-russischen Beziehungen als „Kooperation und Wettbewerb“ (ebd.: 70-71, 35). Nach Erel Tellal (2012) ${ }^{61}$ sind die TR und RU in der Lage, den 2001 unterzeichneten „Aktionsplan zur Zusammenarbeit ...“ ins Leben zu rufen. Er sieht in der Zusammenarbeit einen Vorteil für beide Staaten. Auch L. Matunina (2008: 93) ${ }^{62}$ hält den Aktionsplan von 2001 für realisierbar, auch in ZA.

Sina Kisacik (2014) $)^{63}$ und Ilyas Kamalov $(2010)^{64}$ halten nicht den Aktionsplan von 2001, sondern die Gründung des „Hohen Kooperationsrats“ von 2010 durch die TR und RU für den Anfang der „Strategischen Partnerschaft“. Nach Kisacik (ebd.) müssen beide Staaten noch eine gemeinsame politische Agenda sowie gemeinsame Interessen entwickeln, um eine strategische Partnerschaft zu erreichen. Ilyas Kamalov (ebd.: 15) bezeichnet die türkischrussischen Beziehungen als „multi-dimensionelle strategische Zusammenarbeit“. Laut Kamalov (ebd.) werden die beiden Länder ihre Beziehungen nach dem Medwedew-Besuch im Mai 2010 schrittweise in den Zustand einer strategischen Partnerschaft entwickeln, auch wenn sie um die zentralasiatischen Energiereserven rivalisieren. Wie im Teil 1.2.1 erwähnt wurde, erwartet Kamalov (2011: 66) in ZA allerdings keine türkisch-russische strategische Partnerschaft. Ilter Turan (2008: 104) ${ }^{65}$ hingegen ist der Meinung, dass die TR wegen ZA nicht mit RU rivalisieren werde, weil ihr die wirtschaftliche Zusammenarbeit mit RU wesentlich wichtiger sei als die Zusammenarbeit mit allen zentralasiatischen Staaten zusammen. Andererseits hat die Region für die TR keine strategische Priorität wie für RU, schreibt Turan (ebd.: 99, 101). Eine Zusammenarbeit beider Staaten in ZA hält er für möglich (ebd.: 105).

\footnotetext{
${ }^{61}$ Tellal, Erel (2012): Rusya ve Türkiye'nin Avrasya'daki işbirliği,ilişkilerin önünü açacaktır [Die türkischrussische Zusammenarbeit in Eurasien wird den Weg für ihre bilateralen Beziehungen öffnen]. In: The Voice of Russia, 27 Aralik 2012, 11:54, http://tr.sputniknews.com/turkish.ruvr.ru/2012_12_27/Rusya-TurkiyeAvrasya/ (Letzter Zugriff:31.12.2012)

${ }^{62}$ Matunina, L. (2008): Rus Dis Politikasinda Türkiye'nin Önemi. In: Kazgan, Gülten (Hrsg.): Türkiye-Rusya Iliskilerinde Ihtilafli Konular ve Cözümleri. Istanbul: Istanbul Bilgi Üniversitesi Yayinlari 213 (SempozyumPanel 2), S. 79-93.

${ }^{63}$ Kisacik, Sina (2012): Rusya'nin Enerji Politikalari Bağlaminda Orta Asya Ülkeleriyle İlişkileri [Russlands Beziehungen zu zentralasiatischen Ländern im Kontext der Energiepolitik]. In: Uluslararasi Politika Akademisi, 23 Aralik 2012, http://politikaakademisi.org/2012/12/23/rusyanin-enerji-politikalari-baglamindaorta-asya-ulkeleriyle-iliskileri/ (Letzter Zugriff: 05.12.2014)

${ }^{64}$ Kamalov, Ilyas (2010): Komsuluktan Stratejik Isbirligine: Türk-Rus Iliskileri [Von der Nachbarschaft zur strategischen Zusammenarbeit: Türkisch-russische Beziehungen]. In: ORSAM, Rapor No: 18, The Black Sea $\begin{array}{lllll}\text { International } & \text { Rapor } & \text { No: } & 3, & \text { Mays }\end{array}$ http://www.orsam.org.tr/tr/trUploads/Yazilar/Dosyalar/201258 3raportum.pdf (Letzter Zugriff: 03.05.2010) ${ }^{65}$ Turan, Ilter (2008): Türkiye'nin Dis Politikasinda Orta Asya Ülkelerinin Rolü ve Önemi. In: Kazgan, Gülten (Hrsg.): Türkiye-Rusya Iliskilerinde Ihtilafli Konular ve Cözümleri. Istanbul: Istanbul Bilgi Üniversitesi Yayinlari 213, (Sempozyum-Panel 2), S. 95-107.
} 


\subsubsection{Literaturkritik}

Die vorhandene Literatur über die „Türkisch-Russische Zentralasienpolitik“ ist lückenhaft, wie schon in der Einleitung erwähnt wurde. Lückenhaft einerseits, weil es an den vergleichenden, das Thema in all seinen Bereichen in Zusammenhängen erklärenden Langzeitstudien mangelt. Andererseits ist die Literatur durch die politisierte, distanzlose unkritische Haltung der Wissenschaftler*innen belastet. Dieses Problem hängt vermutlich zum Teil mit der mangelnden wissenschaftlichen Unabhängigkeit der Wissenschaftler*innen in den defekten Demokratien, bzw. autoritären Staaten, wie z. B. in der TR und RU, zusammen. Allerdings lässt sich selbst in Deutschland und in den USA ein ähnliches Problem in der Literatur über das Thema finden, obwohl diese Länder im Vergleich über bessere demokratische Strukturen verfügen. In diesem Teil werde ich mit Hilfe einiger Beispiele auf die genannten Probleme der Literatur näher eingehen.

\section{ZA als selbstverständliches Hegemonialgebiet der Türkei und Russlands}

Die TR hat eine pantürkistische Zentralasienwahrnehmung und sieht ZA als Teil „ihrer selbstverständlichen Türkenwelt“ (siehe Kap. 4.1), d. h. als „,ihr natürliches Einflussgebiet“ an. RU hat eine ähnliche, aber der türkischen Sichtweise entgegengesetzte Haltung und betrachtet die Region als „sein Nahes Ausland“ (siehe Kap. 4.2), d. h. ebenfalls als „sein natürliches Einflussgebiet“" (siehe Kap. 4.2). Diese politische ZA-Wahrnehmung spiegelt sich nicht nur in ihren außenpolitischen Erklärungen und -Handeln in ZA wider. Sie wird auch in den wissenschaftlichen Arbeiten über das Thema geteilt und gerechtfertigt. Wenn z. B. der/die (türkische) Forscher*in seiner/ihrer Arbeit zentralasiatische Turkstaaten als „Türken“ und ihre Turksprachen als „Türkisch“ definiert und von einer „Türkenwelt“ bzw. „Türkistan“ (Land der Türken) spricht, kann davon ausgegangen werden, dass er/sie die Region als selbstverständliches Hegemonialgebiet der TR betrachtet. Dasselbe gilt auch für RU. Die hegemoniale ZAP RUs wird von vielen russischen Wissenschaftler*innen als selbstverständlich dargestellt und meistens mit russischen sicherheitspolitischen Interessen und gemeinsamer Geschichte mit der Region gerechtfertigt. Aufgrund dieser Sichtweise und Überzeugung sind solche Arbeiten politisiert und unsachlich.

Mit „Nahes Ausland“ meint RU nicht die geographisch angrenzenden Staaten wie Finnland; sondern politisch, die ehemaligen sowjetischen Republiken, wie das nicht an RU 
angrenzende Kirgisistan (Alexandrova 1995) (siehe hierzu Kap. 4.2.1). Dieser Begriff wurde das erste Mal in der Sicherheitsdoktrin von 1993 verwendet (Kolobov/Kornilov/Özbay 2006: 134). Damit meint RU den GUS-Raum („Gemeinschaft der unabhängigen Staaten“ (GUS)), den das Land in all seinen nationalen Dokumenten als Prioritätsgebiet bezeichnet (näheres in Kap. 4.2.1). Im „Außenpolitikkonzept von 2000“ stellte RU den GUS-Raum als Pufferzone bzw „Sicherheitsgürtel“ (President of the Russian Federation 2000: 9) gegen die USA/NATO und den Islamismus usw. dar und unterstrich seine sicherheitspolitische Relevanz für RU (ebd.: 2, 8). In den Anfangsjahren der Sowjetunion begründete Sowjet-RU seinen Imperialismus in seinen „Randgebieten“ bzw. im heutigen „Nahen Ausland, bzw. GUS-Raum“, im Rahmen des Kampfes gegen den westlichen Imperialismus (siehe hierzu Kap. 3.6). Heute wird auf ähnlicher Weise versucht, das russische Verhalten in seinem Nahen Ausland zu rechtfertigen. Die staatsnahe Haltung war in der Krim- (siehe hierzu Kap. 6.7) und Süd-Ossetien- sowie der Abchasienfrage (siehe hierzu Kap. 4.2.2) deutlich zu sehen. Die Trennung der Krim von der Ukraine, Süd-Ossetien und Abchasien von Georgien wurde von RU militärisch, politisch und wirtschaftlich unterstützt. Sein Vorgehen begründete RU mit dem völkerrechtlichen Selbstbestimmungsprinzip. Die Unabhängigkeitsbestrebungen Tschetscheniens und Tatarstans ${ }^{66}$ von der Russischen Föderation bzw. von RU hingegen wird mit allen Mitteln verhindert. Für diese Völker gilt laut RU kein Völkerrecht. Diese Sichtweise prägt auch die russischen Wissenschaftler*innen.

In der TR dominiert eine ähnliche ,politisierte“ Haltung die Wissenschaft über das Thema. Die TR bekämpft z. B. mit allen Mitteln die kurdischen Unabhängigkeitsbestrebungen nicht nur in der TR, sondern in den Staaten mit kurdischen Minderheiten in Syrien, dem Iran und dem Irak. Gleichzeitig unterstützt(e) sie die Tschetschenen und Uighuren bei ihrer Unabhängigkeit. Die pantürkistisch geprägte Sichtweise der TR ist sowohl in der Literatur als auch auf den offiziellen Internetseiten der TR, wie der Homepage des

\footnotetext{
${ }^{66}$ Die Tataren und Tschetschenen stimmten und kämpften nach der Auflösung der Sowjetunion auch für die Unabhängigkeit. 1992 stimmten 61,4\% der tatarischen Bürger für die Autonomie. Der im Februar 1994 unterzeichnete Vertrag zwischen der Russischen Föderation und den Organen der Staatsmacht der Republik Tatarstan, garantierte der Republik Tatarstan zwar die Souveränität; schloss allerdings die Unabhängigkeit aus. Dieses Ereignis wurde von der Kurultay, der Hauptversammlung des Nationalparlaments aller Tataren, als „Tragödie für das tatarische Volk“ definiert (Brüggmann 1996). Auch Tschetschenien rief 1991 die Unabhängigkeit aus, ohne Erfolg. Die Unabhängigkeitskriege gegen Russland waren der erste Tschetschenienkrieg (1994-1996) und der Zweite (1999-2009) (O. V. 2007: Brüchige Unabhängigkeit in den 1990 er ...).
} 
Außenministeriums, zu sehen (siehe Kap. 4.1.2.1). Z. B. wird die usbekische Sprache, Usbekisch in der TR als ,usbekisches Türkisch“ (Türkisch: Özbek Türkcesi) bezeichnet. Die Usbeken bezeichnet die TR hingegen als „usbekische Türken“ (türkisch: Özbek Türkleri). Dabei sind die Usbeken weder Türken, noch ist ihre Sprache Türkisch, sondern Usbekisch, wie im Unterkapitel 4.1.2 detailliert erklärt wird. Das gilt auch für die anderen Turkvölker (Kasachen, Turkmenen und Kirgisen) ZAs (siehe Kap. 4.1.2). Die Turksprachen ZAs gehören wie Türkisch zur gleichen Sprachfamilie, sie sind aber nicht Türkisch. Eine Verständigung zwischen diesen Sprachen und dem Türkischen ist nicht möglich, wie in der Einleitung schon erwähnt wurde. Die türkische „Türkisierungsarbeit“ in der „Türkenwelt“ lässt sich mit dem folgenden Vergleich besser verdeutlichen: Angenommen, würden der deutsche Staat und die deutsche Gesellschaft usw. behaupten, die englische, die holländische und die schwedische Sprache seien keine eigenständigen Sprachen; sondern Dialekte des Deutschen und müssten daher „englisches Deutsch“, „holländisches Deutsch“ und „schwedisches Deutsch“ genannt werden. Zwar gehören Englisch, Holländisch und Schwedisch ebenso wie das Deutsche zu den germanischen Sprachen, sie sind aber keine deutschen Sprachen, bzw. kein Deutsch. Des Weiteren handelt es sich bei der Bevölkerung dieser Länder nicht um Deutsche, sondern um Engländer, Holländer und Schweden.

Noch heute (2019) werden auf der Homepage des türkischen Außenministeriums für die Turkstaaten die Bezeichnung „Türkenwelt“ (türkisch: Türk Dünyasi) und für die Turksprachen die Bezeichnungen „Türksprachen, türkische Sprachen oder Türkensprachen“ (türkisch: Türk Dili) verwendet (Türkiye Cumhuriyeti Disisleri Bakanligi o. J. a). ${ }^{67}$ Die TR betrachtet die Bevölkerung der zentralasiatischen Turkstaaten also offiziell als „türkischsprachige Türken“ (ebd.) (siehe hierzu Kap. 4.1.2). Diese staatliche Sichtweise prägt die Literatur. Die türkischen Professoren Cagri Erhan (2003: 3) und Seyfi Tashan (Tashan 2009: 359) behaupten z. B., dass Türkisch in ZA bis zur bolschewistischen Revolution 1917 Lingua Franca war und in den Staaten der Region Dialekte des Türkischen gesprochen wurde. Der Vater des Pantürkismus, Gaspirali, behauptete am 15. März 1906 in seiner Zeitung „Tercüman-i Ahval-i Zaman“, dass die „Türken“ sich aufgrund ihrer Dialektunterschiede nicht verstehen (Toker 2004: 37). Diese Information ist allerdings

\footnotetext{
${ }^{67}$ „Neben der Entwicklung unserer bilateralen Beziehungen, wird auch auf die Entwicklung der multilateralen Beziehungen innerhalb der Türkenwelt Wert gelegt. In diesem Zusammenhang wird die Türkei die Solidarität der türksprachigen Staaten [...].“ (İkili ilişkilerimizin geliştirilmesinin yanısıra, Türk dünyası içinde çok taraflı işbirliğine de özel önem atfedilmektedir. Bu anlayışla, Türkiye, Türk Dili Konuşan Ülkeler arasındaki dayanışmanın artırılması [...]) (Türkiye Cumhuriyeti Disisleri Bakanligi o. J. a).
} 
falsch, weil in ZA zu der Zeit und auch vor der sowjetischen Zeit die verschiedenen Nationalsprachen gesprochen wurden. Diese Nationalsprachen waren eigenständige Sprachen und keine Dialekte des Türkischen (siehe hierzu Kap. 4.1.2). Wenn in den zentralasiatischen Staaten zu und vor der bolschewistischen Revolution Türkisch bzw. Dialekte des Türkischen gesprochen worden wären, wie Erhan, Tashan und Gaspirali behaupten, hätten Gaspirali und die anderen Pantürkisten nicht versuchen müssen, eine gemeinsame türkische Sprache zu entwickeln, damit sich die Turkvölker verständigen können (siehe Kap. 3.5). Tatsache ist, dass in ZA auch vor der sowjetischen Zeit die verschiedenen Nationalsprachen gesprochen wurden. Diese Nationalsprachen waren eigenständige Sprachen und keine Dialekte des Türkischen (siehe hierzu Kap. 4.1.2). Andererseits begann die Sprachpolitik RUs erst ab Mitte der 1920er Jahre (siehe Kap. 3.6).

\section{Sichtweise des ,,Westen“}

Die US-Literatur zum Thema türkisch-russische ZAP ist von einer türkeifreundlichen Sichtweise geprägt. Die Meinungen über die russische ZAP hingegen sind negativ. Die TR wurde in den 1990er Jahren von den USA als laizistisch-westliches Model für die postsowjetischen Länder dargestellt usw. (siehe Kap. 4.1). Des Weiteren wird der türkische Partürkismus im postsowjetischen Raum von den USA als selbstverständlich gesehen, wie unten erklärt wird. Dabei war/ist das erklärte US-Ziel die Unterstützung der Unabhängigkeit und die Befreiung der postsowjetischen Regionen vor der russischen Hegemonie. Andererseits unterstütz(t)en sie die türkische Hegemonialpolitik bzw. ihre „Türkenweltpolitik“. Diese Sichtweise des „New Great Games“ spiegelt sich in der USLiteratur wider.

Der Geopolitiker und Professor für US-Politik, Zbigniew Brzezinski, ${ }^{68}$ und der ehemalige CIA-Mitarbeiter ${ }^{69}$ Graham Fuller gehören $\mathrm{zu}$ den meistzitierten US-Experten über das Thema. In Brzezinskis 1997 veröffentlichtem Buch $^{70}$ befinden sich einige

\footnotetext{
68 Als Berater des US-Präsidenten Lyndon B. Johnson zwischen 1966 und 1968, als Nationaler Sicherheitsberater von Präsident Jimmy Carter von 1977 bis 1981 und als außenpolitischer Berater von Präsident Barack Obama (2009-2017) hatte Brzezinski großen Einfluss auf die US-Außenpolitik. Er war Verfasser der Carter-Doktrin von 1980, die die Grundlage der US-Außenpolitik im Nahen Osten bildete. Desweiteren war er der Entwickler der Strategie „Grüner Gürtel“ (Hür 2014) für die Einkreisung der gottlosen Sowjetunion durch den "Islam".

${ }^{69}$ Central Intelligence Agency (CIA).

${ }^{70}$ Für diese Arbeit verwende ich die Auflage von 2001 „Die einzige Weltmacht. Amerikas Strategie der Vorherrschaft“" (The Grand Chessboard: American Primacy And Its Geostrategic Imperatives).
} 
Fehlinformationen. Brzezinski (2001: 189) schreibt z. B., die zentralasiatischen Tadschiken seien zum größten Teil Anhänger der schiitischen Glaubensrichtung des Islam. Allerdings ist der größte Teil der tadschikischen Bevölkerung jedoch sunnitisch, und der sunnitische Extremismus nimmt in Tadschikistan in den letzten Jahren zu (siehe Kap. 6.1). Weiterhin behauptet Brzezinski (ebd.), vier der fünf neuen unabhängigen zentralasiatischen Staaten gehörten dem türkischen Sprach- und Kulturraum an. Die zentralasiatischen Turkstaaten gehören allerdings nicht dem türkischen Sprach- und Kulturraum; sondern sie gehören wie die TR zum turksprachigen Sprachraum. Sie gehören auch nicht zum türkischen Kulturraum.

Pantürkistische Ausdrücke schmücken auch die Titel von Büchern der US-Autoren. So verwendete Fuller als Untertitel seines 1993 veröffentlichten Buchs (mit Ian O. Lesser et. al.) den pantürkistischen Ausdruck, „die Türkenwelt vom Adriatischen Meer bis zur Chinesischen Mauer“ als „Turkey’s New Geopolitics: From the Balkans to Western China“ (vgl. Kut 1994: 13). Des Weiteren verwendete der ehemalige Nationale Sicherheitsberater (1969-1973) und Außenminister (1973-1977) der USA, Henry Kissinger, denselben pantürkistischen Ausdruck am 1. Februar 1992 im Weltwirtschaftsforum „Die Türkei, die für die regionale und internationale Kooperation große Kapazitäten hat“ (Kut 1994: 13). Isyar (2005: 32) stellte fest, dass der Ausdruck ,Türkenwelt vom Adriatischen Meer bis zur Chinesischen Mauer“ nach dem Kalten Krieg zum ersten Mal in einem im Oktober 1991 in der Zeitschrift „The Economist“ erschienenen Aufsatz benutzt wurde: „The Blur in Turkey: And a Big Weight on Suleyman Demirel's Shoulders“, Economist, Vol. 321, No. 7730, October 26, 1991, S. 15-16. ${ }^{71}$

Auch die deutschsprachige Literatur ist zum Teil politisiert und ignoriert die Trennung zwischen Turkvölkern und Türken sowie zwischen der Turksprache und dem Türkischen. Gemeint sind damit nicht die Arbeiten von Wissenschaftler*innen wie etwa dem pantürkistisch geprägten Baymirza Hayit, der in Deutschland als Wissenschaftler tätig war und seine Abhandlungen auf Deutsch veröffentlichte, oder dem türkischen nationalistisch

\footnotetext{
71 Der Ausdruck ,vom Adriatischen Meer bis zur Chinesischen Mauer “stammt ursprünglich von den pantürkistischen Parteimitgliedern der ,Ittihat ve Terakki“ und wurde das erste Mal von ihnen am Anfang des 20. Jahrhunderts benutzt. Die Parteifunktionäre Dr. Nazim und Dr. Sakir bezeichneten in ihrem gemeinsam verfassten Brief an den Chefredakteur der Zeitschrift „Surayi Ümmet“, Sami Pasazade Sezai Bey, das Hauptziel der Partei als „Gründung eines Türkenbunds auf dem Territorium vom Adriatischen Meer bis China“. Diese Beschreibung übernahmen sie vom Chefredakteur der Zeitung „Hayat “, Ali Turani Bey (Kuran 1948: 206; zit. nach: Semiz 2014: 222-223). Damit meinten sie das osmanische Herrschaftsgebiet auf dem Balkan und im Nahen Osten sowie die nicht zum Osmanischen Reich gehörenden turksprachigen Staaten.
} 
geprägten Historiker Ilber Ortayli, von dessen Büchern einige ins Deutsche übersetzt wurden. Gemeint sind die deutschen Wissenschaftler*innen, die nicht aus den Turkstaaten stammen. Z. B. heißt es auf der Internetseite des Turkologieprofessors Mark Kirchner von der Universität Gießen unter seinen Forschungsschwerpunkten: „Türksprachen Russlands und der ehemaligen Sowjetunion“ (Justus-Liebig-Universität-Gießen 2019: Kirchner). Es gibt allerdings keine Türksprachen RUs und der ehemaligen Sowjetunion, sondern Turksprachen. Türk als Bezeichnung bezieht sich ausschließlich auf die Türken in/aus der TR und die türkische Sprache. Selbst die dem Türkischen ähnlichste Turksprache, das Aserbaidschanische (Aseri), wird nicht Türkisch genannt (siehe Kap. 4.1.2). Nehmen wir an, Aserbaidschanisch oder Aseri sei eine Türksprache, wie Kirchner (2019) behauptet. Kirchner spricht allerdings von den „Türksprachen“. Man kann also davon ausgehen, dass er alle Turksprachen als „Türksprachen“ oder Sprachen der Türken der ehemaligen Sowjetunion betrachtet; andernfalls hätte er den Begriff Turksprachen benutzt, also die Sprachfamilie betont. Des Weiteren steht an einer anderen Stelle der gleichen Fakultät unter dem Punkt Aktuelles folgendes: „Türk Dilleri ve Kültürleri“ („Türkische Sprachen und Kulturen“), „Türkiye Türkçesi“ („Türkei-Türkisch“) „ikinci bir Türk Dili“ (,eine zweite Türksprache bzw. Türkensprache“ oder „eine zweite türkische Sprache“) usw. (JustusLiebig-Universität Gießen 2019: Aktuelles). Auch hier ist dasselbe Problem zu sehen. Solche Beispiele sind in Deutschland reichlich vorhanden.

\section{Widersprüchliche Information}

Ein weiterer Kritikpunkt an der Literatur sind die widersprüchlichen Daten und Informationen. Mir fiel z. B. die Aussage auf, die trotz intensiver (telefonischer und schriftlicher) Bemühungen nicht bestätigt werden konnte. ${ }^{72}$ Es geht um die Frage, welches Land als erstes die Unabhängigkeit Kasachstans anerkannte. Nach der Darstellung in der türkischen Literatur - und auch auf der Homepage des türkischen Außenministeriums - war die TR das erste Land, das die Unabhängigkeit aller zentralasiatischen Staaten, darunter auch Kasachstans, anerkannte (Türkiye Cumhuriyeti Disisleri Bakanligi o. J. c). ${ }^{73}$ Im Hinblick auf Kasachstan scheint diese Information jedoch zweifelhaft zu sein. Auf der Homepage des amerikanischen Almati-Generalkonsulats heißt es, dass die USA als erster Staat die

\footnotetext{
${ }^{72}$ Meine E-Mail-Anfragen beantwortete das kasachische Konsulat in Frankfurt nicht, und eine telefonische Kontaktaufnahme war nicht möglich.

73 Auf der Homepage des türkischen Außenministeriums heißt es, dass die TR als erstes Land die Unabhängigkeit Kasachstans anerkannte: „Türkiye, Kazakistan'ın bağımsızlığını tanıyan ilk ülkedir“ (Türkiye Cumhuriyeti Disisleri Bakanligi o. J. c).
} 
Unabhängigkeit Kasachstans anerkannten: „The United States was the first country to recognize independent Kazakhstan, on December 25, 1991“ (U. S. Embassy \& Consulate in Kazakstan 2018: History). Welche dieser Informationen zutrifft, bleibt offen vermutlich so lange, bis der kasachische Staat dazu Stellung nimmt.

\section{Zusammenhänge zwischen der türkischen Sicherheitspolitik und} ihrer Türkenwelt- sowie Russlandpolitik

Eine große Lücke der Literatur über die türkisch-russische ZAP ist, dass die Zusammenhänge zwischen der türkischen Sicherheitspolitik und ihrer Türkenwelt sowie Russlandpolitik fehlen. Viele Wissenschaftler*innen schreiben zwar, dass die TR mit ihrer Türkenweltpolitik auf die Schwächung RUs zielt und nur durch ein geschwächtes RU eine erfolgreiche Türkenweltpolitik betreiben und ihren Macht- und Einflussbereich in den postsowjetischen Staaten erweitern kann. Es wird allerdings in keiner mir bekannten Arbeit erwähnt, dass die Schwächung RUs im Rahmen ihrer Türkenweltpolitik in erster Linie mit ihren eigenen sicherheitspolitischen Problemen, nämlich mit RU selbst, und mit dem Armenien- und mit dem Kurdenproblem zusammenhängt. Dieser Zusammenhang wird im Unterkapitel 6.9 „Ist eine türkisch-russische strategische Sicherheitspolitik in Zentralasien möglich? " detailliert erklärt.

\subsection{Methodisches Vorgehen}

Für die Arbeit bevorzugte ich Primärquellen, wie z.B. das theoretische Werk des habilitierten Politikwissenschaftler, des ehemaligen türkischen Außenministers und Premierministers Ahmet Davutoglu „Strategische Tiefe“, des habilitierten bekanntesten russischen Eurasisten Alexander Dugin „Moskova-Ankara Ekseni“, Tagebücher wie von Stalin, ${ }^{74}$ Archivdokumente wie die vom türkischen Ministerpräsidium herausgegebene Quellensammlung über die Beziehungen der TR mit den Turkvölkern zwischen den Jahren 1687-1908, ${ }^{75}$ nationale Dokumente RUs, Protokolle, Parteiprogramme, Gesetz- und Beschlusstexte, Gespräche der Entscheidungsträger*innen, Interviews sowie Daten aus

\footnotetext{
74 Stalin, J. [Josef] W. [Wissarionowitsch] (1951): Werke, 4. November 1917-1920, herausgegeben auf Beschluss des Zentralkomitee der Kommunistischen Partei der Sowjetunion (Bolschewiki), die deutsche Ausgabe erscheint auf Beschluss des Zetralkomitees der Sozialistischen Einheitspartei Deutschlands, Berlin: Dietz Verlag, http://www.kpd-ml.org/doc/partei/stalin-band04.pdf (Letzter Zugriff: 12.11.2016)

${ }^{75}$ T.C. BASBAKANLİK DEVLET ARSIVLERİ GENEL MÜDÜRLÜGÜ (Hrsg.) (1992): Osmanli Devleti ile Kafkasya, Türkistan ve Kirim hanliklari arasindaki münasebetlere dair arsiv belgeleri (1687-1908). Osmanli Arsivi Daire Baskanligi, Yayin Nu: 3, Ankara- Haziran 1992.
} 
amtlichen und nichtamtlichen Statistiken. $\mathrm{Zu}$ den wichtigsten Internetseiten für die Primärquellen gehören die offiziellen Webseiten des russischen Außenministeriums (www.mid.ru), des türkischen Außenministeriums (www.mfa.gov.tr), der russischen Botschaft in der TR (www.turkey.mid.ru), des türkischen Statistikamtes TUIK (www.tuik.gov.tr) und des russischen Statistikamtes Rosstat (http://www.gks.ru/).

Die Sekundärliteratur, wie Monographien, Biographien, Aufsätze von Denkfabriken usw., studierte ich zunächst für die Feststellung des Forschungsstandes. Des Weiteren benutzte ich für diese Arbeit ihre relevantesten Argumente und Ergebnisse. Das verwendete Wissen aus der Sekundärliteratur prüfte ich größtenteils nach seiner Richtigkeit. Größtenteils, weil einige Quellen nicht mehr zu finden waren, auf die die Autor*innen verwiesen haben. Weiterhin ging ich mit einigen Informationen, z. B. von den ehemaligen Geheimdienstlern über die Gülen-Bewegung, vorsichtiger um, da sie das Wissen manipuliert haben könnten und ihre Behauptungen nicht leicht zu prüfen sind. In solchen Fällen recherchierte ich so lange, bis ich auf die mir plausibel und sachlich erschienenen Daten stieß.

Die verwendeten Fachzeitschriften und Aufsätze der Denkfabriken sind größtenteils online abrufbar. Bücher sind zum größten Teil nicht digitalisiert und somit nur in den Bibliotheken (z. B. Universitätsbibliothek Frankfurt und Deutsche Nationalbibliothek Frankfurt usw.) zu finden. Die Mainzer Bibliothek für Turkologie verfügt über einen sehr guten Bestand, in der wertvolle Primär- und Sekundärquellen zu finden sind. Auch in den Istanbuler Bibliotheken (Bibliothek der Universität Istanbul, Bibliothek der Universität Bilgi) sowie in den Archiven der türkischen Denkfabriken (BILGESAM, TASAM) führte ich Recherchen durch und sammelte sachrelevante Daten. In dem von der Denkfabrik USAK (von Habibe Özdal, Osman Bahadir Dincer und Mehmet Yegin) herausgegebenen Werk „Mülakatlarla Türk Dis Politikasi““, Band 1 (2010 [1. Aufl. 2009]), Band 3 (2010) und Band 4 (2011), befinden sich zahlreiche Experteninterviews über die türkische Außenpolitik. Einige Experten bewerten in diesen Interviews $u$. a. auch die türkische und russische ZAP. Des Weiteren führte ich Gespräche mit den Russland- und Türkei-Experten PD Dr. Fatih Özbay, PD Dr. Mustafa Nail Alkan, Dr. Tahir Tamer Kumkale und Prof. Dr. Gazi Caglar. Sie wählte ich gezielt als Gesprächspartner, weil sie unterschiedliche Sichtweisen (eurasistisch, liberal-demokratisch, pantürkistisch und marxistisch) haben. In den Gesprächen setzte ich mich mit den Argumenten meines Gesprächspartners auseinander und versuchte, seine Position und Denkweise zu verstehen. 
Ich verwendete für diese Dissertation hauptsächlich Literatur auf Türkisch, Deutsch und Englisch, darüber hinaus aber auch russische, turkmenische, kasachische, usbekische und kirgisische Primärquellen. Ich bin zwar der russischen Sprache und der zentralasiatischen Turksprachen nicht mächtig. Ich konnte aber auf den offiziellen Internetseiten dieser Staaten (den Seiten der Statistikämter, der Ministerien usw.) teils auf den genannten Landessprachen teils auf Englisch recherchieren, weil diese Seiten auch zum Teil auf Englisch verfasst sind. Die zentralasiatischen Turksprachen ähneln dem Türkischen. Das war für mich ein Vorteil. Allerdings müssen bei den Recherchen neben dem kyrillischen Alphabet auch die Länderalphabete (des Usbekisch und Turkmenischen) beherrscht werden. Trotz der Ähnlichkeiten des Türkischen mit den zentralasiatischen Turksprachen ist eine umfangreiche Recherche nicht möglich. Die offiziellen Internetseiten dieser Staaten sowie RUs benutzte ich daher eher für die staatlichen statistischen Daten.

Der größte Teil der relevanten russischen Primärliteratur für das Thema kann auf Englisch, Deutsch und Türkisch gelesen werden. Des Weiteren veröffentlichten viele russische Wissenschaftler*innen in diesen drei Sprachen. Um die staatliche Sichtweise RUs auf die Ereignisse in RU und in der Welt zu erfahren, genügt es, den Fernsehsender Russia Today (auf Englisch) einzuschalten oder die Online-Seite RT Deutsch (http://deutsch.rt.com) und Online-Zeitung Sputnik (http://de.sputniknews.com auf Deutsch und http://tr.sputniknews.com auf Türkisch) zu lesen. Russischkenntnisse waren für das Thema einerseits aus den oben genannten Gründen nicht notwendig. Die für diese Arbeit relevanten veröffentlichten Primärquellen, wie die nationalen Konzepte RUs, sind andererseits übersetzt auf Englisch, Deutsch oder Türkisch zu finden. Türkischkenntnisse hingegen sind für dieses Thema notwendig, weil die TR nicht wie RU über (übersetzte) offizielle Dokumente verfügt, in denen die außenpolitischen, militärischen und sicherheitspolitischen Ziele der TR nachzulesen sind. Zudem sind viele Dokumente aus der TR nicht ins Englische oder Deutsche übersetzt worden. Das größte Defizit der türkischen Literatur über das Thema ist, dass die Staatsarchive, wie z. B. Cankaya Köskü Arsivi (Archiv vom Cankaya) ungeöffnet sind und somit die Recherchen der türkischen ZAP in der Atatürk-Ära (19201938) fast unmöglich sind. Des Weiteren verhindert bzw. begrenzt ein Gesetz von 1951 „Gesetz über strafbare Handlungen gegen Atatürk, Gesetznummer 5816“ die unabhängigen Recherchen über seine Zeit und Person. 
Diese Dissertation ist, wie in der Einleitung bereits erwähnt wurde, eine empirischanalytische Arbeit. Empirisch-analytische Arbeiten konzentrieren sich auf messbare und beobachtbare Merkmale, wie auf die Statistiken, beobachtbare Transaktionen zwischen den Staaten usw. Das Ziel der empirisch-analytischen Arbeiten ist die „Wirklichkeitssuche“. Für dieses Ziel sind die quantitativen Daten zuverlässiger, da sie kaum Platz zur freien Interpretation anbieten. Da aber die Sinndimension, wie die Absichten, Präferenzen, Interessen und Ideologien, aus der gesellschaftlichen Realität nicht wegzudenken sind (Welzel 2012: 398), berücksichtigte ich sie in dieser Arbeit mit (wenn es z. B. um die Interpretation der pantürkistischen Türkenwelt-Ideologie der TR oder das russische NahesAusland-Konzept geht). Bei der Auswertung der Primär- und Sekundärliteratur verwendete ich die qualitative Inhaltsanalyse.

Ursprünglich ist die Inhaltsanalyse eine Methode der Kommunikationswissenschaft, die sich nicht nur auf Reden und Texte konzentriert, sondern auch auf Bilder. Dem untersuchten Material werden mit diesem Verfahren die klassischen Forschungsfragen der Kommunikationswissenschaft gestellt: Wer sagt was zu wem, warum, wie und mit welchem Effekt? Der zu analysierende Text oder das $\mathrm{zu}$ analysierende Bild wird nach den Grundformen des Interpretierens „Zusammenfassung, Explikation und Strukturierung“ analysiert (Mayring 2010: 64-65). Mit Zusammenfassung ist die Erfassung der Dateninhalte und die Sortierung der Kernaussagen des Materials (Text, Bild usw.) gemeint. Bei der Explikation werden Wissenslücken durch weitere Recherchen geschlossen, falls bei der Untersuchung des Materials Unklarheiten bestehen. Unter Strukturierung wird die Zusammenfassung des für die Analyse formal und inhaltlich aufbereiteten Materials, z. B. in Kategorien, verstanden (Mayring 2010: 65). Wenn die Daten nach diesem Verfahren nach ihren Kernaussagen strukturiert und kategorisiert wurden, können sie miteinander verglichen werden. So weist etwa die Anzahl der Wiederholungen eines Wortes in einem Text darauf hin, wo der Schwerpunkt des Textes liegt. Oder z. B., aufgrund der Häufigkeit der Kriege (15 Kriege $^{76}$ ) zwischen der TR und RU, werden ihre Beziehungen als „konflikthaft“

\footnotetext{
${ }^{76}$ Der erste türkisch-russische Krieg ist der „Astrachan-Krieg“ (1568-1570), der mit einem russischen Sieg endete. Ihm folgte der zweite Krieg, welcher als „Brand von Moskau“ 1571 bekannt ist. Das Osmanische Reich ließ das Khanat Krim das Fürstentum Moskau angreifen und unterstützte die Krim-Tataren gegen die Russen (Inalcik 1999: 29). Dieser Krieg endete mit einer Niederlage der Russen. Ein Jahr später, 1572, wurde das Khanat Krim vom Fürstentum Moskau vernichtend zurückgeschlagen. Der vierte Krieg fand 1676-1681 statt und endete mit dem türkischen Sieg. Der fünfte fand 1686-1700 statt (russischer Sieg); der sechste, der sogenannte Große Nordische Krieg, 1711 (türkischer Sieg); der siebte 1735-1739 (Russisch-Österreichischer Türkenkrieg; türkischer Sieg); der achte 1768-1774 (russischer Sieg), der neunte 1787-1792 (russischer Sieg); der zehnte 1806-1812 (russischer Sieg); der elfte, die Navarin-Schlacht, 1827 (russischer Sieg), der zwölfte 1828-1829 (russischer Sieg); der dreizehnte 1853-1856 (Krimkrieg; türkischer Sieg); der vierzehnte 1877-
} 
bezeichnet. Des Weiteren z. B., um Änderungen im russischen Militärkonzept von 2010 feststellen zu können, müssen die Kernargumente der Militärkonzepte von 1993 und 2000 festgestellt werden. Neben der qualitativen Textanalyse verwendete ich auch die qualitative Bildanalyse. Damit konnte ich nachweisen, dass die pantürkistische Bewegung in ZA von der TR geleitet wurde (siehe Kap. 3.5). Das Defizit der qualitativen Inhaltsanalyse besteht darin, dass die Qualität der Analyse von vielen Faktoren, wie von der Sichtweise, emotionalem Zustand (glücklich oder traurig usw.) und Wissensstand des Autors, bzw. der Autorin abhängt. Daher kann Folgendes gesagt werden: Je besser der/die Forscher*in über das untersuchte Thema informiert ist und je eher er/sie dem Thema sachlich-neutral gegenübersteht, desto wissenschaftlicher sind seine/ihre Ergebnisse

\subsection{Aufbau der Arbeit}

Diese Arbeit besteht aus 7 Kapiteln. Im 1. Kapitel, in der Einleitung wurden Gegenstand, Forschungsinteresse, Forschungsfragen, Ziel und Forschungszeitraum der Arbeit vorgestellt. Der Einleitung folgt der Abschnitt Einführung in das Thema, in dem die Relevanz ZAs im weltpolitischen Kontext sowie die Positionen, die Ziele und die ZAP der TR und RU in ZA kurz dargestellt wurde. Im Abschnitt Stand der Forschung wurde zunächst die zum Thema vorhandene Literatur dargestellt. Die Literatur im Allgemein ist durch zwei Positionen geprägt, die geopolitische und die strategische Position. Anschließend wurden im Unterabschnitt Literaturkritik die Defizite der vorhandenen Literatur angesprochen. Im Abschnitt Methodisches Vorgehen wurde erläutert, welche Literatur warum verwendet wird, und warum sich die qualitative Inhaltsanalyse zur Datenauswertung gut eignet.

Im 2. Kapitel legte ich die zugrundeliegenden Theorien der Arbeit näher dar. Zunächst erklärte ich, warum ich den Neorealismus von Kenneth Waltz und den Soft-Power-Ansatz von Joseph Nye für die Erklärung des Themas ausgewählt habe. Anschließend wurden beide Ansätze genauer erläutert. Das Ziel dieses Kapitels ist die Kategorisierung des konkreten außenpolitischen Verhaltens eines Staates nach diesen Ansätzen und die Auflistung der Kernannahmen des Neorealismus und Soft-Power-Ansatzes in einem knappen Überblick.

1878 (russischer Sieg); der fünfzehnte und letzte im Rahmen des 1. Weltkrieges an der Kaukasus-Front (19141917). RU zog sich infolge der Oktoberrevolution 1917 aus diesem Krieg zurück. 
Die Ergebnisse dieser Dissertation wurden im Fazit vor dem Hintergrund dieser theoretischen Kernaussagen diskutiert.

Das 3. Kapitel konzentriert sich auf die türkisch-russische ZAP von ihren Anfängen 1552 (Eroberung Kasan durch RU) bis zur Unabhängigkeit der zentralasiatischen Staaten 1991. Dieses Kapitel ist wichtig, weil die heutige ZA-Wahrnehmung der TR und RU, bzw. ZAP beider Staaten ohne die Darstellung dieser historischen Ereignisse nicht zu verstehen ist, wie in der Einleitung schon erwähnt wurde. Mit anderen Worten ist die Geschichte der Region in diesem Zeitraum ein wichtiger Bestandteil der heutigen türkischen und russischen ZAP. Selbst in den Regionsbezeichnungen stehen die Machtverhältnisse der damaligen Zeit, die zum Teil die Grundlage der späteren Ideologien wurden, wie die russische offizielle Bezeichnung ZAs als Turkestan vom Pantürkismus.

Im 4., 5. und 6. Kapitel analysierte ich vergleichend die türkisch-russische ZAP von der Unabhängigkeit der zentralasiatischen Staaten bis 2019 im kultur- und bildungspolitischen, wirtschaftlichen und sicherheitspolitischen Bereich. Das 4. Kapitel konzentriert sich auf die außenpolitischen Richtlinien und Ziele sowie die kultur- und bildungspolitischen Aktivitäten der TR und RU in ZA. Ihre Kultur- und Bildungspolitik in ZA zielt auf eine kulturelle Hegemonie ab, deren wichtigste Mittel Sprache und Bildung sind. Die russische Sprache ist bis heute Lingua Franca in ZA. Die TR hingegen versucht mit allen verfügbaren Mitteln, wie etwa mit der Unterstützung der Gülen-Schulen, die türkische Sprache und Kultur in der Region zu etablieren. Die türkisch-russische kultur- und bildungspolitische Rivalität in ZA spiegelt sich am besten am Schriftkrieg (kyrillisches Alphabet gegen das Lateinische) wider.

Das 5. Kapitel behandelt die zentralasiatische Wirtschaftspolitik der TR und RU. Die wirtschaftliche Rivalität zwischen den beiden Staaten um die Region ist durch ihre gegensätzliche Energiepolitik um den Kaspischen Raum klar sichtbar. Weil aber die türkische Energiepolitik für den kaspischen Raum ein Teil des von den USA angeführten New Great Game ist, wird in diesem Kapitel auch die zentralasiatische Wirtschaftspolitik der USA und ihren Partner EU erklärt. Die USA handeln mit ihrer Wirtschaftspolitik in der Region gegen die russische EAWU und die chinesische Seidenstraße-Initiative. Beide Bündnisprojekte schließen ZA mit ein. RU und China sind aktuell die größten Wirtschaftspartner der zentralasiatischen Staaten. Aufgrund der sicherheitspolitischen Interessenkonflikte der TR mit den USA bezüglich der Syrienfrage, wurden in der TR in 
letzten Jahren die eurasistischen Stimmen für einen türkischen EAWU-Beitritt lauter. Die TR erhielt von RU und Kasachstan Einladungen für den EAWU-Beitritt. Es ist allerdings unter heutigen Umständen ein türkischer EAWU-Beitritt nicht möglich, wie in diesem Kapitel gezeigt wurde.

ZA gewann infolge des Afghanistan-Einsatzes 2001 an sicherheitspolitischer Relevanz, weil zum ersten Mal in der NATO-Geschichte am 4. Oktober 2001 der Bündnisfall beschlossen wurde und die USA/NATO in ZA für die Terrorbekämpfung in Afghanistan Militärbasen erwarben. Das NATO-Mitglied TR unterzeichnete gemeinsam mit RU kurz nach dem Afghanistan-Einsatz, im November 2001, einen „, Aktionsplan in Eurasien“, der die aktive Zusammenarbeit von gemeinsamer Terrorbekämpfung bis zur militärischen Zusammenarbeit in Eurasien beinhaltet. Ihre Sicherheitspolitik in ZA war und bleibt allerdings gegensätzlich. Im 6. Kapitel wurde gezeigt, warum die beiden Staaten sicherheitspolitisch um das postsowjetische ZA rivalisieren und warum eine sicherheitspolitische Zusammenarbeit zwischen den beiden Staaten in ZA unter heutigen Bedingungen nicht möglich ist. Die gegensätzliche türkisch-russische Sicherheitspolitik im postsowjetischen Raum zeigt sich am deutlichsten an den Fallbeispielen Karabach- und Krimkonflikt.

Im 7. Kapitel, im Fazit, wurde die gesamte Arbeit nicht zusammengefasst, weil ich bereits zu jedem Kapitel der Arbeit eine Zusammenfassung geschrieben habe. Alle diese machen zusammen die gesamte Zusammenfassung der Arbeit aus. Im Fazit konzentrierte ich mich auf die Ergebnisse der Arbeit und fasste sie vor dem Hintergrund des Ziels, der Vorgehensweise und der theoretischen Annahmen der Arbeit zusammen. Dabei zeigte ich auch, welche Schwierigkeiten oder Vorteile meine Herangehensweise und welche Erkenntnisse ich dadurch hatte. 


\section{ZUGRUNDELIEGENDE THEORIEN DER ARBEIT}

Der Neorealismus-Ansatz von Kenneth Waltz und der Soft-Power-Ansatz von Joseph Nye sind als theoretischer Rahmen für die Erklärung der „Türkisch-Russischen ZAP“ geeignet. Wie im Unterkapitel 1.2 Stand der Forschung dargestellt wurde, besteht in der Literatur Konsens darüber, dass die TR und RU in ZA miteinander geopolitisch rivalisieren. Ich übernahm diese These als meine 1. Hypothese, um die Gründe ihrer Rivalität in ihren Kausalzusammenhängen zu erklären. Ich halte auch in Zukunft unter heutigen Umständen keine strategische Partnerschaft beider Staaten in ZA für möglich (2. Hypothese). Weil es sich bei der türkisch-russischen ZAP um eine Rivalität handelt, kommen als Erklärungsmodell nur (neo)realistische Theorien in Frage. Der Hauptgrund meiner Entscheidung für den Waltz`schen Neorealismus war, dass die türkische als auch die russische Außenpolitik sowohl im Allgemeinen als auch bezüglich ihrer ZAP in erster Linie durch ihre sicherheitspolitischen Interessen gekennzeichnet sind. Um mit neorealistischen Sätzen auszudrücken, ist die Sicherheitspolitik für beide Staaten ,high politics“ (Waltz 1979: 134). D. h. sie steht über allen anderen Zielen (soziale und wirtschaftliche) des Staates (Waltz 1979: 91-92, 126).

RU hat veröffentlichte nationale Dokumente (Militärdoktrin, Außenpolitikkonzept und Nationale Sicherheitsstrategie), in denen die Interessen und Ziele des Staates zu finden sind. In allen Dokumenten hebt das Land die Sicherheitspolitik hervor. In seinen „Außenpolitikkonzepte von 2000 und 2013“ schreibt das Land direkt, dass für RU seine sicherheitspolitischen Interessen höchste Priorität haben (President of the Russian Federation 2000: 1, Präsident Der Russischen Föderation 2013). Diese Dokumente werden von (neo)realistischer Sichtweise geprägt. Der russischen (neo)realistischen Schule sind der „(Neo)Eurasismus“ von Aleksandr Dugin, „Geopolitik“ von Assen Ignatow und Kamaludin S. Gadzhiev sowie die russische „Realistische Denkschule“ zuzuordnen.

Die TR hat zwar keine schriftlich ausformulierten nationalen, außenpolitischen Konzepte wie RU. Allerdings sind die Ideologien, die die türkische Außenpolitik prägen, der (neo)realistischen Schule zuzuordnen. Diese sind der Kemalismus, der die Grundlagen der türkischen Außenpolitik bestimmt, Türk-Islam-Sentezi (Türkisch-Islamische Synthese) von Ibrahim Kafesoglu (siehe hierzu Kap. 4.1.2), Monographie von Ahmet Davutoglu „,Stratejik Derinlik“ (Strategische Tiefe) (siehe hierzu Kap. 4.1.1), die die AKP-Politik geprägt hat und 
auch als Neo-Osmanismus bekannt ist. In allen Ideologien wird als erstes Ziel des türkischen Staates der Schutz der territorialen Integrität und Souveränität genannt. D. h. Sicherheitspolitik ist auch für die TR, ,high politics“.

ZA hat für RU in erster Linie eine sicherheitspolitische Relevanz, weil die Region als Pufferzone die südliche Grenze RUs schützt: Zum einen gegen die USA/NATO; zum Anderen von Afghanistan ausgehenden Probleme, wie z. B. vor dem islamistischen Terror und Drogenhandel aus Afghanistan. Des Weiteren wächst in ZA in den letzten Jahren der religiöse Extremismus. Auch die möglichen pantürkistischen Aktivitäten können sich auf die russische Sicherheit negativ auswirken. Alle diese genannten sicherheitspolitischen Probleme betrachtet RU im Zusammenhang mit in RU lebenden etwa 30 Mio. Muslime (etwa $21 \%$ der Gesamtbevölkerung RUs. O. V. 2018: Rusya da Müslüman Nüfus Problemi) und/oder etwa 20 Mio. turksprachigen Bürger*innen $(14 \%$ der russischen Gesamtbevölkerung). Das Land fürchtet in erster Linie mögliche pantürkistische und/oder islamistische Spill-Over-Effekte aus und/oder via ZA.

Für die TR stellt ZA aufgrund der geographischen Distanz auf den ersten Blick keine sicherheitspolitische Gefahr dar. Ihre sicherheitspolitischen Bemühungen in ZA zielen eher auf die Schwächung RUs bzw. Ersetzen des russischen Einflusses in der Region. RU stellt ein Hindernis vor der Gründung einer von der TR geplanten pantürkistisch-islamischen Vereinigung der Turkstaaten dar. Andererseits sieht die TR RU wegen der Kurden- und Armenierfrage sowie wegen RU selbst als sicherheitspolitische Gefahr gegen ihre territoriale Integrität und Souveränität an. Wegen RU, weil RU die Vereinbarungen mit der TR im Falle eines Interessenkonfliktes aufkündigen kann (siehe hierzu Kap. 6.9). Daher gilt für die TR RU als eine mögliche große sicherheitspolitische Gefahr. Für RU hingegen ist die pantürkistisch-islamische TR ein verlängerter Arm der USA im postsowjetischen Raum und mit ihren pantürkistisch-islamischen Zielen eine sicherheitspolitische Gefahr für seine territoriale Integrität und Souveränität (Basaran 2013: 154; Kazgan 2003: 172-173).

Der Waltz`sche Neorealismus konzentriert sich bei der Analyse auf das internationale System (Third Image), in dem die Staaten nach ihren Kapazitäten, bzw. Machtressourcen platziert sind (Waltz 1979: 131). Diese sind ihre Bevölkerungsgröße, Territorium, Ressourcenausstattung, Wirtschaftskraft, militärische Stärke, politische Stabilität und 
Kompetenz (ebd.). ${ }^{77}$ Er analysierte systemische Effekte des internationalen Systems auf die Staaten (units) und die Interaktionen zwischen den Units (ebd.: 99). Die Einflüsse der subsystemischen Faktoren, die individuelle Akteursebene (First Image) und staatliche Ebene (Second Image) auf die Außenpolitikgestaltung ignoriert der Neorealismus. Das kann im Allgemeinen als Mangel des Neorealismus gesehen werden. Allerdings bezüglich meines Themas kein dramatischer Mangel. Die Entscheidungsträger*innen der TR und RU haben mit Hilfe der Institutionen und Medien starken Einfluss auf die größtenteils „,konservativnationalistisch“ geprägte Bevölkerung ihrer Länder, sodass die Bevölkerung der beiden Staaten mit den Entscheidungen der Entscheidungsträger*innen weitgehend einverstanden ist. Die Medien sind stark kontrolliert und nicht unabhängig, gelten weitgehend als Instrument der Regierung. Regimekritische Meinungen finden als subsystemischen Faktoren aufgrund der autoritären Herrschaftssysteme keinen Einfluss auf die Außenpolitikgestaltung. Die Kritiker werden meistens strafrechtlich verfolgt. Eine gerechte, demokratische Teilnahme an den politischen Entscheidungen, wie die idealistischen Theorien es vorsehen, ist mangelhaft, zum Teil nicht möglich. Es fehlt in beiden Staaten an demokratischen Rechten, wie Meinungsfreiheit, Menschenrechte, Pressefreiheit usw. Auch die Analyse der Akteursebene vernachlässigt der Neorealismus. Allerdings weichen die aktuellen Präsidenten der TR und RU, Erdogan und Putin, von den außenpolitischen Richtlinien ihrer Länder nicht ab. ZA ist für die TR seit ihrer Gründung 1923 ein Teil der „Türkenwelt“ und ihre ZAP war und bleibt pantürkistisch geprägt. Für RU ist diese Region seit der Auflösung der Sowjetunion 1991 „,sein selbstverständliches Nahes Ausland“, und vorher war sie unter russischer Herrschaft.

Der Neorealismus ist trotz all seiner Schwächen, mit seinen Annahmen über Sicherheit, Kooperation, das rationale Handeln und die Kapazitäten der Staaten im anarchischen System, wie im folgenden Teil gründlich dargestellt wird, in besonderer Weise in der Lage, die türkisch-russische ZAP zu erklären. Weil der Waltz`sche Neorealismus bei der Zielverfolgung vorrangig auf Gewalt und Drohung setzt, aber die TR und RU in ZA auch „gewaltfreie“ Soft-Power-Instrumente zur Überzeugung der Zielobjekte für eine Zusammenarbeit einsetzen, beziehe ich ergänzend den Soft-Power-Ansatz von Nye ein, um

\footnotetext{
77 Für Neorealisten im Allgemeinen wird die wirtschaftliche Stärke eines Staates häufig durch ihr Bruttosozialprodukt und Exportvolumen gemessen. Seine militärische Stärke hingegen wird durch seine Militärausgaben, Truppenstärke und den Besitz von atomaren Waffen gemessen. Die Zahl der Bevölkerung ist z.B. hinsichtlich der möglichen Arbeitskräfte und Soldaten relevant. Die Größe und Lage des Staatterritoriums kann seine Handlungsspielraum einschränken oder erweitern, wie z.B. eines Atomtests auf dem eigenen Territorium zu machen ermöglichen oder nicht (Baumann/ Rittberger/ Wagner 1999: 256).
} 
diese Schwäche des Waltz`schen Neorealismus zu überwinden. Ein weiterer Unterschied zwischen dem Neorealismus und Soft-Power-Ansatz ist die Kooperationsmöglichkeiten der Staaten. Im Vergleich zum Soft-Power-Ansatz sind die Allianzen nach Neorealisten in der Regel nur Verteidigungsbündnisse. Andere Kooperationsformen sind nach dem Neorealismus aufgrund der anarchischen Struktur des internationalen Systems kaum denkbar. Das kooperative Verhalten zwischen den Staaten sieht Waltz aus Angst vor ungerechter Gewinnverteilung und möglicher Abhängigkeitsverhältnisse als unwahrscheinlich an (Waltz 1979: 105). Daraus kann geschlussfolgert werden, dass Kooperation nur aufgrund von sicherheitspolitischen Interessen stattfindet und von Dauer ist. Im Vergleich zum Neorealismus ist nach dem Soft-Power-Ansatz eine Kooperation in allen Bereichen möglich. Die Instrumente und Ziele einer Soft Power mögen idealistisch erscheinen, ihr Ziel ist aber immer realistisch: d. h. die Macht. Somit unterscheidet sich der Soft-Power-Ansatz von den idealistischen Ansätzen, bzw. Theorien.

\subsection{Waltz'scher Neorealismus}

Kenneth N. Waltz entwickelte seinen Neorealismus ${ }^{78}$ auf der Theorie des klassischen Realismus von Hans J. Morgenthau, der die Ursache der Konflikte bzw. Kriege mit der bösen und egoistischen Natur der Menschen erklärt (Masala 2005: 26) und sich auf den „,naturgegebenen Machtkampf“ zwischen ihnen konzentriert. ${ }^{79}$ Morgenthau überträgt sein anthropologisches Menschenbild auf den ,einzig relevanten Akteur der Außenpolitik“, auf den Staat und definiert den Staat als zweckorientierter, rationaler, egoistischer Akteur der

\footnotetext{
78 Die Entstehungshintergründe des Waltz’schen Neorealismus waren die Verschärfung der Ost-WestKonfrontation seit 1979 durch den Einmarsch der Sowjetunion in Afghanistan, die islamische Revolution 1979 in Iran und die erneute Erdölkrise 1979. Sein Werk „,Theory of International Politics“ ist 1979 vor diesem historischen Hintergrund entstanden (Siedschlag 2004: 2). Die erste Erdölkrise kam durch das verhängte Ölembargo der „Organization of the Petroleum Exporting Countries“ (OPEC) gegen die USA und andere Industrieländer, weil der Westen im arabisch-israelischen Krieg (Oktoberkrieg) im Jahre 1973 Israel unterstützte. Infolgedessen wurde der Erdölpreis drastisch erhöht und das führte zu den Konflikten in den westlichen Industriestaaten (Spindler 2006: 95).

${ }^{79}$ Das realistische, pessimistische Mensch- und Weltbild gewann 1948 mit dem Werk „Politics Among Nations: The Struggle for Power and Peace (auf Deutsch 1963 unter dem Titel „Macht und Frieden: Grundlegung einer Theorie der internationalen Politik“ erschienen) von Hans J. Morgenthau an Bedeutung. Morgenthau entwickelte seine Theorie als Gegenkonzept zum Idealismus (oder wie Morgenthau den Idealismus selbst nannte, zum „Utopismus“, „Moralismus“ oder „Sentimentalismus“), welche die Zeit zwischen den beiden großen Weltkriegen dominierte (Masala 2005: 23; Moravcsik 1997: 514). Laut Morgenthau liegen falsche moralische Prinzipien und Philosophien dem Liberalismus zugrunde. Die moralischen Sätze sind von der Kultur einzelner Nationen abhängig, wie Norm- und Moralvorstellungen, d.h. sie sind nicht universell. Mit idealistischen Mitteln einen Krieg zur Durchsetzung moralischer Standards zu führen, wie die Kreuzzugsmentalität; würde nach Morgenthau die Vernichtung der gesamten Menschheit im Atomzeitalter bedeuten (Masala 2005: 24 f.).
} 
internationalen Politik. D.h. er betrachtet den Staat wie einen Menschen, welcher bei seinen Entscheidungen und Handeln einen möglichst hohen Nutzen zu erzielen versucht (Schimmelfennig 2009: 140; Hasenclever 2001: 48). Waltz übernahm vom klassischen Realismus die Staaten als Hauptakteure des internationalen Systems sowie die Rationalitätsannahme, ${ }^{80}$ lehnt aber seine zugrundeliegende anthropologische Begründung ab. In seiner Disseration „Man, the State and War“" schreibt er, wenn die Menschen von Natur aus böse sind (Waltz 1959: 29), „we can never hope for peace“ (Waltz 1959: 30). Seinen Analyseschwerpunkt legte er auf das internationale System (third image), ${ }^{81}$ das aus Systemeinheiten (units), d.h. Staaten und Struktur des Systems besteht (Schörnig 2006: 70). ${ }^{82} \mathrm{Er}$ analysierte systemische Effekte des internationalen Systems auf die Staaten (units) und die Interaktionen zwischen den Units, d. h. auf ,the structure of the system and its interacting units“ (Waltz 1979: 99). Da er sich in seiner Arbeit auf die internationale Struktur konzentriert, wird sein Ansatz oft auch als struktureller Realismus bezeichnet. Sein Strukturbegriff ersetzt Morgenthau`s zentralen Begriff „Macht“.

Die Systemstruktur ist nach Waltz (1979: 88-99) durch drei Eigenschaften gekennzeichnet: 1) Ordering Principles (Ordnungsprinzipien), 2) Charakter of the Units, bzw. Qualities, d.h. die funktionelle Differenzierung der Staaten, die Unterscheidung der Einheiten und die Spezifizierung deren Funktion und 3) The Distribution of Capabilities (Verteilung der Fähigkeiten, bzw. Machtverteilung). Unter den Fähigkeiten versteht Waltz die Machtmittel der Staaten (Baumann 2007: 63). Das Ordnungsprinzip des internationalen Systems ist die Anarchie, da es keine Lenkungsinstanz ${ }^{83}$ außerhalb oder oberhalb der Staaten gibt, die ihnen vorschreibt und sie beobachtet, wie sie die Herrschaft in ihrem Territorium zu ordnen und auszuüben haben. Ebenso wenig unterliegen die Staaten herrschaftlich durch gesetzte Regeln

\footnotetext{
${ }^{80}$ Der (Neo-)Realismus geht davon aus, dass die Akteure der internationalen Politik, nämlich Staaten, sich in ihren politischen Handlungen rational (nach Rational-Choice-Ansatz), ziel- und zweckgerichtet verhalten, wie eine Art Homo Oeconomicus. Sie versuchen ihren eigenen Vorteil zu maximieren, ihren Nutzen bestmöglich zu vergrößern und dabei ihre Kosten zu minimieren (Haftendorn 1990: 406).

${ }^{81}$ Waltz unterscheidet in seiner Doktorarbeit drei Analyseebenen. Die „First Image“ ist die individuelle Ebene, die „Second Image“ die staatliche Ebene. Beide Ebenen erklären die internationale Politik mit den subsystemischen Faktoren. Er selbst aber bevorzugt für die Erklärung der internationalen Politik die systemische Ebene, d.h. „Third Image“.

${ }^{82}$ Waltz schreibt, dass die Interaktionen zwischen den Staaten die Struktur des internationalen politischen Systems formen: „States are the units whose interactions form the structure of international-political systems. They will long remain so.“(Waltz 1979: 95).

83 Die nach dem Zweiten Weltkrieg zum Schutz vor außenpolitischen Gewaltaktionen und Friedensbedrohungen errichteten „Vereinten Nationen“ („United Nations Organization“, UNO) stellen in diesem Sinne keine regierungsähnliche Weltautorität dar (Wilhelm 2006: 290). Die UNO ist trotzdem ein wichtiger Akteur im internationalen System. Wie Wilhelm (ebd.) schreibt, unterstützt sie die staatlichen wechselseitigen Bestandgarantien, schafft einen internationalen Kooperationsrahmen und verhandelt in den Konfliktfällen zwischen den Staaten usw.
} 
für ihre Beziehungen untereinander (Schimmelfennig 2009: 135; Kindermann 1986: 27). Da es im internationalen System keine übergeordnete Schutz- und Sanktionsmacht gibt und die Staaten deshalb zur „Selbsthilfe“ gezwungen sind, entsteht das realistische Sicherheitsdilemma (John Herz) (Krell 2009: 155). Das realistische Weltbild ist eher durch Misstrauen geprägt, das gleichzeitig der Grund und das Ergebnis der Anarchie ist. Nach Herz haben die Staaten im anarchischen System immer Angst, von den anderen Staaten angegriffen zu werden. Diese Angst führt zu Rüstungsbemühungen und zur Selbsthilfe, um ihre Sicherheit durch eine besonders technologisch-militärischen Macht zu gewährleisten. Ein Beispiel für das Sicherheitsdilemma in der internationalen Politik war die Kuba-Krise 1962. Der Kirchenbesuch des US-Präsidenten John Kennedy während dieser Krise wurde von den sowjetischen Geheimdiensten KGB nach Moskau als das Vorspiel zum Nuklearangriff der USA auf die Sowjetunion wahrgenommen und weitergeleitet (Krell 2009: $154 \mathrm{f})$.

Aufgrund der Anarchie gibt es zwischen den Staaten keine funktionelle Differenzierung, da alle Staaten um ihr Überleben kämpfen. „In any self-help system, units worry about their survival, and the worry conditions their behavior" (Waltz 1979: 105). Das anarchische internationale System zwingt die Staaten als Hauptakteure der internationalen Politik für ihre Sicherheit selbst zu sorgen: „The international imperative is 'take care of yourself!'“(Waltz 1979: 107). Mit anderen Worten entsteht das Problem der Gewalt durch die Anarchie (Krell 2009: 157), was sie wiederum zur Selbsthilfe zwingt. Sicherheitspolitik ist daher laut strukturellem Neorealismus als „high politics“, d.h. als „höchstes Ziel“ für den Erhalt eines Staates definiert. Alle anderen Inhalte, wie z.B. ökonomische und soziale Fragen, sind der Sicherheitspolitik untergeordnet. Die Sicherheit und das Überleben ist für Waltz (1979: 9192) die Vorbedingung für einen Staat, die anderen Ziele zu erreichen. Deshalb müssen sich die Staaten in erster Linie auf ihre Sicherheit und Überleben konzentrieren; nicht auf Gewinne oder Machtmaximierung: „In anarchy, security is the highest end. Only if survival is assured can states safely seek such other goals as tranquility, profit, and power. Because power is a means and not an end [...] The first concern of states is not to maximize power but to maintain their positions in the system.“(Waltz 1979: 126). Das Überleben ist für Waltz das wichtigste nationale Interesse eines Staates und steht allen seinen Zielen vor (Waltz 1979: 134). 
Während es zwischen den Staaten keine funktionelle Differenzierung gibt (Waltz 1979: 97), gibt es zwischen ihnen Unterschiede hinsichtlich ihrer relativen Machtposition (capabilities). D.h. die Staaten sind im internationalen System nach ihrer Machtposition positioniert (Waltz 1979: 97), d.h. ihre Macht ist relativ: „Power is estimated by comparing the capabilities of a number of units.“ (Waltz 1979: 98). Da ihre Macht (capabilities) relativ ist, werden sich die Staaten bei ihren Entscheidungen und Handeln entsprechend den Strukturbedingungen des anarchischen internationalen Systems rational verhalten müssen: „Competitive economic and international-political systems work differently. Out of the interactions of their parts they develop structures that reward or punish behavior that conforms more or less nearly to the system`s requirements.“ (Waltz 1979: 92). Irrationales Handeln kann das Überleben, Unabhängigkeit und Sicherheit des Staates riskieren. Die Staaten streben danach, ihre Autonomie zu bewahren: „States strive to maintain their autonomy.“ (Waltz 1979: 204). Jeder Staat hat Interesse, Einflusspolitik auszuüben. Dabei muss er aber darauf achten, dass er mit seinem außenpolitischen Handeln im SelbsthilfeSystem seine Sicherheit und Autonomie nicht in Gefahr bringt: „A self-help system is one in which those who do not help themselves, or who do so less effectively than others, will fail to prosper, will lay themselves open to dangers, will suffer. Fear of such unwanted consequences stimulates states to behave in ways that tend toward the creation of balance of power." ${ }^{\text {84 }}$ (Waltz 1979: 118). Die Macht (politische, wirtschaftliche und militärische Fähigkeiten), d.h. Capabilities, bestimmt also die Handlungsgrenzen der Staaten, nach denen sie rational handeln müssen.

Macht hat eine zentrale Bedeutung im Neorealismus. Waltz (1959: 205) definiert Macht in seiner Doktorarbeit ,[...] following Hobbes, as the capacity to produce an intended effect“. D.h. die Fähigkeit, das erwünschte Resultat zu erzeugen. Später sagte Waltz (1979: 192), dass die Macht „,has to be defined in terms of the distribution of capabilities [...]. “D.h. die Macht musste im Hinblick auf die Verteilung der Machtressourcen definiert werden. Im Vergleich zu Morgenthau, ${ }^{85}$ der die Macht als Motivation und Erklärungsfaktor definiert,

\footnotetext{
${ }^{84}$ Waltz zufolge entsteht ein Machtgleichgewicht (balance-of-power) durch die anarchische Systemstruktur, in dem die Staaten überleben wollen: „Balance-of-power politics prevail wherever two, and only two, requirements are met: that the order be anarchic and that it be populated by units wishing to survive." (Waltz 1979: 121). In dieser Systemstruktur ist zu beobachten, ob die Staaten ihr internationales Gewicht wechselseitig auszutarieren (balancing) versuchen oder ob die Schwächeren (um Gewinne zu erzielen) sich -wenn die interne und externe Machtsteigerung nicht möglich ist- dem Stärkeren anschließen (bandwagoning) (Waltz 1979: 126; Masala 2005: 57; Siedschlag 2004: 7 f.; Krell 2009: 160).

${ }^{85}$ Morgenthau sagt, dass der Machttrieb für die Menschen ein Grundtrieb ist: ,Jeder begreift, daß der einzelne nach Macht strebt ..." (Morgenthau 1963: 124). Der Machttrieb ist nach ihm wie der Trieb zu leben, sich fortzupflanzen und zu herrschen (Morgenthau 1963: 76) anthropologisch bedingt. Macht wird bei Morgenthau
} 
versteht Waltz (1979: 126) die Macht als Mittel zum Ziel: „[...] power is a means and not

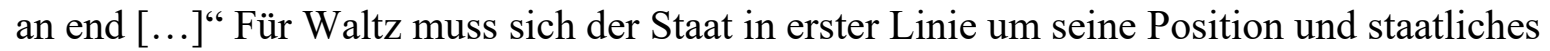
Überleben (Status Quo) ${ }^{86}$ im internationalen System bemühen und nicht um Macht: „... The first concern of states is not to maximize power but to maintain their positions in the system“" (Waltz 1979: 126). Die Macht ist nach diesem Verständnis eher für die Sicherheit nötig, damit der Staat seine Position aufrechterhalten kann. Nach Waltz (1979: 126) ist das höchste Ziel eines Staates das Überleben und Sicherheit im anarchischen internationalen System. Erst nachdem die Sicherheit gewährleistet ist, werden die Staaten nach Gewinnen und Macht suchen. Mit anderen Worten betreibt der Staat eine Machtpolitik (d. h. eine autonomie- und einflussteigernde Politik), ${ }^{87}$ da seine Sicherheit mit zunehmender Autonomie und zunehmendem Einfluss wächst (Baumann/Rittberger/Wagner 1999: 254): „Je prekärer die Sicherheitslage eines Staates ist, desto stärker wird er auf die Wahrung oder gar den Ausbau seiner Autonomie bedacht sein. Je weniger hingegen die Sicherheit eines Staates unmittelbar bedroht ist, desto eher können für Einflußgewinne auch Autonomieverluste in Kauf genommen werden.“ (Baumann/ Rittberger/ Wagner 1999: 268).

Wie wird aber Macht als Mittel eingesetzt und was sind die Machtressourcen nach Waltz? Für Waltz muss der Staat seine Ziele mit der Kombination seiner Machtressourcen durchsetzen. Diese Machtressourcen sind ökonomische, militärische und die anderen Kapazitäten bzw. Fähigkeiten und können nicht getrennt betrachtet und eingesetzt werden:

verstanden, als „die Macht des Menschen über das Denken und Handeln anderer Menschen“ (Morgenthau 1963: 124). Laut Morgenthau ist die internationale Politik ,wie alle Politik, ein Kampf um die Macht. Wo immer die letzten Ziele der internationalen Politik liegen mögen, das unmittelbare Ziel ist stets die Macht“" (Morgenthau 1963: S. 69). Demgemäß ist die Macht nach Morgenthau sowohl Gegenstand und Mittel als auch Selbstzweck des außenpolitischen Interesses (Morgenthau 1963: 54 f.). Morgenthau erklärt den Begriff Interesse „im Sinne von Macht“ (Morgenthau 1963: 51, 54). Die innenpolitischen und außenpolitischen Ziele der Staaten fasst er als Kampf um Macht (Morgenthau 1963: 80) in drei Gruppen zusammen: „Politik im engeren Sinn sucht entweder Macht zu erhalten, Macht zu vermehren oder Macht zu demonstrieren.“ (Morgenthau 1963: 81).

${ }^{86}$ Die defensiven Neorealisten wie Waltz, Walt und Grieco vertreten die Meinung, dass die Staaten im anarchischen System in erster Linie am Machterhalt, bzw. Status Quo interessiert sind (Baumann 2007: 64). Diese Annahme gilt sowohl für die TR als auch RU und die zentralasiatischen Staaten. Die offensiven Neorealisten hingegen wie Mearsheimer vertreten die Meinung, dass die Staaten im anarchischen System nach so viel Macht streben wie möglich. „,Die Strukturbedingungen des internationalen Systems machen es für einen Staat erforderlich, zumindest ein defensiver Positionalist zu sein, aber sie schaffen auch Anreize für eine offensiv-positionalistische Orientierung. Das Verhalten von Staaten ist davon bestimmt, ob sie revisionistische Ziele verfolgen oder statusquo-orientiert sind.“ (Baumann/Rittberger/Wagner 1999: 252).

87 „Die Autonomie eines Staates aus neorealistischer Sicht ein Maß dafür ist, wie wenig andere Staaten (also seine Umwelt) Kontrolle über ihn ausüben können (Kontrolle über seine Handlungen, über seine Machtressourcen, über sein Territorium etc.), ist sein Einfluß ein Maß dafür, wie stark er selbst auf seine Umwelt, insbesondere auf das Verhalten anderer Staaten einwirken kann. Diese Einwirkung schließt die Mitsprache bei Kollektiventscheidungen ebenso ein wie die Möglichkeit, die Außenpolitik eines anderen Staates im eigenen Sinne zu beeinflussen” (Baumann/Rittberger/Wagner 1999: 251). 
„A systems theory requires one to define structures partly by the distribution of capabilities across units. States, because they are in a self-help system, have to use their combined capabilities in order to serve their interests. The economic, military, and other capabilities of nations cannot be sectored and separately weighed." (Waltz 1979: 131). Die Staaten sind nach Waltz (1979: 131) nach ihren Capabilities, d. h. Machtressourcen geordnet. Deren Platz im internationalen System ist durch ihre Bevölkerungsgröße, Territorium, Ressourcenausstattung, Wirtschaftskraft, militärische Stärke, politische Stabilität und Kompetenz bestimmt (ebd.). Für Waltz (1979: 113) versuchen die Staaten, egal mit oder ohne Gewalt, ihre Interessen am besten zu verwirklichen: „Whether or not by force, each state plots the cource it thinks will best serve is interests."

Stephen M. Walt's „Balance-of-Threat“ Theorie (1987) nennt ebenfalls wie Waltz die wirtschaftlichen, technologischen und militärischen Faktoren als Machtressourcen des Staates. Diese Machtressourcen werden aber nur in Kombination mit den geographischen Gegebenheiten und Wahrnehmungen der Staaten voneinander bei ihrem Balancing- oder Bandwagoning-Verhalten ${ }^{88}$ eine entscheidende Rolle spielen (Walt 1987: 22). Z.B. der Staat B wird von dem Staat A als „Bedrohung, bzw. Gefahr“ wahrgenommen; wenn die „Aggregate Power“ (Gesamtleistung, z.B. die Bevölkerung, industrielle, technologische und militärische Kapazität) des Staates B stärker als seine ist, wenn der Staat B geographisch zu A nahe liegt und wenn der Staat B von dem A als aggressiv gegen sich wahrgenommen wird. Laut Walt (1987: 23) stellen die Staaten, die geographisch näher liegen, eine größere Bedrohung füreinander dar, als jene, die weit weg liegen: „Because the ability to project power declines with distance, states that are nearby pose a greater threat than those that are far away.“ (Walt 1987: 23). Die militärischen Entwicklungen in den geographisch näher liegenden Staaten werden in seinen Nachbarstaaten aufmerksamer beobachtet als in einem geographisch entfernten Staat (Walt 1987: 23). Auch die aggressiven Intentionen sowie das expansive Verhalten und die starke Gesamtleistung eines Staates provozieren die anderen Staaten, gegen ihn eine Allianz zu bilden (Walt 1987: 22, 25). Für Walt (1987: 32) bilden die Staaten Allianzen in Form von Balancing oder Bandwagoning gegen eine Bedrohung, wenn sie ihre Unabhängigkeit, Sicherheit in Gefahr sehen. Wenn die Gefahr durch die Balancing überwunden ist, werden die Allianzen zerfallen.

\footnotetext{
${ }^{88}$ Im „Balancing“ schloss sich der Staat an den Schwachen gegen den starken Staat an; im „Bandwagoning“ an den Stärkeren (Walt 1987: 21), da dieser starke Staat mit seinen großen Kapazitäten die Feinde bestrafen oder die Freunde unterstützten kann (Walt 1987: 23).
} 
Die Allianzen sind nach Neorealisten in der Regel nur Verteidigungsbündnisse. Andere Kooperationsformen sind nach Neorealismus aufgrund der anarchischen Struktur des internationalen Systems kaum denkbar. Das kooperative Verhalten zwischen den Staaten sieht Waltz aus Angst vor ungerechter Gewinnverteilung und möglichen Abhängigkeitsverhältnisse als unwahrscheinlich an:

\begin{abstract}
„When faced with the possibility of cooperating for mutual gain, states that feel insecure must ask how the gain will be divided. They are compelled to ask not 'Will both of us gain?' but 'Who will gain more?' If an expected gain is to be divided, say, in the ratio of two to one, one state may use is disproportionate gain to implement a policy intended to damage or destroy the other. Even the prospect of large absolute gains for both parties does not elicit their cooperation so long as each fears how the other will use its increased capabilities "(Waltz 1979: 105).
\end{abstract}

Waltz zufolge haben die Staaten Angst, dass einige Staaten aus der Kooperation mehr Gewinne ziehen und diese Überlegenheit gegen sie verwenden können (Waltz 1979: 105106). Der Staat hat auch Angst, durch die Kooperation von dem anderen Kooperationspartner abhängig zu werden: „A state also worries lest it become dependent on others through cooperative endeavors and exchanges of goods and services“ (Waltz 1979: 106). Die ,asymetrische Interdependenz“ (Robert Keohane, Joseph Nye) wird dem starken Kooperationspartner ermöglichen, den schwächeren Partner für ihre Zwecke zu beeinflussen und zu instrumentalisieren: ,If I depend more on you than you depend on me, you have more ways of influencing me and affecting my fate than I have of affecting yours." (Waltz 2000: 15-16). Das Misstrauen und die Unsicherheit in der Anarchie vertiefen die Ängste der Staaten voneinander und verhindern die Zusammenarbeit. Supranationale Organisationen bedeuten für die Neorealisten den Autonomie- und Einflussverlust des Staates (Baumann/Rittberger/Wagner 1999: 264). Für Waltz ist der Staat im internationalen System immer einer hohen Sicherheitsbedrohung ausgesetzt. Daher hat laut ihm die Autonomiewahrung und -steigerung des Staates Priorität (Waltz 1979: 204), besonders in sicherheitsrelevanten Politikfeldern, da auf den Partner kein Verlass ist. Ein unabhängiger Staat entscheidet nach Waltz souverän, wie er mit seinen Problemen und mit anderen Staaten umgeht: „To say that a state is sovereign means that it decides for itself how it will cope with its internal and external problems, including whether or not to seek assistance from others and in doing so to limit its freedom by making commitments to them." (Waltz 1979: 96). 


\section{Wichtige Annahmen des Neorealismus im Überblick}

* Staaten (units) sind die ziel- und zweckgerichteten, rationalen Hauptakteure im anarchischen System. Die subsystemischen Faktoren haben keinen oder kaum Einfluss auf die Außenpolitik.

* Aufgrund der Anarchie gibt es keine funktionelle Differenzierung zwischen den Staaten, da alle Staaten um ihr Überleben kämpfen. Der einzige Unterschied zwischen denen ist ihre relative Machtposition, d.h. Capabilities im internationalen System.

* Da die Macht der Staaten relativ ist, werden sie sich im Rahmen ihrer Capabilities rational verhalten müssen, um ihre Sicherheit und Unabhängigkeit nicht in Gefahr zu bringen. D.h. ihr Machtpotential bestimmt ihre Handlungsgrenzen.

* Anarchie des internationalen Systems zwingt die Staaten für ihre Sicherheit selbst zu sorgen, weil es keine übergeordnete Kontrollinstanz gibt, die die zwischenstaatlichen Beziehungen regelt. Deshalb ordnen die Staaten alle anderen Ziele ihrem Überleben, Sicherheit und Unabhängigkeit runter. D. h. Sicherheitspolitik ist „high politics““

* Macht ist nach Waltz ein Mittel zum Ziel, um die erwünschten Resultate zu erzielen. Die Staaten brauchen sie in erster Linie, um ihre Position im internationalen System aufrechtzuerhalten, d.h. für ihre Sicherheit. Erst nachdem ihre Sicherheit gewährleistet ist, können sie Machtpolitik betreiben, um ihre nationalen Interessen besser zu verfolgen und durchzusetzen. Mit zunehmendem Einfluss und Autonomie wird auch die Sicherheit der Staaten wachsen.

* Neorealismus konzentriert sich bei der Zielverfolgung auf die Anwendung der materiellen Machtressourcen, wie z.B. Militär- (Drohungen, Zwang, Gewalt) und Wirtschaftsressourcen (Zahlungen, Sanktionen usw.). Das Ziel ist die Verwirklichung der nationalen Interessen, egal mit oder ohne Gewalt.

* Aus Angst vor ungerechter Gewinnverteilung, Misstrauen und Entstehung der möglichen Abhängigkeitsverhältnisse im anarchischen System kooperieren die 
Staaten nicht. Denn laut Neorealismus kann die „Asymmetrische Interdependenz“ (Robert Keohane, Joseph Nye) dem starken Kooperationspartner ermöglichen, den schwächeren für ihre Zwecke zu beeinflussen und ihn zu instrumentalisieren. Die Allianzen sind deshalb nur Verteidigungsbündnisse. Die Staaten werden Allianzen bilden, wenn sie ihre Unabhängigkeit und Sicherheit in Gefahr (Walt, Balance-ofThreat) sehen. Wenn die Gefahr aber durch die Allianzbildung überwunden ist, werden die Allianzen wieder zerfallen.

* Nach Walt spielen bei dem „Balancing- oder Bandwagoning-Verhalten“ eines Staates neben seinen Machtressourcen (wirtschaftlich, militärisch, technologisch) auch seine geographische Lage und seine Wahrnehmungen von seinen Nachbarn eine große Rolle. 


\subsection{Soft Power}

Soft Power (Weiche Macht bzw. sanfte Macht) ist ein Konzept, das zuerst von Joseph S. Nye, Jr. in seinem Buch „Bound to Lead: The Changing Nature of American Power“ 1990 entwickelt wurde. Nye findet in diesem Buch heraus, dass die USA außer ihrer militärischen und wirtschaftlichen Macht durch ihre Soft Power Vorteile haben, die den Thesen über den amerikanischen Niedergang entgegenstehen. Sein Konzept der „Soft Power“ entwickelte er in seinem 2004 veröffentlichten Buch „Soft Power: The Means to Success in World Politics“ weiter. In diesem Buch führt er den Begriff „Smart Power“(Intelligente Macht) ein, der eine Kombination aus harter (Zuckerbrot und Peitsche operierender) und weicher (auf Überzeugung und Attraktion setzender) Macht ist (Nye 2004: 5; Nye 2011: 15). Für Nye (2011: 15) ist Soft Power nicht die Lösung für alle Probleme. Deshalb soll sie, wenn es nötig ist, mit Hard Power (harte Macht) kombiniert werden. Nye fasst 2011 sein durch Jahrzehnte Nachdenkens gesammeltes Wissen über Macht in seinem Buch „The Future of Power“ (dt. Macht im 21. Jahrhundert. Politische Strategien für ein Neues Zeitalter) zusammen.

Es besteht kein Widerspruch zwischen Realismus und Soft Power. Sie hat mit Idealismus und Liberalismus nichts zu tun. Laut Nye (2011: 135) ist sie einfach ,eine Spielart von Macht", eine Art und Weise, erwünschte Ergebnisse zu erzielen.“ Nye (2011: 49) definiert die Soft Power als „die Fähigkeit, andere mit kooptiven Mitteln zu beeinflussen, durch Agendasetting, Überredungskunst oder die Verabreichung positiver Anreize mit dem Ziel, erwünschte Ergebnisse zu erzielen“. Mit anderen Worten ist Soft Power die Fähigkeit, „,andere so weit zu bringen, dass sie dasselbe wollen wie Sie.“ (Nye 2011: 345). D.h. die Soft Power konzentriert sich auf die Präferenzen des Zielobjektes. Dabei ist für sie wichtig, bei den Betroffenen Legitimität zu gewinnen, weil Legitimität eine Machtrealität ist (Nye 2011: 135). Nicht nur die Staaten besitzen Soft Power, sondern auch Unternehmen, Institutionen, nichtstaatliche Organisationen und transnationale terroristische Netzwerke bis hin zu einzelnen berühmten Persönlichkeiten (Nye 2011: 135).

Nach Nye teilte der Realist E. H. Carr die internationale Macht bereits 1939 in drei Kategorien ein: militärische Macht, wirtschaftliche Macht und Meinungsmacht (power over opinion) (Nye 2004: 8; 2011: 134). Diese differenzierte Sichtweise von Carr aber ging verloren, weil 
„,zeitgenössische Neorealisten Macht für ihre strukturellen Analysen unbedingt quantifizieren wollten [...] Sie reduzierten Macht auf messbare, handfeste Ressourcen. Macht war für sie etwas, das man auf Menschen oder Städte loslassen konnte, nicht etwas, womit man von vornherein dem Wunsch, auf andere loszugehen, entgegenwirken konnte. " (Nye 2011: 134-135).

Der Einsatz von Gewalt, Drohungen und Zahlungen (Hard Power) ist für die Realisten die ultima ratio, weil alle Staaten im anarchischen System ihre Unabhängigkeit bewahren wollen und dafür nach Macht streben (Nye 2011: 47). (Neo)realismus betrachtet die Weltpolitik gleich als „Machtpolitik“. Die realistische Spielart von Macht aber führt im Informationszeitalter, in dem die Staaten vernetzt sind, nicht mehr zu den erwünschten Ergebnissen, weshalb sie mit Soft Power kombiniert werden sollen:

„In einer Ära der Informationsgesellschaft bekommen Kommunikationsstrategien eine zunehmende Bedeutung, und Ergebnisse politischen Handelns hängen nicht mehr ausschließlich davon ab, wessen Streitkräfte den Krieg gewinnen, sondern auch davon, wessen 'Story' am besten ankommt." (Nye 2011: 48).

Bei dieser Story geht es darum, wie Nye (2011: 48) sagt, um die Gewinnung der „Herzen und Köpfe“ der Bevölkerungsmehrheit:

„,Wenn Gewalt (Peitsche) und/oder Zahlungen (Zuckerbrot) mit dem Ziel eingesetzt werden, Agendapunkte zu bestimmen, nenne ich das harte Macht. Ein Durchsetzen von Themenschwerpunkten, das die davon Betroffenen selbst als legitim erachten, positive Anreize und Überredung sind Elemente eines Verhaltensspektrums, das dem Bereich der sanften Macht zugehört. Harte Macht entwickelt Schubkraft, sanfte Macht Zugkraft. " (Nye 2011: 49)

Eine vollkommen saubere Trennung der Soft Power von Hard Power (gemeint ist die Gewalthandlung, wie Drohungen, militärische Eingriffe, wirtschaftliche Sanktionen usw.) ist allerdings nicht möglich, wie Nye (2011: 50) sagt. Selbst militärische Interventionen können als Soft Power gelten, wenn sie aus humanitären Gründen durchgeführt werden. „Kriegsschiffe können dafür eingesetzt werden, Schlachten zu gewinnen (harte Macht), aber auch dafür, Herzen und Köpfe zu erobern [Soft Power]“" (Nye 2011: 50). Wenn die militärischen Ressourcen nichtrepressiv und für einen guten Zweck eingesetzt werden, können sie zu einer wichtigen Quelle weicher Macht werden, etwa für das Agendasetting oder für Strategien der Überredung und Sympathiewerbung (Nye 2011: 55). Zur Legitimität des ,gerechten Krieges“ gehört sowohl die gute Sache, ,für die man kämpft, als auch die Art und Weise, wie man das tut." (Nye 2011: 81). Die Ausbildung ausländischer Truppen kann sowohl als Instrument der Hard Power als auch der Soft Power betrachtet werden: 
„,Wenn die USA zum Beispiel irakische oder afghanische Truppen ausbilden, tun sie dies vor allem in dem Bemühen, sie für die Bekämpfung von Aufständischen fit zu machen. Wenn solche Schulungs-, Ausbildungs- oder humanitären Hilfsprogramme darüber hinaus auch der Sympathiegewinnung dienen, kann man sagen, dass die eingesetzten militärischen Ressourcen weiche Macht generieren. " (Nye 2011: 8586).

Für Nye (2004: 8) sind diejenigen, die die Wichtigkeit der Soft Power bestreiten, wie Menschen „,who do not understand the power of seduction.“

Die Soft Power eines Landes stützt sich auf drei grundlegenden Ressourcen: „seine Kultur (in den Bereichen, in denen sie attraktiv für andere ist), seine politischen Werte (soweit es ihnen im Innern und nach außen hin gerecht wird) und seine Außenpolitik (soweit andere sie als legitim und moralisch unangreifbar ansehen).“ (Nye 2011: 137). Mit diesen Ressourcen versucht die Soft Power, sich attraktiv und sympathisch für das Zielobjekt zu machen, seine Präferenzen zu ändern und die erwünschten Resultate zu erzielen. Das Erlangen der Sympathie und Attraktion ist das Ziel des Handelnden (Nye 2011: 146). Beim Einsatz von Soft Power kommt es besonders darauf an, ,was das Zielobjekt denkt - die Zielobjekte sind in der Tat ebenso wichtig wie die Handelnden. [...] Weiche Macht ist ein Tanz, für den man Partner braucht.“ (Nye 2011: 137). Weil die Zielobjekte andere Bedürfnisse haben, muss die Soft Power sie bei ihren Strategien mitberücksichtigen. Sie ist für den Erfolg mehr auf die willigen Interpreter und Empfänger angewiesen (Nye 2004: 16). Die Wirksamkeit der Machtressourcen (sowohl für Soft- als auch für Hard Power) ist vom Kontext abhängig: ,,Tanks are not a great military power resource in swamps or jungles. Coal and steel are not major power resources if a country lacks an industrial base." (Nye 2004: 12).

Neben Kultur, Werte und Politik können, wie oben erklärt wurde, militärische und wirtschaftliche Ressourcen Soft Power erzeugen (Nye 2011: 138). Wirtschaft kann durch sowohl positive (Zollerleichterungen, Vergünstigung beim Marktzugang, Hilfsleistungen usw.) als auch negative (Embargos, Ausschlusskäufen, Einfrieren von Guthaben usw.) Sanktionen als Soft Power angewendet werden: „Was alle Sanktionen gemein haben, ist das Element der Manipulation wirtschaftlicher Transaktionen zur Durchsetzung politischer Absichten.“ (Nye 2011: 118). Das Ziel der Entwicklungshilfegeldern RU im „,neuen Ausland“ dient z. B. dazu, seinen Einfluss in der Region auszuweiten (Nye 2011: 126). Durch die positiven Sanktionen, wie z.B. wirtschaftliche Hilfen entsteht positive Stimmung 
der Nehmerländer zu dem Geberland: „Ein Geberland kann sich mit Hilfsleistungen die Gunst von Teilen der Elite des Nehmerlandes erkaufen, aber wenn die Hilfe zu Korruption führt und das bestehende Machtgleichgewicht zwischen den gesellschaftlichen Gruppen durcheinanderbringt, kann sie auch Unmut bei breiten Schichten der Bevölkerung auslösen, statt Sympathie zu wecken.“ (Nye 2011: 129). Die Absicht des Handelnden ist Nye (ebd.: 95) zufolge, dass die „Abhängigkeit des Anderen von ihm größer ist als seine Abhängigkeit von dem Anderen.“ (Nye 2011: 95). Staaten mit einem größeren Markt können die Marktzugänge leichter kontrollieren und Sanktionen verhängen (Nye 2011: 119). Z.B. der Besitz des Erdöls und Erdgases kann als Marktasymmetrie gegen die Abnehmer politisch instrumentalisiert werden. Russische Bemühungen, durch die Nutzung von Marktasymmetrien mehr Macht zu erlangen, treten auf dem Erdgassektor wesentlich deutlicher hervor als beim Erdöl (Nye 2011: 115).

Das Soft-Power-Konzept hat sich zwar mit Joseph Nye`s Werken in der Politikwissenschaft verwurzelt, ihre Verwendung in der Praxis ist aber vermutlich so alt wie die Geschichte der Menschheit. Sie änderte sich in Raum und Zeit (Nye 2004: 44). Soft Power haben kann manchmal Jahrhunderte dauern, da sie sich aus den Qualitäten der Lauterkeit, der Kompetenz, der Legitimität und des Vertrauens (Nye 2011: 86-87) ergibt. Sie ist auf die Glaubwürdigkeit angewiesen, und wenn Regierungen als manipulativ wahrgenommen werden und Informationen als Propaganda empfunden werden, ist die Glaubwürdigkeit schnell dahin. Daher; „Die beste Propaganda ist keine Propaganda.“ (Nye 2011: 136). Glaubwürdigkeit und Vertrauen sind die Bedingungen der erfolgreichen Bündnisbeziehungen (Nye 2011: 83). Die Überzeugung des Zielobjekts ist der Schlüsselbegriff der Soft Power. Der Präsident Inguschetiens der Russischen Föderation stellte folgendes fest: „Terrorismusbekämpfung ist im Wesentlichen eine Sache weicher Macht. Die schwerste Bestrafung sollte ein Prozent ausmachen. 99 \% sollten Überzeugung, Überzeugung, Überzeugung sein“ (in Nye 2011: 72). Die Überredung des Zielobjektes versucht die Soft Power durch direkten- und indirekten Weg zu erreichen, da sie bei einem erfolgreichen Handeln auf die Akzeptanz des Zielobjektes angewiesen ist.

Soft Power zielt auf die positive Anziehung im Sinne einer „Verlockung“ (Nye 2011: 148). Die Erzeugung der Soft Power hängt nicht nur von den Qualitäten des Handelnden ab, sondern auch davon, wie er vom Zielobjekt wahrgenommen wird (Nye 2011: 148). Wenn der Handelnde bei einem Zielobjekt Anziehung erzeugt, kann er bei einem anderen Abneigung 
hervorrufen, wenn sein Handeln als böswillig, manipulativ, inkompetent oder hässlich empfunden wird. Z.B. ein Hilfsprogramm, das als manipulativ wahrgenommen wird, kann Soft Power zunichtemachen (Nye 2011: 148-149).

Die „Ähnlichkeit“ kann zur Erzeugung von Soft Power beitragen. Psychologen erklären, wie Nye (2011: 148) berichtet, „,ass wir Menschen mögen, die uns ähnlich sind oder mit denen wir die Zugehörigkeit zu einer Gruppe teilen, und natürlich fühlen wir uns auch von körperlichen Merkmalen sowie von gleichgerichteten Einstellungen angezogen.“ Dieser Faktor, d.h. Ähnlichkeit, wird sowohl von der türkischen ZAP als auch von der russischen ZAP als Instrument benutzt. Für die beiden Staaten hat die Überredung des Zielobjekts eine entscheidende Bedeutung. Überredung enthält immer einen gewissen Grad an Manipulation, da der Überredende einige Punkte in seinem Interesse betont und die anderen weglässt (Nye 2011: 149). Agendasetting, d.h. die Festlegung von Themenschwerpunkten, hängt eng mit dem Modus der Überredung zusammen. Wenn das Zielobjekt die attraktive Agenda als legitim empfinden wird, hat die Agenda eine größere Chance, zu überzeugen (Nye 2011: 150). Bei diesem direkten Weg ist das Ziel des Handelnden durch seine Güte, Kompetenz und das Charisma, die gesellschaftliche Elite des Zielobjektes zu beeinflussen (Nye 2011: 151).

Bei dem indirekten Verhaltensweg werden für die Überredung des Zielobjektes Massenmedien (Hörfunk- und Fernsehprogramme), Austausch- und Hilfsprogramme, Kulturinstitute, PR-Kampagnen usw. eingesetzt (Nye 2011: 151). Sie können für die Wahrnehmungsänderung des Zielobjekts und die Legitimität der Agenda eingesetzt werden. Diese Verhaltensweise zielt eher auf die Emotionen und Narrative des Zielobjektes (Nye 2011: 150). Z.B. die große Mehrheit der Austauschstudenten und -schüler, die in den USA studierten, fühlen sich dem Land verbunden, wie die Erhebungen ergeben (Nye 2011: 153): „46 amtierende und 165 ehemalige Regierungschefs in aller Welt haben an amerikanischen Universitäten studiert.“ (Nye 2011: 152), wie z.B. Helmut Schmidt, Margaret Thatcher, Anwar Sadat, Mikhail Sakaschwili usw. (Nye 2011: 166). Hollywood oder amerikanische Werbefirmen exportieren die amerikanische Kultur und Werte, die z. B. zu den Präferenzänderungen der öffentlichen Meinung beitragen können. Laut Nye sollen sich aber die Taten der Handelnden nicht widersprechen. Nach ihm (Nye 2011: 167) widersprachen die Taten der USA in Abu Ghraib und Guantanamo ihren Werten, weshalb die USRegierung als heuchlerisch wahrgenommen wurde. Der Satelliten-TV-Sender al-Hurrah 
schaffte es trotz seiner effektvollen Programme nicht, im Nahen Osten nennenswerten Anklang zu finden. Dieser Sender wurde dort als staatliche amerikanische Propaganda wahrgenommen (Nye 2011: 167). 


\section{Wichtige Annahmen des Soft-Power-Konzeptes im Überblick}

* Nye (2011: 49) definiert die Soft Power (weiche Macht, sanfte Macht) als ,die Fähigkeit, andere mit kooptiven Mitteln zu beeinflussen, z. B. durch Agendasetting, Überredungskunst oder die Verabreichung positiver Anreize mit dem Ziel, erwünschte Ergebnisse zu erzielen.“ Mit anderen Worten ist die Soft Power die Fähigkeit, ,,andere so weit zu bringen, dass sie dasselbe wollen wie Sie.“ (Nye 2011: $345)$.

* Es besteht kein Widerspruch zwischen Realismus und Soft Power. Sie hat mit Idealismus und Liberalismus nichts zu tun. Laut Nye (2011: 135) ist sie einfach ,eine Spielart von Macht, eine Art und Weise, erwünschte Ergebnisse zu erzielen.“

* Nicht nur die Staaten besitzen Soft Power; sondern auch Unternehmen, Institutionen, nichtstaatliche Organisationen und transnationale terroristische Netzwerke oder einzelne berühmte Persönlichkeiten (Nye 2011: 135).

* Soft Power nutzt zahlreiche Ressourcen, wie Kultur, Werte, legitime politische Anliegen, ein attraktives Gesellschaftsmodell, eine erfolgreiche Wirtschaft und kompetente Streitkräfte (Nye 2011: 158). Diese Ressourcen werden für die Ausübung der Soft Power instrumentalisiert und ,in Form gebracht“ (Nye 2011: 158), wie z.B. in Form von nationalen Nachrichtendiensten, Kulturinstitute, diplomatische Vertretungen, Austausch-, Hilfs- und Schulungsprogramme. Ob sie bei den Zielobjekten positive oder negative Reaktionen auslösen, hängt vom Kontext und von der Qualität der eingesetzten Machtkonversionsstrategien ab (Nye 2011: 158).

* Soft Power versucht mit ihren Ressourcen und Machtstrategien beim Zielobjekt eine Sensibilität für ihre Qualitäten, wie Güte, Kompetenz und Charisma, zu wecken (Nye 2011: 158). Die Wahrnehmungen, die dabei erzeugt werden, können durchaus falsch sein - was bei Propaganda nicht selten der Fall ist. Wichtig ist, ob das Zielobjekt die Botschaft glaubt und die erwünschte Reaktion zeigt (Nye 2011: 159). 
* Eine Soft Power ergibt sich aus den Qualitäten der Lauterkeit, der Kompetenz, der Legitimität und des Vertrauens (Nye 2011: 86-87). Sie ist auf die Glaubwürdigkeit angewiesen. Wenn Regierungen als manipulativ wahrgenommen werden und Informationen als Propaganda empfunden wird, ist die Glaubwürdigkeit schnell dahin. Es gilt daher: „Die beste Propaganda ist keine Propaganda.“ (Nye 2011: 136).

* „Ähnlichkeit“ kann zur Erzeugung von Soft Power beitragen. Wie Nye (2011: 148) berichtet, mögen wir Menschen, „die uns ähnlich sind oder mit denen wir die Zugehörigkeit zu einer Gruppe teilen, und natürlich fühlen wir uns auch von körperlichen Merkmalen sowie von gleichgerichteten Einstellungen angezogen.“ 


\section{TÜRKISCH-RUSSISCHE ZENTRALASIENPOLITIK VON IHREM ANFANG BIS ZUM ENDE DES KALTEN KRIEGES}

Die Vorfahren der Türken wanderten laut der Geschichtsschreibung aus ZA nach Anatolien 1071 ein, d. h. Richtung Westen, und gründeten hier 1299 den Vorgängerstaat der TR, das Osmanische Reich (siehe Kap. 3.2). Die Russen hingegen erweiterten ihre Territorien u. a. auch Richtung Osten und eroberten zwischen den Jahren 1731-1895 die gesamte Region (siehe Abbildung 2). Als Anfang der türkisch-russischen Rivalität gelten die russischen Eroberungen der Nachfolgerkhanate der mongolisch-turksprachigen Goldenen Horde, des Khanates Kasan 1552 und des Khanates Astrachan 1554.

Abbildung 2: Russische Expansion in Zentralasien

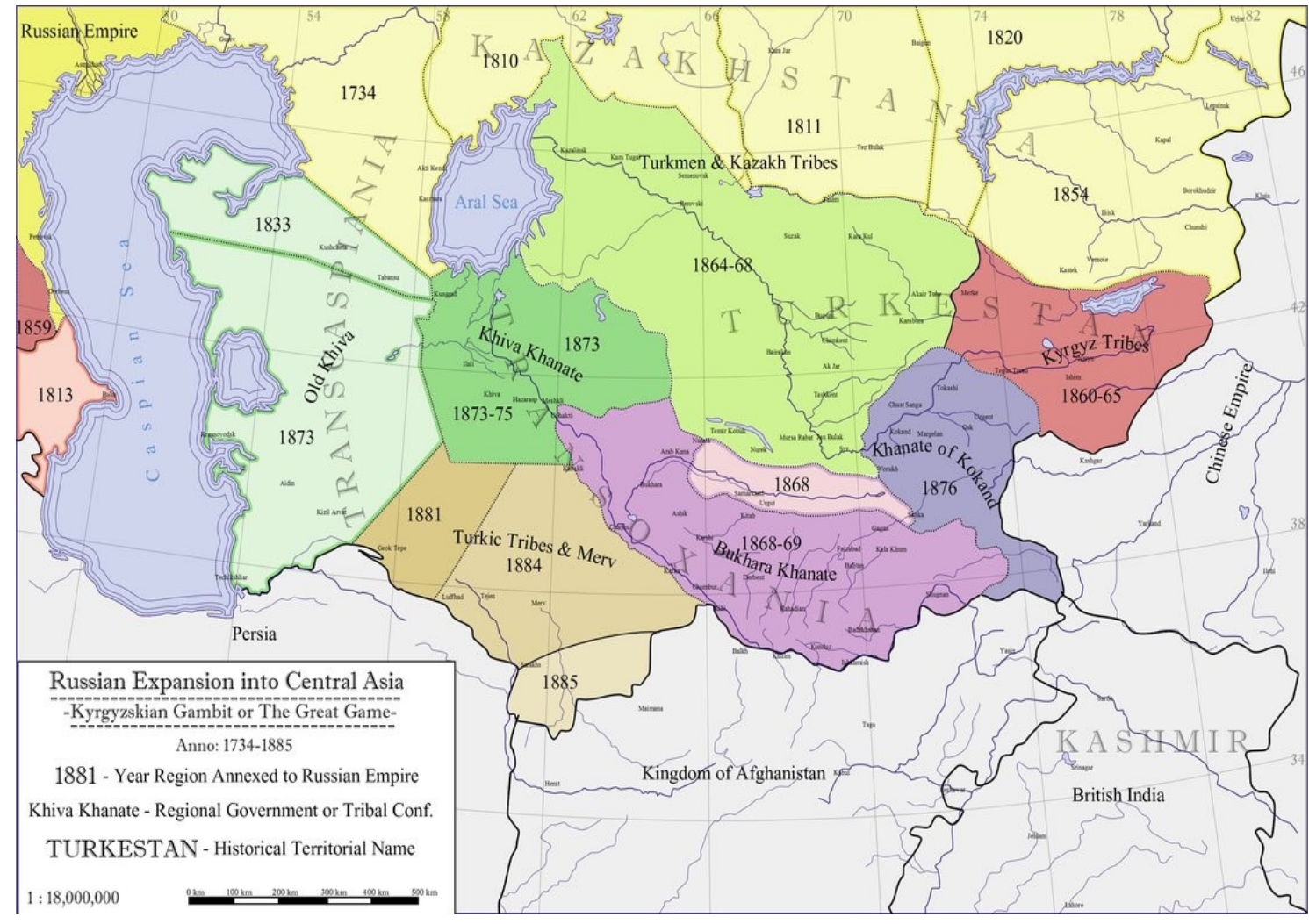

Quelle: Zalezsky o. J.

Aus türkischer Sicht trat das Zarenreich dadurch das Erbe des Osmanischen Reiches an, weil das Osmanische Reich sich als Erbfolge der turksprachigen Reiche bzw. Khanate sah. Aus russischer Sicht hingegen trat das Osmanische Reich mit der Eroberung Istanbuls 1453 das Erbe des christlichen Byzanz an, in dessen Erbfolge sich die russischen Zaren sahen. Diese machtpolitische, religiös und ethnisch begründete Sichtweise spiegelte sich in 15 türkischrussischen Kriege wider. Muslimisch und/oder turksprachig geprägter ZA war vom Beginn 
der türkisch-russischen Rivalität bis zur Auflösung der Sowjetunion ein Rivalitätspunkt in der türkisch-russischen Geschichte.

\subsection{Bezeichnungen Zentralasiens und die Machtverhältnisse}

ZA wurde im Laufe der Geschichte durch die je nach der regional und/oder international herrschenden Macht nach unterschiedlichen Kriterien (geographisch, politisch oder ethnokulturell) mehrmals umbenannt, z. B. in Transoxanien, Mawarannahr, Turkestan, Mittelasien, Innerasien usw. Diese Fremdbezeichnungen werden bis heute teilweise synonym für ZA verwendet. Die englische Bezeichnung Zentralasien (Central Asia) setzte sich ab Mitte des 20. Jahrhunderts in der wissenschaftlichen Literatur sukzessive durch. Es gibt allerdings bis heute keine einheitliche Verwendung der Bezeichnung ZAs (Stadelbauer 2004b: 318). Roy (2007: 1) zufolge kann der Begriff ZA, der ein variables Geographiekonzept impliziert, sich einmal nur auf Transoxanien beziehen, das andere Mal für alles, was zwischen Istanbul und Xinjiang liegt. Diese Bezeichnungen spiegeln einerseits die jeweiligen Machtverhältnisse wider; andererseits die aktuellen Zentralasienwahrnehmungen der Akteure. In der TR z. B. ist die Bezeichnung Turkestan als Türkistan (Land der Türken) besonders unter den Pantürkisten gängig.

\section{Transoxanien}

Im großen Teil des heutigen ZAs begann durch die wirtschaftliche Organisation und Arbeitsteilung schon in der Jungsteinzeit und später in der Bronzezeit eine Kultur, die „Andronovo-Kultur“ (2300 v. Chr. - 1000 v. Chr.) (Stadelbauer 2004a: 28) genannt wird. Die sozio-ökonomischen Entwicklungen führten zu einer gegenseitigen Kontaktaufnahme und zum Zusammenleben mehrerer Kulturen nebeneinander. Als Beispiel hierzu kann der Nomadismus im nördlichen Kasachstan und die Sesshaftigkeit über die Oasen am Gebirgsrand und an den großen Strömen samt deren Deltabereichen im Süden (Stadelbauer 2004a: 28-29) genannt werden. Zu dieser Zeit waren die wichtigsten Siedlungs- und Herrschaftsräume im Süden Choresm am unteren Amu Darja und Sogd ${ }^{89}$ (griechisch Sogdiane), östlich des mittleren Amu Darja (Oxus) am Serafschan (Stadelbauer 2004a: 29), d. h. die heutige Städte Buchara und Samarkand Usbekistans (siehe Abbildung 3). Des

\footnotetext{
${ }^{89}$ Herodot (ca. 485-430 v. Chr.) machte den Okzident mit der Bezeichnung Sogd vertraut. Sogd war ein historischer Teil des heutigen ZA (Sidikov 2004: 68).
} 
Weiteren gab es im heutigen Afghanistan und Tadschikistan Baktrien. Westlich von Baktrien lebten die Parther im 1. Jahrtausend v. Chr. in Merw, in der Flussoase des Murghab, deren erste Hauptstadt die heutige Nisa im Turkmenistan war. Vor allem war Merw mit seinem ausgedehnten Siedlungs- und Festungsbereich als Handelszentrum an der Seidenstraße von großer Bedeutung (Stadelbauer 2004a: 29).

Das persische Archämenidenreich (559-330 v. Chr.) schloss die genannten Teile ein und dehnte sich bis zum Syr Darja (Jaxartes) aus (siehe Abbildung 3) und erfasste damit einen großen Teil des „Turan“ (Stadelbauer 2004a: 30). Turan nannten die Perser das Land der Anderen, der Gegenpol zum ,reinen“ Iran. D. h. diese persische Bezeichnung der Region ist ein Antipode zum Iran und daher nicht wertfrei (Paul 2012: 20; Soucek 2003: 6). Den Kulturen in seinem Herrschaftsgebiet ermöglichte die Archämenidische Oberherrschaft recht eigenständige Territorien (Stadelbauer 2004a: 30). Der Eroberungszug (329-327 v. Chr.) Alexander des Großen in ZA beendete die Herrschaft der Achämeniden und brachte hellenistische Einflüsse nach ZA. Die Flüsse Amu Darja und Syr Darja markierten wichtige Grenzen, das dazwischenliegende Land wurde als Transoxanien bezeichnet (siehe Abbildung 3), d.h. jenseits des Oxus (Amu Darja) (Stadelbauer 2004a: 30; 2000: 4).

\section{Abbildung 3: Amu Darja und Syr Darja}
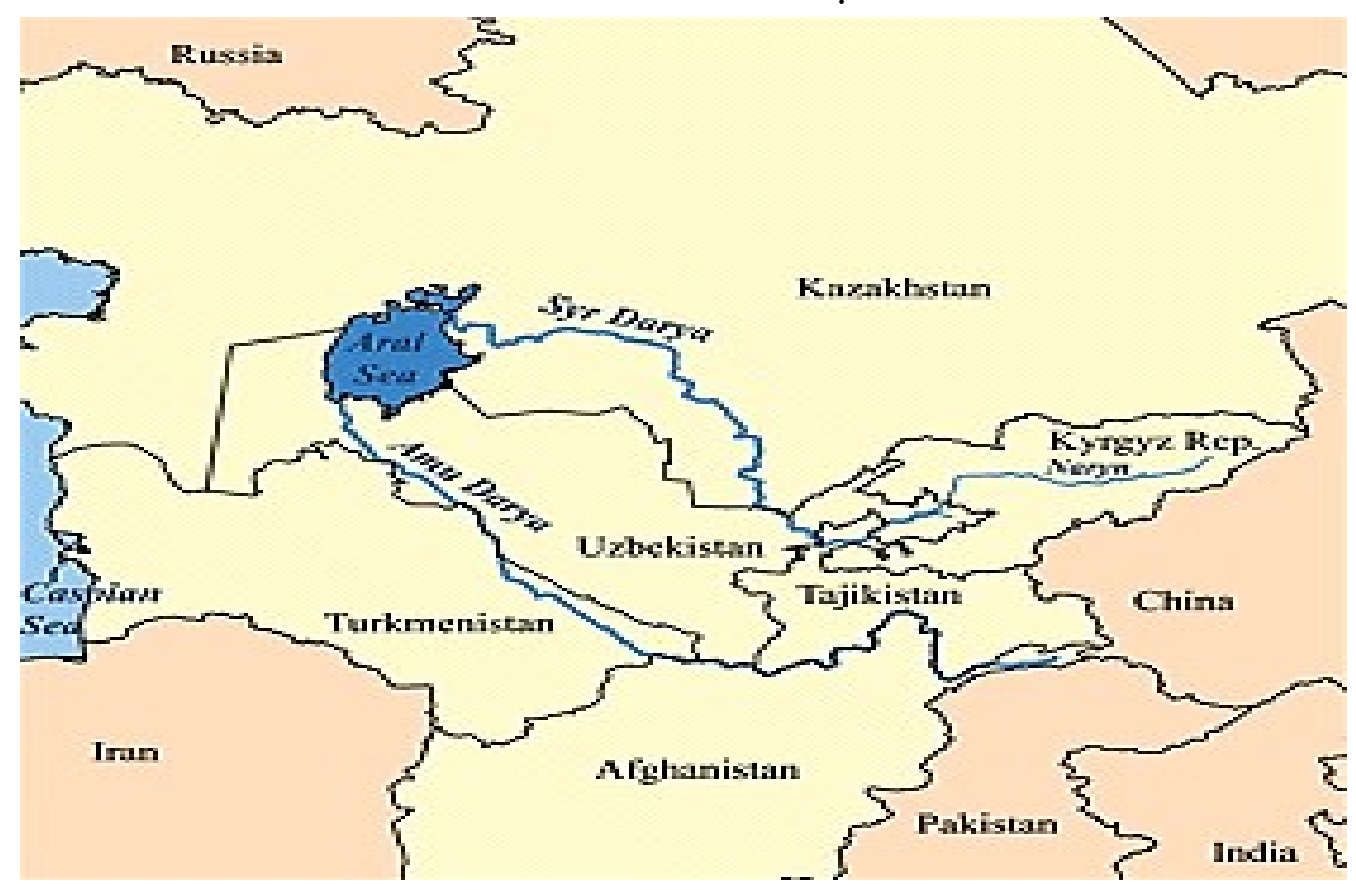

Quelle: Wikipedia 2018 
Buchara und Samarkand (Städte Usbekistans) waren die wichtigen Städte Transoxaniens. Transoxanien ist heute eine in der Region gebräuchliche Bezeichnung für das Land zwischen Amu Darja und Syr Darja (Paul 2012: 20) (siehe Abbildung 3)

\section{Mawarannahr}

Im 6. Jahrhundert noch im östlichen Sibirien und in der Mongolei siedelnde „Türken“ wanderten nach Transoxanien ein (Stadelbauer 2004a: 31-32). Diese gingen teilweise zur Sesshaftigkeit über und übernahmen die Herrschaft über die zerfallenden Vorgängerreiche der Hepthaliten (425-ca. 560) und der Sassaniden (224-651). Ab Mitte des 7. Jahrhunderts fingen die arabischen Eroberungszüge in ZA an. Ab Anfang des 8. Jahrhunderts eroberten die Araber ${ }^{90}$ südliche Teile ZAs, den historischen Raum Transoxaniens. So begann auch eine neue Phase der geschichtlichen Entwicklung in diesem Raum (Stadelbauer 2004a: 31-32). Die Araber drängten die Türken nach Norden zurück (Linska/Handl/Rasuly-Paleczek 2003: 9). Sie bezeichneten Transoxanien als „Mawarannahr“. Mawarannahr bedeutet auf Arabisch jenseits des Flusses, gemeint ist der Fluss Amu Darja (arabisch: Dscheihun). Die arabischen Geographen benannten im 10. Jahrhundert die persophone Region auch „Bilad al-Sugdh“ (Land der Sogdianer) (Soucek 2003: 5) um. Das Gebiet nördlich des Mawarannahr nannten die Araber „Bilad al-Turk“ (Land des Turkvolks) (Soucek 2003: 14). Die Schilderungen von den berühmten arabischen Reisenden Ibn Battuta im Jahre 1333 erhellen zwar einige Geschichtslücken über die Region (Sidikov 2004: 69). Die Geschichte der Region muss trotzdem bis zum Beginn des 13. Jahrhunderts größtenteils indirekt erschlossen werden, da der Mongolensturm (1218-1220) viele Zeugen der früheren Jahrhunderte, wie archäologische Funde und Erkenntnisse, auslöschte (Stadelbauer 2004a: 27).

\section{Tartarei und Turkestan}

In Europa wurde für die Region während des gesamten Mittelalters und in früher Neuzeit die Bezeichnung Transoxanien benutzt. Im 17. und 18. Jahrhundert stand auf den europäischen Karten für die Region noch sehr allgemein die Bezeichnung „Tartarei“, die im 19. Jahrhundert mit ethnopolitischer Komponente in die wissenschaftliche Terminologie als

\footnotetext{
${ }^{90}$ Unter ihrem Heerführer Kutaiba ben Muslim konnten die Araber große Erfolge verbuchen. Kutaiba ben Muslim ging es sowohl um Beutezüge, als auch um die Eroberung ZAs und die Bekehrung der dortigen Bevölkerung zum Islam. Bis zu den arabischen Invasionen waren dortige Einwohner Anhänger des Buddhismus oder Zoroastrismus (Linska/Handl/Rasuly-Paleczek, 2003: 61).
} 
„Turkestan“ einging (Stadelbauer 2004b: 321). Bei der Bezeichnung der Tartarei handelt es sich um eine nicht ganz unschuldige Fehlbezeichnung (Paul 2012: 21). Der Begriff Tataren wurde in Europa vor allem für die Mongolen ,als Eroberer und Feinde der europäischen Zivilisation“"verwendet. Die Europäer ordneten die Tataren - mehr oder weniger bewusst zu den Bewohnern der Unterwelt, bzw. der Hölle (wegen der lautlichen Nähe des Wortes Tatars zum griechischen Tartaros), zu (Paul 2012: 21). Die europäische ZA-Wahrnehmung ist durch zwei Bilder geprägt: Zum einen, wie das Beispiel Tartarei/Tartaros zeigt, durch die wilden Steppenkrieger und Inkarnation der Barbarei; zum anderen durch die Seidenstraße und damit in Verbindung gebrachte Ideenwelt (Paul 2012: 21-22).

In der Ära des Zaren Peter I. (1682-1725) fingen die russischen Eroberungszüge in ZA an. Peter I. glaubte, das Zarenreich wie die europäischen Kolonialmächte (wie das Britische Imperium, Spanien, Portugal usw.) ebenfalls Kolonien brauche, um ein Imperium nach europäischer Art zu gründen (Donnelly 1975: 207-208). Deshalb wollte er nach Indien einmarschieren und dafür musste er zunächst die dazwischenliegenden Regionen erobern, wie ZA (siehe hierzu Kap. 3.3). Ab 1717 fing das Zarenreich an, ZA schrittweise zu erobern und beherrschte 1895 das gesamte ZA (siehe Abbildung 2). 1867 gründete das Zarenreich nach der Eroberung eines Teils ZAs das Generalgouvernement Turkestan (russisch: Turkestanski Kraj). Taschkent wurde die Hauptstadt. Somit wurde der Terminus „Turkestan“ das erste Mal offiziell benutzt. Die Khanate Buchara und Chiwa erhielten zunächst einen Sonderstatus und waren dadurch im Verhältnis zum restlichen ZAs autonomer. Größtes Territorium des heutigen nördlichen Kasachstans gehörte dem Zarenreich (siehe Abbildung 4). 


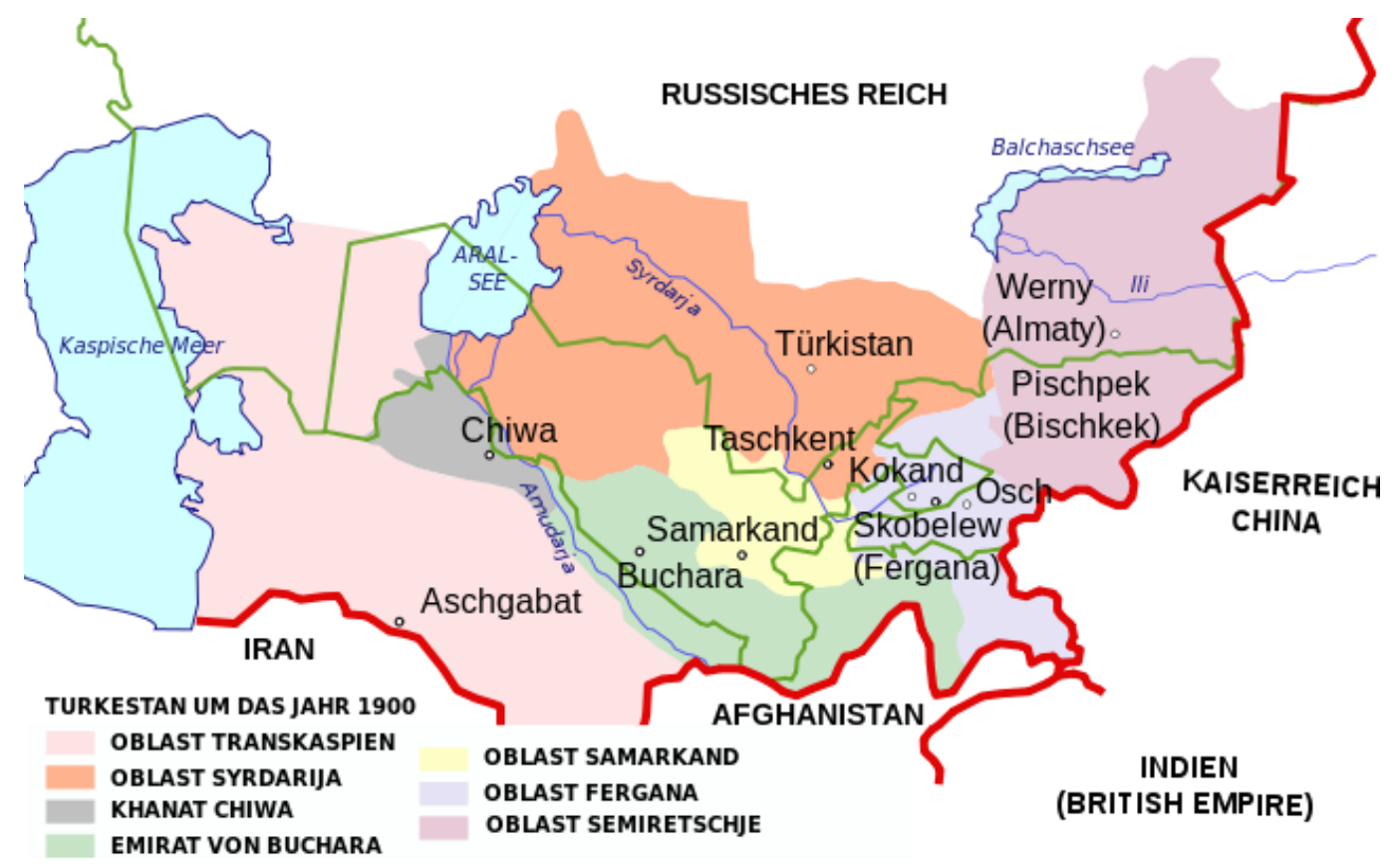

Quelle: Wikipedia 2009

Nach der bolschewistischen Revolution in RU entstand in ZA zunächst die einige Jahre bestehende „Autonome Sozialistische Sowjetrepublik (ASSR) Turkestan“, bzw. Turkestanische ASSR. Diese Republik bestand bis 1924. Der Terminus Turkestan wurde von den sowjetischen Behörden verboten (Linska/Handl/Rasuly-Paleczek 2003: 9; Hayit 1988: 25-27; Sidikov 2004: 79), weil er stark politisiert war, wie der pantürkistische BasmatschiAufstand zeigte (Stadelbauer 2004b: 322; Carrère d'Encause 1988: 184).$^{91}$ Der BasmatschiAufstand zwischen Sowjetrussland und Zentralasiaten 1918-1924 führte zu heftigen Auseinandersetzungen. Die zentralasiatischen Staaten wurden ab 1924 nach dem „Nationalitätenprinzip“ der Sowjetunion als Titularnation" umbenannt. Die damalige Sowjetregierung teilte die Region allerdings bis 1936 mehrere Male neu ein (Dschafarow 2009: 22). ${ }^{93}$ Somit waren die innersowjetischen Verwaltungsgrenzen (Halbach 2006: 7), mit

\footnotetext{
${ }^{91}$ Nach Hayit (1956: 31) entstand der Nationalismus unter den „Turkvölkern“ als Reaktion auf das russische Vorgehen, da sie ihre türkisch-islamische Kultur pflegen und den zunehmenden russischen Kultureinfluss Widerstand leisten wollten.

${ }^{92}$ Unter „Titularnation“ wurde die jeweils zahlenmäßig größte Gruppe einer Republik verstanden.

${ }^{93} 1924$ wurden zunächst die sozialistischen Republiken Usbekistan und Turkmenistan, 1927 Tadschikistan gegründet. Kirgisistan wurde 1929 in Kasachstan umbenannt und Kara-Kirgisistan in Kirgisistan. Schließlich wurden 1936 Kirgisistan und Kasachstan als sozialistische Republiken Teil der Sowjetunion. Zunächst hatten Tadschikistan und Kasachstan den Status von autonomen Republiken, Kirgisistan den des autonomen Gebiets innerhalb der UdSSR, bevor sie Unionsrepubliken wurden (List 2004: 24; Hayit 1956: 227-232; Stein 2004: 95).
} 
anderen Worten die „Nationale Abgrenzung“, abgeschlossen. Die räumliche Verteilung der Bevölkerung war so verwoben, dass eine ethnisch begründete Grenzziehung nicht schlüssig sein konnte (Stein 2004: 101). Dazu kam die Umsiedlung der Russen, Tataren und Tschetschenen usw. in die Region. Diese Grenzziehung prägt bis heute die territorialen Grenzkonflikte zwischen den zentralasiatischen Ländern, wie z.B. um das Länderdreieck Fergana Tal zwischen Usbekistan, Kirgistan und Tadschikistan (Halbach 2006: 7). Nach Hayit (1980: 14) stellte sich die Einheit Turkestans für RU als große Gefahr dar, weshalb es von RU aufgeteilt wurde.

ZA wurde/wird oftmals als Chinesisch-Turkestan, Russisch-Turkestan, AfghanischTurkestan oder West- und Ost-Turkestan bezeichnet. Unter Ost Turkestan, bzw. ChinesischTurkestan wird das uigurisches autonome Gebiet Xinjiang (veraltet Sinkiang) mit einer Größe von 1,8 Mio. $\mathrm{km}^{2}$ in China verstanden. In Xinjiang leben etwas über 20 Mio. Uiguren. Afganisch Turkestan, bzw. Südturkestan umfasst den nördlichen Raum von Afganistan, in dem etwa 5 Mio. Usbeken und Turkmenen leben. Auch Irans an Turkmenistan angrenzender Teil wird diesem Raum zugeordnet. Russisch-, bzw. West-Turkestan umfasst einen 4 Mio. km² großen Raum (Aynural/Kesici, 2005: 1212), in dem 2019 etwa 73 Mio. Menschen leben (United Nations, Department of Economic and Social Affairs, Population Division 2019). Zentralasiatische Staaten befinden sich in West-Turkestan. Laut Yazici (1997: 67) dienten die Bezeichnungen Russisch- und Chinesisch-Turkestan eher den politischen Interessen RUs und Chinas. Damit beabsichtigten diese Staaten, dass die Bezeichnung der Region als Turkestan, nur im Zusammenhang mit den beiden Staaten erwähnt wird und dadurch der Terminus Turkestan in die Vergessenheit gerät.

\section{Mittelasien}

Der Terminus Mittelasien erschien erstmals Ende des 18. Jahrhunderts in der europäischen Literatur. ${ }^{94}$ Diese Bezeichnung konnte sich allerdings nicht durchsetzen (Stadelbauer 2004b: 320). Er wurde erst bekannt, als die Sowjetunion die Bezeichnung „Turkestan“ 1924 durch die Bezeichnung „Mittelasien und Kasachstan“ (russisch: Sredn`jaja Aziya i Kazakhstan) (Linska/Hand1/Rasuly-Paleczek 2003: 9) ersetzte. Als Mittelasien (russisch: Sredn`jaja

\footnotetext{
${ }^{94}$ Samuel Friedrich Günther veröffentlichte 1795 in Leipzig eine Schrift „Altes und neues Vorder- und MittelAsien oder pragmatisch-geographische, fysische und statistische Schilderung und Geschichte des Persischen Reichs von den ältesten Zeiten bis auf diesen Tag.“ Unter dem Titel „Neuste Kunde von Asien“ gliederte später Theophil Friedrich Ehrmanns den Kontinent 1812 u.a. in West- und Mittelasien (Stadelbauer 2004b: 320).
} 
Aziya) bezeichnete die Sowjetunion die im 19. Jahrhundert durch das Zarenreich eroberten transkaspischen Staaten. Aus historisch-geographischen Gründen $^{95}$ rechnete die Sowjetunion zu diesem Raum den Süden Kasachstans. Der Rest Kasachstans wurde als Teil des Zarenreichs dargestellt. Nach Roy (2007: 1) entspricht diese russische Trennung des ZAs dem Terminus der Region als Transoxanien oder Mawarannahr, bzw. Turkestan. Diese alten Bezeichnungen der Region umfassten auch nur einen kleinen Teil des heutigen Kasachstans. Hayit (1980: 17) vertritt die Meinung, dass die Trennung Kasachstans von Mittelasien ein politisches Ziel der Sowjetunion war. Sie wollte damit die „Trennung der Turkvölker“ (Hayit 1980) erreichen. Rashid (1994: 5) betont eher den „,muslimischen Charakter“ Zentralasiens. Ihm zufolge versuchte die Sowjetunion seit ihrer Gründung 1917, Kasachstan von dem muslimischen ZA zu trennen und ihm als Teil des Zarenreichs eine Nicht-Asiatische- und Nicht-Muslimische-Identität zu verleihen (ebd.). Hierzu ist zu bemerken, dass Kasachstan vom Zarenreich im Vergleich zu den anderen zentralasiatischen Staaten früher, d. h. ab Anfang des 18. Jahrhunderts schrittweise erobert und von der Sowjetunion als einen geographisch verlängerten Teil seines Territoriums wahrgenommen wurde. Der Terminus „Mittelasien und Kasachstan“ wurde von der Sowjetunion bis zu ihrer Auflösung verwendet. Die TR verwendet für ZA die Bezeichnung Mittelasien und gelegentlich Türkistan (Land der Türken).

\section{Innerasien}

Um die festen Grenzen der Region $\mathrm{zu}$ bestimmen, schlugen die Geographen die Abflusslosigkeit als entscheidendes Merkmal vor. Demnach wäre ZA derjeniger Raum in Asien, dessen Gewässer nicht in einen Ozean münden (Paul 2012: 23; Hambly 1966: 1). Für Soucek ist die Bezeichnung Innerasien (russisch: Vnutren jaja Aziya) nicht nur geographisch, sondern auch historisch und politisch richtiger. Er zählt neben den zentralasiatischen Staaten auch Xinjiang und Mongolei zu Innerasien (Soucek 2003: ix). Stadelbauer (2004b: 320) ist auch wie Soucek für die Bezeichnung Innerasien, da diese Bezeichnung die neutralste und politisch am wenigstens belastete sei. Trotzdem konnte sich diese Bezeichnung nicht durchsetzen. ${ }^{96}$ Laut Davutoglu (2011: 457-458) wurde die

\footnotetext{
${ }^{95}$ Laut dem ehemaligen türkischen Außen- und Premierminister Davutoglu (2011: 457) bezeichnete RU ZA als Mittelasien, weil dieser geokultureller Raum mittig zwischen dem osmanischen, iranischen und indischen Kulturraum liegt.

${ }^{96}$ Sehr guter Überblick über die Bezeichnungen in Hauner, Milan (1990): What is Asia to Us? Boston: Unwin Hyman, S. 72-73.
} 
Bezeichnung Innerasien eher als eine geokulturelle Bezeichnung verwendet, weshalb sie neben ZA auch die Mongolei umfasst. Die TR verwendet für ZA die Bezeichnung Mittelasien (türkisch: Orta Asya). Diese entspricht offiziell der Bezeichnung Innerasien, weil sie dazu auch die Mongolei zählt, wie auf der Homepage des Türkischen Außenministeriums zu sehen ist (Türkiye Cumhuriyeti Disisleri Bakanligi o. J. a). Im Allgemeinen aber werden in der TR unter ZA die heutigen fünf zentralasiatischen Staaten ohne die Mongolei verstanden.

\section{Zentralasien}

Seit den 1950er Jahren des vergangenen Jahrhunderts wurde im Westen für die Region zunehmend der Begriff Zentralasien verwendet (Linska/Handl/Rasuly-Paleczek 2003: 9; Hayit 1988: 25-27). Die Bezeichnung der Region als Zentralasien (Central Asia, Asie Centrale, russisch: Central naja Aziya) geht auf Alexander von Humboldt ${ }^{97}$ zurück. Humboldt meinte mit Zentralasien allerdings das geographische „Zentrum Asiens“.

Abbildung 5: Tian Shan und Altai Gebirge

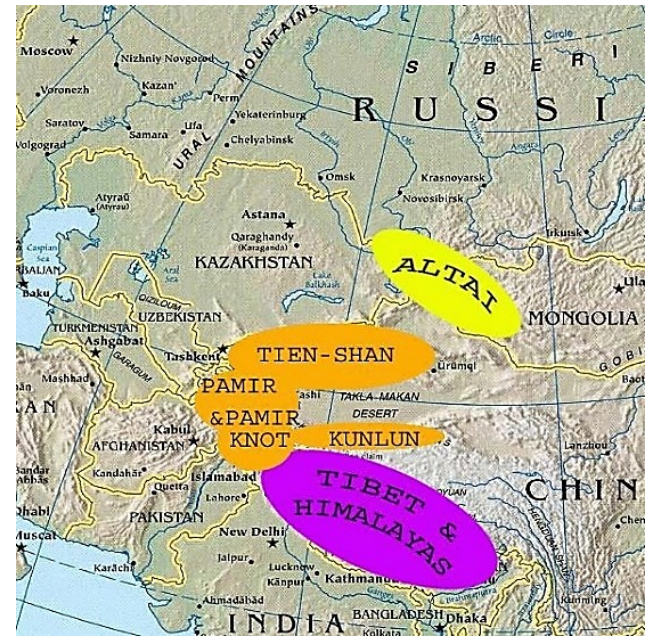

Quelle: boolim.blogspot.com

Nach Humboldt lag das „Zentrum Asiens“ zwischen den Gebirgsketten Tian-Schan und Altai in der Nähe des Sees Ayar (Humboldt 2009: 17), d.h. im heutigen nordwestlichen Teil des Xinjiang in China $^{98}$ (siehe Abbildung 5). Die Sowjetunion definierte als ZA den Westen Chinas (Ost-

\footnotetext{
${ }^{97}$ Auf Einladung des russischen Zaren 1829 im asiatischen RU machte Humboldt seine russisch-sibirische Expedition. Sein ganzes Werk wurde im Jahre 1843 in französischer Sprache unter dem Titel ,Asie centrale. Recherches sur les chaines de montagnes et la climatologie comparée; par A. de Humboldt“ in Paris bei Gide publiziert. Das Werk wurde 1844 ins Deutsche übersetzt und unter dem Titel „Central-Asien. Untersuchungen über die Gebirgsketten und die vergleichende Klimatologie“ in Berlin bei Carl J. Klemann veröffentlicht. Humboldts Zentral-Asien-Studie besteht aus drei Bänden. Der erste Band und der komplette zweite Band beschäftigt sich mit den Gebirgsketten Thian-Shan, Kuen-lun und Bolor (Humboldt 2009: 16), nach denen Humboldt ZA orographisch definierte.

${ }^{98}$ Laut dieser geographischen Berechnungen umfasst ZA die Gebiete zwischen dem Kunlun-Gebirge, den Thian-Schan Gebirge sowie den Hochebenen Himalaya, Altai Gebirge und einen großen Teil der KirgisischenSteppen bis zum Aral See. Humboldt bestimmte Amu Darja als westliche Grenze ZAs (Humboldt 2009: 17, 47, 77, 85 f., 103, 178, 412, 431).
} 
Turkestan) (Stadelbauer 2003: 61) und für das heutige ZA „Mittelasien und Kasachstan“, wie oben erklärt wurde.

Nach der Auflösung der Sowjetunion verlangten die zentralasiatischen Staaten Kasachstan, Kirgisistan, Usbekistan, Tadschikistan und Turkmenistan von der Weltgemeinschaft, ihre Region künftig als ZA zu bezeichnen. Am 4. Januar 1993 beschlossen die fünf zentralasiatischen Staaten auf einem Treffen für die regionale Kooperation, die sowjetische Bezeichnung „Mittelasien und Kasachstan“ durch ZA zu ersetzen. Dieser Wunsch der Republiken kann als Versuch verstanden werden, sich von ihrer kolonialen Vergangenheit unter russischer Herrschaft loszulösen. Des Weiteren schloss die sowjetische Bezeichnung „Mittelasien und Kasachstan“ Kasachstan von den anderen Staaten aus. Die Bezeichnung ZA hingegen umfasst auch das gesamte Kasachstan. Weiterhin ist die Bezeichnung ZA im Vergleich zu den oben genannten Bezeichnungen politisch weniger belastet. Abschließend sind weiterere Gründe für die Bezeichnung der Region als ZA die wirtschaftlichen, politischen, sozio-kulturellen Ähnlichkeiten und Probleme der zentralasiatischen Staaten.

\subsection{Zentralasien, Fürstentum Osman und Fürstentum Moskau}

Der Geschichtswissenschaft zufolge wanderten die im 6. Jahrhundert noch im östlichen Sibirien und in der Mongolei siedelnden Vorfahren der „Türken“ nach ZA ein (Stadelbauer 2004a: 31-32) und gründeten hier das Reich namens „Kök-Türk“ (552-742). Der Name „Türk“ wurde in der Geschichte das erste Mal durch das Reich „Kök-Türk“ verwendet. Dieses Reich streckte sich über den gesamten ZA sowie Mongolei und Nordchina. Die ältesten Grabstelen der Herrscher (Orchun-Monumente) dieses Reiches befinden sich in der heutigen Mongolei. Nach Paul (2012: 75) war die Bezeichnung „Türk“ eine Selbstbezeichnung für eine politische Konföderation und bestand aus verschiedenen ethnischen und linguistischen Gruppen, wie z. B. aus Mongolen, Turkvölker und Chinesen.

Im 7. Jahrhundert begann eine Islamisierung der Region infolge der arabischen Züge. Unter arabischer Herrschaft und dem Islam wurde der Süden ZAs im 9. und 10. Jahrhundert eines der Zentren des Wissens, besonders die Städte Buchara und Samarkand. Hier wurden Observatorien und Bibliotheken gegründet, versammelten sich Wissenschaftler, um die philosophischen naturwissenschaftlichen Probleme aufzugreifen und zu lösen. Besonders bei den Naturwissenschaften wurden vom 9. bis 15. Jahrhundert große Fortschritte erzielt, 
die die Welt Jahrhunderte geprägt hatten. ${ }^{99}$ Im 13. Jahrhundert wurden die Kultur- und Wissenszentren, die Archietektur wie Moscheen sowie Infrastruktur, Bazaare allerdings durch die Mongolen unter Dschengis Khan größtenteils zerstört (Mamajonov 2012: 13-14). Deshalb kann die Geschichte der Region bis zum Beginn des 13. Jahrhunderts großenteils indirekt erschlossen werden (Stadelbauer 2004a: 27).

ZA erlebte unter der Herrschaft von Amir Timur bzw. Tamerlan (1336-1405) im 14. und 15. Jahrhundert seine Wiedergeburt. Unter seiner Herrschaft wurde Kunst, Kultur und Wissenschaft gefördert (Mamajonov 2012: 13-14). Er ließ die durch den Mongolensturm zerstörten Städte wiederaufbauen, insbesondere die Hauptstadt Samarkand, welche anschließend die Hauptstadt des Timuridenreiches (1368-1501) wurde. Unter seiner Herrschaft erlebte ZA seine Blütenzeit. Buchara und Samarkand wurden wieder Kultur- und Wissenszentren und neben Mekka und Jerusalem wichtige heilige Städte des Islam. Der zentralasiatische Timur spielte beim Schicksal des Osmanischen Reiches und des Zarenreiches eine entscheidende Rolle. So vernichtete er z. B. in der Schlacht von Ankara 1402 das „Fürstentum Osman“ (türkisch: Osmanli Beyligi, später das Osmanische Reich) ${ }^{100}$ nahezu vollständig. Timur nahm den osmanischen Sultan Bayazid I. als Geisel. Sein Sieg führte im Osmanischen Fürstentum zu einem osmanischen Interregnum bzw. Brüderkrieg (türkisch: Fetret-Devri 1402-1413) zwischen den Söhnen des Sultans um die Herrschaft des osmanischen Fürstentums. Das Überleben verdankte das osmanische Fürstentum dem Rückzug der Armee des Timuridenreiches (Menzel 2008: 15).

Als Nachkomme des Dschengis Khans erhob Timur den Anspruch auf die Leitung des in der Schlacht von Ankara besiegten Osmanischen Reiches. Für Timur hatten nur die Mongolen Recht auf die Herrschaft, wie es im Mongolenreich des Dschengis Khans der Fall war. Die nicht-mongolischen Völker sollten versklavt werden (Nigehi 2006, übersetzt von Khalily 2018: 203). D. h. das mongolische Herrschaftsgeschlecht war für ihn den anderen, wie z. B. dem Osmanischen, überlegen. Nach Halil Inalcik (O. V. 2009: Kayi Soyu Teorisi ...) mussten die Söhne des osmanischen Sultans Bayazid I. nach dieser Schlacht die

\footnotetext{
${ }^{99}$ Hier sind exemplarisch einige Namen zu nennen: Muhammed Ibn Musa Al-Choresmi (in latinisierter Form als Al Gorismi, ging als Algoritma in die Mathematik ein), Imam Al-Buchari (ein wichtiger Religonsgelehrte), Achmad al-Fargani (Grundlagen der Astronomie und Entwicklung der Trigonometri), Abu Ali Ibn-i Sina (in latinisierter Form Avicenna schrieb die Grundlagen der Medizin, die für die Medizin ein Highlight war) usw. (Mamajonov 2012: 13-14).

${ }^{100}$ Den türkischen Historiker*innen zufolge entwickelte sich das Fürstentum Osman in dem Zeitraum vom osmanischen Herrscher Orhan (1326-1359) bis zur Eroberung Istanbul 1453 vom Fürstentum Osman zum Osmanischen Reich.
} 
Überlegenheit des zentralasiatischen Timuridenreiches anerkennen. Später schickte Timurs Sohn Schahruh dem osmanischen Sultan Murad II. (1421-1451 und 1444-1446) etwa um 1435 ein königliches Gewand als Geschenk (türkisch: Hilat) und bat ihn, dieses anzuziehen. Das Anziehen solcher Gewänder symbolisierte die Akzeptanz der Überlegenheit des Absenders. Daraufhin ließ Sultan Murad II. den Historiker Yazicizade Ali, die Geneologie der osmanischen Sultane schreiben. Dieses Werk heißt „Tevârîh-i Âl-i Selçûk“ oder „Oğuznâme“ (1436-1437) und gilt als erstes Geschichtsbuch über die Geneologie der osmanischen Sultane im Osmanischen Reich (ebd.). Laut dieser Geschichte stammen die osmanischen Sultane vom Hunnenkönig Oghus Khan (bekannt auch als Mao Tun) ab, der 209 v. Chr. sein Reich in der heutigen Mongolei gegründet hatte. ${ }^{101}$

Für das Fürstentum Moskau (später das Zarenreich, Russisches Reich) hingegen bedeuteten Timurs Siege gegen die Goldene Horde, unter deren Herrschaft das Fürstentum Moskau stand, den Aufstieg. Das Fürstentum Moskau befand sich etwa 250 Jahre (1238-1480) unter der tatarisch-mongolischen Fremdherrschaft der „Goldenen Horde“ (1227-1480). Timur griff Ende des 14. Jahrhunderts die Goldene Horde an. Zwar dauerte der Untergang der

\footnotetext{
${ }^{101}$ Oghus Khans Reich bestand aus den altaischen Völker, d. h. aus den Turkvölkern, Tunguzen und Mongolen. Laut Inalcik (O. V. 2009: Kayi Soyu Teorisi ...) ist die Geschichte von Yazicizade Ali eine selbsterfundene Geschichte und als eine politische Antwort auf das Timuridenreich zu verstehen. In Anlehnung an diese Geschichtsschreibung erhob das Osmanische Reich ab dem 15. Jahrhundert Anspruch auf die Leitung der Nachkommekhanate der mongolischen Goldenen Horde. Dieses Khanat wird ethnisch als mongolisch, als Nachkomme des Dschengis Khans, akzeptiert. Sie sprach aber eine Turksprache, tatarisch. Tataren wiederum gelten als Turkvolk. Allerdings wurde das Wort Tataren in den arabischen Quellen für die „,muslimisierten Mongolen" benutzt. Tatsächlich hat die Goldene Horde den Islam übernommen. Auch westliche Quellen nannten die Mongolen Tataren. Hier ist vermutlich wichtig, warum die Tataren eine Turksprache sprechen und nicht mongolisch. Eine plausible Antwort dafür ist, dass die mongolische Sprache und Tatarisch vermutlich eine einheitliche Sprache waren und sich erst im Laufe der Zeit durch die äußeren Einflüsse zu den eigenständigen Sprachen entwickelt haben. Im Endeffekt gehören beide zur gleichen Sprachfamilie, zur Altaischen. Das Osmanische Reich wollte durch die Eroberung des Khanats Krim, ein Nachfolgekhanat der zerfallenen Goldenen Horde, am Erbe der Goldenen Horde teilhaben, schreiben die Quellen der Zeit (T.C. Basbakanlik Devlet Arsivleri Genel Müdürlügü 1992: XXXIX). D. h. es sah sich in der Erbfolge der Goldenen Horde. Sein erster Krieg gegen das Zarenreich führte das Reich für die Eroberung eines weiteren Nachfolgerkhanat der Goldenen Horde, des Khanats Astrachans. Das Geschichtsbuch „Oguzname“, die Eroberung des Khanats Krim und der Astrachan-Expedition können meiner Meinung nach als Anfang der pantürkistischen Theorie im Osmanischen Reich gelten und nicht wie bisher angenommen wird, die Entwicklungen im 19. Jahrhundert. Heute (2020) wird diese pantürkistischen Geschichtsschreibung auf den Internetseiten des türkischen Außenministeriums (türkisch: Disisleri Bakanligi), des Präsidialamtes (türkisch: Cumhurbaskanligi) und des Türkischen Heers (türkisch: Kara Kuvvetleri Komutanligi) zu sehen. Z. B. steht im Jahre 2020 auf der Homepage des Türkischen Heeres für das Gründungsjahr des „Türkischen Heers“ das Datum der Thronbesteigerung des Oghus Khans im Jahre 209 v. Chr.: „Kara Kuvvetlerinin kuruluş tarihi olarak, Büyük Hun İmparatoru Mete Han'ın tahta çıkış tarihi olan M.Ö. 209 yılı esas alınmıştır.“ (Kara Kuvvetleri Komutanligi 2020). Wie die Symbole des türkischen Präsidialamtes zeigen, akzeptiert die TR als erster „Türkenstaat“ das Hunnenreich von Oghus Khan (Türkiye Cumhuriyeti Cumhurbaskanligi o. J.). Des Weiteren werden 2 mongolische Reiche als „Türkenstaaten“ akzeptiert, die Goldene Horde und Timuridenreich. Das türkische Außenministerium akzeptiert alle Nachkommen dieser Reiche und/oder anderen turksprachigen Völker als „Türken“ (Türkiye Cumhuriyeti Disisleri Bakanligi o. J. a).
} 
Goldenen Horde nach den Angriffen 1391 und 1395 noch Jahrzehnte. Nach der Niederlage allerdings bezahlte das Fürstentum Moskau an die geschwächte Goldene Horde keine Tribute mehr. Für die Goldene Horde, deren Wirtschaft größtenteils aus den Tributzahlungen und Kriegsplünderungen bestand, bedeutete das in erster Linie ein wirtschaftlicher Verlust. In zweiter Linie war das der Kontrollverlust über das Fürstentum Moskau.

Kurzum wirkte sich das zentralasiatische Timuridenreich auf das Fürstentum Osman und Fürstentum Moskau unterschiedlich aus. Timur ermöglichte dem Fürstentum Moskau seinen Aufstieg zum Zarenreich. Das Osmanische Fürstentum hingegen hätte er fast vernichtet.

\subsection{Zentralasien, das Osmanische Reich und das Zarenreich}

Das Osmanische Reich erweiterte seine Gebiete 1321 in Thrakien und wurde besonders durch die Eroberung der für das Orthodoxie-Christentum heiligen Stadt Istanbul von Byzanz 1453 (T.C. Basbakanlik Devlet Arsivleri Genel Müdürlügü 1996: 4) eine europäische Macht. So trat es das Erbe des orthodox-christlichen Byzanz an, in dessen Erbfolge sich die russischen Zaren sahen. Nach der Eheschließung mit Prinzessin Zoe (Sophia) ${ }^{102} 1472$ erklärte sich Fürst Iwan III. zum Hüter der Orthodoxie, wie oben schon erwähnt wurde. Die Eheschließung, bzw. Ehediplomatie verlieh Iwan III. Imperiale Aura. Daraufhin wurde der byzantinische Staatsbegriff der Symphonia zur Staatsdoktrin, d. h. die Idee der Einheit von Kirche und Staat. Das Zarenreich nahm den Titel „III. Rom“103 (Seebaß 2006: 87; Hamel 1998: 23) an. Ab der Ära der Zarin Katharina II. (1762-1796) versuchte das Zarenreich die Vertreibung der Türken aus Istanbul und Europa sowie die Wiedergeburt Byzanzs (Hopkirk 2001: 21). Neben seiner religiösen Bedeutung hatte Istanbul wirtschaftliche und strategische Relevanz. Die Meerengen sind der „Schlüssel“ zum Schwarzen Meer bzw. zum Mittelmeer. Für dieses Ziel sollte das Zarenreich zunächst die umliegenden Gebiete um das Schwarze Meer erobern. Mit der Eroberung des Khanats Krim 1783 gewann das Zarenreich die Oberhand in den nördlichen Schwarzmeergebieten.

\footnotetext{
${ }^{102}$ Die Nichte des letzten Byzantinischen Kaisers Konstantin XI. Palaiologos.

103 I. Rom ist Westrom und II. Rom ist Ostrom (Byzanz). Die byzantinischen Symbole, wie z. B. der Doppeladler, wurden vom Fürstentum Moskau als Wappensymbol übernommen. Der linke Adlerkopf symbolisiert das Westrom, der rechte hingegen das Ostrom.
} 
Das Khanat Krim war einer von den Nachfolgerstaaten der zerfallenen Goldenen Horde. ${ }^{104}$ Das Osmanische Reich wollte durch die Eroberung des Khanats Krim am Erbe der Goldenen Horde teilhaben (T.C. Basbakanlik Devlet Arsivleri Genel Müdürlügü 1992: XXXIX). Das Khanat Krim akzeptierte 1475 die osmanische Herrschaft (Inalcik 1999: 28) und wurde ein wichtiger Verbündeter von ihm. Es unterstützte das Osmanische Reich bei Bedarf mit Soldaten und ermöglichte, dass das Osmanische Reich lange auf dem Balkan und Europa herrschen konnte. Des Weiteren bemühte es sich, den russischen Expansionismus zu stoppen (T.C. Basbakanlik Devlet Arsivleri Genel Müdürlügü 1992: 192-204, Quellennr.: 120, 124, $125,126,130) .{ }^{105}$ Wirtschaftlich war sein Verlust für das Osmanische Reich ein schwerer Schlag, weil die nördlichen Territorien des Schwarzen Meeres für die Osmanen ein wichtiger Lebensmittellieferant waren. Aus diesen Gebieten importierte das Osmanische Reich günstig Getreide, Honig, Salz, Fisch und Fleisch usw. Für das Zarenreich hingegen war die Eroberung der Gebiete um das Schwarze Meer von großer strategischer Relevanz, da das Schwarze Meer die Kontrolle der Handelswege und durch die türkischen Meerengen die Öffnung zur Welt bedeutete (Inalcik 1999: 34).

Das Zarenreich eroberte im 16. Jahrhundert alle Nachfolgestaaten der Goldenen Horde ${ }^{106}$ außer des Khanats Krim. Als Beginn der türkisch-russischen geopolitischen Rivalität gilt die Eroberung des Khanats Kasan 1552 und des Khanats Astrachan 1554 durch das Zarenreich (Inalcik 1999: 28). ${ }^{107} 108$ Dadurch trat das Zarenreich das Erbe der muslimischen, tatarischmongolischen Goldene Horde an, in deren Erbfolge sich die osmanischen Sultane sahen (siehe das Kap. 3.5). Mit dem Kalifat-Titel, ${ }^{109}$ den der osmanische Herrscher Yavuz Sultan

\footnotetext{
${ }^{104}$ Das Fürstentum Moskau lebte etwa 250 Jahre (bis 1480) unter der Herrschaft der Goldenen Horde.

105 Als Anfang der türkisch-russischen Diplomatie gilt die schriftliche Anfrage des Zaren Iwan III. an den Osmanischen Sultan für die Entsendung einer diplomatischen Delegation im Jahre 1492 (Türkiye Cumhuriyeti Moskova Büyükelciligi o. J.). Obwohl es zwischen dem Osmanischen Reich und Zarenreich diplomatische Beziehungen gab, waren die krimtatarischen Khane der Ansprechpartner für die russischen Botschafter. Der protokollarische Rang Russlands war für das Osmanische Reich um diese Zeit nämlich nicht mit dem Österreichs und Irans oder Venedigs vergleichbar. Der erste offiziell russische Botschafter wurde im Jahr 1700 infolge des Vertrages Konstantinapol nach Istanbul entsandt. Der Schriftverkehr dieser Beziehungen ist im russischen Archiv „Posolski Prikaz“ in der Abteilung für diplomatische Berichte zu finden (Ortayli 2013: 7778).

${ }^{106}$ Die Goldene Horde zerfiel 1420 in folgende Khanate: Krim, Kasan, Astrachan, Sibir, Kasak und Kasimow. 107 Das Osmanische Reich definierte die Eroberung der Khanate als „Gefahr“ für seine Einflussgebiete und nahm das Zarenreich seit diesem Datum als Rivale wahr (Inalcik 1999: 28).

${ }^{108}$ Mit der Eroberung des Khanats Astrachan sicherte das Zarenreich den Zugang zum kaspischen Meer und die Kontrollpunkte der Handelswege (Karawanenwege aus ZA und aus dem Iran) am nördlichen Kaspischen Meeres.

${ }^{109}$ Nach Auffassung sunnitischer Muslime soll der Herrscher der muslimischen Gemeinschaft dem Stamm Mohammads, den Quraysh, angehören und von der Gemeinschaft bestätigt werden. Dieser, d.h. der Kalif, ist der rechtmäßige Herrscher, der die Scharia (islamisches Recht nach Koran) einrichtet. Er ist Richter und
} 
Abbildung 6: Khanate Kasan, Astrachan, Krim ${ }^{110}$

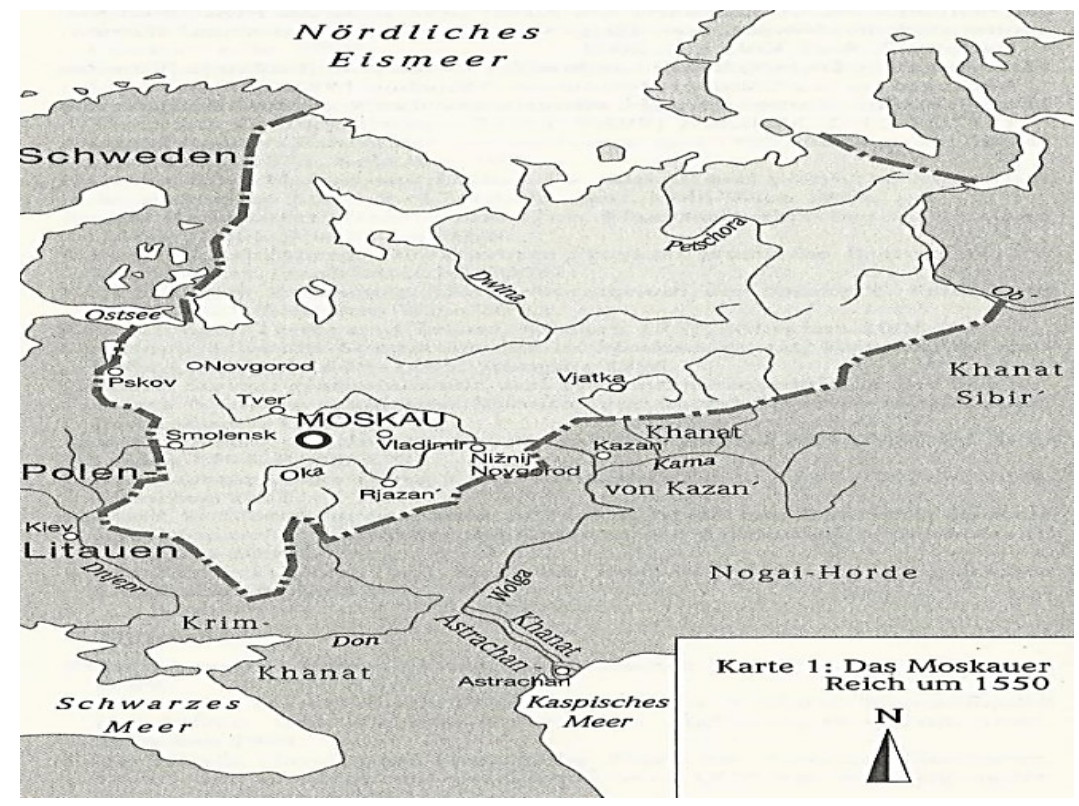

Selim (1512-1520) vom eroberten Ägypten 1517 holte, erhob das Osmanische Reich den Anspruch auf das religiöse Oberhaupt der sunnitischen Muslime, die heiligen Städte und Pilgerwege. So waren die osmanischen Sultane seit 1517 das religiöse Oberhaupt der sunnitisch-

islamischen Welt. Ab diesem Datum bekamen sie von den sunnitischen Staaten Akzeptanz und Unterstützung, z. B. aus dem sunnitischen ZA (T.C. Basbakanlik Devlet Arsivleri Genel Müdürlügü 1992: XLII; Sofuoglu 2009: 226). ${ }^{111}$ Den ersten Dschihad-Aufruf in der türkischislamischen Geschichte bekam der osmanische Kalif durch die Zentralasiaten gegen das christliche Zarenreich (Inalcik 1999: 30), weil das Zarenreich die Pilgerwege im unter seiner Herrschaft stehenden Khanat Astrachan geschlossen haben sollte (ebd. 29-30). Dem Aufruf folgte die Belagerung des Astrachans durch das Osmanische Reich (1568-1570). Dieser Krieg gilt als erster türkisch-russischer Krieg. Mit einem Kanalprojekt eines Don-WolgaKanals plante das Osmanische Reich eine direkte Wasserstraße bis ins Kaspische Meer zu eröffnen. Dieser Kanal sollte die Verbindung zwischen den zentralasiatischen Khanaten und dem Osmanischen Reich ermöglichen (Siehe Abbildung 6). Des Weiteren versuchte das Osmanische Reich mit diesem Krieg die russischen Eroberungen Richtung Süden, dem Kaukasus und dem Asowschen Meer (das würde ja den russischen Zugang zum Schwarzen Meer bedeuten), zu stoppen (Kurat 1966: 102-103). Den Krieg gegen das Zarenreich verlor das Osmanische Reich.

\footnotetext{
Heerführer, bringt das Gesetz Gottes zur Anwendung. Nach Meinung der Schiiten kann hingegen nur ein direkter Verwandter Mohammads ein rechtmäßiger Führer der muslimischen Gemeinschaft, der Imam sein (Schirrmacher 2009: 3) (Siehe hierzu auch Sonn (2005 [2004]: 84-85).

${ }^{110}$ Quelle: Kappeler, Russische Geschichte, S. 102; kopiert nach: O. V. (2016): Dynastien kommen und ...

${ }^{111}$ Die zentralasiatischen Khane sahen das Osmanische Reich in der Rivalität zum christlichen Zarenreich als ihr religiöses Oberhaupt und ihren Verbündeten an, wie die osmanischen Quellen belegen (T.C. Basbakanlik Devlet Arsivleri Genel Müdürlügü 1992: XXXV).
} 
Das Khanat Krim bekam vom Osmanischen Reich militärtechnische Unterstützung und nahm auf der osmanischen Seite ebenso an der Belagerung Astrachans teil. ${ }^{12}$ Das Osmanische Reich ließ den krimschen Khan Devlet Giray 1571 Moskau angreifen (Inalcik 1999: 29). Das Khanat Krim wurde ein Jahr nach seinem Angriff in Moskau vom Zarenreich vernichtend zurückgeschlagen. Das Osmanische Reich zog sich nach den russischen Siegen ganz aus der Region zurück und überließ auch den Nordkaukasus den Russen, den sie bis heute behalten haben (Menzel 2008: 28).

Nach dem Krieg um die Ukraine schlossen das Osmanische Reich, das Zarenreich und das Khanat Krim 1681 den Frieden von Bahcesaray. Dieser Frieden ist der erste offizielle Vertrag zwischen dem Osmanischen Reich und dem Zarenreich, in dem das erste Mal die offizielle Grenze (Fluss Dnepr) zwischen der Krim und dem Zarenreich festgeschrieben wurde. Nach diesem Vertrag gewannen russische Händler Bewegungs- und Handelsfreiheit auf der Krim (Gürsel 1968: 42-43). ${ }^{113}$

Der Vertrag von Konstantinopel 1700 nach dem türkisch-russischen Krieg (1686-1700) markiert den Anfang der Machtverschiebung vom Osmanischen Reich zugunsten des Zarenreiches (Inalcik 1999: 34). ${ }^{114}$ Nach diesem Vertrag behielt das Zarenreich die strategisch wichtige Asow-Festung. Sie galt, wie die Krim, als Schlüssel zum Schwarzen Meer. Des Weiteren ließ sich mit diesem Vertrag ein Zar das erste Mal einem osmanischen Sultan gleichstellen. Nach diesem Sieg konzentrierte sich das Zarenreich auf den Westen. Infolge des nach dem russisch-schwedischen Krieg abgeschlossenen Friedens von Nystad

\footnotetext{
112 Wie die Krim-Tataren kämpften auch die zentralasiatischen Khanate auf der Osmanischen Seite und unterstützten das Reich z. B. gegen das Safawidenreich (Iran). Der Grund ihrer Unterstützung war die religiöse Gemeinsamkeit. Während der Iran schiitisch und Feind des überwiegend sunnitischen Osmanischen Reiches war, waren die zentralasiatischen Khanate sunnitisch und akzeptierten den herrschenden osmanischen Sultan als ihr religiöses Oberhaupt. Z. B. als das Osmanische Reich 1533-1535 vom Westen aus den Iran und Irak angriff, ließ es den Iran vom Norden aus durch die zentralasiatischen Khanate angreifen. Den usbekischen Khan Abdüllatif (1540-1551) unterstützte der osmanische Sultan Kanuni Sultan Süleyman mit Kanonen. Der Khan kämpfte für das Osmanische Reich gegen den iranischen Schah Tahmasb I. In der Ära Sultan Murad III. (1574-1595) unterstützte das Osmanische Reich die zentralasiatischen Khane militärtechnisch (Gündogdu 1997: 296-297) weiter.

${ }^{113}$ Im 16. Jahrhundert hatten das Osmanische Reich und das Zarenreich auch Handel betrieben. Laut Nekrasov (1999: 96) war die Austauschware (größtenteils aus Sibirien) Pelze. Sie waren kein lebenswichtiges Gut, weshalb sie zu keiner Interdependenz und Konflikt führten (ebd.).

${ }^{114}$ Mit dem Frieden von Karlowitz (türkisch: Karlofca) 1699 mit der Heiligen Liga (Österreich, Polen und Venedig) wurde das Osmanische Reich aus seinen europäischen Besitzungen hinausgedrängt (Steinbach 2007: 16). Er zwang das Reich zu einer Status-Quo-Außenpolitik. Es gelang der Heiligen Liga, die europäischen Züge des Osmanischen Reiches zu stoppen. Laut Ayata und Gökberk (2013: 77) datiert dieses Datum deshalb den Anfang des Niederganges des Osmanischen Reiches.
} 
1721 bekam das Reich einen breiten Zugang zur Baltischen See. Der Zugang zum Schwarzen Meer und zur Baltischen See war von (militärisch)strategischer und wirtschaftlicher Relevanz, weil sich dadurch das Zarenreich zu einer Seemacht entwickeln und weltweit Handel treiben konnte. Seit der Herrschaft Iwan III. (1462-1505) glaubte das Zarenreich, dass die Kontrolle der beiden Seewege unter russischer Herrschaft stehen sollte. Deshalb sollten die südlichen Handelswege von Osmanen erobert und kontrolliert werden (Inalcik 1999: 34-35). So drängte das Zarenreich weiter nach Süden.

Bis zur Ära des Peter I. (1682-1725) galten sowohl das Osmanische Reich als auch das Zarenreich für die Europäer als Vertreter der „,barbarischen Welt“ außerhalb Europas (Parker 1960: 280). Mit der Herrschaft Peter I. änderte sich die negative europäische Sichtweise ins Positive. Er machte sein Land auf europäische Weise zu einer europäischen Großmacht. Besonders nach dem Sieg gegen Schweden 1709 erweiterte das Zarenreich seine europäischen Grenzen und führte europäische Reformen im wirtschaftlichen, technischen, sozialen und besonders im militärischen Bereich durch (Utz 2008: 33-46). Peter I. war während seiner Europareise von Europa dermaßen beeindruckt, dass er sich nach seinen neuen Reformen nicht mehr Zar nannte, sondern Imperator. Damit wollte er die Gleichrangigkeit des russischen Zaren mit dem römischen Kaiser aufzeigen (Utz 2008: 41). Den Namen des Zarenreiches änderte er auch nach europäischer Art auf „Russisches Reich“. Er führte eifrig zahlreiche Pflichten ein und dachte bis in die kleinsten Details, wie Rasierpflicht für Männer, nach usw. Er ließ seinen Sohn Alexej hinrichten, weil dieser kein Verständnis für die Umstrukturierungen des Zarenreiches nach europäischem Muster zeigte (Ortayli 2013: 71). Mit Peter I. trat Rom als Bezugspunkt an die Stelle des byzantinischen Kaisertums. D.h. die Rolle als Hüter der Orthodoxie versetzte er in seiner Ära mit Vernunft und Aufklärung (Utz 2008: 46) nach europäischem Muster.

Peter I. hatte während seiner Europa-Reise den Eindruck gewonnen, dass die führenden europäischen Kolonialmächte wie Spanien, Holland, England und Portugal ihren Reichtum durch ihre Kolonien erwarben, wie ich im Unterkapitel 3.1 „Tartarei und Turkestan“ erwähnt habe. Um ein Imperium nach europäischer Art zu ergründen, glaubte Peter I., brauche das Zarenreich ebenfalls Kolonien: „Asien ist Rußlands Zukunft, und diese Zukunft muß erobert werden“, sagte Peter (Hayit 1956: 17). Seine Ziele waren Indien und ZA (ebd.). Er glaubte, dass es neben exotischen indischen Schätzen auch in ZA, in der Nähe des Flusses Amu Darja Goldgruben gäbe. Deshalb ließ er 1717 den Fürsten Alexander Bekovich nach 
Chiwa (im heutigen Nordwesten Usbekistans) einmarschieren, wo er jedoch eine militärische Niederlage erlitt (Hopkirk 2001: 16-19). Dieser Angriff gilt als erster russischer Angriff in ZA. Um 1731 baten die kasachische Khane die russischen Zaren um die Aufnahme als russische Untertanen (Paul 2012: 354). ${ }^{115}$ Die Kasachen sind somit die ersten, die die russische Herrschaft akzeptierten.

Die Zarin Katharina II. (1762-1796), wie Peter I. expansionistisch ausgerichtet, schloss mit dem österreichischen Kaiser Joseph II. (1765-1790) 1781 ein Bündnis gegen das Osmanische Reich und schlug dem Kaiser vor, „das Griechische Projekt“ durchzuführen. Nach diesem Bündnisprojekt teilten die beiden Akteure das Osmanische Reich untereinander auf. Laut Hopkirk (2001: 21) war das einzige Ziel der Katharina II. die Vertreibung der Türken aus Istanbul und Europa sowie die Wiedergeburt Byzanzs. Kaiser Joseph II. teilte mit ihr die gleichen Ideen. Frankreich und Preußen wurden osmanische Gebiete versprochen, falls sie sich im Falle eines russisch-österreichischen Krieges gegen das Osmanische Reich zurückhalten würden. Die damalige Weltmacht England befand sich zu jener Zeit mit seiner Kolonie Amerika im Krieg (1775-1783). Das Bündnisprojekt des Zarenreichs und des Habsburger Reichs gefiel England überhaupt nicht, da dieses Vorhaben ohne seine Kenntnis vereinbart und ihm kein Land zugesprochen wurde. Deshalb hetzte England das Osmanische Reich zu einem Präventivkrieg (Gürsel 1968: 60) gegen das Zarenreich auf. Da das osmanische Ziel die Eroberung des Khanats Krim war, erklärte das Reich dem Zarenreich 1787 den Krieg. Das kaukasische Dagestan war in diesem Krieg ein Verbündeter des Osmanischen Reiches. ${ }^{116}$ Der Krieg endete mit einer Niederlage des Osmanischen Reiches und dem Frieden von Jassy 1792.

Das Khanat Krim sowie die anderen von Tataren bewohnten Gebiete im Süden der Ukraine verlor das Osmanische Reich nach dem türkisch-russischen Krieg von 1768-1774 bzw. dem Friedenvertrag Kücük Kaynarca 1774. Die Krim sollte nach Wunsch der Russen als von Osmanen unabhängiges Khanat weiterbestehen. Der Verlust der von Tataren bewohnten

\footnotetext{
${ }^{115}$ Kasachen verlangten vom Zarenreich Schutz und Hilfe gegen die Kalmücken und Dschungaren, da diese die kasachisch-kirgisischen Steppe ausbeuteten. Die chinesischen Quellen erwähnen die russische Unterstützung der Dschungaren gegen die Kasachen, damit die Kasachen die russische Hilfe anfordern und unter ihre Herrschaft geraten (Devriseva 2007: 21-23).

${ }^{116}$ Das Osmanische Reich beschenkte die muslimischen Verbündeten, um sich für ihre Unterstützung zu bedanken (T.C. Basbakanlik Devlet Arsivleri Genel Müdürlügü (1992), Quellennr.: 42, 43, 44, 46, 47, 48, 51, $53,54,62,63,64,80,81,104)$. Des Weiteren wurden die sunnitischen Verbündete militär-technisch unterstützt, wie die vom türkischen Innenministerium herausgegebenen osmanischen Quellen bestätigen (T.C. Basbakanlik Devlet Arsivleri Genel Müdürlügü (1992): XXIV., XXVI).
} 
Gebiete, wie die Krim, bedeutete für das Osmanische Reich einen Herrschafts- und Einflussverlust im Norden des Schwarzen Meeres. Die Kontrolle des nördlichen Schwarzmeergebietes war für die Osmanen größtenteils nur mit Hilfe der Krim möglich gewesen. Nach dem Verlust dieser strategisch sehr wichtigen Halbinsel konzentrierte sich das Reich nun auf den Südkaukasus, um ihre nördlichen und östlichen Grenzen gegen das Zarenreich und den Iran besser schützen zu können (Kantarci 2006: 50). Der russische KrimSieg bedeutete den Anfang der langen russischen Herrschaft im gesamten Südkaukasus und auch in den zentralasiatischen Staaten (Steinbach 2010: 92), die bis zum Zerfall der Sowjetunion andauerte. Des Weiteren brachte der Krim-Sieg das Zarenreich seinem Ziel bezüglich der Eroberung der türkischen Meerengen (Dardanellen und Bosporus) näher. Nach diesem Frieden wurde das Zarenreich ein Schwarz-Meer-Land und das Osmanische Reich zog sich weiter nach Süden zurück. Russische Wirtschaftsschiffe konnten ohne Hindernisse das Schwarze- sowie das Mittelmeer durch die türkischen Meerengen passieren. Mit diesem Vertrag akzeptierte das Osmanische Reich weiterhin die Einflussnahme des Zarenreiches in osmanischen christlichen Gebieten. Das Zarenreich akzeptierte im Gegenzug, dass der Osmanische Sultan der Kalif der Muslime im Zarenreich sowie auf der Krim (Gürsel 1968: 59; Steinbach 2007: 16) ist. Nach dem Frieden Kücük Kaynarca zogen immer mehr KrimTataren ins Osmanische Reich um (T.C. Basbakanlik Devlet Arsivleri Genel Müdürlügü 1992: XL). Das Osmanische Reich kämpfte auch nach diesem Frieden um die Krim, welche weiterhin ein Konfliktpunkt zwischen ihm und dem Zarenreich blieb (T.C. Basbakanlik Devlet Arsivleri Genel Müdürlügü 1992: 206-212, Quellennr.: 134, 135, 136, 137, 138). Das Zarenreich verbreitete auf der Krim politische Unruhen, um die seit dem Frieden von Kücük Kaynarca unabhängig gewordene Krim zu besetzen. Und 1783 besetzte sie es. Die Kontrolle der Krim brachte ihm enorme militärisch-strategische sowie wirtschaftliche Vorteile.

Obwohl die türkisch-russische Geschichte eine Geschichte der Kriege ist, gab es trotz der kriegerischen Auseinandersetzungen zwischen den beiden Imperien auch sicherheitspolitische Kooperationen. Die erste Kooperation fand in Form eines Militärbündnisses gegen Napoleon statt. 1798 marschierte Napoleon in das unter osmanischer Herrschaft stehende Ägypten und Malta ein. Aus sicherheitspolitischen und machtpolitischen Interessen kooperierten beide Reiche gegen Frankreich und unterschrieben am 23. Dezember 1798 für 8 Jahre ein Bündnisabkommen (Özbay 2011: 68; Gürsel 1968: 69). Das erste Mal durfte die russische Kriegsmarine die türkischen Meerengen passieren (Gürsel 1968: 69). Das erste Mal unterschrieb das Osmanische Reich mit einer christlichen 
Macht ein Bündnisabkommen (Isyar 2008: 120). Napoleon wurde besiegt. Das zweite Bündnisabkommen schlossen sie wieder gegen Napoleon im Jahre 1805 ab. Durch dieses Abkommen bekam das Zarenreich Durchgangsrecht durch die türkischen Meerengen und sicherte sich zudem das Recht, die türkischen Meerengen im Falle eines Fremdangriffes zu beschützen. Grundsätzlich durften keine sonstigen fremden Akteure die türkischen Meerengen durchfahren. Der russischen Kriegsmarine aber waren sie erstmal frei zugänglich (Gürsel 1968: 72; Özbay 2011: 68). Für das Zarenreich war die freie Bewegung seiner Kriegsmarine durch die türkischen Meerengen aus sicherheitspolitischen Gründen von großer Relevanz. Vor allem konzentrierte sich das Reich auf Kriegsschiffe der Fremdmächte und versuchte sie vom Schwarzen Meer fern zu halten.

1833 bat das Osmanische Reich das Zarenreich noch einmal um Hilfe gegen den Aufstand seiner Vasallen Ägyptens unter Mehmet Ali Pascha. Im selben Jahr wurde ein Verteidigungsabkommen, „Hünkar Iskelesi“, wegen der möglichen sicherheitspolitischen Gefahren unterschrieben. Beide Imperien sicherten sich gegenseitigen Beistand zu. Das Zarenreich forderte vom Osmanischen Reich als Gegenleistung, dass keine fremden Kriegsschiffe die türkischen Meerengen passieren durften. Mit diesem Abkommen akzeptierte das Osmanische Reich die russische Herrschaft, bzw. Überlegenheit (Gürsel 1968: 96). Wie diese Bündnisabkommen zeigen, suchten beide Akteure Kooperationen im sicherheitspolitischen Bereich, wenn es sich um eine oder mögliche sicherheitspolitische „,Gefahren “ handelte. Sobald die Gefahr aber vorbei war, lösten sie die Bündnisse wieder auf.

\subsection{Zentralasien im Great Game}

Der Wettbewerb, bzw. der Machtkampf zwischen dem Zarenreich und dem Britischen Imperium um Afghanistan und ZA wird in der Literatur als „Great Game“ bezeichnet. Das Zarenreich besetzte bis Mitte des 19. Jahrhunderts die Kasachisch-Kirgisischen Steppen. Die zaristischen Eroberungen in ZA sowie dessen Einmarsch in Persien im Jahre 1828 lösten britische Ängste um seine Kolonie Indien aus. Deshalb glaubten sie, Afghanistan besetzen zu müssen, um die russische Expansion zu stoppen. Um dieses Ziel zu erreichen, führte das Britische Imperium Kriege gegen Afghanistan. Laut Ucarol (2000: 268) kennzeichnet der erste Afghanistan-Einsatz des Britischen Imperiums den Anfang des Great Games zwischen ihm und dem Zarenreich. Räumlich lagen zwischen ihnen neben Afghanistan, noch die 
zentralasiatischen Gebiete, die das Zarenreich erst nach dem Krim-Krieg (1853-1856) eroberte.

Im Krim-Krieg versuchte das Zarenreich, sich zu Lasten des zerfallenden Osmanischen Reiches zu vergrößern. ${ }^{117}$ Das russische Ziel war die Eroberung Istanbuls und der türkischen Meerengen sowie das Erlangen der Vorherrschaft über die christlichen Kolonien des Osmanischen Reiches auf dem Balkan. ${ }^{118}$ Um das Schwarze Meer sowie das Mittelmeer militärisch und wirtschaftlich zu kontrollieren, brauchte das Zarenreich die Kontrolle der türkischen Meerengen. Das russische Interesse am Osmanischen Reich verstieß allerdings gegen die Interessen der anderen europäischen Akteure. Deshalb kämpften sie im KrimKrieg, allen voran England, Frankreich und später das Königreich Sardinien, auf Osmanischer Seite gegen das Zarenreich und siegten. Ohne die europäischen Verbündeten hätte das Osmanische Reich diesen Krieg eventuell verloren, da das Reich seit dem 18. Jahrhundert enorm an Macht verloren hatte. Laut Sander (2000: 273-275) halfen England und Frankreich dem Osmanischen Reich deshalb, weil sie glaubten, dass nur so die europäische Machtbalance zu schützen wäre. Sie wollten das Zarenreich außerhalb Europas halten und das russische Vordringen in Richtung osmanische Herrschaftsgebiete auf dem Balkan verhindern. Das Osmanische Reich sollte laut Frankreich und England noch eine Weile bestehen, um es später ohne das Zarenreich untereinander aufteilen zu können. Nach der Niederlage im Krim-Krieg konzentrierte sich das Zarenreich auf die Eroberung der zentralasiatischen Khanate, da der Pariser-Frieden russische Ziele am südlichen Schwarzen Meer erstmal gestoppt hatte. Laut Ortayli (2013: 83) wurde das Osmanische Reich mit diesem Vertrag von seinen europäischen Verbündeten als gleichberechtigten Partner akzeptiert und als Teil Europas gesehen.

Nach der Niederlage im Krim-Krieg konzentrierte sich RU wieder auf den Osten und setzte seine Eroberungen fort. Die turkmenischen Stämme innerhalb der zentralasiatischen Khanate Buchara und Choresm baten das Osmanische Reich 1870 um Hilfe gegen die

\footnotetext{
${ }^{117} \mathrm{Ab}$ der zweiten Hälfte des 16. Jahrhunderts vergrößerte sich das Zarenreich am Tag etwa um $80 \mathrm{~km}^{2}$ und erreichte bis zur Sowjet-Zeit ein Territorium von 22,4 Mio. $\mathrm{km}^{2}$, vom Osten bis zum Westen eine Ausdehnung von 10.000 km, vom Norden bis zum Süden von $5.000 \mathrm{~km}$ (Davletov 2003: 3; Sapmaz 2008: 86).

${ }^{118}$ Die osmanischen Balkankolonien werden als seine Herrschaftsgebiete auf dem Balkan angesehen und nicht als seine Kolonien. Allerdings waren die osmanischen Beziehungen zu den von ihm besetzten Balkan-Staaten eher kolonial geprägt. Diese mussten dem Osmanischen Reich Humanressourcen, d. h. Menschen, zum Staatdienst zur Verfügung stellen. 62 der 215 Großwesire des Reiches z. B. stammten aus dem Balkan (siehe hierzu Sancaktar 2010). Des Weiteren mussten die Christen dem muslimischen Osmanischen Reich Tribut zahlen.
} 
zaristischen Angriffe. Das Osmanische Reich begründete seine Zurückhaltung mit der geographischen Entfernung und dem dazwischenliegenden Iran. Den Khanaten empfahl das Reich mit dem Zarenreich einen Friedensvertrag zu schließen und $\mathrm{zu}$ versuchen, mit Minimalverlusten davon zu kommen (T.C. Basbakanlik Devlet Arsivleri Genel Müdürlügü 1992: 135-136 ${ }^{119}$ ). Nach zwei Jahren bat das Khanat Buchara das Osmanische Reich um technisch-militärische Unterstützung und diplomatische Beziehungen sowie um Lehrkräfte (T.C. Basbakanlik Devlet Arsivleri Genel Müdürlügü 1992: 136-138 ${ }^{120}$ ). Diesen Wünschen konnte das Osmanische Reich einerseits wegen seiner $\mathrm{zu}$ jener Zeit mangelnden militärischen und wirtschaftlichen Lage nicht nachkommen. Andererseits versuchte das Reich bei seiner ZAP die Interessen seines geopolitischen Rivalen (Zarenreich) zu berücksichtigen und sich im Rahmen der Verträge mit ihm zu bewegen, um seine Sicherheit nicht zu gefährden. Das gesamte ZA wurde vom Zarenreich bis zum Ende des 19. Jahrhunderts besetzt. Der Unterwerfung ZAs folgten massive slawische Einwanderungswellen, die in den folgenden Jahrzehnten immer wieder Anlass für Konflikte waren (List 2004: 23).

Die Besetzung ZAs brachte dem Zarenreich in erster Linie sicherheitspolitische Vorteile und Prestigegewinn, da das Gebiet zu einer Pufferzone gegen England, Iran und Afghanistan wurde. In zweiter Linie brachte die Region z.B. durch die Erschließung der Rohstoffe (besonders Baumwolle, später fossilen Brennstoffe) und die Absicherung der Handelswege wirtschaftliche Vorteile. In ZA wurde Erdöl und Erdgas im Vergleich zum Südkaukasus erst viel später gefördert. ${ }^{121}$ Die Region wurde seit Mitte des 19. Jahrhunderts die Baumwollanbauregion des zaristischen RUs. RU baute hier die Bewässerungssysteme aus, weil sich der Baumwollpreis während des amerikanischen Bürgerkrieges (1861-1865) vervierfachte (Shtaltovna/Hornidge 2015: 2). Das Beispiel Baumwolle und die Erdöl- und

\footnotetext{
${ }^{119}$ Quellennr.: 78, (9 Ekim 1870), BA. Irade-Meclis-i Mahsus, Nr. 1627

${ }^{120}$ Quellennr.: 79, 11 Agustos 1872, (S.32). BA. Irade-Hariciye, Nr. 15225.

${ }^{121} \mathrm{Im}$ erdölreichen Kasachstan wird das Erdöl seit etwa 100 Jahren gefördert. Erste Reserven wurden 1899 in Karagüngül endeckt (Ismayilov/Budak 2015: 1-2). In der aserbaidschanischen Hauptstadt Baku und Umgebung hingegen begann 1871 die industrielle Erdölförderung, die der Stadt einen schnellen, gewaltigen Reichtum bescherte (Quiring 2009: 59). Schon um 1900 machte die Erdölförderung in der Bakuer Provinz fast 60 \% der Weltförderung aus (Gumppenberg/Gumppenberg 2010: 52) und $194070 \%$ aus (Bimboes 2000: 187). Für das aus dem Erdöl gewonnene Petroleum stand ein riesiger Binnen- und Exportmarkt bereit. Erdöl wurde immer wichtiger, besonders für militärische und wirtschaftliche Zwecke (Bimboes 2000: 186). Die erste zentralasiatische Erdgaspipeline wurde 1967 gebaut (von Usbekistan via Turkmenistan und Kasachstan nach RU) und wurde bis 1985 ausgebaut (Kisacik 2012).
} 
Erdgaspipelines aus ZA nach RU zeigen, dass die russische Wirtschaftspolitik für ZA auf die wirtschaftliche Ausbeutung der Region ausgelegt war.

Das Zarenreich und das Britische Imperium unterzeichneten 1895 das Pamir-Abkommen, womit sie die Grenzen ihrer Interessengebiete festlegten (Hayit 1980: 92) und die Nordgrenze Afghanistans zu ZA festschrieben. Mit dem Frieden von Sankt Petersburg von 1907 mit dem Britischen Imperium vereinbarten sie die Beendigung der gegenseitigen Invasionen (Dschafarow 2009: 18-21; Sapmaz 2008: 88). Nach diesem Vertrag teilten sie den Iran in drei Teile auf: der Nord-Iran ging unter russische, der Süd-Iran unter englische Herrschaft und der mittlere Teil blieb neutral. Des Weiteren akzeptierte das Zarenreich, dass Afghanistan außerhalb seiner Interessensphäre liegt, d. h. es akzeptierte Afghanistan als englisches Protektorat. England sicherte dadurch seine Kolonie Indien (Dschafarow 2009: 21).

\subsection{Zentralasien, Panslawismus und Pantürkismus}

Die Niederlage im Krim-Krieg (1853-1856) und die Revolutionen in Europa 1848-49 verstärkten den russischen Panslawismus in großem Maße (Gürsel 1968: 120). Seine goldene Zeit erlebte der Panslawismus in der Ära Alexander II. (1855-1881) und erreichte seinen Höhepunkt im türkisch-russischen Krieg 1877-1878. Das Ziel des Panslawismus war die Vereinigung aller Slawen unter russischer Herrschaft. Diese nationalistische, antiwestliche Ideologie entwickelte sich zum außenpolitischen Konzept des Zarenreiches. Sie diente als Rechtfertigung für die expansiven Ziele des Reiches auf dem Balkan, in Mitteleuropa und Istanbul. Mikhail Pogodin (1800-1875) war einer der berühmtesten Vertreter dieser Ideologie. Nach ihm sollte das Zarenreich die Slawen von der osmanischen und habsburgischen Herrschaft befreien und sie unter seiner Herrschaft vereinigen (Kohn 1955: 59). Als Ideenvater des Panslawismus gilt Nikolai Y. Danilevski (1822-1885).

Danilevskis 1869 veröffentlichtes Buch „Rossiya i Yevropa“ (Russland und Europa) propagiert die Überlegenheit der Russen und russischen Kultur. Für Danilevski vertritt die römisch-germanische Zivilisation Europa und diese befindet sich in einer Niedergangsphase. Er sah die byzantisch-russische Kultur dem römisch-germanischen Europa überlegen und war tief davon überzeugt, dass die Russen im Vergleich zu dem kriegerischen und plutokratischen Geist des Westens die idealen Werte vertreten. Er sah einen unvermeidlichen 
Kampf zwischen Europa und der slawischen Welt um Istanbul und die Türkei voraus. RUs Sieg würde nach ihm eine Weltordnung und einen anhaltenden Frieden schaffen, da er die russische Expansion als eine Friedensmission ansah. Der westliche plutokratische Imperialismus hingegen würde die Menschen versklaven und ihr kulturelles Wachstum abstumpfen (Kohn 1955: 191-194, Kohn 1957: 45). Die Ideologie des Panslawismus hat etwa bis zum Tode Stalins (1953) 100 Jahre die russische Außenpolitik beeinflusst. ${ }^{122}$

Das Zarenreich unterstützte die orthodox-christlichen und/oder slawischen Völker des Osmanischen Reiches auf dem Balkan bei ihrem Widerstand (Kohn 1957: 46-47). Seine panslawistische Außenpolitik führte zum türkisch-russischen Krieg 1877-1878. Beide Reiche kämpften an zwei Fronten: Auf dem Balkan und im Kaukasus. Für europäische Akteure war dieser Krieg ein Zeichen, dass das Zarenreich das Ostproblem, d.h. die Aufteilung des Osmanischen Reiches, allein zu lösen versuchte. An dessen Aufteilung wollten sie aber auch beteiligt sein und gleichzeitig die russische Machterweiterung verhindern. Deshalb akzeptierten England, Frankreich und Österreich den Frieden von San Stefeno (türkisch: Ayastefanos oder Yesilköy) zwischen dem Zarenreich und dem Osmanischen Reich nicht. Sie vereinbarten anstelle dieses Friedens den Berliner Kongress 1878, dessen Bedingungen sowohl dem Osmanischen Reich als auch den europäischen Akteuren günstiger erschienen.

Mit dem Berliner Kongress wurden die osmanischen Herrschaftsgebiete, Rumänien, Serbien und Montenegro, unabhängig. Bulgarien näherte sich der Unabhängigkeit an. BosnienHerzegowina überließ das Osmanische Reich Österreich und akzeptierte die Höhe der Reparaturkosten an das Zarenreich (802.500.000 Frank, Tarihi Bilgi o. J.). Die östlichen Städte Kars, Ardahan und Batumi verlor das Osmanische Reich an das Zarenreich. Nach dieser Vereinbarung sollte das Osmanische Reich die armenische Minderheit schützen und für sie Reformen durchführen. Für seine Vermittlungstätigkeit verlangte England vom Osmanischen Reich die Insel Zypern und besetzte sie anschließend. 1881 besetzte Frankreich das osmanische Tunesien und 1882 besetzte England das osmanische Ägypten usw. (Gürsel 1968: 121-133; Kohn 1957: 48). Auf dem Berliner Kongress wurde das Osmanische Reich zwar als europäischer Staat anerkannt, was aber dem Reich außer „Prestige“ nichts einbrachte (Palmer 1978: 504-506). Besonders durch die Kapitulationen

\footnotetext{
122 Ein Zweig vom Panslawismus entwickelte sich in Panrussismus, dessen wichtigster Vertreter Konstantin Petrowitsch Pobedonoszew war.
} 
sicherten sich die Siegermächte eine ungehinderte Einfuhr europäischer Manufakturprodukte. Dadurch überschwemmten sie das Land mit billigen europäischen Waren, wodurch die Entwicklung einheimischer Industrien erschwert oder verhindert wurde (Steinbach 2007: 18). Die handwerkliche Produktion ging rapide zurück (ebd.).

Aus russischer Sicht war der Berliner Kongress ein Desaster. Nach dem Panslawisten Danilevski sollte dieser Kongress zum „Berliner Verrat“ umbenannt werden, da dadurch die russischen Erfolge und Ziele begraben wurden (Gürsel 1968: 133). Nach dem Zarenreich verhinderte der Westen, dass das Zarenreich seinen Sieg in einen triumphalen Friedensvertrag umsetzen konnte (Utz 2008: 258). Trotz dieses Misserfolgs gab es seinen Traum, die Eroberung Istanbuls, nicht auf. Der neue Zar Alexander III. (1881-1894) hielt in einem Memorandum 1882 fest, sein wichtigstes Ziel sei die Eroberung Istanbuls und der Meerengen und sie „dauerhaft in der Hand zu haben“ (Utz 2008: 243). Im 1. Weltkrieg (1914-1918) versuchte zwar das Zarenreich noch mal, dieses geopolitische Ziel zu verwirklichen; allerdings schied das Reich nach der Oktober-Revolution 1917, im Dezember, aus dem Krieg aus.

Nach den territorialen Verlusten infolge des Berliner Kongresses sowie den Ereignissen auf dem Balkan entwickelte das Osmanische Reich eine neue Ideologie. Die bis dahin tragende Ideologie Osmanismus ${ }^{123}$ reichte nicht mehr, um die Balkanvölker zum Zusammenleben zu überzeugen. Um den Rest des Reiches zusammenzuhalten, wurde die Ideologie Panislamismus entwickelt. Der Ideenvater des Panislamismus ist der türkische Sultan Abdülhamid II. (1876-1909). Außenpolitisch zielte er auf die Vereinigung der sunnitischen Staaten unter dem Osmanischen Kalifat. ${ }^{124}$ Innenpolitisch hatte er zwei bestimmende Komponenten: Einerseits betonte der Panislamismus die islamische „Glaubensgemeinschaft“, die Umma, für die „muslimischen Untertanen“, um ihre Unabhängigkeitsbestrebungen vom Osmanischen Reich zu verhindern. Gemeint waren die Albaner, Araber, Kurden, Lasen usw. Andererseits betonte er den Türkismus und erklärte die türkische Sprache in der Verfassung von 1876 als offizielle Landessprache. Parallel zum

\footnotetext{
${ }^{123}$ Im 19. Jahrhundert versuchte das Osmanische Reich mit Osmanismus, die Christen im Osmanischen Reich mit der Einführung der Reformen zum Zusammenleben zu überzeugen. Diese Ideologie war zum Erhalt der Multikulturität des Reiches bestimmt.

${ }^{124}$ Nach Mardin (2008: 92) unterstützte Deutschland für seine machtpolitischen Interessen, wie die damalige Zeitung „Basiret“ berichtete, die panislamistische ZAP des Osmanischen Reiches. Hierzu ist zu bemerken, dass diese Zeitung eine anti-imperialistische Haltung gegen die französische, russische und englische Außenpolitik hatte und pro-deutsch eingestellt war.
} 
Panislamismus gewann der Pantürkismus stark an Gewicht. Er erklärte die türkische Ethnie zum Kernelement des Osmanischen Reiches. ${ }^{125}$ Dies verstärkte allerdings die nationalistischen Gegenbewegungen im Osmanischen Reich. Und die religiöse Gemeinsamkeit reichte nicht aus, die Albaner und Araber unter der Osmanischen Herrschaft zu halten.

Die Gebiets- und Prestigeverluste des Osmanischen Reiches durch die Kriege, der russische Panslawismus, das Zeitalter des Nationalismus sowie der Einfluss der Revolutionen in Europa waren einige wichtige Entstehungsgründe des Pantürkismus. Der Pantürkismus wurde in erster Linie durch die osmanische Oberschicht (Entscheidungsträger, Wissenschaftler und Künstler) vertreten. Im Osmanischen Reich beeinflussten der Historiker Ahmet Vefik Pascha, der Turkologe Necib Asim und der Sprachwissenschaftler Semseddin Sami usw. die Entwicklung des Pantürkismus. Auch einige fremdsprachige Arbeiten über die Herkunft der „Türken und/oder Turkvölker“ sowie „Türkisch und/oder Turksprachen“ wurden im Osmanischen Reich rezipiert und dienten der Weiterentwicklung des Pantürkismus. ${ }^{126}$ Pantürkismus als Ideologie zielt auf die Vereinigung ,aller turksprachigen

125 Bis zur Entwicklung des Pantürkismus im Osmanischen Reich identifizierten sich die muslimischen Osmanen mit ihrer Religion, dem Islam. Die anderen Gläubigen des Reiches, wie Christen, Juden und Weitere, wurden „Nicht-Muslime“ genannt. D.h. das Osmanische Reich teilte seine Bevölkerung in zwei Gruppen auf: Muslime und Nicht-Muslime. Diese Trennung war u. a. deshalb wichtig, weil die Christen des Reiches eine Kopfsteuer (Cizye) für ihre Sicherheit zahlen sollten.

126 Laut Paksoy (1997: 44-45) sandten die Engländer 1861 den ungarischen Geheimdienstler und Sprachforscher Armin Vambery nach ZA, damit er die Turkvölker gegen das Zarenreich mobilisiert. Paksoy fügt hinzu (ebd.), dass der Pantürkismus als Ideologie für diesen Zweck das erste Mal von Vambery während seiner ZA-Reise erfunden wurde. Im Grunde genommen ging es Vambery eher darum, den Ursprung der ungarischen Sprache zu finden. Ob er dabei auch geheimdienstliche Tätigkeiten für England ausübte, gibt es unter den Historikern keine Einigkeit. Bezüglich meiner Arbeit könnte gesagt werden, dass er zwar mit seinen Arbeiten, wie z. B. seinem 1864 veröffentlichten Reisebericht „Travels in Central Asia“ den Pantürkismus beeinflusst hatte. Diese Ideologie etablierte sich allerdings schon vor seiner ZA-Reise im Osmanischen Reich. Vambery arbeitete vor seiner ZA-Reise ab 1854 einige Jahre als Lehrer (wie z. B. beim Haus vom nationalistischen Rifat Pascha) im Osmanischen Reich, wo er von den türkischen Nationalisten, die sogenannten „Jung-Osmanen“(türkisch: Genc Osmanlilar), beeinflusst wurde. Jung-Osmanen veröffentlichten 1860 die erste Zeitung auf Türkisch im Osmanischen Reich, ,,Tercüman-i Ahval““. Die Veröffentlichung dieser Zeitung zeigt, dass der Pantürkismus sich in der osmanischen Oberschicht schon vor der Veröffentlichung dieser Zeitung etabliert hatte. Die Jung-Osmanen gründeten 1865 die geheime Organisation „Neu-Osmanen“ und gingen aufgrund ihrer Regimekritik ins Exil. Aus dieser Gruppe gingen später die pantürkistische Gruppe „Jung-Türken“ (türkisch: Jön Türkler) hervor. Das Osmanische Reich strebte seit dem 15. Jahrhundert die Herrschaft über das Erbe des zentralasiatischen Reiches „Kök-Türk“ und tatarisch-mongolischen Reiches Goldene Horde, wie die Quellen belegen (T.C. Basbakanlik Devlet Arsivleri Genel Müdürlügü 1992: XXXIX). Das Werk, das die europäischen Sprachwissenschaftler und Historiker über die Herkunft der zentralasiatischen Völker und Sprachen beeinflusst hatte, war: Shajare-i Tarakime (Genealogie der Turkmenen) 1659 und Shajare-i Turk (Genealogie der Turk) 1665 vom usbekischen Feldherr und Historiker Abu al-Ghazi Bahadur. Das letztere Werk wurde in mehrere europäischen Sprachen wie Latein, Englisch, Deutsch, Franzözisch usw. übersetzt und fand in Europa große Aufmerksamkeit. Als eins von den bekanntesten Werken des Pantürkismus gilt "Histoire generale des Huns, des Mongoles, des Turcs et des autres Tartares occidentaux" (1756) von Pariser Sinologen und Orientalisten Joseph de Guignes. Er verteidigte in seiner Arbeit die These, dass die Hunnen, die das Römische Reich zerstört hatten, denselben Ursprung mit dem Volk haben, das die 
Völker" unter türkischer Herrschaft. Nach dieser Ideologie sind alle turksprachigen Völker gleicher Ethnie, d. h. „türkischsprachige Türken.“127 128

Der Pantürkismus wurde zunächst an den Militärschulen, danach an den öffentlichen Schulen als Ideologie gelehrt und verbreitet. 1910 wurde Türkisch als Türkisierungsmaßnahme in allen Schulen im Osmanischen Reich obligatorisch (Semiz 2014: 231-233). Dabei wurde die Verbreitung der türkischen Sprache durch die Medien und Literatur gefördert. Eine ,gemeinsame Sprache“ hatte das heterogene Osmanische Reich bis dahin nicht. Jede Gruppe im Reich benutzte ihre Muttersprache (Belge 2011: 573), wie Kurdisch, Griechisch usw. Laut Karpat (2008) fingen die leitenden pantürkistischen Eliten an, die Kurden, Lasen, Albaner und andere Muslime zu türkisieren, um aus den Muslimen eine einheitliche türkische Nation zu schaffen. Die Schaffung der sprachlichen Einheit war die erste Phase der Nationswerdung.

Außenpolitisch leitete der türkische Sultan Abdülhamid II. eine verstärkte Missionierung unter der muslimischen Bevölkerung im Zarenreich ein. Es wurden engere Kontakte zu einzelnen muslimischen Bevölkerungsgruppen im Zarenreich geknüpft und versucht, sie stärker an sich zu binden. Die Unterstützung der Russlands-Muslime, Kaukasier und Zentralasiaten durch das Osmanische Reich war eine Art Politik der Unterwanderung (Ortayli 2013: 85). Diese Politik ließ der türkische Sultan größtenteils über seine Botschafter im Zarenreich betreiben. Die osmanischen Botschaften waren Vertreter des Osmanischen Reiches, bzw. des religiösen Führers (des Kalifen), für die muslimische Bevölkerung zuständig. Sie achteten drauf, dass die Verbindung zwischen dem Osmanischen Reich und Muslime im Zarenreich verstärkt wird (Ortayli 2013: 79). Dafür schickte das Osmanische

chinesischen Quellen als „Xiongnu“ erwähnen. Die Türken akzeptieren Xiongnu als Türken. Das andere berühmte Werk für den Pantürkismus war von Arthur Lumley Davids „A Grammar of the Turkish Language with a Preliminary Discourse on the Language and Literature of the Turkish Nations: Copious Vocabulary, Dialogues, A Collection of Extracts in Prose and Verse, and Lithographed Specimens of Various Ancient and Modern Manuscripts“ (London 1832). Und ein anderes bekannte Werk ist vom französischen Sprachforscher Leon Cahun „Introduction à l'histoire de l'Asie ; Turcs et Mongols des origines à 1405“ 1896. Alle diese genannten Werke genossen im Osmanischen Reich und seinem Nachfolgestaat TR große Aufmerksamkeit.

${ }^{127}$ In der Görsch der Standarte des türkischen Präsidenten ist auf der oberen linken Seite eine Sonne mit 16 Sternen umgeben. Laut dem türkischen Präsidialamtes symbolisiert die Sonne die TR und jeder Stern um die Sonne eines von den Türken gegründeten „Türkenreiche“ in der Geschichte. Dabei werden auch die mongolische Goldene Horde und das mongolische Timuridenreich (Türkiye Cumhuriyeti Cumhurbaskanligi o. J.) aufgezählt. Diese Görsch wird seit 1922, seit der Atatürk-Ära benutzt. Obwohl diese Reiche mongolischer Herkunft sind, gelten sie für die TR aufgrund ihrer Turksprachen als „Türkenreiche bzw. -Staaten“.

${ }^{128}$ Hier ist zu bemerken, dass die Turksprachen und Mongolisch zu der altaischen Sprachgruppe gehören. Die Wissenschaftler*innen vermuten, dass diese Sprachen gleicher Herkunft sind und sie sich erst im Laufe der Zeit durch die Einflüsse der anderen Sprachen zu den eigenständigen Sprachen entwickelt haben. Des Weiteren wurden die turksprachigen Tataren von den Arabern als „,muslimisierte Mongolen“ bezeichnet. 
Reich im August 1906 z. B. die osmanischen Drucktypen ins Zarenreich, um die Verbreitung und Entwicklung der Bildung innerhalb der Muslimen zu fördern (T.C. Basbakanlik Devlet Arsivleri Genel Müdürlügü 1992: 48). ${ }^{129}$ Die zentralasiatischen Staaten benutzten zu jener Zeit das arabische Alphabet wie das Osmanische Reich. Um die „religiösen Gefühle“ zu pflegen, schickte das Osmanische Reich an die Muslime den Koran (T.C. Basbakanlik Devlet Arsivleri Genel Müdürlügü 1992: 173-174). ${ }^{130}$

Die Pantürkisten aus dem Zarenreich - wie die Aserbaidschaner Ahmed Agaoglu (auch Agayev) und Hüseyinzade Ali oder die Tataren Yusuf Akcura (auch Akcurin) und Ismail Gaspirali (auch als Gasprinsky bekannt) - kooperierten eng mit dem Osmanischen Reich. Gaspirali gilt als Vater des Pantürkismus. Er wurde während seines einjährigen Aufenthalts 1874 im Osmanischen Reich stark von den Debatten und publizierten Werken über das Türkentum und die türkische Sprache beeinflusst. Ihn prägten die Ideen von Semseddin Sami, Mehmed Emin, Ahmed Mithat und Necip Asım sowie der pantürkistischen JungOsmanen (türkisch: Genc Osmanlilar oder Yeni Osmanlilar), wie Namık Kemal, Şinasi Efendi und Ziya Pascha (Toker 2004: 32). Nach seiner Rückkehr auf die Krim arbeitete er mit Erfolg an einer künstlichen Sprache. Osmanisch nahm er dafür als Basissprache (Toker 2004: 36; Kalsin 2014: 110). Sie sollte die „gemeinsame Sprache“ der Türkenwelt sein. Allerdings sollten ihre persischen und arabischen Wörter durch tatarische Wörter und/oder mit den Wörtern aus den anderen Turksprachen ersetzt werden (Toker 2004: 36, Kalsin 2014: 110, Kafali o. J.). D. h. die Osmanische Sprache sollte „türkischisiert“131 werden. D. h. Gaspirali verfolgte die Ziele der türkischen Jung-Osmanen bzw. Pantürkisten. Sein Hauptziel war die „, kulturelle und politische Einheit“ aller Turkvölker unter osmanischer, d. h. ,türkischer“ Herrschaft. Die sprachliche Einheit war die erste Stufe eines pantürkistischen

\footnotetext{
${ }^{129}$ Quelle: BA. Yildiz Sadaret Resmi Maruzati, Nr. 138/27, 6 B. 1324 (25 Agustos 1906).

${ }^{130}$ Quellennr.:105, 12 Kasim 1894, BA. Yildiz Mütenevvi Maruzati, nr. 108/110.

131 Die Osmanische Sprache zu der Zeit war eine Mischsprache aus dem Persischen, Arabischen und Türkischen. Etwa die Hälfte ihrer Wortschatze machte Arabisch und Persisch aus. Dass diese Sprache als „AltTürkisch“ bezeichnet wird, ist m. E. falsch. Sie war eher eine eigenständige Sprache, die durch die Pantürkisten intensiv zum Türkischen reformiert wurde.
} 
Bündnisses. Für dieses Ziel gab er 1883 die Zeitung Tercüman ${ }^{132}$ heraus, die vom Osmanischen Reich bis nach ZA gelesen werden konnte (Caman 2005: 70). ${ }^{133}$

Für Gaspirali sind die turksprachigen Völker ein einheitliches Volk, d. h. Türken, und zwischen ihren Sprachen existieren nur Dialektunterschiede (Toker 2004: 37). Er schrieb am 15. März 1906 in seiner Zeitung „Tercüman-i Ahval-i Zaman“, dass die „Türken“ (er meinte damit alle Turkvölker) sich aufgrund ihrer Dialektunterschiede nicht verstehen (Toker 2004: 37). Hier stellt sich die Frage, warum sich denn die Turkvölker nicht verstanden haben, wenn sie nur die unterschiedlichen Dialekte des Türkischen sprachen? Wenn es sich wirklich nur um die Dialektunterschiede des Türkischen gehandelt hätte, wären Gaspiralis pantürkistische Arbeiten unnötig gewesen. Die Tatsache aber war, dass jedes Turkvolk damals eine eigenständige Turksprache hatte/sprach. Neben der Pressearbeit, konzentrierte sich Gaspirali auf die Bildungsarbeit (Roy 2007: 36). Sein bekanntester Satz lautet die „Einheit in der Sprache, Ideen und Arbeit“ (türkisch: dilde, fikirde, iste birlik). Seine Bildungsarbeit konzentrierte sich auf die „Dschedid-Bewegung“134 unter den Turkvölkern im Zarenreich. Gaspirali und die anderen tatarischen Denker waren die wichtigsten Leiter der DschedidBewegung (Keller 2001: 21; Carrère d’Encause 1988: 82, 85-86) im Zarenreich.

\section{Dschedid-Schulen}

Der erste Reformismus im Schulsystem, d. h. Usul-i Dschedid, begann im Osmanischen Reich im Jahre 1847 durch die Eröffnung der 5 Reform bzw. Dschedid-Schulen

\footnotetext{
${ }^{132}$ Gaspirali änderte 1905 den Namen der Zeitung Tercüman als „Tercüman-i Ahval-i Zaman“ um. Tercümani Ahval war die Zeitung der nationalistischen Jung Osmanen im Osmanischen Reich, die die Osmanische Sprache von ihren persischen und arabischen Wörtern zu bereinigen versuchten. Der Zeitungsname von Gaspirali stammt mit sehr großer Wahrscheinlichkeit aus dieser Zeitung der Jung-Osmanen. Sie inspirierten Gaspirali während seines Istanbuler-Aufenthalts. Aus der Gruppe Jung-Osmanen ging später die pantürkistische Gruppe „Jung-Türken“, bzw. die „Ittihat ve Terakki“ heraus.

${ }^{133}$ Diese Zeitung inspirierte die Tataren im Zarenreich so, dass sie auch einige Zeitungen herausgaben, die die „Dschedid-Idee“, d.h. Reformismus, vertraten. Diese waren die Zeitungen Ulfat (Versöhnung) aus St. Petersburg, Yulduz (Stern) aus Kasan, Irschad (Der Leitfaden) aus Baku usw. Diesen Zeitungen folgten die Zeitungen in ZA, wie Taraqqi (Fortschritt), die von Tataren Ismail Abidi 1906 in Taschkent herausgegeben wurde. Ihm folgten die usbekischen Zeitungen: Von Munavvar Qari Abd al- Rashid Khan-ughli (Abdurrashidov) Churschid (Sonne) in 1906, von einer usbekischen Gruppe herausgegebene Shuhrat (Ruhm) in 1906 und 1907 Tüccar (Händlers) (Carrère d'Encause 1988: 79-81). In Khurshid rief z.B. Munavvar Qari die Muslime auf, sich bei einer Muslim-Union (Ittifaq al-Muslimen) zu beteiligen und kritisierte die zaristische Kolonialpolitik. Als die Zeitung wegen der Propaganda verboten wurde, schrieb Qari an den turkestanischen Generalgouverneur folgendes: „Das Ziel unserer Zeitung war, einfach die Einheimischen über die DumaAktivitäten und seine Bedeutung zu informieren. D. h. auf diesem Weg wollten wir die Einheimischen für die kommenden Wahlen vorbereiten und nicht irgendwelche antigouvermentale Propaganda durchführen." (Qari in: Carrère d'Encause 1988: 80).

${ }^{134}$ Dschedid bedeutet neue Lehrmethode bzw. Reformismus.
} 
(Ergün/Ciftci 2006: 3). Die erste Dschedid-Schule im Zarenreich eröffnete Gaspirali 1884 auf der Krim nach osmanischem Modell (ebd.: 5). Das pantürkistische Ziel der DschedidSchulen war die Türkisierung der Turkvölker und Türkischisierung der Turksprachen im Zarenreich. In ZA wurden die ersten Dschedid-Schulen 1897 in Andican und 1898 in Samarkand (Usbekistan), 1898 in Tokmok (Kirgisistan) und 1900 in Taschkent (Usbekistan) gegründet (Carrère d’Encause 1988: 82). Zwischen 1900 bis 1907 wurden auch in Buchara Dschedid-Schulen gegründet, die größtenteils auf tatarisch unterrichteten (Carrère d’Encause 1988: 82, 85-86). Die Lehrer waren Tataren. Am Anfang nahmen diese Schulen in ZA nur tatarische Kinder auf, danach wurden immer mehr Kinder von anderen Turkvölkern akzeptiert. Die wichtigste Reform dieser Schulen war besonders im sprachlichen Bereich.

Die leitenden Dschedidisten wie Gaspirali und Qari schickten regelmäßig die turksprachigen Schüler und Studierende aus dem Zarenreich zur Ausbildung ins Osmanische Reich (Kalsin 2014: 111; Ergün/Ciftci 2006: 8). Bei ihrer Rückkehr arbeiteten diese Schüler und Studierende als Lehrer in den Dschedid-Schulen in ZA (Somuncuoglu 2008: 92). 1906 vereinbarten die Dschedidisten auf einem Kongress, dass in allen Dschedid-Schulen neben der Landessprache auf Osmanisch-Türkisch unterrichtet wird (Ergün/Ciftci 2006: 5). Die Sprache der traditionellen Schulen in ZA war arabisch. Die Dschedisten versuchten das Arabische durch die Landessprache und Türkisch zu ersetzen (Carrère d'Encause 1988: 8486; Somuncuoglu 2008: 92). Das Zarenreich verbot 1912 die Lehrtätigkeiten der Tataren in ZA. Als Lehrer durften nur diejenigen arbeiten, die die Staatsangehörigkeit des jeweiligen Landes besaßen, wie z. B. in Kirgisistan nur die Kirgisen usw. (ebd.). ${ }^{135}$

Die Dschedid-Schulen auf der Krim, in Kasan, Ufa oder Orenburg nahm das Zarenreich nicht als Gefahr für seine Herrschaft wahr; die Dschedid-Schulen in ZA aber aufgrund der Zusammenarbeit dieser Schulen mit den osmanischen Pantürkisten schon (Koncak 2013: 109). Anfang des 20. Jahrhunderts gründeten Krim- und Kasan-Tataren sowie pantürkistische Osmanen zahlreiche nationalistische Vereine in Istanbul. Nach der Durchsetzung der konstitutionellen Monarchie durch die „Jung-Türken“ (türkisch: Jön Türkler) 1908, d.h. die Partei „Ittihat ve Terakki“, wurde der Pantürkismus die Ideologie der

\footnotetext{
135 Die Pantürkisten konnten sich in ZA nur im Rahmen der kulturellen Beziehungen frei bewegen, da die politischen Beziehungen zu dieser Region nach der russischen Besetzung nicht mehr möglich waren (Koncak 2013: 112). Es ist bekannt, dass Gaspirali zur Leitung des Zarenreichs gute Beziehungen pflegte. Das Beispiel von Qari zeigt, welche Konsequenzen eine anti-russische Arbeit haben könnte.
} 
Innen- und Außenpolitik des Osmanischen Reiches. ${ }^{136}$ Die „Ittihat ve Terakki“ ergriff 1913 unter Leitung Enver Pascha ${ }^{137}$ durch einen Staatsstreich die Macht. „Militarisierung und Nationalisierung“ der anatolischen Bevölkerung war das erste Ziel dieser Partei. Sie war autoritär und verbot alle oppositionellen Parteien, Vereine und Organisationen. Ihre Ideologie verbreitete sie in den staatlichen Schulen, Jugendvereinen und Bildungseinrichtungen, wie z.B. in dem Jugendverein „Türk Gücü Cemiyeti“ (Vereinigung der türkischen Kraft). ${ }^{138}$

Die zentralasiatischen Studenten und Pilger, wie z. B. Mahmud Khoja Behbudi, brachten bei ihren Aufenthalten im Osmanischen Reich die ,pantürkistischen Ideen“ mit zurück nach Hause (Keller 2001: 21; Koncak 2013: 111). Sie gründeten nationalistische Parteien nach dem Vorbild der pantürkistischen „Jung-Türken“, wie z.B. „Junge Bucharaner“, „Jung Chiwaner“ in ZA. Nach Carrère d'Encause (1988: 97) ist bewiesen, dass viele „Liberale“ von Buchara Mitglied in der geheimen türkischen Organisation „Jung-Türken“ waren. Die pantürkistischen Ideen setzten sie für die „Befreiung Türkistans“ von der russischen Herrschaft ein. Der wichtigste Beweis für die Unterstützung der Dschedid-Bewegung durch das Osmanische Reich ist m. E. der Istanbul-Aufenthalt der leitenden pantürkistischen Dschedidisten. Die gesamte leitende Gruppe der Bewegung war mindestens einmal in Istanbul (Carrère d’Encause 1988: 96-97) und/oder wurde größtenteils in Istanbul ausgebildet, wie der Vater des Pantürkismus Ismail Gaspirali 1874, Bekir Çobanzade 19091914, Abdulrauf Fitrat 1909-1913. Z. B. Fitrat wurde von den Pantürkisten zum Studium nach Istanbul geschickt. Nachdem er sein Studium absolviert hatte, kehrte er zurück nach ZA und übernahm wegen des Verbots der Lehrtätigkeit der Tataren in ZA durch das Zarenreich im Jahre 1912 die Leitung der Dschedid-Bewegung im Jahre 1913 (Carrère d'Encause 1988: 78; 96). Er war vor seinem Istanbul-Aufenthalt in Buchara (Usbekistan)

\footnotetext{
136 Der Pantürkismus wurde die türkische Kriegsideologie im 1. Weltkrieg (Ayata/Yücel 2013: 77). Gleichzeitig wurde innerhalb des Osmanischen Reiches die Türkisierung der muslimischen Bevölkerung vorangetrieben. Die alten Konzepte Osmanismus oder Panislamismus wurden nach den Aufständen auf dem Balkan, vor allem nach den albanischen Aufständen 1909, 1910, 1911 in Frage gestellt. Diese nach JungTürken „versagten“ Ideologien sollten durch den Pantürkismus ersetzt werden, da sie nicht einmal die muslimischen Albaner zum Zusammenleben überzeugen konnten. Der Pantürkismus sollte die Konstruktion und Verbreitung einer ethnisch-türkischen Identität schaffen (Bilgin 2011: 155-156) und als langfristiges Ziel die Vereinigung aller „Türken“ der Welt ermöglichen. Den größten Anteil der Jung-Türken machten zu jener Zeit die Militärangehörigen aus (Yelkenci 2010: 56).

${ }^{137}$ Der Jung-Türke Enver Pascha war einer der wichtigsten Führer der ,Ittihat ve Terakki“ und wurde 1914 Kriegsminister, Oberbefehlshaber und Generalmajor des Osmanischen Reiches.

${ }^{138}$ Laut Bilgin (2011: 157-158) war diese erste paramilitärische Organisation durch die nationalistischen Einrichtungen Europas inspiriert, wie z.B. durch die Pfadfinderbewegung Preußens.
} 
ein streng gläubiger Muslim gewesen und träumte von einer einheitlichen Islamischen Welt. Wie er in Istanbul ein Pantürkist wurde, erklärt er wie folgt:

„Ich wurde in einer der religiös-konservativsten Zentren Asiens, Buchara, geboren... Nach der Grundschule ging ich in eine Medrese [Schulen, in denen die islamische Wissenschaft unterrichtet wird], habe gebetet, war ein konservativer Muslim. Und damals war ich gegen die Dschedidisten in Buchara [...] Später schloss ich mich ihnen an. Durch sie ging ich in die Türkei, um dort zu studieren. Als ich in der Türkei war, träumte ich von dem Panislamismus. [...] Allerdings als ich die Mystik im Islam näher untersuchte, merkte ich besser als alle anderen, wie gefährlich, wie giftig sie ist. Danach brachte mich das Leben zum Pantürkismus. " (F1trat 1996: 242; zit. nach Acik 2002: 1). ${ }^{139}$ (Übers. d. d. Verfasserin)

Die pantürkistischen Bemühungen in ZA mündeten im Basmatschi-Aufstand (1918-1924) gegen das Sowjetrussland, wie im folgenden Unterkapitel erklärt wird. Die wichtigsten Leiter dieses Aufstandes waren der türkische Pantürkist Enver Pascha und nach seinem Tod 1922 sein Nachfolger Hadschi-Sami (Hayit 1956: 197). Die Flagge der TR und die Flaggen der ehemaligen zentralasiatischen Staaten können meiner Meinung nach als wichtigster Beweis für die türkische Planung und Leitung dieser Bewegung angesehen werden. ${ }^{140}$ Ihre Ähnlichkeit zur türkischen Flagge ist verblüffend. Bevor ich die Flaggen darstelle, möchte ich die Bedeutung der Flaggenfarben und -Symbole aus der Sicht der TR und der muslimischen Welt erklären.

Grün und Schwarz symbolisieren den Islam. Grün war die Lieblingsfarbe des Propheten Mohammed. Eine schwarze Flagge benutzte Mohammed während seiner Dschihad-Kriege für die Verbreitung des Islams. Seine schwarze Flagge heißt „raye“. Bis heute benutzen die islamistischen Dschihadisten, wie Al-Qaida und der Islamische Staat (IS), eine schwarze Flagge. Die Farbe Rot gilt als Farbe der TR, Blau ist die traditionelle Farbe der Mongolen und Turkvölker. Seit der Ära des osmanischen Sultans Murad I. (1359-1389). benutzte das Osmanische Reich als Flagge zunächst ein rotes Tuch. Es ist bis heute ein Rätsel, wie diese Flagge entstand bzw. welche Bedeutung sie hat. Meiner Meinung nach ist ein plausibler

\footnotetext{
139 „, Asya'nın en koyu dinî merkezlerinden olan Buhara' da doğdum... Mektep sonrası medreseye gittim, namaz kıldım, mutaassıp bir müslüman idim. Hatta Buhara' da yeni gelişmeye başlayan ceditlere karşı idim. Sonraları onların saflarına geçtim. Onların maslahatları ile Türkiye’ye okumaya gittim. Türkiye'de iken Panislamizm hayaline kapıldım. Dini reforma taraftar oldum. Fakat hiç bir vakit tasavvufa meyletmedim. Lakin edebiyat tarihini inceleyen bir öğretmen olduğum için tasavvufu derinlemesine inceledim... Tasavvufun ne kadar zararlı, nasıl zehirli bir iş olduğunu herkesten daha iyi öğrendim. Sonraları hayat beni Pantürkizm fikrine getirdi “ (Fitrat 1996: 242; zit. nach Acik 2002: 1).

${ }^{140}$ Alle Flaggen entnommen aus der Homepage von Flaggenlexikon o. J., https:/www.flaggenlexikon.de
} 
Erklärungsansatz dafür, dass die TR die rote Flagge vom Umayyadenreich übernahm, welches zwischen den Jahren 660-750 im heutigen Damaskus (Syrien) das Kalifat (Oberhaupt der sunnitischen Muslime) eingerichtet hatte. Der letzte umayyadische Kalif Marwan II. (745-750) benutzte im Kampf gegen den Sieger (Abbasidenreich) eine Rote Flagge (Bardakci 2014). Ab 750, d. h. nach der Niederlage des Umayyadenreiches, ging das Kalifat bis 1517 an die Abbasiden. Es ist auch bekannt, dass, bevor der osmanische Herrscher Yavuz Sultan Selim (1512-1520) das Kalifat während seines Ägyptenfeldzuges 1517 von den Abbasiden offiziell eroberte, sich der Osmanische Sultan Murad I. offiziell zum Kalifen erklärt hatte. ${ }^{141}$ Die Rote Flagge benutzte das Osmanische Reich erst seit seiner Herrschaft. D. h. parallel zu seinem selbsternannten Kalifat benutzte er die Rote Flagge wie der letzte Kalif des Umayyidenreiches.

Nach islamischem Gesetz sollte der Kalif vom Volk gewählt werden oder wie die Schiiten behaupten, ein Nachkomme des muslimischen Propheten Mohammeds sein. Weder der osmanische Sultan Murad I. noch der letzte Kalif des Umayyidenreiches Marwan II. wurden zum Kalifen gewählt. Sie sind auch mit Mohammed nicht verwandt. Der erstere ernannte sich selbst zum Kalifen. Und dem Marwan II. übertrug sein Vater das Kalifat, weil im Umayyidenreich das Kalifat eine Art Erbmonarchie wurde, d. h. vom Vater auf den Sohn übertragen wurde. Dieses Modell übernahmen später auch die osmanischen Sultane. ${ }^{142}$ Mit sehr großer Wahrscheinlichkeit sahen die osmanischen Sultane das Abbasidenreich wegen ihres Kalifats als Rivale und Feind an und assoziierten sich daher eher mit dem umayyedischen Kalifat. In Anlehnung an das Umayyedenreich mussten die osmanischen Sultane weder vom Volk zum Kalifen gewählt werden, noch wie die Abbasidenkalifen die Nachkommen des Mohammeds sein. So konnten sie ihre hegemoniale Politik in der islamischen Welt mit der Rolle eines religiösen Oberhauptes rechtfertigen.

Die Symbole auf seiner roten Flagge fügte das Osmanische Reich erst später hinzu. Auch hier gibt es keine festen Informationen, warum und ab wann das Reich das erste Mal einen Halbmond und Stern auf der Flagge dargestellt hatte. Der Halbmond bzw. die Mondsichel ist im Grunde genommen ein sehr altes, vorislamisches Symbol und wurde als Symbol der Götter benutzt, wie z. B. bei den Sumerern (Nanna) und alten Ägyptern (Jah, Thot). Später wurde sie zu einem Symbol des Islams. Der Stern wurde auch von den Sumerern benutzt.

\footnotetext{
${ }^{141}$ Allerdings wurde sein Kalifat von den muslimischen Staaten nicht anerkannt. Erst seit 1517, d. h. seit Yavuz Sultan Selim wurden die osmanischen Sultane offiziell als Kalifen anerkannt.

${ }^{142}$ Der erste Abbasienkalif Ebu'l-Abbas Seffah (750-754) war Verwandte des muslimischen Propheten.
} 
Im Byzanz symbolisierte der Stern die Heilige Maria, bzw. die Stadt Istanbul. Im Allgemeinen wird vermutet, dass das Osmanische Reich den Halbmond und das SternSymbol nach der Eroberung Istanbuls 1453 vom christlichen Byzanz übernommen hatte, weil sie damals von Byzanz benutzt wurden. Es gibt noch andere Erklärungsansätze, woher die Symbole kommen. Meiner Meinung nach hätte ein muslimisches Land, das Anspruch auf die Leitung der gesamten muslimischen Welt erhob, keine christlichen Symbole für seine Flagge übernommen. Vermutlich hatte das Osmanische Reich den Stern als Symbol Istanbuls von Byzanz übernommen und nicht als Symbol der Heiligen Maria. Ich vermute, dass das Osmanische Reich die Mondsichel von dem tatarisch-mongolischen Reich der Goldenen Horde ${ }^{143}$ übernommen hatte. Wie die osmanischen Quellen aus der Zeit belegen (T.C. Basbakanlik Devlet Arsivleri Genel Müdürlügü 1992: XXXIX), wollte das Osmanische Reich mit der Eroberung des Khanats Krim (geschah 1475) das Erbe der tatarisch-mongolischen Goldenen Horde antreten. Sein erster Krieg gegen das Zarenreich führte das Osmanische Reich für das Erbe der Goldenen Horde, nämlich für die Eroberung eines anderen Nachfolgekhanats der Goldenen Horde, des Khanats Astrachan (1568-1570).

Türkei

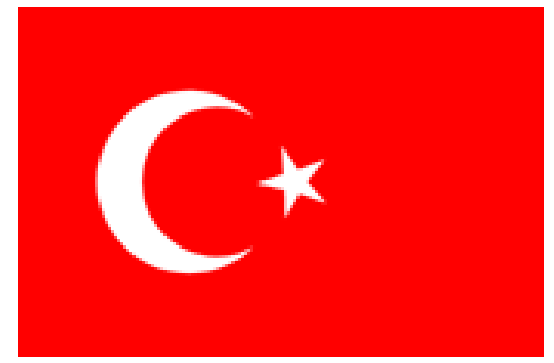

Heute gelten der Mond und Stern als Symbol der TR. In der Ära des Sultans Selim III. (1789-1807) wurde die Sichel mit einem achtstrahligen Stern benutzt. Die türkische Flagge in ihrer heutigen Form (mit fünfstrahligem Stern) wird seit 1844 benutzt. Ihre heutige Form ist der Flagge der zentralasiatischen Alasch-Orda zum Verwechseln ähnlich.

\section{Alasch-Orda}

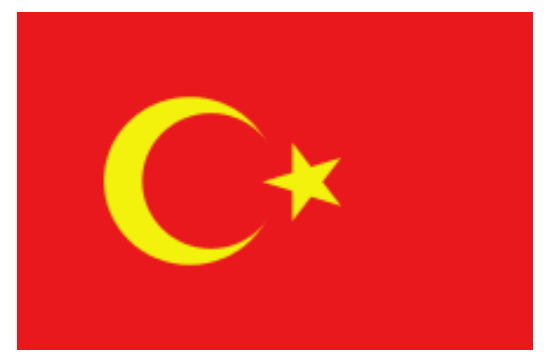

Die Flagge der pantürkistischen kirgisisch-kasachischen Alasch-Orda (1917-1920) war mit der türkischen Flagge fast identisch und unterschied sich nur durch die gelbe Farbe des Mondes und Sternes sowie etwa durch die dunklere rote Farbe. Die Alasch-Orda kämpfte für ein unabhängiges „Türkistan“ und ihre Mitglieder nahmen am Baschmatschi-Aufstand (siehe Kap. 3.6) teil. Die Flagge des Khanates Buchara wurde oft geändert. Zwischen 1920-1923

\footnotetext{
${ }^{143}$ Auf der Flagge der Goldenen Horde ist auf dem weißen Tuch eine rote Mondsichel und das heute noch von den Krim-Tataren benutzte Symbol Tamga zu sehen.
} 
schmückten der gelbe Mond und Stern das grün und rot gestreifte Tuch. Zwischen 19231925 wurde sie der türkischen und der Flagge der Alasch-Orda ähnlicher.

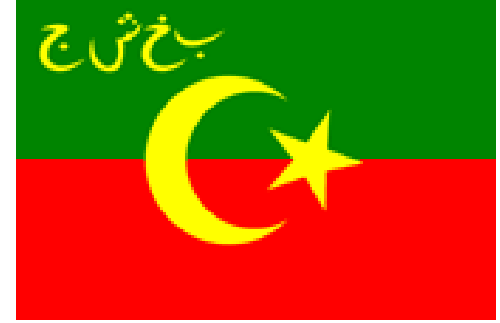

Khanat Buchara (1920-1921)

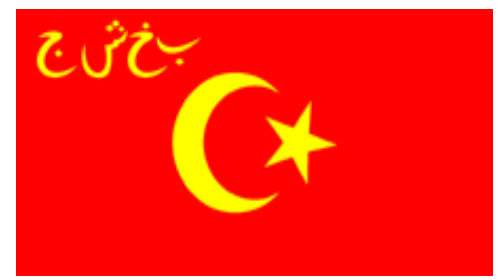

Sozialistische Volksrepublik Buchara (1923-1924)

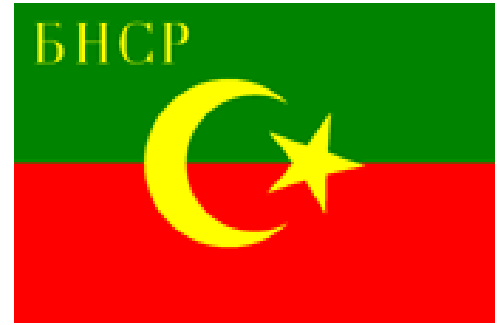

Khanat Buchara (1921-1923)

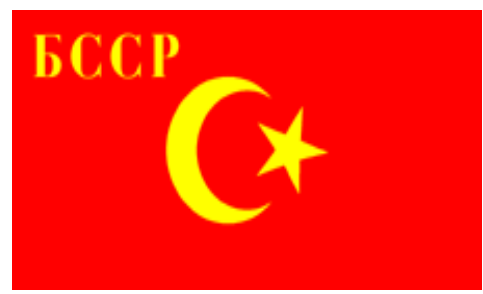

Sozialistische Republik Buchara (1924-1925)

Auch bei den Flaggen der Khanate Kokand und Khanat Chiwa (siehe unten) fehlten die „türkischen Symbole, türkischen und islamischen Farben sowie die Farbe der Turkvölker“ nicht. Die Farben des Islam (Grün und Schwarz), der Turkvölker (Blau) und der Türkei (Rot) wurden von diesen zentralasiatischen Khanaten auf ihren Flaggen benutzt. Diese Flaggen können als Beweise der engen Zusammenarbeit zwischen dem Osmanischen Reich und der pantürkistischen Basmatschi-Bewegung gesehen werden. Sie können des Weiteren als Beweis zur Osmanischen Leitung des Panntürkismus in ZA angenommen werden. Gleichzeitig zeigen sie, dass die Zentralasiaten die türkische Leitung des Osmanischen Reiches akzeptiert hatten.

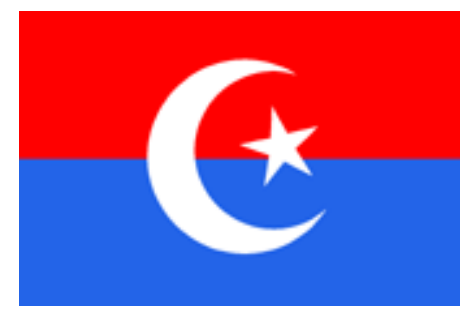

Khanat Kokand (1917-1920)

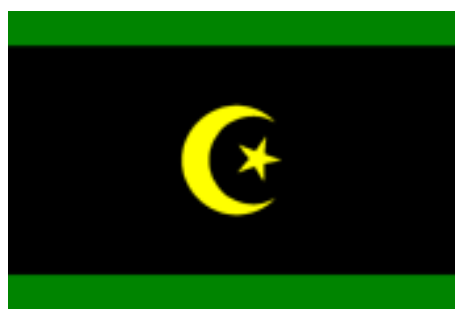

Khanat Chiwa (1918- Jan. 1920)

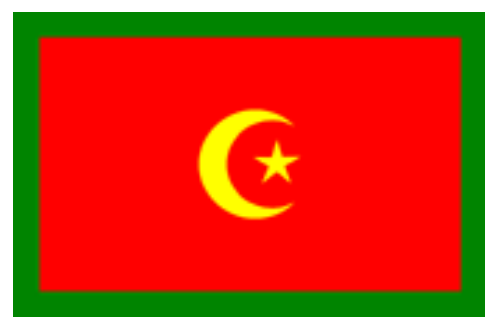

Khanat Chiwa (bis April 1920) 


\title{
3.6 Die türkisch-russische Zentralasienpolitik während der sowjetischen Ära
}

Das zaristische RU zerbrach 1917 infolge der russischen Revolution und proklamierte sich ein Jahr später zur Sozialistischen Föderativen Sowjetrepublik (RSFSR). ZA blieb zunächst autonom, war jedoch durch Wirtschaftsabkommen und Militärallianzen mit Russland verbunden (List 2004: 23). Stalin (1951: 209) beschreibt 1920 die Lage folgendermaßen:

„Im Jahre 1918 bestand Sowjetrußland nur aus dem inneren Rußland, das von den Rohstoff-, Lebensmittel- und Brennstoffquellen (der Ukraine, dem Kaukasus, Sibirien, Turkestan) abgeschnitten war, keine ernst zu nehmende Armee hatte und keine Unterstützung durch das Proletariat Westeuropas genoss. “

Wie aus diesem Zitat $\mathrm{zu}$ verstehen ist, meint Stalin mit innerem Russland das Sowjetrussland. Und die Randgebiete wie ZA, Kaukasus usw. dementsprechend als ,äußeres Russland“. Laut Stalin (1951: 196) brauchte Sowjetrussland mit seinen Randgebieten (der Ukraine, dem Kaukasus, Sibirien, Turkestan (d. h. ZA) ein Bündnis. Stalin zufolge brauchten die Randgebiete „Zentralrussland“ genauso, wie Zentralrussland sie brauchte, um einer „,imperialistischer Knechtung“ zu entgehen:

\begin{abstract}
„Drei Jahre Revolution und Bürgerkrieg in Rußland haben gezeigt, dass ohne die wechselseitige Unterstützung Zentralrußlands und seiner Randgebiete der Sieg der Revolution unmöglich ist, die Befreiung Rußlands aus den Fängen des Imperialismus unmöglich ist. Zentralrußland, dieser Herd der Weltrevolution, kann sich nicht lange ohne die Hilfe der Randgebiete halten, die Roh-und Brennstoffe sowie Lebens-mittel [sic.] in Hülle und Fülle haben. Die Randgebiete Rußlands sind ihrerseits ohne die politische, militärische und organisatorische Hilfe des höher entwickelten Zentralrußlands unausbleiblich zu imperialistischer Knechtung verurteilt. Wenn die These zutrifft, dass der höher entwickelte proletarische Westen ohne die Hilfe des weniger entwickelten, aber an Roh-und Brennstoffen reichen bäuerlichen Ostens der Weltbourgeoisie nicht den Garaus machen kann, so ist die andere These ebenso zutreffend, dass das höher entwickelte Zentralrußland ohne die Hilfe der weniger entwickelten, aber an den notwendigen Hilfsquellen reichen Randgebiete Rußlands die Sache der Revolution nicht zu Ende führen kann. “
\end{abstract}

Aus Stalins Verlautbarungen geht die russische Sichtweise deutlich hervor. Einerseits redet er vom Kampf gegen den westlichen Imperialismus. Andererseits versucht er die imperialistischen Ziele RUs an seinen Randgebieten zu rechtfertigen. Zu dieser Zeit gab es den Basmatschi-Aufstand aus ZA gegen Sowjetrussland. Während dieser Aufstand 1918 auf das Fergana-Gebiet beschränkt gewesen war, dehnte er sich bis 1920 in allen von Turkvölkern bewohnten Gebieten aus (Hayit 1956: 201). Die türkischen Offiziere von der 
pantürkistischen Partei „Ittihat ve Terakki“ modernisierten und gründeten moderne Armeen der Basmatschi-Bewegung (Hayit 1956: 201) und leiteten sie. Während eines Aufstandes wurde der türkische Anführer Enver Pascha durch die Rote Armee am 4. August 1922 in Baldschuan, im heutigen Tadschikistan getötet (Hayit 1956: 196). Nach dem Tod von Enver Pascha übernahm den Oberbefehl der Basmatschi-Bewegung ein anderer türkischer Offizier, namens Hadschi Sami (Hayit 1956: 197). Die Bewegung wurde durch die Rote Armee besiegt und ZA in die Sowjetunion eingegliedert (Hambly 1966: 214-215).

Die Große Nationalversammlung der Türkei (türkisch: Türkiye Büyük Millet Meclisi) bemühte sich zu Anfang der 1920er Jahre, schon vor der Ausrufung der Republik Türkei 1923, um die Vertiefung der Beziehungen mit den zentralasiatischen „Turkvölkern“ und unterstützte sie bei ihrer Unabhängigkeitsbewegung. Allerdings verfolgte die TR in der Atatürk-Ära (1920-1938) ${ }^{144}$ keine offene pantürkistische ZAP, weil Atatürk für den Aufbau der TR die politische, wirtschaftliche und militärische Unterstützung der Sowjetunion brauchte (Kücük/Bekar 2019: 180). Die weiteren Gründe seiner vorsichtigen Politik gegenüber der Sowjetunion können wie folgt zusammengefasst werden: Erstens, Sowjetrussland sah die Turkstaaten als ihren „,natürlichen Einfluss- und Machtbereich“ an und kontrollierte sie weitgehend. Den Pantürkismus duldete Sowjetrussland inner- und außerhalb der Union nicht und bekämpfte ihn mit aller Härte, wie es z. B. im BasmatschiAufstand in ZA der Fall war. Zweitens, Atatürk verfolgte offiziell eine Status-Quo-Politik, da die Folgen der Sevres-Traumata noch frisch in Erinnerung waren, und er mögliche Konfrontationen mit der Sowjetunion vermeiden wollte, weil die Konfrontation mit ihr nur Nachteile nach sich ziehen konnte (Fuller 1993: 67). Im Falle einer offenen pantürkistischen Politik in ZA hätte die TR mit der Sowjetunion nur Konflikte bekommen. Den Folgen möglicher Konflikte zu begegnen war die TR weder politisch noch militärisch oder wirtschaftlich in der Lage. Drittens, Die Sowjetunion war eine Großmacht, die den türkischen Befreiungskampf (1919-1923) militärisch und wirtschaftlich (Altan 2011a) unterstützt hatte und die TR zu ihr aus pragmatischen Gründen gute Beziehungen pflegen wollte. ${ }^{145}$ Viertens, die Vereinbarungen mit der Sowjetunion verhinderten einen offenen

\footnotetext{
${ }^{144}$ In der TR erhielten die Menschen die Nachnamen erst nach dem türkischen Namengesetz vom 1934. Den Nachnamen Atatürk nahm Mustafa Kemal erst ab diesem Datum an.

${ }^{145}$ Als noch die osmanische Regierung in Istanbul an der Macht war, erkannte die russische Leitung das in Ankara am 23. April 1920 gegründete türkische Parlament (Türkiye Büyük Millet Meclisi, abk. TBMM) im Juni 1920 an; d.h. schon vor der Ausrufung der Republik Türkei 1923. Atatürk schrieb Lenin am 26. April 1920 als „Präsidenten des türkischen Parlaments“, Türkiye Büyük Millet Meclisi (TBMM), einen Brief und forderte von ihm die militärische und politische Zusammenarbeit gegen die imperialistischen Mächte an und des Weiteren bat ihn um 5 Mio. Gold, Waffen, Munition und militärische Geräte (Topal 2018: 317). Die TR
} 
Pantürkismus. Am 16. März 1921 unterschrieben die TR und RU einen „Freundschafts- und Brüderlichkeitvertrag“ (Frieden von Moskau), wonach sie sich u. a. verpflichteten, keine politischen Gruppen gegeneinander $\mathrm{zu}$ instrumentalisieren. Atatürk versprach, die pantürkistischen Organisationen innerhalb der Sowjetunion nicht zu unterstützen und im Gegenzug die Sowjetunion, die Kommunistische-Untergrund-Parteien in der Türkei ${ }^{146}$ nicht zu unterstützen (Webster 1939: 92-93; zit. nach: Carley 1995: 179, Topal 2018: 323-324; Kücük/Bekar 2019: 175, 183). Trotz all dieser Vereinbarungen suchte Atatürk nach Gelegenheiten, die pantürkistischen Ziele in ZA, ohne RU zu verärgern, vorsichtig zu unterstützen.

Atatürk vereinbarte mit Afghanistan in dem „Vertrag der türkisch-afghanischen Freundschaft und Zusammenarbeit“" am 1. März 1921, dass Afghanistan die Unabhängigkeit der zentralasiatischen Chiwa und Buchara anerkennen und sie im Falle eines Angriffes schützen soll (Andican 2003: 90-93; Özlü 2012: 36). Diese Vereinbarung sowie die gegenseitigen Besuche und Zusammenarbeit zwischen der TR und den zentralasiatischen Pantürkisten sind nach Andican (2003: 90-93) die wichtigsten Beweise des aktiven pantürkistischen Austauschs in der Atatürk-Ära. Weil er aus den oben genannten Gründen keine offene pantürkistische ZAP verfolgen konnte, schickte er eine Gruppe Pantürkisten ${ }^{147}$

bekam von der Sowjetunion Unterstützung, von Waffen bis Geld (10 Mio. Rubel) und Nahrungsmittel (siehe Topal 2018: 316; Kücük/Bekar 2019: 184). Die im Jahre 1921 unterschriebenen Frieden von Moskau (16.03.1921) und Kars (13.10.1921) bestimmten die türkisch-sowjetische Grenze. Die Sowjetunion verzichtete laut Moskauer-Frieden von 1921 auf die Kapitulationen gegen die TR und schrieb die gesamten türkischen Schulden ab (Topal 2018: 323; Kücük/Bekar 2019: 183) und half ihr wirtschafltich und technisch (Büyükakinci 2012: 785). Beide Staaten unterschrieben 1925 einen „Freundschafts- und Nichtangriffsvertrag“ und verpflichteten sich dazu, ,keinem Bündnissystem beizutreten, das ihre Beziehungen gefährden könnte. Dieser Vertrag wurde noch zweimal, 1929 und 1935, verlängert. Auch die Aufnahme der Türkei in den Völkerbund (1932) kam mit Hilfe der Sowjetunion zustande." (Centrum für die angewandte Politikforschung an der LMU München 2007). Die Sowjetunion half der jungen TR in erster Linie wegen ihrer sicherheitspolitischen Sorgen. Sie wollte in der TR das kommunistische Regime einführen und sie unter ihre Kontrolle bringen. Die Kontrolle der Meerengen war für die Sowjetunion sehr wichtig gegen die ,imperiale Mächte“. Durch die TR könnte sie auch in der gesamten islamischen Welt Einfluss ausüben (Kücük/Bekar 2019: 175).

146 Atatürk war innenpolitisch anti-kurdisch, anti-religiös und antikommunistisch eingestellt. Laut dem türkischen Journalisten und Schriftstellern Ahmet Altan (2011a) definierte Atatürk drei Gefahren für den türkischen Staat: Religiöser Machtübernahmeversuch (türkisch: irtica), Kurdische Nationalbewegung und Kommunismus. Obwohl er antikommunistisch war, arbeitete er mit der kommunistischen Sowjetunion eng zusammen und forderte von ihr Hilfe an, die er auch bekam. Im Lande bekämpfte er gleichzeitig den Kommunismus auf Schärfste. Er verbot z. B. die im Mai 1920 gegründete kommunistische Gemeinschaft Yesil Ordu Cemiyeti (Grüne Armee Gemeinschaft) und verbannte z. B. Aktionäre wie Cerkez Ethem und seine zwei Brüdern ins Exil. Im Sommer 1920 gründeten die (türkischen) Kommunisten, darunter befand sich auch der erste sowjetische Vertreter der TR Şerif Manatov als Mitglied, der Hafi Türkiye Komünist Fırkası (Geheime Kommunistische Partei der Türkei). Alle Mitglieder dieser Partei wurden verurteilt, Manatov sollte die TR verlassen. Am 18. Oktober 1920 ließ Atatürk die Offizielle Kommunistische Partei der Türkei (Resmî Türkiye Komünist Firkas1) gründen, um die kommunistische Bewegung zu vereinigen, bzw. zu kontrollieren. Diese Partei bestand drei Monate und wurde anschließend aufgelöst (siehe Topal 2018).

${ }^{147}$ Diese waren Abgeordnete im türkischen Parlament: Tevfik Rüstü, Ismail Suphi, Besim Atalay und Fuat Beyler (Baysal 2009: 147). 
1921 unter dem Deckmantel des „wissenschaftlichen Zwecks“ nach Moskau. Aus dieser Gruppe ging der angeblich kommunistische Abgeordnete aus der TR, Ismail Suphi Bey, nach ZA, um dort die pantürkistischen Aktivitäten zu organisieren. Das Ziel der geheimen Organisation „Nationale Einheit Türkistans“ (türkisch: Türkistan Milli Birligi) war die Mobilisierung der Turkvölker für das unabhängige „Türkistan“ (Ünal 2017). Des Weiteren gründete Atatürk 1924 das „Institut für die Türkologie“ (türkisch: Türkiyat Enstitüsü). Nach Bozdag (1998: 62) wollte er dadurch, dass die türkischen Wissenschaftler ohne auf große Hindernisse zu stoßen, die Sprache, Kultur, Geschichte usw. in ZA recherchieren konnten. Sie sollten gute Beziehungen zu ZA aufbauen und die bestehenden Beziehungen pflegen. Das Ziel dieses Instituts war die Schaffung einer gemeinsamen Sprache, Identität, Kultur und Geschichte (ebd.: 30-32), d. h. Schaffung der ersten Stufe, nämlich der historischkulturellen Einheit als Voraussetzung für die politische Einheit der Türkenwelt (ebd.: 18).

Die Bemühungen der TR konnten aber die Eingliederung ZAs in die Sowjetunion nicht verhindern. Mit einem Dekret des Zentralkomitees der Kommunistischen Partei RUs aus 1924 wurden fünf neue sowjetische Republiken gegründet (Hayit 1956: 224; Dschafarow 2009: 22). Die Bezeichnung ZAs als Turkestan wurde nach dem Basmatschi-Aufstand von der Sowjetunion verboten, da diese mit dem Pantürkismus in Verbindung gebracht wurde (Carrère d'Encause 1988: 184). Die Staatenbildung in ZA ist ein „künstlich initiierter Prozess“, geprägt durch die Nationale Abgrenzung Josef Stalins von 1924 bis 1936 (Stein 2004: 2). Die ethnische Zusammensetzung der zentralasiatischen Nationalstaaten ${ }^{148}$ war sehr vielfältig (List 2004: 24). Dazu kam die Umsiedlung der Russen (sowie anderen Ethnien wie Tschetschenen, Deutschen, Tataren usw.) in die Region (List 2004: 23). Laut Hayit (1956: 232-233) diente diese Aufteilung der radikalen Umgestaltung „Türkistans“, nach dem römischen Außenpolitikprinzip ,Divide et impera“149 in kultureller und wirtschaftlicher Weise.

Die Schaffung der russischen Sprache als Linqua Franca (Datletov 2003: 13) und die Schaffung eines „homo sovieticus“ (Datletov 2003:11), d.h. eines modernen, homogenen „sovetskii narod“ (sowjetischer Mensch) (Wälzholz 1997) war ein fester Bestandteil der

\footnotetext{
${ }^{148}$ Vor den Nationalstaaten lebten die Zentralasiaten in den Khanaten und definierten sich nicht nach ihren Ethnien, bzw. Kulturen, als Kirgisen oder Usbeken. Sie definierten sich eher nach ihrer Lebensform, als Nomaden oder Sesshafte. Innerhalb der Landesgrenzen wurden mehrere Sprachen gesprochen, meistens eine Turksprache und Persisch, aber auch Arabisch.

${ }^{149}$ D.h. „Teile und herrsche“: säe Zwietracht unter deinen Gegnern, um sie einzeln leichter beherrschen zu können.
} 
sowjetischen Nationalitätenpolitik in ZA. Sowjetrussland wusste, dass dafür zunächst die territoriale Integrität und innere Stabilität der Union gesichert werden musste, was teils durch Kompromisse mit den Nationen, teils durch die Bewältigung separatistischer Bestrebungen ermöglicht werden sollte (Wälzholz 1997). Im Grunde genommen wertete der sowjetische Mensch die russische Sprache und Kultur innerhalb der sowjetischen Staaten auf. Die Bildungs- und Sprachenpolitik waren zwei wichtige Soft-Power-Instrumente für die Verschmelzung der Völker zum ,sowjetischen Menschen“. In den Schulen wurde einerseits die kommunistische Ideologie propagiert, andererseits sollte die Herausbildung partikularer, kulturell tradierter Solidaritäten verhindert werden (Wälzholz 1997). ${ }^{150}$

In ZA wurde zwischen 1924-1928 das lateinische Alphabet ${ }^{151}$ eingeführt, vorher benutzten die Zentralasiaten das arabische Alphabet wie die TR. Daraufhin führte auch die TR 1928 das lateinische Alphabet ein (Andican 2009: 432-438). In den 1930er Jahren trieb Atatürk die Sprach- und Geschichtsforschung in der TR voran. 1931 gründete er die „Türk Tarihi Tetkik Cemiyeti“ (Vereinigung zur Erforschung der Türkischen Geschichte) und 1932 das „Türk Dil Kurumu“ (Institut für die Türkische Sprache). Laut Belge (2011: 610) versuchte Atatürk in den 30ern, eine neue Geschichte zu schreiben. Nach dieser Geschichtsthese gingen alle Sprachen der Welt aus dem Türkischen hervor, waren z. B. Buddha und Konfuzius Türken. Diese Theorie wird „Günes-Dil-Teorisi““ (Sonnensprachtheorie) ${ }^{152}$ genannt. Die Forschungstätigkeiten in/über ZA wurden in dieser Zeit weitergeführt. Weiterhin versuchte Atatürk, eine türkische Sprache zu schaffen, in der die arabischen und persischen Wörter durch Wörter aus anderen Turksprachen, besonders aus dem Tatarischen, ersetzt werden (siehe hierzu Türk Dil Kurumu o. J.). D. h. es fand in der Atatürk-Ära in der TR eine aktive Türkisierung und Türkischisierung statt.

\footnotetext{
${ }^{150}$ Russischunterricht war seit 1938 an allen Schulen obligatorisch (Wälzholz 1997). Die russische Sprache wurde ab Ende der fünfziger Jahre als ,zweite Muttersprache“ aller nichtrussischen Völker eingeführt (ErsanliBehar 1994: 191).

${ }^{151}$ Das lateinische Alphabet der Turkvölker wurde während des 2. Weltkrieges auf das kyrillische umgestellt (Malek 1994: 743).

${ }^{152}$ Atatürk versuchte mit der neuen Geschichtsschreibung, die Geschichte des Türkentums über die Geschichte des Osmanischen Reiches zu stellen. Er versuchte zu beweisen, dass die Ur-Zivilisationen Anatoliens, wie z.B. die Hettiter und Sumerer Türken waren und eine „Turksprache“ sprachen. Das war für ihn wichtig und nötig, damit die anderen Völker, wie z. B. Griechen, keine Gebietsansprüche erheben können. Die Türken sollten laut dieser Geschichtsschreibung als „Ur-Einwohner“ Anatoliens dargestellt werden. Er versuchte auch, die Einheimischen Anatoliens zu türkisieren, wie z. B. die Kurden. Für den Zweck verbot er die kurdische Sprache und Identität durch den „Sark Islahat Plani“ (Reformplan für den Osten. Mit dem Osten sind kurdische Gebiete gemeint) von 1925 .
} 
In der TR ist die Ära-Atatürk historisch nicht ausreichend untersucht. Deshalb bleiben viele Fragen über seine ZAP offen. Die Gründe dafür sind die ungeöffneten Staatsarchive ${ }^{153}$ und das seit 1951 gültige „Gesetz über strafbare Handlungen gegen Atatürk, Gesetznummer 5816“ (türkisch: Atatürk Aleyhine İşlenen Suçlar Hakkında 5186 sayili Kanun). Der türkische Journalist und Schriftsteller Ahmet Altan z. B. nannte Atatürk in einem Artikel von 2011 Diktator ${ }^{154}$ und wurde deshalb nach dem Gesetz 5816 verurteilt (Cemal 2012). Der türkische Historiker Yavuz Bahadiroglu (Bahadiroglu 2015) erklärte in einem Fernsehprogramm „Pergel“ beim Fernsehsender „Ülke“ am 23. Januar 2015, dass in der TR seit 90 Jahren „Angst davor besteht, dass die Lügen herauskommen.“ Bahadiroglu sagte (ebd.), dass die türkische Geschichte eine „erfundene Geschichte“ sei und vieles durch die Historiker aufgrund des Gesetzes 5816 nicht recherchiert werden dürfte. Auch der Historiker Mustafa Armagan (2015) beschwerte sich über die gleichen Probleme und verfälschte Geschichtsschreibung. Armagan erzählte, dass er zufälligerweise eine 94 Jahre alte, sehr wichtige Quelle von Cerkez Ethem gefunden habe, die die Ereignisse über die kemalistische Ära ausleuchtet. Er überlegte allerdings mit Sorge, ob er diese Quelle veröffentlichen soll und wenn ja, mit wie vielen Monaten Gefängnis er dafür rechnen müsse. Er beschwerte sich über die staatliche Zensur, den Druck und das Gesetz 5816 sowie die ungeöffneten Staatsarchive, da durch sie ernsthafte historische Recherchen verhindert werden. Deshalb forderte er die Aufhebung dieses Gesetzes und die Öffnung der Staatsarchive, um die Geschichte richtig darstellen zu können (Armagan 2015). ${ }^{155}$ Nach Atatürks Tod 1938 widmete sein Nachfolger Ismet Inönü (1938-1950) seinen kulturellen Arbeiten keine große Aufmerksamkeit und verfolgte keine pantürkistische Außenpolitik und Ziele, schreibt Ortayli (2013: 87). Mit dieser Aussage bestätigt Ortayli indirekt, dass Atatürks außen(kultur)politische Arbeiten pantürkistisch geprägt waren.

Die TR distanzierte sich im 2. Weltkrieg vom Pantürkismus offiziell, da sie Angst vor möglichen russischen Angriffen hatte (Ortayli 2005: 60). Trotz ihrer Neutralität im 2. Weltkrieg - trotz „Freundschafts- und Nichtangriffsvertrag“ mit der Sowjetunion seit dem

\footnotetext{
${ }^{153}$ „Cankaya Köskü Arsivi“ (Archiv des Cankaya-Schlosses), auch „Atatürk Arsivi“ (Archiv von Atatürk) genannt, verfügt z. B. über alle wichtigen Quellen über die Atatürk-Ära. Allerdings ist es bis heute verschlossen.

154 Altan, Ahmet (2011b): Atatürk bir Diktatördü! In: Analiz Merkezi, 20.09.2011, 18:16, http://www.analizmerkezi.com/ahmet-altan-ataturk-bir-diktatordu-25383h.htm

${ }^{155}$ Die Historiker Bahadiroglu und Armagan sind religiös-konservativ geprägt und haben eine Anti-AtatürkHaltung. Sie sympathisieren mit dem Osmanischen Reich und träumen von seiner Wiedergeburt. Das soll nicht unbedingt bedeuten, dass sie die Geschichte aufgrund ihrer Sichtweise und Interessen umzuschreiben versuchen. Ihr Interesse liegt allerdings besonders an den historischen Quellen, die sich auf Atatürks Fehler konzentrieren. In der TR wird bis heute die Person Atatürks gesetzlich geschützt.
} 
17.12.1925 und den Allianzen mit England und Frankreich vom 19.10.1939 - unterschrieb die TR mit der „Feindseite“ Deutschland, am 18.06.1941 einen „Nichtangriffspakt und Freundschaftsvertrag“ (Önder 1977: 264). Der ehemalige Präsident der TR Ismet Inönü sagte in einem Interview mit Zehra Önder, dass der Pakt mit Deutschland um ,eine gewisse Sicherheit zu erreichen“" abgeschlossen wurde, da die Lage der Alliierten in der Zeit noch unklar war (ebd.: 267). Der ehemalige türkische Ministerpräsident Sükrü Saracoglu (19421946) sagte, dass die TR zwar ein vitales Interesse an der Vernichtung des Bolschewismus hatte. Sie wollte aber zunächst abwarten, bis die deutschen Operationen fortgeschritten sind. Da sich die türkische Regierung im Krieg offiziell zurückhielt, ließ Saracoglu nichtamtliche Persönlichkeiten mit der deutschen Regierung verhandeln. Daraufhin setzten sich der pensionierte General Hüseyin Hüsnü Emir Erkilet, ein glühender Pantürkist, und General Ali Fuad Erdem mit dem Mitarbeiter des deutschen Auswärtigen Amtes, Werner Otto von Hentig, in Verbindung (Önder 1977: 150). Auch der ehemalige Außenminister Numan Menemencioglu (1942-1944) äußerte sich über die vitalen Interessen der TR ,an dem Schicksal von 40 Mio. Türken in Rußland“, aber keine Aspiration außerhalb ihrer Grenzen (ebd.: 146).

Die Pantürkisten arbeiteten gegen die Sowjetunion. Die überzeugten Pantürkisten, der Generalstabchef der TR, Fevzi Cakmak ${ }^{156}$ und Nuri Pascha boten Deutschland ihre Hilfe, Informationsaustausch sowie die Mobilisierung der Turkvölker innerhalb der Sowjetunion für die deutsche Seite, an (Önder 1977: 146-147). Mit türkischer Unterstützung wurden seit 1942 Hilfstruppen aus sowjetischen Turkvölkern, die Kriegsgefangene waren, aufgestellt. 180.000 Mann wurden den Waffen-SS-Verbänden unterstellt. Sie kämpften an den verschiedenen Fronten: im Kaukasus, in Norditalien, vor Stalingrad und noch in Berlin (ebd.: 149). Die türkischen Pantürkisten glaubten, mit der Unterstützung Nazi-Deutschlands die Befreiung der sowjetischen Turkvölker und die Verwirklichung der pantürkistischen Ziele ermöglichen zu können. Nuri Pascha zufolge war Atatürks vorsichtige ZAP rein opportunistisch motiviert, da er vor einem möglichen sowjetischen Angriff Angst hatte (ebd.). Wenn aber Deutschland im 2. Weltkrieg siegen würde, würde die TR vor RU keine

\footnotetext{
${ }^{156}$. Nach der Einführung des Mehrparteinsystems in der Türkei 1946 gründete der ehemalige Generalstabchef Fevzi Cakmak 1948 die pantürkistische „Millet Partisi“ (Volkspartei), aus der später die „Cumhuriyetci Köylü Millet Partisi“ (Republikanische Bauern-Volkspartei) hervorging, welche wiederum seit 1969 „Milliyetci Hareket Partisi“" (Partei der Nationalistischen Bewegung) hieß.
} 
Angst mehr $\mathrm{zu}$ haben brauchen und vor ihren pantürkistischen Bestrebungen im sowjetischen Gebiet würde kein Hindernis mehr stehen (ebd.: 147).

Die TR kooperierte im 2. Weltkrieg - trotz ihrer Neutralität und Vereinbarungen mit den Allierten - mit Deutschland. Sie ließ die deutschen Kriegsschiffe ins Schwarze Meer passieren, verkaufte Deutschland den strategisch wichtigen Rohstoff Chrom, verweigerte Kriegsmateriallieferungen der Alliierten in die Sowjetunion durch die Meerengen und behinderte die sowjetischen Kriegsoperationen an ihrer Ostgrenze (Önder 1977: 242-245). Deshalb erklärte Stalin auf der Moskauer Außenministerkonferenz gegenüber dem ehemaligen britischen Außenminister Ernest Bevin (1945-1951) am 19. Dezember 1945, dass die Sowjetunion die türkischen Städte Kars und Ardahan ${ }^{157}$ zurück will (Office of the Historian 1945a). Des Weiteren beabsichtige die Sowjetunion, die türkischen Meerengen mit der TR zusammen zu verwalten (ebd.). D.h. Stalin plante, neben dem Moskau-Vertrag auch das Montreux-Meerengen-Abkommen vom 1936 mit der TR aufzukündigen. Schon vor diesem Gespräch fand am 7. Juni 1945 ein Gespräch zwischen dem ehemaligen sowjetischen Außenminister Wjatscheslaw Michailowitsch Molotow (1939-1949 und 1953-1956) und dem türkischen Botschafter in Moskau, Selim Rauf Sarper (1944-1946), statt. Der britische Diplomat John Balfour leitete die Informationen aus diesem Gespräch an das US-Außenministerium weiter. Laut Balfour machte Molotow Sarper in diesem Gespräch für die Verhandlung eines neuen türkisch-russischen „Freundschafts- und Nichtangriffsvertrags" "158 die Änderungen des Moskau-Vertrages von 1921 und des Meerengen-Abkommens von 1936 zur Bedingung (Office of the Historian 1945c). Molotow forderte (ebd.) die Neuverhandlung der türkisch-russischen Grenze. D. h. er forderte von der TR Kars und Ardahan zurück. Gleichzeitig sollte Molotow die Mitverwaltung der Meerengen mit der TR gefordert haben (ebd.). Wie aber der ehemalige türkische Ministerpräsident Sükrü Saracoglu (1942-1946) am 3. Juli 1945 dem amerikanischen Botschafter in Ankara mitteilte, stünde die Abtretung der türkischen Städte an die Sowjetunion der türkischen territorialen Integrität und die gemeinsame Kontrolle oder Verteidigung der türkischen Meerengen mit der Sowjetunion der türkischen Souveränität

\footnotetext{
157 Kars und Ardahan hatte die TR von der Sowjetunion infolge des Moskau-Vertrages am 16.03.1921 zurückerhalten. Diese beiden Städte waren zuvor infolge des „Berliner Kongress“ 1878 vom Zarenreich annektiert.

${ }^{158}$ Am 19. März 1945 teilte der sowjetischer Außenminister Molotow seinem türkischen Kollegen Sarper mit, dass die Sowjetunion den "Freundschafts- und Nichtangriffsvertrag" vom 1925 aufkündigen werde, weil dieser nicht mehr den neuen Bedingungen entspreche (Office of the Historian 1945b).
} 
entgegen (Office of the Historian 1945d). Er forderte die amerikanische und britische Unterstützung gegen die Sowjetunion (ebd.).

Die USA unterstützten die TR gegen die Sowjetunion und ließen sie 1945 durch ihren Botschafter in Ankara wissen, dass die territorialen Ansprüche der Sowjetunion gegenüber der TR kein türkisch-russisches Problem sei; sondern ein internationales und deshalb müsse das Problem vor die UNO gebracht werden (Erkin 1968: 272 f.; zit. nach: Önder 1977: 245). So begann die türkische Westorientierung. Wegen der sowjetischen Gefahr näherte sich die TR dem Westen, besonders den USA an. Sie sandte 1950 auf der amerikanischen Seite Soldaten in den Korea-Krieg und trat 1952 der NATO bei (Önder 1977: 242-245; Sandikli 2006: 8; Davutoglu 2011: 125; Steinbach 2007: 66). ${ }^{159}$

Im Kalten Krieg befanden sich die TR und RU aufgrund der Block-Konfrontation auf gegnerischen Seiten: NATO gegen Warschauer-Pakt. Beide Staatenbünde verschlossen sich gegenseitig. Die kulturellen und wissenschaftlichen Beziehungen waren eingefroren. Es war nicht einmal den wissenschaftlichen Institutionen in der TR erlaubt, Literatur aus der Sowjetunion zu nutzen, sagt Ortayli (2013: 87). Aus der Sowjetunion durften keine Touristen in die TR einreisen und das war sogar Wissenschaftlern und Fachleuten untersagt. Laut Ortayli (ebd.: 85) galt dieses Reiseverbot insbesondere für die „kaukasischen und zentralasiatischen Republiken “, deren Kontakte zur TR streng verboten waren. Erst Ende der 1980er Jahre änderte sich diese Situation und eine Öffnung war allmählich möglich (Ortayli 2013: 87, Steinbach 2007: 79, Turan 2008: 95, Caman 2013: 176). ${ }^{160}$

Obwohl die zentralasiatischen Staaten nach dem Basmatschi-Aufstand mit Zwang in die Sowjetunion integriert wurden, wollten sie sich von ihr in der Auflösungsphase nicht

\footnotetext{
${ }^{159}$ Steinbach (2007: 66) schreibt, dass die nationale Integrität und Souveränität Griechenlands und der TR von den USA für die westliche Sicherheit als wichtig eingestuft wurde. Deshalb machte der Westen diesen beiden Staaten mit der Truman-Doktrin den Weg zu massiver Militär- und Wirtschaftshilfe frei.

${ }^{160}$ Das heißt aber nicht, dass die TR und Sowjetunion während des Kalten Krieges keine Beziehungen hatten. Nach dem Johnson-Brief des US-amerikanischen Präsidenten Johnson an den türkischen Ministerpräsidenten Ismet Inönü im Juni 1964 näherte sich die TR an die Sowjetunion an. 1967 unterschrieben beide Staaten ein Wirtschaftsabkommen, das zwischen den beiden Staaten einen Warenaustausch vorsah und die Sowjetunion der TR die Gründung von Industrieanlagen versprach. In diesem Zusammenhang wurden deren Zahlungsbedingungen vereinbart (Ulcenko 2003: 184-185). In den 70er Jahren verbesserten sich die Beziehungen: die Sowjetunion half der TR finanziell und gründete zahlreiche Industrieanlagen, wie die EisenStahl-Fabrik in Iskenderun, die Erdölraffinerie in Aliaga, eine Aliminium Fabrik in Seydisehir und eine ErdölChemie-Fabrik in Bandirma. 1984 unterschrieben die TR und Sowjetunion ein Gasabkommen, anschließend importiert die TR seit 1987 Erdgas aus der Sowjetunion. Die türkisch-russischen Beziehungen waren jedoch auf den wirtschaftlichen Bereich begrenzt. Es gab zwischen beiden Staaten weiterhin keine politischen Beziehungen (Sandikli 2006: 8-9).
} 
trennen. Das zeigte eine Repräsentativbefragung für die Unabhängigkeitsbestrebungen der Bevölkerung im August 1990. Nur 24 \% der Zentralasiaten sprachen sich für einen Austritt aus der Sowjetunion aus. Im Vergleich zu Zentralasiaten waren 92 \% der Georgier und 91 \% der Balten für einen Austritt (Simon 1991: 28; zit. nach: List 2004: 26). Der ehemalige kasachische Präsident Nasarbajew z. B. kritisierte Gorbatschow wegen seiner Reformen scharf, weil sie die Auflösung der Sowjetunion beschleunigten (Mominkulov/Tumbayeva/Kaliollakizi 2012: 159). D. h. in ZA wurde die staatliche Unabhängigkeit weder von der politischen Elite noch von der Bevölkerung aktiv angestrebt (List 2004: 26). Diese Ereignisse zeigen, dass die russische Nationalitäten- oder Assimilationspolitik in ZA bis zur Auflösung der Sowjetunion „erfolgreich“ war. Die zentralasiatischen Staaten wurden 1991 unabhängig und somit wieder ein offener Rivalitätspunkt zwischen der TR und RU. 


\subsection{Zusammenfassung}

In ZA wurden im Laufe der Zeit zahlreiche Kulturen ansässig, wie Mongolen, Turkvölker, Russen, Iraner und Araber. Heute ist die Region, bis auf das persophone Tadschikistan, turksprachig geprägt. In ihrer Geschichte wurde sie je nach der führenden regionalen oder internationalen Macht der Zeit als Zeichen der Machtdemonstration neu umbenannt. Mal hieß ZA nach den geographischen Merkmalen Transoxanien, Innerasien oder Mawarannahr; mal nach den historisch-kulturellen (ethnisch, sprachlich) Merkmalen Turan, Turkestan oder Tartarei usw. Jede dieser Bezeichnungen beinhaltet die Geschichte der Region und der damaligen Machtverhältnisse. Aus türkischer Sicht ist ZA Türkistan, d. h. die Ur-Heimat der Türken, auch wenn sie die Region aus politischen Gründen vorwiegend Mittelasien nennt. Laut der türkischen Geschichtsschreibung wurde der erste Türkenstaat „Hunnenreich“ (220 v. Chr.-216) durch „die türkischen oghuischen Vorfahren“ im heutigen ZA und der Mongolei gegründet, wie auf der Internetseite des türkischen Präsidialamtes zu lesen ist (Türkiye Cumhuriyeti Cumhurbaskanligi o. J.). Das türkische Heer übernimmt das Datum der Thronbesteigung des Oghus Khans des Hunnenreichs im Jahre 209 v. Chr. als Gründungsjahr des türkischen Heeres (Kara Kuvvetleri Komutanligi 2020). Das zeigt, wie tief sich die TR mit ZA verbunden fühlt und die heutige ZAP der TR ohne Darstellung der Geschichte nicht zu verstehen ist.

Im ersten Geschichtsbuch (Oguzname, 1436-1437) des Osmanischen Reiches wurde das osmanische Herrschaftsgeschlecht als Nachkomme des zentralasiatischen Oghus Khans (209-174 v. Chr.) dargestellt. In Anlehnung an dieses Werk erhoben die osmanischen Sultane Anspruch auf die Leitung der altaischen Völker (Turkvölker, Mongolen und Tunguzen usw.), die damals Oghus Khan im Hunnenreich unter seine Herrschaft gebracht hatte. Meiner Meinung nach legte das Osmanische Reich mit dieser Geschichtsschreibung den Grundstein zum Pantürkismus, dessen Ziel im engsten Sinne die Vereinigung der turksprachigen Völker und im breiten Sinne die Leitung der altaischen Völker unter türkischer Herrschaft ist. Daher kann das 15. Jahrhundert als Anfang der pantürkistischen Idee im Osmanischen Reich gesehen werden und nicht wie bis jetzt angenommen wird, das 19. Jahrhundert. Als die tatarisch-mongolische Goldene Horde im 15. Jahrhundert zerfiel, erhob das Osmanische Reich als „Nachkomme des Hunnenreichs“ den Anspruch auf die Leitung der Nachfolgekhanaten der Goldenen Horde, wie die osmanischen Quellen aus der Zeit belegen (T.C. Basbakanlik Devlet Arsivleri Genel Müdürlügü 1992: XXXIX). Von den 
Nachfolgekhanaten ging nur das Khanat Krim 1475 unter die osmanische Herrschaft. Die anderen gingen unter die russische Herrschaft. Somit trat RU aus osmanischer Sicht das türkische Erbe an.

Als Anfang der türkisch-russischen geopolitischen Rivalität gelten die russischen Eroberungen der Nachfolgekhanate der Goldenen Horde, des Khanats Kasan 1552 und des Khanats Astrachan 1554. Sein erster Krieg (Astrachan Expedition 1568-1570) gegen das Zarenreich führte das Osmanische Reich für die Eroberung des Khanats Astrachan vom Zarenreich. Neben dem „historisch-ethno-kulturell“ begründeten Herrschaftsanspruch des Osmanischen Reiches spielte auch seit 1517 sein Titel als Kalif der Muslime eine Rolle in seinem außenpolitischen Verhalten. Als offizieller Grund der Astrachan-Expedition ging der zentralasiatische Hilfe-Ruf in die Geschichte ein. Die Zentralasiaten riefen den osmanischen Kalifen gegen das Zarenreich zur Hilfe, welches die Pilgerwege in Astrachan geschlossen halten sollte. Dieser Hilfe-Ruf gilt als erster Dschihad-Ruf(Inalcik 1999: 30) in der türkischislamischen Geschichte und zeigt gleichzeitig, dass die zentralasiatischen Khanate zu jener Zeit das Kalifat des Osmanischen Reiches schon anerkannten.

Aus russischer Sicht hingegen trat das Osmanische Reich mit der Eroberung der für das orthodoxe Christentum heilig gesehenen Stadt Istanbul 1453 das russische Erbe an. Die Eroberung Istanbuls und der türkischen Meerengen vom Osmanischen Reich wurde seit der Ära der Zarin Katharina II. (1762-1796) das zentrale Ziel des Zarenreichs. Des Weiteren erhoben sich beide Mächte gegenseitig zur Schutzmacht ihrer religiösen und ethnischen Minderheiten. Ab Mitte des 19. Jahrhundert prägte der Pantürkismus die osmanische und der Panslawismus die zaristische Politik. Um diese Zeit war eine aktive pantürkische Außenpolitik des Osmanischen Reiches im Zarenreich aufgrund der Machtverhältnisse nicht möglich. Deshalb konzentrierte sich das Reich auf die Bildungs- und Kulturpolitik und unterstützte gleichzeitig die Pantürkisten im Zarenreich.

Die Dschedid-Schulen und die Pressearbeit waren die wichtigsten Soft-Power-Instrumente der pantürkistischen Politik in ZA. Das erste Ziel des Pantürkismus in ZA war die Schaffung einer gemeinsamen Sprache, d. h. Verbreitung des Türkischen als gemeinsame Sprache und Schaffung einer gemeinsamen türkischen Identität. Für dieses Ziel arbeiteten die Pantürkisten unter türkischer Leitung zusammen. Die Aufenthalte aller leitenden zaristischen Pantürkisten (wie Gaspirali, Fitrat, Cobanzade) im Osmanischen Reich, die 
Ähnlichkeit der Zeitungsnamen von Gaspirali (Tercüman-i Ahval-i Zaman) und von JungOsmanen (Tercüman-i Ahval), die Ähnlichkeit der zentralasiatischen Flaggen mit der türkischen Flagge während des Basmatschi-Aufstandes (1918-1924) gegen das Zarenreich und die Leitung dieses Aufstandes durch die türkischen pantürkistischen Offiziere (Enver Pascha und nach seinem Tod Hadschi Sami Pascha) sind für mich Belege für die türkische Leitung der pantürkistischen Aktivitäten in ZA. Der Basmatschi-Aufstand wurde von Sowjetrussland niedergeschlagen und ZA nach Nationalitätenprinzip in die Sowjetunion integriert. Alles was pantürkistische Assoziation hatte, wurde von Sowjetrussland verboten, wie die Bezeichnung des ZAs als Turkestan. Hierzu ist zu bemerken, dass die türkischen Staatsarchive, wie z. B. Cankaya Köskü Arsivi (Archiv vom Cankaya) ungeöffnet sind und somit Recherchen zur türkischen ZAP in der Atatürk-Ära (1920-1938) fast unmöglich sind. Gleichzeitig begrenzt ein Gesetz von 1951 die unabhängigen Recherchen über seine Zeit und Person.

In der Atatürk-Ära (1920-1938) wurden die pantürkistischen Ziele aufgrund der Vereinbarungen mit Sowjetrussland sowie wegen der russischen finanziellen und militärischen Hilfen an die TR vorsichtig verfolgt. Als z. B. die Sowjetunion in ZA das arabische Alphabet zwischen den Jahren 1924-1928 durch das Lateinalphabet ersetzte, ersetzte Atatürk auch das türkische arabische Alphabet mit dem Lateinischen. Während des 2. Weltkrieges ersetzte RU das Lateinalphabet der Turkvölker mit dem kyrillischen und Russisch wurde seit den fünfziger Jahren die „zweite Muttersprache“ aller nichtrussischsprachigen Völker. Im 2. Weltkrieg unterstützte die TR Deutschland, obwohl sie im Krieg offiziell neutral war, damit die Sowjetunion besiegt wird und die turksprachigen Völker ihre Unabhängigkeit erreichen würden. Nach dem Sieg der Sowjetunion kündigte Sowjetrussland die „Freundschafts- und Nichtangriffsvertrag“ mit der TR auf. Sie wollte aufgrund des vertragswidrigen Verhaltens der TR die Moskau- und Montreux-MeerengenAbkommen mit ihr aufkündigen; die türkischen Städte Kars und Ardahan besetzen und mit ihr die türkischen Meerengen gemeinsam verwalten. So begann sich die TR in der Zeit aufgrund der sowjetischen Gefahr und der US-amerikanischen Unterstützung dem Westen anzunähern und trat 1952 der NATO bei. Im Kalten Krieg war für die TR eine Beziehung zu den zentralasiatischen Staaten aufgrund der Blockkonfrontation mit der Sowjetunion nicht möglich. Erst mit der Auflösung der Sowjetunion wurden die zentralasiatischen Staaten unabhängig. Sie selbst wollten sich von der Sowjetunion nicht trennen, nur $24 \%$ der Zentralasiaten sprachen sich für einen Austritt aus der Sowjetunion aus, obwohl sie mit 
Zwang in die Sowjetunion integriert wurden. Das zeigt, dass die russische ZAP bis zum Ende des Kalten Krieges erfolgreich war. 


\section{TÜRKISCH-RUSSISCHE KULTUR- UND BILDUNGSPOLITIK IN ZENTRALASIEN (1991-2019)}

Die Auflösung der Sowjetunion löste in der TR eine pantürkistisch geprägte Euphorie aus, weil erst dadurch die Kontaktaufnahme $\mathrm{zu}$ den aus der türkischen Sicht als „türkischsprachige Türken“ gesehenen turksprachigen Turkvölker wieder möglich wurde. Im Kalten Krieg waren die Kontakte des NATO-Landes TR zu diesen Staaten aufgrund der Blockkonfrontation mit der Sowjetunion nicht möglich gewesen. Für die TR gab es nun kein Hindernis mehr vor der Gründung einer „Türkenwelt" unter ihrer Herrschaft. Mit Hindernis meinte sie RU. Die pantürkistischen Erklärungen prägten die türkischen Medien, Öffentlichkeit und Bildungseinrichtungen usw. Die TR war überzeugt, dass die zentralasiatischen Turkstaaten die türkische Herrschaft akzeptieren werden, ohne zu wissen, dass sich die zentralasiatischen Staaten von der Sowjetunion nicht trennen wollten (siehe Kap. 3.6).

Kurz nach der Unabhängigkeit der Turkstaaten 1992 vereinbarte die TR ein „TürkenGipfeltreffen“ mit den Turkstaaten. Sie erwartete von ihnen die Akzeptanz der türkischen Sprache als gemeinsame Sprache und die Türkische Lira als gemeinsame Währung in einem gemeinsamen Markt usw. Politisch erwartete sie Rückdeckung bei der Karabach- und Zypern-Frage. Ihre Erwartungen wurden gleich auf diesem Gipfeltreffen zurückgewiesen (Caman 2013: 184) und die zentralasiatischen Turkstaaten distanzierten sich vom türkischen Pantürkismus (siehe Kap. 4.1.2.1). Die türkische Kultur- und Bildungspolitik konzentrierte sich auf die pantürkistischen Ziele der TR, wie z.B. die Schaffung der Türkischen Sprache als gemeinsame Sprache der Turkvölker und einer einheitlichen historisch-kulturellen „Türkenwelt“. Dafür setzt sie pantürkistische Soft-Power-Mittel wie die Gülen-Schulen, staatliche Organisationen, Medien, Stipendien usw. ein.

Die pantürkistische Kultur- und Bildungspolitik der TR wurde von den zentralasiatischen Staaten als sicherheitspolitische Gefahr für ihre territoriale Integrität und Souveränität angesehen, weil die TR mit ihrer „Türkenweltpolitik“ ihre nationale, historisch-kulturelle und sprachliche Eigenständigkeit nicht anerkannte. RU hingegen gilt nach wie vor als Schutzmacht des Status Quo in ZA und unterstützt die Eigenständigkeit der zentralasiatischen Staaten. ${ }^{161}$ RU hatte in der Geschichte „schlechte Erfahrungen“ mit dem

\footnotetext{
${ }^{161}$ In seiner aktuellen „Militärdoktrin von 2014“ (Präsident der Russischen Föderation 2014: 22) steht, dass
} RU im Falle eines bewaffneten Überfalls auf einen Mitgliedstaat der GUS (u. a. alle zentralasiatischen Staaten) 
pantürkistischen Basmatschi-Aufstand gemacht (1918-1924) (siehe Kap. 3.6), in dem die Zentralasiaten gemeinsam gegen die russische Herrschaft kämpften. Aktuell ist für RU eine mögliche Vereinigung der „Turkvölker“ und/oder „Muslime“ mit der TR in ZA wegen seiner turksprachig und/oder muslimischen Minderheiten eine sicherheitspolitische Gefahr für ihre territoriale Integrität (siehe Kap. 6.6). Daher ist für RU wichtig, dass das Land ZA weitgehend kontrollieren kann. Seine Kultur- und Bildungspolitik konzentriert sich auf den Erhalt und Verbreitung der russischen Sprache und Kultur sowie auf die Pflege des positiven RU-Images in ZA. Bis heute ist Russisch Lingua Franca und Wissenschaftssprache in der Region und RU von zentralasiatischen Staaten akzeptierte Schutzmacht in ZA. Das positive Image RUs als Schutzmacht und die gemeinsamen sicherheitspolitischen Interessen sowie die sicherheitspolitische Zusammenarbeit zwischen den zentralasiatischen Staaten und RU bestimmen die Grenzen der Kultur- und Bildungspolitik zwischen ihnen. D. h. Je tiefer die sicherheitspolitische Zusammenarbeit eines zentralasiatischen Staates mit RU ist, desto stärker ist seine kultur- und bildungspolitische Zusammenarbeit mit RU.

\subsection{Türkische Kultur- und Bildungspolitik in Zentralasien}

Die Beziehungen der TR zu den Turkstaaten fingen kurz vor der Auflösung der Sowjetunion an. Der türkische Präsident Turgut Özal (1989-1993) besuchte im März 1991 die Sowjetunion, Aserbaidschan und Kasachstan. Sein Besuch wurde in der TR als ein wichtiges Ereignis angesehen. Kurz nach diesem Besuch benutzte er am 22. Mai 1991 bei einer Rede in Bursa das erste Mal den folgenden Satz: „, das 21. Jahrhundert wird das Jahrhundert der Türkei und Türken sein “(türkisch: „21. Asir Türkiye ’nin ve Türklerin Asri Olacaktir“) (Özal 1991: 8). Er sprach nicht nur von den Türken aus ZA; sondern auch von den Türken auf dem Balkan, die alle zusammen 140 Mio. Menschen ausmachen sollen (Özal 1991: 33-35). Der ehemalige Ministerpräsident Süleyman Demirel (1991-1993) erklärte die Grenzen der „Türkenwelt“ im Februar 1992 als das Gebiet „vom Adriatischen Meer bis zur Chinesischen Mauer“. ${ }^{162}$ Diese offiziellen Aussagen der türkischen Entscheidungsträger auf höchster

oder eine andere beliebige Handlung unter Einsatz von militärischer Gewalt gegen sich als einen Akt der Aggression gegen den Unionsstaat betrachtet und Antwortmaßahmen ergreifen wird. D. h. es akzeptiert seine Rolle als Schutzmacht im „Nahen Ausland“.

162 Isyar (2005: 32) stellte fest, dass der Ausdruck „Türkenwelt vom Adriatischen Meer bis zur Chinesischen Mauer" nach dem Kalten Krieg das erste Mal von der Zeitschrift „The Economist“ im folgenden Aufsatz im Oktober 1991 benutzt wurde: „The Blur in Turkey: And a Big Weight on Suleyman Demirel's Shoulders“ (Economist, Vol. 321, No.7730, (October 26, 1991), pp. 15-6). Der ehemalige nationale Sicherheitsberater (1969-1973) und Außenminister (1973-1977) der USA, Henry Kissinger, benutzte diesen Ausdruck am 1. Februar 1992 während eines Weltwirtschaftsforums (Kut 1994: 13). Der ehemalige CIA-Mitarbeiter Graham 
Staatsebene zeigten ihre pantürkistische ZA-Wahrnehmung und ließen die Inhalte der späteren türkischen ZAP nach dem Kalten Krieg erahnen. ${ }^{163}$

Die Quelle des pantürkistischen Ausdruckes „eine Türkenwelt auf dem Gebiet vom Adriatischen Meer bis zur Chinesischen Mauer" sind die pantürkistischen Entscheidungsträger der „Ittihat ve Terakki“ (Komitee der Vereinigung und Fortschritt) am Anfang des 20. Jahrhunderts. Die Parteifunktionäre Dr. Nazim und Dr. Sakir zitierten in ihrem gemeinsam verfassten Brief an den Chefredakteur der Zeitschrift „Surayi Ümmet“, Sami Pasazade Sezai Bey, das Hauptziel der Partei sei die „Gründung eines Türkenbunds auf dem Territorium vom Adriatischen Meer bis China“. Diese Beschreibung übernahmen sie vom Chefredakteur der Zeitung „Hayat“, Ali Turani Bey (Kuran 1948: 206; zit. nach: Semiz 2014: 222-223). Damit meinten sie das osmanische Herrschaftsgebiet auf dem Balkan und dem Nahen Osten sowie die nicht zum Osmanischen Reich gehörenden Gebiete der Turkvölker. Um dieses Bündnis zu gründen, wurde die „sprachliche Einheit“ der genannten Gebiete als Hauptziel definiert (Kuran 1948: 206; zit. nach: Semiz 2014: 223). 1910 wurde Türkisch als Türkisierungssmaßnahme in allen Schulen im Osmanischen Reich obligatorisch (Semiz 2014: 231-233). In ZA wurde der Dschedidismus unterstützt, dessen erstes Ziel die „sprachliche Einheit“" der Turkvölker war. Als Endziel hatte diese Bewegung die Gründung einer „Türkenwelt“. Nach dem Kalten Krieg hatten die türkischen GülenSchulen in ZA ähnliche Ziele wie die ehemaligen Dschedid-Schulen. Bis heute ist die türkische ZAP pantürkistisch geprägt und die Region wird von der TR als Teil ihrer „Türkenwelt"“ angesehen.

Fuller (mit Ian O. Lesser, Paul Henze u. a.) benutzte ihn als Untertitel seines 1993 veröffentlichten Buchs „Turkey's New Geopolitics: From the Balkans to Western China“ (ebd.).

${ }_{163}$ Der ehemalige türkische Präsident Süleyman Demirel besuchte zwischen 27. April - 3. Mai 1992 zunächst ZA und am 25. - 26. Mai 1992 Moskau. Er wollte mit seinem Moskau-Besuch RU über die türkische ZAP informieren, wie Kolobov/Kornilov/Özbay (2006: 132) berichten. Er garantierte RU, dass die TR nicht beabsichtige, in ZA den ,großen Bruder“ zu spielen; sondern dass sie eher an die Zusammenarbeit mit RU für die gemeinsamen Ziele interessiert ist (ebd.). Während dieses Besuches unterschrieben die beiden Staaten am 25. Mai 1992 das „Türkiye Cumhuriyeti ile Rusya Federasyonu Arasindaki Iliskilerin Esaslari Hakkinda Antlasma“ (Abkommen über die Grundlagen der Beziehungen zwischen der Russischen Föderation und der Republik Türkei). Mit diesem Abkommen garantierten sie sich gegenseitig, ihre territoriale Integrität und Souveränität zu respektieren, über die regionalen Probleme Information auszutauschen, ihre wirtschaftlichen und kulturellen Beziehungen zu vertiefen und gegen den Terrorismus gemeinsam vorzugehen (ebd.). 


\subsubsection{Der Pantürkismus und Islam in der türkischen Zentralasienpolitik}

Der Pantürkismus und der Islam sind zwei prägende Elemente der türkischen ZAP. ${ }^{164}$ Nach der Auflösung der Sowjetunion 1991 wurde der Pantürkismus wieder das prägende Merkmal der ZAP der TR unter Özal und Demirel. Özal glaubte, dass die ethnischen Probleme innerhalb der TR (z. B. die Kurdenfrage) durch die ,,islamische Identität““ zu lösen sei, wie es im Osmanischen Reich (Yavuz 1998) der Fall war. Er glaubte, dass das wichtigste Identitätsmerkmal der türkischen Gesellschaft der „Islam“ sei (ebd.). Nach ihm bedeutet das „Türke sein“ im Osmanischen Reich Muslim zu sein oder genauso umgekehrt (Yavuz 1998). In den ehemaligen osmanischen Herrschaftsgebieten, wie z. B. auf dem Balkan oder dem Nahen Osten, versuchte die TR durch die Betonung des „Islam“ und in den „Türkstaaten“, wie in ZA, mit der Betonung des „Türkentums“ an Einfluss zu gewinnen. Sein außenpolitisches Verhalten während des Bosnien-Krieges und des Berg-Karabach-Krieges sind zwei gute Beispiele für die Haltung Özals.

Die TR half Bosnien aufgrund der ,religiösen Gemeinsamkeit und historischen Vergangenheit" mit Militärtechnik, ${ }^{165}$ als das Land 1992 von Serbien angegriffen wurde. Laut Kolobov/Kornilov/Özbay (2006: 140-141) half die TR das erste Mal seit ihrer Republiksgründung 1923 einem Land aufgrund „seiner Religion“, da die Bosniaken auch mehrheitlich sunnitische Muslime sind wie die TR. ${ }^{166}$ Sie bat die NATO um den militärischen Angriff auf Serbien (ebd.). Für Aserbaidschan wollte Özal im Berg-KarabachKrieg (zwischen Armenien und Aserbaidschan) auf der aserbaidschanischen Seite bei dem Krieg intervenieren (siehe hierzu Kap. 6.8). ${ }^{167}$ RU drohte der TR im Falle einer Einmischung mit dem 3. Weltkrieg (Fuller 1993: 78; Cornell 1999; Kolobov/Kornilov/Özbay 2006: 143), weshalb sie eine Intervention nicht wagen konnte. Bei der Unterstützung Aserbaidschans handelte es sich nicht um den ,religiösen Zusammenhalt", da die Aseris überwiegend schiitisch sind und die Staatsreligion der TR - trotz Laizismus - das Sunnitentum ist. Hierbei handelte es sich in erster Linie um die ,ethnisch-sprachliche Gemeinsamkeit“

\footnotetext{
${ }^{164}$ Siehe auch Kap. 3 für die Einflüsse des Islams und Pantürkismus in der türkischen ZAP bis zum Ende des Kalten Krieges.

165 Ümit Kivanc sagte in einem Interwiev mit Murat Sevki Coban 2015, dass die TR nach Bosnien Waffen und Mudschaheddin sandte (Kivanc 2015).

166 Bosnien war osmanisches Herrschaftsgebiet. Das Osmanische Reich sah die Bosniaken aufgrund „der religiösen und historischen Gemeinsamkeit“ als „Türken“. Hierzu ist zu bemerken, dass die Serben auch genauso lange unter Osmanischer Herrschaft standen wie die Boschniaken; sie sind aber christlich geprägt.

${ }_{167}$ Die Türkei begründete ihren Interventionswillen mit dem Vertrag von Kars 1921, nach dem sie die Schutzmacht der aserbaidschanischen Exklave Nachitschewan ist.
} 
(Kolobov/Kornilov/Özbay 2006: 143). Aserbaidschan ist ein Turkstaat und spricht die dem Türkischen ähnlichste Turksprache. RU hingegen stand als Schutzmacht Armeniens auf der armenischen Seite. 1994 erklärte der Chef des Generalstabes der türkischen Streitkräfte, Dogan Güres, RU als große sicherheitspolitische Gefahr und sagte folgendes:

„Ich habe vor einem Jahr gemerkt, dass Russland eine hegemoniale Politik betreibt. Das Land verfolgt die Ziele des Zarenreiches. Russland berücksichtigt die russische Diaspora im Ausland, deren Zahl 30 Mio. Menschen beträgt. Das Land spielt in Georgien, Ukraine und Aserbaidschan Spiele. An unserer Grenze zu Armenien gibt es russische Streitkräfte. Wir sind in schwierigen Zeiten. "168 (in: Basaran 2013: 156), (Übers. d. d. Verfasserin).

RU hingegen setzt die Aktivitäten der TR in Kaukasus und ZA bis heute mit dem Pantürkismus (und auch mit dem Panislamismus) gleich. Das Land sieht die TR als Gefahr für seinen Einfluss in seinem „Nahen Ausland“ und für seine eigene Sicherheit. Der russische Botschafter in Ankara, Albert Sergejewitsch Tschernyschew (1987-1995), warnte die TR wegen ihrem Pantürkismus in ZA und sagte folgendes:

„Einige in der Türkei sehen die zentralasiatischen Staaten als ihre Satellitenstaaten an und vertreten die Ansicht, die TR müsse in der Region das Machtvakuum füllen. Dort exisiert jedoch kein Machtvakuum. Auch Russland hat in den zentralasiatischen Staaten tiefe historische, ökonomische und politische Interessen." (zit. nach: Kolobov/Kornilov/Özbay 2006: 126). ${ }^{169}$ (Übers. d. d. Verfasserin)

Der ehemalige Präsident der TR, Süleyman Demirel, sicherte RU 1994 zu, dass die TR in den postsowjetischen Staaten weder einen Pantürkismus noch einen Panislamismus betreibt. Das türkische Ziel sei die Unterstützung dieser Staaten, damit sie auf eigenen Beinen stehen können (Basaran 2011: 157).

In der Ära von Necmettin Erbakan (1995-1997) wurde der Islam das prägende Merkmal der türkischen Außenpolitik. So bekam Erbakans religiös gesinnte Refah-Partei 1995 die meisten Wählerstimmen (21 \%). Erbakan allerdings verfolgte während seiner Ministerpräsidentenzeit (1996-1997) eine von der NATO unabhängige Außenpolitik, was

\footnotetext{
168 Güreş: „Bir yıl önce Rusya’nın yayılmacı bir politika izlediğinin farkına vardım. Çarlık döneminin iddialarıyla hareket eden bir Rusya ortaya çıkıyor. Rusya, sınırları dışında yaşayan 30 milyon Rus konusunda da iddialı. Gürcistan, Kırım, Ukrayna ve Azerbaycan'da oyunlar oynuyor. Ermenistan sınırımızda Rus tümenleri var. Zor günler yaşıyoruz.“ (Basaran 2013: 156).

169 „Türkiye`de bazi cevreler Türk cumhuriyetlerini ,[sic] Türkiye`nin uydulari olarak kabul etmekteler ve oradaki boslugun Türkiye tarafindan doldurulmasi gerektigini savunmaktalar. Fakat orada bir bosluk yok. Rusya nin da bu cumhuriyetlerde derin tarihi, ekonomik ve politik cikarlari bulunmaktadir.“
} 
in der türkischen Geschichte ein Novum darstellt (Yavuz 1998). Erbakan konzentrierte sich auf die Beziehungen zu den muslimischen Ländern des Nahen Ostens. Er schloss mit dem Iran, Libyen und dem Irak 1996 Handelsabkommen ab, mit dem Iran noch ein Gasabkommen. Am 28. Februar 1997 diktierte das türkische Militär Erbakan den Rücktritt (postmoderner Putsch). Er musste im Juni 1997 zurücktreten.

Der Pantürkismus gewann mit kurzer Unterbrechung in der Ära des ehemaligen, „eurasistisch“ orientierten türkischen Außenministers Ismail Cem (1997-2002) erneut an Bedeutung. In dieser Zeit rückte der postsowjetische Raum wieder in den Mittelpunkt. Cem benutzte anstelle des pantürkistischen Begriffes “Türkenwelt” den Begriff ,historischer Raum der Türkei“ (Tinc 2000). Nach Cem (in: Kireyev 2003: 204) hat die TR mit ihrem historisch-kulturellen Erbe zwischen dem Westen und Osten die Gelegenheit, das Zentrum Eurasiens zu werden. In seiner Amtszeit unterschrieb er mit RU (Außenminister Igor Ivanov) am 16. November 2001 ein sicherheitspolitisches Abkommen namens „Aktionsplan zur Zusammenarbeit zwischen der TR und der RF in Eurasien (Von bilateraler Kooperation zur multidimensionalen Partnerschaft)“. Beide Staaten verpflichteten sich damit zur Anerkennung ihrer territorialen Integrität, Souveränität, Unabhängigkeit und zur aktiven Zusammenarbeit in Eurasien, besonders in Fragen des internationalen Terrorismus, des Drogenhandels, der Konfliktlösung sowie der wirtschaftlichen und militärischen Kooperationen (Gül 2003).

$2002 \mathrm{kam}$ in der TR die AKP-Regierung an die Macht, welche sich in den ersten Jahren seiner Regierung auf die „EU-Mitgliedschaft“ konzentrierte. Ahmet Davutoglu ${ }^{170}$ gewann mit seiner realistischen Theorie „Strategische Tiefe“ bei der Gestaltung der türkischen Außenpolitik zunehmend an Bedeutung. Seine Theorie entwickelte er Ende der 1990er Jahre. Nach Davutoglu entsteht die „Strategische Tiefe“ in der türkischen Außenpolitik am Schnittpunkt des geographischen, historischen und religiös-kulturellen Erbe des Landes (Kramer 2010a: 2). Mit dem Erbe meint er das Erbe des Osmanischen Reiches, weshalb sein Konzept auch als „Neo-Osmanismus“(Kramer 2010a: 2) bezeichnet wird. Davutoglu vertritt die Meinung, dass die TR ihre geopolitische Lage gut ausnutzen muss und ihren Einfluss in den historischen Osmanischen Gebieten sowie auf die Turkstaaten ausdehnen soll. Er sieht

\footnotetext{
${ }^{170}$ Davutoglu war der ehemalige Chefberater des Ministerpräsidenten Erdogans (2002-2009), Außenminister (2009-2014) und Ministerpräsident (2014-2016) der TR.
} 
die postsowjetischen Turkstaaten, bzw. Turkvölker, genauso wie Özal, Demirel zuvor und der türkische Generalstab sie ansahen, als „Türken“ (Kivanc 2015, im Interview mit Coban).

Seit 2007 gewannen die pantürkischen Inhalte und das Handeln in der ZAP der AKP an Bedeutung. Beim 11. „Türkenkongress“ (türkisch: Türk Kurultayi) 2007 in Baku fing Erdogan an, von der „Einheit der Türkenwelt“ und Entwicklung der multilateralen Beziehungen zu reden (Özdamar 2010). Laut Cutler (2012) wandte sich Erdogan nach dem Scheitern seiner „Null-Problem-Politik mit den Nachbarn“ nun in die „eurasische Richtung“. Erdogan versprach bei seinem Kasachstan-Besuch die Handelsbilanz zu erhöhen und von seinem Wirtschaftsminister Zafer Caglayan wurden für die Investoren in Kasachstan Eximbank-Kredite versprochen. Cutler (ebd.) sieht diese Entwicklung als eine Rückkehr zur pantürkistischen Türkenweltpolitik der Özal-Ära.

Seit dem „Arabischen Frühling“ 2010 rückte allerdings die Rolle der Religion (auch innenpolitisch) in den Mittelpunkt, was weltweit als „Neuorientierung“ der TR, als NeoOsmanismus, interpretiert wurde. In dieser Zeit war Davutoglu bei der Gestaltung der Außenpolitik sehr aktiv. Allerdings wäre die Behauptung falsch, dass sich die türkische Außenpolitik unter der AKP gewandelt habe, wie auch Kivanc (2015, im Interview mit Coban) sagt. Es handelt sich vielmehr um eine Anpassung der türkischen Staatsideologie an die neuen Gegebenheiten wie die kurdische Freiheitsbewegung in Nord-Syrien und dem „Arabischen Frühling “. Besonders gegen die Kurden in Syrien geht die TR mit aller Härte vor. Ihre Unterstützung der Islamisten ${ }^{171}$ muss auch in erster Linie in diesem Zusammenhang gesehen werden. Im Januar 2018 erklärte Erdogan als Ziel des Afrin-Einsatzes in Syrien (Operation Olivenzweig) gegen die Kurden den „Roten Apfel“ (O. V. 2018: Erdoğan: Afrin'den geri ....). ${ }^{172}$ „Roter Apfel“ (türkisch: Kizil Elma) ist eines der wichtigsten Symbole des Pantürkismus und symbolisiert für die TR die Herrschaft in der „Türkenwelt“ sowie die Herrschaft in den ehemaligen osmanischen Gebieten. Erdogans Erklärung zeigt, wie das ethnisch-religiöse Ziel der Partei Ittihat ve Terakki in neuer Form als „Türkisch-Islamische

\footnotetext{
${ }^{171}$ Nach Brauns (2016) bildete die türkische Söldnerfirma SADAT die Söldner der „Freien Syrischen Armee“ und IS-Kämpfer in Ausbildungscamps in der TR gegen Assad und Kurden in Syrien aus.

Der türkische Journalist Can Dündar erklärte, dass die TR an die Islamisten (Islamischer Staaat (IS), Al Nusra usw.) in Syrien Waffen liefert (Varli 2016). Infolge seiner Äußerungen wurde er verhaftet. Aktuell lebt er in Deutschland im Exil. Der russische Präsident Wladimir Putin behauptete beim G-20 Gipfel 2015, dass die Türkei mit dem IS illegalen Öl- und Waffenhandel betreibt (ebd.).

${ }^{172}$ Erdogan benutzte den pantürkistischen Begriff "Roter Apfel" schon im April 2015 während der Einweihung eines Forschungszentrums. Er sagte: "Der Kampf für die Neue Türkei ist unser Roter Apfel" (Ghement 2015).
} 


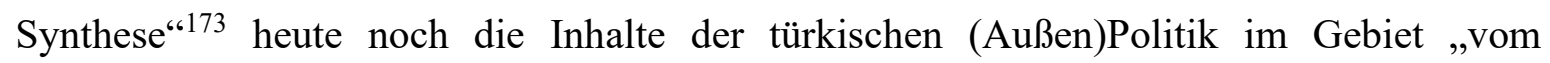
Adriatischen Meer bis zur Chinesischen Mauer" prägt.

\subsection{2, ,Türkenwelt"}

Die Unabhängigkeit der zentralasiatischen Staaten durch die Auflösung der Sowjetunion feierten die türkischen Medien als Befreiung der „Gefangenen Türken“ (Esir Türkler). Sie berichteten zu dieser Zeit überwiegend über die sogenannten „Türkrepubliken“ (Türk Cumhuriyetleri), die aus der türkischen Sicht ethnisch als „Türken“, sprachlich als „türkisch sprachige“ Republiken gesehen werden. Aufgrund der historisch-kulturell (ethnisch, sprachlich, religiös) geprägten Wahrnehmung wird ZA in der TR bis heute als natürliche „Türkenwelt“, bzw. als „natürlicher Einflussraum der TR“ gesehen. Zwar gehörte ZA in der Geschichte weder der TR noch ihrem Vorgänger, dem Osmanischen Reich, an. Da aber laut der offiziellen Geschichtsschreibung die Türken aus ZA in die heutige Türkei einwanderten, werden die turksprachigen zentralasiatischen Staaten als „,ethnisch-sprachliche“ Verwandte gesehen. Dazu kommt die „religiöse Gemeinsamkeit“ mit der Region. Die Bevölkerung ZAs ist überwiegend sunnitisch geprägt, deren religiöses Oberhaupt (Kalif) seit 1517 bis $1924^{174}$ die osmanischen Sultane waren. Das türkische Ziel war, sich mit der Gründung der Türkenwelt unter ihrer Leitung zu einer regionalen, vielleicht auch zu einer internationalen Macht zu entwickeln.

Die Machtzunahme des Pantürkismus nach dem Kalten Krieg wurde von innen- und außenpolitischen Faktoren begünstigt. Als innenpolitische Faktoren können die folgenden Gründe genannt werden: a) die pantürkistische „Zentralasienwahrnehmung“ der türkischen Entscheidungsträger und Bevölkerung, b) die unbefristete Zurückstellung ihres Antrages auf die Vollmitgliedschaft durch die EU im Jahre 1989, ${ }^{175}$ c) die separatistischen Bestrebungen

\footnotetext{
${ }^{173}$ Türkisch-islamische Synthese wurde in den 1970er Jahren vom konservativen Historiker Ibrahim Kafesoglu entwickelt. Die Religion gewann in diesem Konzept wieder an Relevanz. Sie vertritt eine anti-westliche Innenund Außenpolitik. Mit dem Militärputsch vom 12. September 1980 wurde die türkisch-islamische Synthese zur offiziellen Staatsideologie der TR. Die Religion wurde vom Militärregime unterstützt. Hür (2014) zufolge ist bei der Zunahme der Religiosität seit dem Militärregime der Einfluss der USA auf die TR nicht zu unterschätzen. Nach ihr (ebd.) strebten die USA mit der vom amerikanischen Strategen Zbigniew Brzezinski entwickelten Strategie "Grüner Gürtel” die Einkreisung der gottlosen, kommunistischen Sowjetunion durch den „Islam“ an und förderten deshalb die Religiosität (Siehe Kap. 6. 5).

${ }^{174}$ Das Kalifat wurde am 3. März 1924 abgeschafft.

175 Die TR bemüht sich seit 1959 mit ihrem Assoziierungsantrag mit der Europäische Wirtschaftsgemeinschaft (EWG) um den Beitritt in die EWG, der Vorgängerorganisation der Europäischen Gemeinschaft, bzw. Europäische Union. Nach dem als Ankara-Vertrag bezeichneten Assoziierungsabkommen 1963 sollte die TR spätestens nach 17 Jahren als Vollmitglied in die EWG aufgenommen werden, was der Militärputsch 1980 in
} 
der pro-kurdischen „Partiya Karkeren Kurdistan“(PKK) für ein unabhängiges Kurdistan, d) die wirtschaftlichen Probleme der TR, e) ihr geopolitischer Werteverlust für die NATO, da sie bis zum Ende des Kalten Krieges das einzige an die Sowjetunion angrenzende NATOLand war. Ihr geopolitischer Werteverlust bedeutete für die TR gleichzeitig den Verlust der westlichen Wirtschaftshilfen.

Die außenpolitischen Faktoren bei den pantürkistischen Aktivitäten der TR waren hingegen Folgende: a) international fand die TR die US-amerikanische Unterstützung für ihre ZAP und wurde von ihnen für ZA als laizistisch-demokratisches Modell mit freier Marktwirtschaft als Modelstaat dargestellt (Caman 2013: 193; Turan 2014: 859). Unter anderem wollten die USA mit dem türkischen Modell, den möglichen religiösen Einfluss des Iran und den Einfluss RUs in der Region eindämmen. Die TR unterstützte die Integration der Regionsstaaten in die westlichen Organisationen wie z. B. von Kasachstan. Das Land war in kürzester Zeit nach seiner Unabhängigkeit 1992 Mitglied der OSZE (Organisation für Sicherheit und Zusammenarbeit in Europa), Weltbank, UN und IMF (International Monetary Fund) geworden. Des Weiteren, b) RU ignorierte die Region in den Anfangsjahren der 1990er Jahren wegen seiner Neuorientierung (Atlantismus) und den bestehenden „Abhängigkeitsverhältnissen“ mit ZA aus der sowjetischen Zeit. C) In dieser Zeit orientierten sich die zentralasiatischen Staaten neu und suchten nach neuen Kooperationspartnern. Sie nahmen das „westliche-NATO-Mitglied“ TR als politische und wirtschaftliche Brücke wahr, um ihre Unabhängigkeit zu festigen.

Das Konzept „Türkenwelt““ unter der türkischen Herrschaft umfasst alle Turkstaaten bzw. Turkvölker wie Krim-Tataren in der Ukraine oder Gagavuzen in Moldawien. Das verbindende Merkmal der Türkenwelt ist die „ethnisch-sprachliche Zugehörigkeit“ und nicht die Religion. Aserbaidschan ist schiitisch, Gagavuzen sind Christen. Tadschikistan ist sunnitisch, aber weil das Land persophon (ethnisch, sprachlich) geprägt ist, wird es ausgeschlossen. Als erster Schritt zur Vereinigung aller „Türken“ zielte die TR auf die „einheitliche Schrift“ und arbeitete daran, dass die turksprachigen zentralasiatischen Staaten

der TR verhindert hat. Der türkische Antrag auf die Mitgliedschaft im Jahre 1987 wurde 1989 abgelehnt. Die Gründe der EU waren die schlechte wirtschaftliche Situation, der starke Bevölkerungswachstum, ein schlecht funktionierendes demokratisch-ziviles Rechtsystem und die kulturellen Unterschiede zur EU. Besonders der letzte Grund wurde in der TR als Diskriminierung des Landes wegen seiner religiösen Unterschiede zur EU interpretiert. Der ehemalige Außenminister der TR Mesut Yilmaz sagte über die Absage, dass die EU eine kulturelle Berliner Mauer zur Abwehr der TR baue und die TR wegen ihrer muslimischen Identität diskriminiere (Yavuz 1998). Laut Shireen Hunter (2001: 6) wandte die TR nach dieser Absage ihr Gesicht Richtung Osten und das war der Anfang des Neo-Osmanismus und Neo-Turanismus. 
ihre Alphabete vom Kyrillischen ins Türkische-Latein umstellen. Sie arbeitete für eine „einheitliche Türkenwelt“, wie es der Vater des Pantürkismus Ismail Gaspirali tat. Gaspiralis Satz gilt bis heute als das berühmteste Ziel des Pantürkismus: „Einheit in der Sprache, Meinung und Arbeit“ (türkisch: dilde, fikirde, iste birlik). Dieses pantürkistische Motto von Gaspirali war im März 1993 in der türkischen Stadt Antalya als Name der „1. Allgemeinen Konferenz der Türkstaaten, die Bruderschaft der Türkvölker und ihre Zusammenarbeit“" (Türk Devletlerinin Birinci Genel Toplantısı, Türk Halklarının Kardeşliği ve İş Birliği Grubu).

Die TR versuchte mit dem Pantürkismus, die Sprache und Kultur der Turkstaaten zu türkisieren und behandelt sie nicht auf gleicher Augenhöhe. Diese Haltung der TR unterscheidet sich stark von der Selbstwahrnehmung der zentralasiatischen Staaten. Die zentralasiatischen Staaten sehen sich nicht als Türken und eine einwandfreie Kommunikation zwischen der TR und den zentralasiatischen Staaten ist nicht möglich, wie die türkischen „Pantürkisten“ nach wie vor behaupten. Die TR unterscheidet nicht zwischen einem Turkstaaten und Türkstaaten bzw. Türkenstaaten. Für sie sind die Turkstaaten „Türkstaaten bzw. Türkenstaaten“. Daher benutzt sie die Bezeichnungen kirgisischer Türke (türkisch: Kirgiz Türkü), usbekischer Türke (türkisch: Özbek Türkü), kasachischer Türke (türkisch: Kazak Türkü) und Turkmene (türkisch: Türkmen ist in der TR gleichbedeutend mit Türke). Die turksprachigen Zentralasiaten sehen/nennen sich aber nicht als Türke; sondern als Kirgiser, Kasacher, Usbeker und Turkmener. ${ }^{176}$ Ihre Sichtweise zeigten sie mit der Forderung, den Namen des seit 1992 von der TR organisierten jährlichen Gipfeltreffens „Türkengipfel“ (türkisch: Türk Zirvesi) ${ }^{177}$ in „Gipfeltreffen der Präsidenten der turksprachigen Länder“ (türkisch: Türki dili konusan ülkeler devlet baskanlari zirvesi) zu ändern. Die turkophonen zentralasiatischen Staaten wollten damit nur ihre Sprachfamilie als Gemeinsamkeit betonen, keine ethnische Verwandtschaft mit den Türken. Der Name des Gipfeltreffens wurde zwar auf ihren Wunsch von der TR umbenannt, allerdings als

\footnotetext{
176 Nach Erzählungen meiner Verwandten, die in Kasachstan und Kirgisistan leben, definieren sich einige Studenten, die an den von der TR und/oder auf ihrer Initiative gegründeten Universitäten in diesen Staaten studieren, als „,kasachische Türken“ oder „kirgisische Türken“. Im Allgemeinen aber findet diese Bezeichnung in den breiten Bevölkerungsschichten der beiden Staaten keine Akzeptanz. Die Ahmet Yesevi Universität in Kasachstan wurde von der TR gegründet. Die Kirgisistan-Türkei Manas Universität wurde von der TR und Kirgisistan gegründet, auf der die Seminare auf Türkisch und Kirgisisch angeboten werden. Die von Gülenisten betriebenen Universitäten in diesen Staaten sind die Süleyman-Demirel-Universität in Almaty (Kasachstan) und die Internationale Atatürk-Alatoo Universität in Bischkek (Kirgisistan).

${ }^{177}$ Das nächste geplante Gipfeltreffen im Jahre 1993 fiel aufgrund des Machtwechsels in Aserbaidschan aus. In dieser Dekade wurden insgesamt 5 Gipfeltreffen organisiert: Im Oktober 1992, Oktober 1994, August 1995, Oktober 1996 und Juni 1998.
} 
„Gipfeltreffen der Präsidenten der türksprachigen Länder“ (türkisch: Türk Dili Konusan Ülkeler Devlet Baskanlari Zirvesi). RU bezeichnete 1994 diese Gipfeltreffen als „pantürkische Gehirnwäscheversuche der Türkei“ (Basaran 2013: 158).

Auch bei den Turksprachen der Region zeigt die TR eine ähnliche außenpolitische Haltung wie bei ihren nationalen Identitäten. Sie ignoriert, größtenteils bewusst, den Unterschied zwischen der „Turksprache“ und „Türksprache“, bzw. „Türkisch“ bei ihren Formulierungen. Die Turksprachen der Region bezeichnet sie z. B. als kirgisisches Türkisch (türkisch: Kirgiz Türkcesi), kasachisches Türkisch (türkisch: Kazak Türkcesi), usbekisches Türkisch (türkisch: Özbek Türkcesi) und Turkmenisch (türkisch: Türkmence). Die zentralasiatischen Staaten nennen ihre Sprachen nicht Türkisch oder Türksprache; sondern als eine Turksprache wie Kirgisisch, Kasachisch, Usbekisch und Turkmenisch, zu der Sprachfamilie auch Türkisch gehört.

Die deutsche Sprache verwendet für die Sprachfamilie die Bezeichnung „Turksprachen“, die englische Sprache die Bezeichnung „Turkic Languages“ und die russische Sprache die Bezeichnung „Tyurkskie Yazyki“, was im Türkischen der Bezeichnung „Türki Diller“ (Turksprachen) entspricht. Die Bezeichnung „Turksprachen“ ist in der TR nicht gängig. Die dominierende Meinung in der TR ist, dass die aktuellen zentralasiatischen Nationalsprachen erst durch die Sprach- und Bildungspolitik des Zarenreiches und seinem Nachfolger Sowjetunion entstanden sind und die turksprachigen Zentralasiaten davor die Dialekte des Türkischen sprachen. ${ }^{178}$ Diese Behauptung ist allerdings problematisch. Die russische Herrschaft beeinflusste zwar die Nationalsprachen der Region. Aber jede Sprache der Welt entwickelte sich im Laufe der Zeit durch Fremdeinflüsse weiter. Andererseits wurden in ZA schon vor der russischen Herrschaft unterschiedliche Sprachen gesprochen, wie die Turksprache Uighurisch (Tschagataisch, d. h. alt-usbekisch), Oughusisch (Turkmenisch), kiptschakische Sprachen (wie Kirgisisch und kasachisch), die indoeuropäische Sprache Persisch, die semitische Sprache Arabisch usw. Die Turksprachen ZAs haben zwar aufgrund der gleichen Sprachfamilie (Turksprachen) Ähnlichkeit mit dem Türkischen. Eine Verständigung zwischen dem Türkischen und diesen Sprachen ist jedoch nicht möglich, ${ }^{179}$

\footnotetext{
${ }^{178}$ Die Wissenschaftler Cagri Erhan (2003: 3) und Seyfi Tashan (Tashan 2009: 359) glauben z. B., dass in ZA türkisch bis zu der Bolschewistischen Revolution lingua franca war und die Regionsstaaten die Dialekte des Türkischen sprachen. Diese Meinung ist bis heute in der TR gängig.

${ }^{179}$ Zwar ist die Kommunikation zwischen Türkisch und Aserbaidschanisch möglich, mit den zentralasiatischen turksprachigen Staaten ist das aber nicht der Fall.
} 
und war schon vor der sowjetischen Zeit nicht möglich. ${ }^{180}$ Sonst hätten Pantürkisten, wie Ismail Gaspirali, nicht versucht, eine gemeinsame Sprache für die Turkvölker zu entwickeln und durch die Dschedid-Schulen in ZA die tatarische und türkische Sprache zu verbreiten, bzw. an der sprachlichen Einheit zu arbeiten. Andererseits begann die russische Sprachpolitik in ZA erst nach der Eingliederung der zentralasiatischen Staaten in die Sowjetunion (siehe hierzu Kap. 3.6), d. h. Jahre später nach den pantürkistischen Sprachpolitik, Bildungs- und Pressearbeit.

In der TR ist die Meinung gängig, eine Verständigung zwischen den Turksprachen mit einem „einheitlichen Alphabet“ sei weitgehend möglich. Damit wäre die erste Stufe des Pantürkismus, nämlich die sprachliche Einheit, erreicht. Zu diesem Zweck versuchte die TR die zentralasiatischen Turkstaaten von der Einführung des lateinischen Alphabets zu überzeugen. Usbekistan und Turkmenistan beschlossen $1993 \mathrm{ihr}$ kyrillisches Alphabet durch das Lateinische zu ersetzen. Sie benutzen seit 1995 das lateinische Alphabet. Ihr neues Alphabet ist allerdings mit dem lateinischen Alphabet der TR nicht identisch, wie es sich die TR wünschte. Sie haben einige andere Buchstaben, ${ }^{181}$ die das Türkische nicht hat, wie z. B. das Turkmenische ä, ž, w, ẏ und Usbekische ch, sh, q, o“ usw. Laut Erdal (2013: 453) beabsichtigten die beiden Staaten mit der Einführung des lateinischen Alphabets sich vom russischen Einfluss zu befreien. Mit dem eigenartigen Alphabet allerdings wollten sie sich auch vor dem türkischen Einfluss schützen. Nach Nogayeva (2012: 188) hingegen führten Turkmenistan und Usbekistan das lateinische Alphabet ein, weil sie sich an die Internetsprache anpassen wollten. Alle dieser Gründe dürften eine Rolle bei ihrer Alphabetreform gespielt haben. Kasachstan und Kirgisistan benutzen allerdings bis heute das kyrillische Alphabet. Somit ist es bis heute der TR in ZA nicht gelungen, ihr lateinisches Alphabet in allen Turkstaaten ZAs durchzusetzen. Damit scheiterte sie schon an der ersten Stufe ihres sprachlichen Einigungsversuchs für eine einheitliche „Türkenwelt“.

\subsubsection{Türkische Soft-Power-Mittel in Zentralasien}

Für die Kultur- und Bildungspolitik setzt die TR sowohl staatliche als auch nichtstaatliche Soft-Power-Mittel ein. Der Schwerpunkt der Soft-Power-Mittel der TR in ZA ist die

\footnotetext{
${ }^{180}$ Der Vater des Pantürkismus, Ismail Gaspirali, schrieb am 15. März 1906 in seiner Zeitung „Tercüman-i Ahval-i Zaman“, dass sich die Türken aufgrund ihrer Dialektunterschiede nicht verstehen (Toker 2004: 37).

${ }^{181}$ Sehr gute Darstellung über die Kulturarbeit der TR in ZA in: Sahin 2013: 449-457.
} 
Schaffung einer gemeinsamen Sprache als erstes und eines ethno-kulturellen politischen Raumes als Endziel. Die Mittel für das Ziel konzentrieren sich auf die Verbreitung der türkischen Kultur und die Überzeugung der zentralasiatischen Staaten zur Intensivierung der Beziehungen sowie Vertrauensbildung usw. Ihre Soft-Power-Mittel sind Kredite, Entwicklungshilfen, jährliche staatliche Gipfeltreffen „Türkengipfel“ (türkisch: Türk Zirvesi), die Institution TIKA, ${ }^{182}$ seit 1993 TÜRKSOY, ${ }^{183}$ seit 2009 „Yunus Emre Institut“ (türkisch: Yunus Emre Enstitüsü) in Kasan (Russische Föderation) und Astana (Kasachstan) (Yunus Emre Enstitüsü 2015), staatliche und nicht staatliche Bildungseinrichtungen, wie die Gülen-Schulen (siehe Kap. 4.1.2.2), die staatlichen und nichtstaatlichen türkischen Universitäten, Stipendien, die Stiftung TDAV (türkisch: Türk Dünyasi Arastirmalari Vakfi, Stiftung für die Erforschung der türkischen Welt), die Medien, wie der türkische staatliche Fernsehsender TRT-Avrasya, private Fernsehsender, wie z. B der pro-islamische Samanyolu und TGRT, die pro-islamische Zeitung Zaman u.a., Zusammenkünfte, wie der „Kongress der Türksprachen“ (türkisch: Uluslararası Türk Dili Kurultayları), die „Union der Nachrichtenagenturen der Türkisch Sprechenden Welt“"(türkisch: Türkçe Konusan Ülkeler Haber Ajansları Birligi), die „Eurasischen Studien“ (türkisch: Avrasya Etüdleri) usw.

Die Herrschaft über die Turkstaaten war und ist der türkische Traum. Gleich auf dem ersten Gipfeltreffen mit den Turkvölkern 1992 zählte die TR ihre Erwartung von ihnen auf: Politisch erwartete sie von diesen Staaten, die Besetzung des aserbaidschanischen Territoriums durch Armenien offiziell zu kritisieren sowie Nord-Zypern als unabhängigen Staat anzuerkennen. Sie wollte einen Wirtschaftsraum schaffen, in dem z. B. die fossilen Brennstoffe ZAs gemeinsam verwaltet werden können und die türkische Lira als Währung fungiert. Die „Türkenwelt“ sollte kulturell eine Einheit bilden, in der „türkisch“ die gemeinsame Sprache und das türkische Alphabet das gemeinsame Alphabet ist. Die Erwartungen der TR lehnten die zentralasiatischen Staaten gleich auf diesem Gipfeltreffen (Caman 2013: 184) ab. Der ehemalige kasachische Präsident Nursultan Nasarbajew

\footnotetext{
${ }^{182}$ TIKA (Türk İşbirliği ve Koordinasyon Ajansı Başkanlığı, Präsidentschaft der türkischen Kooperation und Entwicklungsagentur) wurde 1992 gegründet, um mit den Turkrepubliken wirtschaftliche, ökonomische, technische, soziale und kulturelle Kooperation zu koordinieren. Diese Organisation ist staatlich und dem Ministerpräsidium unterstellt (T. C. BASBAKANLIK, TIKA 2015).

${ }^{183}$ TÜRKSOY (Uluslararasi Türk Kültürü Teskilati, Internationale Organisation für Türkkulturen) wurde 1993 gegründet, „um die Einheit und Brüderlichkeit der türkischen Völker zu fördern, die gemeinsame türkische Kultur an die Folgegenerationen weiterzugeben und der Welt zu präsentieren“ („Türk halklarının gönül birlikteliğini ve kardeşliğini güçlendirmek, ortak Türk kültürünü gelecek nesillere aktarmak ve dünyaya tanıtmak için çalışmaktadır.“ (Übers. d. d. Verfasserin) (TÜRKSOY o. J. a). Alle turksprachigen Staaten ZAs und das südkaukasische Aserbaidschan sind Mitglieder der TÜRKSOY. Die turksprachigen Republiken in der Russischen Föderation, wie die Republiken Tatarstan, Altai, Tuwa, Sacha, Chakassien, Baskordostan sowie Nord-Zypern und Gagausien (Moldawien), haben einen Beobachterstatus (TÜRKSOY o. J. b).
} 
definierte die türkischen Herrschaftsansprüche als nicht akzeptabel. ${ }^{184}$ Der usbekische Präsident Islam Karimow sagte, dass sein Land nicht nur mit der TR, sondern auch mit anderen Staaten Beziehungen aufnehmen und die bestehenden Beziehungen pflegen möchte (Caman 2005: 288). Auch die anderen Turkstaaten hielten sich gegenüber den türkischen Vorstellungen zurück (Caman 2013: 196). Diese Äußerungen zeigten deutlich, dass sich die Erwartungen der TR von den Erwartungen der zentralasiatischen Staaten von der TR vehement unterscheiden. Es muss hier unterstrichen werden, dass in allen postsowjetischen Turkstaaten Parteien verboten werden, die sich auf ethnischer oder religiöser Grundlage definier(t)en (Halbach 2018: 18). Diese innenpolitische Haltung spiegelt sich in ihren außenpolitischen Entscheidungen wider. Sie wollten mit der TR nur ihre kulturelle und sprachliche Nähe betonen, wie ihre Mitgliedschaften in solchen Organisationen zeigt (Siehe Tabelle 3).

Erhellend ist in diesem Zusammenhang ein Interview der türkischen Politikwissenschaftlerin Nur Bilge Criss (2010: 138) über den bekanntesten türkischen ultranationalistischen, ehemaligen Militärangehörigen und Politiker Alparslan Türkes und seine ZA-Reise. Der Pantürkist Türkes war mit dem türkischen Staatspräsidenten Turgut Özal ${ }^{185}$ auf einer ZA-Reise. Als sie zurück waren, hat Criss (ebd.) von Türkes` ultra-nationalistischer Partei MHP (Milliyetci Hareket Partisi, Partei der nationalistischen Bewegung) nicht mehr gehört, dass sie Zentralasiaten als ,unsere türkischen Brüder“ (türkisch: Türk kardeslerimiz) nennt. Nach Criss (ebd.) wurde Türkes in ZA mit der Realität konfrontiert, wonach die Turksstaaten sich eher mit der sowjetischen Kultur identifizieren als mit der türkischen. Die Rede des kasachischen Präsidenten Nursultan Nasarbayew auf der Weltwirtschaftsmesse im Jahre 2000 bestätigt Criss`Aussage. Seine Botschaft drückte er folgendermaßen klar aus:

„Es gibt für die ehemaligen Sowjetrepubliken keine Alternative zur Wiedervereinigung mit Russland. Unsere Kultur ist dieselbe, unsere Geschichte ist dieselbe, unsere Vorfahren sind dieselben. Wir haben ähnliche wirtschaftliche

\footnotetext{
${ }^{184}$ Nasarbajew äußerte sich über die türkischen Wünsche im negativen Sinn folgendermaßen:

„Es ist eine Tatsache, dass wir gemeinsame Wurzeln haben. Doch lebten wir seit langer Zeit ziemlich entfernt voneinander. Ich schlug vor, die bereits abgetrennten Bindungen unserer Kultur wieder zu knüpfen, indem wir gegenseitig die Souveränität jeden Staates respektieren. Ich fügte aber auch hinzu, dass wir unsere Beziehungen zu anderen Völkern und Staaten nicht abbrechen werden bzw. nie mehr Beziehungen aufnehmen werden, bei denen wir nicht gleichberechtigt sind... Karimow unterstützte mich“ (In: Caman 2005: 287-288).

${ }^{185}$ Laut Özal (1991: 33-35) nahmen die zentralasiatischen Staaten die TR als Retter und Führer positiv wahr.
} 
Infrastruktur-Probleme. Nur so [mit RU zusammen] können wir uns auch in den Westen integrieren. "186 (zit. nach: Tinc 2000). (Übers. d. d. Verfasserin)

Diese Rede zeigt, dass die türkische Idee von einer „Türkenwelt“ und ihre Bemühungen in den 1990er Jahre in ZA keinen Erfolg hatte. Die TR unterschrieb mit den Turkstaaten zahlreiche Abkommen und versprach ihnen wirtschaftliche Hilfen. Ihre großen Hilfsversprechen konnte sie allerdings aufgrund ihrer schwachen wirtschaftlichen Kapazitäten nicht halten. Die schwache wirtschaftliche Situation der TR sowie ihre unrealistischen pantürkistischen Erwartungen an die Turkstaaten ließen die Turkstaaten von der TR Abstand nehmen. Die TR musste daher ihre pantürkistische ZAP überdenken.

Die TIKA verfolgte bis 1995 wirtschaftliche, soziale und kulturelle Ziele in ZA. Ab 1995 konzentrierte sie sich auf die Kultur- und Bildungspolitik in der Region (T. C. Basbakanlik, TIKA: Türk Isbirligi ve Koordinasyon Ajansligi Baskanligi (2015): Hakkimizda), weil der TR ab diesem Datum klar wurde, dass ohne Berücksichtigung der russischen Interessen und Interessen der zentralasiatischen Staaten eine erfolgreiche ZAP nicht möglich ist. Unter der Erdogan-Regierung stiegen die Entwicklungshilfen an die Turkstaaten enorm (siehe Kap. 5.6).

Die zentralasiatischen Turkstaaten empfanden den türkischen Pantürkismus und ihre Ziele als Gefahr für ihre eigene nationale Identität und Sprache, wie oben schon erwähnt wurde. Sie forderten von der TR z. B. den Namen des Gipfeltreffens „Türkengipfel“ (türkisch: Türk Zirvesi) zum „Gipfeltreff der turksprachigen Präsidenten“ (türkisch: Türki dili konusan ülkeler baskanlari zirvesi) umzubenennen. Mit den Gipfeltreffen wollten sie zwar ihre „sprachliche Nähe“ zu der TR betonen, aber sich gleichzeitig von der „ethnischen Verwandtschaft mit der TR“ distanzieren. Allerdings hieß dieses Treffen seit dem 5. Gipfeltreffen in Astana 1998 bis zum Gipfeltreff in Istanbul 2010 „Gipfeltreff der Präsidenten der türksprachigen Länder“ (türkisch: Türk dili konusan ülkeler devlet baskanlari zirvesi). ${ }^{187}$ „,Türk Dili“ bedeutet die Sprache der Türken, also türkisch. Auf dem Gipfeltreffen in Istanbul 2010 wurde der Name dieser Treffen erneut geändert und ihm wurden zwei weitere Namen hinzugefügt: TDIK (Türk Dili Konusan Ülkeler Isbirligi

\footnotetext{
186 „Eski Sovyet Cumhuriyetleri'nin, Rusya ile birleşmelerinden başka şansları yoktur. Kültürümüz bir, tarihimiz bir, atalarımız bir. Aynı ekonomik alt yapının, benzer sorunlarını yaşıyoruz. Ancak bu şekilde Batı ile de entegrasyonu sağlayabiliriz."“ (zit. nach: Tinc 2000).

${ }^{187}$ Siehe über die historische Entwicklung: Asker 2009.
} 
Konseyi, Der Kooperationsrat der türksprachigen Staaten), Türk Konseyi (Türkenrat) und Türk Kenesi (Türkenparlament). ${ }^{188}$

Mit der Bezeichnung TDIK für den ständigen Rat, versucht die TR, die sprachliche Nähe mit den turksprachigen postsowjetischen Völkern hervorzuheben. Sie hebt gleichzeitig die ethnische Nähe hervor, in dem sie den Namen „Türk“ (Türke) verwendet und nicht etwa „Türki“ (Turk oder Turkvolk). Mit den anderen Bezeichnungen Türkenrat und Türkenparlament werden besonders die ethnische Gemeinsamkeit mit den zentralasiatischen Staaten betont. Anstelle des Türkenrates wäre die wissenschaftlich richtige Bezeichnung „Rat der Turkstaaten“ oder „Rat der turksprachigen Länder“ eine adäquatere Alternative gewesen, die auch die zentralasiatischen Staaten zufrieden gestellt hätte. Für die Bezeichnung des Türkenparlamentes wäre dann die Bezeichnung „das Parlament der Turkstaaten, bzw. turksprachigen Länder“" die neutrale und politisch wertfreie richtige Form gewesen. Diese Bezeichnungen belegen die aktuelle pantürkistische Sichtweise der TR. Das Beharren der TR auf die pantürkistisch geprägten Bezeichnungen zeigen, dass die TR die turksprachigen Nationalstaaten ZAs bis heute nicht als unabhängige Staaten mit eigener Identität und Nationalsprache akzeptiert und sie nicht auf gleicher Augenhöhe ansieht.

Die pantürkistische Zentralasienwahrnehmung der TR lässt sich auch auf vielen amtlichen Internetseiten nachweisen. Auf der Homepage des türkischen Außenministeriums steht für die Turkstaaten „Türkenwelt“ (türkisch: Türk Dünyasi) und für die Turksprachen „Türkische Sprache, bzw. Türkensprache“ (türkisch: Türk Dili) (Türkiye Cumhuriyeti Disisleri Bakanligi o. J. a). ${ }^{189}$ D. h. für die TR gelten die zentralasiatischen Turkstaaten offiziell als „türkischsprachige Türken“. ${ }^{190}$ Die adäquate Form wäre „Turkstaaten mit Turksprachen“ (türkisch: Türki dilli Türki Devletler oder Türki dili konusan Türki Devletler). Aktuell steht auf TIKA`s Homepage vom Ministerpräsidium, dass die TR mit den turksprachigen Staaten

\footnotetext{
${ }^{188}$ Die Mitglieder sind neben der Türkei die zentralasiatischen Staaten Kasachstan und Kirgisistan sowie das kaukasische Aserbaidschan. Als Aufgaben nennen sie von Vertrauensbildung bis zu den gemeinsamen sicherheitspolitischen Maßnahmen und außenpolitischen Zusammenhalt (Türk Dili Konuşan Ülkeler İşbirliği Konseyi o. J.).

189 „Neben der Entwicklung unserer bilateralen Beziehungen, wird auch auf die Entwicklung der multilateralen Beziehungen innerhalb der Türkenwelt Wert gelegt. In diesem Zusammenhang wird die Türkei die Solidarität der türksprachigen Staaten [...]“ (Übers. d. d. Verfasserin) (İkili ilişkilerimizin geliştirilmesinin yanısıra, Türk dünyası içinde çok taraflı işbirliğine de özel önem atfedilmektedir. Bu anlayışla, Türkiye, Türk Dili Konuşan Ülkeler arasındaki dayanışmanın artırılması [...]) (Türkiye Cumhuriyeti Disisleri Bakanligi o. J. a).

${ }^{190}$ Z. B. im Buch von Kolobov/Kornilov/Özbay (2006: 127) werden diese turksprachigen Republiken ZAs als „türkisch sprachige Republiken“ und als „Türken“ definiert. Diese Sichtweise ist bei den türkischen Wissenschaftlern gängig und ließ sich in zahlreichen Beispielen belegen.
} 
„eine gemeinsame Sprache, eine „gemeinsame Geschichte und eine gemeinsame Kultur ${ }^{\text {(191 }}$ teilt. Auf der Homepage des hauptsächlich vom türkischen Kultusministerium unterstützte TÜRKSOY steht sein Name als „Uluslararasi Türk Kültürü Teskilati“ (Organisation der internationalen türkischen Kultur). Seine englische Definition von TURKSOY „International Organization of Turkic Culture“ wurde allerdings richtig benutzt (TÜRKSOY, Uluslararasi Türk Kültürü Teskilati o. J.).

In den von der TR gegründeten Organisationen TÜRKPA (Türk Dili Konuşan Ülkeler Parlamenter Asamblesi) und TDIK sind von den zentralasiatischen turksprachigen Staaten nur Kasachstan und Kirgisistan Mitglied. Die Mitgliedschaften Kasachstans und Kirgisistans in TÜRKPA und TDIK verdankt die TR größtenteils den türkischen Gülen-Schulen der Gülen-Bewegung. Besonders in Kirgisistan hat diese Bewegung eine starke Vernetzung auf der Staatsebene. Usbekistan und Turkmenistan halten sich von den türkischen Organisationen weitgehend zurück. Usbekistan nimmt seit dem Attentat auf den ehemaligen usbekischen Präsidenten Karimow 1999 an keinem Gipfeltreffen mehr teil und schloss alle türkischen Schulen im Lande. Turkmenistan hatte sich auch wegen dieser Schulen von der TR distanziert, weil sie pantürkistische und islamistische Ziele verfolgt haben sollen und laut Turkmenistan mit der CIA zusammenarbeiteten.

\subsubsection{Die Gülen-Bewegung: Ein gemeinsames Soft-Power- Instrument der Türkei und USA in Zentralasien?}

Fethullah Gülen ist ein ultra-nationalistischer ${ }^{192}$ und muslimischer Prediger. Er wird von seinen Anhängern als „Mahdi“193 angesehen (Özgan 2016) und setzt sich für die Durchsetzung des islamischen Rechtes, d. h. der Scharia sowie die Einheit der „Türkenwelt““ ein. Im Jahre 1958, als er 20 Jahre alt war, erhielt er die staatliche Predigererlaubnis in der TR. Bis zum Militärputsch 1980 arbeitete er als Beamter des „Diyanet Isleri Baskanligi““ (Präsidium für Religionsangelegenheiten) und war gleichzeitig aktiv in der

\footnotetext{
191 „Wir haben mit Kasachstan, Turkmenistan, Usbekistan, Aserbaidschan und Kirgisistan eine gemeinsame Sprache, eine gemeinsame Erinnerung [Geschichte] und eine gemeinsame Kultur [...]“ (Kazakistan, Türkmenistan, Özbekistan, Azerbaycan ve Kırgızistan'dan oluşan bu devletlerle ortak bir dile, ortak bir hafızaya ve ortak bir kültüre sahip olmamız [...]). (Übers. d. d. Verfasserin) (T. C. BASBAKANLIK, TIKA (TÜRK ISBIRLIGI VE KOORDINASYON AJANSLIGI BASKANLIGI) 2015).

${ }^{192}$ In seinem 2006 veröffentlichten Buch „Kücük Dünyam“ (meine kleine Welt) definiert sich Gülen als „Türkischer Nationalist und Panturanist, bzw. Pantürkist (Cakir 2016b). Laut Cakir (ebd.) besuchte Gülen wegen seiner ultra-nationalistischen Sichtweise seinen, sich in der Stadt Isparta im Exil befindenden Lehrer, Said-i Nursi (auch als Said-i Kurdi genannt), deshalb nicht, weil Nursi ein Kurde war.

${ }^{193}$ Mahdi ist ein Nachkomme des Propheten Mohammed - der entschwundene 12. Imam - und wird dann auf die Welt zurückkehren, wenn das totale Chaos herrscht, um das Unrecht in der Welt zu beseitigen.
} 
antikommunistischen Bewegung. Danach widmete er sein Leben der nach ihm benannten Gülen-Bewegung, die auch unter den Namen „Cemaat“ (Gemeinschaft) oder „Hizmet“ (Dienst) bekannt ist. Die Putschisten der ,laizistisch-kemalistischen Militär“ des Jahres 1980 machten den Religionsunterricht in den Schulen wieder obligatorisch, was bis dahin nicht Pflicht war. ${ }^{194}$ Weiterhin unterstützten sie die Eröffnung von weiteren Koran-Kursen und religiösen Gymnasien (türkisch: Imam Hatip Liseleri). ${ }^{195}$ Offiziell erklärte das Militärregime, dass Gülen verhaftet wurde. Im Prinzip aber, schreibt der Journalist Ahmet Ş1k in seinem Buch, dass Gülen von der Militärjunta unterstützt wurde.

Gülen eröffnete ab 1983 Privat-Schulen, Schüler- und Studentenheime sowie Hunderte von Vorbereitungsschulen für die Universitätsaufnahmeprüfung in der TR (Simsirgil 2016). Des Weiteren verfügte die Bewegung bis zu ihrem Verbot im Jahre 2016 u. a. über Krankenhäuser, eine Bank (Bankasya), die auflagestärkste Zeitung „Zaman“, den Fernsehsender „Samanyolu“. Nach der Auflösung der Sowjetunion begann die GülenBewegung zunächst in den postsowjetischen Turkstaaten Schulen zu eröffnen. Die erste Auslandsschule der Gülen-Bewegung wurde 1992 (in der aserbaidschanischen Exklave Nachitschewan) und die erste Gülen-Universität 1993 in Aserbaidschan (Baku) eröffnet (O. V. 2012: İlk Türk Okulu'nun ...). Seine Schulen im Ausland sind im Allgemeinen als „türkische Schulen“ bekannt. In der „Türkenwelt“ war die Gülen-Bewegung bildungs- und kulturpolitisch besonders aktiv. Hier hatten sie auch ihre mediale Präsenz, insbesondere durch den Fernsehsender Samanyolu und die Zeitung Zaman. Mit der Zeit verbreiteten sich diese Schulen in über 170 Ländern. Er, bzw. seine Anhänger sollten bis zum offenen Streit

\footnotetext{
${ }^{194}$ Laut türkischer Verfassung ist die TR seit 1928 eine laizistische Republik. Allerdings wurde die Religion nie vom Staat getrennt. Atatürk schaffte zwar einerseits das Kalifat 1924 ab, andererseits gründete er das „Präsidium für Religionsangelegenheiten“ (türkisch: Diyanet Isleri Baskanligi) und nahm damit die Religion unter staatliche Kontrolle. Das Präsidium für Religionsangelegenheiten bekommt bis heute den Löwenanteil vom staatlichen Budget. Das staatliche Budget des Präsidiums für Religionsangelegenheiten für das Jahr 2016 betrug 6, 5 Mrd. türkische Lira (TL), während die Präsidentschaft 434 Mio. und Ministerpräsidentschaft 1 Mrd. 99 milyon lira erhält (Gökdemir 2016). Laut Koldas (2014) ist dieses Präsidium ein politisches und ideologisches Instrument der Regierung, da der Präsident der Religionsangelegenheiten von der Regierung einberufen wird. Deshalb ist er von der Regierung abhängig und arbeitet für die politischen Ziele der Regierung mit (ebd.). Die Fatwas (religiöse Rechtsauskünfte) des Präsidenten des Präsidiums für Religionsangelegenheiten sind zwar rechtlich nicht bindend. Dennoch wirken sie auf die Millionen von Muslime, die in den Moscheen diese Fatwas anhören und werden als verbindlich wahrgenommen (Koldas 2014). Die Imame (religiöser Gelehrte in den Moscheen) sind zudem Beamte des Staates.

195 Mit der AKP-Regierung nahm die Macht der Religion im Staat weiter zu. Die Schülerzahl der Religionsschulen (Imam Hatip Liseleri) stieg seit dem Amtsantritt der AKP-Regierung von 65.000 auf 1 Million. Die Absolventen dieser Schulen dürfen sich heute für die Militärakademie bewerben, was zuvor nicht möglich war (Hermann 2016: 3). Der Juli-Putsch am 15. Juli 2016 zeigte, dass die Gülenisten schon das Militär unterwandert hatten.
} 
zwischen Erdogan und Gülen in $2013^{196}$ weltweit zwischen 2000 bis 3000 Schulen, mehrere Universitäten, Studentenwohnheime usw. betrieben haben. ${ }^{197}$

Zwischen Gülen und seiner Gülen-Bewegung und Ismail Gaspirali (Vater des Pantürkismus) und seiner Dschedid-Bewegung sind Parallelen zu finden. Sowohl Gülen als auch Gaspirali sind pantürkistisch geprägt, beide versuchten durch ihre kultur- und bildungspolitische Arbeit die „Türkvölker“ zu vereinigen bzw. eine „Türkenwelt“ zu gründen. Dafür setzten beide sowohl Schulen als auch Medien ein. Selbst der Name der auflagestärksten Zeitung „Zaman“ der Gülen-Bewegung wurde meiner Meinung nach mit sehr großer Wahrscheinlichkeit aus dem Zeitungsnamen von Gaspirali „Tercüman-i Ahval-i Zaman“ abgeleitet. Gaspiralis Zeitungsname wiederum stammte vermutlich vom Zeitungsnamen „Tercüman-i Ahval“ ab, die seit 1860 von den türkischen Nationalisten im Osmanischen Reich herausgegeben wurde (siehe hierzu Kap. 3.5). Gülen kann meiner Meinung nach als Nachfolger von Gaspirali angesehen werden.

Das Vermögen der Gülen-Bewegung beläuft sich nach Engdahl (2016) auf über 50 Mrd. US-Dollar. Die genauen Finanzierungsquellen der Bewegung bleiben zwar unklar, wie Carley schon 1995 schrieb (Carley 1995: 193). Laut den Berichten einiger Wissenschaftler*innen, Journalist*innen, Juristen*innen, Politiker*innen und Geheimdienstmitarbeiter*innen usw. aber wurde und wird die Gülen-Bewegung

\footnotetext{
${ }^{196}$ Gülen erlebte seine goldene Zeit bis zum Ausbruch des Streits mit Erdogan 2013 unter der AKP-Regierung. Laut Yarkadas (2013) geht der Gülen-Erdogan-Streit im Grunde genommen bis zum türkischen Referendum im Jahre 2010 zurück. Erdogan erhielt 58 \% der gültigen Stimmen und stellte damit fest, dass er der Unterstützung Gülens nicht mehr bedurfte. Die gleiche Ansicht vertritt auch der Journalist Rusen Cakir (2013). Kálnoky (2016) gibt auch das Datum 2010 als Anfang des Gülen-Erdogan-Streits an, allerdings begründet er ihn anders. Laut ihm änderte sich das Verhältnis zwischen den beiden, als Gülen im "Wall Street Journal" eine Aktion des Erdogan-Lagers kritisierte:
}

„Ein Ableger der Milli-Görüs-Bewegung hatte eine sogenannte Hilfsflotte für Gaza organisiert, deren Schiffe die Gaza-Blockade brechen sollten, die Israel seit 2007 nach der gewaltsamen Machtübernahme der Hamas eingerichtet hatte. Neun Türken sind dabei von israelischen Kommandos erschossen wurden. Diese Aktion schien die politische Schlagkraft der Bewegung zu unterstreichen. Das missfiel Gülen. Er sagte dem 'Wall Street Journal' damals, die Organisatoren hätten eine Lösung mit Israel suchen müssen“ (Kalnoky 2016).

Im Jahre 2013 ist der Gülen-Erdogan-Streit dann eskaliert, weil vermutlich Gülennahe Staatsanwälte gegen den damaligen Ministerpräsidenten Erdogan und einige seiner Minister Ermittlungen wegen Korruption aufgenommen haben. Als Beweise wurden die abgehörten Telefonmitschnitte präsentiert, die sich in den sozialen Medien rasch verbreiteten.

${ }^{197}$ Die genaue Zahl dieser Schulen kann nicht beziffert werden, da diese Schulen offiziell nicht Gülen gehören, sondern von seinen Anhängern eröffnet und betrieben werden. Schätzungsweise gibt es in 150, nach anderen Schätzungen in 170, Länder insgesamt ca. 2000-3000 Gülen-Bildungseinrichtungen (Aksay 2016). 
hauptsächlich vom türkischen Staat und den USA gefördert. ${ }^{198}$ Wurde deshalb, weil die TR seit 2013 die Gülen-Bewegung offen bekämpft. Vor dieser Zeit waren die Gülen-Schulen, Medien und Aktivitäten in ZA die wichtigsten inoffiziellen Soft-Power-Mittel der TR. Die Bewegung arbeitete im Ausland wie die offiziellen Botschafter und Kulturinstitute der TR. Die ehemaligen Präsidenten der TR, Turgut Özal (1989-1993) und Süleyman Demirel (1993-2000), besuchten während ihrer Staatsbesuche häufig die Gülen-Schulen und ermutigten die türkischen Geschäftsleute, weitere Schulen zu eröffnen (Türk 2014: 3). Der ehemalige türkische Präsident Abdullah Gül (2007-2014) bat 2012 den turkmenischen Präsidenten Gurbanguly Berdimuhamedow um Unterstützung für die türkischen Schulen. In seiner Zeit als türkischer Außenminister (2003-2007) verschickte er ein geheimes Rundschreiben an die türkischen diplomatischen Vertretungen und bat sie, diese Bildungseinrichtungen zu unterstützen. Erdogan erhielt 2012 anlässlich des 10. Jubiläums der Türkisch-Olympiaden ${ }^{199}$ sogar einen Preis der Gülen-Bewegung für seine Unterstützung der Gülen-Bewegung (Türk 2014: 4). Selbst auf die offiziellen Organisationen der TR in ZA, TÜRKSOY und TIKA, hatte die Bewegung großen Einfluss

Paul L. Williams, der ehemalige FBI-Berater und Wissenschaftler, berichtete, dass Gülen vom ehemaligen US-Botschafter in Ankara (Marc Grossman) entdeckt und von ihm für das Ziel „Unterstützung des radikalen Islams gegen die Sowjetunion“ unterstützt wurde (In: O. V. 2015: Kerimov'a suikastın taşeronu ...). Die Historikerin Ayse Hür (2014) vertritt die gleiche These wie Williams. Laut Hür (ebd.) wurde Gülen von den USA zunächst im Rahmen der vom amerikanischen Strategen Zbigniew Brzezinski entwickelten Strategie „Grüner Gürtel“ für die Einkreisung der gottlosen Sowjetunion durch den „Islam“ gefördert. Der Islamisierung der TR folgte die Islamisierung der postsowjetischen Gebiete nach dem Kalten Krieg. Der ehemalige türkische Geheimdienstler (zwischen 1964-1986) Osman Nuri Gündes (Gündes in Dündar 2010) behauptete 2010, dass die Gülen-Bewegung von der CIA gesteuert wird. Ihm zufolge (ebd.) sind die Englischlehrer in den Gülen-Schulen im Grunde genommen US-Geheimdienstmitarbeiter. Er behauptete weiterhin, dass es allein in Kirgisistan 2010 bereits 60 US-Englischlehrer gab (ebd.). Der türkische Auslandsgeheimdienstmitarbeiter Kasif Kozinoglu war jahrelang für die Region ZA

\footnotetext{
${ }^{198}$ Dabei ist zu berücksichtigen, dass die Gülen-Bildungseinrichtungen Privatschulen sind, d. h. kostenpflichtig sind. Weiterhin erwirtschaft(ete) die Bewegung Gewinne aus ihren Medienanstalten.

${ }^{199}$ Die Türkisch-Olympiaden (türkisch: Türkçe Olimpiyatları) fanden zwischen den Jahren 2003-2013 jährlich statt. Sie waren ein Sprachwettbewerb auf Türkisch in verschiedenen Kategorien wie Singen, Rezitation von Gedichten usw. International haben jährlich zahlreiche Schüler*innen daran teilgenommen, deren Muttersprache Türkisch oder Nicht-Türkisch war.
} 
zuständig. Kurz nach seinem Tod im Gefängnis am 15. November 2011 wurden seine Notizen aus dem Gefängnis in der Zeitung „Aydinlik“ veröffentlicht. Laut dem Bericht dieser Zeitung behauptete Kozinoglu, dass die Gülen-Schulen in den ehemaligen Sowjetrepubliken CIA-Quartiere seien und finanziell von den USA unterstützt würden (O. V. 2011: Kozinoğlu'yla birlikte gömülmeyen ...). William Engdahl (2016) vertritt ebenfalls die These, dass Gülen für die USA arbeitet und er mit CIA-Unterstützung für die Regionen Kaukasus und ZA zuständig ist. Engdahl (2016) zufolge ist Gülens Aufgabe in diesen Regionen die Destabilisierung der Reste des russischen Imperiums und die Eindämmung des chinesischen Einflusses in ZA. Der türkische Gülen-Experte Rusen Cakir untersucht seit über 30 Jahren die Gülen-Bewegung und erklärte in einem Interview am 13. August 2016, dass die Gülen-Bewegung im Ausland mit Sicherheit durch die CIA instrumentalisiert wurde (Cakir 2016a: Gülen cemaatini CIA ...). Nach Cakir (ebd.) stand Gülen sein Leben lang nie mit den US-Politiken im Konflikt, was für ihn ein starkes Indiz für die Zusammenarbeit zwischen den USA und Gülen ist. Die USA unterstützten das ,gemäßigte Islamverständnis“ von Gülen, so Cakir (ebd.).

Die folgenden Beispiele zeigen, dass die Gülen-Bewegung in den ehemaligen postsowjetischen Staaten pantürkistisch-islamistische Ziele verfolgte. Der Vorsitzende des Fachbereiches der Architektur der staatlichen Universität Nachitschewan z. B. erklärte folgendes:

„,Wir haben von ihnen [Gülen-Schulen und Mitarbeiter] viel gelernt. [...] Sie haben nicht nur meine, sondern auch die [religiösen, nationalen] Feste meines Staates akzeptiert und verteidigt. Wir haben alles, was es in der Welt gibt, was die Türkenwelt ist, von ihnen gelernt. Sie bildeten nicht nur unsere Kinder gut aus; sondern sie erzogen sie auch hervorragend. " ${ }^{200}$ (O. V. 2012: İlk Türk Okulu'nun bu ...), (Übers. d. d. Verfasserin).

Ein anderes Beispiel für die „erfolgreiche“ Arbeit, bzw. für die Islamisierung und Türkisierung der Bewegung, ist aus der Krim zu berichten. Eine Krim-Tatarin, Elmas Tazegül, die als Türkisch-Lehrerin in einer Gülen-Schule in Kenia unterrichtete, berichtete

\footnotetext{
200 „Onlardan çok şey kazandık. Sadece benim değil, ülkemin de Bayram'larına sahip çıktılar. Dünyada ne var ne yok, Türk dünyası nedir, hepsini onlardan öğrendik. Çocuklarımızı iyi eğitmek kadar, onların iyi yetişmesinde de unutulmaz katkılar yaptılar.“(O. V. 2012: İlk Türk Okulu'nun bu ...).
} 
in einem Interview über ähnliche Erfahrungen mit der Gülen-Bewegung wie im obigen Fall. Sie sagte:

„,Ursprünglich bin ich eine Krim-Türkin [...] Das war 1992, ich glaube, als die ersten [Gülen]Lehrer aus der Türkei [auf die Krim] kamen. Wir haben das erste Mal 1992 die Türken gesehen. Als sie uns sagten, dass wir auch Türken sind, waren wir überrascht. [...] In der sowjetischen Zeit hatte der Begriff Türke eine sehr negative Bedeutung; er galt als jemand, der unterentwickelt ist, bzw. sich kein bisschen weiterentwickelte. Besonders mein Vater zeigte eine ablehnende Haltung für unser Türkesein. [...] Zunächst wurde [auf der Krim] eine Jungen-Schule eröffnet. [...] An den Wochenenden kümmerten sich die Lehrer dieser Schulen um uns Mädchen [...] und erzogen uns. Nach meinem Abitur überredete ein Lehrer meine Mutter und brachte mich in die Türkei. [...] In Istanbul absolvierte ich zunächst eine KoranSchule, um meine Religionskentnisse zu zu vervollkommnen. Danach bereitete ich mich in der FEM-Dersanesi [Gülen-Vorbereitungsschule für die Universitätsaufnahmeprüfung] auf die Prüfung vor. Ich habe die Aufnahmeprüfung bestanden. [...] Sobald ich mein Studium absolviert hatte, bin ich zunächst auf die Krim zurückgekehrt, um [der Gülen-Bewegung] zu dienen und arbeitete dafür an den Türk-Schulen [...] “201 (O. V. 2015: 'Elmas' ruhlu öğretmenin ...), (Übers. d. d. Verfasserin).

Hierzu ist zu bemerken, dass die Krim-Tatarin zunächst einen Koran-Kurs absolvieren sollte und sich nach einigen Jahren in der Gülen-Bewegung nicht mehr als Tatarin; sondern als Krim-Türkin definierte. Sie ist in dieser Hinsicht ein gutes Beispiel für die pantürkistische und religiöse Arbeit (türkisch-islamische Synthese) der Gülen-Bewegung.

In zentralasiatischen Staaten erzielten die türkischen Schulen unterschiedliche Erfolge. Usbekistan ist der erste Turkstaat, der die 18 Gülen-Schulen nach dem Attentat gegen Karimow 1999 bis 2000 schloss, deren Lehrer auswies und seine Beziehungen zur TR unterbrach, weil Karimow hinter diesem Attentat türkische und CIA-Unterstützung vermutete. Carley (1995: 190) berichtete schon 1995, d. h. 4 Jahre vor diesem Attentat, über die türkische Unterstützung der usbekischen Opposition. Laut Türk (2014: 4) warf Karimow den Lehrern der Gülen-Schulen schon 1994 Propaganda eines ,,nicht staatskonformen Islam “ und die Radikalisierung der jungen Menschen vor. Laut Karimow war der Aufenthalt

\footnotetext{
${ }^{201}$ „Aslen Krim Türküyüm. 1992 yilinda zannedersem ilk hocalarimiz Türkiye`den o zamanlar gelmislerdi. 1992 yilinda ilk defa Türkleri görmüs bulunduk. [...] Onlar da 'siz de Türksünüz' diyince sasirmistik. [...] Sovyetler döneminde Türk kelimesinin cok kötü bir anlami vardi; yani böyle gelismemis, kendini hicbir sekilde gelistirmemis bir anlami var. 'Biz Türk degiliz' diye, özellikle babam hani böyle cok büyük bir tepki göstermisti $[\ldots]$ Ilk acilan okul erkek okuluydu. Ama [...] hafta sonlari hocalarimiz bizimle cesitli kurslar vesilesiyle iletisime gecip, bizi yetistirdiler. Liseden mezun oldugumda bir hocamiz sadece annemle görüsüp hani ‘Türkiye 'ye götürmek istiyorum müsade ederseniz götüreyim, Türkiye`de okusun' demisti. [...] Ilk önce Istanbul'daki bir Kuran Kursu nu bitirdim, hani dini bilgilerimi tamamlamak icin. Ondan sonrada Fem Dersanesi`nde hazirlanip üniversiteyi kazandim. [...] mezun olur olmaz ilk önce borc ödemek icin Krim`a döndüm, ordaki Türk okullarinda calistim."
} 
des bekanntesten usbekischen Oppositionellen, Mohammed Salih sowie der anderen usbekischen Oppositionellen, in der TR ein Beweis für die türkische Unterstützung des versuchten Putsches. 1994 forderte Karimow von der TR während seiner Türkei-Reise den pantürkisch-islamistischen usbekischen Oppositionellen Mohammed Salih nach Usbekistan auszuliefern. Nach Karimow arbeitete Salih mit der türkischen Regierung an der Radikalisierung der usbekischen Studenten zusammen, die sich in der TR zu Studienzwecken aufhielten (Özlem 2013: 45). Diese radikalisierten usbekischen Studenten in der TR wurden Karimow zufolge zunächst nach Tschetschenien geschickt, um dort Kriegserfahrung zu sammeln, und um später in Usbekistan gegen ihn zu putschen (ebd.). Williams (O. V. 2015: Kerimov‘a suikastın taşeronu ...) zufolge stand hinter dem Attentat auf Karimow die Gülen-Bewegung, bzw. einige Lehrer der Gülenschulen, die Verbindungen zur CIA hatten. Usbekistan schloss nach dem Karimow-Attentat nicht nur die GülenSchulen, sondern auch die offiziellen türkischen Schulen der TR (Devlet 2016). ${ }^{202}$ Seitdem nimmt Usbekistan an keinem von der TR organisierten „Gipfeltreffen der Türkstaaten“ teil (ebd.). Somit kann behauptet werden, dass die Türkische Soft-Power-Politik in Usbekistan nicht erfolgreich war.

Turkmenistan verstaatlichte alle 15 Gülen-Schulen 2011 außer der Mustafa Kemal Lisesi die wollte das Land erst verstaatlichen, nachdem ihre Schüler das Abitur abgelegt hatten. Diesen Schulen warf das Land die Verbreitung von pantürkistischen Gedankengut und Bestechen der Staatsbeamten vor. Das mit dem Ziel, der Schaffung von einflussreichen Positionen im Staatsapparat für die Absolventen dieser Schulen (Türk 2014: 4) sowie die Verbreitung des Weges des sunnitischen Nurcu-Ordens (Aksay 2016). In der turkmenischen Hauptstadt Aschchabad gab es eine „Turkmen-Türk-Universität“, die von der GülenBewegung gegründet wurde. Diese Universität wurde 2016 geschlossen (O. V. 2016: Aşkabat'taki "Gülen'cilerin yuvası" ...).

Kasachstan, Kirgisistan und Tadschikistan werden seit dem Streit zwischen Erdogan und Gülen Ende 2013 vom türkischen Präsidenten Erdogan unter Druck gesetzt, die türkischen Schulen in ihren Ländern zu schließen. Laut Erdogan drangen Anhänger der Gülenbewegung in Schlüsselpositionen der türkischen Polizei, Justiz und Militär ein und

\footnotetext{
${ }^{202}$ Im Vergleich zu Devlet (2016) schreibt Türk (2014: 7), dass im Schuljahr 2012-2013 in Usbekistan eine offizielle Schule der TR gab. Da Usbekistan nach dem Attentat gegen Karimow 1999 alle Gülen-Schulen schloss und auch seine Beziehungen zu der TR auf Eis legte, ist davon auszugehen, dass das Land auch alle offiziellen türkischen Schulen geschlossen hatte.
} 
brachten gegen ihn im Dezember 2013 Korruptionsermittlungen (17-25 Aralik) in Gang, um die Regierung zu stürzen. Laut dem Journalisten und Politiker Baris Yarkadas (2013) geht es im Gülen-Erdogan-Streit um die ,politische Macht“ sowie um die Stellung des „religiösen Oberhauptes“ in der TR. Um die Gülenbewegung zu zerschlagen, versuchte Erdogan in erster Linie seine Einnahmequellen aus den privaten Schulen, Studentenheimen, Krankenhäusern und Universitäten $\mathrm{zu}$ beschlagnahmen. Er verstaatlichte die GülenNachhilfeschulen in der TR, gründete eigene Studentenheime und strich die staatlichen Zuschüsse für die Gülen-Krankenhäuser. Das kaukasische Aserbaidschan, in dem die erste Gülen-Schule gegründet wurde, schloss im Juni 2014 auf Wunsch Erdogans alle diese Schulen (O. V. 2014: Azerbaycan Gülen okullarını ...).

Erdogan bezeichnete die Gülen-Bewegung laut einem Bericht der Zeitung Sabah vom 20. Mai 2015 als Terrororganisation, mit dem Ziel die Regierung zu stürzen.

„Sie [Gülen und seine Anhänger] versuchten bei uns zu putschen. Wir als Republik Türkei bürgen für sie [Gülen-Schulen] nicht mehr. Es ist herausgekommen, dass sie eine Terrororganisation sind, die unter dem Deckmantel Bildung die Regierungen zu stürzen versuchen " (In: Cantürk 2015). ${ }^{203}$ (Übers. d. d. Verfasserin)

Es kam am 15. Juli 2016 zu einem Putschversuch in der TR. Laut offiziellen Verlautbarungen stand die Gülen-Bewegung dahinter. Es folgten Verhaftungen Tausender Beamter sowie Schriftsteller, Journalisten, Unternehmer usw. Der türkische Justizminister Bekir Bozdag erklärte nach dem gescheiterten Putschversuch gegenüber dem türkischen Fernsehsender HaberTürk, Gülen wäre im Falle eines erfolgreichen Putsches, wie Chomeini nach der Islamischen Revolution in Iran, aus seinem Exil in den USA in die TR zurückgekehrt und hätte die Macht ergriffen. Bozdag fügte hinzu, Gülen wolle mit der Machtergreifung die Demokratie in der TR abschaffen (O. V. 2016: Bekir Bozdag: Basarsalardi ...). ${ }^{204}$ Erdogan wiederholte seine Thesen über die Gülen-Bewegung nach dem Putschversuch erneut und sagte, dass die Gülen-Bewegung die weltweit größte Terrororganisation und jede ihrer Schulen im Ausland eine Niederlassung dieser Terrororganisation sei (O. V. 2016: Cumhurbaşkanı Erdoğan: Fethullah ...). Hier ist die Frage aufzuwerfen, warum die AKP, bzw. Erdogan die Gülen-Bewegung solange unterstützte, wenn diese eine Terrororganisation ist? Gülen erklärte im September 2016, dass

\footnotetext{
203 „Bizde darbe yapmak istediler. Biz Türkiye Cumhuriyeti Devleti olarak artık bunlara kefil değiliz. Eğitim maskesi altında, devleti yıkmaya çalışan bir terör örgütü oldukları ortaya çıktı“ (Cantürk 2015).

${ }^{204}$ Der Gülen-Experte Rusen Cakir sagte in einem Interview mit Nur Banu Kocaaslan 2016, die Gülen-Gefahr sei allerdings noch nicht beendet und dass Gülen seine Ziele nicht so leicht aufgeben wird (Kocaaslan 2016).
} 
die Gülen-Bewegung Erdogan und seine Partei mit Wählerstimmen und medialer Unterstützung an die Macht verhalf (O. V. 2016: Gülen, Erdoğan'la ilişkisini ...). Erdogan bat Gott und die türkische Bevölkerung öffentlich um Verzeihung, da er angeblich „Gülens wahres Gesicht“ bis zum Putschversuch im Juli 2016 nicht erkannt habe (O. V. 2016: Cumhurbaşkanı Erdoğan: Fethullah ....). ${ }^{205}$

Die tadschikische Regierung verstaaatlichte ab 2015 die türkischen Schulen (O. V. 2015: Gülen cemaatinin Tacikistan'daki ...). Der kasachische Präsident erklärte in einem Treffen mit Erdogan am 5. August 2016, er werde zunächst die 33 Gülen-Schulen in seinem Land nach den Kriterien prüfen lassen, ob diese für Kasachstan tatsächlich eine sicherheitspolitische Gefahr darstellen und danach über die Schließung entscheiden. Bis jetzt habe Kasachstan keine Probleme mit diesen Schulen, sagte Nasarbajew. In Kasachstan sind $90 \%$ der Lehrer dieser Schulen Kasachen und 8 bis $9 \%$ kommen aus der TR, sagte er. Da die Gülen-Schulen unter staatlicher Kontrolle sind und vom kasachischen Staat finanziert werden, mit vier Sprachen auf höchstem Niveau ausbilden (Kasachisch, Englisch, Russisch und Türkisch), möchte er diese Schulen erst einmal nicht schließen. Nasarbajew sagte zudem, dass er die Gründung dieser Schulen mit dem ehemaligen Präsidenten der TR, Turgut Özal vereinbart habe. Das vereinbarte Ziel dieser Schulen war, der Jugend beider Staaten die Sprachen der beiden Länder zu vermitteln, um in Zukunft miteinander zu kooperieren, bzw. sich näher kommen zu können (O. V. 2016: Kazakistan'daki Gülen okulları ...). Nasarbajews Statements bestätigen, dass der türkische Staat diese Schulen - nicht wie oft behauptet - ,nur“ inoffiziell unterstützte, sondern ihre Gründung offiziell regelte. Das gilt zumindest für die Gründung dieser Schulen in Kasachstan.

Kirgisistan möchte die 18 Gülen-Schulen bisher nicht schließen. Die türkische Regierung teilte Kirgisistan nach dem gescheiterten Putsch im Juli 2016 mit, dass die Gülen-Bewegung auch in Kirgisistan wie in der TR putschen kann. Der kirgisische Präsident Almasbek Atambajew (2011-2017) erklärte daraufhin, er finde die türkische Erklärung ,absurd“ und

\footnotetext{
${ }^{205}$ Gülen reiste im März 1999 zunächst aufgrund eines gesundheitlichen Problems in die USA und erhielt laut Seidel/Dantschke/Yildirim (2001: 69-70) mit CIA-Hilfe eine unbefristete Aufenthaltserlaubnis in den USA. Am 18. Juni 1999 strahlte der türkische Fernsehsender ATV eine Rede von Gülen an seine Anhänger aus. In dieser Rede forderte er von seinen Anhängern eine umsichtige Unterwanderung der gesamten Justiz zum Zwecke der Machtergreifung in der TR. Bis sie alle Staatsgewalten in der Hand haben, sollten sie sich vorsichtig und unauffällig verhalten (O. V. 2016: Gülen'in 1999'da yayınlanan ...). Es gab in der TR zwar Gegenstimmen gegen die Gülen-Bewegung. Allerdings wurden diese Stimmen von „Gülens Anhänger innerhalb der Polizei und Justiz" zum Schweigen gebracht. Der türkische Staatsanwalt Nuh Mete Yüksel z. B. wagte 2000 gegen die Gülen-Bewegung vorzugehen und wurde durch „Sexvideos“ zum Schweigen gebracht (siehe hierzu O. V. 2015: Nuh Mete Yüksel'e ...).
} 
die Gülen-Schulen werden in Kirgisistan weiterhin tätig bleiben, weil sie die besten Bildungseinrichtungen seines Landes sind (zit. nach: Kasapoglu 2016). Nach Süleyman Yesilyurt (2016) ist die Gülen-Bewegung am stärksten in Kirgisistan vertreten. Seine Anhänger besetzen hier die wichtigsten staatlichen Positionen, wie z. B. das Amt des Vizeministers.

Im Juni 2016 erklärte Erdogan, dass eine türkische staatliche Stiftung, namens „Maarif Vakfi“ (Bildungsstiftung) gegründet wird. Diese Bildungsstiftung würde mit finanzieller Hilfe des Staates und Privatunternehmen unter Federführung des türkischen Bildungsministeriums die Gülen-Schulen übernehmen und leiten (O. V. 2016: Erdoğan, 'Türkiye Maarif ...). Am 17. Juni 2016 wurde sie gegründet. Mit dieser Stiftung versucht Erdogan bis heute das wichtigste ,(in)offizielle“ Soft-Power-Mittel der TR im Ausland, d. h. Gülens Bildungseinrichtungen, unter „offizielle“ staatliche Kontrolle zu bringen. Die offizielle kultur- und bildungspolitische Arbeit der TR in ZA ist im Vergleich zu den GülenSchulen dagegen bedeutungslos. Im Verhältnis zu den Gülen-Schulen gab es laut Türk (2014: 7) im Schuljahr 2012-2013 vom türkischen Staat in Kasachstan eine, in Kirgisistan und Turkmenistan 3 offizielle Schulen (Türk 2014: 7). In Tadschikistan gründete die TR keine Schulen. Es liegt vermutlich daran, dass Tadschikistan kein Turkstaat ist. Die GülenBewegung hingegen hatte in Tadschikistan bis 2015 mindestens 10 türkische Schulen (O. V. 2015: Tacikistan 'da paralel okullar ...), bevor sie verstaatlich wurden. Des Weiteren gründete die AKP-Regierung eine Stiftung namens „Yunus Emre Enstitüsü“ im Jahre 2007 für die „Verbreitung der türkischen Kultur, Sprache und Kunst im Ausland und Pflegen der guten Beziehungen“ (Yunus Emre Enstitüsü 2016). ${ }^{206}$ Seit 2009 eröffnet die Yunus Emre Institut zu diesem Zweck Einrichtungen im Ausland. In ZA gibt es bis jetzt nur im kasachischen Astana eine Yunus Emre Einrichtung. ${ }^{207}$

Die Gülen-Bewegung (Schulen und Medien) war bis jetzt das stärkste türkische Soft-PowerInstrument in ZA (Balci 2014). Mit deren Schließung und/oder Verstaatlichung in

\footnotetext{
${ }^{206}$ In den postsowjetischen Staaten gibt es im kaukasischen Aserbaidschan (Baku) und Georgien (Tbilisi) sowie in Kasan (Russische Föderation) Yunus Emre Institute. Siehe in: Yunus Emre Enstitüsü (2016): Yunus Emre Enstitüsü. http://www.yee.org.tr/tr/kurumsal/yunus-emre-enstitusu

${ }^{207}$ Balci (2014) berichtet, dass ein einflussreicher Gülen-Funktionär in den USA in einem Interview erklärte, dass die AKP-Regierung die „Yunus Emre Institut“ im Jahre 2007 als Konkurrenz zu den Gülen-Einrichtungen im Ausland gegründet habe. Diese Information trifft allerdings nicht zu, weil die Yunus Emre Institute keine Bildungseinrichtungen betreibt wie die Gülen-Bewegung und bis jetzt in ZA nur in Kasachistan aktiv ist und nicht wie die Gülen-Bewegung in allen zentralasiatischen Staaten. Des Weiteren ist diese Stiftung zu einem Zeitpunkt gegründet worden, in dem es keinen Streit zwischen Erdogan und Gülen gab.
} 
Usbekistan, Turkmenistan und Tadschikistan verlor die TR in der Region ihr wichtigstes Soft-Power-Instrument. Es ist kein Geheimnis, dass die USA die türkische ZAP unterstützten und wie schon dargestellt wurde, die TR von ihnen als Modellstaat für die postsowjetischen Staaten präsentiert wurde. Daher ist es naheliegend, dass sie die GülenSchulen auch für ihre Interessen instrumentalisiert haben. RU vertritt die Ansicht, dass die Gülen-Bewegung ein türkisch-amerikanisches Instrument für den postsowjetischen Raum sei (siehe hierzu Kapital 6.6). Spätestens aber seit dem Putschversuch von 2016 in der Türkei ist Gülen ein Streitthema zwischen der TR und den USA. Erdogan fordert von den USA seine Auslieferung, bis jetzt ohne Erfolg. Bezüglich der Bewegung kann gesagt werden, dass die Gülen-Bewegung erheblich an Macht und Einfluss verloren hat, weil sie nicht mehr von der TR unterstützt wird und durch die TR ihrer Einnahmequellen entrissen wurde.

\subsection{Russische Kultur- und Bildungspolitik in Zentralasien}

Die russische Kultur- und Bildungspolitik für/in ZA ist klarer strukturiert als die türkische ZAP. In seinen nationalen Dokumenten (Sicherheitsstrategie, Militärdoktrin und Außenpolitikkonzept) fasst RU seine Ziele und Strategien für seine ZAP zusammen. Die wichtigsten Soft-Power-Instrumente der russischen Kultur- und Bildungspolitik in ZA sind die russische Diaspora und Sprache. Der Erhalt der russischen Sprache sowie deren Verbreitung ist das Hauptziel der russischen Kultur- und Bildungspolitik in ZA. Des Weiteren zielt RU auf die Sympathie- und Vertrauensgewinnung in der Region. Die russischen Medien, Bildungsinstitute, Außenministerium, Ministerpräsidium, Vereine, Stiftungen arbeiten für diese Ziele.

\subsection{1 „Nahes Ausland“" in russischen nationalen Dokumenten}

RU und ZA verbindet eine lange Geschichte (siehe Kap. 3), die ihre Beziehungen bis heute prägt. Bis zu ihrer Unabhängigkeit lebten die Zentralasiaten etwa 250 Jahre unter russischem Einfluss. ${ }^{208}$ Aufgrund der gemeinsam verbrachten Zeit mit ZA nimmt RU die Region als „Nah“ zu sich wahr, sieht das Gebiet als einen Teil seines „Nahen Auslands“ an. Unter der Bezeichnung „Nahes Ausland“ versteht RU nicht die geographisch angrenzenden Staaten

\footnotetext{
${ }^{208} \mathrm{Ab} 1717$ fingen die russischen Eroberungszüge in ZA an. Allerdings blieb der erste Eroberungszug erfolglos. Nach einigen Jahren, 1731, baten die kasachischen Khane die russischen Zaren um Schutz und Hilfe gegen die Angriffe der Kalmücken und Dschungaren (Paul 2012: 354). Die Kasachen sind die ersten, die die russische Herrschaft akzeptierten. Bis 1895 eroberte RU das gesamte ZA (siehe Abbildung 2).
} 
wie Finnland; sondern politisch die ehemaligen sowjetischen Republiken, die auch Staaten wie Kirgisistan umfassen, die nicht an ihn angrenzen. (ebd.) In seinem Tagebuch „Auf des Messers Schneide“ schreibt der ehemalige russische Präsident Boris Jelzin: „Die Sowjetunion, die heute anders heißt, ist trotz allem ein einheitlicher Raum [Hervorhebung der Verfasserin] geblieben. Wir können uns nicht von dem abschotten, was in diesen Republiken geschieht.“ (Jelzin 1994: 176). Nach Jelzin (ebd.: 176-177) ist die Aufgabe RUs die Forcierung der wirtschaftlichen Integration auf dem ehemaligen Gebiet der UdSSR, die Gewährleistung der kollektiven Sicherheit und die Weiterentwicklung der politischen Zusammenarbeit. RU versuchte Ende 1993 zunächst die postsowjetischen slawischen Staaten (RU, die Ukraine und Weißrussland) in einem gemeinsamen „Wirtschaftsraum“ zu vereinigen. Dieses Vorhaben wurde jedoch nicht umgesetzt (Donaldson 2009: 177f., 208; zit. nach: Wipperfürth 2011: 38). Innerhalb der GUS allerdings gelang es RU, die ehemaligen sowjetischen Republiken außer den baltischen Staaten (Estland, Lettland und Litauen) zu vereinigen (siehe hierzu Kap. 6.7).

Der GUS-Raum wird von RU in allen seinen nationalen Dokumenten seit 1993 als „Prioritätsraum“ definiert. Sein Interesse gegenüber dem GUS-Raum ist in erster Linie durch seine sicherheitspolitischen Sorgen um die territoriale Integrität und Souveränität der Russischen Föderation bestimmt. In der „Sicherheitsdoktrin 1993 erklärte RU den GUSRaum offiziell als „Nahes Ausland“, als einen für die russischen Interessen wichtigen strategischen Raum (Kolobov/Kornilov/Özbay 2006: 134), um die nationalen Interessen RUs zu schützen (Wipperfürth 2011: 37). In seinem „Außenpolitikkonzept“ im selben Jahr erklärte das Land den GUS-Raum als zu seinem $\mathrm{zu}$ integrierenden Prioritätsgebiet (President Of The Russian Federation 1993). Die sicherheitspolitischen Interessen prägten den Inhalt dieses Konzeptes, gefolgt von wirtschaftlichen und bildungs- und kulturpolitischen Interessen. Zwar wurde seine Kultur- und Bildungspolitik in diesem Konzept nicht als Soft-Power-Politik explizit beim Namen genannt. Die formulierten Ziele aber, wie „die Unterstützung der russischen Kultur und Sprache sowie positive Images des Landes im Ausland“" sind klassische Soft-Power-Strategien (ebd.).

In der „Militärdoktrin 1993“ (Dresdener Studiengemeinschaft Sicherheitspolitik (DSS 1994) unterstreicht RU seine sicherheitspolitischen Interessen in erster Linie im innenpolitischen Bereich. Im außenpolitischen Bereich konzentriert sich das Land auf die „unmittelbaren Nachbarn“, wie auf ZA (Dresdener Studiengemeinschaft Sicherheitspolitik (DSS) 1994: 4). 
Die Priorität legt RU auf die Zusammenarbeit mit den GUS-Staaten, danach mit den KSZEStaaten (Vorgänger von OSZE). Auf globaler Ebene erwähnt das Land seinen Willen zur Zusammenarbeit mit allen UN-Mitgliedstaaten (ebd.: 11). Als Hauptziel des Landes wurde der „Schutz der Souveränität und territorialen Integrität und anderer lebenswichtiger Interessen der Russischen Föderation im Falle einer Aggression gegen sie oder ihre Verbündeten“ (ebd.: 6, 19) definiert.

Die Inhalte der nationalen Dokumente von 1993 wurden sowohl durch die subsystemischen als auch systemischen Faktoren beeinflusst: Der zunehmende Einfluss der russischen Nationalisten und Kommunisten auf die Gestaltung der (Außen)Politik, der ossetischinguschische Konflikt und die wirtschaftlichen Interessen (besonders energiepolitische) RUs am Kaspischen Meer waren die subsystemischen Faktoren. Der Fremdeinfluss im Südkaukasus und ZA, wie z. B. der türkische Pantürkismus und die gegnerische türkische Haltung im Karabach-Konflikt, die Bürgerkriege in den ehemaligen Sowjetrepubliken (in Georgien, Tadschikistan und Moldawien (Transnistrien)), die westlichen Aktivitäten in Jugoslawien, die russische Diaspora im GUS-Raum waren die systemischen Faktoren. Mit nationalen Dokumenten erklärte RU, dass das Land hier den fremden Einfluss nicht dulden wird. Als die TR z. B. auf aserbaidschanischer Seite in den Karabach-Konflikt zu intervenieren versuchte, wurde sie von RU mit einem 3. Weltkrieg bedroht (Fuller 1993: 78; Cornell 1999; Kolobov/Kornilov/Özbay 2006: 143). Sie wurde zugleich vom russischen Botschafter in Ankara, Tschernyschew, wegen ihres Pantürkismus in ZA gewarnt. Der Ausbruch des Tschetschenienkrieges 1994 (Dschafarow 2009: 40) und die NATOOsterweiterung seit 1994 (Deutscher Bundestag 2016a: 13) verstärkten den russischen Kurswechsel vom Atlantismus auf Eurasismus. Die Vereinbarung auf dem NATO-Gipfel in Brüssel am 10.-11. Januar 1994 für die Osterweiterung (NATO 1994) löste in RU heftige Proteste aus. RU wurde bei der deutschen Wiedervereinigung ${ }^{209}$ versprochen, dass sich die Nato nicht über Ostdeutschland hinaus nach Osten erweiteren wird (Rötzer 2017, Ganser 2016a, Deutscher Bundestag 2016b: 10). Mit der Osterweiterung fühlte sich RU hintergangen und konzentrierte sich ab dem Zeitpunkt stärker auf sein eurasistisches Konzept „Nahes Ausland“. Der ehemalige russische Außenminister Andrei Wladimirowitsch Kosyrew (1990-1996) erklärte im Januar 1994 die Länder der GUS und

\footnotetext{
${ }^{209}$ An den Verhandlungen zum Zwei-plus-Vier-Vertrag haben neben der Sowjetunion, die USA, Frankreich, Großbritannien, BRD und DDR teilgenommen (Rötzer 2017).
} 
des Baltikums zu Regionen, wo die erstrangigen vitalen Interessen Russlands konzentriert sind (Wilhelmi 2002: 61).

Die Primakow-Ära (1996-1999) ist durch „Eurasismus und Multipolarität“ geprägt. Er legte seine außenpolitischen Richtlinien 1996 in der „Primakow-Doktrin“ fest. Der GUS-Raum wurde als außenpolitische Priorität genannt. Dessen Integration und die Lösung der Konflikte innerhalb dieses Raumes wurden als Schwerpunkt der Doktrin genannt (Mammadov 2014: 29). Des Weiteren wurde in dieser Doktrin festgelegt, dass RU im Rahmen seiner Westpolitik Europa (Deutschland und Frankreich) den USA vorziehen wird; in seiner Ostpolitik hingegen seine Beziehungen mit China, Indien, Japan und Nordkorea vertiefen wird und die multipolare Weltsicht Chinas teilt. Die Beziehungen zu den islamischen Staaten (gemeint sind die TR und der Iran) werden laut Doktrin gepflegt, bzw. vertieft. Die Doktrin schreibt RU für die Lösung der internationalen Probleme in Jugoslawien, dem Nahen Osten sowie Tadschikistan mehr Verantwortung zu. Laut Primakow wird das Land versuchen, ein regionales Gleichgewicht herzustellen und dafür mit den anderen Staaten zu kooperieren. Laut Mammadov (ebd.) ist die Primakow-Doktrin gegen die USA und ihre hegemoniale Außenpolitik gerichtet. Die Primakow-Doktrin war eine eurasistische Doktrin. Ein von den wichtigsten Ereignissen der Primakow-Ära war die Gründung der „Shanghai Five“ (Vorgänger von Shanghaier Organisation für Zusammenarbeit, SOZ) im Jahre 1996 zwischen der Volksrepublik China, RU, Kasachstan, Kirgisistan und Tadschikistan. 1997 erklärte RU mit China zusammen, dass die USHegemonie und NATO-Erweiterung ,nicht zu akzeptieren“ seien (ebd.; O. V. 1997: Jiang in Moscow ...). Weitere wichtige Ereignisse dieser Ära waren die russischen Reaktionen auf die US-Bombardierung des Iraks im Dezember 1998 sowie die NATO-Osterweiterung (Beitritt von Polen, Tschechien und Ungarn im Jahre 1999).

Die Putin-Ära (seit 1999 im Amt) ist durch die ,patriotisch-nationalistische Denkrichtung“ geprägt. Diese Denkrichtung ist laut Dschafarow (2009: 42) ein Sammelbecken aller russischen Denkrichtungen (wie z. B. Eurasismus, Realismus usw.) und Interessengruppen, die für ein geographisch großes, militärisch mächtiges und wirtschaftlich wohlhabendes RU auftreten und sich mit dem Niedergang der Sowjetunion nicht abfinden können. Das Hauptziel dieser Denkrichtung ist die endgültige Einbeziehung der ehemaligen Sowjetrepubliken in die russische Einflusssphäre und die Wiederherstellung des Großmachtstatus RUs (Dschafarow 2009: 42). Die Relevanz des GUS-Raumes in der 
russischen Außenpolitik nahm mit der Putin-Ära weiter zu. Auf der Weltwirtschaftsmesse 2000 betonte der damals stellvertretende Ministerpräsident der Russischen Föderation Michael Kassjanow die russischen Prioritäten im GUS-Raum folgendermaßen: „Die Beziehungen zu den Mitgliedern der Gemeinschaft der Unabhängigen Staaten ist der wichtigste Bestandteil unserer Außenpolitik.“ (Tinc 2000), ${ }^{210}$ (Übers. d. d. Verfasserin). In den offiziellen nationalen Dokumenten der Russischen Föderation 2000 (Außenpolitikkonzept, Sicherheitspolitische Strategie und Militärdoktrin der Russischen Föderation) wurde die Relevanz des GUS-Raumes in erster Linie im sicherheitspolitischen Zusammenhang unterstrichen. Diese Dokumente teilen ein gemeinsames Ziel: Die Verteidigung der territorialen Integrität und Souveränität der Russischen Föderation.

In der „Nationalen Sicherheitsstrategie der Russischen Föderation von 2000“ wird als russisches Ziel die Gewährleistung seiner Souveränität, territorialen Integrität, Festigung seiner Position als eine Großmacht und als eine der einflussreichen Zentren der multipolaren Welt festgeschrieben (Außenministerium der Russischen Föderation 2000). Obwohl das Land die Entwicklung der gleichberechtigten und gegenseitig vorteilhaften Beziehungen zu allen Ländern und Integrationsvereinigungen propagierte, betonte es gleichzeitig, dass die Beziehungen vor allem zu den Teilnehmern der GUS und traditionellen Partnern Russlands bevorzugt werden. Der Terrorismus wurde als weltweites Problem definiert, für dessen Bekämpfung RU zur Vereinigung der Kräfte der internationalen Gemeinschaft aufforderte. Als Hauptgefahren wurden die NATO-Erweiterung, eventuelles Aufkommen von ausländischen Militärstützpunkten und großen Truppenkontingenten in unmittelbarer Nähe der russischen Grenze, die Weiterverbreitung von Massenvernichtungswaffen und deren Trägermitteln, die Ansprüche auf das Territorium der Russischen Föderation, die Schwächung der Integrationsprozesse im GUS-Raum, die Entstehung und Eskalation der Konflikte in der unmittelbaren Nähe RUs genannt (ebd.). Die sicherheitspolitischen Gefahren wie in der Sicherheitsstrategie wurden auch in der „Militärdoktrin der Russischen Föderation von 2000“ wiederholt. RU erklärte in dieser Doktrin, dass das Land gegen diese Gefahren militärisch vorgehen wird (Präsident der Russischen Föderation 2000).

Die sicherheitspolitischen Interessen RUs prägten auch sein „Außenpolitikkonzept der Russischen Föderation von 2000“. RU schrieb den Schutz der Interessen des Einzelnen und der Gesellschaft als oberste Priorität des außenpolitischen Kurses Russlands vor (President

\footnotetext{
210 „Bağımsız Devletler Topluluğu ile ilişkiler ise dış politikamızın en önemli maddesidir.“
} 
of the Russian Federation 2000: 1). Dafür sollte sich das Land in erster Linie auf die Gewährleistung seiner Sicherheit, seiner territorialen Integrität und Souveränität konzentrieren (ebd.: 1). Den GUS-Raum nannte RU aus sicherheitspolitischen Gründen als Prioritätsraum der russischen Außenpolitik (ebd.: 8), zu dem RU in erster Linie wegen des Schutzes seiner Grenzen ,gutnachbarschaftliche Beziehungen“" aufbauen und pflegen solle (ebd.: 2, 8). D. h. RU sah den GUS-Raum sicherheitspolitisch als Sicherheitsgürtel gegen die sicherheitspolitischen Gefahren wie den Terrorismus, Extremismus (ebd.: 9) an. Als wirtschaftliches Ziel hingegen sah das Land die Schaffung einer Freihandelszone und die Nutzung der fossilen Brennstoffe des Kaspischen Meeres vor (ebd.: 9). 2000 ernannte Putin einen speziellen Gesandten für Fragen des Kaspischen Meers, der gleichzeitig auch stellvertretender Außenminister RUs war. Laut Dschafarow (2009: 42) folgte Putin hier mit jahrelanger Verspätung dem amerikanischen Beispiel, denn die USA haben schon lange einen Botschafter für Kaspische Fragen, der regelmäßig die Region bereist und amerikanische Interessen vertritt (Dschafarow 2009: 42). Des Weiteren forderte RU in diesem Außenpolitikkonzept gleichberechtigte Partnerschaften zwischen den Staaten sowie die Einhaltung der internationalen Normen und Rechte, wie z. B. der Ziele und Prinzipien der UN-Charta (President of the Russian Federation 2000: 1). Zwar wurde der Begriff „Soft Power“" auch in diesem Konzept wie in seinem Vorgänger Konzept 1993 nicht beim Namen genannt. Die russischen Soft-Power-Strategien aber wurden folgendermaßen formuliert: Die Unterstützung der russischen Diaspora, die Förderung des positiven Images RUs, die Popularität der russischen Sprache und Kultur weltweit (ebd.: 2) und im GUS-Raum zusätzlich die Förderung des kulturellen Erbes RUs (ebd.: 9).

Nach den Terroranschlägen in den USA am 11.09.2001 kooperierte RU mit den USA/NATO sicherheitspolitisch und unterstützte sie beim Erwerb der NATO-Militärbasen in seinem „Nahen Ausland“, in ZA (Wipperfürth 2011: 61) (siehe hierzu Kap. 6.6). Allerdings zog RU seine Unterstützung nach den Ereignissen, wie die Kündigung des ABM-Vertrages (AntiBallistic Missiles Treaty) mit RU durch die USA im Jahre 2001, der Irakkrieg der USA/NATO ohne UN-Mandat 2003, die NATO-Erklärungen über das russische „Nahe Ausland“ (Kaukasus und ZA) von 2002 und 2004, NATO-Erweiterungen, Farbenrevolutionen im postsowjetischen Raum, Raketenabwehrsysteme usw., zurück (siehe hierzu Kap. 6.6). Diese Ereignisse definierte das Land als sicherheitspolitische Gefahr für seine territoriale Integrität und Souveränität bzw. als seine Einkreisung. Das NATO-Land TR sieht RU in seinem „Nahen Ausland“ als verlängerten Arm der USA, die in ZA einerseits 
ihre eigenen Interessen verfolgt (Erol 2012: 7), andererseits versucht sie, die Rahmenbedingungen für die US-Zentralasienpolitik zu schaffen (ebd.).

In seinen aktuellen nationalen Dokumenten (Nationale Sicherheitsstrategie 2015, Militärdoktrin 2014 und Außenpolitikkonzept 2016) definiert RU neben dem Islamismus die NATO und die amerikanischen Aktivitäten, wie Raketenabwehrsysteme, als sicherheitspolitische Gefahren. Dem Westen wirft RU in seiner „Nationalen Sicherheitsstrategie von 2015“ vor, den Regierungswechsel der legitim gewählten Regierungen herbei führen $\mathrm{zu}$ wollen, z. B. durch Unterstützung der sogenannten Farbenrevolutionen o. Ä. vor (President Of The Russian Federation 2015, Artikel 18). Des Weiteren wirft RU dem Westen die Unterstützung bzw. der Stärkung von islamistischen Organisationen vor, z.B. infolge militärischer Aktivitäten z. B. in Irak und Syrien (ebd.). Den GUS-Raum sieht RU in diesen Dokumenten als Pufferzone, d. h. in erster Linie aus sicherheitspolitischen Gründen. Zum Vertrauenaufbau und Sympathiegewinn in ZA sieht RU als Soft-Power-Mittel in ZA die russische Sprache und Diaspora in der Region an.

\subsubsection{Russische Diaspora und Russisch als russische Soft-Power- Mittel}

Die Strategien und Ziele einer Soft-Power-Politik wurden schon im ersten „Außenpolitikkonzept der Russischen Föderation von 1993“211 festgeschrieben. 1993 sah RU als kulturpolitische Aufgabe die Unterstützung der russischen Kultur und Sprache im Ausland vor, um das russische Fremdbild positiv zu beeinflussen (President Of The Russian Federation 1993). Im „Außenpolitikkonzept der Russischen Föderation von 2000“ hob RU die Förderung des „kulturellen Erbe Russlands“ im GUS-Raum hervor. (Außenministerium der Russischen Föderation 2000: 9). In seiner „Nationalen Sicherheitsstrategie“ führt das Land $u$. a. die möglichen negativen Folgen der als inszenierte Revolutionen betrachteten Farbenrevolutionen in seinem „Nahen Ausland“ u. a. an, die seine ,traditionellen geistigmoralischen russischen Werte“ zu zerstören drohen (President Of The Russian Federation 2015, Artikel 43). Die kultur- und bildungspolitische Arbeit RUs im GUS-Raum

\footnotetext{
${ }^{211}$ Den Begriff „Soft-Power“ benutzte RU als Begriff das erste Mal im aktuellen „Außenpolitikkonzeption der Russischen Föderation von 2013“ (Präsident der Russischen Föderation 2013, O. V. 2013: Rusya'nın Yeni Diş Politika ...).
} 
konzentriert sich somit auf die Aufrechterhaltung und Erweiterung der Sprache und des kulturellen russischen Einflusses sowie des Sympathie- und Vertrauengewinns.

Die russische Diaspora ermöglicht RU, sich in die inneren Angelegenheiten der zentralasiatischen Staaten einzumischen. In der „Außenpolitikkonzeption 2013“ schreibt RU in Artikel 4 als Ziel den „Schutz der Rechte und legitimen Interessen der russischen Bürger und der im Ausland ansässigen Landsleute“ (Präsident Der Russischen Föderation 2013). In der aktuellen „Außenpolitikkonzeption von 2016“ (The Ministry of Foreign Affairs of the Russian Federation 2016, Artikel 45) fügt RU als weiteres Ziel die Unterstützung ihrer Bindung zur historischen Heimat sowie ihrer freiwilligen Übersiedlung in die Russische Föderation hinzu. Die größte russische Diaspora in ZA befindet sich in Kasachstan. Diese machte etwa $24 \%$ der Gesamtbevölkerung Kasachstans (18,3 Mio.) aus (Auswärtiges Amt 2018a). Sie lebt größtenteils im Norden des Landes. Obwohl schon nach Sprachregeln 1989 das Kasachische als Amtsprache und das Russische als Dialogsprache zwischen den Völkern Kasachstans gilt, sprachen 2000 nur $1 \%$ der russischen Diaspora Kasachisch (Nogayeva 2012: 185). Russisch wird bis heute in kasachischen Bildungseinrichtungen benutzt. In Kasachstan sind die russischen NGOs (Non-Governmental Organization), wie z. B. Russische Vereinigung (russisch: Russkaya Obshina), sehr gut organisiert. Sie erhalten 30 bis 40 \% ihres Gesamtbudgets vom russischen Außenministerium (Nogayeva 2012: 185186).

Die russische Diaspora im Norden Kasachstans kann den Norden Kasachstan in ein Unruhegebiet verwandeln, falls sie sich von Kasachstan politisch, wirtschaftlich, kulturell benachteiligt empfindet. Laut Brzezinski (2001: 216-217) macht die ethnische Spaltung Kasachstans dieses Land gegenüber russischem Druck wehrlos. Er fügt hinzu, dass die wirtschaftliche Entwicklung des Landes die ethnische Spaltung überwinden könnte, weshalb das geostrategisch wichtige Kasachstan die wirtschaftliche Unterstützung des Westens verdient. Die „Annexion“ der Krim im März 2014 durch RU und die russische Unterstützung der russischen Separatisten in der Ost-Ukraine beunruhigte besonders Kasachstan. Obwohl in Kasachstan die doppelte Staatsangehörigkeit nicht erlaubt ist, ist bekannt, dass RU selbst die ethnischen Nicht-Russen innerhalb kürzester Zeit russifizieren kann, wie sie es z. B. in den abtrünnigen Republiken Georgiens, Südossetien und Abchasien getan hat. Die russische Diaspora in diesen Republiken hat RU erst durch Verteilen von russischen Pässen geschaffen 
(Gruska 2010: 108; König 2010: 134 f.; Quiring 2009: 30) 212 $^{21}$ Das ermöglichte ihr, diese „abtrünnigen Republiken“ nach dem August-Krieg 2008 gegen Georgien anschließend als „unabhängige Staaten“‘213 anzuerkennen.

Kirgisistan ist hinsichtlich der russischen Diaspora nicht so stark betroffen wie Kasachstan. Hier machte sie 6,7 \% (Stand: 2016) seiner Gesamtbevölkerung (6,1 Mio.) aus (Auswärtiges Amt 2018b). ${ }^{214}$ Usbekistan versuchte, sich kulturell vom russischen Einfluss möglichst loszulösen. Daher hat das Land viele Reformen durchgeführt, um den Einfluss des Russischen (Sprache, Kultur, Bildung usw.) massiv einzugrenzen. Mit den Andijan-Unruhen 2005 in Usbekistan, hinter denen der Westen vermutet wird, näherte sich Usbekistan wieder an RU an. Das Land erlaubte z. B. die Eröffnung der russischen Fakultäten der Moskauer Universität sowie die russischen Klassiker als Schullektüre (Kamalov 2011: 57). 2018 machte die russische Diaspora in Usbekistan 5 \% der usbekischen Gesamtbevölkerung (32 Mio.) aus (Auswärtiges Amt 2018c). Turkmenistan verfolgt eine anti-russische Haltung, wie z. B. Verbot der Doppelstaatlichkeit, Verbot der russischen Sprache an den Bildungseinrichtungen, Verbot der Einfuhr der russischen Literatur ins Land usw. zeigt. Nach der Erdgasvereinbarung 2003 für 25 Jahre mit RU lockerte das Land allerdings seine Haltung und erkannte z. B. ab 2004 die russischen Diplome an (Kamalov 2011: 58). Russisch hat in Turkmenistan keinen offiziellen Status, die Diaspora hat keine Vereinigung (Nogayeva 2012: 187). Ihr Anteil in der Gesamtbevölkerung (5,6 Mio.) lag 2018 bei 6,7 \% (Auswärtiges Amt 2018d). Tadschikistan verfügt über eine sehr kleine russische Diaspora. Mit Kirgisen, Russen und Turkmenen zusammen machten sie 2018 etwa $3 \%$ der

\footnotetext{
${ }^{212}$ Seit 2002 verteilten die russischen Behörden in Abchasien russische Pässe. Mehr als die Hälfte der Bevölkerung sind russische Staatsangehörige. Laut Gruska konnte Moskau daher jede Intervention in Abchasien mit dem „Schutz eigener Staatsbürger“ (Gruska 2010: 108) begründen. In Süd-Ossetien besaßen 90 $\%$ der Osseten bereits 2006 einen russischen Pass. Sie haben damit das Recht auf die russische Rente. RU war jahrelang der einzige Investor in Süd-Ossetien. Ein russischer Mobilfunknetzbetreiber in Süd-Ossetien ist Hauptanbieter, der Aufbau der Elektrokraftwerke bei Zchinwali ist ein weiteres Beispiel (König 2010: 134 f.; Quiring 2009: 30).

${ }^{213}$ Georgische Annäherung an die NATO für eine Mitgliedschaft, NATO-Vorgehen gegen den russischen Verbündeten Serbien in Bezug auf die Anerkennung des Kosovo als unabhängigen Staat waren die wichtigen Ursachen für RUs Angriff auf Georgien. Im November 2014 unterschrieb RU mit dem von ihm als unabhängigen Staat anerkannten Abchasien ein „Abkommen für die Zusammenarbeit und strategische Partnerschaft“. Ein halbes Jahr später, im März 2015, unterschrieb RU mit Südossetien ebenfalls ein „Abkommen für Zusammenarbeit“ (Bilgic 2016: 8).

${ }_{214}$ Der Anteil der russischen Diaspora in Kirgisistan war in der sowjetischen Zeit, wie in Kasachstan, hoch. 1991 machten sie noch 21,5 \% der Gesamtbevölkerung Kirgisistans aus (Kamalov 2011: 59). Allerdings sind viele Russen aufgrund der anti-russischen staatlichen Maßnahmen und schlechten sozio-ökonomischen Strukturen zurück nach RU gegangen.
} 
Gesamtbevölkerung (8,7 Mio.) aus (Auswärtiges Amt 2018e). Viele Russen haben im Laufe des tadschikischen Bürgerkrieges (1992-1997) das Land verlassen.

RU versucht die russische Sprache als Lingua Franca in ZA zu erhalten bzw. zu verbreiten. weil sie die wichtigste Säule seiner Kultur- und Bildungspolitik ist. Seine Sprach- und Bildungspolitik stellt das Land in seiner aktuellen „Außenpolitikkonzeption von 2016“ (The Ministry of Foreign Affairs of the Russian Federation 2016, Artikel 45) folgendermaßen dar:

„,das Erlernen und die Verbreitung der russischen Sprache als unveräußerlichen Teil der Weltkultur und als Instrument der internationalen und interethnischen Kommunikation zu fördern, das System russischer Bildungsorganisationen im Ausland zu unterstützen und zu entwickeln sowie Filialen und Vertretungen russischer Bildungsorganisationen in anderen Staaten zu unterstützen. "

Als Soft-Power-Instrument betreiben einige Stiftungen wie z. B. die „Russkij Mir“ (Welt Russlands) seit 2007 Kultur- und Bildungspolitik. Russkij Mir wird vom russischen Außenministerium und dem Bildungs- und Wissenschaftsministerium unterstützt (siehe seine Ziele in: Russkij Mir 2015). Das andere wichtige Soft-Power-Instrument des russischen Außenministeriums ist „Rossotrudnitschestwo“ („Russische Zusammenarbeit“, „Föderalagentur für Angelegenheiten der GUS, für Fragen der im Ausland lebenden Mitbürger und für internationale humanitäre Zusammenarbeit" ). Diese Instrumente umfassen vom Studentenaustausch, Vergabe von Stipendien bis zur Verbreitung der russischen Sprache und Unterstützung des positiven Images RUs. Die russischen Medien sind ein weiteres wichtiges Soft-Power-Instrument für das positive Image RUs und dienen der Meinungsmache. In Kasachstan und Kirgisistan erscheinen 50 \% der gesamten Medien auf Russisch. Russisch ist in ZA die Wissenschafts- und Literatursprache. Die russischen Universitäten in Kasachstan, Kirgisistan und Tadschikistan haben einen sehr guten Ruf und werden von Studienbewerbern bevorzugt, weil RU für die Absolventen ein großer Arbeitsmarkt ist.

RU versucht seit 2010 die Nutzung und Verbreitung der kyrillischen Schrift als Internetsprache durchzusetzen. Laut Nogayeva (2012: 188) ist dieses Ziel nicht zu realisieren, weil Turkmenistan und Usbekistan allein wegen des Internets das lateinische Alphabet einführten. Kasachstan beschloss ab 2025 die Umstellung des kyrillischen Alphabets auf das Lateinische und möchte, dass bis zu diesem Datum 95 \% der Bevölkerung Kasachisch beherrscht (Kalimullin 2012). Kirgisistan und Tadschikistan benutzen weiterhin 
das kyrillische Alphabet. Die beiden Staaten sind die wirtschaftlich schwächsten zentralasiatischen Staaten und sicherheitspolitisch sowie wirtschaftlich auf RU angewiesen. 2016 belief sich das Bruttoinlandsprodukt pro Kopf in Kirgisistan auf 1077 US-Dollar (Auswärtiges Amt 2018b) und in Tadschikistan auf 796 US-Dollar (Auswärtiges Amt 2018e). $10 \%$ der kirgisischen (Auswärtiges Amt 2018b) und etwa $10 \%$ der tadschikischen Bevölkerung (Ballin 2017) arbeiteten in RU als Gastarbeiter und leisteten mit dem Geldtransfer ihren Ländern einen wirtschaftlichen Beitrag.

Ich habe festgestellt, dass in ZA eine positive Korrelation zwischen der sicherheitspolitischen Zusammenarbeit und kultur- und bildungspolitischen Zusammenarbeit zu beobachten ist. D. h. die sicherheitspolitische Zusammenarbeit und Interessen bestimmen die Grenzen der kultur- und bildungspolitischen Zusammenarbeit. Mit anderen Worten, je tiefer die sicherheitspolitische Zusammenarbeit und Ziele zwischen den Akteuren, desto tiefer ist ihre kultur- und bildungspolitische Zusammenarbeit. RU ist in der Region das einzige Land, das Hard Power anwenden kann, d. h. militärisch eingreifen darf und kann. Im Tadschikischen Bürgerkrieg (1992-1997) griff RU ein und regelte den Konflikt. Während der Unruhen in Usbekistan 2005 half RU der usbekischen Regierung. Als in Kirgisistan 2010 Unruhen ausbrachen und die Gewalt eskalierte, bat die kirgisische Übergangsregierung RU um Hilfe (O. V. 2010: Gewalt in Kirgistan ...).

Die zentralasiatischen Staaten Kasachstan, Kirgisistan und Tadschikistan sind Mitglieder der russisch geprägten sicherheitspolitischen Organisation OVKS und ihre sicherheitspolitischen Beziehungen mit RU sind strategisch begründet (siehe hierzu Kap. 6.7). In Kirgisistan verfügt RU über einen Luftwaffenstützpunkt in Kant, ein Testgelände für Unterwasserwaffen in Karakol, ein seismisches Labor in Mailuu- Suu und ein Zentrum für Militärkommunikation. In Tadschikistan hat RU mit 7000 Soldaten seine größte Militäreinheit im Ausland. In Kasachstan unterhält RU den weltweit bekannten Weltraumbahnhof Baikonur, das Raketentestgelände Saryschagan, Luftwaffenkommando in Karaganda u. a. Dieses Land ist für RU sicherheitspolitisch das wichtigste zentralasiatische Land, da RU mit Kasachstan eine 7600 km lange Grenze teilt und zwischen ihm und den anderen zentralasiatischen Ländern als Pufferzone gilt. Alle dieser Staaten sind Mitglieder 
der OVKS. In allen diesen Ländern hat RU ein positives Image, wie Meinungsumfragen in Kasachstan und Kirgisistan zeigen ${ }^{215}$ (siehe Kap. 5.6).

Usbekistan hält sich zurzeit bei einer OVKS-Mitgliedschaft zurück. Als das Land als Reaktion auf die USA infolge des Andijan-Aufstands 2005 der OVKS beitrat, erlaubte das Land die Eröffnung der russischen Fakultäten der Moskauer Universität sowie die russischen Klassiker als Schullektüre (Kamalov 2011: 57) im Lande. Allerdings trat sie 2012 wieder aus und näherte sich wieder dem Westen an. Es ist wahrscheinlich, dass Usbekistan im Falle einer ernsthaften sicherheitspolitischen Gefahr wieder der OVKS beitreten wird, was wiederum die Türen zur russischen Kultur- und Bildungspolitik weit öffnen würde. Seit der Ära des Präsidenten Mirsijojew 2016 nähert sich Usbekistan sicherheitspolitisch wieder an RU an (siehe Kap. 6.7), was die russische Kultur- und Bildungspolitik in Usbekistan positiv beeinflussen wird. Turkmenistan ist aufgrund seiner Neutralität ${ }^{216}$ kein Mitglied der OVKS. Das Land wird aber im Falle eines sicherheitspolitischen Problems russische Hilfe anfordern bzw. mit ihm sicherheitspolitisch zusammenarbeiten. In so einem Fall wird in Turkmenistan die russische Kultur- und Bildungspolitik Erfolge erzielen. Trotz Zurückhaltung Usbekistans und Turkmenistans von RU, wird RU von diesen Staaten als Schutzmacht akzeptiert, ist die Russische Sprache Lingua Franca in diesen beiden Staaten und RU ein wichtiger Arbeitsmarkt.

\footnotetext{
${ }^{215}$ In den zentralasiatischen EAWU-Mitgliedstaaten Kasachstan und Kirgisistan findet die EAWU laut Meinungsumfragen hohe Zustimmungswerte: $80 \%$ der kasachischen und $86 \%$ der kirgisischen Bevölkerung sind für die EAWU (Schiek 2016: 1).

${ }^{216}$ Im Dezember 1995 erklärte Turkmenistan bei den Vereinten Nationen immerwährende Neutralität des Landes.
} 


\subsection{Zusammenfassung}

Die TR und RU rivalisieren in ZA kultur- und bildungspolitisch. Ihre Rivalität ist in ihrer gegensätzlichen ZA-Wahrnehmung und Sprachpolitik in der Region deutlich zu sehen. Beide Staaten nehmen ZA als ihr ,selbstverständliches Einflussgebiet“ wahr; die TR als ihre „Türkenwelt“ und RU als sein „Nahes Ausland“. Diese Wahrnehmungen spiegeln sich in ihren ZAP-Konzepten als „Türkenweltpolitik“ und „Nahes-Ausland-Politik“ wider. Die TR nimmt die Turkstaaten ZAs als „türkischsprachige bzw. türksprachige Türken“ wahr, wie auf den aktuellen offiziellen Internetseiten einer Unterorganisation des türkischen Ministerpräsidialamtes (TIKA) und des türkischen Außenministeriums zu sehen ist. Die zentralasiatischen Staaten sind allerdings weder Türken noch sprechen sie Türkisch. Alle Turkstaaten haben ihre eigene Nationalität, Sprache, Geschichte und Kultur. So wollen sie auch wahrgenommen werden, d. h. als souveräne unabhängige Staaten mit ihrer eigenen historisch-kulturellen Eigenschaften. Diese Realität will die TR mit ihrer pantürkistischen ZAP ändern und die Turkstaaten türkisieren. Gleich auf dem 1. von der TR organisierten (Türken)Gipfeltreffen 1992 nach der Unabhängigkeit der Turkstaaten forderte die TR die Turkstaaten auf, unter ihrer Herrschaft eine politisch, wirtschaftlich, militärisch und kulturell einheitliche „Türkenwelt““ zu gründen. Die türkischen Anforderungen lehnten die zentralasiatischen Turkstaaten gleich ab und kritisierten den türkischen Hegemonieversuch.

Die turksprachigen zentralasiatischen Staaten wollen mit der TR nur im Rahmen „,kulturpolitischer“ Organisationen wie TURKSOY, TÜRKPA und TDIK (Siehe Tabelle 3) zusammenarbeiten und vermeiden die Erwähnung/Betonung einer ethnischen Verwandtschaft mit ihr. Weil die TR diesen Wunsch der Regionsstaaten ignoriert und weiterhin an ihrer „Türkenweltpolitik“ beharrt, wird sie von den zentralasiatischen Turkstaaten als sicherheitspolitische Gefahr gegen ihre historisch-kulturelle Identität und Landesgrenzen angesehen. Die als das wichtigste (inoffizielle) Soft-Power-Instrument der TR gesehenen Gülen-Schulen schlossen Usbekistan und Turkmenistan wegen ihrer pantürkistisch-islamistischen Arbeit und ihrer Zusammenarbeit mit der CIA. Usbekistan brach zusätzlich seine Beziehungen zu der TR ab. Als die TR seit 2013 nach dem offenen Gülen-Erdogan-Krieg nicht mehr für die Gülen-Schulen bürgte und Kasachstan und Kirgisistan unter Druck setzte, die Gülen-Schulen zu schließen, wurde sie ignoriert. Diese Beispiele zeigen, dass der kulturelle Einfluss der TR in ZA mäßig ist. 
RU akzeptiert im Gegensatz zur TR die Turkstaaten mit ihren eigenen historisch-kulturellen Eigenschaften als souveräne Staaten und hält sich weitgehend von ihren inneren Angelegenheiten zurück. Sein Verhalten ist allerdings taktisch. Es unterstützt die Eigenständigkeit dieser Staaten in erster Linie deshalb, weil das Land gegen die möglichen pantürkistischen und religiösen Bewegungen und Vereinigungen ist. In seiner Geschichte musste RU den pantürkistischen (Basmatschi)Aufstand (1918-1924) der Zentralasiaten gegen sich bekämpfen. Andererseits möchte RU aus sicherheitspolitischen Gründen (wegen seines turksprachigen und/oder muslimischen Bevölkerungsanteils) keine ethnischreligiösen Bewegungen oder Regierungen in ZA, wie im Kapitel 6 erklärt wird. Sonst sieht RU ZA im Rahmen seines „Nahen Auslands“ und seine „Nahes-Ausland-Politik“ ist hegemonial geprägt.

Das russische Image in ZA ist positiv, wie die Meinungsumfragen in Kasachstan und Kirgisistan bezüglich der EAWU zeigten. Für die zentralasiatischen Staaten ist RU in erster Linie aus sicherheitspolitischen Gründen wichtig und gilt als Schutzmacht des Status Quo in der Region. In ZA ist eine positive Korrelation zwischen der sicherheitspolitischen und kultur- und bildungspolitischen Zusammenarbeit $\mathrm{zu}$ beobachten. D. h. die sicherheitspolitische Zusammenarbeit und -Interessen bestimmen die Grenzen der kulturund bildungspolitischen Zusammenarbeit. Mit anderen Worten, je tiefer die sicherheitspolitische Zusammenarbeit und die Ziele zwischen den Akteuren sind, desto tiefer ist ihre kultur- und bildungspolitische Zusammenarbeit. Kasachstan, Kirgisistan und Tadschikistan sind die drei zentralasiatischen Mitgliedstaaten der russisch geprägten sicherheitspolitischen Organisation OVKS, d. h. sie arbeiten mit RU sicherheitspolitisch eng zusammen. In diesen Mitgliedsstaaten unterhält RU Militärbasen sowie Streitkräfte. Der russische kultur- und bildungspolitische Einfluss in diesen Staaten ist dementsprechend größer als in Turkmenistan und Usbekistan. Usbekistan hält sich derzeit von einer OVKSMitgliedschaft zurück. Das Land war allerdings als Reaktion auf den Westen nach den Andijan-Unruhen, hinter denen das Land den Westen vermutete, OVKS Mitglied zwischen den Jahren 2005-2012. Als Usbekistan der OVKS beitrat, erlaubte das Land die Eröffnung der russischen Fakultäten der Moskauer Universität sowie die russischen Klassiker als Schullektüre (Kamalov 2011: 57) im Lande. Usbekistan nähert sich sicherheitspolitisch seit der Ära des Präsidenten Mirsijojew 2016 wieder an RU an (siehe Kap. 6.7), was die russische Kultur- und Bildungspolitik in Usbekistan unterstützten wird. Turkmenistan ist aufgrund 
seiner Neutralität kein Mitglied der OVKS. Hier ist der russische kultur- und bildungspolitische Einfluss am geringsten.

Die Alphabetpolitik der zentralasiatischen Turkstaaten zeigt ganz deutlich, dass die zentralasiatischen Turkstaaten weder die türkische noch die russische kulturelle Hegemonie akzeptieren wollen. Des Weiteren wollen sie, dass ihre historisch-kulturelle Identität akzeptiert und respektiert wird. Usbekistan und Turkmenistan beschlossen z. B. 1993, ihr kyrillisches Alphabet durch das lateinische Alphabet zu ersetzen. Sie benutzen seit 1995 das lateinische Alphabet. Ihr neues Alphabet ist allerdings mit dem lateinischen Alphabet der TR nicht identisch und hat z. B. andere Buchstabencharaktere, die das Türkische nicht hat. Kasachstan und Kirgisistan benutzen bis heute das kyrillische Alphabet wie RU. Kasachstan verabschiedete allerdings die Umstellung auf das lateinische Alphabet ab 2025. Dabei spielte die russische Diaspora in Kasachstan eine entscheidende Rolle, da diese sich sprachlich nicht in Kasachstan integriert. Abschließend kann es gesagt werden, dass die Staaten für eine erfolgreiche Kultur- und Bildungspolitik in ZA die nationale und historisch-kulturelle Identität der zentralasiatischen Staaten anerkennen müssen. Das ist die Bedingung einer erfolgreichen Zusammenarbeit nicht nur in kultur- und bildungspolitischen, sondern auch in wirtschaftlichen und sicherheitspolitischen Bereichen. 


\section{TÜRKISCH-RUSSISCHE WIRTSCHAFTSPOLITIK IN ZENTRALASIEN (1991-2019)}

ZA trat infolge seiner Unabhängigkeit 1991 zunächst mit seinen fossilen Brennstoffen in die mediale Weltöffentlichkeit. Es begann ein Wettbewerb um deren Ausbeutung, der hauptsächlich zwischen der US-geprägten westlichen Achse und RU läuft. Dieser Wettbewerb wird von der Literatur „New Great Game“ bezeichnet. Die TR befindet sich auf der westlichen Seite gegen RU. Energiepolitisches Ziel der westlichen Achse ist die Ausbeutung der kaspischen fossilen Brennstoffe unter Umgehung RUs (und des Irans) nach Europa. New Great Game kann im weitesten Sinne als Wettbewerb um die Ausbeutung der fossilen Brennstoffe der Strategischen Ellipse (siehe Abbildung 7) verstanden werden, wozu neben den zentralasiatischen fossilen Brennstoffen auch die fossilen Brennstoffe RUs und des Nahen Ostens gezählt werden. Die „strategische Ellipse“ verfügt insgesamt über 72,4 \% der fossilen Erdgasressourcen und 58 \% der Erdölreserven ${ }^{217}$ der Welt (Bundesanstalt für Geowissenschaften und Rohstoffe (BGR) 2015:119, 109). Die Kontrolle der fossilen Brennstoffe bedeutet nicht nur Energiesicherheit und wirtschaftliche Gewinne; sondern auch politischer Einfluss auf die energiehungrigen Industriestaaten, wie Japan und die EUStaaten.

Die energiereichen Staaten ZAs sind Kasachstan, Turkmenistan und Usbekistan. Kasachstan ist das erdölreichste Land ZAs. 2014 hatte Kasachstan ein verbleibendes Potenzial ${ }^{218}$ von 16,2 Mrd. Tonnen Erdöl (2,9 \% des verbleibenden Potenzials der Welt, Platz 10), Turkmenistan 1,9 Mrd. Tonnen und Usbekistan 481 Mio. Tonnen Erdöl (Bundesanstalt für Geowissenschaften und Rohstoffe (BGR) 2015: 104, 107). Beim Erdgas ist Turkmenistan sehr reich mit einem verbleibenden Potenzial von 24,9 Billionen $\mathrm{m}^{3}$ (2,9\% das verbleibende Potenzial der Welt, Platz 10) (ebd.: 114, 117). Kasachstan verfügt über 6,1 Billionen $\mathrm{m}^{3}$ und Usbekistan 3 Billionen $\mathrm{m}^{3}$ Erdgas (ebd.). Kirgisistan und Tadschikistan sind energiearme,

\footnotetext{
${ }^{217}$ Reserven sind ,nachgewiesene, zu heutigen Preisen und mit heutiger Technik wirtschaftlich gewinnbare, Energierohstoffmengen“ (Bundesanstalt für Geowissenschaften und Rohstoffe (BGR) 2015: 160).

218 Verbleibendes Potenzial ist die Gesamtsumme der Gesamtreserven und Gesamtressourcen des Landes. Ressourcen sind ,nachgewiesene, aber derzeit technisch-wirtschaftlich und/oder wirtschaftlich nicht gewinnbare sowie nicht nachgewiesene, aber geologisch mögliche, künftig gewinnbare Energierohstoffmengen“ (Bundesanstalt für Geowissenschaften und Rohstoffe (BGR) 2015: 160).
} 
aber wasserreiche Staaten. Ihre Wasserquellen sind für die gesamte Region von großer Bedeutung, besonders für den Baumwollanbau. ${ }^{219}$

Die energiepolitischen Rivalen der westlichen Achse im New Great Game, RU und der Iran, sind sehr reich an fossilen Brennstoffen. RUs verbleibendes Potenzial von Erdöl 2014 war mit etwa 48 Mrd. Tonnen Erdöl (8,5 \% des verbleibenden Weltpotenzials, Platz 3) ${ }^{220}$ sehr hoch (ebd.: 104, 107). Bei Erdgas belegte RU im selben Jahr mit einem Anteil von 199,8 Billionen $\mathrm{m}^{3}$ Erdgas den 1. Platz (23,5 \% des verbleibenden Gesamtpotenzial der Welt) (ebd.: 114, 117). ${ }^{221}$ Der Iran hingegen hatte ein verbleibendes Potenzial von 28,6 Mrd. Tonnen Erdöl (6. Platz weltweit) (ebd.: 106, 107) und von 44 Billionen $\mathrm{m}^{3}$ Erdgas (4. Platz weltweit) (ebd.: 116, 117). Ein anderer energiereiche Nachbarstaat ZAs und Rivale der USA ist China. China verfügt 2014 über verbleibendes Potenzial von 23,2 Mrd. Tonnen Erdöl (Platz 8 weltweit) und 71,4 Billionen $\mathrm{m}^{3}$ Erdgas (Platz 2) (Bundesanstalt für Geowissenschaften und Rohstoffe (BGR) 2015: 106, 116). Gegen alle dieser Staaten führen die USA einen stillen Krieg und erklärten diese Staaten (mit Nord-Korea zusammen) in ihrer aktuellen „Nationalen Verteidigungsstrategie von 2018“ (National Defense Strategy) als größte sicherheitspolitische Gefahr. Alle diese Staaten werden von den USA sanktioniert.

RU und China wurden weiterhin als die politischen, wirtschaftlichen und militärischen Herausforderer der USA (United States Department of Defense 2018: 2-2, 2-3) definiert. Als langfristige Hauptpriorität des US-Verteidigungsministeriums wurde der strategische Wettbewerb mit China und Russland genannt (ebd.: 2-3). ${ }^{222}$ Die Kontrolle und Einkriesung

\footnotetext{
${ }^{219}$ ZA ist auch reich an Metallen und weiteren fossilen Brennstoffen, wie Kohle. Kirgisistan ist reich an Gold. In den letzten Jahren machten die Goldausfuhren bis zu $50 \%$ der Gesamtexporte aus. In Tadschikistan wird Aluminium ab- und Baumwolle angebaut. Auch an Gold und Silber ist dieses Land reich und verfügt über die zweitgrößten Silberreserven. Usbekistan ist reich an Bodenschätzen (Gold, Kupfer, Uran, Kohle). Das Land hat mit 42.000 Tonnen Uran 3,4 \% der Weltreserven und befindet sich auf Platz 8 weltweit (Bundesanstalt für Geowissenschaften und Rohstoffe (BGR) 2015: 142). Kasachstan befindet sich mit 236.000 Tonnen Uran (19,5 $\%$ der Weltreserven) auf dem 2. Platz nach Canada (275.000 Tonnen, 22,7 \% der Weltreserven) (Bundesanstalt für Geowissenschaften und Rohstoffe (BGR) 2015: 142). Das geförderte Uran wird zum größten Teil von nur sehr wenigen Ländern verbraucht. Über die Hälfte des globalen Uranbedarfs entfallen auf die drei Länder: USA (30, 2 \%), Frankreich (14,3\%) und China (10,3\%) (Bundesanstalt für Geowissenschaften und Rohstoffe (BGR) 2014: 43-44; Bundesanstalt für Geowissenschaften und Rohstoffe (BGR) 2015: 50). In der ersten Hälfte des Jahres 2014 exportierte Kasachstan 55 \% seines Uran-Exportes nach China (World Nuclear Association 2015).

${ }^{220}$ Auf dem 1. Platz war Venezuela mit einem verbleibenden Potenzial von 92,1 Mrd. Tonnen Erdöl, gefolgt von Kanada mit 83,9 Mrd. Tonnen Erdöl (Bundesanstalt für Geowissenschaften und Rohstoffe (BGR) 2015: $106,107)$.

${ }^{221}$ Auf dem 2. Platz befindet sich China mit 71,4 Billionen $\mathrm{m}^{3}$ verbleibenden Potenzial an Erdgas, gefolgt von den USA mit 63 Billionen $\mathrm{m}^{3}$ (Bundesanstalt für Geowissenschaften und Rohstoffe (BGR) 2015: 116-117). ${ }^{222}$ China hat sich zur Weltwirtschaftsmacht entwickelt. Außerdem ist das Land eine starke Militär- und Atommacht. In 2018 gaben die USA laut dem Bericht des „Stockholm International Peace Research Institute“
} 
dieser Staaten sowie die Sabotage ihrer eurasistischen Initiativen („Eurasische Wirtschaftsunion“" von RU und „Seidenstraße Wirtschaftsgürtel“ von China) ist das erklärte Ziel der USA. Somit erweitern sich die Grenzen des New Great Games bis einschließlich China. Sowohl die russische als auch die chinesische Initiative beinhaltet ZA. Das Ziel der rivalisierenden Akteure in diesem Spiel kann als „Vorherrschaft in Eurasien“ definiert werden. Die Relevanz Eurasiens für die USA schrieb Brzezinski wie folgt:

\begin{abstract}
„Eine Macht, die Eurasien beherrscht, würde über zwei der drei höchstentwickelten und wirtschaftlich produktivsten Regionen der Erde gebieten. Ein Blick auf die Landkarte genügt, um zu erkennen, daß die Kontrolle über Eurasien fast automatisch die über Afrika nach sich zöge und damit die westliche Hemisphäre und Ozeanien gegenüber dem zentralen Kontinent der Erde geopolitisch in eine Randlage brächte. [...] Nahezu 75 Prozent der Weltbevölkerung leben in Eurasien, und in seinem Boden wie auch Unternehmen steckt der größte Teil des materiellen Reichtums der Welt. Eurasien stellt 60 Prozent des globalen Bruttosozialprodukts und ungefähr drei Viertel der weltweit bekannten Energievorkommen. [...] Eurasien beherbergt auch die meisten der politisch maßgeblichen und dynamischen Staaten. Die nach den USA sechs größten Wirtschaftsnationen mit den höchsten Rüstungsausgaben liegen in Europa und Asien. Mit einer Ausnahme sind sämtliche Atommächte und alle Staaten, die über heimliche Nuklearwaffenpotentiale verfügen, in Eurasien zu Hause. Die beiden bevölkerungsreichsten Anwärter auf regionale Vormachtstellung und weltweiten Einfluss sind in Eurasien. [...] Eurasien ist mithin das Schachbrett, auf dem der Kampf um globale Vorherrschaft auch in Zukunft ausgetragen wird" (Brzezinski 2001: 54, 57).
\end{abstract}

Eurasien ist heute wirtschaftlich viel relevanter als im Jahr dieses Zitates. ${ }^{223}$ ZA bekommt für die rivalisierenden Akteure sowohl eine wirtschaftliche Relevanz, weil die russischen und chinesischen Initiativen die Region beinhalten; als auch eine strategische Relevanz, weil die Region an RU, China und Iran angrenzt. Aufgrund dieser Tatsache wird das berüchtige Zitat von Sir Halford Mackinder (1861-1947) sehr oft verwendet:

„Wer über Osteuropa herrscht, beherrscht das Herzland [Russland, Zentralasien ${ }^{224}$ ]: Wer über das Herzland herrscht, beherrscht die Weltinsel [Eurasien]. Wer über die Weltinsel herrscht, beherrscht die Welt. “ (Mackinder; zit. nach Brzezinski 2001: 63)

(SIPRI) 649 Mrd. US-Dollar für ihr Militär aus; gefolgt von China mit 250 Mrd. US-Dollar und RU mit 61,4 Mrd. US-Dollar (Jeppesen 2019).

${ }^{223}$ Brzezinskis Buch ,The Grand Chessboard: American Primacy and Its Geostrategic Imperatives” wurde das erste Mal 1997 veröffentlich. Ich benutzte in dieser Arbeit die deutsche Ausgabe von 2001. Derzeit (2019) ist Eurasien für die USA viel relevanter als 1997.

${ }^{224}$ Nach Grewlich (2011: 29) ist unter dem Herzland ZA zu verstehen. 
RU versucht die TR durch die Pipelines und Einladungen zur EAWU-Mitgliedschaft sowie andere lukrative Geschäfte auf seine Seite zu ziehen. Die EAWU ist allerdings für die TR momentan keine Option.

\subsection{Energiepolitische Rivalität zwischen der Türkei und Russland um das kaspische Erdöl}

Der wichtigste Energieträger weltweit ist weiterhin Erdöl mit einem Anteil von rund 32 \% am globalen Primärenergieverbrauch (Bundesanstalt für Geowissenschaften und Rohstoffe (BGR) 2015: 35). ${ }^{225}$ Da das Kaspische Meer ein Binnenmeer ist und keine Verbindung zu internationalen Häfen hat, kamen für den Transport des zentralasiatischen Erdöls drei mögliche Pipelinerouten in Frage: Zum russischen Schwarzmeerhafen Noworossijsk (BakuNoworossijsk), von dort aus mit den Öltankern durch die türkischen Meerengen ins Mittelmeer; über den Iran in den türkischen Mittelmeerhafen Ceyhan oder über den Iran nach Afghanistan und Pakistan an den Indischen Ozean (Kolobov/Kornilov/Özbay 2006: 175). Die USA und ihre westlichen Verbündeten unterstützten aufgrund der Sanktionen gegen den Iran die Projekte mit dem Iran nicht. Die Route nach RU war aufgrund der geographischen Nähe die rentabelste. Die westliche Achse suchte allerdings eine Alternativroute, die RU und den Iran umgehen sollte. Michael Croissant zufolge ist das Ziel der USA, die postsowjetischen Staaten in den Westen zu integrieren, die geopolitische Karte Eurasiens $\mathrm{zu}$ bestimmen und hier den Einfluss RUs und des Iran einzudämmen. Schlüsselstaaten für die US-Kaukasus- und Zentralasienpolitik sind nach Croissant die TR und Aserbaidschan (Croissant in: Kolobov/Kornilov/Özbay 2006: 185).

Der kaukasische Staat Armenien bot sich dem Westen als Transitland für das aserische und kasachische Erdöl aufgrund seiner guten geographischen Lage an. Aufgrund des KarabachKrieges (1992-1994) zwischen Aserbaidschan und Armenien aber waren die beiden Staaten verfeindet, so dass diese Route nicht in Frage kam. Während des Karabach-Krieges schloss

\footnotetext{
225 „Sämtliche Mitgliedsstaaten der OPEC befinden sich unter den 20 führenden Ländern und umfassen knapp 70 \% der globalen Reserven“ (Bundesanstalt für Geowissenschaften und Rohstoffe (BGR) 2015: 36). Mit den Reserven des GUS-Raums zusammen haben sie etwa 80 \% der Erdölreserven der Welt (ebd.: 107). „Nur etwa $20 \%$ der globalen Erdölreserven befinden sich im Besitz privater Erdölunternehmen, während die restlichen 80 \% von staatlichen Firmen kontrolliert werden“ (IEA 2013, In: Bundesanstalt für Geowissenschaften und Rohstoffe (BGR) 2015: 36). „Nach wie vor liegen die wichtigsten Förderregionen im Nahen Osten, in Nordamerika und in den GUS-Staaten. Knapp 68 \% der weltweiten Erdölproduktion stammen aus diesen Regionen“ (Bundesanstalt für Geowissenschaften und Rohstoffe (BGR) 2015: 36).
} 
die TR 1993 ihre Grenze zu Armenien. ${ }^{226}$ Auch die historisch bedingten Probleme zwischen der TR und Armenien über den Völkermord waren ein Faktor bei der türkischen Entscheidung. Daher gewann das südkaukasische Georgien für die TR und die USA als Transitland für das Erdöl und Erdgas des Kaspischen Meeres an Relevanz. ${ }^{227}$ Die westliche Alternativroute sollte das aserbaidschanische und kasachische Erdöl (d. h. aus den beiden Turkstaaten) über Georgien in den türkischen Mittelmeerhafen Ceyhan transportieren.

Die TR führte früh, seit 1992, mit Aserbaischan und Kasachstan Gespräche für den Transport des kaspischen Erdöls in den türkischen Hafen Ceyhan (Kolobov/Kornilov/Özbay 2006: 177). Die fossilen Brennstoffe der Turkstaaten wollte sie innerhalb der „Türkenwelt““ managen. Sie unterschrieb am 9. März 1993 mit Aserbaidschan ein Abkommen für die Erdölpipeline aus Baku nach Ceyhan (ebd.: 181). Im Juni 1993 wurde der pantürkistisch ausgerichtete aserbaidschanische Präsident Ebulfeyz Eltschibej kurz vor dem Beginn der Pipelineverhandlungen mit amerikanischen und englischen Konzernen durch einen vermutlich von RU und Iran unterstützten Putsch gestürzt. Eltschibej pflegte intensive Kontakte zur TR, setzte sich für die türkischen Interessen im postsowjetischen Raum ein und versuchte dabei RU möglichst auszuklammern. ${ }^{228}$ Der Sturz des Türkei-Freundes Eltschibejs erschwerte die Verhandlungen um die westlichen Pipelineprojekte. Um ihr Erdölpipelineprojekt durchzusetzen, erklärte die TR im August 1993, dass eine neue Meerengen-Satzung ${ }^{229}$ nötig sei, was den russischen Interessen entgegenstand. Als Grund gab sie die Gefahr von Umweltkatastrophen durch potentielle Unfälle russischer Öltankerbei der Durchfahrt durch die türkischen Meerengen (Istanbul und Canakkale) an. RU kritisierte diese Erklärung, weil RU für die Verschiffung seines Erdöls aus Noworossijsk auf die türkischen Meerengen angewiesen war. Die neue Satzung wurde am 23. November 1993 beschlossen und trat am 1. Juli 1994 in Kraft (ebd.: 168). Für RU bedeutete die türkische

\footnotetext{
${ }^{226}$ Armenien wurde von der TR in den 1990er Jahre einerseits als geographisches Hindernis zwischen der TR und den Turkrepubliken, andererseits als Hindernis für die Pipelines aus dem Kaspischen Meer in die TR angesehen (Balci 2011: 306).

${ }^{227}$ Die TR sieht Georgien des Weiteren als „Brücke“ zu der „Türkenwelt“, zu Aserbaidschan und ZA.

${ }^{228}$ Eltschibej wurde nach den Präsidentschaftswahlen im Juni 1992 zum Präsidenten gewählt und verhielt sich zu Gunsten der TR und zu Ungunsten des Iran und RUs. Er wollte den Nordiran, in der eine große aserische Minderheit lebt, mit Aserbaidschan vereinigen und verweigerte den Beitritt Aserbaidschans in die GUS (Kolobov/Kornilov/Özbay 2006: 143).

${ }^{229}$ Das Montreux-Abkommen (unterschrieben am 20. Juli 1936) regelt den Schiffsverkehr durch die türkischen Meerengen. Artikel 2 dieses Abkommens schreibt die ungehinderte Passage der Handelsschiffe durch die Meerengen in Friedenzeiten vor (Baskent Üniversitesie o. J.: 3).
} 
Entscheidung die Verletzung des Montreux-Meerengenabkommens und wirtschaftlichen Verlust.

Die Satzungsänderung des Montreux-Abkommens hatte im Grunde genommen nichts mit dem Schutz der türkischen Meerengen bzw. der Umwelt zu tun. Es war eher eine politisch geprägte Entscheidung, um das kaspische Erdöl unter Umgehung RUs über das türkische Territorium nach Westen $\mathrm{zu}$ transportieren. In dieser Haltung hatte die TR die volle Zustimmung der USA. In ihrem „Report of the National Energy Policy“ (National Energy Policy Development Group 2001: 8-12) vom Mai 2001 beschrieben die USA die Unterstützung der Erdölförderung in Kasachstan und die Bestimmung der Transportroute als Ziel. Mit den Öltankern sollte Kasachstan sein Erdöl an die geplante westliche Erdölpipeline Baku-Tiflis-Ceyhan verschiffen. Das BTC-Vorhaben begründeten die Vertragspartner als umweltschonend, weil laut der USA die türkischen Meerengen durch die russischen Öltankerunfälle verschmutzt würden (ebd). Kolobov/Kornilov/Özbay (2006: 145) zufolge versuchte die TR mit der Satzungsänderung RU auch hinsichtlich des Karabach-Konfliktes zu einer Lösung zu zwingen.

Der ölreiche Turkstaat Aserbaidschan versuchte einerseits durch die westliche Erdölpipeline RU zu umgehen und sich neue Wirtschaftspartner zu schaffen; andererseits die geplante westliche Erdölpipeline u. a. als politisches Mittel für die Lösung der Karabach-Frage einzusetzen. Aserbaidschan schloss im September 1994 durch „Azerbaijan International Operating Company“ (AIOC) den „Jahrhundertvertrag“ mit den westlichen und westlich geprägten Staaten. ${ }^{230}$ Das Konsortium bestand unter der Führung von British Petrol (Großbritannien) aus Chevron (USA), SOCAR (Aserbaidschan), INPEX (Japan), Statoil (Norwegen), ExxonMobile (USA), TPAO (Türkei), Devon (USA), ITOUCHU (Japan) und Amerada Hess (USA). Gumppenberg (2010: 168) zufolge regelten die USA mit diesem Vertrag die Ausbeutungsrechte für 30 Jahre und schufen den ersten Schritt für die Realisierung der BTC. Nach dem ehemaligen türkischen Außenminister Ismail Cem hatte die westliche Erdölleitung BTC auch einen strategischen Wert: Durch sie konnten Aserbaidschan und Georgien mit dem Westen verbunden werden (in: Kolobov/Kornilov/Özbay 2006: 177).

\footnotetext{
${ }^{230}$ Die Präsidenten Kasachstans und Turkmenistans kritisierten das aserbaidschanische Vorgehen. Nach ihnen hätte Aserbaidschan zunächst versuchen müssen, sich mit den anderen Anrainerstaaten des Kaspischen Meers zu einigen (Caman 2005: 289).
} 
Die USA waren energiepolitisch früh am Kaspischen Meer tätig. Sie beriefen einen Botschafter für Kaspische Fragen, der regelmäßig die Region bereisen und amerikanische Interessen vertreten soll (Dschafarow 2009: 42). In Kasachstan waren seit 1993 die großen US-Erdölfirmen Chevron, Texaco und ExxonMobil in den Ölfeldern Tengiz und Karachaganak tätig. Am 29. Oktober 1998 trafen die USA die Präsidenten Kasachstans, Aserbaidschans, Georgiens und der TR in Ankara und erklärten gemeinsam die „Deklaration von Ankara“ (Kolobov/Kornilov/Özbay 2006: 184). Für den sicheren Transport sahen die USA die PKK in Ost- und Südosten der TR als sicherheitspolitisches Problem für den Bau der BTC an, da diese Pipeline teilweise durch die kurdisch geprägten Städte verlaufen sollte, in denen die PKK als aktiv eingestuft wurde. Laut Kolobov/Kornilov/Özbay (2006: 185) wurde der PKK-Führer Abdullah Öcalan im Februar 1999 in Nairobi deshalb mit amerikanischer Unterstützung festgenommen. Die Verhaftung von Abdullah Öcalan beendete die PKK-Anschläge schlagartig. D. h. die Pipelines bringen dem Transportland mehr Sicherheit und Unterstützung des Exportlandes und der Abnehmer.

Im April 1999 wurde die Baku-Supsa(georgischer Schwarzmeerhafen)-Pipeline offiziell eröffnet. Am 17. November 1999 unterschrieben Georgien, die TR und Aserbaidschan unter US-Aufsicht in Istanbul das Abkommen für den Bau der BTC. Am 28. April 2000 wurden die letzten Dokumente für die BTC in Washington unterschrieben (ebd.: 186). ${ }^{231}$ Am 1. März 2001 verhandelten die TR, Georgien und Aserbaidschan wieder mit amerikanischer Unterstützung mit Kasachstan. Laut der Vereinbarung sollte Kasachstan ab 2005 in die BTC Erdöl transportieren, am Anfang 7,5 Mio. Tonnen, anschließend 20 Mio. Tonnen Erdöl (Atmaca 2006). Am 25. Mai 2005 wurde die BTC offiziell eingeweiht. Seit 2008 transportiert Kasachstan mit Öltanker Erdöl nach Aserbaidschan, welches dort in die BTCPipeline eingespeist wird oder von dort aus per Zug an den georgischen Hafen Batumi transportiert wird. ${ }^{232}$

Kasachstan kooperiert energiepolitisch eng auch mit RU und China. Die Caspian Pipeline Consortium (CPC) verbindet seit 2001 die kasachischen Ölreserven in Tengiz mit dem

\footnotetext{
${ }^{231}$ Die sicherheitspolitischen Probleme in Tschetschenien stellte die TR immer als Gegenargument für die kaspischen Pipelines nach RU. 2000 stellte RU die neue Erdölpipeline fertig, die durch Dagestan lief und somit Tschetschenien umgeht (Kolobov/Kornilov/Özbay 2006: 186) dar. Trotzdem führte die westliche Achse ihre Aktivitäten für die Durchsetzung der BTC-Pipeline weiter, welche RU umgeht.

${ }^{232}$ Die jährliche Kapazität der BTC ist bis zu 50 Mio. Tonnen Erdöl. Die Transitgebühren brachten der TR jährlich, je nach der Menge des exportierten Erdöls, zwischen 250 bis 300 Mio. Dollar (O. V. 2006: BTC Boru Hatti ...).
} 
russischen Hafen Noworossijsk. 2017 wurden 55,1 Mio. Tonnen Öl durch diese Leitung transportiert (AzerNews 2018). Die Anteilhaber der CPC sind (Caspian Pipeline Consortium o. J. a) nicht nur die russischen und kasachischen Firmen, sondern auch die amerikanischen, englischen sowie mit verhältnismäßig kleinerem Anteil italienische und niederländische Firmen: mit $31 \%$ Russland (24\% für Transneft, 7\% für CPC Company), mit 20,75\% Kasachstan (19\% für JSC National Company „KazMunaiGaz“ und 1,75 \% Kazakhstan Pipeline Ventures LLC), mit 15 \% die amerikanische Chevron Caspian Pipeline Consortium Company, mit 12,5 \% russisch-amerikanische, später russisch-englische Firma LUKARCO B.V., gefolgt mit jeweils 7,5 \% von Mobil Caspian Pipeline Company und russischniederländische Rosneft-Shell Caspian Ventures Ltd., mit $2 \%$ die italenische Eni International (N.A.) N.V. S.ar.1. and Oryx Caspian Pipeline LLC (1.75\%) (Caspian Pipeline Consortium o. J. b). Wie diese Anteile zeigen, hat RU den größten Anteil an der CPC. Die Atyrau-Samara Pipeline ist eine andere wichtige kasachische Ölpipeline nach RU, die im Jahr etwa 15 Mio. Tonnen Öl transportiert (O. V. 2017: A new route ...). Die größten Anteilhaber sind die kasachische KazMunaiGas und die russische Transneft.

China ist ein weiterer großer Abnehmer des kasachischen Erdöls und Investor im Erdölbereich. Kazakhstan-China Pipeline LLP (KCP) gehört Kasachstan und China paritätisch und besteht aus zwei Pipelines: Die Pipeline vom kasachischen Atasu zu dem chinesischen Alashankou (Atasu-Alashankou-Ölpipeline) wurde im Dezember 2005 fertig gestellt und liefert seit 2006 Erdöl nach China. Die zweite Linie ist die Kenkiyak-KumkolÖlpipeline. Sie liefert China seit 2009 Erdöl. 2017 transportierten sie 12 Mio. Tonnen Erdöl nach China (KazTransOil 2018). Die Erdölpipeline Kenkiyak - Atyrau gehört zu 51 \% dem kasachischen KazTransOil und zu $49 \%$ der chinesischen CNPC Exploration and Development Company Ltd. Diese Pipeline hat 6 Mio. Tonnen Kapazität im Jahr (ebd.). Bei dem Besuch des chinesischen Präsidenten Xi Jinping in Kasachstan im September 2013 wurde ein Vertrag über eine chinesische Beteiligung am Erdölfeld Kashagan unterzeichnet.

\subsection{Energiepolitische Rivalität zwischen der Türkei und Russland um das kaspische Erdgas}

Erdgas blieb im Jahr 2014 mit einem Anteil von 23,7 \% am globalen Primärenergieverbrauch hinter Erdöl (32\%) und Kohle (30\%) drittwichtigster Energieträger (Bundesanstalt für Geowissenschaften und Rohstoffe (BGR) 2015: 35, 39). Die USA 
versuchten mit ihren Verbündeten, wie zuvor beim Erdöl, auch das kaspische Erdgas ${ }^{233}$ der postsowjetischen Turkstaaten, unter Umgehung RUs und des Irans in den Westen zu transportieren. Besonders reich an Erdgas ist Turkmenistan (siehe Kap. 5, Einleitung). Die USA versuchten gleichzeitig, ein östliches Pipelineprojekt TAP (Turkmenistan-AfghanistanPakistan) durchzusetzen. Für das Ziel unterschrieb die US-Energiefirma UNOCOL mit der saudischen Energiefirma Delta Ö1 1995 zusammen ein Erdgasabkommen mit Turkmenistan. Aufgrund der sicherheitspolitischen Probleme in Afghanistan wurde dieses Projekt allerdings von keiner Bank unterstützt und konnte deshalb nicht verwirklicht werden. ${ }^{234}$ Turkmenistan verhandelte 1996 mit dem Iran und der TR über eine Erdgaspipeline nach Europa (Turkmenistan-Iran-Türkei Pipeline). Wegen der Beteiligung Irans übten die USA Druck aus und verhinderten dieses Vorhaben. Die USA unterstützten als Alternative zu dieser Pipeline eine Transkaspische Pipeline durch das Kaspische Meer und den Südkaukasus in die TR. RU unterschrieb im Mai 2000 mit Turkmenistan einen Vertrag über die Erhöhungsmenge des turkmenischen Erdgases. Ab diesem Moment stand fest, dass Turkmenistan für das westliche Projekt Transkaspische Pipeline kein Erdgas mehr übrig hat (Ulcenko 2003: 195-196).

Die TR unterschrieb mit dem Iran 1996 ein Erdgasabkommen unter dem religiöskonservativen Ministerpräsidenten der TR, Necmettin Erbakan. Sie bezieht seit 2001 Erdgas aus dem Iran, das heute etwa $20 \%$ ihres gesamten Erdgasimportes ausmacht. Erbakan behauptete bei einer Rede 2009 im Iran, dass der damalige US-Botschafter, Marc Grossman, ihn kurz nach seiner Amtsübernahme besucht und ihm 6 Punkte diktiert habe, nach denen er als türkischer Ministerpräsident außenpolitisch zu handeln habe (Refah Ajans 2014). Das jährliche Handelsvolumen solle 50 Mio. Dollar nicht überschreiten und Erbakan dürfe den Iran niemals besuchen (ebd.). Erbakan handelte aber dem zuwider und machte als türkischer Ministerpräsident seinen ersten Besuch im August 1996 in den Iran und unterschrieb mit dem Iran ein Erdgasabkommen im Wert von 2,5 Mrd. US-Dollar. Laut Erbakan hat daraufhin der US-Außenminister Warren Christopher dem US-Botschafter Grossman in Ankara beauftragt, die Regierung Erbakans durch das türkische Militär von der Regierung

\footnotetext{
${ }^{233}$ Weltweit stieg der Erdgasverbrauch 2014 um rund 1,4\% (Vorjahr 1,3\%) auf $3.483 \mathrm{Mrd}^{3} \mathrm{~m}^{3}$ an. Der Zuwachs war damit in der gleichen Größenordnung wie ein Jahr zuvor. Etwa 80 \% der globalen Reserven befinden sich in den Ländern der OPEC und der GUS (Bundesanstalt für Geowissenschaften und Rohstoffe (BGR) 2015: 40).

234 Turkmenistan kündigte erst 2014 den Baubeginn für 2015 an. Diese Pipeline soll weiterhin vom pakistanischen Häfen aus das verflüssigte Erdgas (Liquified Natural Gas (LNG)) nach Japan, Südkorea und Taiwan transportieren.
} 
zu stürzen (Refah Ajans 2014). Nach Yavuz (1998) war der Hauptgrund dieses „postmodernen Putsches“ Erbakans Anti-Nato-Haltung, was bis dahin in der türkischen NATO-Geschichte einmalig war. Am 28. Februar 1997 zwang das türkische Militär Erbakan zum Rücktritt. Er musste im Juni 1997 zurücktreten. Sein Nachfolger wurde Mesut Yilmaz.

Mesut Yilmaz unterschrieb im Dezember 1997 mit RU während des Türkei-Besuchs des russischen Ministerpräsidenten Wiktor Tschernomyrdin am 15-16. Dezember ${ }^{235}$ einen Vertrag für die Blue-Stream Erdgasleitung, die durch das Schwarze Meer in die türkische Stadt Samsun führen sollte. Tschernomyrdin verwendete während dieses Besuches das erste Mal die Bezeichnung ,strategische Partnerschaft“ zwischen den beiden Staaten im Falle einer gelungenen wirtschaftlichen Zusammenarbeit. Yilmaz erklärte später, dass die USA gegen das Projekt Blue-Stream-Pipeline waren und er zweimal von dem US-Botschafter in Ankara besucht und ihm Konsequenzen angedroht wurden (O. V. 2010: Y1lmaz: Mavi Akım'dan ...). Laut Yilmaz versuchten die USA anderen Ländern (z. B. der TR) das Erdgas der unter ihrer Kontrolle stehenden Förderländer (wie z. B. Katar) als Flüssiggas (LNG) zu verkaufen. Deshalb sollten sie versucht haben, die Blue-Stream zu sabotieren (ebd.). Da eine Erdgaspipeline aus RU weniger als die Hälfte der LNG-Import kostete, handelte er nach eigenen Aussagen im Interesse der TR (ebd.). Yilmaz berichtete, dass er deshalb von einigen türkischen Journalisten als „Verräter gegen die Türkenwelt“ bezeichnet wurde, weil er durch diese Entscheidung das Vorhaben der Erdgaspipelines „der Türkstaaten“ (aus Turkmenistan via Aserbaidschan in die TR) verworfen hatte (ebd.). Ihm sei des Weiteren vorgeworfen, während der Verhandlungen mit RU korrupt gewesen zu sein (ebd.). Die Blue-Stream setzte sich trotz aller Widerstände durch und liefert seit 2003 Erdgas (offizielle Einweihung 2005) in die TR. Eine weitere russisch-türkische Erdgaspipeline ist die West-Pipeline. Das Projekt wurde zwischen der TR und der Sowjetunion bereits 1984 unterschrieben und liefert seit 1987 Erdgas in die TR. Beide russischen Leitungen decken etwa 55-65 \% des gesamten Erdgasbedarfes der TR ab.

Die TR unterschrieb im März 2001 Verträge für die BTE. Diese Pipeline liefert seit Juli 2007 Erdgas in die TR und seit November 2007 nach Griechenland im Rahmen des Projekts der Europäischen Union INOGATE (Türkiye Cumhuriyeti Disisleri Bakanligi o. J. b). Ein

${ }^{235}$ Kolobov/Kornilov/Özbay (2006: 190) zufolge wurde Tschernomyrdin von Yilmaz eingeladen (2006: 191192), um der EU zu zeigen, dass sie nicht die einzige Alternative für die türkische Außenpolitik ist. Die TR schätzte, dass der Europäische Rat bei der Tagung am 12.-13. Dezember 1997 in Luxemburg die TR nicht als Beitrittskandidat nennen wird. 
weiteres alternatives Erdgasprojekt war die NABUCCO Pipeline. In 2002 wurde sie durch die österreichische Firma OMV initiert, die unter Umgehung RUs das kaspische Erdgas und das Erdgas aus dem Nahen Osten (Irak, Iran) durch die TR über den Balkan und Ungarn bis nach Österreich transportieren sollte. Für das Projekt wurde zwischen der türkischen BOTAS und mit dem österreichischen OMV im Mai 2002 ein Zusammenarbeit-Protokoll unterschrieben. Die Pipeline sollte durch ein Konsortium finanziert, gebaut und betrieben werden.

Das Pipeline-Projekt NABUCCO wurde durch die Regierungschefs der Transitländer, die TR, Bulgarien, Rumänien, Ungarn und Österreich im Juli 2009 in Ankara unterschrieben und durch die Parlamente der Vertragsländer im März 2010 ratifiziert. Das Ziel war eine Alternative Erdgaspipeline zu RU zu bauen, da über die Hälfte des europäischen Gasbedarfs durch RU gedeckt wird. Die NABUCCO-Pipeline $(3300 \mathrm{~km}$, davon $2000 \mathrm{~km}$ über die TR unter Umgehung RU) sollte ab 2014 jährlich mindestens 25 Mrd. m³ Gas, ab 202031 Mrd. $\mathrm{m}^{3}$ Erdgas aus der kaspischen Region und dem Nahen Osten nach Europa transportieren. Die TR unterschrieb nach einem Monat des NABUCCO-Vertrages während Putins Türkei-Reise im August 2009 (Aras 2009b) auch den Erdgasvertrag für die South-Stream-Pipeline mit RU. Diese Pipeline sollte das russische Erdgas wiederum unter Umgehung der Ukraine über die türkischen Hoheitsgewässer im Schwarzen Meer durch Bulgarien, Serbien, Ungarn, Slowenien und Österreich nach Europa transportieren. Kramer schrieb schon 2010, dass das NABUCCO-Projekt zur Isolation RUs gedacht war und dieses Projekt solange in der Schwebe bleiben wird, bis seine Betreiber unmissverständlich erklären, dass sie die russische Alternative verwerfen (Kramer 2010b: 6, 32, 35). Aber die TR verwarf die russische Alternative nicht. Erdogan sagte in einer Pressekonferenz, dass NABUCCO und der South-Stream keine Konkurrenten seien. Sie sollen zur Diversifizierung der Energiequellen dienen (O. V. 2009: Rusya ile Türkiye ...). Tatsache war aber, dass beide Projekte miteinander auf denselben Markt, d. h. dem Europäischen, konkurrierten (Kramer 2010b: 32). Beide Projekte sind letztendlich gescheitert.

NABUCCO ist nicht nur wegen der türkischen Haltung gescheitert. Das Projekt fand keine finanzielle Unterstützung durch wirtschaftlich starke europäische Staaten wie Deutschland, da dieses mit RU seine Gasangelegenheiten direkt verhandelt (z. B. über die Nord-StreamPipeline) oder Italien und Frankreich. Des Weiteren tauchten zu dieser Zeit andere Erdgasprojekte auf, die rentabler erschienen, wie die Trans-Adria-Pipeline (TAP). Im 
September 2010 schlug BP das Erdgasprojekt SEEP vor und im Dezember 2011 unterschrieben die TR und Aserbaidschan das Pipelineprojekt Transanatolische Pipeline (TANAP). Von diesen Projekten setzte sich TANAP durch: Der Baubeginn war im März 2015. TANAP soll das aserbaidschanische Erdgas in die TR leiten und von dort aus an die geplante Erdgaspipeline TAP (durch Griechenland, Albanien, Adriatisches Meer nach Süditalien) führen (TANAP 2016: Hakkimizda). Ende 2019 wurde TANAP mit der TAP verbunden. Die South-Stream ist dagegen aufgrund der Ukraine-Krise und auf Druck der EU auf die möglichen europäischen Transitländer gescheitert. Im Dezember 2014 erklärte Putin das Ende dieses Projektes. Die TR und RU unterzeichneten im Oktober 2016 in Istanbul in Anwesenheit Erdogans und Putins ein Regierungsabkommen für den Bau der Erdgaspipeline TurkStream. Mit TurkStream will RU die Ukraine bei der Belieferung der EU mit Erdgas umgehen. Turkstream wurde Ende 2019 eingeweiht.

China ist der größte Abnehmer des turkmenischen Erdgases. Die Central Asia Gas Pipeline $(C A P G)$ besteht aus 4 Erdgaspipelines. Die Linie A (Einweihung Dezember 2009), B (Einweihung Oktober 2010) und C (Einweihung Mai 2014) verlaufen parallel zueinander von Turkmenistan, durch Usbekistan und Kasachstan ins chinesische Xinjiang. Insgesamt transportierten sie $201555 \mathrm{Mrd} . \mathrm{m}^{3}$ Erdgas nach China, d. h. $20 \%$ des chinesischen Gasbedarfs. An der Linie D (über Tadschikistan und Kirgisistan nach China) wird aktuell noch gebaut. Mit ihrer Inbetriebnahme werden alle Linien (A, B, C und D) insgesamt 85 Mrd. $\mathrm{m}^{3}$ Erdgas nach China transportieren. Chinesische Importe machten 201675 \% der turkmenischen Gesamtexporte aus. Mit diesem Anteil befand sich China auf dem 1. Platz des turkmenischen Gesamtexportes. Der Iran ist ein weiterer wichtiger Energiepartner Turkmenistans. Das Land hat mit dem Iran drei Gas-Pipelines, die insgesamt etwa $20 \mathrm{Mrd}$. $\mathrm{m}^{3}$ jährliche Kapazität haben: Korpeje-Kordkuy-Pipeline (Inbetriebnahme 1997), ArtykLotfabad-Gaspipeline (Inbetriebnahme 2000) und Dauletabad-Sarakhs-Khangiran-Pipeline (Inbetriebnahme 2010). Die Lieferungen in den Iran wurden allerdings nach Unstimmigkeiten über angebliche iranische Zahlungsrückstände am 01.01.2017 ausgesetzt (Auswärtiges Amt 2018f).

Kasachstan ist nicht nur ein Transitland für das turkmenische und usbekische Erdgas nach China, sondern selbst ein Erdgas-Lieferant für China. Seit 2017 liefert das Land jährlich 5 Mrd. $\mathrm{m}^{3}$ Erdgas nach China. Des Weiteren ist das Land ein Transitland nach RU. Die östliche Pipeline von Central Asia Center Pipeline (CAC) transportiert hauptsächlich das 
turkmenische Erdgas und die westliche Pipeline noch das usbekische Erdgas nach RU. Sie beide transportierten insgesamt 65 Mrd. $\mathrm{m}^{3}$ Erdgas nach RU. Seit dem 01.01.2016 stellte RU allerdings die Gaskäufe aus Turkmenistan ein (Auswärtiges Amt 2018f). Von Usbekistan aus gibt es weitere Erdgaspipelines. Die Buchara-Ural-Pipeline verläuft durch Kasachstan nach RU. Die Taschkent-Schymkent-Bischkek-Almati-Pipeline verläuft innerregional von Usbekistan durch Kirgisistan in die kasachische Stadt Almati. Das US-Projekt TAPI (Turkmenistan-Afghanistan, Pakistan und Indien) ist bereits in Bau.

\subsection{US-Wirtschaftspolitik in Zentralasien}

Nach der Auflösung der Sowjetunion fingen die USA an, im Kaspischen Raum energiepolitisch aktiv zu werden. Vorher war das aufgrund der Blockkonfrontation mit der Sowjetunion nicht möglich. Die großen US-Erdölfirmen Chevron, Texaco und ExxonMobil sind sehr früh, seit 1993 in den kasachischen Ölfeldern Tengiz und Karachaganak tätig geworden (siehe hierzu Kap. 5.1 und Kap. 5.2). Die US-Wirtschaftspolitik in ZA kann unter zwei Punkten zusammengefasst werden:

1) Die Kontrolle der fossilen Brennstoffe, die politische und wirtschaftliche Macht bedeuten.

Das ist für die USA wichtig, denn durch die Kontrolle der fossilen Brennstoffe können die USA einerseits Energiequellen sichern und wirtschaftliche Gewinne erzielen. Andererseits können sie dadurch die energieabhängigen östlichen und westlichen Verbündeten (Ganser 2015: 282) sowie andere energiehungrigen Staaten (wie z. B. China) kontrollieren. Weiterhin können sie den Erhalt des „Dollars als Weltleitwährung“ sichern. Die Ölpreise, bzw. Erdgaspreise sind größtenteils an den Dollar gekoppelt und werden in Dollar notiert und bezahlt. Und solange der Dollar als Weltleitwährung fungiert, sind die Staaten als Zahlungsmittel auf Dollar-Reserven angewiesen, ${ }^{236}$ wobei in letzter Zeit China, RU und der Iran beim Energiehandel zunehmend ihre Nationalwährung nutzen. Wenn z. B. China die fossilen Brennstoffe aus RU in Yuan bezahlt, muss Peking weniger US-Dollar als Währungsreserven halten. Yuan kann RU wiederum nutzen, um aus China zu importieren.

\footnotetext{
${ }^{236}$ Seit der Etablierung des Währungssystems von Bretton Woods im Jahr 1944 ist der Dollar die mit Abstand wichtigste Welthandelswährung - und auch Reservewährung, da jedes Land Dollarreserven halten muss, um Zugang zum Ölmarkt zu haben. Nach dem Ende von Bretton Woods und der Etablierung des inoffiziellen „Petrodollar“-Systems in den 1970ern ist die Verbindung zwischen Dollar und Öl nur noch enger geworden (O. V. 2014: Währungen: China und Russland ...).
} 
Dadurch wird sich der Yuan wahrscheinlich neben dem Dollar und dem Euro als dritte Reservewährung etablieren (O. V. 2014: Währungen: China und ...).

2) Die Verhinderung der politisch, wirtschaftlich und militärischen Entwicklungen der möglichen Rivalen (RU und China) sowie ihrer wirtschaftlichen Bündnissprojekte (EAWU von $R U$ und Seidenstraße-Wirtschaftsgürtel von China). Beide Projekte beinhalten ZA. Sollten diese eurasistische Projekte erfolgreich sein, ist die Wahrscheinlichkeit groß, dass die europäischen und asiatischen Partner der USA zunehmend mit RU und China kooperieren. Dadurch können die USA ihren politischen Einfluss und ihre wirtschaftliche und militärische „Überlegenheit“ über sie verlieren. Eurasien nannte der US-amerikanische Geopolitiker Zbigniew Brzezinski daher bereits 1997 als „Schachbrett, auf dem der Kampf um globale Vorherrschaft auch in Zukunft ausgetragen wird.“ (Brzezinski 2001: 57). ZA steht wie ein Verbindungszentrum zwischen RU, China und dem Iran.

Energiepolitisch arbeiten die USA mit der TR eng zusammen. Dabei ist ihr Ziel, die kaspischen fossilen Brennstoffe unter Umgehung RUs und Irans via TR nach Europa zu transportieren. Des Weiteren sind sie gegen die türkisch-russische und türkisch-iranische energiepolitische Zusammenarbeit (siehe Kap. 5.1 und Kap. 5.2). Allerdings sind diese beiden Staaten wichtigste Energieexporteure der TR. Die TR importierte 2015 etwa $60 \%$ ihres Erdgases aus RU und 20 \% aus dem Iran (O. V. 2016: 2015 Ekim Döneminde ...). Auch beim Erdöl steht RU mit einem Anteil von 23 \% nach dem Irak (29 \% der türkischen Erdölimporte) auf dem Platz 2 der türkischen Energielieferanten. Gefolgt vom Iran mit einem Anteil von $13 \%$ (ebd.). Diese Anteile sind bis heute gleich geblieben. Mit der Inbetriebname des Turkstream wird die TR mehr Erdgas aus RU importieren als jetzt. Bis jetzt konnte die westliche Achse aus dem Kaspischen Raum die Pipelines BTC, BTE, TANAP, TAP und eine Erdölvereinbarung mit Kasachstan verwirklichen (siehe Kap. 5.1 und Kap. 5.2).

Im Verhältnis zum Erdöltransport sind die Staaten stärker auf die Erdgaspipelines angewiesen, weil die Transferkosten des Erdgases durch Pipelines im Verhältnis zu LNGTransport viel günstiger sind. ${ }^{237}$ Aufgrund dessen ist für die Akteure neben der Kontrolle und Energiesicherheit auch die Routenbestimmung sehr wichtig. Sehr reich an fossilen

\footnotetext{
${ }^{237}$ Das Erdgas wird bei der LNG-Herstellung gekühlt und dadurch verflüssigt. Diese Methode ist wesentlich
} teurer als der Erdgastransport per Pipeline. Bei LNG-Herstellung geht auch etwa $25 \%$ des Erdgases verloren. 
Brennstoffen ist der „Strategische Ellipse“ genannte Raum. Sie verfügt insgesamt über 72,4 \% der fossilen Erdgasreserven und 58 \% der Erdölreserven der Welt (Bundesanstalt für Geowissenschaften und Rohstoffe (BGR) 2015: 107, 119).

\section{Abbildung 7: Strategische Ellipse}

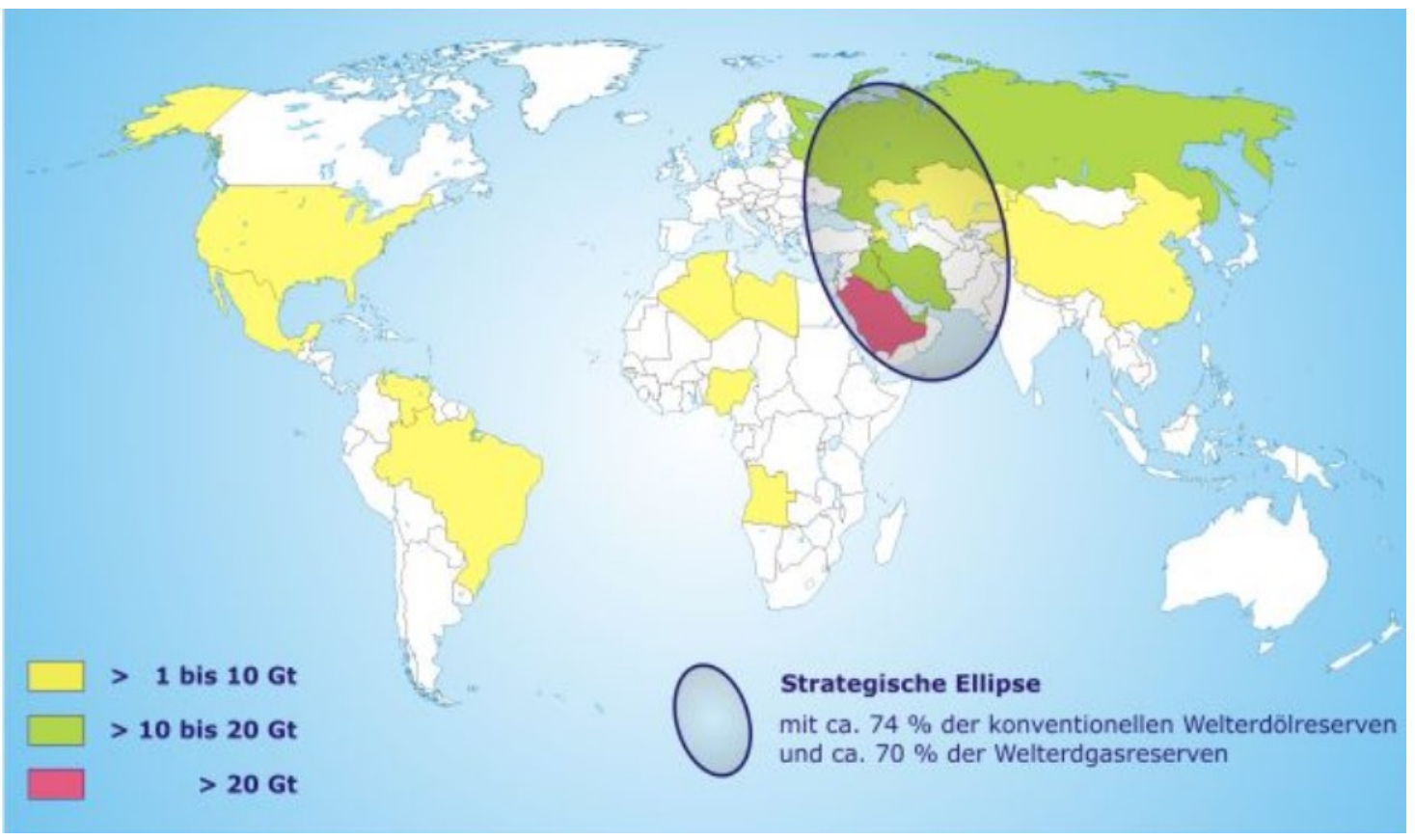

Quelle: Bundesanstalt für Geowissenschaften und Rohstoffe (BGR) 2009: 253.

Der Grund des Syrien-Krieges ist laut Ganser (2016b) der Wettbewerb zwischen der westlichen Achse einerseits und RU, Iran und Syrien andererseits um den Transport des Erdgases nach Westen. Ganser (ebd.) zufolge versuchten RU und Iran, die Erdgasreserven Irans und vielleicht auch Iraks gemeinsam zu managen und via Syrien nach Europa zu transportieren. Die USA und seine Verbündeten, darunter auch die TR, versuchten hingegen, die fossilen Brennstoffe aus Katar durch Syrien nach Europa zu transportieren, sagt Ganser (ebd.). Da die von den beiden Achsen geplanten Routen durch Syrien führen, sollte sich der syrische Präsident Basar Assad für eine Option entscheiden. Und laut Ganser (ebd.) entschied sich Assad für das Erdgaspipeline-Projekt aus dem Iran via Syrien nach Europa, was laut Ganser zum Syrienkrieg führte (ebd.).

Die USA erklärten bereits in der Carter Doktrin $1980^{238}$ ihre energiepolitischen Interessen am Persischen Golf, in der sie ihre Vormachtstellung unter allen Umständen - auch

\footnotetext{
${ }^{238}$ Das Interesse am Erdöl an der Golf-Region verkündete der US-Präsident Jimmy Carter am 23. Januar 1980 in seiner „Rede zur Lage der Nation“, die als Carter-Doktrin bekannt ist. Der Anlass für seine Rede war der sowjetische Angriff auf Afghanistan am 24. Dezember 1979. Die theoretische Grundlage der Carter-Doktrin
} 
militärisch verteidigen würden (Ganser 2015: 222). Laut Ganser (ebd.) wurde „The United States Central Command“ CENTCOM ${ }^{239}$ im März 1980²40 gegründet, um „den Nahen Osten und die größte Erdölreserve der Welt zu kontrollieren“(ebd.). Infolge der Auflösung der Sowjetunion standen auch die kaspischen fossilen Brennstoffe der zentralasiatischen Staaten zur „Ausbeutung“ frei. Die USA waren sehr früh in den kaspischen Staaten energiepolitisch aktiv und erweiterten ihre energiepolitischen Interessen nach Norden. Die fossilen Brennstoffe des Kaspischen Raums und der Golf-Region von den USA werden im Rahmen der Strategischen Ellipse als einheitliches Gebiet betrachtet. Der Beweis dafür ist das Zuständigkeitsgebiet des CENTCOM. ${ }^{241}$

ZA wurde 1999 zum CENTCOM zugeordnet. Im gleichen Jahr, im März 1999, verabschiedete der US-Kongress das sogenannte „Seidenstraßen-Strategiegesetz“ (Silk Road Strategy Act) (Govtracks.us o. J.). Des Weiteren wurde in diesem Jahr der BTCVertrag unterschrieben. Das zeigt, wie eng die Energie- und Sicherheitspolitik zusammenhängen. Der türkische General und Kommandeur der Akademie der türkischen Streitkräfte, Hasan Aksay, bestätigte in seiner Rede auf einem internationalen Symposium in Istanbul am 28. - 29. April 2009 die Interdependenz der westlichen Energie- und Sicherheitspolitik. Laut Aksay (2009: 9-10) entwickelte sich die gemeinsame

war Zbigniew Brzezinski, der zu jener Zeit als Nationaler Sicherheitsberater Carters tätig war. In dieser Doktrin erklärte Carter die Region am Persischen Golf als „,vitales Interessengebiet“ der USA, indem sie ihre Vormachtstellung unter allen Umständen - auch militärisch verteidigen würden (Ganser 2015: 222).

${ }^{239}$ CENTCOM`s Aufgabe formulierten Biermann/Klönne (2003: 21) folgendermaßen:

„Das Zentralkommando ist zuständig für ein Gebiet von großer strategischer Bedeutung: Mehr als $65 \%$ der Weltvorräte an Erdöl befinden sich hier. Ihre Sicherung ist lebenswichtig für die Weltwirtschaft. Das Einsatzgebiet schließt auch Hauptseewege ein, die den Nahen Osten, Europa, Süd- und Ostasien und die westliche Hemisphäre verbinden. Der Schiffsverkehr und die maritimen Nadelöhre, Straße von Hormos, Suezkanal, Bab-el-Mandeb, sichern den Transport der Erdölprodukte, die die Volkswirtschaften unserer europäischen und asiatischen Allierten [sic!] antreiben', so der Befehlshaber des Kommandos. Vor diesem Hintergrund wird deutlich, daß die Seestreitkräfte eine zentrale Rolle bei der US-amerikanischen Machtpräsenz besitzen. Die 5. Flotte wurde als eigenständige Einheit 1991 wieder ins Leben gerufen. Der Verband war nach 1945 aus operativen Gründen aufgelöst und mit anderen Verbänden zur Pazifikflotte zusammengefaßt worden. Das Hauptquartier dieser Flotte befindet sich in Bahrain. “

\footnotetext{
${ }^{240}$ Zunächst als schnelle Eingreiftruppe „Rapid Deployment Joint Task Force“ (RDJTF) benannt, 1983 als USCentral Command (CENTCOM) umbenannt.

${ }^{241}$ CENTCOM ist zuständig für die folgenden Länder: Iran, Irak, Syrien, Libanon, Ägypten, Jordanien, SaudiArabien, Yemen, Oman, Vereinigte Arabische Emirate, Bahrain, Katar, Kuwait, Pakistan, Afghanistan, Tadschikistan, Kirgisistan, Usbekistan, Turkmenistan, Kasachstan. Hierzu ist zu bemerken, dass Israel nicht aufgezählt wird, obwohl das Land auch im Zuständigkeitsgebiet, im Nahen Osten, liegt. Die Kriege in Afghanistan und dem Irak werden unter CENTCOM-Kommando geführt (Hippler 2007). Diese Operationen und Syrien-Operation werden von der zusätzlichen Kommandobasis des CENTCOM in Katar befehligt (Poppe 2020). Auffällig ist auch, dass alle dieser Staaten müslimisch geprägt sind und entweder an fossilen Brennstoffen sehr reich sind oder bei deren Transport strategisch liegen.
} 
Energiesicherheit des euro-atlantischen Raumes nach dem Kalten Krieg zu einer neuen Aufgabe der NATO.

Die USA/NATO erwarben infolge des Afghanistan-Einsatzes Militärbasen in ZA. Der ehemalige britische Umweltminister Michael Meacher (1997-2003) sah den USAfghanistan-Einsatz als Versuch für die Aufrechterhaltung ihrer Weltherrschaft an und kritisierte die britische Unterstützung der US-Außenpolitik (Meacher 2003), was ihm sein Amt kostete (siehe hierzu Kap. 6.2). Paul Craig Roberts, der ehemalige stellvertretende Finanzminister der USA unter der Reagan-Regierung, erklärte, dass die Grundlagen der USAußenpolitik schon im März 1992 vom ehemaligen Staatssekretär unter George Bush, Paul Wolfowitz, im sogenannten „Wolfowitz-Doktrin“ verfasst wurde (In: Curtin 2016). Roberts (ebd.) zufolge ist das Hauptziel der Wolfowitz-Doktrin die Verhinderung des neuen Rivalen, bzw. der neuen Rivalen, der/die amerikanische Vorherrschaft in Frage stellen kann/können (siehe Kap. 6.2). Nach John F. Mearsheimer (2001: 46) war das 1992 von Pentagon formulierte Hauptziel der USA ebenfalls die Verhinderung der Entstehung eines neuen Rivalen, der im Kalten Krieg die Sowjetunion war. Der andere US-Rivale ist China. Auch Brzezinski schrieb bereits 1997, die Aufgabe der USA sei die Verhinderung der erneuten Entstehung eines eurasischen Imperiums unter russischer Herrschaft (Brzezinski 2001: 130) (siehe hierzu Kap. 6.2). Weder RU noch eine andere Nation dürfe sich nach Brzezinski (2001: 278) mit den USA in den Schlüsselbereichen der Macht (im militärischen, wirtschaftlichen, technologischen und kulturellen Bereich) messen können, „die gemeinsam die entscheidende globale politische Schlagkraft ausmachen.“

RU sieht die USA als (sicherheits)politische und wirtschaftliche Gefahr für sich. In seinen aktuellen Sicherheitsdokumenten beschreibt das Land die USA/NATO als sicherheitspolitische Gefahr, die mit allen möglichen Mitteln RU zu schaden versuchen (siehe hierzu Kap. 5.6). Das russische Außenministerium ist der Ansicht, dass die USA mit ihren Verbündeten versuchen, den russischen Energiehandel zu sabotieren (Ulcenko 2003: 197) und RU dadurch in den Konkurs zu treiben. Der russische Staatshaushalt ist von den Rohstoffeinnahmen abhängig. ${ }^{242} 2016$ machte der Export der fossilen Brennstoffe 59 \% (169

\footnotetext{
${ }^{242}$ Europa ist der größte Abnehmer der russischen Brennstoffe. Etwa Zwei Drittel der fossilen Brennstoffe RUs gehen nach Europa (Steiner 2016; Bundeszentrale für politische Bildung o. J.). Im Jahr 2017 lag der russische Anteil an den EU-Erdgasimporten bei 37,0 \% (39,5\% im Jahr 2016) und sein Anteil an den Erdölimporten der EU bei 30,9 \% (31,7 \% im Jahr 2016). Erdöl dominiert die EU-Importe von Energieprodukten mit einem Anteil von 69 \% im Jahr 2017, gefolgt von Erdgas in gasförmigem Zustand mit einem Anteil von 20 \% (Eurostat 2018: EU imports of energy products ...).
} 
Mrd. US-Dollar) des russischen Gesamtexportes (285 Mrd. US-Dollar) aus (GKS (Federal State Statistic Service) 2016). 2013 war dieser Anteil (vor den westlichen Sanktionen infolge der Ukraine-Krise und niedrigem Ölpreis) viel höher. Er machte 71,4 \% (376 Mrd. USDollar) seiner gesamten Exporte (526 Mrd. US-Dollar) aus (GKS (Federal State Statistic Service) o. J.).

RU geht davon aus, dass es sich bei dem Ölpreisverfall seit Juni 2014 um ein amerikanisches Komplott handelt. Schuld am Ölpreisverfall um mehr als 1/3 war das Überangebot durch die US-Fracking-Öl sowie die Ausweitung der Ölförderung durch Saudi-Arabien (Dittmer 2014). Nikolaj Patruschej, Sekretär des Nationalem Sicherheitsrat RUs, erinnerte in Zusammenhang an die 1980er-Jahre. Patruschej zufolge führten die USA damals einen Ölpreisverfall herbei, um der Sowjetunion wirtschaftlich zu schaden (ebd.). Wie Dittmer (ebd.) berichtet, textete die russische Zeitung Prawda nach dem Besuch von US-Präsident Barack Obama in Riad im März 2014 inmitten der Ukraine-Krise: „Obama will, dass SaudiArabien die russische Wirtschaft zerstört“. Durch die westlichen Atom-Sanktionen seit 2011 hat auch ein weiterer Rivale der USA, der Iran, mehr als die Hälfte seiner Öleinnahmen verloren (Dittmer 2014). Wenn in Betracht gezogen wird, wie die russische Wirtschaftsleistung nach der Weltwirtschaftskriese 1998/1999 parallel zu dem weltweit stetig angewachsenen Ölverbrauch ${ }^{243}$ und hohen Ölpreis gewachsen ist und diese Einnahmen RU wirtschaftlich und politisch stabilisierte, wird die Abhängigkeit der russischen Wirtschaft vom Export seiner fossilen Energiestoffe viel deutlicher.

\footnotetext{
${ }^{243}$ Gold.de (2018) schreibt über die Ölpreisentwicklung folgendes: „Der Zeitraum zwischen 2001 und 2013 war von steigenden Ölpreisen und zunehmenden Preisschwankungen gekennzeichnet. Maßgeblich verantwortlich für den Anstieg ist die rasante wirtschaftliche Entwicklung der Volksrepublik China in diesen Jahren. Das chinesische Bruttoinlandsprodukt vervielfachte sich von 1,3 Mrd. Dollar im Jahr 2001 auf rund 9,5 Mrd. Dollar im Jahr 2013. Der Ölpreis stieg im selben Zeitraum auf Jahresschlussbasis von 19,84 Dollar auf 98,61 Dollar. Die produzierende Industrie hatte erheblichen Anteil am chinesischen Wirtschaftswunder. Entsprechend stark entwickelte sich auch die Nachfrage nach Öl. 2013 lag der Bedarf bei rund 10,5 Millionen Barrel pro Tag.“ (Gold.de 2018).
} 
Abbildung 8: Ölpreisentwicklung

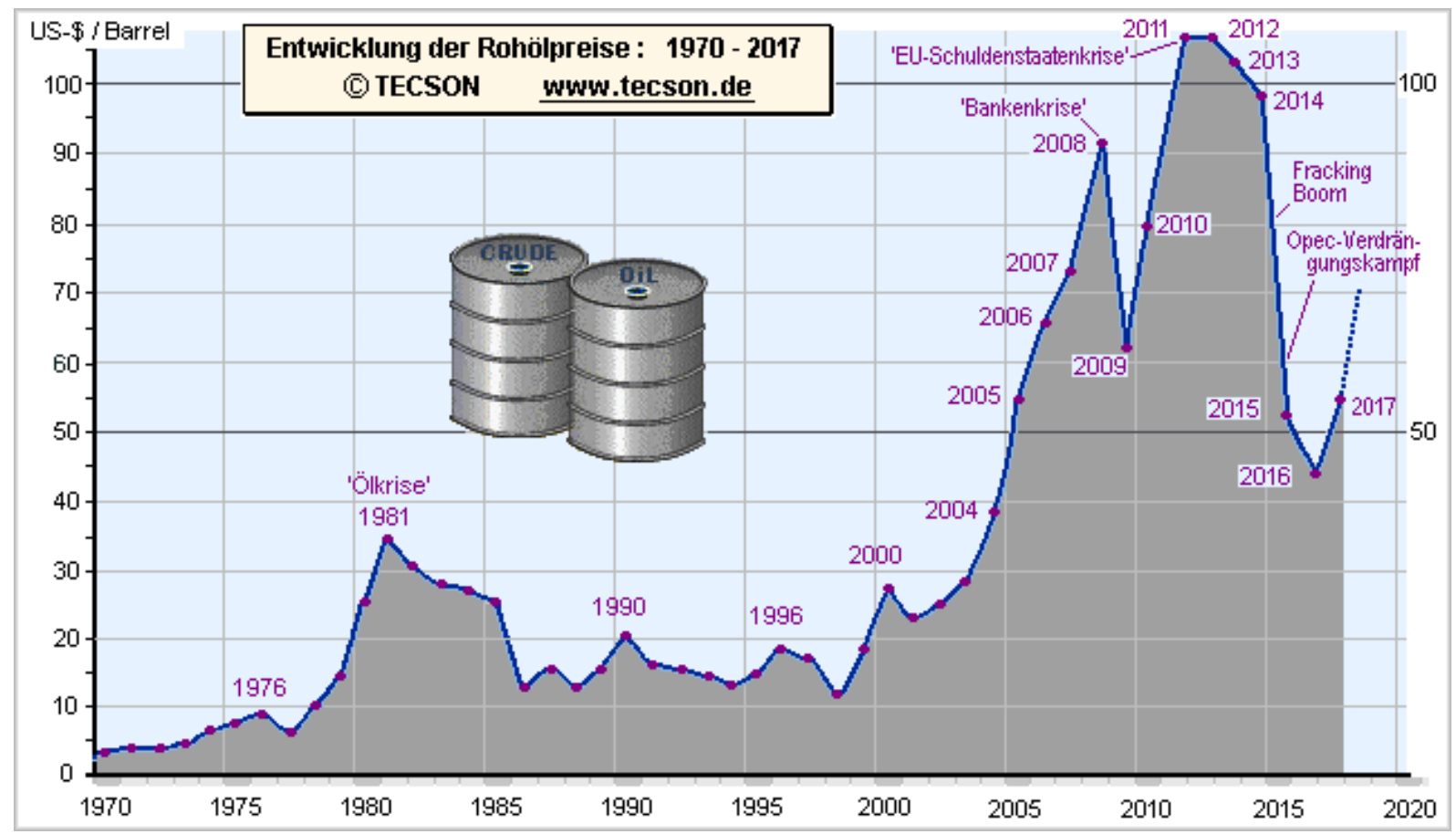

Quelle: TECSON 2018

Die USA werfen RU Re-Sowjetisierung vor. Das Russische Bündnisprojekt EAWU sehen sie als „Re-Sowjetisierung“ an. Die ehemalige US-Außenministerin Hillary Clinton erklärte Ende 2012, dass RU mit seinem Integrationsprozess auf dem ehemaligen Sowjetgebiet eine „Re-Sowjetisierung“ betreibt. Als Ziel der USA erklärte Clinton die Verlangsamung, bzw. die Verhinderung dieses Integrationsprozesses:

"There is a move to re-Sovietise the region [...] It's not going to be called that. It's going to be called a customs union, it will be called Eurasian Union and all of that [...] But let's make no mistake about it. We know what the goal is and we are trying to figure out effective ways to slow down or prevent it." (Clover 2012).

Die Mitglieder der EAWU sehen aber keine „Re-Sowjetisierungsgefahr" des russischen Bündnisprojektes und die Bevölkerungen der Mitgliedsstaaten zeigen in den Meinungsumfragen hohe Zufriedenheit mit dieser Organisation (siehe Kap. 5.6).

Die Nachbarschaft zu China und Chinas wirtschaftliche Dynamik erleichtert es den zentralasiatischen Staaten „das Interesse der Welt auf sich zu ziehen“, schreibt Brzezinski (2001: 215). Bereits 2001 schrieb Mearsheimer (2001: 56), dass die USA weiterhin im Pazifikraum stationiert bleiben, um sich vor der chinesischen Hegemonie zu schützen. Der US-Präsident Barack Obama (2009-2017) erklärte im November 2011 den Pazifikraum zur 
Priorität der USA. Laut Obama will sein Land eine größere und langfristigere Rolle in der Gestaltung dieser Region und ihrer Zukunft spielen (O. V. 2012: USA wollen Großteil ...). Im Jahre 2012 erklärte der US-Verteidigungsminister Leon Panetta auf einer Sicherheitskonferenz in Singapur, bis zum Jahr 202060 \% der US-Seestreitkräfte in den Pazifik verlegen zu wollen. Laut Panetta werden die USA ihre Allianzen mit Japan, Südkorea, Thailand, den Philippinen und Australien verstärken (ebd.). Auch in der TaiwanFrage vertreten sie eine gegensätzliche Meinung zu China. Dieses Vorgehen interpretiert China wiederum als seine Einkreisung durch die USA und sieht die unmittelbarere Nähe der USA und NATO als sicherheitspolitische Gefahr an.

Eine russisch-chinesische Vereinigung, bzw. Zusammenarbeit gegen die USA sieht der USamerikanische Geopolitiker Brzezinski (2001: 87) als das „gefährlichste Szenario“ für die USA an. Im Falle einer erfolgreichen wirtschaftlichen Integration innerhalb Eurasiens können die USA laut Mearsheimer (2001: 46) ihren Einfluss in Europa und Nordasien verlieren, was das endgültige Ende der US-Hegemonie bedeuten würde. Eine russischchinesische Zusammenarbeit versuchen die USA $\mathrm{zu}$ sabotieren. In ihrer aktuellen „Nationalen Verteidigungsstrategie“ (National Defense Strategy) von 2018 definierten sie den internationalen (islamistischen) Terror nicht mehr als größte sicherheitspolitische Gefahr; sondern RU und China. Der Iran und Nord-Korea werden als weitere sicherheitspolitische Gefahren definiert. Alle diesen Staaten werden von den USA sanktioniert. Der Vizeaußenminister Sergej Rjabkow erklärte, dass die USA gegen RU seit 201160 Strafmaßnahmen verhängten, um RU die amerikanischen Bedingungen zu diktieren. Die Sanktionen haben wirtschaftliche Folgen. 2017 z. B. wurden gegen RU wegen möglicher Wahlmanipulationsversuche in den USA und Ukraine-Konflikt Sanktionen verhängt. Laut der US-Regierung verhinderten diese Sanktionen potenzielle Rüstungsexporte aus RU im Wert von Mrd. von Dollar. Laut USA müssen die Staaten mit Sanktionen rechnen, wenn sie mit Personen oder Einrichtungen auf der Sanktionsliste der USA Geschäfte machen.

2018 verhängten die USA gegen eine chinesische Militärbehörde wegen des Kaufs russischer Kampfjets und Raketen (Kampfflugzeuge vom Typ Su-35 sowie S-400 BodenLuft-Raketensysteme) Sanktionen (O. V. 2018: USA verhängt Sanktionen ...). Strafzölle im Volumen von 200 Mrd. US-Dollar waren die Folge. China reagiert auf diese Sanktionen nun seinerseits mit Strafzöllen auf US-Importe im Wert von 60 Mrd. US-Dollar. Daraufhin 
eskalierte der Streit zwischen den beiden Staaten und der US-Präsident Donald Trump (2017 - im Amt) drohte China mit weiteren Strafzöllen in Wert von fast 267 Mrd. US-Dollar (Micijevic/Schneider/Hua 2018: China reagiert auf Trump ...).

Die Zentralasienstrategie der USA ist gegen die russischen, chinesischen und iranischen Interessen gerichtet. Im März 1999 verabschiedete der US-Kongress das sogenannte „Seidenstraßen-Strategiegesetz“ (Silk Road Strategy Act). Dieses Strategiegesetz forderte die Unterstützung der politischen und wirtschaftlichen Unabhängigkeit der südkaukasischen und zentralasiatischen Staaten, Bekämpfung des Anti-Semitismus, Verbesserung der Infrastruktur dieser Länder, die Unterstützung der amerikanischen Investoren in der Region usw. (Govtracks.us o. J.). Die US-Ziele wurden 2011 in der „The New Silk Road Initiative“ aktualisiert. Sie legten darin fest, dass die USA die wirtschaftliche regionale Kooperation der zentralasiatischen Staaten mit Afghanistan, Pakistan und Indien voranzutreiben versuchen. Das bedeutet, sie werden die Kooperation der zentralasiatischen Staaten mit RU, dem Iran und China weiter zu verhindern versuchen. Als Maßnahme dafür schreiben die USA die Verbesserung der Handels- und Transitwege bis zu den Grenzüberwachungen vor (U. S. Department of State o. J.). TAP(I) ist das Erdgasprojekt der USA (siehe hierzu Kap. 5.2). Des Weiteren wollen die USA mit dem CASA-1000-Projekt Wasser aus dem wasserreichen Kirgisistan und Tadschikistan nach Afghanistan und Pakistan transportieren sowie Strom aus den Wasserkraftwerken. ${ }^{244}$

Für die Lösung der regionalen Probleme organisierten die USA eine „C5+1“ Plattform (U.S.-Central Asia (C5+1) Joint Projects), die die zentralasiatischen Staaten und die USA zusammenbringen sollte. Auf dem ersten C5+1 Ministertreffen in Samarkand im November 2015 vereinbarten die sechs Minister, gemeinsame Projekte für die Verbesserung der sicherheitspolitischen Probleme der Region, Förderung der wirtschaftlichen Konnektivität und den Klimawandel zu entwickeln. Auf dem zweiten C5 + 1 Ministertreffen, das im August 2016 in Washington stattfand, stimmten die sechs Minister zu, fünf entsprechende Projekte zu starten, die die Vereinigten Staaten bis zu 15 Mio. Dollar zu unterstützen planen (O. V. 2016: U.S.-Central Asia ...). Ein drittes Treffen fand im Juli 2017 in Duschanbe statt. Der Schwerpunkt war eine Strategie zur Terrorbekämpfung (U. S. Department of State 2017). Die niedrigen Summen der US-Hilfen zeigen, dass es sich nicht um eine intensive

\footnotetext{
244 Turkmenistan, Usbekistan und Kasachstan sind gegen diese Wasserstrategie der USA, weil sie das Wasser für ihre Landwirtschaft, besonders für den Baumwollanbau, brauchen.
} 
Zusammenarbeit handelt. Wie aus der Tabelle 1 und Tabelle $2 \mathrm{zu}$ entnehmen ist, befinden sich die USA weder als Importeur noch als Exporteuer unter den drei wichtigsten Handelspartnern der zentralasiatischen Staaten. Sie sind allerdings in ZA als Investoren, besonders in der kasachischen Erdölbranche, sehr aktiv. Bis heute investieren die USErdölfirmen (z. B. Chevron und ExxonMobil) etwa 50 Mrd. US-Dollar in die kasachische Erdölindustrie, sind Aktionäre einiger Pipelines und sie beabsichtigen weitere Investitionen (O. V. 2018: Trump in Zentralasien ...). Diese Zahlen, Ereignisse und Erklärungen zeigen, dass das Hauptinteresse der USA in ZA an der Erdöl- und Erdgasbranche sowie Einkreisung RUs und Chinas liegt.

\subsection{EU-Wirtschaftspolitik in Zentralasien}

Die Europäische Union (EU) ist in $\mathrm{ZA}^{245}$ mit Programmen, Initiativen, Partnerschaftsabkommen, Organisationen, Strategien usw. aktiv. Die EU verabschiedete 1991 die Initiative TACIS (Technical Assistance to the Commonwealth of Independent States), um u. a. die zentralasiatischen Staaten technisch-wirtschaftlich zu unterstützen. Im Jahre 2007 ging diese Initiative in die „Development Cooperation Instrument“ (DCI) auf, welche sich auf die politische und wirtschaftliche Entwicklung in ZA konzentriert. Die EU stockte die Entwicklungshilfe für ZA im Rahmen der DCI für den Zeitraum von 2014-2020 auf 1,028 Mrd. EUR auf, „d.h. gegenüber dem Programmplanungszeitraum von 2007-2013 (750 Mio. EUR) um 56 \% erhöht““ (Europäisches Parlament 2016).

1993 verabschiedete die EU das Programm „The Europe-Caucasus-Asia Transport Corridor" (TRACECA), welches die Entwicklung der wirtschaftlichen Beziehungen und Handelswege zwischen den Staaten des Schwarzen und Kaspischen Meeres, ZAs und der EU zum Ziel hat. Außer Turkmenistan sind alle zentralasiatischen Staaten Mitglied dieser Organisation. Auch der Schwarzmeeranrainer TR ist seit 2002 Mitglied des TRACECA (TRACECA o. J.). Das andere Programm der EU ist die INOGATE seit 1996, um die energiepolitische Arbeit zwischen der EU, Osteuropa, Südkaukasus und ZA zu fördern. Alle zentralasiatischen Staaten und die TR sind seit 1996 Mitglied (INOGATE o. J.). Seit November 2007 liefert die BTE-Pipeline das aserbaidschanische Erdgas via TR nach

\footnotetext{
245 Das Europäische Parlament schreibt 2019 folgendes: „Die Mongolei wird zwar nicht zu Zentralasien im allgemeinen Sinne gezählt und fällt auch nicht unter die Strategie der EU für Zentralasien, wird jedoch vom Parlament als Teil der Region und deren Struktur der ständigen Delegationen eingestuft.” (Jiracek 2019).
} 
Griechenland im Rahmen des Projekts der Europäischen Union INOGATE (Türkiye Cumhuriyeti Disisleri Bakanligi o. J. b).

In den 1990er Jahren konzentrierte sich die EU auf die wirtschaftliche Zusammenarbeit mit den Regionsstaaten. Ihr sicherheitspolitisches Interesse gewann infolge des 11. Septembers an Bedeutung, die sie im Rahmen der OSZE, NATO (,Euro-atlantischer Partnerschaftsrat““ (EAPR) und „Partnership for Peace” (PfP) usw.), „Black Sea Regional Energy Center“ (BSREC), „Border Management Programme in Central Asia“ (BOMCA) und „Central Asia Drug Action Programme“ (CADAP) verfolgt (siehe auch Kap. 6.4). Nach den AndijanUnruhen in Usbekistan 2005 beauftragte die EU einen Sonderbeauftragen (Sadyrbek 2014) für ZA. Die Aufgabe des Sonderbeauftragten in ZA ist die Koordinierung und Förderung der EU-Politik, die Überwachung der Umsetzung der EU-Strategie und die Unterstützung der regionalen Sicherheit in ZA (Europäischer Rat 2015: Neuer EU-Sonderbeauftragter für Zentralasien ...). Ihre Strategie für ZA fasste die EU im Juli 2007 auf Initiative der deutschen EU-Präsidentschaft „EU und Zentralasien - eine Partnerschaft für die Zukunft“ zusammen. Diese Strategie wurde zuletzt 2015 überarbeitet. ${ }^{246}$ Sie basiert auf vorangegangenen Abkommen, Hilfsprogrammen und Initiativen der EU und enthält grundlegende Leitlinien für die zukünftigen Beziehungen zu ZA (Fayos 2016):

„Stabilität und Wohlstand zu schaffen und gleichzeitig offene Gesellschaften, Rechtsstaatlichkeit und Demokratisierung zu fördern. Auf dem Gebiet der Energiesicherheit und-diversifizierung sollen Beziehungen gefördert werden, die stärker auf Zusammenarbeit ausgerichtet sind. Die Kohlenwasserstoffe Kasachstans und Turkmenistans könnten sich in Zukunft für die EU als wichtig erweisen. Ein wichtiges Anliegen für eine Reihe von Staaten ist der Abzug der Internationalen Sicherheitsunterstützungstruppe (ISAF) aus Afghanistan, der im Dezember 2014 abgeschlossen wurde, wenngleich 13000 Angehörige der US- und NATOStreitkräfte im Land bleiben werden. Um den möglichen Folgen des Truppenabzugs zu begegnen, wurde im Jahr 2013 ein neuer hochrangiger Dialog über Sicherheitsfragen eingeleitet. "

Wie aus diesen Ausführungen zu entnehmen ist, ist das vorrangige EU-Ziel in ZA energieund sicherheitspolitisch. Die Ziele der EU bezüglich der Förderung der Rechtstaatlichkeit, Demokratie und Menschenrechte in ZA werden von den autoritären Führern der Regionsstaaten als Gefahr für ihre Herrschaft und Sicherheit angesehen. Obwohl die EU die

\footnotetext{
${ }^{246}$ Im Juni 2019 wurde die neue „Strategie der EU für Zentralasien“ überarbeitet und vom europäischen Rat gebilligt. „Die Förderung von Resilienz (in Bereichen wie Menschenrechte, Grenzsicherheit und Umwelt), Wohlstand (mit besonderer Betonung der Konnektivität) sowie regionale Zusammenarbeit“" wurden als EUZielen in ZA definiert (Jiracek 2019).
} 
europäischen Werte, wie z. B. Meinungsfreiheit und Rechtstaatlichkeit, in ihren Abkommen, Strategiepapiern, Hilfsprogrammen mit ZA betont, macht sie jedoch diese Werte nicht zur Bedingung für die Verhandlungen mit den autoritären Herrschern der Region. Sie hob z. B. die Sanktionen gegen Usbekistan auf, obwohl weiterhin Rechtsdefizite in allen Bereichen bestanden. Formal aber verurteilte das europäische Parlament Usbekistan wegen des Einsatzes von Zwangsarbeit und forderte die Beobachtung der Menschenrechtslage (Fayos 2016). Oder z. B. sie versucht aktiv, ihre wirtschaftlichen Beziehungen zu Turkmenistan zu verbessern, auch wenn sie die Überprüfung der Fortschritte im Bereich der Menschenrechte zur Ratifizierung des 1998 unterzeichneten „Partnerschafts- und Kooperationsabkommen“ (PKA) mit Turkmenistan macht (Jiracek 2019).

Die EU schloss seit 1990er Jahren PKA mit den zentralasiatischen Staaten. In Kasachstan, Kirgisistan, Usbekistan traten sie 1999 und in Tadschikistan aufgrund des Bürgerkrieges erst 2010 in Kraft (EUR-Lex 2010). Diese Abkommen wurden für eine Laufzeit von zehn Jahren geschlossen und verlängern sich nach dieser Frist automatisch um ein Jahr, solange keine Vertragspartei Einspruch erhebt. Die Hauptziele der PKA sind die Förderung des politischen Dialogs, der Marktwirtschaft, Demokratie und Menschenrechte auf bilateraler Ebene (EURLex 2010). Mit Tadschikistan hat die EU eine PKA seit 2010 und forderte das Land auf, die Menschenrechte, das Gesundheitswesen und die Bildung zu verbessern und Korruption zu bekämpfen. Ein neues, verbessertes PKA - dessen Name in EPKA (Erweitertes Partnerschafts- und Kooperationsabkommen) umgeändert wurde - wurde am 21. Dezember 2015 mit dem ölreichen Kasachstan unterzeichnet. Mit Kirgisistan verhandelte die EU ein neues EPKA aus, welches 2019 paraphiert wurde (Jiracek 2019). Mit Usbekistan nahm die EU im November 2018 neue Verhandlungen für das EPKA auf (ebd.).

Im Januar 2015 brachte das europäische Parlament seine Sorge über Gesetzentwürfe zu LGTBI-(Abkürzung für Lesbian, Gay, Bisexual, Transgender, Intersex) „Propaganda“ in Kirgisistan zum Ausdruck (Fayos 2016). Sadyrbek (2014) schreibt, dass die europäischen Bemühungen in ZA inzwischen mit dem negativen Image begleitet und die EU in der Region als Union gesehen wird, die die Homosexualität sowie Kinderlosigkeit, sexuelle Freiheit propagiert und NGOs fördert, die die Traditionen und kulturellen Werte zerstören würden. Dieses Misstrauen ist ein Hindernis für die erfolgreiche Zusammenarbeit mit der EU. Sadyrbek (2014) zufolge brachten auch viele Plattformen und Pilotprojekte der EU in den 
Bereichen Wasser, Sicherheit und Umwelt keine konstruktive regionale Zusammenarbeit zustande.

Die wirtschaftlichen Beziehungen der EU-Staaten zu ZA ist trotz der gemeinsamen Strategien und Programme bilateral geprägt. Italien und Deutschland sind die beiden wichtigen Handelspartner der zentralasiatischen Staaten. Italien ist eher ein Importeuer und Investor, Deutschland hingegen ein Exporteur. Italien ist ein energiepolitischer Partner von Kasachstan und Turkmenistan und hauptsächlich Aluminiumimporteuer aus Tadschikistan. Das Land befindet sich 2016 auf dem 1. Platz der kasachischen Exporteure mit einem Anteil von 20,3 \%. 97,9 \% seiner Importe aus Kasachstan machten fossile Brennstoffe und Produkte aus. Hier investiert das Land in die Erdölindustrie. Im selben Jahr befand sich Italien auf dem 3. Platz der turkmenischen Importeure mit einem Anteil von 5,6 \%, wovon 99,5 \% fossile Brennstoffe und deren Erzeugnisse ausmachten. Ebenso auf dem 3. Platz der tadschikischen Importeure befand sich das Land mit einem Anteil von 10,7 \%. Hauptsächlich importierte das Land aus Tadschikistan Aluminium (83,9 \% seiner Exporte). Außer Italien befand sich kein EU-Land unter den ersten wichtigsten drei Importeuren der zentralasiatischen Staaten im Jahre 2016 (Siehe Tabelle 1, Tabelle 2). Deutschland hingegen befand sich 2016 als drittwichtigster Exporteur Kasachstans und Turkmenistans. Deutsche Exporte machten 5,7 \% der kasachischen Importe aus, wovon 29,4 \% Maschinen, 17,4 \% Eisen und Stahlprodukte und 11,3\% Pharmazeutische Produkte usw. ausmachten. An turkmenischen Gesamtimport hatte Deutschland einen 8,5-prozentigen Anteil, wovon 37,6 \% Maschinen, 11,5 \% Kontroll-, Mess- und Präzisionsgeräte, $10 \%$ elektrische Geräte ausmachten (siehe Tabelle 1, Tabelle 2).

\subsection{Chinas Zentralasienpolitik}

Chinas Interesse an ZA ist in erster Linie aufgrund des autonomen westchinesischen Uighuren-Gebiets (Xinjiang) sicherheitspolitisch bestimmt. Daher kooperiert das Land mit den zentralasiatischen Staaten und RU im Rahmen der sicherheitspolitischen Organisation SOZ und versucht, die sicherheitspolitische Zusammenarbeit mit den anderen Regionsstaaten, wie Afghanistan und Pakistan, zu vertiefen. Die TR erhielt den Status des Beobachtermitgliedes innerhalb der SOZ. Für die Stabilität und wirtschaftliche Entwicklung Xinjiangs und der Region sowie für seine wirtschaftliche Initiative „Seidenstraße Wirtschaftsgürtel“" investiert China in ZA (Auswärtiges Amt 2016). Staatspräsident der 
Volksrepublik China Xi Jinping kündigte während seiner Zentralasienreise in Kasachstan am Anfang September 2013 den Aufbau des „Seidenstraße Wirtschaftsgürtel“ (Silk Road Economic Belt) an. Diese Initiative soll die wirtschaftlichen Beziehungen Chinas mit ZA verbessern und die Region sicherheitspolitisch stabilisieren.

China wird für seinen „Seidenstraße Wirtschaftsgürtel“ mindestens $900 \mathrm{Mrd}$. Dollar in den Bau der Straßen, Bahngleise, Pipelines, Kraftwerke, Telekommunikationsnetze, Häfen und Flughäfen von Asien bis nach Europa und Afrika investieren (Satra 2019). Laut der aktuellen EU-Zentralasienstrategie erhöhte die chinesische Seidenstraße-Initiative die strategische und wirtschaftliche Bedeutung ZAs (Europäisches Parlament 2016) für die Welt. Während des Nasarbajews-Chinabesuches im Mai 2014 vereinbarten China und Kasachstan den Ausbau der Transportinfrastruktur. Chinas wirtschaftliche Beziehungen mit den zentralasiatischen Staaten nahmen in letzter Zeit kontinuierlich zu. Xi unterschrieb 2014 Verträge mit Kasachstan im Wert von 30 Mrd. Dollar, mit Usbekistan mit 15 Mrd. Dollar und Kirgisistan mit 3 Mrd. Dollar (McBride 2015). Die ersten nennenswerten Erfolge der chinesischen Seidenstraße-Initiative sind die Gründung der „Asiatischen Infrastrukturinvestmentbank" und der eigens geschaffenen Seidenstraßenfonds für die Finanzierung der Initiative. RU und China einigten sich im Mai 2015 ,auf die Verknüpfung der Seidenstraßeninitiative mit dem russischen Entwicklungsprogramm für Sibirien sowie der Eurasischen Wirtschaftsunion“" (Rudolf 2015).

China plant mit der Seidenstraße-Initiative gleichzeitig, ihre wirtschaftlichen Verbindungen via ZA mit Europa zu vertiefen. Im Juni 2015 unterschrieben Ungarn und China eine Absichtserklärung, wonach beide Staaten gemeinsam die Seidenstraße-Initiative vorantreiben wollen (ebd.). Seit 2008 fährt der reguläre Güterzug aus Deutschland nach China. Der Transport kostet die Hälfte des Lufttransports. Er ist zwar teurer als der Schiffstransport, nimmt aber im Vergleich die Hälfte der Zeit (14-16 Tage) eines Schiffstransportes in Anspruch (Doll 2016). In Europa wachsen die chinesischen Investitionen von Jahr zu Jahr. 2015 erreichten chinesische Übernahmen in Europa mit 44 \% Steigerung im Verhältnis zu 2014 (14 Mrd. Euro) von etwa 20 Mrd. Euro (Hanemann/Huotari 2016: 3). 2018 stiegen Chinas Investitionen in der EU um 77 \% auf mehr als 35 Mrd. Euro (Satra 2019). Obwohl die Kooperationspartner Chinas durch diese Investitionen wirtschaftliche Vorteile haben werden, werden sie langfristig von ihm politisch stärker beeinflussbar. China erwarb 51 \% der Anteile am griechischen Hafen Piräus (ebd.). 
Der Europaabgeordnete Jo Leinen warnte vor einem eventuellen Griechenland-Veto davor, „dass chinesische Investitionen in Athen nicht nur wirtschaftliche, sondern auch politische Abhängigkeiten schaffen.“ (In: Satra 2019). Schon öfter sei aufgefallen, „dass EUMitgliedsländer, in denen China in größerem Stil investiert, sich scheuen, auch EU-Werte oder EU-Interessen gegenüber China zu vertreten“, so der SPD-Politiker (ebd.). Ungarn z. B. setzte sich für China ein, als die EU China wegen seiner territorialen Ansprüche im Südchinesischen Meer kritisieren wollte (ebd.).

China ist seit 2014 nach Kaufkraft die größte Volkswirtschaft der Welt und sein Energiebedarf wächst rasant. Sein Handel versucht China mit seiner eigenen Währung „Yuan“ abzuwickeln, was gegen den US-Dollar als Reservewährung gilt. 40-50 \% des iranischen Erdölexportes bekommt China (O. V. 2016: İran y1llar sonra ...). Das machte 2015 etwa 9,5 \% des gesamten chinesischen Erdölimportes aus. China bezahlt seit 2012 einen Teil seiner Erdölimporte aus dem Iran in Yuan (Geinitz/Höfinghoff/Kuls 2012). Haupt- bzw. größter Erdölexporteur nach China war 2015 RU. 16,9 \% seines Erdölimportes erhielt China aus RU. Der Handel zwischen China und RU wird in Yuan abgerechnet (Nestler 2015). Im Mai 2014 unterzeichneten China und RU ein Erdgasabkommen. Der Bau der Pipeline „Kraft von Sibirien“ begann im Juli 2015. Ab Ende 2019 soll sie China mit jährlich 38 Mrd. Kubikmeter Erdgas versorgen. Eine weitere Erdgaspipeline mit RU ist in Planung. Den Handel mit China plant Gazprom fortan in russischen Rubel oder in Yuan abzuwickeln (O. V. 2015: „Strategische Energiepartnerschaft“ ...), was gegen die USInteressen ist.

Moskau drohte dem Westen, die Gasleitungen in Richtung China umzuleiten, ,als sich im Gefolge der russisch-ukrainischen Gaskrisen 2006 und 2009 und der Implementierung des Dritten EU-Energie-Binnenmarktpaketes von 2009 die Beziehungen zur EU verschlechterten.“ (Klein/Westphal 2015: 3). Das ist einerseits wegen der Auseinandersetzung mit dem Westen wegen des Ukraine-Konfliktes und der Sanktionen, andererseits wegen der rapiden Nachfrage nach Öl und Gas im Asien-Pazifik-Raum. RU formulierte 2010 , in seiner ,Energiestrategie 2030` den Ausbau des Handels mit Asien als Ziel und konkretisierte dies Anfang 2014: Bis 2035 sollen die Öl- und Gasexporte nach Asien verdoppelt werden.“(Klein/Westphal 2015: 4). 
Die Erdölpipeline Eastern Siberia Pacific Ocean (ESPO) liefert seit 2011 Erdöl nach in China. Diese Pipeline gilt als längste Ölpipeline der Welt mit einer Kapazität von 50 Mio. Tonnen Erdöl jährlich (ebd.: 5). „Zwischen 2010 und 2014 haben sich die russischen Rohölexporte nach China auf fast 30 Millionen Tonnen weit mehr als verdoppelt. Chinas Anteil an Russlands Rohölausfuhr beträgt gut 13 Prozent.“ (Klein/Westphal 2015: 5). So wurde RU, wie oben geschrieben, der größte Erdölexporteur Chinas (Nestler 2015). Laut Statistiken erhöhten sich die russischen Ölexporte nach China im Vergleich zu 2015 um fast ein Viertel auf 1,05 Mio. Barrel am Tag (0.147 Mio. Tonne) (O. V. 2017: Russland ist jetzt ...). Des Weiteren bleibt RU wichtigster Kooperationspartner Chinas im Rüstungsbereich (Auswärtiges Amt 2016). Das russisch-chinesische Handelsvolumen erreichte 2018 die Höhe von 108,3 Mrd. Dollar (Schütz 2019). RU exportierte Waren in Wert von 56,1 Mrd. nach China und importierte aus China Waren in Wert von 52,2 Mrd. Dollar (ebd.). Das entsprach einem Handelswachstum von rund $28 \%$ gegenüber dem Vorjahr (ebd.). Dadurch wurde das wichtigste Importland Russlands im Jahr 2018 China mit einem Anteil von 21,7 $\%$ an den Importen (Statista 2020a). Im selben Jahr wurde China auch das wichtigste Exportland Russlands, mit einem Anteil von 12,4 \% an den Exporten (Statista 2020b).

China arbeitet mit den energiereichen zentralasiatischen Staaten sehr eng zusammen. $70 \%$ der turkmenischen, $23 \%$ der usbekischen und 11,4\% der kasachischen Energieexporte gingen 2016 nach China. Das Land ist ein wichtiger Exporteur der zentralasiatischen Staaten geworden und verdrängte RU 2016 vom Platz 1 in Usbekistan, Kirgisistan und Tadschikistan. 53,2\% der tadschikischen, $38 \%$ der kirgisischen, $22 \%$ der usbekischen, 14,5 $\%$ der kasachischen und 7,2 \% der turkmenischen Importe kamen aus China (siehe Tabelle 2). Laut Lo (2008: 99 f.) versucht RU die wirtschaftlichen Beziehungen Chinas zu den zentralasiatischen Staaten nicht zu sabotieren, weil das Land dadurch seine Beziehungen zu den zentralasiatischen Staaten und China nicht belasten will. Schließlich teilen alle genannten Regionsstaaten ähnliche sicherheitspolitische und wirtschaftliche Interessen und sind besonders sicherheitspolitisch aufeinander angewiesen. Allerdings ist zu erwarten, dass mit der Zunahme der wirtschaftlichen Verflechtungen der politische Einfluss Chinas in den zentralasiatischen Staaten sowie in RU wachsen wird. Trotz dieser Tatsache ist nicht zu erwarten, dass China in Zukunft seine wirtschaftlichen (sowie sicherheitspolitischen) Interessen nicht selbst sabotieren wird. Schließlich umfasst die Seidenstraßeninitiative 68 Länder und alle diese Länder müssen wirtschaftlich und politisch ,gut“ funktionieren, damit China seine wirtschaftlichen und politischen Gewinne maximieren kann. 


\subsection{Russlands Eurasische Wirtschaftsunion gegen die türkischen Initiativen in Zentralasien}

RU verfolgte nach der Auflösung der Sowjetunion zunächst eine westliche Außenpolitik, die in der Wissenschaft Atlantismus genannt wird. Seit 1993 ersetzte der russische Eurasismus allmählich den Atlantismus, der sich in erster Linie auf „Nahes Ausland“ konzentriert. Die aus der sowjetischen Zeit bestehende Infrastruktur erleichterte die weitere wirtschaftliche Zusammenarbeit. Z. B. alle bestehenden Pipelines aus ZA liefen bis zum Ende des Kalten Krieg nach Sowjet-RU, die Baumwolle ZAs wurde in Sowjet-RU verarbeitet usw. Die Wirtschaftssysteme dieser Staaten waren unter der russischen Kontrolle. Zwölf Teilnehmerstaaten der GUS unterzeichneten 1993 einen Vertrag über die Bildung einer Wirtschaftsunion (Sagorskij 2014: 3). Der kasachische Präsident Nasarbajew propagierte am 29. März 1994 in einer Rede an der Lomonossow-Universität Moskau die Gründung einer einheitlichen Eurasischen Union (Nurbekov 2014). ${ }^{247} 1995$ unterzeichnete RU mit Weißrussland und Kasachstan ein Abkommen über die Formierung einer Zollunion, der sich 1996 Kirgisistan und 1999 Tadschikistan anschlossen. Dieses Projekt wurde 2000 in eine „Eurasische Wirtschaftsgemeinschaft“ (EAWG) transformiert (Sagorskij 2014: 3).

Kasachstan, RU und Weißrussland unterzeichneten im Oktober 2007 ein Abkommen über die Gründung eines einheitlichen Zollgebiets und die Bildung einer Zollunion. Am 1. Juli 2010 wurde ein einheitlicher Zollkodex auf dem Territorium Kasachstans und RUs eingeführt und am 6. Juli 2010 auf das gesamte Territorium der Zollunion ausgedehnt. Alle drei Länder unterzeichneten 2011 eine Erklärung zur Eurasischen Wirtschaftsintegration, die im Januar 2012 (basierend auf 17 internationalen Verträgen, die die Grundlage des gemeinsamen Wirtschaftsraums bildeten) in Kraft trat. Im Februar 2012 wurde im Rahmen dieser Integrationsprojekte als erste supranationale Struktur die Eurasische Wirtschaftskommission gegründet. Armenien und Kirgisistan unterzeichneten 2014 ein Beitrittsabkommen. Die Eurasische Wirtschaftsunion nahm ihre Arbeit am 1. Januar 2015 offiziell auf (Satpajew 20014: 1-2) und hat einen gemeinsamen Binnenmarkt mit Zollunion. In seiner „Außenpolitikkonzeption von 2016“ beschrieb RU die Aufgabe und Ziele der

\footnotetext{
${ }^{247}$ In seiner Rede sagte Nasarbajew folgendes: „How do I see the future of that space that used to be one country? Nowadays, in the conditions of sovereignty, recognising equal rights of all, respecting the sovereignty and independence of each state, we could create a completely new unity. I would call it the Eurasian Union“ (In: Nurbekov 2014).
} 
EAWU (The Ministry of Foreign Affairs of the Russian Federation 2016, Artikel 51) folgendermaßen:

„,Russland hält für zentral die Aufgabe der Vertiefung und Erweiterung der Integration im Rahmen der Eurasischen Wirtschaftsunion (EAWU) mit der Republik Armenien, der Republik Weißrussland, der Republik Kasachstan und der Republik Kirgisien zum Zweck stabiler Entwicklung, umfassender technologischer Modernisierung, Kooperation, Erhöhung der Konkurrenzfähigkeit der Volkswirtschaften der Mitgliedstaaten der EAWU und der Anhebung des Lebensstandards ihrer Bevölkerungen. Die EAWU soll den freien Verkehr von Waren, Dienstleistungen, Kapital und Arbeitnehmern gewährleisten und zum Standort für die Umsetzung gemeinsamer Infrastruktur- und Investitionsprojekte werden. Die auf Basis universaler Integrationsprinzipien gebildete EAWU ist durchaus in der Lage, eine wichtige Rolle bei der Harmonisierung der Integrationsprozesse in der europäischen und eurasischen Region zu spielen."

2015 wurden konkrete Vorschläge für einen gemeinsamen Energiemarkt entwickelt (Pastukhova/Westphal 2016: 1). RU hat eine sehr dominante Rolle in der EAWU, 87 \% des EAWU-BIP (Bruttoinlandsprodukt) fallen auf RU. Somit ist das Land mit Abstand das größte und das wohlhabendste Land der EAWU (Giucci/ Mdinaradze 2017: 5). RU konzentriert sich auf die Gewinnung neuer Mitglieder und Partner. Mit China einigte sich das Land über eine Strategische Partnerschaft (O. V. 2018: EAWU weitetet Kooperationen ...). Mit dem Iran beschloss die EAWU die Senkung von Handelsbarrieren für drei Jahre. Laut Vereinbarung wird innerhalb der kommenden drei Jahre eine gemeinsame Freihandelszone gegründet werden (ebd.). RU handelt auch mit Indien. Im Oktober 2018 erklärte die EAWU, sie befinde sich kurz vor dem Abschluss eines Freihandelsabkommens mit Indien (O. V. 2018: EAWU kurz vor ...). Vietnam hat sich zu einer Freihandelszone der EAWU angeschlossen. Die TR erhielt von RU (2011) und Kasachstan $(2013,2014)$ eine Einladung zum EAWU-Beitritt (Siehe hierzu Kap. 5.7). ${ }^{248}$

Der Westen wirft RU vor, die EAWU primär aus politischen Gründen gegründet zu haben, „um seinen Status als Vormacht in Eurasien zu festigen und den eigenen Einfluss in der Region zu bewahren.“ (Pastukhova/Westphal 2016: 2). Clinton erklärte 2012, RU betreibe

\footnotetext{
${ }^{248}$ In seiner aktuellen „Außenpolitikkonzeption von 2016“schreibt RU, dass RU die Aufgabe der Vertiefung und Erweiterung der Integration innerhalb der EAWU für zentral hält. Des Weiteren schreibt das Land auch, dass die EAWU durchaus in der Lage ist, eine wichtige Rolle bei der Harmonisierung der Integrationsprozesse in der europäischen und eurasischen Region zu spielen (The Ministry Of Foreign Affairs Of The Russian Federation 2016, Artikel 51).
} 
mit seinem Integrationsprozess auf dem ehemaligen Sowjetgebiet eine „Re-Sowjetisierung“. Ziel der USA sei daher die Verlangsamung, bzw. die Sabotage dieses Integrationsprozesses:

"There is a move to re-Sovietise the region [...] It's not going to be called that. It's going to be called a customs union, it will be called Eurasian Union and all of that [...] But let's make no mistake about it. We know what the goal is and we are trying to figure out effective ways to slow down or prevent it." (Clover 2012).

Die Unions-Mitglieder sehen aber keine „Re-Sowjetisierungsgefahr“ in der EAWU. Der Präsident von Weißrussland, Lukaschenko, sagte: „Politische Unabhängigkeit, Souveränität, Stabilität des Landes - das ist das Entscheidende. Wir wollen unabhängige und souveräne Staaten bleiben.“ (Timtschenko 2015). Der kasachische Präsident Nasarbajew, der gleichzeitig Ideenvater der EAWU ist (ebd.), betrachtet die EAWU als ausschließlich wirtschaftliches Projekt, wie er im Rahmen einer Rede bei der international renommierten Denkfabrik Carnegie Endowment in Washington, DC zum Ausdruck brachte: „Ich würde gerne betonen, dass es nicht die Wiederbelebung der Sowjetunion anstrebt ${ }^{\prime \prime}$, sagte er und fügte hinzu, dass es notwendig ist ,diese Stereotypen aus dem Kalten Krieg loszuwerden.“ (O. V. 2016: Kasachstan: Eurasische Wirtschaftsunion ...). In den zentralasiatischen EAWU-Mitgliedstaaten Kasachstan und Kirgisistan findet die EAWU laut Meinungsumfragen hohe Zustimmung: 80 \% der kasachischen und $86 \%$ der kirgisischen Bevölkerung sind für die EAWU (Schiek 2016: 1). ${ }^{249}$ RU definierte in seiner „Sicherheitsstrategie von 2015“ die westlichen Aktivitäten als Hindernis für die regionalen Integrationsprozesse und Grund für die Spannungen in Eurasien.

Tadschikistan äußerte sich im Juli 2016, dass die tadschikische Regierung den Beitritt des Landes in die EAWU prüfen wird (O. V. 2016: Tadschikische Regierung prüft ...). Usbekistan näherte sich nach dem Andijan-Aufstand 2005, hinter dem das Land den Westen vermutete, an RU an und trat 2006 der OVKS bei, unterschrieb das Beitrittsprotokoll für die EAWU. Den Beitrittsprozess in die EAWU allerdings kündigte das Land 2008 und trat 2012 aus OVKS wieder aus. Seit der Ära des usbekischen Präsidenten Mirsijojew (2016 - im Amt) nähert sich Usbekistan an RU an (siehe hierzu Kap. 6.2 und Kap. 6.7). Im Mai 2020 bewilligte der usbekische Senat mehrheitlich den Beobachterstatus Usbekistans in der EAWU (O. V. 2020: Özbekistan Senatosundan Avrasya ...). Turkmenistan hält sich wegen seiner Neutralität von den multilateralen Organisationen möglichst fern. Der turkmenische

\footnotetext{
${ }^{249}$ Die Umfrageergebnisse wurden im Rahmen des „Integrationsbarometers“ ermittelt, das die Eurasische Entwicklungsbank (EABR) seit 2012 jährlich herausgibt (Schiek 2016: 1).
} 
Botschafter in Moskau, Berdimurad Recepov, erklärte 2014, dass Turkmenistan RU zwar als strategischen Partner sieht und mit ihm im Rahmen der Vereinten Nationen, OSZE und GUS zusammenarbeitet. Das Land wird aber der EAWU nicht beitreten (O. V. 2014: Türkmenistan Avrasya Birliği'ne ...). Trotzdem ist RU der größte Arbeitsmarkt auch für keine EAWU-Mitglieder ZAs. Schätzungen zufolge arbeiten 2017 etwa 5 bis 10 Mio. Zentralasiaten in RU (Ibrahimov 2017). Die Zahl der illegalen Arbeiter dürfte sehr viel höher liegen.

Die TR versuchte im Rahmen ihrer „Türkenweltpolitik“ die Turkstaaten wirtschaftlich auszubeuten, politisch zu beherrschen und kulturell zu prägen. Für das Ziel gründete sie Organisationen wie z. B. den „Türkengipfel“, TURKSOY (Mitglieder sind alle zentralasiatischen turksprachigen Staaten, Aserbaidschan und die TR), TÜRKPA (TR, Kasachstan, Kirgisistan und Aserbaidschan) und die TDIK (Mitglieder wie TÜRKPA). Sie forderte auf dem ersten Türkengipfel 1992 einen wirtschaftlichen Raum zu gründen, in dem die türkische Lira als Währung gilt und die fossilen Brennstoffe gemeinsam vermarktet wird. Gleich nach ihrer Unabhängigkeit bekamen die zentralasiatischen Staaten von der TR EximBank Kredite im Wert von 1,1 Mrd. US-Dollar. Bis 2011 erreichte die Kredit-Summe 1,8 Mrd. US-Dollar (Türkiye Cumhuriyeti Disisleri Bakanligi o. J. a). Unter der ErdoganRegierung stiegen die Entwicklungshilfen an die Turkstaaten enorm: Als die AKP 2002 an die Macht kam, beliefen sich die Entwicklungshilfen der TIKA auf eine Höhe von insgesamt 85 Mio. Dollar. In 2014 hingegen betrugen sie bereits 3,591 Mrd. Dollar. Die TIKA fasste die Daten über die Entwicklungshilfen an ZA nicht getrennt, sondern mit Südasien zusammen. Sie befanden sich auf dem 2. Platz als Empfänger und erhielten 486,6 Mio. USDollar. ${ }^{250}$ Laut Daten des „Ministerpräsidentschaft-Büro für die Öffentliche Diplomatie“ (türkisch: Kamu Diplomasisi Koordinatörlügü) erhielt 2014 allein Kirgisistan 84,8 Mio. US-Dollar Entwicklungshilfe, fast so hoch wie 2002 die gesamte Entwicklungshilfe der TR für die gesamte Welt. Und Kasachstan erhielt 2014 40,5 Mio. Dollar Entwicklungshilfe (T.C. Basbakanlik Kamu Diplomasisi Koordinatörlügü o. J.). Aufgrund der türkischen pantürkistischen und/oder islamischen politischen und kulturpolitischen Ziele allerdings nahmen die zentralasiatischen Staaten von der TR Abstand (siehe hierzu Kap. 4.1.2.1 und Kap. 6.1).

${ }^{250}$ Der größte Teil der Entwicklungshilfe (2,5 Mrd.) ging 2014 in den Osten, unter anderem an die syrischen Flüchtlinge (davon 2,291 Mrd.) in der TR (T. C. BASBAKANLIK, TIKA (TÜRK ISBIRLIGI VE KOORDINASYON AJANSLIGI BASKANLIGI) 2015). 
Usbekistan nimmt seit dem Attentat am ehemaligen usbekischen Präsidenten Karimow 1999 an keinen Gipfel mehr teil und unterbrach seine Beziehungen zu der TR, und schloss die gesamten türkischen Schulen im Lande. Das Land ist auch nicht in der TÜRKPA und TDIK als Mitglied zu sehen. Turkmenistan ist aufgrund seiner Neutralität zurückhaltend und schloss die türkischen Schulen und Universität aufgrund der pantürkistisch-islamistischen Arbeiten dieser Bildungseinrichtungen. Kirgisistan und Kasachstan sind zwar TÜRKPA und TDIK-Mitglieder, schlossen aber die Gülen-Schulen trotz der türkischen Anforderungen nicht. Im Gegensatz zur TR arbeiten sie mit RU sicherheitspolitisch (OVKS) und wirtschaftspolitisch (EAWU) strategisch eng zusammen. D. h. sie sind eher russlandnah.

Die TR versuchte auch im Rahmen der internationalen Organisationen, wie die „Economic Cooperation Organization“ $(\mathrm{ECO})^{251}$ und die „Organisation of Islamic Cooperation“ $(\mathrm{OIC})^{252}$ mit den zentralasiatischen Staaten zu kooperieren. Sowohl in der ECO als auch in der OIC sind alle zentralasiatischen Staaten sowie die TR Mitglieder. Die ECO konnte bis jetzt keine Erfolge erzielen. Ihre Projekte blieben nur auf dem Papier. Die OIC benutzte die TR zur Verstärkung ihrer Außenpolitik. Der ehemalige Ministerpräsident der TR, Davutoglu z. B., forderte von den OIC-Mitgliedern auf dem 13. Gipfeltreffen ihre Unterstützung für Palästina, Karabach sowie für die Krim (AKP 2016: Başbakan Davutoğlu ...) ein. Auch im Rahmen der OIC konnte die TR hinsichtlich ihrer ZAP keine Erfolge erzielen. Die TR konnte sowohl im Rahmen ihrer nationalen als auch internationalen Organisationen mit den zentralasiatischen Staaten keinen gemeinsamen wirtschaftlichen Raum unter ihrer Herrschaft gründen. Ihre schwache wirtschaftliche Kapazität, unrealistische pantürkistische Erwartungen und Ziele sowie das Misstrauen der zentralasiatischen Staaten ihr gegenüber (siehe hierzu Kap. 4.1) spielten dabei eine entscheidende Rolle. Ihre wirtschaftlichen Beziehungen zu den zentralasiatischen Staaten sind eher bilateral geprägt (siehe Kap. 5.8).

\footnotetext{
${ }^{251}$ ECO wurde 1985 von der TR, dem Iran und Pakistan gegründet, um die wirtschaftlichen, technischen und kulturellen Beziehungen zwischen den Mitgliedern zu vertiefen. 1992 wurden alle zentralasiatischen Staaten Mitglieder. ECO ist die Nachfolgerorganisation von „Regional Cooperation for Development (RCD), welche zwischen den Jahren 1964-1979 existierte (ECO o. J.).

${ }^{252} \mathrm{OIC}$ hat 57 Mitgliedsstaaten in vier Kontinenten. Sie ist zum Zweck der Interessenvertretung der „muslimischen Welt“ und für die Gewährleistung des internationalen Friedens 1969 gegründet. Alle zentralasiatischen Staaten sowie die TR sind Mitglied in dieser Organisation. Für weitere Informationen siehe: Organisation of Islamic Cooperation (2016).
} 


\subsection{Ist eine türkisch-russische strategische Wirtschaftspolitik im Rahmen der EAWU möglich?}

Der russische Präsident Putin lud die TR im November 2011 ein, anstelle der EU der EAWU beizutreten. Erdogan äußerte sich bei seiner Russlandsreise am 18. Juli 2012 allerdings nicht über den Beitrittswunsch der TR in die EAWU, sondern in die SOZ. Er forderte von RU Unterstützung für ihren möglichen SOZ-Beitritt an (O. V. 2012: Bizi de Sanghay ...). ${ }^{253}$ Der Berater von Putin, Sergej Markow, erklärte, die TR könne aufgrund ihrer NATOMitgliedschaft und den engen Beziehungen mit den USA nicht der SOZ beitreten. Markow zufolge solle sich die TR daher für den EAWU-Beitritt entscheiden (Erem 2016). Eine ähnliche Einladung erhielt die TR vom kasachischen Präsidenten Nasarbajew am 24. Oktober 2013 auf einem Treffen der EAWU (Dügen 2013). Laut Nasarbajew erkundigte sich Erdogan in einem Telefongespräch mit ihm über die Möglichkeit eines EAWU-Beitritts der TR (O. V. 2013: Erdogan Birlige Girmek ...). Der kasachische Präsident wiederholte seine Einladung beim 4. Gipfeltreffen des Präsidentenrats der türksprachigen, bzw. türkischsprachigen Länder (4. Türk Dili Konuşan Ülkeler İşbirliği Konseyi Devlet Başkanları Zirvesi) im Juni 2014 in der TR (O. V. 2014: Avrasya Birliği kuruldu...). Kasachstans Einladung zeigt meiner Einschätzung nach einerseits, dass Kasachstan die TR im Statusvergleich unter RU einstuft, da der führende Akteuer der EAWU RU ist. Andererseits zeigt sie, dass die „Türkenwelt“ der TR von Kasachstan keine Akzeptanz findet.

Die türkisch-russischen Beziehungen verschlechterten sich durch den Abschuss eines russischen Kampfjets Su-24 durch die TR am 24. November 2015, infolgedessen RU die Beziehungen zu der TR abbrach. Politische und wirtschaftliche Sanktionen ${ }^{254}$ gegen die TR waren die Folge. In der politischen Eiszeit (bis etwa August 2016) brach der Handel zwischen beiden Ländern um 42 \% zu Ungunsten der TR ein (Bidder 2016) und eine EAWUMitgliedschaft der TR war nicht mehr auf der Tagesordnung. RU führte wieder die Visumpflicht für die türkischen Bürger ein. Erdogan entschuldigte sich bei Putin Ende Juli

\footnotetext{
${ }^{253}$ Seine Äußerungen bezüglich der SOZ wurden von einigen türkischen Wissenschaftler*innen und Journalist*innen als Botschaft an die EU interpretiert, um sie zu Wiederaufnahme der Beitrittsverhandlungen zu bewegen (Sezer 2013). Die EU erklärte im Oktober 2013, dass sie die Beitrittsverhandlungen mit der TR nach 3-jähriger Pause wieder aufnehmen wird (O. V. 2013: Türkiye-AB müzakereleri ...).

254 „Neben verbalen Drohungen unterschrieb Putin am 28. November 2015 in Moskau einen Erlass, der Sanktionen gegen die Türkei enthält, die vom Tourismus bis zur Einführung der Visapflicht für die türkischen Bürger umfassen. Der Import vieler Waren aus der Türkei, von Gemüse und Obst bis zu Fleischwaren, wurde gestoppt“"(Varli 2016).
} 
2016 schriftlich für den Abschuss des Kampfjets. Anschließend trafen sich beide Präsidenten im August 2016 in RU und vereinbarten die schrittweise Aufhebung der Sanktionen, den Bau eines Kernkraftwerkes im türkischen Mersin/Akkuyu, den Bau einer Erdgaspipeline Namens TurkStream, die sowohl die TR als auch via TR Europa unter Umgehung der Ukraine mit Erdgas versorgen soll (Bidder 2016). Im Dezember 2016 einigten sich die TR, RU und der Iran darauf, zukünftig in Syrien gemeinsam vorzugehen. Die Zusammenarbeit dieser drei Staaten wird von den Eurasist*innen dieser Länder unterstützt. Die EAWUMitgliedschaft der TR kam wieder als Alternative zu den westlichen Organisationen auf die Tagesordnung. Der damalige türkische Wirtschaftsminister Zeybekci erklärte 2017, die TR wolle auch der EAWU-Zollunion beitreten, ohne die Zollunion mit der EU verlassen zu müssen und verhandelt dieses Ziel mit RU aus (O. V. 2017: Alternatif Avrasya Gümrük ...). ${ }^{255}$ In der TR wird der EAWU-Beitritt der TR bis heute als Alternative zu einem EUBeitritt bzw. zum westlichen Bündnis dargestellt. Die türkischen Verlautbarungen über den EAWU-Beitritt wurden im Westen als Druck auf die EU-Beitrittsverhandlungen interpretiert. Aktuell ist die TR von einem EU-Beitritt weit entfernt und wird schrittweise autoritär. Ist aber eine türkisch-russische strategische Wirtschaftspolitik im Rahmen der EAWU-möglich?

Die EU erwartet von der TR für den EU-Beitritt die Erfüllung der politischen und wirtschaftlichen Kopenhagener Kriterien, welche 1993 in Kopenhagen vom Europäischen Rat festgelegt wurden. Die politischen Beitrittskriterien für eine EU-Mitgliedschaft sind, eine stabile demokratische und rechtstaatliche Ordnung und die Wahrung der Menschenrechte sowie Minderheitenschutz. Von der Erfüllung dieser Kriterien würde die Bevölkerung der TR profitieren. Sollte die TR allerdings das Ziel für eine EU-Mitgliedschaft aufgeben, könnte sie die Motivation für die Verbesserung ihres politischen und wirtschaftlichen Systems verlieren, was momentan der Fall ist. Im Verhältnis zur EU wird der TR von der EAWU keine Bedingung für eine Mitgliedschaft gemacht. In den EAWUMitgliedsstaaten (RU, Belarus, Armenien, Kasachstan und Kirgisistan) mangelt es selbst an diesen Kriterien. Auch die wirtschaftlichen Beitrittskriterien einer EU-Mitgliedschaft, wie eine funktionierende und wettbewerbsfähige Marktwirtschaft, müssen Mitgliedskandidaten

\footnotetext{
255 Zeybekci: „Türkiye olarak, Avrupa Birliği ile Gümrük Birliği anlaşması çerçevesini bozmadan Avrasya Gümrük Birliğiyle de bir serbest ticaret anlaşmasını gerçekleştirmek, birliğe üye olmak istiyoruz. Bu, net olarak bizim onlara ilettiğimiz bir talebimiz. Bu yönde de genel itibarıyla olumlu görüşmeler var. Kendi aramızda yaptığımız ikili görüşmelerde bu yönde ilk temasları bu sene içinde başlatabileceğimizi düşünüyoruz" dedi (O. V. 2017: Alternatif Avrasya Gümrük ...).
} 
erfüllen. Für die EAWU-Mitgliedschaft hingegen gibt es keine derartigen wirtschaftlichen Beitrittskriterien. Die Mitgliedschaften der wirtschaftlich sehr schwachen Länder in der EAWU, Kirgisistan und Armenien, zeigen das deutlich. RU hat eine sehr dominante Rolle in der EAWU. $87 \%$ des EAWU-BIP fallen auf RU. Somit ist das Land mit Abstand das größte, aber auch das wohlhabendste Land der EAWU (Giucci/Mdinaradze 2017: 5).

Für die TR ist ein Beitritt in die EAWU formell möglich, aber unter heutigen Bedingungen aus den folgenden Gründen derzeit nicht zu erwarten:

* Die wirtschaftlichen Vorteile der TR durch den Handel mit der EU ist keineswegs mit ihrem Handel mit der EAWU vergleichbar. Der größte Handelspartner der TR ist die EU. 2017 exportierte die TR Waren in Wert von insgesamt 156,9 Mrd. USDollar. Fast die Hälfte davon (46,8 \%, 73,9 Mrd. US-Dollar) gingen in die EU (TUIK 2016: Ülke guruplarina göre yillik ihracaat). In die EAWU hingegen lieferte sie im selben Jahr 2,7 \% (4,2 Mrd. US-Dollar) ihrer Gesamtexporte, ${ }^{256}$ davon entfallen 2,7 Mrd. US-Dollar, bzw. 1,7 \% auf RU. Bei den Importzahlen hat die EAWU einen höheren Anteil. 2017 kamen etwa 9,1 \% (21,3 Mrd. US-Dollar) der türkischen Gesamtimporte (233,8 Mrd. US-Dollar) aus der EAWU. Ihr größter Exporteur war RU. Seine Exporte in die TR beliefen sich auf 19,5 Mrd. US-Dollar und machten 8,3 $\%$ der türkischen Gesamtimporte aus. 58,7 \% davon machten die fossilen Brennstoffe sowie deren Erzeugnisse aus (Trade Map 2018: Bilateral trade between Turkey and Russian Federation: Imports...). Im selben Jahr importierte die TR hingegen 36,5 \% (85,2 Mrd. US-Dollar) ihrer Gesamtimporte aus der EU. Am Außenhandelsvolumen der TR hat die EU einen knapp über 40 prozentigen Anteil, die EAWU hingegen 6,5 $\%$. Wie diese Zahlen zeigen, ist die EAWU momentan keine wirtschaftliche Alternative zur EU. Wenn sich die TR trotzdem für die EAWU entscheiden würde, würde sie auf die Zollunion mit der EU und ihre mögliche EU-Beitrittschance verzichten müssen. Laut Ankara-Abkommen von 1963 und Zollabkommen 1995 mit der EU kann die TR gleichzeitig nicht in einer anderen Zollunion Mitglied werden.

* Ihr Handelshaushalt mit der EU ist ausgeglichener (kein großes Handelsdefizit) im Vergleich zu ihrem Handel mit der EAWU, genauer gesagt mit RU. Der türkisch-

\footnotetext{
${ }^{256}$ Diese wirtschaftlichen Daten entnahm ich aus der Homepage Trade Map (https://www.trademap.org/) und bereitete sie auf.
} 
russische energiepolitisch geprägte Handel ist zum Nachteil der TR und die TR ist von RU energiepolitisch abhängig. Diese Abhängigkeit wurde mit der Inbetriebnahme der Erdgaspipeline TurkStream Ende 2019 größer.

* EAWU ist zwar eine wirtschaftliche Organisation; aber ihre Mitglieder sind gleichzeitig Mitglied der von RU dominierten (sicherheits)politischen Organisationen GUS und OVKS. D. h., wenn die TR der EAWU beitreten würde, müsste sie auch sehr wahrscheinlich mit RU im Rahmen der OVKS sicherheitspolitisch und/oder GUS strategisch zusammen arbeiten und auf ihre NATO-Mitgliedschaft verzichten.

* Der EAWU-Beitritt der TR würde somit eine Abwendung der TR von den USA und der NATO bedeuten, weil die USA/NATO gegen die EAWU (siehe hierzu Kap. 5.3) sind. Die sicherheitspolitischen Probleme der TR mit RU, mit Armenien und mit den Kurden*innen sind die Hindernisse vor einer strategischen sicherheits- sowie wirtschaftspolitischen Zusammenarbeit der TR mit RU (siehe hierzu Kap. 6.9).

* Die TR sanktioniert Armenien seit 1993 und Armenien ist ein Mitglied der EAWU. D. h. im Falle eines EAWU-Beitrittes ist die TR zur Öffnung ihrer Grenzen, Aufhebung der Sanktionen und wirtschaftliche Zusammenarbeit mit Armenien gezwungen. Armenien hat Gebietsansprüche gegenüber der TR und möchte den Völkermord an den Armeniern im Osmanischen Reich weltweit anerkennen lassen. RU ist auf dieser Frage auf der armenischen Seite, ist armenische Schutzmacht und erkennt den Völkermord an (siehe hierzu Kap. 6.9). Bei einem EAWU-Beitritt müsste die TR den Völkermord an den Armeniern offiziell anerkennen, was wiederum für die TR mögliche Gebietsverluste und Wiedergutmachungszahlungen an Armenien bedeuten würde. Eine gegensätzliche Haltung haben die TR und RU auch über die PKK und YPG (Yekineyen Parastina Gel, die Volksverteidigungseinheiten) (siehe hierzu Kap. 6.9).

* Einige türkische Entscheidungsträger, wie der Politiker Ahmet Davutoglu, glauben, dass die TR für eine erfolgreiche ZAP eine Landverbindung zu der Region braucht: Diese ist entweder durch den Iran oder RU möglich (Davutoglu 2011: 497-498). Die TR arbeitet aber politisch und wirtschaftlich eng mit den USA zusammen, wie der 
Wettbewerb um die kaspischen fossilen Brennstoffe belegt. Mit einem möglichen EAWU-Beitritt müsste die TR auf ihre (energiepolitische) Rivalität mit RU um/in ZA verzichten. Sie soll auch auf ihre pantürkistische, zum Teil islamistische ZAP verzichten und ZA als russisches „Nahes Ausland“ anerkennen. Ein Beitritt in die EAWU würde für die TR die endgültige Akzeptanz des russischen Einflusses über „ihre Türkenwelt“ bedeuten. Die TR verfolgt aber weiterhin ihre pantürkistischen Ambitionen in den postsowjetischen Turkstaaten; und zwar seit letzten Jahren wieder stärker.

\subsection{Wirtschaftliche Beziehungen der zentralasiatischen Staaten mit der Türkei und Russland}

Die Wirtschaften der Region sind unterschiedlich geprägt. ${ }^{257}$ Kasachstan ist das ölreichste Land ZAs. Die kasachische Wirtschaft ist auf die Exporte seiner fossilen Brennstoffexporte angewiesen. 2016 exportierte das Land Waren im Wert von 36,8 Mrd. US-Dollar. Etwa 60 \% (22,3 Mrd. US-Dollar) seiner gesamten Exporte machten die mit dem Produktcode 27 gekennzeichneten fossilen Brennstoffe und deren Produkte aus, gefolgt von Eisen und Stahl (Produktcode 72) mit 7,4\% und anorganische Chemikalien; organische oder anorganische Verbindungen von Edelmetallen, von Seltenerdmetallen (Produktcode 28) mit 6,6 \%. ${ }^{258} 20,3$ $\%$ der kasachischen Exporte gingen nach Italien. ${ }^{259} 11,4 \%$ nach China ${ }^{260}$ und 9,5 \% nach RU (3,5 Mrd. US-Dollar). ${ }^{261}$ Die wichtigsten Exportwaren nach RU waren Erze, Schlacken und Aschen (Produktcode 26). Diese machten $19 \%$ der kasachischen Exporte nach RU, gefolgt von anorganischen Chemikalien; organischne oder anorganischen Verbindungen

\footnotetext{
${ }^{257}$ In diesem Unterkapitel verwendete ich die Wirtschaftsdaten (Export und Import) der zentralasiatischen Staaten von 2016, um einen Vergleich dieser Daten zu ermöglichen, weil z. B. Tadschikistan 2018 seine Wirtschaftsdaten von 2017 noch nicht veröffentlicht hatte. Betrachtet werden auch die Daten der drei wichtigsten Exports- und Importspartner dieser Staaten sowie ihr Handel mit der TR und RU. Des Weiteren gab ich in diesem Unterkapitel die Literaturangaben über die Wirtschaftsdaten für die bessere Lesbarkeit als Fußnote an. Alle Daten von Trade Map aus dem Jahr 2017 hatte ich zuletzt am 22.10.2018 abgerufen. Nach einiger Zeit waren andere wirtschaftlichen Daten mit diesen Links verknüpft.

258 Trade Map (2017): List of products exported by Kazakhstan http://www.trademap.org/Product_SelCountry_TS.aspx?nvpm=1|398||||TOTAL||2|1|1|2|2|1|1|1|1

${ }^{259}$ 20,3 \% (7,5 Mrd. US-Dollar) der kasachischen Exporte gingen nach Italien. 97,9 \% davon fossile Brennstoffe und deren Erzeugnisse. Trade Map (2017): Bilateral trade between Kazakhstan and Italy. Product: TOTAL All products, http://www.trademap.org/Bilateral_TS.aspx?nvpm=1|398||381||TOTAL|||2|1|1|2|2|1|1|1|1

${ }^{260} 11,4 \%$ (4,2 Mrd. US-Dollar) der kasachischen Exporte gingen nach China, davon $24 \%$ fossile Brennstoffe und deren Erzeugnisse, 20,5 \% Kupfer und Kupferartikel, 19,6 \% Chemikalien, Seltene Erden und Edellmetalle. Trade Map (2017): Bilateral trade between Kazakhstan and China. Product: TOTAL All products. http://www.trademap.org/Bilateral_TS.aspx?nvpm=1|398||156||TOTAL|||2|1|1|2|2|1|1|1|1 261 Trade Map (2017): List of importing markets for a product exported by Kazakhstan. https://www.trademap.org/Country_SelProductCountry_TS.aspx?nvpm=1|398||||TOTAL|||2|1|1|2|2|1|2|1|1
} 
von Edelmetallen, von Seltenerdmetallen (17\%), Eisen und Stahl (16,7\%) und fossilen Brennstoffen und deren Produkte usw. $(12,7 \%) .{ }^{262}$ Die TR importierte aus Kasachstan Waren in Wert von 851 Mio. US-Dollar und befand sich mit einem Anteil von 2,3\% auf dem 12. Platz der kasachischen Abnehmer. ${ }^{263}$ Die wichtigsten Exportwaren davon waren fossile Brennstoffe und deren Produkte mit einem Anteil von 32,6 \%, Kupfer und Kupferprodukte (31, 6 \%, Produktcode 74) und Zink und Zinkprodukte (19,6 \%, Produktcode 79). ${ }^{264}$

Kasachstan importierte 2016 Waren in Wert von 25,2 Mrd. US-Dollar. 17,5 \% seiner Importe machten unter dem Produktcode 84 gelisteten Waren Maschinen, mechanische Geräte, Kernreaktoren, Speichererhitzer und Teile davon aus, gefolgt von 9,6 \% elektrische Maschinen und Geräte und deren Teile; Tonaufnahme- und Tonwiedergabegeräte, Fernseher (Produktcode 85) und mit 7,8 \% Waren aus Eisen und Stahl. ${ }^{265}$ Aus RU importierte das Land 36,3 \% (9,1 Mrd. US-Dollar), aus China 14,5 \% ${ }^{266}$ und aus Deutschland $5,7 \%{ }^{267}$ seiner gesamten Importe. Die TR befand sich auf dem 7. Platz der kasachischen Exporteure mit 618,1 Mio. US-Dollar (2,5\% der gesamten kasachischen Importe). ${ }^{268}$ Die drei wichtigsten Warengruppen aus RU waren fossile Brennstoffe und deren Produkte für 1,06 Mrd. US-Dollar. Diese machten 11,7 \% seiner Importe aus RU aus, gefolgt mit 9,3\% Maschinen, mechanischen Geräten, Kernreaktoren, Speichererhitzer und Teile davon und mit 6,8 \% elektrische Maschinen und Geräte und deren Teile; Tonaufnahme- und Tonwiedergabegeräte, Fernseher. ${ }^{269} 16 \%$ der kasachischen Importe aus der TR machten Maschinen, mechanische Geräte, Kernreaktoren, Speichererhitzer, Teile davon, 9,8 \%

\footnotetext{
${ }^{262}$ Trade Map (2017): Bilateral trade between Kazakhstan and Russian Federation. Product: TOTAL All products, http://www.trademap.org/Bilateral TS.aspx?nvpm=1|398||643||TOTAL|||2|1|1|2|2|1|1|1|1 ${ }^{263}$ Trade Map (2017): List of importing markets for a product exported by Kazakhstan. Product: TOTAL All products.

http://www.trademap.org/Country SelProductCountry TS.aspx?nvpm=1|398||||TOTAL|||2|1|1|2|2|1|2|1|1 ${ }^{264}$ Trade Map (2017): Bilateral trade between Kazakhstan and Turkey. Product: TOTAL All products, http://www.trademap.org/Bilateral TS.aspx?nvpm=1|398||792||TOTAL|||2|1|1|2|2|1|1|1|1

${ }^{265}$ Trade Map (2017): List of products imported by Kazakhstan. http://www.trademap.org/Product SelCountry TS.aspx?nvpm=1|398||||TOTAL||2|1|1|1|2|1|1|1|1 $26624 \%$ der kasachischen Importe aus China machten die Maschinen, mechanische Geräte, Kernreaktoren, Speichererhitzer und Teile davon, $19 \%$ elektrisch-elektronische Geräte und $9 \%$ Waren aus Eisen und Stahl aus. Trade Map (2017): Bilateral trade between Kazakhstan and China. Product: TOTAL All products, http://www.trademap.org/Bilateral TS.aspx?nvpm=1|398||156||TOTAL|||2|1|1|1|2|1|1|1|1 ${ }^{267}$ Davon 29,4 \% Maschinen, 17,4 \% Waren aus Eisen und Stahl, 11,3\% Pharmazeutische Produkte usw. Trade Map (2017): Bilateral trade between Kazakhstan and Germany. Product: TOTAL All products, http://www.trademap.org/Bilateral TS.aspx?nvpm=1|398||276||TOTAL|||2|1|1|1|2|1|1|1|1

${ }^{268}$ Trade Map (2017): List of supplying markets for a product imported by Kazakhstan. Product: TOTAL All products, http://www.trademap.org/Country_SelProductCountry TS.aspx?nvpm=1|398|||TOTAL|||2|1|1|1|2|1|2|1|1 ${ }^{269}$ Trade Map (2017): Bilateral trade between Kazakhstan and Russian Federation. Product: TOTAL All products, http://www.trademap.org/Bilateral_TS.aspx?nvpm=1|398||643||TOTAL|||2|1|1|1|2|1|1|1|1
} 
elektrische Maschinen und Geräte und deren Teile aus; Tonaufnahme- und Tonwiedergabegeräte, Fernseher und 6,3 \% Bekleidung und Bekleidungswaren usw. (Produktcode 62). ${ }^{270}$

Turkmenistan ist das erdgasreichste Land ZAs. Das Land exportierte 2016 Waren im Wert von 7,9 Mrd. US-Dollar. Fossile Brennstoffe und deren Produkte sowie Baumwolle waren die Haupt-Exportwaren des Landes. ${ }^{271}$ China war der größte Importeur Turkmenistans. ${ }^{272}$ Etwa 70 \% (5,6 Mrd. US-Dollar) der turkmenischen Exporte gingen nach China. Davon 98,5 $\%$ machten die fossilen Brennstoffexporte aus. ${ }^{273}$ Die TR war mit 5,7 \% (422 Mio. USDollar, davon 85 \% Baumwolle (Produktcode 52), 4,4 \% fossilen Brennstoffe und deren Produkte) $)^{274}$ der 2. größte Abnehmer Turkmenistans, gefolgt von Italien mit 5,6 \% (davon 99,5 \% fossilen Brennstoffe und deren Produkte). ${ }^{275}$ RU befand sich auf dem 5. Platz der turkmenischen Abnehmer mit 4,7 \% (331 Mio. US-Dollar, davon 65 \% Schiffe und Boote (Produktcode 89), 15 \% Kunststoffe und Kunststoffwaren (Produktcode 39), 10,6 \% Baumwolle, 3 \% Textilwaren (Produktcode 63). ${ }^{276}$

Turkmenistan importierte 2016 Waren in Höhe von 5,5 Mrd. US-Dollar. 26,3 \% (1,24 Mrd. US-Dollar) seiner Gesamtimporte kamen aus der TR (TUIK 2016). 19,7 \% davon machten Eisen und Stahlprodukte (Produktcode 73) aus, gefolgt mit 16,8 \% elektrische Maschinen und Geräte und deren Teile; Tonaufnahme- und Tonwiedergabegeräte, Fernsehen und 10 $\%$ Maschinen, mechanische Geräte, Kernreaktoren, Speichererhitzer, Teile davon. ${ }^{277}$ RU war mit $12 \%$ (570,6 Mio. US-Dollar) der turkmenischen Importe auf Platz 2 und

\footnotetext{
${ }^{270}$ Trade Map (2017): Bilateral trade between Kazakhstan and Turkey. Product: TOTAL All products, http://www.trademap.org/Bilateral TS.aspx?nvpm=1|398||792||TOTAL||2|1|1|1|2|1|1|1|1

${ }^{271}$ Laut des turkmenischen Statistikamtes „Türkmenistanyň Statistika baradaky döwlet komiteti” importierte Turkmenistan 2016 Waren in Wert von 13,2 Mrd. US-Dollar. Diese Zahl stimmt allerdings weder mit den turkmenischen Export-Import-Daten aus dem türkischen Statistikamt TUIK noch mit Trade Map überein. Daher werden hier die Daten von Trade Map herangezogen.

272 Trade Map (2017): List of importing markets for a product exported by Turkmenistan. Product: TOTAL All products.

http://www.trademap.org/Country_SelProductCountry_TS.aspx?nvpm=1|795||||TOTAL|||2|1|2|2|2|1|2|1|1

${ }^{273}$ Trade Map (2017): Bilateral trade between Turkmenistan and China. Product: TOTAL All products, https://www.trademap.org/Bilateral TS.aspx?nvpm=1|795||156||TOTAL |||2|1|2|2|2|1|1|1|1

${ }^{274}$ Trade Map (2017): Bilateral trade between Turkmenistan and Turkey. Product: TOTAL All products, https://www.trademap.org/Bilateral TS.aspx?nvpm=1|795||792||TOTAL|||2|1|2|2|2|1|1|1|1

${ }^{275}$ Trade Map (2017): Bilateral trade between Turkmenistan and Italy. Product: TOTAL All products, http://www.trademap.org/Bilateral TS.aspx?nvpm=1|795||381||TOTAL||2|1|2|2|2|1|1|1|1

${ }^{276}$ Trade Map (2017): Bilateral trade between Turkmenistan and Russian Federation. Product: TOTAL All products, http://www.trademap.org/Bilateral TS.aspx?nvpm=1|795||643||TOTAL|||2|1|2|2|2|1|1|1|1

277 Trade Map (2017): Bilateral trade between Turkey and Turkmenistan. Product: TOTAL All products, http://www.trademap.org/Bilateral_TS.aspx?nvpm=1|792||795||TOTAL|||2|1|1|2|2|1|1|1|1
} 
Deutschland mit 8,5\% auf Platz 3. ${ }^{278} 279$ Eisen- und Stahlprodukte (Produktcode 73) waren mit $28 \%$ die größte Warengruppe aus RU nach Turkmenistan, gefolgt von Eisen und Stahl (Produktcode 72) mit 12,5\%. ${ }^{280}$ China war mit 7,2 \% ${ }^{281}$ auf Platz 6 der Lieferländer Turkmenistans.

In Usbekistan ist das Gold eine wichtige Exportware. Auch seine Kupfer-, Eisen-, Uraniumund Baumwollausfuhr machen einen beträchtlichen Teil seiner Gesamtexporte aus. Außerdem ist das Land reich an Erdgas. Das Land exportierte 2016 Waren in Wert von 7,5 Mrd. US-Dollar. Etwa 38 \% seiner Gesamtexporte machte der Goldexport (Produktcode 7108) aus, gefolgt mit $11 \%$ fossilen Brennstoffen und deren Produkte und $10 \%$ Baumwolle. $^{282} 38 \%$ der usbekischen Exporte gingen in die Schweiz. ${ }^{283} 21 \%$ nach China ${ }^{284}$ und $10 \%$ (761 Mio. US-Dollar) nach RU. Die TR befand sich auf dem 4. Platz der Abnehmer mit $9 \%$ (709 Mio. US-Dollar). ${ }^{285} 26 \%$ der usbekischen Exporte nach RU machten Baumwolle, 21 \% Bekleidung und Bekleidungszubehör (Produktcode 61), 8 \% essbare Früchte und Nüsse; Schale von Zitrusfrüchten oder Melonen (Produktcode 08) aus. ${ }^{286}$ 50,6 $\%$ der usbekischen Exporte in die TR machten Kupfer und Kupferartikel (Produktcode 74), $15,8 \%$ Kunststoffe und Kunststoffwaren und 12,3\% Zink und Zinkwaren aus. ${ }^{287}$

\footnotetext{
278 Trade Map (2017): Bilateral trade between Turkmenistan and Germany. Product: TOTAL All products, http://www.trademap.org/Bilateral_TS.aspx?nvpm=1|795||276||TOTAL|||2|1|2|1|2|1|1|1|1

${ }^{279}$ Trade Map (2017): List of supplying markets for a product imported by Turkmenistan (Mirror). Product: TOTAL All products, http://www.trademap.org/Country SelProductCountry TS.aspx?nvpm=1|795||||TOTAL|||2|1|2|1|2|1|2|1|1 ${ }^{280}$ Trade Map (2017): Bilateral trade between Turkmenistan and Russian Federation. Product: TOTAL All products, https://www.trademap.org/Bilateral TS.aspx?nvpm=1|795||643||TOTAL||2|1|2|1|2|1|1|1|1 ${ }^{281}$ Davon 26,2 Maschinen, mechanische Geräte, 13,5 \% elektrisch-elektronische Geräte, 12,7 \% Fahrzeuge und Teile davon usw. Trade Map (2017): Bilateral trade between Turkmenistan and China. Product: TOTAL All products, http://www.trademap.org/Bilateral_TS.aspx?nvpm=1|795||156||TOTAL|||2|1|2|1|2|1|1|1|1 282 Trade Map (2017): List of products exported by Uzbekistan. https://www.trademap.org/Product_SelCountry TS.aspx?nvpm=1|860|||TOTAL|||2|1|2|2|2|1|1|1|1 283 99,9 \% der usbekischen Exporte in die Schweiz machte der Goldexport aus. Trade Map (2017): Bilateral trade between Uzbekistan and Switzerland. Product: TOTAL All products, http://www.trademap.org/Bilateral_TS.aspx?nvpm=1|860||757||TOTAL || $2|1| 2|2| 2|1| 1|1| 1$

$28443 \%$ der usbekischen Exporte nach China machten die fossilen Brennstoffe und deren Erzeugnisse, $22 \%$ Baumwolle und 12,8 \% anorganische Chemikalien, organische oder anorganische Verbindungen von Edelmetallen sowie von Seltenerdmetallen usw. aus.

Trade Map (2017): Bilateral trade between Uzbekistan and China. Product: TOTAL All products, http://www.trademap.org/Bilateral_TS.aspx?nvpm=1|860||156||TOTAL || $2|1| 2|2| 2|1| 1|1| 1$

285 Trade Map (2017): List of importing markets for a product exported by Uzbekistan (Mirror). Product: TOTAL All products, http://www.trademap.org/Country_SelProductCountry TS.aspx?nvpm=1|860||||TOTAL||2|1|2|2|2|1|2|1|1 286 Trade Map (2017): Bilateral trade between Uzbekistan and Russian Federation. Product: TOTAL All products, http://www.trademap.org/Bilateral_TS.aspx?nvpm=1|860||643||TOTAL|||2|1|2|2|2|1|1|1|1

287 Trade Map (2017): Bilateral trade between Uzbekistan and Turkey. Product: TOTAL All products, http://www.trademap.org/Bilateral_TS.aspx?nvpm=1|860||792||TOTAL|||2|1|2|2|2|1|1|1|1
} 
Usbekistan importierte 2016 Waren in Wert von 9,7 Mrd. US-Dollar. Maschinen, Fahrzeuge, elektrische Maschinen, Eisen und Stahl waren die wichtigsten Importwaren des Landes. China war mit $21 \%{ }^{288}$ das größte Importeur Usbekistans, gefolgt von RU (20\%, 1,96 Mrd. US-Dollar) und Korea (9,6 \%). ${ }^{289}$ Die TR befand sich mit 5,5 \% (533 Mio. USDollar) auf dem 5. Platz der usbekischen Lieferländer. ${ }^{290}$ Aus RU machte 17,9 \% der usbekischen Importe fossile Brennstoffe und deren Produkte, 13,4 \% Holz- und Holzwaren sowie Holzkohle (Produktcode 44), 11 \% Eisen und Stahl aus. ${ }^{291}$ 24,7 \% der Importe aus der TR machten Maschinen, mechanische Geräte, Kernreaktoren, Kessel und Teile davon, 10,6 \% Kunststoff und Kunststoffwaren, 8,2 \% unter Produktcode 96 verfasste Waren, wie Damenbinden (Tampons) und Tampons, Windeln und Windeleinlagen für Babys und ähnliche Waren usw. ${ }^{292}$

Kirgisistan exportierte 2016 Waren in Wert von 1,4 Mrd. US-Dollar. Seine wichtigste Exportware war Gold, die 49,3 \% seiner Gesamtexporte ausmachte. Erze, Schlacken und Aschen sowie die mit der Produktcode 99 gekennzeichnete nicht-klassifizierte Waren, wie z. B. Waffen, machten jeweils etwa 4,8 \% seiner Gesamtexporte aus. ${ }^{293}$ Drei der wichtigsten Abnehmer der kirgisischen Gesamtexporte waren die Schweiz mit einem Anteil von 45,5 $\%,{ }^{294}$ Kasachstan mit 10,6 \% ${ }^{295}$ und RU mit 10,2 \% (145 Mio. US-Dollar). Die TR befand

\footnotetext{
${ }^{288}$ Maschinen, mechanische Geräte, Kernreaktoren usw. machten $24 \%$, elektrische Maschinen und Geräte 16 $\%$ und Kunststoffe und Kunststoffwaren 7,5 \% der Importe aus China aus. Trade Map (2017): Bilateral trade between Uzbekistan and China. Product: TOTAL All products, http://www.trademap.org/Bilateral TS.aspx?nvpm=1|860||156||TOTAL || $2|1| 2|1| 2|1| 1|1| 1$

$28942 \%$ der usbekischen Importe aus Korea machten die Fahrzeuge, 29,4 \% Maschinen, mechanische Geräte, elektrische Maschinen und Geräte aus. Trade Map (2017): Bilateral trade between Uzbekistan and Korea, Republic of. Product: TOTAL All products, http://www.trademap.org/Bilateral_TS.aspx?nvpm=1|860||410||TOTAL||2|1|2|1|2|1|1|1|1

${ }^{290}$ Trade Map (2017): List of supplying markets for a product imported by Uzbekistan (Mirror). Product: TOTAL All products, http://www.trademap.org/Country SelProductCountry TS.aspx?nvpm=1|860||||TOTAL|||2|1|2|1|2|1|2|1|1 ${ }^{291}$ Trade Map (2017): Bilateral trade between Uzbekistan and Russian Federation. Product: TOTAL All products, http://www.trademap.org/Bilateral TS.aspx?nvpm=1|860||643||TOTAL|||2|1|2|1|2|1|1|1|1 ${ }^{292}$ Trade Map (2017): Bilateral trade between Uzbekistan and Turkey. Product: TOTAL All products, http://www.trademap.org/Bilateral_TS.aspx?nvpm=1|860||792||TOTAL|||2|1|2|1|2|1|1|1|1

${ }^{293}$ Trade Map (2017): List of products exported by Kyrgyzstan.

https://www.trademap.org/Product_SelCountry_TS.aspx?nvpm=1|417||||TOTAL|||2|1|1|2|2|1|1|1|1

294 99,9 \% der schweizerischen Importe aus Kirgisistan machte Goldexport aus.

Trade Map (2017): Bilateral trade between Kyrgyzstan and Switzerland. Product: TOTAL All products, http://www.trademap.org/Bilateral TS.aspx?nvpm=1|417||757||TOTAL|||2|1|1|2|2|1|1|1|1

${ }^{295}$ Davon 19,3 \% Bekleidung- und Bekleidungsartikel, 16,7 \% Erze, Schlacken und Aschen, $16 \%$ nichtklassifizierte Postpakete, Sondergeschäfte usw., 10,3 \% usw. Trade Map (2017): Bilateral trade between Kyrgyzstan and Kazakhstan. Product: TOTAL All products, http://www.trademap.org/Bilateral_TS.aspx?nvpm=1|417||398||TOTAL|||2|1|1|2|2|1|1|1|1
} 
sich mit 6,3\% (89,9 Mio. US-Dollar) auf dem 5. Platz der kirgisischen Abnehmer. ${ }^{296}$ 28,6 $\%$ der russischen Importe aus Kirgisistan machten nicht-klassifizierte Waren aus, ${ }^{297}$ gefolgt von mit der Produktnummer 62 gelisteten Textilien mit $14 \%$ und 61 gelisteten Textilien mit $12 \%{ }^{298} 33,7 \%$ der türkischen Importe aus Kirgisistan machten essbares Gemüse und gewisse Wurzeln und Knollen (Produktcode 07), 28,9 \% Flugzeuge, Raumfahrzeuge und Teile davon (Produktcode 28) und 19,6 \% fossile Brennstoffe und deren Produkte. ${ }^{299}$

Kirgisistan importierte 2016 Waren in Wert von 3,8 Mrd. US-Dollar. Die wichtigsten Lieferländer waren China mit $38 \%,{ }^{300}$ RU mit $20 \%$ (799,8 Mio. US-Dollar) und Kasachstan mit 16,5 \%. ${ }^{301}$ Die TR befand sich auf Platz 4 mit $5 \%$ (190,8 Mio. US-Dollar). ${ }^{302} 33 \%$ seiner Importe aus RU machten die fossilen Brennstoffe und deren Produkte, 9 \% Eisen und Stahl, 6,5 \% Holz- und Holzwaren sowie Holzkohle usw. (Produktcode 44), 5,3 \% nichtklassifizierte Waren aus. ${ }^{303} 32,8$ \% seiner Importe aus der TR waren Textilien (Produktcode 61 und 62) 10,5 \% Maschinen, mechanische Geräte, Kernreaktoren usw., 7,9 \% gestrickte oder gehäkelte Stoffe (Produktcode 60). ${ }^{304}$

Tadschikistan ist das ärmste zentralasiatische Land. Landwirtschaftlich kann es nur $7 \%$ seiner Fläche nutzen. Etwa 70 \% der Bevölkerung ist in diesem Teil tätig. Baumwoll-, Obst, Gemüse-, Nüsse- und Getreideanbau dominieren seine Landwirtschaft. Getreideanbau deckt nicht den Eigenbedarf, weshalb das Land Getreide importieren muss. Seine

\footnotetext{
296 Trade Map (2017): List of importing markets for a product exported by Kyrgyzstan. Product: TOTAL All products,

http://www.trademap.org/Country_SelProductCountry TS.aspx?nvpm=1|417||||TOTAL|||2|1|1|2|2|1|2|1|1

297 Trade Map (2017): Bilateral trade between Kyrgyzstan and Russian Federation. Product: 99 Commodities not elsewhere specified. https://www.trademap.org/Bilateral TS.aspx?nvpm=1|417||643||99||4|1|1||2|2|1|1|1|1

298 Trade Map (2017): Bilateral trade between Kyrgyzstan and Russian Federation. Product: TOTAL All products, http://www.trademap.org/Bilateral_TS.aspx?nvpm=1|417||643||TOTAL|||2|1|1|2|2|1|1|1|1

299 Trade Map (2017): Bilateral trade between Kyrgyzstan and Turkey. Product: TOTAL All products, http://www.trademap.org/Bilateral TS.aspx?nvpm=1|417||792||TOTAL|||2|1|1|2|2|1|1|1|1

30017 \% seiner Importe aus China machten Schuhe und Schuhartikel (Produktcode 64), 14 \% Maschinen, mechanische Geräte usw., 10 \% künstliche Spinnfasern (Produktcode 55) aus. Trade Map (2017): Bilateral trade between Kyrgyzstan and China. Product: TOTAL All products, http://www.trademap.org/Bilateral_TS.aspx?nvpm=1|417||156||TOTAL || $2|1| 1|1| 2|1| 1|1| 1$

$30118 \%$ der kirgisischen Importe aus Kasachstan machten die fossilen Brennstoffe und deren Erzeugnisse, 12 \% nicht-klassifizierte Waren und 9 \% ätherische Öle, Parfümerie usw. (Produktcode 33) aus. Trade Map (2017): Bilateral trade between Kyrgyzstan and Kazakhstan. Product: TOTAL All products, http://www.trademap.org/Bilateral_TS.aspx?nvpm=1|417||398||TOTAL||2|1|1|1|2|1|1|1|1

302 Trade Map (2017): List of supplying markets for a product imported by Kyrgyzstan. Product: TOTAL All products,

http://www.trademap.org/Country_SelProductCountry TS.aspx?nvpm=1|417||||TOTAL||2|1|1|1|2|1|2|1||

${ }^{303}$ Trade Map (2017): Bilateral trade between Kyrgyzstan and Russian Federation. Product: TOTAL All products, http://www.trademap.org/Bilateral_TS.aspx?nvpm=1|417||643||TOTAL|||2|1|1|1|2|1|1|1|1

304 Trade Map (2017): Bilateral trade between Kyrgyzstan and Turkey. Product: TOTAL All products. https://www.trademap.org/Bilateral_TS.aspx?nvpm=1|417||792||TOTAL||2|1|1|1|2|1|1|1|1
} 
Stromversorgung kann das Land durch Wasserkraft decken. Seine wichtigsten Exportwaren sind Aluminium, Gold, Silber und Baumwolle. ${ }^{305}$ Tadschikistan hat die zweitgrößten Silberreserven (60.000 Tonnen) der Welt. ${ }^{306}$ Das Land exportierte 2016 Waren in Wert von 899 Mio. US-Dollar. 26,6 \% Erze, Schlacken und Aschen, 23 \% seiner Gesamtexporte machten Aluminium und Waren daraus (Produktcode 76) und $15 \%$ Baumwolle sowie $11 \%$ Gold aus. ${ }^{307}$ Die drei größten Abnehmer waren mit $22 \%$ (200,7 Mio. US-Dollar) die TR, $21,6 \%$ Kasachstan $^{308} \%$ und $11 \%$ Schweiz. ${ }^{309}$ RU befand sich mit 5,6 \% (50,6 Mio. USDollar) auf dem 5. Platz. ${ }^{310}$ Den tadschikischen Export in die TR prägten die Aluminium und Aluminiumprodukte (75\% der gesamten türkischen Importe aus Tadschikistan) sowie Baumwolle $(22,8 \%){ }^{311} 52 \%$ seiner Exporte nach RU waren andere Fahrzeuge wie Eisenbahn- oder Straßenbahnfahrzeuge sowie deren Teile und Zubehör (Produktcode 87), gelistete Waren, davon 87,8 \% Panzer und andere Kampffahrzeuge. 38,6 \% seiner Exporte nach RU Baumwollexport. ${ }^{312}$

Tadschikistan importierte 2016 Waren in Wert von 3 Mrd. US-Dollar. Importwaren sind von Maschinen bis Textilien und Rohstoffe sehr vielfältig. ${ }^{313}$ Fossile Brennstoffe machten 15,5 $\%, 10 \%$ Maschinen und Geräte und Teile davon und $8 \%$ Getreide. ${ }^{314}$ 32,5\% seiner

\footnotetext{
305 Auswärtiges Amt (2015a): Tadschikistan: Wirtschaft. März 2015, http://www.auswaertigesamt.de/DE/Aussenpolitik/Laender/Laenderinfos/Tadschikistan/Wirtschaft_node.html ${ }^{306}$ Dusanbe Ticaret Müsavirligi (2015): Tacikistan Ülke Raporu 2015. http://www.ekonomi.gov.tr/portal/content/conn/UCM/path/Contribution $\% 20$ Folders/web/D $\% \mathrm{C} 4 \% \mathrm{~B} 1 \% \mathrm{C} 5 \%$ 9F\%20\%C4\%B0li\%C5\%9Fkiler/\%C3\%9Clkeler/Tacikistan/Ticaret $\% 20$ Temsilcili $\% \mathrm{C} 4 \% 9$ Fimiz/M $\% \mathrm{C} 3 \% \mathrm{~B}$ C\%C5\%9Favirlik\%20Raporlar\%C4\%B1/TAC $\%$ C4\%B0K\%C4\%B0STAN\%20\%C3\%9CLKE $\% 20$ RAPORU \%202015.pdf;jsessionid=biDEoiLxxczvv28DHIphvt2uesD8JGFA2ct65kVr6AKLg B IvX!-1462769997 307 Trade Map (2017): List of products exported by Tajikistan. http://www.trademap.org/Product SelCountry TS.aspx?nvpm=1|762||||TOTAL||2|1|2|2|2|1|1|1|1 308 89,2 \% der kasachischen Exporte aus Tadschikistan machten Erze, Schlacken und Aschen aus, genauer Zink-, Blei- und Kupfererze und deren Konzentrate. Trade Map (2017): Bilateral trade between Tajikistan and Kazakhstan. Product: TOTAL All products, http://www.trademap.org/Bilateral TS.aspx?nvpm=1|762||398||TOTAL|||2|1|2|2|2|1|1|1|1

${ }_{309}$ Davon 99,9 \% Gold. Trade Map (2017): Bilateral trade between Tajikistan and Switzerland. Product: TOTAL All products. https://www.trademap.org/Bilateral_TS.aspx?nvpm=1|762||757||TOTAL ||$|2| 1|1| 2|2| 1|1| 1 \mid 1$

310 Trade Map (2017): List of importing markets for a product exported by Tajikistan (Mirror). Product: TOTAL All products, http://www.trademap.org/Country_SelProductCountry_TS.aspx?nvpm=1|762||||TOTAL|||2|1|2|2|2|1|2|1|1 311 Trade Map (2017): Bilateral trade between Tajikistan and Turkey. Product: TOTAL All products. https://www.trademap.org/Bilateral TS.aspx?nvpm=1|762||792||TOTAL||2|1|1|2|2|1|1|1|1

312 Trade Map (2017): Bilateral trade between Tajikistan and Russian Federation. Product: TOTAL All products. https://www.trademap.org/Bilateral TS.aspx?nvpm=1|762||643||TOTAL||2|1|1|2|2|1|1|1|1 313 Trade Map (2017): List of products imported by Tajikistan. http://www.trademap.org/Product SelCountry TS.aspx?nvpm=1|762||||TOTAL|||2|1|2|1|2|1|1|1|1 314 Trade Map (2017): List of products imported by Tajikistan. https://www.trademap.org/Product_SelCountry_TS.aspx?nvpm=1|762||||TOTAL|||2|1|1|1|2|1|1|1|1
} 
gesamten Importe kamen aus RU (985,8 Mio. US-Dollar), 27,7 \% aus China (841,3), ${ }^{315} 15,8$ $\%$ aus Kasachstan. ${ }^{316}$ Die TR befand sich mit 4,4 \% (114,5 Mio. US-Dollar) auf dem 4. Platz der tadschikischen Exporteure. ${ }^{317}$ Aus RU machten 28 \% seiner Importe fossile Brennstoffe und deren Produkte, 12 \% anorganische Chemikalien; organische und anorganische Verbindungen von Edelmetalle, von Seltenerdmetallen und 11 \% Holz-und Holzwaren sowie Holzkohle aus. ${ }^{318} 13 \%$ der tadschikischen Importe aus der TR waren elektrische Maschinen und Geräte und deren Teile usw., 12,3\% Fleisch (Produktcode 02) und 11 \% Papier und Pappe, deren Produkte (Produktcode 48). ${ }^{319}$

\footnotetext{
315 27,6 \% seiner Importe aus China machten Maschinen, mechanische Geräte, Kernreaktoren, $12 \%$ elektrische Maschinen und Geräte und Teile davon; Tonrekorder und Reproduzierer, Fernsehen, 10,8 \% Eisen und Stahl, 10 \% Eisen- und Stahlprodukte usw. aus. Trade Map (2017): Bilateral trade between Tajikistan and China. Product: TOTAL All products, https://www.trademap.org/Bilateral TS.aspx?nvpm=1|762||156||TOTAL |||2|1|1|1|2|1|1|1|1

$31650 \%$ der Importe aus Kasachstan machte die Getreide aus, gefolgt mit $27 \%$ fossile Brennstoffe und deren Erzeugnisse und 6,4 \% Eisen und Stahl. Trade Map (2017): Bilateral trade between Tajikistan and Kazakhstan. Product: TOTAL All products, http://www.trademap.org/Bilateral_TS.aspx?nvpm=1|762||398||TOTAL|||2|1|2|1|2|1|1|1|1

317 Trade Map (2017): List of supplying markets for a product imported by Tajikistan (Mirror). Product: TOTAL All products, https://www.trademap.org/Country_SelProductCountry TS.aspx?nvpm=1|762||||TOTAL|||2|1|2|1|2|1|2|1|1 318 Trade Map (2017): Bilateral trade between Tajikistan and Russian Federation. Product: TOTAL All products. https://www.trademap.org/Bilateral TS.aspx?nvpm=1|762||643||TOTAL||2|1|1|1|2|1|1|1|1 319 Trade Map (2017): Bilateral trade between Tajikistan and Turkey. Product: TOTAL All products.. https://www.trademap.org/Bilateral_TS.aspx?nvpm=1|762||792||TOTAL||2|1|1|1|2|1|1|1|1
} 


\section{Tabelle 1: Anteile der wichtigsten drei Handelspartner* an den Exporten zentralasiatischen Staaten 2016}

*Die Türkei und Russland werden an den Exporten und Importen der zentralasiatischen Staaten immer mitberücksichtigt, weil es in diesem Kapitel um ihre wirtschaftlichen Beziehungen mit den zentralasiatischen Staaten geht.

\begin{tabular}{|c|c|c|c|c|}
\hline $\begin{array}{l}\text { KASACHSTAN } \\
\text { Gesamtexport: } \\
\text { 36,8 Mrd. US-Dollar }\end{array}$ & $\begin{array}{l}\text { TURKMENISTAN } \\
\text { Gesamtexport: } \\
\text { 7,9 Mrd. US-Dollar }\end{array}$ & $\begin{array}{l}\text { USBEKISTAN } \\
\text { Gesamtexport: } \\
\text { 7,5 Mrd. US-Dollar }\end{array}$ & $\begin{array}{l}\text { KIRGISISTAN } \\
\text { Gesamtexport: } \\
\text { 1,423 Mrd. US-Dollar }\end{array}$ & $\begin{array}{l}\text { TADSCHIKISTAN } \\
\text { Gesamtexport: } \\
899 \text { Mio. US-Dollar }\end{array}$ \\
\hline $\begin{array}{l}\text { ITALIEN } 20,3 \% \\
\text { ( } 97,9 \% \text { davon fossile Brennstoffe } \\
\text { und deren Produkte) }\end{array}$ & $\begin{array}{l}\text { CHINA } 70 \% \\
\text { (davon 98,5 \% }\end{array}$ & $\begin{array}{l}\text { SCHWEIZ } 38 \% \\
\text { (99,9\% Gold, inklusive mit } \\
\text { Platin vergoldet) }\end{array}$ & $\begin{array}{l}\text { SCHWEIZ } 45,5 \% \\
\text { ( } 99,9 \% \text { Gold, inklusive mit Platin } \\
\text { vergoldet) }\end{array}$ & $\begin{array}{l}\text { TR } 22 \%(200,7 \text { Mio. US-\$) } \\
(75 \% \text { davon } \% \text { Aluminium und } \\
\text { Aluminiumprodukte, } 22,8 \% \text { Baumwolle })\end{array}$ \\
\hline $\begin{array}{l}\text { CHINA } 11,4 \% \\
\text { (davon } 24 \% \text { fossile Brennstoffe, } \\
\text { deren Produkte, } \\
20,5 \% \text { Kupfer und Kupferartikel, } \\
19,6 \% \text { Chemikalien, Seltene Erden } \\
\text { und Edelmetalle) }\end{array}$ & $\begin{array}{l}\text { TR 5,7 \% (422 Mio. US-\$) } \\
\text { (davon } 85 \% \text { Baumwolle, } \\
4,4 \% \text { fossile Brennstoffe, } \\
\text { deren Produkte) }\end{array}$ & $\begin{array}{l}\text { CHINA 21\% } \\
\text { (davon } 43 \% \\
\text { Brennstoffe und fossile } \\
\text { Produkte, 22\% Baumwolle } \\
\text { und 12,8\% anorganische } \\
\text { Chemikalien, organische } \\
\text { oder anorganische } \\
\text { Verbindungen } \\
\text { Edelmetallen usw.) }\end{array}$ & $\begin{array}{l}\text { KASACHSTAN } 10,6 \% \\
\text { (davon 19,3\% Bekleidung- und } \\
\text { Bekleidungsartikel, 16,7 \% Erze, } \\
\text { Schlacken und Aschen, } 16 \% \text { nicht- } \\
\text { klassifizierter Postpakete, } \\
\text { Sondergeschäfte usw., 10,3\% usw.) }\end{array}$ & $\begin{array}{l}\text { KASACHSTAN } 29,3 \% \\
(89,2 \% \text { Zink-, Blei- und Kupfererze und deren } \\
\text { Konzentrate.) }\end{array}$ \\
\hline $\begin{array}{l}\text { RU 9,5\% (3,5 Mrd. US-\$) } \\
\text { (davon } 19 \% \text { Erze, Schlacken und } \\
\text { Aschen, } 17 \% \text { Chemikalien, } \\
\text { Edelmetalle und Seltene Erden, } \\
16,7 \% \text { Eisen und Stahl und } \\
12,7 \% \text { fossile Brennstoffe und } \\
\text { deren Produkte.) }\end{array}$ & $\begin{array}{l}\text { ITALIEN 5,6\% } \\
\text { (99,5\% fossile Brennstoffe } \\
\text { und deren Produkte) }\end{array}$ & $\begin{array}{l}\text { RU 10,8\% (761 Mio. US \$) } \\
\text { (davon 26\% Baumwolle, } 21 \\
\% \text { Bekleidung und } \\
\text { Bekleidungszubehör, 8\% } \\
\text { essbare Früchte und Nüsse; } \\
\text { Schale von Zitrusfrüchten } \\
\text { oder Melonen usw.) }\end{array}$ & $\begin{array}{l}\text { RU 10,2 \% (145 Mio. US-\$) } \\
\text { (28,6 \% davon nicht-klassifizierte } \\
\text { Postpakete, Sondergeschäfte, wie z. } \\
\text { B. Waffen, Goldmünzen usw., } 26,3 \\
\% \text { die Bekleidung und } \\
\text { Bekleidungszubehör usw.) }\end{array}$ & $\begin{array}{l}\text { SCHWEIZ } 11 \% \\
\text { (davon } 99 \% \text { Gold, inklusive mit Platin vergoldet) }\end{array}$ \\
\hline $\begin{array}{l}\text { TR 2,3\% (851 Mio. US-\$) } \\
\text { (davon } 32,6 \% \text { fossile Brennstoffe } \\
\text { und deren Produkte, } 31,6 \% \text { Kupfer } \\
\text { und Kupferprodukte und } 19,6 \% \\
\text { Zink usw.) }\end{array}$ & $\begin{array}{l}\text { RU 4,7\% (331 Mio. US-\$) } \\
\text { (davon } 65 \% \text { Schiffe und } \\
\text { Boote, } 15 \% \text { Kunststoffe und } \\
\text { Kunststoffwaren, 10,6 \% } \\
\text { Baumwolle) }\end{array}$ & $\begin{array}{l}\text { TR } 9 \% \text { (709 Mio. US-\$) } \\
\text { (davon 50,6\% Kupfer und } \\
\text { Kupferartikel, 15,8 \% } \\
\text { Kunststoffe r und } \\
\text { Kunststoffwaren und 12,3\% } \\
\text { Zink und Zinkwaren usw.) } \\
\text { Platz } 4\end{array}$ & $\begin{array}{l}\text { TR 6,3\% (89 Mio. US-\$) } \\
\text { (33,7\% davon essbare Gemüse und } \\
\text { gewisse Wurzeln und Knollen, 28,9 } \\
\% \text { Flugzeuge, Raumfahrzeuge und } \\
\text { Teile davon und } 19,6 \% \text { fossile } \\
\text { Brennstoffe und deren Produkte) } \\
\text { Platz } 5\end{array}$ & $\begin{array}{l}\text { RU 5,6 \% (Platz 7) } \\
(46,4 \% \text { Panzer und andere Kampfkraftzeuge, } 38.6 \\
\% \text { Baumwolle) }\end{array}$ \\
\hline
\end{tabular}


Tabelle 2: Anteile der drei wichtigsten Handelspartner an den Importen der zentralasiatischen Staaten 2016

\begin{tabular}{|c|c|c|c|c|}
\hline $\begin{array}{l}\text { KASACHSTAN } \\
\text { Gesamtimport: } \\
\text { 25,2 Mrd. US-Dollar }\end{array}$ & $\begin{array}{l}\text { TURKMENISTAN } \\
\text { Gesamtimport: } \\
\text { 5,5 Mrd. US-Dollar }\end{array}$ & $\begin{array}{l}\text { USBEKISTAN } \\
\text { Gesamtimport: } 9,7 \text { Mrd. US- } \\
\text { Dollar }\end{array}$ & $\begin{array}{l}\text { KIRGISISTAN } \\
\text { Gesamtimport: } \\
\text { 3,8 Mrd. US-Dollar }\end{array}$ & $\begin{array}{l}\text { TADSCHIKISTAN } \\
\text { Gesamtimport: } \\
3 \text { Mrd. US-Dollar }\end{array}$ \\
\hline $\begin{array}{l}\text { RU 36,3\% (9,1 Mrd. US-\$) } \\
\text { (davon } 11,7 \% \text { fossile Brennstoffe } \\
\text { und deren Produkte, 9,3\% } \\
\text { Maschinen, mechanische Geräte } \\
\text { usw., 6,8\% elektrische Maschinen } \\
\text { und Geräte und Teile davon, wie } \\
\text { Fernsehen usw.) }\end{array}$ & $\begin{array}{l}\text { TR 26,3\% (1,24 Mrd. US- } \\
\text { \$) } \\
\text { (davon 19,7\% Eisen und } \\
\text { Stahlprodukte, 16,8\% } \\
\text { elektrische Maschinen und } \\
\text { Geräte sowie deren Teile } \\
\text { und } 10 \% \text { Maschinen, } \\
\text { mechanische Geräte, } \\
\text { Kernreaktoren usw.) }\end{array}$ & $\begin{array}{l}\text { CHINA } 21 \% \\
(24 \% \text { davon Maschinen, } \\
\text { mechanische Geräte, } \\
\text { Kernreaktoren usw., } 16 \% \\
\text { elektrische Maschinen und } \\
\text { Geräte und 7,5\% Kunststoffe } \\
\text { und Kunststoffwaren usw.) }\end{array}$ & $\begin{array}{l}\text { CHINA } 38 \% \\
(17 \% \text { davon Schuhe und } \\
\text { Schuhartikel, } \\
14 \% \text { Maschinen, mechanische } \\
\text { Geräte usw., } \\
10 \% \text { künstliche Spinnfasern usw.) }\end{array}$ & $\begin{array}{l}\text { RU } 32,5 \%(985,8 \text { Mio. US-\$) } \\
(28 \% \text { davon fossile Brennstoffe und deren } \\
\text { Produkte, } 12 \% \text { anorganische Chemikalien, } \\
\text { organische oder anorganische Verbindungen usw., } \\
11 \% \text { Holz- und Holzwaren })\end{array}$ \\
\hline $\begin{array}{l}\text { CHINA } 14,5 \% \\
\text { (davon } 24 \% \text { Maschinen, } \\
\text { mechanische Geräte, Kernreaktoren, } \\
\text { Speichererhitzer, Teile davon, } 19 \% \\
\text { elektrische Maschinen und Geräte } \\
\text { und Teile davon, wie Fernsehen } \\
\text { usw.) und } 9 \% \text { Eisen- und } \\
\text { Stahlprodukte usw.) }\end{array}$ & $\begin{array}{l}\text { RU } 12 \%(570,6 \text { Mio. US- } \\
\$ \text { ) } \\
\text { (davon } 28 \% \text { Eisen- und } \\
\text { Stahlprodukte, gefolgt von } \\
\text { Eisen und Stahl } 12,5 \%)\end{array}$ & $\begin{array}{l}\text { RU } 20 \%(1,96 \text { Mrd. US- } \$) \\
(17,9 \% \text { davon fossile } \\
\text { Brennstoffe und deren } \\
\text { Produkte, } 13,4 \% \text { Holz- und } \\
\text { Holzwaren sowie Holzkohle, } \\
11 \% \text { Eisen und Stahl usw. })\end{array}$ & $\begin{array}{l}\text { RU } 20 \% \text { (799,8 Mio. US- } \$) \\
(33 \% \text { davon fossile Brennstoffe, } \\
\text { deren Erzeugnisse, } 9 \% \text { Eisen und } \\
\text { Stahl, 6,5\% Holz- und Holzwaren } \\
\text { sowie Holzkohle usw., 5,3\% nicht- } \\
\text { klassifizierte Sondergeschäfte usw.) }\end{array}$ & $\begin{array}{l}\text { CHINA 27,7\% } \\
\text { (davon } 27,6 \% \text { Maschinen, mechanische Geräte, } \\
\text { Kernreaktoren, Speichererhitzer, Teile davon, } 12 \\
\% \text { elektrische Maschinen und Geräte und Teile } \\
\text { davon, wie Fernsehen usw., } 10,8 \% \text { Eisen und } \\
\text { Stahl, } 10 \% \text { Eisen- und Stahlprodukte usw.) }\end{array}$ \\
\hline $\begin{array}{l}\text { DEUTSCHLAND 5,7 \% } \\
\text { (davon } 29,4 \% \text { für Maschinen, } 17,4 \\
\% \text { Eisen- und Stahlprodukte, } 11,3 \% \\
\text { Pharmazeutische Produkte usw.) }\end{array}$ & $\begin{array}{l}\text { DEUTSCHLAND } 8,5 \% \\
\text { (davon } 37,6 \% \text { Maschinen, } \\
11,5 \% \text { Kontroll-, Mess-, } \\
\text { Präzisionsgeräte, } 10 \% \\
\text { elektrische Geräte usw.) }\end{array}$ & $\begin{array}{l}\text { KOREA 9,6\% } \\
\text { (42\% davon Fahrzeuge, } \\
29,4 \% \text { Maschinen, } \\
\text { mechanische Geräte, } \\
\text { elektrische Maschinen und } \\
\text { Geräte usw.) }\end{array}$ & $\begin{array}{l}\text { KASACHSTAN } 16,5 \% \\
(18 \% \text { davon fossile Brennstoffe, } \\
\text { deren Erzeugnisse, } 12 \% \text { nicht- } \\
\text { klassifizierte Postpakete, } \\
\text { Sondergeschäfte usw., } 9 \% \\
\text { ätherische Öle, Parfümerie usw.) }\end{array}$ & $\begin{array}{l}\text { KASACHSTAN } 15,8 \% \\
(50 \% \text { davon Getreide, } \\
27 \% \text { fossile Brennstoffe und deren Produkte, } 6,4 \\
\% \text { Eisen und Stahl })\end{array}$ \\
\hline $\begin{array}{l}\text { TR 2,5\% (618,1 Mio. US-\$) } \\
\text { (davon } 16 \% \text { Maschinen, } \\
\text { mechanische Geräte, Kernreaktoren } \\
\text { usw., } \\
9,8 \% \text { elektrisch-elektronische } \\
\text { Geräte und } 8,2 \% \text { die Bekleidung } \\
\text { und Bekleidungswaren usw.) } \\
\text { Platz } 7\end{array}$ & $\begin{array}{l}\text { CHINA 7,2 \% } \\
\text { (davon 26,2 Maschinen, } \\
\text { mechanische Geräte, 13,5 } \\
\text { \% elektrisch-elektronische } \\
\text { Geräte, 12,7 \% Fahrzeuge } \\
\text { und Teile davon usw.) } \\
\text { Platz } 6\end{array}$ & 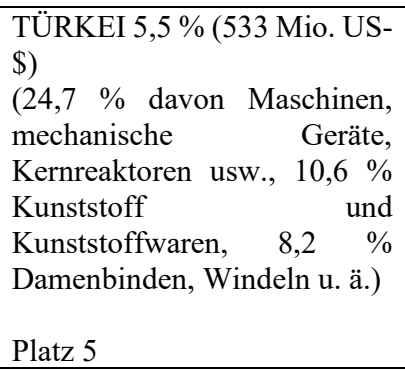 & $\begin{array}{l}\text { TR \% } 5 \text { (190,8 Mio. US-\$) } \\
(32,8 \% \text { Bekleidung und } \\
\text { Bekleidungszubehör, } \\
10,5 \% \text { Maschinen, mechanische } \\
\text { Geräte, Kernreaktoren usw., } 7,9 \% \\
\text { gestrickte oder gehäkelte Stoffe } \\
\text { usw.) } \\
\text { Platz } 4\end{array}$ & $\begin{array}{l}\text { TR 4,4 \% (114,5 Mio. US-\$) } \\
(13 \% \text { elektrische Maschinen und Geräte und Teile } \\
\text { davon, wie Fernsehen usw., 12,3\% Fleisch, } 11 \% \\
\text { Papier und Pappe) }\end{array}$ \\
\hline
\end{tabular}




\subsection{Zusammenfassung}

ZA wurde/wird nach seiner Unabhängigkeit 1991 von der Literatur mit einer energiepolitischen Rivalität um die kaspischen fossilen Brennstoffe in Verbindung gebracht, die als „New Great Game“ bezeichnet wird. Das ist ein Null-Summen-Spiel und läuft hauptsächlich zwischen der von den USA geführten westlichen Achse - wozu auch die TR gehört - und RU. Es geht dabei um die Kontrolle und Ausbeutung der kaspischen fossilen Brennstoffe unter Umgehung RUs und Irans. Von den USA werden die kaspischen fossilen Brennstoffe mit den fossilen Brennstoffen des Nahen Ostens als einheitlichenRaum betrachtet, der auch „Strategische Ellipse“ (siehe Abbildung 7) genannt wird. Die russischen Brennstoffe werden auch zur Strategischen Ellipse gezählt. Die strategische Ellipse verfügt über $72,4 \%$ der fossilen Erdgasreserven und $58 \%$ der Erdölreserven der Welt (Bundesanstalt für Geowissenschaften und Rohstoffe (BGR) 2015: 107, 119), sowie die relevanten Transportländer und -Wege.

Die Kontrolle der fossilen Brennstoffe bedeutet politische und wirtschaftliche Macht. Nach Michael Meacher (2003), dem ehemaligen britischen Umweltminister (1997-2003), brauchen die USA für die Aufrechterhaltung ihrer Weltherrschaft die Kontrolle der Ölreserven. Dafür werden politische, wirtschaftliche und militärische Strategien eingesetzt. Auf einem internationalen Symposium im April 2009 erklärte der NATO-General und Kommandeur der Akademie der türkischen Streitkräfte, Hasan Aksay, dass sich nach dem Kalten Krieg die Energiesicherheit des euro-atlantischen Raumes zu einer neuen Aufgabe der NATO entwickelte (Aksay 2009: 9-10). Ganser (2015: 222) zufolge gründeten die USA 1980 die militärische Einheit CENTCOM für die Verfolgung der US-amerikanischen energiepolitischen Ziele in der Golf-Region. ZA wurde 1999 dem CENTCOMZuständigkeitsgebiet zugeordnet. Bis zur Unabhängigkeit der zentralasiatischen Staaten war eine solche Einordnung aufgrund der Blockkonfrontation mit der Sowjetunion nicht möglich. Das Zuständigkeitsgebiet des CENTCOM konzentriert sich größtenteils auf die Länder der Strategischen Ellipse. Die Kriege in Afghanistan, Irak und Syrien wurden unter dem CENTCOM-Kommando durchgeführt.

Paul Craig Roberts, dem ehemaligen stellvertretenden Finanzminister der USA unter der Reagan-Regierung, zufolge, ist das Hauptinteresse der US-Außenpolitik nach der 
„Wolfowitz-Doktrin“ 1992, die Verhinderung eines neuen Rivalen bzw. der neuen Rivalen, der/die amerikanische Vorherrschaft in Frage stellen kann/können (in: Curtin 2016). Der Politikwissenschaftler John F. Mearsheimer (2001: 46) bestätigt Roberts`Aussage. Nach ihm (Mearsheimer 2001: 53-55) sind RU und China die Herausforderer der USA, deren mögliche Vereinigung gegen die US-Hegemonie Brzezinski (2001: 87) als ,gefährlichstes Szenario" sieht. Im Falle einer erfolgreichen wirtschaftlichen Integration innerhalb Eurasiens können die USA laut Brzezinski (1997) und Mearsheimer (2001: 46) ihren Einfluss über ihren Verbündeten in Europa und Nordasien verlieren, was das endgültige Ende der US-Hegemonie bedeuten würde. In der „Nationalen Verteidigungsstrategie“ von 2018 schreiben die USA als langfristige Hauptpriorität des US-Verteidigungsministeriums den strategischen Wettbewerb mit China und Russland als Ziel vor (ebd.: 2-3). Sie versuchen mit allen Mitteln, ihre Vorherrschaft zu behalten. Sanktionen, Einkreisungen, Sabotageversuche der russischen (EAWU) und chinesischen (SeidenstraßeWirtschaftsgürtel) Bündnisprojekte sowie die US-Zentralasienstrategie (The New Silk Road Initiative) und -Projekte (wie z. B. CASA-1000-Projekt) usw. für die Region können als USStrategien für dieses Ziel gesehen werden.

Der russische Staatshaushalt ist stark von den Energieexporten abhängig. Das Land verdankt seine politische und wirtschaftliche Stabilität dem nach der Weltwirtschaftskriese 1998/1999 weltweit stetig angewachsenen Ölverbrauch und hohen Ölpreis. 2016 machte der Export der fossilen Brennstoffe 59 \% (169 Mrd. US-Dollar) der gesamten russischen Exporte (285 Mrd. US-Dollar) aus (GKS (Federal State Statistic Service) 2016). 2013, vor den westlichen Sanktionen infolge der Ukraine-Krise und dem niedrigen Ölpreis, war dieser Anteil viel höher. Er machte 71,4 \% (376 Mrd. US-Dollar) der gesamten Exporte RUs (526 Mrd. USDollar) aus (GKS (Federal State Statistic Service) o. J.). Größter Abnehmer der russischen fossilen Brennstoffe ist Europa. Etwa Zwei Drittel der fossilen Brennstoffe RUs gehen nach Europa (Steiner 2016; Bundeszentrale für politische Bildung o. J.).

Die USA und die TR konnten die kaspischen Erdölpipeline BTC, die Erdgaspipelines BTE und TANAP unter Umgehung RUs nach Westen verwirklichen. Ein großes Erdgasprojekt, NABUCCO, allerdings scheiterte. Der Vertrag für NABUCCO wurde 2010 durch die Vertragsländer ratifiziert. Nach einem Monat der Ratifizierung des NABUCCO-Vertrages unterschrieb die TR auch mit RU einen Erdgasvertrag für die South-Stream-Pipeline. Diese Pipeline sollte das russische Erdgas unter Umgehung der Ukraine durch das türkische 
Hoheitsgewässer nach Europa transportieren. Wie Kramer (2010b: 6, 32, 35) schrieb, war aber das NABUCCO-Projekt zur Isolation RUs gedacht. Die TR versuchte mit ihrem Handel, mehr wirtschaftliche (durch Transportgebühren) und (sicherheits)politische Gewinne zu erzielen. Obwohl sie energiepolitisch mit RU weiterhin um die kaspischen fossilen Brennstoffe rivalisiert, kooperiert die TR mit RU gleichzeitig energiepolitisch eng. RU ist der größte Energiepartner der TR. Die TR importiert etwa 60 \% ihres Erdgases und 25 \% ihres Erdöls aus RU. Mit der Inbetriebnahme des TurkStreams Ende 2019 wird dieser Anteil erhöht.

RU versucht, die TR durch die lukrativen Angebote und die Zusammenarbeit von der NATO loszulösen und enger an sich zu binden. Das Land lädt die TR ein, der von RU geprägten EAWU beizutreten. Aktuell ist eine wirtschaftliche Zusammenarbeit zwischen der TR und RU im Rahmen der EAWU wegen der Zollunion der TR mit der EU, ihrer NATOMitgliedschaft, gegensätzlicher türkischer und russischer Haltung über die Kurden- und Armenierfrage, das mögliche armenische Veto im Falle einer türkischen EAWU-Beitrittes sowie wegen der pantürkistischen (und islamistischen) Politik der TR im postsowjetischen Raum nicht zu erwarten. Weder die EAWU noch der Handel der TR mit den zentralasiatischen Turkstaaten ist derzeit eine Alternative zu ihrem Handel mit der EU.

Für die zentralasiatischen Staaten ist RU der wichtigste Arbeitsmarkt. Schätzungen zufolge arbeiten in RU 5 bis 10 Mio. Zentralasiaten (Ibrahimov 2017). RU versucht die wirtschaftliche Zusammenarbeit mit den Regionsstaaten im Rahmen der EAWU weiter zu vertiefen. Kasachstan und Kirgisistan sind EAWU-Mitglieder, Tadschikistan prüft den Beitritt. Usbekistan hat Beobachterstatus. Turkmenistan bewahrt seine Neutralität. Die türkischen pantürkistischen Vorschläge hingegen, wie Gründung eines wirtschaftlichen „Türkenraums“ unter ihrer Kontrolle, fand in ZA keine Akzeptanz. Der bilaterale Handel der zentralasiatischen Staaten zeigt (siehe Tabelle 1, Tabelle 2), dass die zentralasiatischen Staaten sowohl mit den westlichen Staaten, wie Italien, Schweiz und Deutschland, als auch mit den östlichen Staaten, wie China und Korea handeln.

China eher als Importeur, RU eher als Exporteur prägen den bilateralen Handel mit den zentralasiatischen Staaten. Italien und China waren 2016 die größten Abnehmer der fossilen Brennstoffe der Region. 70 \% der turkmenischen, $23 \%$ der usbekischen und 11,4\% der kasachischen Exporte gingen 2016 nach China. Die Schweiz war der größte Abnehmer des 
Edelmetalls (99,9 \% Gold) aus Usbekistan, Kirgisistan und der drittgrößte Importeur Tadschikistans. Turkmenistan ist der wichtigste zentralasiatische Handelspartner der TR und Kasachstan von RU (siehe Tabelle 1, Tabelle 2). Die USA befinden sich weder als Importeur noch als Exporteur unter den drei wichtigsten Handelspartner der zentralasiatischen Staaten. Bis 2018 investierten die US-Erdölfirmen allerdings etwa 50 Mrd. US-Dollar in die kasachische Erdölindustrie, sind Aktionäre der Pipelines, wie z. B. der CPC, und beabsichtigen weitere Investitionen (O. V. 2018: Trump in Zentralasien ...). Auf dem zweiten C5+1 Ministertreffen der USA mit 5 zentralasiatischen Staaten im August 2016 in Washington erklärten die USA, für die Entwicklung und Problemlösung in ZA bis zu 15 Mio. Dollar zur Verfügung zu stellen (O. V. 2016: U.S.-Central Asia ...). Wie diese Zahlen zeigen, liegt das wirtschaftliche Interesse der USA hauptsächlich auf der Energiebranche des Kaspischen Raumes. 


\section{TÜRKISCH-RUSSISCHE SICHERHEITSPOLITIK IN ZENTRALASIEN (1991-2019)}

ZA erweiterte seine energiepolitische Relevanz infolge der Terrorattacke am 11. September 2001 in den USA auf geostrategische Relevanz, weil die Region an Afghanistan angrenzt und die USA/NATO ${ }^{320}$ infolge des Afghanistan-Einsatzes im Oktober 2001 in ZA Militärbasen erwarben. Dadurch wurde ZA der Ort, in dem die größten militärischen Bündnisse der Welt zusammentrafen: Die westliche, von den USA geprägte NATO, von RU geprägte OVKS und von RU und China geprägte SOZ. Die OVKS und SOZ sind aufgrund ihrer zentralasiatischen Mitglieder regionale Organisationen. Die USA rief die Welt auf, ihre Terrorbekämpfung zu unterstützen: ,Jede Nation, in jeder Region, muss sich entscheiden: Entweder sind Sie mit uns oder mit den Terroristen.“ (O. V. 2001: Bush vor dem ...). RU unterstützte am Anfang die USA/NATO bei der Terrorbekämpfung, zog allerdings seine Unterstützung aus den folgenden Gründen schrittweise zurück:

* die Kündigung des ABM-Vertrags (Anti-Ballistic Missiles Treaty, 1972 mit der Sowjetunion abgeschlossen) mit RU durch die USA im Dezember 2001,

* die Bezeichnung des Kaukasus und ZAs auf dem NATO-Gipfel vom Mai 2002 als NATO-Interessengebiete (Deutscher Bundestag o. J.: 7, Artikel 10.2),

* die Erklärung der USA von Anfang 2003, dass RU ein Ziel nuklearer Erstschlagwaffen sei (Wipperfürth 2011: 62, 64),

* der Irak-Einsatz der USA/NATO im März 2003 ohne UN-Mandat,

\footnotetext{
${ }^{320}$ Die NATO rief am 4. Oktober 2001 zum ersten Mal in ihrer Geschichte den Bündnisfall aus und begann nach drei Tagen, am 7. Oktober, mit dem Afghanistan-Krieg. Die NATO ist das größte Militärbündnis. Laut den Schätzungen des schwedischen Friedensforschungsinstituts SIPRI beliefen sich Rüstungsausgaben aller 29 NATO-Mitgliedern 2017 auf rund 900 Mrd. Dollar - das waren 52 \% der Ausgaben weltweit (1,74 Billionen US-Dollar) (O. V. 2018: Weltweit wird mehr ...). Die USA gaben 2017 umgerechnet 610 Mrd. US-Dollar (35 \% der militärischen Ausgaben weltweit) für ihr Militär aus. Dieser Betrag war mehr als doppelt so hoch wie die russischen (66 Mrd. US-Dollar, 3,8 \% der weltweiten Militärausgaben) und chinesischen (228 Mrd. USDollar, $13 \%$ der weltweiten) Militärausgaben insgesamt (ebd.). In 2018 gaben die USA laut dem SIPRIBericht 649 Mrd. US-Dollar, China 250 Mrd. US-Dollar und RU 61,4 Mrd. US-Dollar für ihr Militär aus. Wie aus den Zahlen zu sehen ist, sind die US-Ausgaben mehr als zehnfacher als die Russischen (Jeppesen 2019). Des Weiteren sind die USA in über 70 Ländern militärisch präsent. RU hingegen verfügt außerhalb des GUSRaums nur in Syrien über Militärbasen und China am Horn von Afrika, in Dschibuti.
} 
* die Erklärung des Kaukasus und ZAs auf dem NATO-Gipfeltreffen in Istanbul im Juni 2004 als Schwerpunkt der NATO-Arbeit (NATO 2016a),

* die Farbenrevolutionen, Unruhen und Kriege im „russischen Nahen Ausland“: 2003 in Georgien (Rosenrevolution), 2004 in der Ukraine (Orange Revolution), 2005 in Kirgisistan, 2005 Andijan-Aufstand in Usbekistan, 2006 Unruhen in Weißrussland, 2008 Georgienkrieg (Augustkrieg), seit 2013 Unruhen in der Ukraine, 2015 erneute Eskalation des Berg-Karabach-Konfliktes,

* die NATO-Erweiterung durch den Beitritt der baltischen Staaten (Litauen, Lettland, Estland), der Schwarzmeeranrainerstaaten (Bulgarien, Rumänien), der Slowakei und Sloweniens 2004, Albaniens und Kroatiens 2009 sowie durch die NATO-Beitrittsverhandlungen mit Montenegro 2016,

* die Äußerungen der US-Entscheidungsträger*innen auf höchster Staatsebene gegen die russischen Interessen, wie z. B. von Zbigniew Brzezinski und der ehemaligen Außenministerin Hillary Clinton (2009-2013) (siehe Kap. 6.2),

* der Bau eines NATO-Abwehrsystems in Rumänien im Mai 2016, die Planung des Baus eines 2. Abwehrsystems in Polen,

* die Erklärung der USA nach dem milliardenschweren Waffendeal zwischen Polen und den USA im November 2017, nach der Raketenabwehrsysteme in Polen der Abwehr einer möglichen russischen Aggression dienen (O. V. 2017: US-Regierung genehmigt...),

* die Erklärung RUs, Chinas, des Iran und Nord-Koreas als größte sicherheitspolitische Gefahren in der aktuellen Nationalen Verteidigungsstrategie (National Defense Strategy) der USA von 2018 (United States Department of Defense 2018: 2-2).

Für RU sind diese Ereignisse Belege seiner Einkreisung durch die USA/NATO. Das Land sieht die USA/NATO daher als sicherheitspolitische Gefahr für seine territoriale Integrität und Souveränität an, wie es in seinen Nationalen Dokumenten zu lesen ist. Das NATOMitglied TR handelt in ZA sicherheitspolitisch im Rahmen der NATO (Somuncuoglu 2011) 
und ist aus russischer Sicht ein verlängerter Arm der USA, bzw. eine sicherheitspolitische Gefahr im postsowjetischen Raum (Basaran 2013: 154; Kazgan 2003: 172-173). Alle Bemühungen der TR in ZA, seien es ihre Gülen-Schulen oder ihre „Türkengipfel“ sowie ihre „Türkenarmee“ TAKM (Avrasya Askeri Statülü Kolluk Kuvvetleri Teşkilat1, Vereinigung der eurasischen Strafverfolgungskräfte mit militärischem Status), betrachtet RU im Rahmen des von den USA unterstützten türkischen Pantürkismus und/oder Islamismus. Diese beiden Ideologien empfindet RU aufgrund seiner turksprachigen (etwa 20 Mio. Menschen, $14 \%$ der russischen Gesamtbevölkerung) und/oder muslimischen Bevölkerungsanteils (30 Mio. Muslime, etwa 21 \% der russischen Gesamtbevölkerung) ${ }^{321}$ (Schmoller 2018) als sicherheitspolitische Gefahr für sich. Wenn sich diese Bevölkerungsgruppen radikalisieren und gegen RU erheben würden, würde die territoriale Integrität RUs in Gefahr geraten. Zum anderen kann ein pantürkistisch- und/oder islamistischer Extremismus in ZA durch Spill-Over-Effekte russische Sicherheit ebenfalls betreffen. Die Gefahren für RU aus Afghanistan via ZA, sei es durch Terrorismus oder Drogenhandel, ist ein weiteres, sowohl sicherheitspolitisches als auch gesundheitspolitisches Problem. Diese genannten sicherheitspolitischen Sorgen teilt RU mit den zentralasiatischen Staaten.

Obwohl die TR und RU um den postsowjetischen Raum geopolitisch rivalisieren, unterschrieben sie nach einem Monat des amerikanischen Afghanistan-Einsatzes, am 16. November 2001, einen „Aktionsplan zur Zusammenarbeit zwischen der Türkei und der Russischen Föderation in Eurasien (Von bilateraler Kooperation zur multi-dimensionalen Partnerschaft)“. Beide Staaten verpflichteten sich zur Anerkennung ihrer territorialen Integrität, Souveränität, Unabhängigkeit und zur aktiven Zusammenarbeit in Eurasien, wie z. B. in ZA, besonders in Fragen des internationalen Terrorismus, des Drogenhandels, der Konfliktlösung sowie der wirtschaftlichen und militärischen Kooperationen (Gül 2003). Zu einer türkisch-russischen sicherheitspolitischen Zusammenarbeit in ZA kam es allerdings bis jetzt nicht, weil die beiden Staaten in der Region geopolitisch rivalisieren.

\footnotetext{
${ }^{321}$ Die Turkvölker (Tataren, Baschkiren, Jakuten, Tschuwaschen, Tuwinen, Altaier, Nogaier usw.) machen etwa 8,3 \% (12 Mio.) der Gesamtbevölkerung aus (Yigit o. J: 1017). Die größte Gruppe machen mit 5,5 Mio. die Tataren aus (Halbach 2013: 1). Mit den Krim-Tataren ist die Zahl der Russlands-Tataren jetzt auf etwa 5,7 Mio. (3,9 \% der Gesamtbevölkerung) angestiegen. Mit den zentralasiatischen (zwischen 5 bis 10 Mio. Menschen) und aserbaidschanischen (2 Mio.) Gastarbeitern wird der Anteil der turksprachigen Völker der Russischen Föderation auf über 20 Mio. Menschen geschätzt und/oder muslimischen Bevölkerungsanteils etwa 30 Mio. Menschen (21\% der russischen Gesamtbevölkerung).
} 


\section{1 (Sicherheits)Politische Probleme der zentralasiatischen Staaten}

Alle zentralasiatischen Staaten haben ein autoritäres präsidiales Herrschaftssystem. Nach der Unabhängigkeit kamen in allen zentralasiatischen Staaten Präsidenten an die Macht, die schon in der Sowjetunion zur Nomenklatura zählten. Bis jetzt kam es in Kirgisistan durch die „Tulpen-Revolution“ 2005, in Turkmenistan erst durch den Tod des turkmenischen Präsidenten Saparmurad Nijazow (Turkmenbasi) 2006 und in Usbekistan durch den Tod Islam Karimows 2016 zum Machtwechsel. In Kasachstan löste Kassym-Jomart Tokayev durch die Wahlen am 9. Juni 2019 den amtierenden Präsidenten, Nursultan Nasarbajew, ab. Aktuell (2019) regieren in Turkmenistan Gurbanguly Berdimuhammedow, in Tadschikistan Emomali Rahmon, in Kirgisistan Sooronbaj Jeenbekow und in Usbekistan Schawkat Mirsijojew als Präsidenten.

Das autoritäre Herrschaftssystem in ZA spiegelt sich in dem Bericht von Freedom House von 2018, Freedom in the World 2018, wider. Außer Kirgisistan wurden alle zentralasiatischen Staaten als ,nicht frei“ eingestuft. Analysiert werden die politischen Rechte und bürgerlichen Freiheiten, bzw. der demokratische Entwicklungsstand. Auf der Skala symbolisiert 0 den schlechtesten und 100 den besten Wert. Turkmenistan hat mit 4 Punkten von 100 den niedrigsten Wert und gilt als ,unfreies“ Land, gefolgt von Usbekistan mit 7, Tadschikistan mit 11 und Kasachstan mit 22 Punkte. Kirgisistan ist das einzige zentralasiatische Land, das mit 37 Punkte als ,,zum Teil frei“ gilt (Fredoom House 2018). ${ }^{322}$ Das autoritäre Herrschaftssystem setzen die zentralasiatischen Herrscher mit nationaler Sicherheit und Unabhängigkeit ihres Staates gleich, definieren jede Gegenbewegung, jede Opposition als Gefahr und bekämpfen sie. Der verstorbene usbekische Präsident Karimow rechtfertigte z. B. sein repressives Herrschaftssystem als Maßnahme gegen die Gefahr, „die vom radikalen Islam ausgehe“ (Lüders 2003).

Die Bevölkerungen der zentralasiatischen Staaten sind überwiegend sunnitisch-muslimisch. In allen zentralasiatischen Staaten nimmt der Einfluss der Religion sukzessive zu. Im Jahre 2000 verstanden sich z. B. 79 \% der Tadschiken als Muslime, in 2010 ist dieser Anteil auf 94,8 \% gestiegen (Seifert 2012: 7). ${ }^{323}$ Mit der Zunahme des Einflusses der Religion in allen

\footnotetext{
${ }^{322}$ Die TR mit 32 und RU mit 20 Punkten gelten auch als „unfreies Land“ (Fredoom House 2018).

${ }^{323}$ Tadschikistan ist das einzige postsowjetische zentralasiatische Land, in dem bis 2015 eine Partei der Islamischen Wiedergeburt registriert war. „In allen übrigen Nachfolgestaaten der Sowjetunion wurden Parteien
} 
zentralasiatischen Staaten, werden die sozialen Grundlagen des Säkularismus ausgedünnt (Seifert 2012: 7, 9). Paul Stronski von der Carnegie Endowment for International Peace erklärt in einem Interview mit Catherine Putz (2018), dass die zentralasiatischen Staaten weniger säkularer sind als vor 20 Jahren. Besonders betroffen sind die Staaten Tadschikistan, Usbekistan und Kirgisistan. In Kirgisistan erhöhte sich die Anzahl der Moscheen in kürzester Zeit, von 2009 bis 2015, von 1973 auf 2669 (O. V. 2017: Islam und Politik...). Weiterhin gibt es in Kirgistan 102 Koranschulen, sieben islamische Institute und eine islamische Universität. In Tadschikistan kommt ein Imam auf 2210 Menschen (ebd.). In Kasachstan stieg die Zahl der Moscheen von 68 im Jahr 1991 auf 2516 im Jahre 2016 (ebd.). Trotz dieser Angaben ist Kasachstan viel säkularer als andere zentralasiatischen Staaten. Sicherlich spielen beim Erhalt der säkularen Strukturen in Kasachstan neben den besseren sozioökonomischen Strukturen in Kasachstan, nomadische Traditionen sowie der hohe Anteil der russischen Diaspora ${ }^{324}$ eine große Rolle.

Die sozioökonomischen Probleme der Region, wie z. B. Perspektivlosigkeit, Arbeitslosigkeit, Armut und Korruption, begünstigen die Zunahme des religiösen Extremismus. Wie Roth (2015: 4) berichtet, lockt der IS männliche Zentralasiaten mit Arbeitsversprechen und weibliche mit Eheversprechen an, wie einige zentralasiatische ISOpfer und der Sprecher des kirgisischen Innenministeriums, Samir Sydykow, berichten. Die kirgisische Politologin Elmira Nogoijbajew erklärte, dass in den Gebieten außerhalb der Hauptstadt Bischkek der Hauptsozialisierungsort für junge Menschen die Moschee sei. Die Jugendarbeitslosigkeit (zwischen 15-24 Jahre) in ZA fasste die Weltbank 2016 wie folgt zusammen: In Usbekistan 16,6 \% der Männer und 18,8 \% der Frauen, in Turkmenistan 16,6 \% der Männer und 18,3 \% der Frauen, in Kirgisistan 12,6 \% der Männer und 18,7 \% der Frauen, in Tadschikistan 16,8 \% der Männer und 13,5 \% der Frauen und in Kasachstan 4 \% der Männer und 5,2 \% der Frauen (World Bank 2017). Die Dunkelziffer soll höher liegen.

Das Bruttoinlandsprodukt pro Kopf betrug 2016 in Kasachstan 7,456 US-Dollar, in Turkmenistan 6,622 US-Dollar, in Usbekistan 2,133 US-Dollar, in Kirgisistan 1,073 US-

verboten, die sich auf ethnischer oder religiöser Grundlage definierten.", schreibt Halbach (2018: 18). Die Partei „Islamische Wiedergeburt“ war am tadschikischen Bürgerkrieg beteiligt und wurde später ein Vertragspartner bei der Friedensregelung. Ihr wurde 2015 vorgeworfen, sie habe ein Staatsreich vorbereitet und daraufhin kriminalisiert und verboten (ebd.).

${ }^{324}$ Die russische Diaspora macht etwa 24 \% der Gesamtbevölkerung Kasachstans (18,3 Mio.) aus (Auswärtiges Amt 2018a). Gleich nach der Auflösung der Sowjetunion machte sie noch $37 \%$ der kasachischen Gesamtbevölkerung aus (Kamalov 2011: 59). 
Dollar und in Tadschikistan 800 US-Dollar (Statistisches Bundesamt 2017). Seit der Abwertung der nationalen Währungen der zentralasiatischen Staaten im zweiten Halbjahr 2015 sind ein sinkender Lebensstandard der großen Masse der Bevölkerung und eine zunehmende soziale Polarisierung zu beobachten. Auch der kontinuierliche Anstieg der Lebensmittelpreise verarmt die Bevölkerung, da vor allem die Löhne niedrig sind und bleiben. Selbst im reichsten zentralasiatischen Staat stieg der Preis für Zucker um fast $20 \%$, Öle und Fette um 18,5 \% und Brot um 14,4 \% (Sultanow 2016: 2-3). Korruption ist ein weiteres Problem der Region. Nach dem Corruption Perceptions Index 2016 ist Usbekistan das korrupteste zentralasiatische Land mit 21 Punkten (Platz 156 von 176 Ländern), ${ }^{325}$ gefolgt von Turkmenistan mit 22 Punkten (Platz 154), Tadschikistan 25 Punkte (Platz 151), Kirgisistan 28 Punkte (Platz 136) und Kasachstan 29 Punkte (Platz 131) (Transparency International 2018).

Der religiöse Extremismus in ZA wird von einigen auswärtigen Staaten unterstützt. Nach der Unabhängigkeit ZAs 1991 kamen u.a. aus den arabischen Ländern (wie aus SaudiArabien) zahlreiche islamistische Aktivisten nach ZA und verbreiteten z. B. in den KoranSchulen die salafistisch-wahhabitische Ideologie. Die Zentralasiaten erhielten Stipendien, um in den arabischen Ländern zu studieren. Bei ihrer Rückkehr nahmen sie ihr radikalisiertes Religionsverständnis mit (ebd.). Die TR schickte hunderte von Imamen und andere Religionsaktivisten nach ZA, restaurierte hier die alten Moscheen und baute neue Moscheen (Abay 2018). Roth (2015: 2) zufolge weisen die zentralasiatischen Entscheidungsträger den „fremden Mächte“ die Schuld zu, „die die passive, naive eigene Bevölkerung verführt hätten." Die türkischen Gülen-Schulen wurden in Usbekistan und Turkmenistan wegen ihres Islamismus und Pantürkismus geschlossen. Karimow warf der TR die Unterstützung der usbekischen Pantürkisten und Islamisten, wie z. B. Mohammed Salih, vor. Seit dem Arabischen Frühling zeigt die TR offene Sympathie für Islamisten, wie z. B. in Ägypten für die Muslimbrüder und/oder die Unterstützung der Islamisten in Syrien. Die TR hat in ZA im Allgemeinen kein positives Image, weil sie in der Region mit ihren pantürkistischen und islamistischen Zielen und Handeln als sicherheitspolitische Gefahr für die territoriale Integrität und Souveränität der zentralasiatischen Staaten angesehen wird: Einerseits, weil sie mit ihrer „Türkenweltpolitik“ die Turkstaaten unter ihre Leitung zu bringen versucht und sie nicht als eigenständige, unabhängige Staaten mit ihrer eigenen Identität, Kultur,

\footnotetext{
${ }^{325}$ Dieser Index wurde 2016 in 176 Ländern als Maßstab angelegt. 0 gilt als sehr korrupt und 100 als sehr sauber.
} 
Geschichte und Sprache ansieht (siehe Kap. 4.1). Andererseits, weil sie den Islamismus unterstützt, zumindest mit ihm sympathisiert. Putin warf der TR, die Unterstützung der IS vor (Smirnova 2015).

Die Rückkehr der Islamisten aus dem GUS-Raum, die z. B. in Irak oder in Syrien im Ausland-Einsatz sind, ist für die zentralasiatischen Staaten und RU ein weiteres sicherheitspolitisches Problem. Putin zufolge beträgt die Zahl der Dschihadisten in den Reihen des IS aus GUS-Staaten 7000 Menschen; davon 1500 aus der Russischen Föderation (davon 400 Tschetschenen), 3000 aus Usbekistan (ebd.) und nach Angaben des Komitees für Religionsangelegenheiten circa 500 aus Kasachstan und 500 aus Kirgisistan (Sultanow 2016: 4). Der Generalstaatsanwalt Tadschikistans gab 2016 die Zahl der tadschikischen Dschihadisten im Ausland mit 1094 an (Halbach 2018: 18). Der Rest ist aus den anderen GUS-Staaten. Nach den Zahlen des russischen Geheimdienstes „Federalnaja sluschba besopasnosti Rossijskoi Federazii“ (FSB, Föderaler Dienst für Sicherheit der Russischen Föderation) machen die Kämpfer aus dem GUS-Raum etwa 23,3 \% der ausländischen Islamisten (von 30.000) aus (O. V. 2015: Şok Rakam! ...). Nach Ibrahimov (2017) beläuft sich die Zahl der Dschihadisten aus ZA (allein) im Syrien-Krieg auf insgesamt mehr als 5000 Menschen. Einige davon kämpfen innerhalb der Oppositionsgruppe Kataib al-Bukhari, die hauptsächlich Usbeken umfasst. Laut Oguz (2016) ist die zweite meist gesprochene Sprache des IS nach dem Arabischen das Russische. Am meisten ist das zentralasiatische Land Usbekistan durch den islamistischen Terror bedroht: Einerseits wegen der hohen Anzahl der usbekischen IS-Kämpfer und die Aktivitäten der IBU gegen Usbekistan, anderseits wegen ihrer Grenze zu Afghanistan und allen anderen zentralasiatischen Staaten.

Die Nachbarschaft zu Afghanistan ist bezüglich des Islamismus und Drogenhandels ein großes sicherheitspolitische Problem. Eine erneute Machtübernahme der Taliban in Afghanistan oder Spill-Over-Effekte aus Afghanistan kann hier die Anzahl der Islamisten erhöhen (Seifert 2012: 4). Die Taliban soll laut Schätzungen etwa 40.000 Mitglieder haben und kontrolliert etwa 60 \% der afghanisch-tadschikischen Grenze (Aidarbek 2015). D. h. der Islamismus aus Afghanistan kann sich leicht in ZA ausbreiten. Putin sieht ZA als Ziel von religiös-extremistischen Gruppierungen und erklärte folgendes (O. V. 2015: Putin: 7.000 Dschihadisten ...): 
Ziele ist Zentralasien. Wir müssen bereit sein, um auf diesen Notfall reagieren zu können."

Am 4. September 2015 ist in der tadschikischen Stadt Wahdat ein Anschlag gegen eine tadschikische Militäreinheit verübt worden. Dem tadschikischen Staatspräsidenten nach waren die Attentäter IS-Anhänger (Aidarbek 2015). Am 5. Juni 2016 ist in der kasachischen Stadt Aktobe ein Anschlag verübt worden, an dem laut dem kasachischen Außenministerium der IS beteiligt gewesen sein soll (Oguz 2016, O. V. 2016: Kasachstans Außenminister: IS ...). Seit 2014 kämpfen die Islamisten an der afghanisch-turkmenischen Grenze gegen die turkmenischen Sicherheitskräfte (Ydyrys 2017). In Kirgisistan wurde im Oktober 2017 ein Polizist von einem IS-Anhänger angegriffen (Halbach 2018).

Als Maßnahme gegen den Islamismus schlossen Usbekistan und Tadschikistan alle religiösen Schulen in ihren Ländern und verboten wahhabitische Aktivitäten (Oguz 2016). Kasachstan und Tadschikistan führten 2014 Gesetze ein, die die Teilnahme ihrer Bürger an bewaffneten Konflikten oder Militäroperationen im Ausland unter Gefängnisstrafe (in Kasachstan zu drei bis sieben, in Tadschikistan 12 bis 20 Jahren) stellen. Diese Gesetze sollen zur Abschreckung dienen (Roth 2015: 3). Die zentralasiatischen Sicherheitsdienste fordern die Hilfe der Bürger beim Aufspüren der Dschihadisten in den sozialen Netzwerken (Roth 2015: 3) an. Die Beamten der religiösen Institutionen kritisieren offiziell den IS und Al-Qaida. Laut Roth (2015: 4) allerdings leiden sie unter einem Glaubwürdigkeitsdefizit, da sie „meist als religiös verbrämtes Sprachrohr der Regierung betrachtet werden.“ Laut Malasenkov (in: Ydyrys 2017) müssen die zentralasiatischen Staaten gegen den religiösen Extremismus zusammenarbeiten, wenn sie ihn effektiv bekämpfen wollen.

Seit einigen Jahren erkannten die zentralasiatischen Staaten, dass sie sicherheitspolitisch zusammenarbeiten müssen. Usbekistan und Kasachstan unterschrieben zwar im Juni 2013 einen „Vertrag über die strategische Partnerschaft zwischen der Republik Usbekistan und der Republik Kasachstan“. Mit diesem Vertrag kündigten sie ihren Willen für die Zusammenarbeit in regionalen sicherheitspolitischen Fragen an, besonders nach dem amerikanischen Abzug aus Afghanistan 2014 (Die Botschaft der Republik Usbekistan in der Bundesrepublik Deutschland o. J.). Während eines Treffens der Präsidenten der OVKS am 14. - 15. September 2015 wurden Maßnahmen vereinbart, die von Informationsaustausch bis zur Grenzsicherung reichen. Kurz danach, am 7. Oktober 2015, vereinbarten der turkmenische Präsident Berdimuhammedow und der ehemalige usbekische Präsident 
Karimow eine sicherheitspolitische Zusammenarbeit zur Grenzsicherung (Aidarbek 2015). Am 16. September 2016 trafen sich alle GUS-Mitglieder, um die Vertiefung der sicherheitspolitischen Zusammenarbeit hinsichtlich der Grenzsicherung zu vereinbaren (Ydyrys 2017). 2017 verabschiedeten Usbekistan mit Kasachstan einen gemeinsamen Plan zur Militärkooperation, der die Zusammenarbeit bei Training, Übungen und Ausbildung vorsieht (Klein 2018: 39). Im März 2018 trafen sich die zentralasiatischen Staats- und Regierungschefs in Astana und im November 2019 in Taschkent, um die gemeinsame Bekämpfung des Islamismus und den Umgang mit islamistischen Kriegsrückkehrern aus Syrien und Irak sowie das Afghanistan-Problem zu besprechen (Jiracek 2019).

Der islamistische Terror und der Drogenhandel hängen eng zusammen. Der Drogenhandel ist nicht nur ein Sicherheitsproblem, sondern auch ein Gesundheitsproblem. ZA ist durch den Drogenhandel aus Afghanistan stark betroffen. Afghanistan produziert $80 \%$ des weltweiten Opiums ${ }^{326}$ (UNODC 2014: 21, 27) und $95 \%$ des Heroins. Die Grenzen Turkmenistans, Usbekistans und Tadschikistans zum weltweit größten Opium-Produzenten Afghanistan sind $2600 \mathrm{~km}$ lang. Tadschikistan hat die längste Grenze $(1387 \mathrm{~km}) \mathrm{zu}$ Afghanistan und ist die Hauptroute des Drogenhandels nach ZA. Etwa $60 \%$ der tadschikisch-afghanischen Grenze wird von der Taliban kontrolliert (Aidarbek 2015).

In der afghanischen Provinz Helmand kontrolliert die Taliban die Mohnanbaugebiete und Handelsrouten. Wie Aidarbek 2015 berichtete, stieg die Drogenherstellung in Afghanistan in den letzten 14 Jahren trotz der bis heute andauernden westlichen militärischen Präsenz um 40 \% an. 2016 wuchs die Fläche zum Anbau von Schlafmohn in Afghanistan um zehn Prozent auf 201.000 Hektar (O. V. 2016: Opium für die Taliban). Das sei das dritthöchste Niveau seit mehr als 20 Jahren. Das UN-Büro für Drogen- und Verbrechensbekämpfung (UNODC) schätzte, dass die Ernte 2016 um 43 \% höher ausfallen werde als 2015 (ebd.). Und 2017 erhöhte das Land seinen Ertrag bei der Schlafmohnernte im Vergleich zum Vorjahr um 87 \% (O. V. 2017: Milliardengeschäft der Taliban ...). Taliban erzielte laut dem UN-Sicherheitsrat im Jahre 2016 etwa die Hälfte ihrer Einnahmen (400 Mio. Dollar) durch den Drogenhandel (ebd.). Diese Einnahmen bedeuten mehr Waffenkauf und Soldatengehälter (ebd.) sowie das Rekrutieren neuer Kämpfer.

\footnotetext{
${ }^{326}$ Opium ist der Rohstoff für Heroin.
} 
Den Recherchen nach wird $80 \%$ des afghanischen Opiums auf der Nordroute durch Tadschikistan geschmuggelt. „Mittlerweile leben ganze tadschikische Dörfer an der Grenze zu Afghanistan vom Drogenschmuggel“", schreibt Tappeiner (2018) in ihrem Aufsatz über das Drogenproblem in ZA. Laut Tappeiner (ebd.) liegt nahe, dass sich die kriminellen Netzwerke bis in die Regierung erstrecken. Sie fügt hinzu, dass Tadschikistan als NarcoStaat bezeichnet wird. So werden die Staaten bezeichnet, die einen gewissen Anteil ihres BIPs aus dem Drogenhandel beziehen, wie z. B. Kolumbien, Mexico oder Guinea-Bissau (ebd.). Auch in Kirgisistan sollte sich der Drogenhandel zur Haupteinkommensquelle der Bevölkerung entwickelt haben und einige Mitarbeiter der Sicherheitskräfte und der Rechtsschutzorgane des Landes seien darin verwickelt (Sultanow 2016: 5). An den Folgen sterben in diesem Land jedes Jahr 1500 Menschen an einer Überdosis, mehrheitlich Kinder und Jugendliche (ebd.). ${ }^{327}$

Es wurde ein Zusammenhang zwischen dem Transit und Konsum festgestellt, schreibt Tappeiner (2018). Laut einer Umfrage des UNODC von 2007 in Tadschikistan scheint sich die These zu bestätigen. „Demnach gaben $96 \%$ der befragten Jugendlichen zwischen 15 und 16 Jahren an, Drogen seien ,ziemlich leicht zu besorgen “" (Tappeiner 2018). 2008 gab es in ZA insgesamt 283.000 Heroin- und 60.000 Opium-Konsumenten (UNODC 2010: 40, 41). Nach Global State of Harm Reduction Report von 2016 gab es 25.000 Heroinkonsumenten in Kirgistan und Tadschikistan, 80.000 in Usbekistan und 117.000 in Kasachstan, die injizieren (Tappeiner 2018). Das HIV-Virus ist die häufigste gesundheitliche Folge des Heroinkonsums durch Injektion. In ZA steigt die Zahl der HIV-Infizierten stark an. Nach UNAIDS $^{328}$ lebten in Kasachstan im Jahre 201626.000 HIV-Infizierte. Seit 2010 sind die HIV-Neuinfektionen um $39 \%$ gestiegen (UNAIDS 2018a). In Kirgisistan lebten im Jahr 20168500 Menschen mit HIV. Seit 2010 sind die HIV-Neuinfektionen um $21 \%$ gestiegen (UNAIDS 2018b). In Tadschikistan lebten im Jahr 2016 14.000 Menschen mit HIV. Seit 2010 haben sich die HIV-Neuinfektionen um 23 \% erhöht (UNAIDS 2018c). In Usbekistan lebten laut dem usbekischen Gesundheitsministerium im Jahre 2015 32.500 HIV-Infizierte (O. V. 2015: Özbekistan'a AIDS'le mücadele ...). Turkmenistan veröffentlicht keine Statistik über das Thema.

\footnotetext{
${ }^{327}$ Siehe weiteres in UNAIDS (2018).

328 „Joint United Nations Programme on HIV/AIDS“ (UNAIDS) ist ein Projekt der Vereinten Nationen für die AIDS-Bekämpfung.
} 
Die ungelösten Grenzprobleme ${ }^{329}$ in ZA sind ein weiteres Problem der Region. Besonders stark sind diese Probleme zwischen Kirgisistan, Tadschikistan und Usbekistan um das Fergana-Tal, das gleichzeitig ein Zentrum der Islamisten ist. Zwischen Kirgistan und Usbekistan wurde bis jetzt von den $1378 \mathrm{~km}$ der gemeinsamen Staatsgrenze erst $75 \%$ endgültig festgelegt, zwischen Tadschikistan und Usbekistan lediglich $80 \%$ der $1400 \mathrm{~km}$ langen Grenze (Sultanov 2016: 5) und zwischen Kirgisistan und Tadschikistan 60 \% der 970 km langen Grenze (Yegenov 2018: 88). Folge der unklaren Grenzen sind ständige Zwischenfälle. Z. B. gab es an der kirgisisch-tadschikischen Grenze im Zeitraum 2012-2015 insgesamt 78 Zusammenstöße und Konflikte, bei denen es u. a. zu Straßenblockaden, Brandstiftungen und Massenschlägereien zwischen Kirgisen und Tadschiken kam (Sultanow 2016: 5). Die Minen an der usbekisch-tadschikischen Grenze schaffen zusätzliches Konfliktpotential zwischen beiden Staaten. In den letzten 20 Jahren wurden dadurch mehr als 800 tadschikische Staatsangehörige Opfer von Gewalt. Laut Sultanow (2016: 5) können sich die Grenzzwischenfälle jederzeit in zwischenstaatliche Konflikte verwandeln. Um die Grenzstreitigkeiten zu lösen, müssen die Staaten miteinander kooperieren. Da sie aber gegenwärtig von einer effektiven Zusammenarbeit für die Lösung der Grenzfragen weit entfernt sind, werden die Konflikte bei diesem Problem fortbestehen (Sultanow 2016: 5).

Die Wasserteilung ist ein weiteres Problem der Region. Tadschikistan, Kirgisistan, Turkmenistan und Usbekistan haben wegen der Wasserteilung der Flüsse Syr Darja und Amu Darja Probleme. Die ersten beiden Staaten sind zwar die ärmsten Staaten der Region, aber sind die reichsten an Wasserquellen. Für wirtschaftliche Gewinne beabsichtigen Kirgisistan und Tadschikistan Wasserkraftwerke zu bauen und Strom zu exportieren. Diese Idee wird von den USA unterstützt. Usbekistan und Turkmenistan hingegen haben Angst, da deren Wirtschaft wegen des Baumwollanbaus von diesen Wasserquellen abhängt, dass diese Staaten wegen der politischen und wirtschaftlichen Probleme und Gewinne das Wasser abstellen können. Durch die alte Infrastruktur und das Bewässerungssystem sowie das Austrocknen des Aral-Sees wird das Wasserproblem weiterhin als Problem bestehen bleiben (Domínguez 2014).

Die zentralasiatischen Staaten sind, wie oben dargestellt wurde, vom islamistischen Terrorismus bis zu Grenz- und Wasserproblemen mit sehr vielen (sicherheitspolitischen)

${ }^{329}$ Eine Datenbank am Moskauer Institut für Geographie erfasste 164 Streitfälle um nationale Hoheit über bestimmte Teile der Sowjetunion, als im Dezember 1991 die Sowjetunion aufgelöst wurde (Halbach 1995: 2). 
Problemen konfrontiert. Die Lösung dieser Probleme erfordert eine intensive Zusammenarbeit, weil z. B. der Drogenhandel, der Islamismus oder die illegale Migration grenzüberschreitend sind und daher nur gemeinsam bekämpft werden können. Die machtorientierte Sichtweise der zentralasiatischen Machthaber auf die Probleme, der Machtkampf um regionale Vorherrschaft zwischen Kasachstan und Usbekistan und die ungelösten Grenzprobleme zwischen den zentralasiatischen Staaten erschweren jedoch die regionale Zusammenarbeit. 1994 gründeten Kirgisistan, Usbekistan und Kasachstan die „Central Asian Union“ (CAU, dt. Zentralasiatische Union). Nach dem tadschikischen Bürgerkrieg schloss sich auch Tadschikistan 1998 der Zentralasiatischen Union an, welche 2001 zur „Central Asian Cooperation Organisation“ (CACO, dt. Zentralasiatische Organisation für Kooperation) umbenannt wurde. Das 1995 bei den Vereinten Nationen seine Neutralität erklärende Turkmenistan trat dieser Organisation nicht bei. RU trat 2004 der CACO bei. Mit seinem Beitritt war die CACO keine zentralasiatische Organisation mehr. Ende 2005 verabschiedeten die Mitglieder, die Organisation aufgrund der ähnlichen Ziele mit der Eurasischen Wirtschaftsgemeinschaft sich in diese aufgehen zu lassen. CACO konnte keine nennenswerten Erfolge erzielen. Bis heute prägen die sicherheitspolitischen Organisationen GUS und OVKS (mit RU) und SOZ (mit RU und China) die zentralasiatische sicherheitspolitische Zusammenarbeit (siehe hierzu Kap. 6.7). RU ist in der Region der einzige Akteur, der militärisch eingreifen kann und darf, wie es z. B. im Tadschikischen Bürgerkrieg und in kirgisischen Unruhen der Fall war. Die Schließung der amerikanischen Militärbasis in Usbekistan 2005 wurde im Rahmen der SOZ und in Kirgisistan 2014 im Rahmen der OVKS vereinbart.

Die einzige sicherheitspolitische Organisation, in der neben den zentralasiatischen Staaten (außer Turkmenistan) die TR, RU und China u. a. Mitglied sind, ist die 2002 gegründete „Conference on Interaction and Confidence building Measures in Asia“ (CICA). Der kasachische Präsident Nasarbajew ist der Ideenvater dieser Organisation. Er schlug 1992 seine Ideen bei der UN-Generalversammlung vor. Sie wurde gegründet, um die Sicherheit und Stabilität in Asien zu gewährleisten, als eine Art asiatischer OSZE (auch asiatische NATO genannt). Bis jetzt ist allerdings keine nennenswerte sicherheitspolitische Zusammenarbeit zwischen der TR und RU im Rahmen der CICA in ZA zu beobachten. Im Gegenteil. Beide Länder verfolgen in der Region gegensätzliche sicherheitspolitische Interessen. Daher brachte auch der nach einem Monat des amerikanischen AfghanistanEinsatzes am 16. November 2001 unterschriebene „Aktionsplan zur Zusammenarbeit 
zwischen der Türkei und der Russischen Föderation in Eurasien (Von bilateraler Kooperation zur multi-dimensionalen Partnerschaft)“ keine sicherheitspolitische Zusammenarbeit zwischen den beiden Staaten in ZA zur Stande. 
Tabelle 3: Die Mitgliedschaften zentralasiatischen Staaten in regionalen und internationalen Organisationen

\begin{tabular}{|c|c|c|c|c|c|c|c|c|c|}
\hline Staaten & Kas. & Kirgis. & Tads. & Turkm. & Usb. & RU & TR & China & Andere \\
\hline $\begin{array}{l}\text { Gemeinschaft } \\
\text { Unabhängiger } \\
\text { Staaten (GUS, engl. } \\
\text { CIS) }\end{array}$ & $\mathrm{X}$ & $\mathrm{X}$ & $\mathrm{X}$ & $\mathrm{X}$ & $\mathrm{X}$ & $\mathrm{X}$ & & & $\begin{array}{l}\text { Armenien, } \\
\text { Aserbaidschan, } \\
\text { Moldawien, } \\
\text { Weißrussland, } \\
\text { Ukraine } 330\end{array}$ \\
\hline $\begin{array}{l}\text { Organisation des } \\
\text { Vertrags über } \\
\text { kollektive } \\
\text { Sicherheit (OVKS, } \\
\text { engl. CSTO) }\end{array}$ & $\mathrm{X}$ & $\mathrm{X}$ & X & & & $\mathrm{X}$ & & & $\begin{array}{l}\text { Armenien, } \\
\text { Weißrussland }\end{array}$ \\
\hline $\begin{array}{l}\text { Eurasische } \\
\text { Wirtschaftsunion } \\
\text { (EAWU) }\end{array}$ & $\mathrm{X}$ & $\mathrm{X}$ & & & & $\mathrm{X}$ & & & $\begin{array}{l}\text { Armenien, } \\
\text { Weißrussland }^{331}\end{array}$ \\
\hline $\begin{array}{l}\text { Shanghaier } \\
\text { Organisation für } \\
\text { Zusammenarbeit } \\
\text { (S0Z, eng. SCO) }\end{array}$ & $\mathrm{X}$ & $\mathrm{X}$ & $\mathrm{X}$ & & $\mathrm{X}$ & $\mathrm{X}$ & & X & Indien, Pakistan \\
\hline $\begin{array}{l}\text { Organisation für } \\
\text { Sicherheit und } \\
\text { Zusammenarbeit in } \\
\text { Europa (OSZE, } \\
\text { früher KSZE) } \\
\text { (eng. OSCE) })^{332}\end{array}$ & $\mathrm{X}$ & $\mathrm{X}$ & $\mathrm{X}$ & $\mathrm{X}$ & $\mathrm{X}$ & $\mathrm{X}$ & $\mathrm{X}$ & & $\begin{array}{l}333 \text { Insgesamt } 57 \\
\text { Staaten aus } \\
\text { Europa, ZA (auch } \\
\text { Mongolei) und } \\
\text { Nord-Amerika }\end{array}$ \\
\hline
\end{tabular}

${ }^{330}$ Turkmenistan ist seit 2005 nur beigeordnetes Mitglied. D. h. das Land ist nicht stimmberechtigt. Siehe TUIÇ (2014). Die Ukraine bezahlt seit dem Staatsstreich 2014 keinen Mitgliedsbeitrag und nimmt an den Tätigkeiten der Organisation nicht teil. Allerdings ist das Land offiziell Mitglied und nicht ausgetreten.

${ }^{331}$ Moldawien hat seit 2018 einen Beobachterstatus in der EAWU.

${ }^{332}$ Für die Ziele der OSZE siehe: Auswärtiges Amt 2015b.

${ }^{333}$ Für die Liste der OSZE-Teilnehmerstaaten siehe OSCE o. J. 


\begin{tabular}{|c|c|c|c|c|c|c|c|c|c|}
\hline Staaten & Kas. & Kirgis. & Tads. & Turkm. & Usb. & RU & TR & China & Andere \\
\hline $\begin{array}{l}\text { NATO Euro- } \\
\text { Atlantic Partnership } \\
\text { Council } \\
\text { (EAPC) und } \\
\text { Partnership for } \\
\text { Peace (PfP) }\end{array}$ & $\mathrm{X}$ & $\mathrm{X}$ & X & $\mathrm{X}$ & $\mathrm{X}$ & $\mathrm{X}$ & $\mathrm{X}$ & & $\begin{array}{l}\text { EAPC } \\
\text { NATO-Staaten } \\
\text { und } 21 \text { Nicht- } \\
\text { NATO-Staaten) }\end{array}$ \\
\hline $\begin{array}{l}\text { Conference on } \\
\text { Interaction and } \\
\text { Confidence } \\
\begin{array}{l}\text { Building in Asia } \\
\text { (CICA) }\end{array}\end{array}$ & X & $\mathrm{X}$ & $\mathrm{X}$ & & $\mathrm{X}$ & $\mathrm{X}$ & $\mathrm{X}$ & $\mathrm{X}$ & $\begin{array}{l}\text { Insgesamt } 26 \\
\text { Mitgliedstaaten }^{334}\end{array}$ \\
\hline $\begin{array}{l}\text { Organisation für } \\
\text { wirtschaftliche } \\
\text { Zusammenarbeit } \\
\text { (ECO) }\end{array}$ & $\mathrm{X}$ & $\mathrm{X}$ & $\mathrm{X}$ & X & $\mathrm{X}$ & & $\mathrm{X}$ & & $\begin{array}{l}\text { Afghanistan, } \\
\text { Aserbaidschan, } \\
\text { Iran, Pakistan }\end{array}$ \\
\hline $\begin{array}{l}\text { Organisation of } \\
\text { Islamic Cooperation } \\
(\mathrm{OIC}, \\
\text { Organisation für } \\
\text { islamische } \\
\text { Zusammenarbeit } \\
(\mathrm{OIZ}))^{335}\end{array}$ & $\mathrm{X}$ & $\mathrm{X}$ & $\mathrm{X}$ & X & $\mathrm{X}$ & & $\mathrm{X}$ & & $\begin{array}{l}57 \text { muslimische } \\
\text { Staaten }\end{array}$ \\
\hline $\begin{array}{l}\text { TURKSOY } \\
\text { (Uluslararasi Türk } \\
\text { Kültürü Teskilati) }\end{array}$ & $\mathrm{X}$ & $\mathrm{X}$ & & $\mathrm{X}$ & $\mathrm{X}$ & & $\mathrm{X}$ & & Aserbaidschan \\
\hline
\end{tabular}

${ }^{334}$ CICA (2017).

335 „Organisation of Islamic Cooperation“ (OIC) ist die zweitgrößte zwischenstaatliche Organisation nach den Vereinten Nationen mit 57 Mitgliedsstaaten in vier Kontinenten. Die OIC ist für die Interessenvertretung der muslimischen Welt und für die Gewährleistug des internationalen Friedens (OIC) 1969 gegründet. Alle zentralasiatischen Staaten sowie die TR sind Mitglieder dieser Organisation. Für weitere Informationen siehe: Organisation of Islamic Cooperation (2016). 


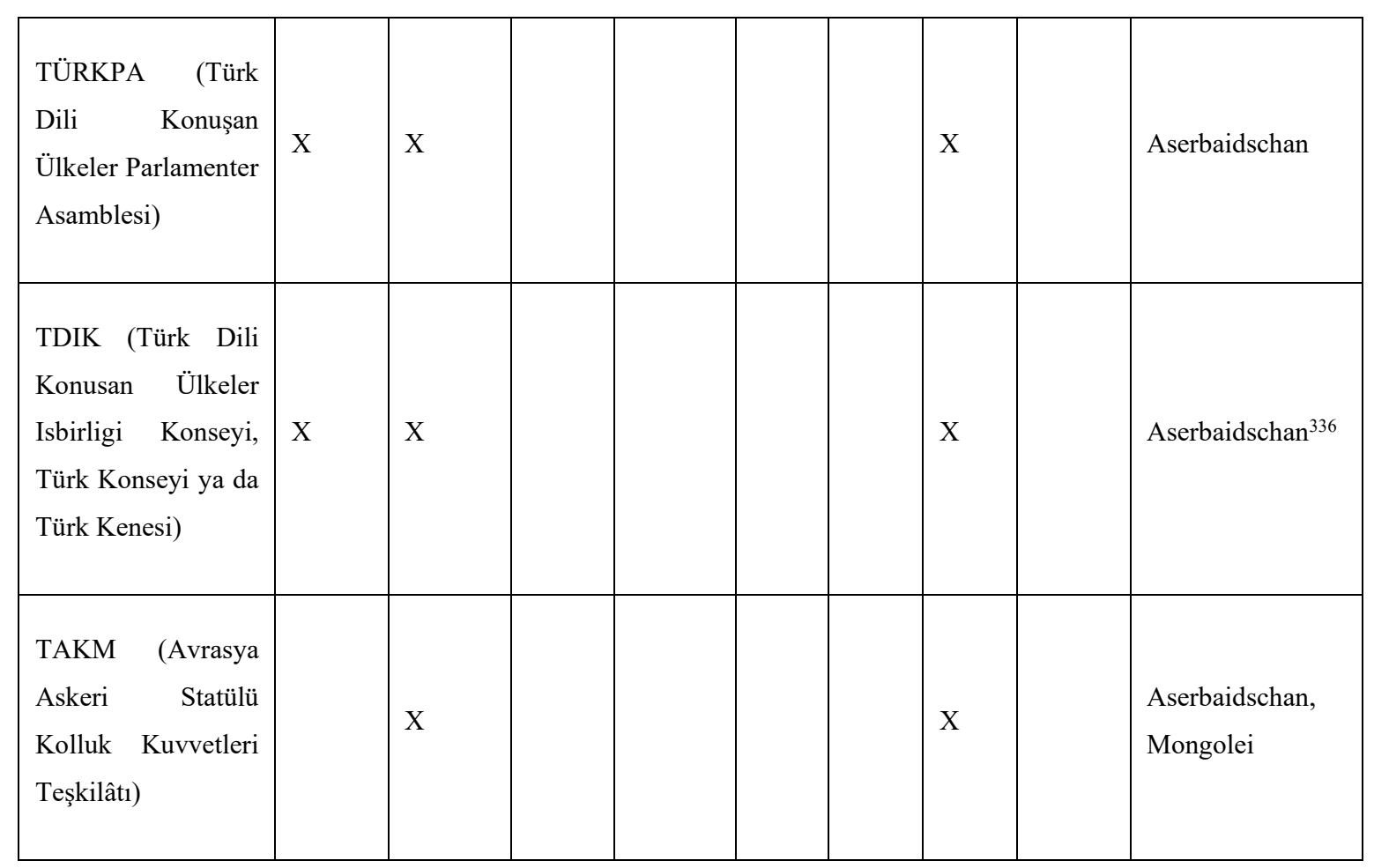

\subsection{US-Sicherheitspolitik in Zentralasien}

Die US-ZAP konzentriert sich auf die Sicherung der fossilen Brennstoffe und auf die Verhinderung der Entstehung der neuen Rivalen, die die US-Herrschaft in Frage stellen können (siehe Kap. 5.3 US-Wirtschaftspolitik in ZA). Die Kontrolle der Energiequellen der Strategischen Ellipse (siehe Abbildung 7) bedeuteten für die USA wirtschaftliche und politische Macht über die energiehungrigen Staaten (wie die europäischen Staaten oder Japan usw.), sei es auf dem diplomatischen oder militärischen Weg. Sie können durch die Kontrolle der Energieressourcen und Märkte den US-Dollar als Weltwährung sichern, welcher bis heute als Reservewährung für den Handel von fossilen Brennstoffen ist (siehe Kap. 5. 3).

Theoretische Grundlage der US-Energiepolitik in/um ZA basiert auf der Carter-Doktrin (siehe Kap. 5.3). Obwohl die USA versuchten, sowohl die Carter-Doktrin als auch die Gründung CENTCOM, als Antwort zur sowjetischen Aggression in/um Afghanistan darzustellen, gab Brzezinski fast 20 Jahre später in einem Interview den wahren Grund bekannt. Im Januar 1998 erklärte Brzezinski in einem Interview mit der französischen

\footnotetext{
${ }^{336}$ Usbekistan nimmt seit dem Attentat an Karimow 1999, hinter dem das Land die türkische Unterstützung vermutete, an keinem Treffen teil.
} 
Zeitschrift „Le Nouvel Observateur“, dass die im Vergleich zur offiziellen Version, schon vor dem sowjetischen Afghanistan-Einmarsch die islamistischen Mudschaheddin unterstützt habe (Lüder 2015: 24-25). Er fügte hinzu, dass Präsident Carter am 3. Juli 1979 „die erste Direktive unterschrieben, um den Gegnern des pro-sowjetischen Regimes in Kabul still und leise Hilfe zu leisten.“ (ebd.: 25). Er gab stolz zu, dass die USA dadurch die Sowjetunion in die Afghanistan-Falle locken konnten (ebd.), was zum Zusammenbruch der Sowjetunion führte (ebd.: 26). Wie dieses Beispiel zeigt, gaben die USA zu, dass sie die Islamisten für ihre Ziele instrumentalisiert haben. Im sowjetischen Afghanistan-Krieg zwischen 1979 und 1989 strömten zu Tausenden Islamisten nach dem Dschihad-Ruf des US-Verbündeten Saudi-Arabien nach Afghanistan, um die ,gottlose Sowjetunion“ zu bekämpfen. Mit Erfolg!? Einige von diesen Islamisten gründeten später die Terrororganisation Al-Qaida, die am 11. September 2001 die USA angegriffen haben. Die USA marschierten daraufhin im Oktober 2001 in Afghanistan ein, um dort die Islamisten zu bekämpfen.

Die an fossilen Brennstoffen sehr reichen Nachbarstaaten ZAs, Iran und RU, glauben, dass die westliche Achse unter der US-Führung durch die „selbstgemachte Instabilität“ im postsowjetischen Raum und im Nahen Osten versucht, die gesamte Energieressourcen der Strategischen Ellipse (siehe Abbildung 7) unter ihre Kontrolle zu bringen, darunter auch die vom Iran und $R U$. Sie gehen weiterhin davon aus, dass die westliche Achse durch die alternativen Energierouten, bzw. Sanktionen der Wirtschaft beider Staaten zu schaden, bzw. sie $\mathrm{zu}$ isolieren versuchen (siehe hierzu Kap. 5.3). RU, der Iran und ein weiteres Nachbarland ZAs, die stärkste Weltwirtschaft der Welt nach Kaufkraft, China, wurden von den USA in ihrer aktuellen „Nationalen Verteidigungsstrategie“ (National Defense Strategy) von 2018 als größte sicherheitspolitische Gefahren definiert (United States Department of Defense 2018: 2-2). ${ }^{337}$

Die Konzentration der „Nationalen Verteidigungsstrategie“ der USA liegt auf RU und China. Laut der Strategie hätten China und RU das Ziel, eine Welt nach ihrem autoritären Model zu schaffen und ein Vetorecht über die ökonomischen, diplomatischen und sicherheitspolitischen Entscheidungen der anderen Staaten $\mathrm{zu}$ erringen (United States Department of Defense 2018: 2-2). China würde durch seine militärische und wirtschaftliche Überlegenheit seine Nachbarstaaten einschüchtern und im indo-pazifischem

\footnotetext{
${ }^{337}$ Nord-Korea ist der vierte Staat, der in dieser Strategie neben RU, der Iran und China als sicherheitspolitische Gefahr definiert wird.
} 
Raum ein regionaler Hegemon werden sowie die USA aus diesem Raum vertreiben wollen (ebd.). RU versuche über die Länder in seiner Peripherie mächtiger zu werden, um über ihre Entscheidungen Vetorecht zu erhalten. Des Weiteren versuche das Land laut dieser Strategie die NATO zu schwächen und die Sicherheits- und Wirtschaftsstruktur Europas und des Nahen Ostens zu seinen Gunsten zu ändern (ebd.). Sein Vorgehen in Georgien, in der Ukraine und auf der Krim sowie seine Kernwaffen werden als besorgniserregend angesehen (ebd.). Des Weiteren werden die „Schurkenstaaten“ Iran und Nordkorea als Terrorsponsoren und wegen ihrer Atomwaffen als sicherheitspolitische Gefahren definiert (ebd.). Für den strategischen Wettbewerb mit diesen Staaten sollen laut Strategie viele Faktoren zusammen eingesetzt werden, wie Diplomatie, Wirtschaft, Militär (ebd.: 2-4). Alle diese Staaten werden von den USA sanktioniert. Die USA versuchen sie einzukreisen und zu isolieren, bzw. zu kontrollieren (siehe hierzu Kap. 5.3).

Der ehemalige britische Umweltminister Michael Meacher (1997-2003) sieht den Afghanistan-Einsatz als einen Versuch zur Aufrechterhaltung der US-Herrschaft, wozu sie die Kontrolle der Ölreserven brauchen (Meacher 2003). Durch den Afghanistan-Einsatz 2001 erhielten die USA/NATO Militärbasen in ZA, ${ }^{338}$ in der Region, die neben Afghanistan an RU, den Iran und China angrenzt. Meacher (ebd.) zufolge, griffen die USA die Staaten erst dann an, nachdem sie sie als sicherheitspolitische Gefahren dargestellt haben. Ein Beispiel dafür ist nach Meacher (ebd.) der von den Neokonservativen USEntscheidungsträgern $^{339}$ schon ein Jahr vor dem 11. September 2001, im September 2000, verfasste Entwurf "Rebuilding America's Defences". ${ }^{340}$ Die Golf-Region wurde als gefährliche Region und die Staaten, wie Nord-Korea, Irak, Iran und Syrien, wurden als gefährliche Staaten definiert (Meacher 2003). In den von den von „Project for the New American Century“ (PNAC) als gefährliche Staaten definierten Staaten, Irak und Syrien sind die USA weiterhin militärisch aktiv. Zu Nord-Korea und dem Iran haben die USA ein schwieriges Verhältnis und können diese Staaten wegen „Terrorunterstützung und/oder ihrer Atomwaffen(bemühungen)“ angreifen, wie sie in ihrer „Nationalen Verteidigungsstrategie

\footnotetext{
${ }^{338}$ RU unterstützte die USA/NATO im Afghanistan-Krieg mit Geheimdiensterkenntnissen und umfangreichen Waffenlieferungen an die Nordallianz sowie Land- und Lufttransport, was wesentlich zu den raschen Siegen der USA und ihrer Verbündeten über die Taliban beitrug (Wipperfürth 2011: 61). Die USA und ihre Verbündeten bekamen für die Bekämpfung des Terrors Militärbasen in ZA, was laut Wipperfürth (2011: 61) ohne die russische Unterstützung vielleicht nicht möglich gewesen wäre.

339 Dick Cheney (Vizepräsident), Donald Rumsfeld (Verteidigunsminister), Paul Wolfowitz (Rumsfeld's Stellvertreter), Jeb Bush (George Bush's jüngerer Bruder) and Lewis Libby (Cheney's Stabchef).

${ }^{340}$ Dieser Entwurf wurde von 1997 gegründeten neokonservativen Think Tank PNAC herausgegeben, in der die Neokonservativen (Cheney, Rumsfeld, Wolfowitz, Jeb Bush, Libby) Mitglied waren.
} 
2018“ noch einmal unterstrichen haben (United States Department of Defense 2018: 2-2). Paul Craig Roberts, ${ }^{341}$ ehemaliger stellvertretende Finanzminister der USA unter der Reagan-Regierung, der Politikwissenschaftler John F. Mearsheimer (2001: 46), der Verfasser der Carter-Doktrin, Zbigniew Brzezinski (2001: 278) und der Verfasser der Wolfowitz-Doktrin, Paul Wolfowitz, bestätigen Meachers Aussagen (siehe Kap. 5.3).

Brzezinski schrieb schon 1997, die Aufgabe der USA sei die Verhinderung der erneuten Entstehung eines eurasischen Imperiums unter russischer Herrschaft (Brzezinski 2001: 130). Ein mögliches eurasisches Imperium könnte nach Brzezinski (2001: 130) „Amerika an der Verwirklichung seines geostrategischen Ziels hindern [...], ein größeres euroatlantisches System zu entwerfen, in welches sich dann Rußland dauerhaft und sicher einbeziehen läßt“. RU müsse sich laut Brzezinski (2001: 288-289) zu Modernisierungszwecken dezentralisieren und zu einem konföderierten $R U$ (bestehend aus einem europäischen RU, einer sibirischen Republik und einer fernöstlichen Republik) wandeln. Auf diese Weise könne RU seine wirtschaftliche Lage und die politischen Beziehungen zu den Nachbarstaaten und zu Europa sowie dem Osten schneller verbessern. Andererseits sei RU dadurch für die imperialistische Propaganda weniger anfällig (ebd.: 288). Für RU wäre aber eine Konföderation, wie Brzezinski sie vorschlägt, der Teilung der Russischen Föderation gleichgekommen. RU ist, wie schon erwähnt, an fossilen Brennstoffen sehr reich. Des Weiteren ist RU eine starke Militärmacht mit Atomwaffen und wird von den USA als potentieller Hegemon (Mearsheimer 2001: 53; Brzezinski 2001: 130) angesehen.

In der „Nationalen Verteidigungsstrategie 2018“ schreiben die USA als langfristige Hauptpriorität des US-Verteidigungsministeriums den strategischen Wettbewerb mit RU und China als Ziel vor (ebd.: 2-3). China, ebenso ein reiches Land an fossilen Brennstoffen, wird wegen seiner wirtschaftlichen, politischen und militärischen Kapazitäten als ein weiterer geopolitischer Herausforderer der USA (Mearsheimer 2001: 54-55; Brzezinski 2001: 87, United States Department Of Defense 2018: 2-3) angesehen. Schon 2001 schrieb Mearsheimer (2001: 56), dass die USA weiterhin in der Region stationiert bleiben, um sie vor „chinesischer Hegemonie“ zu schützen (siehe Kap. 5.3). Dass die USA RU und China zu schwächen versuchen, bestätigen des Weiteren die Ereignisse und Erklärungen auf höchster US-Staatsebene (siehe Kap. 5.3) über die EAWU (Erklärung von Hillary Clinton)

\footnotetext{
${ }^{341}$ Dazu mehr in der Webseite von Paul Craig Roberts: http://www.paulcraigroberts.org
} 
und im Pazifikraum (Erklärung von Barack Obama und Leon Panetta), ihre außenpolitische Haltung über die Farbenrevolutionen im postsowjetischem Raum, ihr Vorgehen im Nahen Osten, in Afghanistan, im Pazifikraum, ihre Ziele in der US-Zentralasienstrategie (The New Silk Road Initiative) und den Projekten (wie z. B. CASA-1000-Projekt) (siehe hierzu Kap. 5.3), ihr Raketenabwehrsystem in Rumänien und Polen, ${ }^{342}$ ihre aktuelle Nationale Verteidigungsstrategie und NATO-Erweiterung und Aktivitäten usw. Die USA erklären offen, dass sie gegen das russische (EAWU $)^{343}$ und chinesische (Seidenstaße-Initative) eurasistische Bündnisprojekte sind und sowohl diese als auch die russisch-chinesische Zusammenarbeit verhindern wollen (siehe hierzu Kap. 5.3). Das gefährlichste Szenario aus US-Sicht ist eine anti-hegemoniale Koalition zwischen RU, China und vielleicht dem Iran, schreibt Brzezinski (2001: 87), welche um jeden Preis verhindert werden soll. Deshalb müssen die USA laut Brzezinski (ebd.:87) geostrategisches Geschick beweisen: „Dies erfordert ein hohes Maß an Taktieren und Manipulieren, damit keine gegnerische Koalition zustande kommt, die schließlich Amerikas Vorrangstellung in Frage stellen könnte ...“ (Brzezinski 2001: 283).

Brzezinski diskutierte in einem 2000 verfassten Artikel, dass die Kontrolle RUs und Chinas durch die USA für das Konsolidieren der Stabilität auf dem eurasischen Mega-Kontinent ein Muss sei. Die beiden Staaten müssen nach ihm (Brzezinski 2000) in zwei Gruppen unter der US-Kontrolle verbunden und integriert werden: RU in die westliche Gruppe (USA, Russland und die EU) und China in die östliche Gruppe (USA, Japan und China). Laut Brzezinski (2000) wird RU spätestens in dem Moment mit den USA ein Kompromiss suchen, wenn das Land eine ,anti-islamische Allianz“ (anti-Islamic alliance) brauchen würde. RU würde die US-Hilfe auch brauchen, wenn das Land die Kontrolle über seine Grenzen, wie z. B. zu ZA, verlieren beginne (ebd.). Er glaubt (ebd.), falls RU gegen die „Muslime“ (oder gegen Chinesen) ${ }^{344}$ kämpfen müsste und das Lauffeuer sich Richtung ZA ausbreiten würde, werde die russische Feindschaft gegenüber dem Westen abnehmen. In so einem Fall geht er davon aus (ebd.), dass RU als russische Konföderation im geplanten

\footnotetext{
${ }^{342}$ In Rumänien wurde 2016 das Raketenabwehrsystem aufgebaut. Die Erklärung der USA nach dem milliardenschweren Waffendeal zwischen Polen und den USA im November 2017, dass die Raketenabwehrsysteme in Polen gegen mögliche russische Aggression dienen (O. V. 2017: US-Regierung genehmigt ...), ist für RU die Bestätigung seiner sicherheitspolitischen Sorgen für seine territoriale Integrität und Souveränität.

${ }^{343}$ Die EAWU sehen die USA als Gefahr, als russische Bemühung seinen Status als „Vormacht in Eurasien zu festigen und den eigenen Einfluss in der Region zu bewahren.“ (Pastukhova/Westphal 2016: 2).

344 Brzezinski stellt die „Muslime und Chinese“ als Gefahr dar! Nicht irgendwelche terroristische Vereinigungen oder ähnliches.
} 
„Transeurasischen Sicherheitssystem“ seinen Platz akzeptieren und sich den USA unterordnen wird. Wie aus Brzezinskis Zeilen zu entnehmen ist, ist das Transeurasische Sicherheitssystem eine erweiterte NATO unter der US-Führung.

Islamismus ist für RU, China und den Iran sowie für die zentralasiatischen Staaten die größte sicherheitspolitische Gefahr. In der Russischen Föderation leben heute etwa 30 Mio. Muslime (21\% der russischen Gesamtbevölkerung). ${ }^{345}$ Der Iran ist schiitisch und wird deshalb von den sunnitischen Islamisten als ein zu vernichtender Feind betrachtet. China könnte wegen seiner turksprachigen-muslimischen Uighuren- (etwa 10 bis 12 Mio. Menschen) und muslimischer Hui-Minderheiten (10 bis 11 Mio. Menschen) sowie anderen muslimischen Minderheiten (kasachischen, usbekischen usw. Ursprungs) ein Problem mit dem Islamismus haben. ZA ist sunnitisch-islamisch geprägt und die Zahl der religiösen Extremisten stieg in letzten Jahren stetig an. Falls sich der Islamismus (aus Afghanistan) wie das Lauffeuer Richtung ZA ausbreiten (Brzezinski 2000) würde, wie Brzezinski 2000 als Zukunftsszenario vorsah, werden alle Regionsstaaten Probleme damit haben. In so einem Fall kann die territoriale Integrität und Souveränität dieser Länder zerstört werden. Die zentralasiatischen Staaten und der US-Verbündete Pakistan sowie der unter US-Einfluss stehende Afghanistan ${ }^{346}$ sind mehrheitlich sunnitische Staaten mit einem Potential an islamistischer Gefahr. Sie liegen genau zwischen dem Iran, RU und China sowie Indien ${ }^{347}$ (siehe Abbildung 9). Die Rückkehr der Islamisten aus den Kriegs- und Krisengebieten wird die Lage in ZA verschärfen.

\footnotetext{
${ }^{345}$ IS erklärte im Oktober 2015 gegen „Kreuzfahrer“ RU (sowie die USA) den Dschihad (O. V. 2015: Reuters: IŞi̇ Rusya'ya ...).

${ }^{346}$ Trotz der militärischen Präsenz des Westens in Afghanistan hat der Islamismus und Drogenhandel hier um mehrfaches zugenommen (siehe Kap. 6.1). Des Weiteren ist Afghanistan ein Rückzugsort der zentralasiatischen islamistischen Organisationen.

${ }^{347}$ In Indien leben etwa 170 Mio. Muslime, mit 14 \% machen sie die größte religiöse Minderheit des Landes aus (Wagner 2018: 29). Im Sommer 2014 erklärte der IS u. a. Indien den Krieg (ebd.).
} 
Abbildung 9: Lage Afghanistans, Pakistans und der zentralasiatischen Staaten

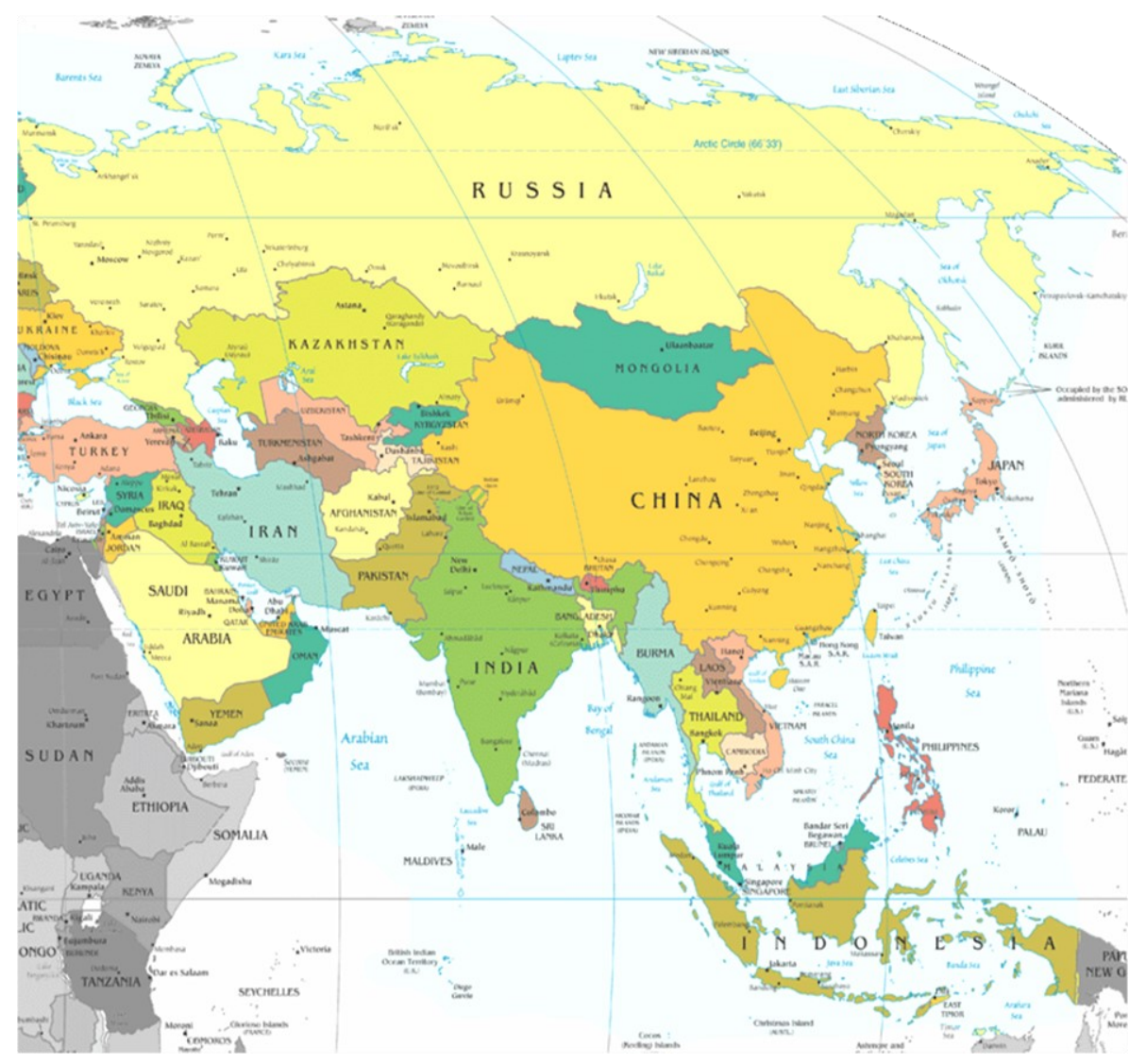

Quelle: Webjaen.es 2010

Die USA legen geopolitisch großen Wert auf Usbekistan. Usbekistan (neben der Ukraine und Aserbaidschan) ${ }^{348}$ wird von Brzezinski (2001: 177) als geopolitisch wichtiger postsowjetische Staat, mit anderen Worten, als „Achsenstaat““349 (Brzezinski 2001: 289-290) im „global play“ (Brzezinski 2001: 58) angesehen. Usbekistan ist mit etwa 33 Mio. Einwohnern (Stand: 2019, United Nations, Department of Economic and Social Affairs,

\footnotetext{
${ }^{348}$ Brzezinski (2001: 166, 177-178) zufolge kann ein unabhängiges Aserbaidschan „dem Westen den Zugang $\mathrm{zu}$ dem an Ölquellen reichen Kaspischen Becken und Zentralasien eröffnen. Umgekehrt würde ein unterworfenes Aserbaidschan bedeuten, daß Zentralasien von der Außenwelt abgeriegelt wird und somit politisch dem russischen Druck nach einer Wiedereingliederung ausgesetzt sein könnte. Usbekistan, volksmäßig der vitalste und am dichtesten besiedelte zentralasiatische Staat, stellt ein Haupthindernis für jede neuerliche Kontrolle Rußlands über die Region dar. Seine Unabhängigkeit ist von entscheidender Bedeutung für das Überleben der anderen zentralasiatischen Staaten, und es versteht sich des russischen Drucks noch am besten zu erwehren. Am wichtigsten allerdings ist die Ukraine. Da die EU und die NATO sich nach Osten ausdehnen, wird die Ukraine schließlich vor der Wahl stehen, ob sie Teil einer dieser Organisationen werden möchte. Es ist davon auszugehen, daß sie, um ihre Eigenständigkeit zu stärken, beiden beitreten möchte.“ Nach Brzezinski (2001: 166) ist für RU ohne die Ukraine eine imperiale Restauration keine realistische Option. ${ }^{349}$ Die Achsenstaaten spielen im „global Play“ (Brzezinski 2001: 58) auf dem Schachbrett (gemeint ist Eurasien) eine entscheidende Rolle. Das Schachbrett umfasst die Gebiete zwischen Lissabon bis Wladiwostok (ebd.). Das Endziel dieses Spieles ist die Etablierung des „Transeurasischen Sicherheitssystem“ und somit der weltweiten amerikanischen Hegemonie.
} 
Population Division 2019) ${ }^{350}$ das bevölkerungsstärkste zentralasiatische Land. Laut Brzezinski (2001: 177) stellt das Land ein Haupthindernis für jede neuerliche Kontrolle RUs über die Region dar. Seine Unabhängigkeit ist nach Brzezinski (ebd.) von entscheidender Bedeutung für das Überleben der anderen zentralasiatischen Staaten, und es versteht, sich des russischen Drucks noch am besten zu wehren. Brzezinski (ebd.: 166) betont, dass Usbekistan die von der Ukraine vorgebrachten Einwände gegen eine Aufwertung der GUS zu einer supranationalen Einheit und den Widerspruch gegen russische Initiativen zur Stärkung der GUS nachdrücklich unterstützte. Hier ist hinzuzufügen, dass Usbekistan über eine enorm wichtige geopolitische Lage verfügt: Das Land grenzt an alle zentralasiatischen Staaten sowie an Afghanistan.

Auch das zentralasiatische Kasachstan (mit RU teilt das Land eine 7600 km lange Grenze) hat für die USA eine strategische Bedeutung. Brzezinski (2001: 216) zufolge verdient Kasachstan wegen seiner geographisch wichtigen Lage, seiner Größe, seines wirtschaftlichen Potentials vorsichtige internationale Rückendeckung und anhaltende Wirtschaftshilfe. Er glaubt, dass es vielleicht mit der Zeit sogar die wirtschaftliche Entwicklung in Kasachstan die ethnische Spaltung überwinden könnte, „die diesen zentralasiatischen Schild gegenüber russischem Druck so wehrlos macht.“(ebd.). Die größte russische Diaspora in ZA befindet sich in Nord-Kasachstan. Diese macht 22 \% (Stand 2013) der Gesamtbevölkerung Kasachstans aus (Auswärtiges Amt 2015c). Die aktuellen Ereignisse in der Ukraine, die Anbindung der ukrainischen Krim an RU 2014, die Unabhängigkeit der georgischen abtrünnigen Republiken infolge des August-Krieges 2008 mit Hilfe des militärischen Eingriffs RUs, wird die kasachische Führung bei ihrem außenpolitischen Verhalten wegen ihrer russischen Minderheit zum vorsichtigen Handel zwingen.

Die USA erzielten bei der Lösung der sicherheitspolitischen Probleme ZAs bis heute keine Erfolge. Im Gegenteil! Die zentralasiatischen Staaten distanzierten sich zunehmend von den USA wegen der US-Haltung zu den Farbenrevolutionen und Unterstützung der Aufstände

\footnotetext{
${ }^{350}$ Als Brzezinski sein Buch „Die einzige Weltmacht. Amerikas Strategie der Vorherrschaft“ (engl. The Grand Chessboard: American Primacy And Its Geostrategic Imperatives, veröffentlicht 1997) schrieb, lebten 1995 in Usbekistan etwa 23 Mio. Menschen, in Kasachstan 16 Mio., in Tadschikistan 5,8 Mio., in Kirgisistan 4,6 Mio. und in Turkmenistan 4,2 Mio. Menschen (United Nations, Department of Economic and Social Affairs, Population Division 2019).
} 
in postsowjetischen Staaten (wie z. B. in Georgien und Ukraine) ${ }^{351}$ und der US-Einsätze im Nahen Osten sowie ihrer Zusammenarbeit mit der TR im Rahmen der türkischen GülenSchulen. Diese Ereignisse näherten die zentralasiatischen Staaten an RU an. Usbekistan forderte die USA nach dem Andijan-Aufstand in Usbekistan 2005 auf, hinter dem die USA vermutet wurde, ihre Militärbasis in usbekischen Karschi-Chanabad zu räumen. Die Entscheidung Usbekistans wurde auf dem SOZ-Gipfeltreffen im Juli 2005 mit anderen Mitgliedern beschlossen. Im November 2005 musste die USA ihre usbekische Militärbasis räumen. Usbekistan trat anschließend vom westlichen GUUAM (Georgien, Ukraine, Aserbaidschan und Moldavien) aus und trat 2006 in die von RU dominierte OVKS und EAWU ein. Allerdings trat 2012 das Land aus der OVKS aus und beendete die Verhandlungen mit der EAWU. Sein OVKS-Austritt wurde in russischen Medien als usbekische Suche nach den Möglichkeiten für die militärische Zusammenarbeit mit den USA interpretiert (O. V. 2012: Özbekistan ABD ile ...). Tatsächlich wurde nach den Verhandlungen mit dem Westen im Mai 2014 in der usbekischen Hauptstadt Taschkent ein NATO-Verbindungsbüro mit einem NATO-Verbindungsoffizier, Rosaria Puglisi, eröffnet. Dieses Büro hatte das Ziel, die Zusammenarbeit von Usbekistan aus mit allen zentralasiatischen Ländern zu fördern. Sein Schwerpunkt lag auf der Unterstützung von Militärreformen und Modernisierung der Armee (Länder-Analysen 2014: 16). Dieses Büro wurde am 1. April 2017 aufgrund der Haushaltsrevision geschlossen (O. V. 2017: NATOBüro in ...). Usbekistan nähert sich seitdem der usbekische Präsident Mirsijojew im Amt ist, seit 2016, wieder an RU an. Im Oktober 2017 wurden auf dem Truppenübungsplatz Forisch erstmals seit 2005 ein russisch-usbekisches Manöver abgehalten (Aripov 2018). Die andere Militärbasis der USA war in Manas, Kirgisistan. RU motivierte Kirgisistan mit Militärhilfen, hier den US-Luftstützpunkt Manas 2014 zu schließen.

Deutschland war der letzte NATO-Staat, der bis 11. Dezember 2015 eine Basis in ZA, in Usbekistan (Termez), nutzte (Bundeswehr (2015): Termez ...). ${ }^{352}$ Kasachstan handelt sicherheitspolitisch eng mit RU zusammen. In Tadschikistan ist die größte Militärbasis RUs im Ausland. In Kirgisistan unterhält RU einen Luftwaffenstütztpunkt und andere

\footnotetext{
${ }^{351}$ Hinter den Unruhen und Farbenrevolutionen im postsowjetischen Raum werden die USA/NATO vermutet. Diese waren: Andijan-Unruhen in Usbekistan (2005), Farbenrevolution und Unruhen in Kirgisistan (2005, 2010), Farbenrevolution und Krieg in Georgien (Rosenrevolution 2003, 2008), Unruhen in Weißrussland (2006), Farbenrevolution und Aufstand, bzw. Krieg in der Ukraine (Orangenrevolution 2004, Unruhen und Krieg seit 2013) (Siehe Kap. 6.6).

${ }^{352}$ Laut dem Bericht von Claudia von Salzen werden die Details des Vertrages über die Basis sowohl von der Bundesregierung als auch von usbekischer Seite geheim gehalten (Salzen 2015).
} 
Militärzentren (siehe hierzu Kap. 4.2.2 oder Kap. 6.7). Turkmenistan hält sich aufgrund seiner Neutralität weitgehend zurück. Neben Farbenrevolutionen verschärften die USEinsätze im Nahen Osten im Rahmen der „Demokratieförderung“ das negative Image der USA in ZA. Der religiöse Extremismus nahm infolge dieser Kriege weiter zu und breitete sich wie ein Lauffeuer Richtung ZA aus, wie Brzezinski schon in seinem Artikel von 2000 als mögliche Entwicklung vorhersagte. Die sunnitisch-islamistische Terrororganisation IS verlor zwar seine Macht in Syrien, wurde aber in Afghanistan immer schlagkräftiger und arbeitet dort mit den zentralasiatischen islamistischen Gruppen wie IBU und Hizbut Tahrir zusammen. Selbst beim IS gibt es tausende zentralasiatische Islamisten. Die Rückkehr der zentralasiatischen Islamisten wird die sicherheitspolitische Lage in ZA verschlechtern. Seit den letzten Jahren nahmen die Terroranschläge in ZA zu (siehe hierzu Kap. 6.1).

\subsection{NATO in Zentralasien}

Die NATO suchte sehr früh die Zusammenarbeit mit den zentralasiatischen Staaten. Alle Staaten der Region wurden Teilnehmer der im Dezember 1991 gegründeten „North Atlantic Cooperation Council“" (Nordatlantischer Kooperationsrat), welcher für das Ziel die Beratung und Förderung des Dialogs zwischen der NATO und ehemaligen Mitgliedern des Warschauer-Paktes gegründet wurde. Dieser Rat wurde 1997 durch den „Euro-Atlantic Partnership Council““ (EAPC, Euro-atlantischer Partnerschaftsrat, EAPR) ${ }^{353}$ ersetzt (NATO 2016b). Die Beratung und Zusammenarbeit der EAPR schließt die sicherheitspolitischen Themen ein, von Menschenhandel bis zur Grenzsicherung und internationaler Terror. Die bilateralen Beziehungen zu den Partnerstaaten regelt die NATO unter dem Programm „Partnership for Peace“ (PfP). Vier zentralasiatische Staaten außer Tadschikistan unterschrieben das PfP-Abkommen mit der NATO im Jahre 1994. Tadschikistan hat es aufgrund seiner inneren Probleme erst 2002 unterschrieben. PfP hat das Ziel, die sicherheitspolitische Zusammenarbeit zwischen der NATO und den nicht NATOMitgliedern zu fördern (NATO 2016a). Obwohl RU auch Mitglied der PfP ist, sieht das Land

\footnotetext{
35350 Staaten sind Mitglieder der EAPR: 29 davon sind NATO-Mitgliedstaaten und 21 Nicht-NATO-Staaten: Montenegro, Kanada, USA, Belgien, Dänemark, Frankreich, Großbritannien, Island, Italien, Luxemburg, Niederlande, Norwegen, Portugal, Griechenland, Türkei, Deutschland, Spanien, Polen, Tschechien, Ungarn, Bulgarien, Estland, Lettland, Litauen, Rumänien, Slowakei, Slowenien, Albanien und Kroatien sind NATO-Mitglieder. Die Nicht-NATO-Mitglieder der EAPC sind: Armenien, Österreich, Aserbaidschan, Belarus, Bosnien und Herzegowina, Finnland, Georgien, Irland, Kasachstan, Kirgisistan, Malta, Moldawien, Russland, Serbien, Schweden, Schweiz, Tadschikistan, Mazedonien, Turkmenistan, Ukraine, Usbekistan. In der EAPR/PfP fehlen nur die folgenden OSZE-Mitglieder: Zypern, Monaco, Andorra, Vatikanstadt, Liechtenstein, San Marino und die Mongolei.
} 
die PfP als Vorstufe zum NATO-Beitritt. Die NATO-Beitritte der früheren PfP-Mitglieder Polen, Tschetschien und Ungarn im März 1999; Bulgarien, Estland, Litauen, Lettland, Rumänien, Slovakei, Slovenien im März 2004; Albanien und Kroatien im April 2009 sind für RU die Belege ihrer Sorgen. RU sieht in den NATO-Aktivitäten in ,seinem Nahen Ausland" seine Einkreisung durch die NATO.

Im Rahmen der „PfP-Planning and Review Process“ (PARP, PfP-Planungs- und Überprüfungsprozess) bietet die NATO den Partnern die Unterstützung ihrer militärtechnischen Reformen an, um deren Kräfte und Fähigkeiten für die NATO-geführten Friedensoperationen zur Verfügung zu haben. Kasachstan nahm 2002 an PARP teil. Usbekistan und Kirgisistan traten dem Prozess im Jahr 2002 und 2007 bei. Allerdings legten diese Staaten ihre Beteiligung seit einigen Jahren auf Eis. Kasachstan und Kirgisistan sind in der „Military Partnership Division“ (militärische Partnerschaft Abteilung) der „Allied Command Operations“ (ACO, Kommandooperationen der Verbündeten) vertreten, welche für die Planung und Ausführung aller Operationen des Bündnisses zuständig ist. Die Planung, bzw. der Befehl von ACO übernimmt „Supreme Allied Commander, Europe - or SACEUR“ (Oberste Allierte Befehlshaber Europa oder SACEUR), der seine Zuständigkeit am Hauptsitz in Mons, Belgien, in „Supreme Headquarters Allied Powers Europe“ (Oberste Hauptquartier der Alliierten Mächte Europa, bekannt als SHAPE) ausübt. Außerdem haben Kasachstan und Usbekistan Militärvertreter im NATO-Hauptquartier in Brüssel (NATO 2016b).

Die zentralasiatischen Staaten sind laut der NATO (2016b) durch die aus Afghanistan ausgehenden sicherheitspolitischen Probleme direkt betroffen. Im Rahmen der „Partnership Action Plan against Terrorism“ (Partnerschaftshandlungsplan gegen Terrorismus) mit der NATO, welche im Rahmen der EAPC ist, suchen sie gemeinsam Lösungen. Die Zusammenarbeit in diesem Bereich schließt Informationsaustausch, Ausbildung und Training der lokalen Kräfte ein, um den Terrorismus zu begegnen. Der NATO zufolge brauchen zentralasiatische Staaten nicht nur wegen der sicherheitspolitischen Probleme aus Afghanistan die NATO-Unterstützung; sondern auch wegen ihrer innenstaatlichen Probleme wie z. B. wegen der ungerechten sozioökonomischen Entwicklung, mangelnder Demokratie, -Good Governance und -Menschenrechte (NATO 2016b). Dafür bietet die NATO den zentralasiatischen Staaten die Bildung von demokratischen Sicherheitsinstitutionen an (ebd.). Laut der NATO (ebd.) ist die sicherheitspolitische Zusammenarbeit mit der NATO 
für die Stabilität und Sicherheit der Region im eigenen Interesse der zentralasiatischen Staaten. Neben der sicherheitspolitischen Zusammenarbeit möchte die NATO die politische und wirtschaftliche Zusammenarbeit zwischen Afghanistan und seinen Nachbarn, wie z. B. mit ZA, vorantreiben. Die NATO unterstützt weiterhin die regionalen Bemühungen unter dem ,Joint Plan of Action for the Implementation of the United Nations Global CounterTerrorism Strategy in Central Asia“ (Gemeinsamer Aktionsplan für die Umsetzung des United Nations Global Strategie zur Terrorismusbekämpfung in ZA).

Die NATO und ihre Ziele für ZA werden von den autoritären zentralasiatischen Entscheidungsträgern negativ, als sicherheitspolitische Gefahr gegen ihre territoriale Integrität und Souveränität wahrgenommen. Des Weiteren wird die NATO als sicherheitspolitisches Instrument der USA wahrgenommen. ${ }^{354}$ Den USA/NATO werden durch RU die Farbenrevolution und Instabilität und Kriege im Namen der Demokratisierung zugeschrieben, wie z. B. in Afghanistan, Irak oder Syrien, die bis jetzt mehr Instabilität als Stabilität brachten (siehe hierzu Kap. 6.6). Im NATO-Russland-Rat versucht RU trotzdem mit der NATO zusammenzuarbeiten (siehe Kap. 6.6).

\subsection{EU UND OSZE in Zentralasien}

Die sicherheitspolitischen Beziehungen der EU mit ZA begann 1992 mit der Aufnahme der zentralasiatischen Staaten in die Organisation KSZE (Konferenz für Sicherheit und Zusammenarbeit in Europa). Sie ist der Vorgänger der OSZE. Die OSZE ist mit 57 Teilnehmer-Staaten (2018) die einzige sicherheitspolitische Organisation, in der alle europäischen Länder, die Nachfolgestaaten der Sowjetunion, die USA, Kanada und die Mongolei vertreten sind (Auswärtiges Amt 2018g). ${ }^{355}$ Die wichtigsten Ziele der OSZE wurden folgendermaßen definiert:

\footnotetext{
354 Der Amerika-Experte Johannes Thimm (2018) schreibt, dass die Nato der Vormachtstellung der USA praktisch und ideell hilft. Sie ist der Katalysator für die militärische Macht der USA: „Sie verleiht der amerikanischen Position unangefochtener Stärke Legitimität. Europäische Verbündete beteiligen sich an zahlreichen Missionen, etwa in Afghanistan, während die USA die Richtung vorgeben. US-Militärstützpunkte in Europa dienen nicht nur der Verteidigung Europas, sondern auch als logistische Drehscheiben und Ausgangsbasis für Einsätze der USA im Nahen Osten.“(Thimm 2018).

355 Die OSZE ist besonders wegen der Wahlbeobachtung durch das BDIMR, des Büros für demokratische Institutionen und Menschenrechte (englisch: Office for Democratic Institutions and Human Rights, Abkürzung ODIHR), in OSZE-Teilnehmerstaaten bekannt (Auswärtiges Amt 2018g).
} 
„Ziel der OSZE ist es, die Sicherheit in Europa durch Zusammenarbeit und Dialog zwischen den europäischen sowie den östlichen und westlichen Nachbarstaaten zu stärken. Dabei wendet die OSZE einen weiten Sicherheitsbegriff an, der die sog. "drei Dimensionen" umfasst: 1. die politisch-militärische Dimension, 2. die wirtschaftliche und ökologische Dimension sowie 3. die menschliche Dimension der Sicherheitspolitik. " (Auswärtiges Amt 2018g).

Die erste Mission der OSZE in ZA fand im Jahr 1994 statt. Sie versuchte, während des tadschikischen Bürgerkrieges einen Beitrag zum Krisenmanagement und zur Konfliktbearbeitung zu leisten. Zunächst war sie mit einem Verbindungsbüro für alle zentralasiatischen Staaten nur in Usbekistan tätig. 1999 eröffnete sie in allen zentralasiatischen Staaten ein Verbindungsbüro (Gumppenberg/Gumppenberg 2006).

Die EU verfolgt ihre sicherheitspolitischen Interessen in ZA im Rahmen der NATO (EAPR, PfP) und OSZE sowie ihrer eigenen sicherheitspolitischen Programme wie BOMCA (für Grenzensicherheit) und CADAP (für Drogenbekämpfung). 2001 begann das Programm CADAP, um die zentralasiatischen Staaten gegen den Drogenhandel zu unterstützten. Für diesen Zweck stellte die EU für den Zeitraum 2001-2013 20,7 Mio. EUR zur Verfügung. Ab 2013 sieht die EU 5 Mio EUR vor. BOMCA wurde 2002 entwickelt und ist seit 2003 aktiv. Bis 2013 stellte die EU für BOMCA 33,6 Mio. EUR zur Verfügung. Die regionale Zentrale von CADAP und BOMCA ist in Bischkek, Kirgisistan. Diese Programme kooperieren mit der OSZE, ADB (Asian Development Bank), USAID (United States Agency for International Development), UNODC (United Nations Office on Drugs and Crime), IOM (International Organisation for Migration) und „Deutsche Gesellschaft für Internationale Zusammenarbeit“ (GIZ) (European Commission 2015: Central Asia - Border ...). Nach den Andijan-Unruhen in Usbekistan 2005 beauftragte die EU einen Sonderbeauftragten für ZA (Sadyrbek 2014). Seine Aufgabe war die Koordinierung und Förderung der EU-Politik, die Überwachung der Umsetzung der EU-Strategie und die Unterstützung der regionalen Sicherheit in ZA (Europäischer Rat 2015: Neuer EU-Sonderbeauftragter ...) (siehe hierzu Kap. 5.4). In ihrer ZA-Strategie 2015 fasste sie ihre Ziele für die Region folgendermaßen zusammen (Fayos 2016):

„Stabilität und Wohlstand zu schaffen und gleichzeitig offene Gesellschaften, Rechtsstaatlichkeit und Demokratisierung zu fördern. Auf dem Gebiet der Energiesicherheit und-diversifizierung sollen Beziehungen gefördert werden, die stärker auf Zusammenarbeit ausgerichtet sind. Die Kohlenwasserstoffe Kasachstans und Turkmenistans könnten sich in Zukunft für die EU als wichtig erweisen. Ein wichtiges Anliegen für eine Reihe von Staaten ist der Abzug der Internationalen 
Sicherheitsunterstützungstruppe (ISAF) aus Afghanistan, der im Dezember 2014 abgeschlossen wurde, wenngleich 13000 Angehörige der US- und NATOStreitkräfte im Land bleiben werden. Um den möglichen Folgen des Truppenabzugs zu begegnen, wurde im Jahr 2013 ein neuer hochrangiger Dialog über Sicherheitsfragen eingeleitet. "

Wie aus diesem Zitat zu entnehmen ist, teilt die EU mit der OSZE ähnliche Ziele bezüglich der Förderung der Rechtstaatlichkeit und Demokratisierung sowie Sicherheit. Des Weiteren unterstreicht sie die Intensivierung ihrer Arbeit mit der Region und die Zusammenarbeit mit den anderen internationalen Organisationen wie mit der OSZE (Europäisches Parlament 2016: Entschließung des Europäischen Parlaments vom 13. April 2016 ...). Auch die NATO bekräftigt in der NATO-Gipfelerklärung von Lissabon vom 20. November 2010 das Ziel, die Zusammenarbeit mit der OSZE zu stärken (Bundesregierung 2010: Gipfelerklärung von Lissabon):

„,Wir [NATO] beabsichtigen, die Zusammenarbeit des Bündnisses mit der OSZE sowohl auf politischer als auch auf operativer Ebene weiter auszubauen, insbesondere in Bereichen wie Konfliktverhütung und -beilegung und Wiederaufbau nach einem Konflikt sowie bei der Bewältigung neuer Bedrohungen für die Sicherheit."

Die OSZE bekräftigte in der Gipfelerklärung von Astana 2010, dass Menschenrechte und Demokratie "nicht ausschließlich zu den inneren Angelegenheiten eines Staates gehören", sondern direkt alle Mitgliedstaaten betreffen (Bundesregierung 2015: Deutschland in der OSZE). ${ }^{356}$ Solche Erklärungen und Ziele der westlichen Organisationen sehen die autoritären Entscheidungsträger der zentralasiatischen Staaten allerdings als Gefahr gegen ihre Herrschaft und Sicherheit des Landes an, auch wenn sie selbst OSZE-Mitglieder sind und zum Teil mit der EU und NATO kooperieren.

RU kritisierte die westlichen Aktivitäten im GUS-Raum „und beschuldigte vor allem westliche NGOs wie Freedom House und das Open Society Institute, aber auch die OSZE und insbesondere das Büro für demokratische Institutionen und Menschenrechte (BDIMR), die Oppositionsbewegungen in der Ukraine, in Georgien und in Kirgisistan unterstützt zu haben.“ (Epkenhans 2006: 235). Unter „westlichem Demokratieexport“ versteht RU Chaos und Instabilität. Die Mehrheit der

356 OSZE-Entscheidungen sind zwar politisch, nicht aber rechtlich bindend (Bundesministerium der Verteidigung o. J.). 
russischen Bevölkerung denkt wie die russischen Entscheidungsträger*innen. Das ergab eine aktuelle repräsentative Umfrage des „Levada-Zentrums“ im Jahre 2016:

„Die Grundfreiheiten und Grundrechte der Meinungsfreiheit, Versammlungsfreiheit, Bewegungsfreiheit und Religionsfreiheit werden von $9 \%$ der befragen Russen für persönlich wichtig erachtet. Die Achtung der Menschenrechte erachten 20\% der Russen für wichtig. In ländlichen Gegenden liegt dieser Wert nur bei $2 \%$. Nur $7 \%$ der Russen nannten Demokratie als ein wichtiges Problem in Russland.“(O. V. 2016: Umfrage: Russen wollen ...).

Das wichtigste Anliegen der russichen Bürger*innen ist politische und wirtschaftliche Stabilität. Etwa $53 \%$ der Befragten zeigten sich mit der Aussage „lieber Stabilität als Freiheit und Demokratie“ einverstanden (O. V. 2016: Umfrage: Russen wollen ...).

Die EU verhält sich in ZA nicht als „Wertegemeinschaft“, sie ist ambivalent. Sie unterstreicht zwar die Werte, wie z. B. Meinungsfreiheit und Rechtstaatlichkeit, in ihren Abkommen, Strategiepapiere, Hilfsprogrammen usw. für ZA; macht sie aber diese nicht zur Bedingung für Verhandlungen mit den autoritären Herrschern der Region (siehe hierzu Kap. 5.4). Die Statistiken über den Entwicklungsstand, die politischen Rechte und Freiheiten, die zunehmende Religiosität und islamistischer Terror in ZA (siehe Kap. 6.1) zeigen, dass sowohl die EU als auch die OSZE-Politik keine nennenswerten Erfolge in ZA erzielen konnten.

\subsection{Türkische Sicherheitspolitik in Zentralasien}

Die TR handelt in ZA sicherheitspolitisch hauptsächlich im Rahmen der NATO (Somuncuoglu 2011, siehe Kap. 6.3). Unabhängig von der NATO versucht sie noch seit 2011 eine sicherheitspolitische Organisation mit den Turkstaaten und mit der Mongolei zu gründen. Der Name dieser Organisation ist „Vereinigung der eurasischen Strafverfolgungskräfte mit militärischem Status“, die auch TAKM oder „Türkenarmee“ genannt wird. Die Abkürzung TAKM leitet sich von den Erstbuchstaben der Staaten Türkei, Aserbaidschan, Kirgisistan und Mongolei ab. Aktuell verhandelt die TR noch mit Kasachstan. Bis jetzt fungiert TAKM allerdings nur als eine sicherheitspolitische „Informationsstelle“. 
Die TR versuchte gleich nach der Auflösung der Sowjetunion, die Turkstaaten unter ihrer Leitung in einer „Türkenwelt“ zu vereinigen (siehe hierzu Kap. 4.1.2). Im Hintergrund dieses Ziels versuchte sie während des ersten Karabach-Krieges (1992-1994) auf der aserbaidschanischen Seite gegen Armenien zu intervenieren. Der Generalstabchef der russischen Armee, General Shaposhnikov, drohte der TR im Falle einer Einmischung mit einem 3. Weltkrieg (Fuller 1993: 78; Cornell 1999; Kolobov/Kornilov/Özbay 2006: 143). In seinen nationalen Dokumenten von 1993 erklärte RU die postsowjetischen Gebiete, wie ZA, als „,sein Nahes Ausland“ (siehe hierzu Kap. 6.6), in dem das Land keine fremden Mächte dulden wird. Weil sie wegen RU keine sicherheitspolitischen Ziele in der postsowjetischen „Türkenwelt“ verfolgen konnte, konzentrierte sie sich auf Bildungs- und Kulturpolitik sowie Wirtschaftspolitik.

In den türkischen Hegemonieversuchen in der Region sehen die zentralasiatischen Staaten eine sicherheitspolitische Gefahr für ihre Souveränität und territoriale Integrität. Die zentralasiatischen Staaten wollen weder die türkische Hegemonie noch die russische. Sie erwarten Akzeptanz und Anerkennung ihrer territorialen Integrität und Souveränität. Vom Pantürkismus und Islamismus distanzieren sie sich. In allen zentralasiatischen Turkstaaten sind die Parteien verboten, die sich auf ethnischer oder religiöser Grundlage definieren (Halbach 2018: 18). Diese innenpolitische Haltung spiegelt sich in ihren außenpolitischen Entscheidungen wider. D. h. die Zusammenarbeit mit der TR auf der ethnischen und/oder religiösen Basis lehnen sie grundsätzlich ab (siehe hierzu Kap. 4.1.2.1) und wollen mit ihr nur in den Organisationen zusammenarbeiten, die ihre kulturelle und sprachliche Nähe betonen (Siehe Tabelle 3).

Gülen-Schulen waren die stärksten halboffiziellen Soft-Power-Mittel der TR in ZA, die u. a. für die „sprachlich-kulturelle Einheit der Türkenwelt“ arbeiteten. RU schloss diese Schulen in den turksprachigen und/oder muslimischen Gebieten der Russischen Föderation, wie z. B. in Tataristan und Dagestan zwischen 2006-2008, infolge des Berichtes des russischen Inlandsgeheimdienstes FSB. Laut dem Bericht arbeiten einige Lehrer dieser Schulen im GUS-Raum für die CIA und diese Schulen verbreiten eine pantürkistische und islamistische Ideologie (O. V. o. J.: Rusya'dan Gülen okullarına ...; O. V. 2015: Erdoğan und Putin ...). 
Ruslan Kurbanow von der „Russischen Akademie der Wissenschaften“ zufolge wurde die Gülen-Bewegung von der CIA gegründet und Gülen erhielt seine Aufenthaltsberechtigung in den USA dank den ehemaligen CIA-Mitarbeitern Graham Fuller und George Fidas sowie dem ehemaligen US-Türkei-Botschafter in Ankara, Morton Abramowitz. Der DumaAbgeordnete Vyatscheslav Nikonow betont ebenso die Zusammenarbeit zwischen der CIA und der Gülen-Bewegung (O. V. 2016: Rusya'dan flaş Fethullah ...). Wie im Unterkapitel 4.1.2.2 erklärt wurde, berichten auch einige türkische und amerikanische Wissenschaftler*innen, Journalist*innen und Geheimdienstmitarbeiter*innen usw. von der türkisch-amerikanischen Zusammenarbeit im Rahmen der Gülen-Schulen. Nach dem russischen Politikwissenschaftler Nikolai Nartov (Erol 2012: 7) verfolgt die TR in ZA einerseits mit der Unterstützung der USA ihre Interessen; andererseits versucht sie, die Rahmenbedingungen für die US-Zentralasienpolitik zu schaffen. D. h., RU sieht die TR in den Turkstaaten als verlängerten Arm der USA und als sicherheitspolitische Gefahr gegen seine Souveränität und territoriale Integrität an (Basaran 2013: 154; Kazgan 2003: 172-173). Des Weiteren ist die TR für RU ein pantürkistisch-islamistisch motiviertes Land in seinem Nahen Ausland, das RU von der westlichen NATO zu lösen und unter seine Hegemonie zu bringen versucht.

Pantürkismus und Islamismus sind für RU große sicherheitspolitische Gefahren. In der Geschichte bekämpfte RU in ZA den von der TR unterstützten, bzw. zum Teil geleiteten pantürkistisch-islamistischen Basmatschi-Aufstand (siehe hierzu 3.6). Russische sicherheitspolitische Sorge ist der mögliche Aufstand seiner Minderheiten gegen RU, die etwa 20 Mio. turksprachige Menschen (etwa $14 \%$ der russischen Gesamtbevölkerung) und etwa 30 Mio. Muslime (21 \% der Gesamtbevölkerung) ausmachen. Die südliche Grenze RUs ist turksprachig und muslimisch geprägt. Die mögliche Instabilität durch den Pantürkismus und/oder religiösen Extremismus in der Russischen Föderation und/oder in ihrer unmittelbaren Nähe könnte die gesamte Region destabilisieren. Aus diesen Gründen hat RU seine Minderheiten streng im Blick. Laut Halbach (2016: 3) kündigte RU einerseits seine Mitgliedschaft in der Organisation für die gemeinsame Entwicklung der Turkkultur auf und verbot gleichzeitig seinen turk- und mongolischstämmigen Minderheiten, an einem turksprachigen Schlagerwettbewerb teilzunehmen, der im Dezember 2015 in Istanbul stattfand. Hierzu ist zu bemerken, dass diese Schlagerwettbewerbe von der Gülen-Bewegung organisiert wurden. Des Weiteren unterstützten die TR und RU gegenseitig ihre „GegnerGruppierungen“, gemeint die PKK für die TR und die radikalen tschetschenischen 
Gruppierungen für RU. Mit den sicherheitspolitischen Abkommen von 1996 und 1999 versicherten sich die TR und RU zwar gegenseitig, die von ihnen als Terroristen eingestuften Gruppen nicht zu unterstützen. Für RU aber ist die PKK und für die TR sind die tschetschenischen islamistischen Gruppierungen keine Terrororganisationen (siehe hierzu Davutoglu 1996).

Die Sicherheitspolitik ist für die zentralasiatischen Staaten wie für RU „high politics“. Sie sind sich über den Status Quo in der Region einig und sehen den türkischen Pantürkismus und ihre in letzten Jahren zugenommene islamistische Haltung als sicherheitspolitische Gefahr. Nachdem Erdogan 2014 Staatspräsident geworden war, nahmen die pantürkistischen und islamistischen Äußerungen und Symbole ${ }^{357}$ in der türkischen Außenpolitik zu. Erdogan sagte während der Einweihung eines Forschungszentrums in Gölbasi am 10. April 2015: „Der Kampf für die Neue Türkei ist gleichzeitig unser ,Roter Apfel'. Mit Allahs Hilfe werden wir bis zum Ende unseres Lebens für dieses Ziel arbeiten.“ (Übers. d. die Verfasserin) (O. V. 2015: "Yeni Türkiye bizim ....). ${ }^{358}$ Roter Apfel (türkisch: Kizil Elma) symbolisiert für die TR die „Türkenwelt“ und ist eines der wichtigsten Symbole des Pantürkismus. Das Ziel des Roten Apfels ist die Vereinigung der Turkvölker. Im Januar 2018 erklärte Erdogan auch das Ziel des Einsatzes „Operation Olivenzweig“ in Kurdisch geprägten Afrin (Syrien) mit dem „Roten Apfel“ (O. V. 2018: Erdoğan: Afrin'den geri ...). Des Weiteren zeigte die TR seine offene Sympathie für den Islamismus während des arabischen Frühlings. Sie solidarisierte mit den Muslimbrüdern in Ägypten und unterstützte die islamistischen Gruppierungen in Syrien gegen Assad. Aufgrund der offenen „pantürkistisch-islamistischen“ Aktivitäten und Ziele der TR sind die zentralasiatischen Staaten gegen die TR vorsichtig, bzw. zurückhaltend. RU sehen sie hingegen als Garant des Status Quo in der Region und akzeptieren seine Hard Power, wie im Tadschikischen Bürgerkrieg (1992-1997), der Andijan-Unruhen (2005) in Usbekistan und Unruhen in Kirgisistan (2010) zu sehen war (siehe hierzu Kap. 6.1).

Der Abschuss eines russischen Kampfflugzeuges Typ Su-24 an der syrischen Grenze zur TR am 24. November 2015 durch die TR ist ein gutes Beispiel, um die sicherheitspolitische

\footnotetext{
${ }^{357}$ Erdogan begrüßt innerhalb und außerhalb der TR das Publikum öfters mit dem Rabia-Gruß. Dabei werden vier Finger gereckt und der Daumen angewinkelt in die Handinnenfläche gedrückt. Rabia-Gruß ist das Symbol der Muslimbrüder. D. h., er ist ein islamistisches Symbol.

${ }^{358}$ Erdogan: ,Yeni Türkiye mücadelesi aynı zamanda bizim 'kızıl elmamız'. İnşallah bu yolda Rabbim ömür verdiği sürece kararlılıkla yürüyeceğiz."
} 
Haltung der zentralasiatischen Staaten gegenüber der TR und RU vergleichend zu zeigen. Die zentralasiatischen Staaten nahmen eine klare Haltung auf der russischen Seite ein. Im Rahmen der GUS-Gipfeltreffen im Dezember 2015, in der alle zentralasiatischen Staaten Mitglied sind (Turkmenistan nur beigeordnetes Mitglied), wurde die TR von den zentralasiatischen Staaten aufgefordert, sich bei RU für den Fall zu entschuldigen (Dogan 2016). Der ehemalige kirgisische Präsident Atambayew beschuldigte die TR am 24. Dezember 2015 öffentlich und forderte sie zur Entschuldigung auf (O. V. 2016: Kirgızistan Cumhurbaşkanı Atambayev ...). Diese Beispiele zeigen deutlich, dass die zentralasiatischen Staaten auf der russischen Seite sind (siehe hierzu Kap. 6.6).

\subsection{Russische Sicherheitspolitik in Zentralasien}

Für RU ist die Sicherheitspolitik high politics. In seinen „Außenpolitikkonzepten von 2000 und 2013“ legt es fest, dass Sicherheitspolitik die höchste Priorität der russischen Außenpolitik ist (President of the Russian Federation 2000: 1, Präsident Der Russischen Föderation 2013). Die USA/NATO und der Islamismus werden in allen nationalen Dokumenten RUs als sicherheitspolitische Probleme benannt. ZA ist für RU in erster Linie aus sicherheitspolitischen Gründen von großer Bedeutung. Sie wird als Pufferzone angesehen: Im Great Game gegen England, im New Great Game gegen die USA/NATO und aus Afghanistan ausgehenden Probleme, wie Terrorismus und Drogenhandel sowie gegen die innerregionalen Probleme, wie Pantürkismus und Islamismus.

RU schrieb schon in seiner ersten „Militärdoktrin von 1993“ als Hauptziel den Schutz seiner „Souveränität und territorialen Integrität und anderer lebenswichtigen Interessen der Russischen Föderation im Falle einer Aggression gegen sie oder ihre Verbündeten“ (DSS 1994: 6, 19) (siehe hierzu auch Kap. 4.2.1). In seiner „Sicherheitsstrategie“ vom selben Jahr definierte RU seine „lebenswichtige Interessen“ als:

„Eindämmung lokaler Konflikte und Kriege an den russischen Grenzen, der Schutz der äußeren Grenzen der GUS, die fortdauernde russische militärische Präsenz in den neuen unabhängigen Staaten sowie der Schutz der 'Menschenrechte' ethnischer Russen in den neuen unabhängigen Staaten. "(Alexandrova 1995).

Nach der Auflösung der Sowjetunion verfolgte RU zunächst eine westlich orientierte Außenpolitik (Atlantismus). 1994 entschied sich RU „für einen Eintritt in das NATOPartnerschaftsprogramm, stimmte im Mai 1997 der Schaffung des ,Ständigen Gemeinsamen 
NATO-Russland-Rates“ als Konsultationsforum zu und unterzeichnete 1998 die ,NATORussland Grundakte' (Grundakte über gegenseitige Beziehungen, Zusammenarbeit und Sicherheit zwischen der NATO und der Russischen Föderation).“ (Deutscher Bundestag 2016a: 13). Im Mai 2002 wurde der seit 1997 bestehende „Ständige Gemeinsame Rat“ von der NATO zum „NATO-Russland-Rat““ aufgewertet. In diesem Rat wird „der Kampf gegen den Terrorismus, die Verbreitung von Massenvernichtungswaffen und die Friedenssicherung diskutiert, nicht jedoch Fragen der Erweiterung“, schreibt Dembinski (2006: 22). Zu einer erfolgreichen Kooperation kam es zwischen RU und der NATO nicht, da für RU die NATO zunehmend, ,als ein politisches Instrument des Westens zur Ausdehnung und Festigung des US-Einflusses in Osteuropa“" angesehen wurde (Deutscher Bundestag 2016a: 13). Laut RU streben die USA nach einer monopolaren Welt, die den russischen Interessen im „Nahen Ausland“ entgegensteht (Deutscher Bundestag 2016a: 14). Wegen des Ukraine-Konflikts 2014 suspendierte die NATO den Dialog mit RU (Auswärtiges Amt 2018h). Nach zweijähriger Unterbrechung finden zwar auf Initiative vom damaligen Außenminister Frank-Walter Steinmeier (2005-2009 und 2013-2017) ab April 2016 die Sitzungen des Nato-Russland-Rats wieder statt (Bundesregierung o. J.). Von diesem Rat sind aber aufgrund des herrschaftspolitischen Wettbewerbs und der sicherheitspolitischen Konkurrenz zwischen den USA und RU (Dembinski 2006: 22) keine sicherheitspolitischen Erfolge zu erwarten. Für eine sicherheitspolitische Zusammenarbeit erwartet RU von den USA/NATO, als gleichberechtigter Partner akzeptiert zu werden und dass sie sich an die Grundsätze und Normen des Völkerrechts, vor allem an diejenigen, die in der UN-Charta verankert sind, strikt halten (The Ministry of Foreign Affairs of the Russian Federation 2016, Artikel 62, Artikel 70, Artikel 74).

Die russische Unzufriedenheit über die NATO ist schon in seinen früheren offiziellen Dokumenten (Nationale Sicherheitsstrategie, Militärdoktrin und Außenpolitikkonzept) von 2000 deutlich formuliert. Die NATO wurde dort namentlich als sicherheitspolitische Gefahr für RU genannt (siehe hierzu Kap. 4.2.1). In der „Nationalen Sicherheitsstrategie 2000“ (Außenministerium der Russischen Föderation 2000) definierte RU als Hauptgefahren die NATO-Erweiterung, den Terrorismus, eventuelles Aufkommen von ausländischen Militärstützpunkten und großen Truppenkontingenten in unmittelbarer Nähe der russischen Grenzen. Im „Außenpolitikkonzept von 2000“ wurden die angrenzenden Staaten zu RU, wie ZA, als „Sicherheitsgürtel“ gegenüber den sicherheitspolitischen Gefahren definiert (President of the Russian Federation 2000: 2, 8-9). Mit Kasachstan teilt das Land eine 7600 
km lange Grenze. In der „Militärdoktrin 2000“ (Präsident der Russischen Föderation 2000) erklärte RU, dass das Land gegen diese Gefahren militärisch vorgehen wird (siehe hierzu auch Kap. 4.2.1).

Der NATO ist das erste Mal im Rahmen des Afghanistan-Einsatzes 2001 gelungen, in ZA Militärbasen zu erwerben, was laut Wipperfürth (2011: 61) ohne russische Unterstützung vermutlich nicht möglich gewesen wäre. RU half den USA/NATO mit Geheimdiensterkenntnissen und umfangreichen Waffenlieferungen (ebd.). Durch sein kooperatives Verhalten beabsichtigte RU einerseits die Bekämpfung des islamistischen Terrors durch die USA/NATO. Andererseits konnte das Land dadurch sein Vorgehen gegen die Tschetschenen rechtfertigen. Gegen Ende des Jahres, im Dezember 2001, kündigten die USA nach den ersten großen Siegen in Afghanistan den ABM-Vertrag mit RU (1972 mit der Sowjetunion abgeschlossen), der die Aufstellung der Raketenabwehrsysteme über eine begrenzte Zahl verbot. Nach einem Monat der Kündigung, im Januar 2002, wurde RU im Bericht des US-Verteidigungsministeriums an den Kongress als potenzielles Ziel von USNuklearwaffen benannt. Nach einem Jahr, am Anfang 2003, wurde RU im strategischen Grundsatzdokument der USA, „Nuclear Posture Review“, als Ziel für nukleare Erstschlagwaffen benannt (Wipperfürth 2011: 62, 64).

Seit dem Irak-Einsatz der USA/NATO Ende März 2003 ohne UN-Mandat zeigt RU zunehmend seine Unzufriedenheit mit der USA/NATO-Politik. Diesen Einsatz sieht das Land als „schweren politischen Fehler“ (ebd.: 65). Schon im Vorfeld des Einsatzes warnte RU über seinen möglichen Folgen, d. h. über das zu erwartende Chaos und zunehmenden Terror (ebd.: 66). Auch über die westlichen Basen in ZA, die temporär wegen des Afghanistan-Einsatzes erworben wurden, zeigte RU zunehmend seine Unzufriedenheit. Die offiziellen Erklärungen der USA/NATO über den Südkaukasus und ZA spitzte die Situation zu. 2002 erklärte die NATO die postsowjetischen Staaten des Kaukasus und ZAs als Gebiete, die für die NATO ,, besondere Aufmerksamkeit und Förderung “verdienen (Deutscher Bundestag o. J.: 7, Artikel 10.2). Die NATO-Teilnehmerstaaten erklärten auf dem Gipfeltreffen in Istanbul 2004, dass der Kaukasus und ZA Schwerpunkt der NATO-Arbeit (NATO 2016a) sind. In ZA wurde ein NATO-Verbindungsbüro eingerichtet und die NATO ernannte einen Special Representative für die Region (Dembinski 2006: 22). Kaukasus und ZA sieht RU allerdings als Teil seines „Nahen Auslandes“ und als „Sicherheitsgürtel“ u. a. gegen die NATO an. 
RU zufolge versuchen die USA/NATO RU einzukreisen. Die Gründung der westlichen GUAM (Georgien, Ukraine, Aserbaidschan und Moldavien) im Jahre 1997, die Farbenrevolutionen in seinem „Nahen Ausland“ und die weitere NATO-Erweiterung durch den Beitritt der osteuropäischen Staaten (Litauen, Lettland, Estland, Bulgarien, Rumänien, die Slowakei und Slowenien) 2004 verschärften die russische Kritik an den USA. RU wurde zur deutschen Wiedervereinigung versprochen, dass sich die NATO nicht über Ostdeutschland hinaus nach Osten erweitern wird (Rötzer 2017, Ganser 2016a, Deutscher Bundestag 2016b: 10). Mit der NATO-Osterweiterung fühlte sich RU hintergangen. Anfang Juni 2005 erklärte der russische Außenminister Lawrow, „RU beabsichtige nicht, der Hauptakteur im postsowjetischen Raum zu sein. Es dürfe aber auch kein anderes Land versuchen, das Gebiet zu seinem exklusiven Einflussgebiet zu machen. Hierbei hatte der Kreml insbesondere die USA im Blick“, schreibt Wipperfürth (2011: 85). Allerdings ist die Realität eine andere. RU nimmt dieses Gebiet als sein natürliches Einflussgebiet, als sein „Nahes Ausland“ wahr (siehe hierzu Kap. 4.2.1). Trotz dieser Sichtweise schlug der russische Außenminister Lawrow im Februar 2006 auf der Münchner Sicherheitskonferenz die Zusammenarbeit der OVKS und der NATO gegen den Drogenhandel in ZA vor. Ähnliche Vorschläge machte RU wenige Monate zuvor im NATO-Russland-Rat für Afghanistan (Scholvin 2009: 7).

RU ist vom Drogenhandel aus Afghanistan stark betroffen. Das Drogenproblem ist für RU sowohl ein Sicherheits- als auch ein Gesundheitsproblem. ZA ist die Hauptroute für den Drogenhandel aus Afghanistan nach RU (siehe Kap. 6.1). Daher ist sein Interesse die Stabilität der Region und die Kontrolle der Drogen-Transportwege. Beim globalen HeroinKonsum nimmt RU mit $21 \%$ den ersten Platz ein. „Zwischen zwei und zweieinhalb Mio. Russen sind drogenabhängig, $90 \%$ dieser Abhängigen konsumieren Heroin aus Afghanistan“, schreibt Ludwig (2013). Die Dunkelziffer soll allerdings viel höher liegen. Laut dem Bericht von Das Erste (Weltspiegel) von 2016 sterben in RU jeden Monat 5.000 Menschen an Drogen (Virnich 2016). Nach einem Bericht von RU-Korrespondentin der Zeitung Die Welt, Julia Smirnova (2016a), lebten 2016 in RU „rund 854.000 HIV-infizierte Menschen, die von Ärzten diagnostiziert wurden. Die tatsächliche Anzahl der Betroffenen dürfte höher sein [, etwa] 1,3 bis 1,4 Mio. Menschen“. Das russische Interesse ist eine „gesunde, arbeitsfähige Bevölkerung“. Des Weiteren hängen Drogenhandel und Terror eng zusammen und somit handelt es sich nicht nur um ein Gesundheitsproblem, sondern auch um ein großes Sicherheitsproblem. Talibans Haupteinnahme ist der Drogenhandel und die 
produzierte Menge erhöhte sich in den lezten Jahren drastisch. Sicherheitspolitisch gesehen bedeutet das, je höher der Drogenverkauf, desto mehr Mittel hat die Taliban für Waffen und Soldatengehälter und wird damit interessanter für die Menschen aus sozio-ökonomisch schwachen, religiösen Gegenden ZAs und Afghanistans (siehe Kap. 6.1).

Im Februar 2007 hielt Präsident Putin eine Rede auf der Münchner Sicherheitskonferenz, in der er die USA in schärfsten Ton kritisierte. Er warf den USA die unbeschränkte und übermäßige Gewaltanwendung und das Überschreiten ihrer Grenzen in jeder Hinsicht (Wipperfürth 2011: 94) vor. Des Weiteren sagte er, dass Moskau Amerika und seine monopolare Welt-nicht mehr dulden werde (Deutscher Bundestag 2016b: 9). Putin kritisierte ferner die NATO-Pläne zum Raketenabwehrsystem in Osteuropa sowie die NATOOsterweiterung $^{359}$ (ebd.). Beim G-8 Gipfeltreffen im Juni 2007 in Deutschland schlug RU der NATO die gemeinsame Nutzung der russischen Radaranlage in Aserbaidschan vor, ein Nachbar des Iran, weswegen die USA vorgaben, in Osteuropa die Raketenabwehrsysteme aufbauen zu wollten (Wipperfürth 2011: 95). Bush antwortete, dass das US-Vorhaben hinsichtlich der Raketenabwehrsysteme in Ostmitteleuropa nicht zur Diskussion stehen kann (ebd.: 96).

Da die USA sich nicht an die Vereinbarungen mit RU halten, das internationale Recht ignorieren (z. B. Irak-Krieg ohne UN-Mandat), nicht auf die sicherheitspolitische Zusammenarbeit mit RU eingehen, die Farbenrevolutionen unterstützen, ${ }^{360}$ die USA und RU über die Unruhen und/oder Kriegen in Jugoslawien, Kosovo, Irak, Georgien, Syrien, Libyen, Ukraine und in Berg-Karabach gegnerischer Meinungen sind, die NATO sich trotz

\footnotetext{
${ }^{359}$ Putin erinnerte in seiner Rede an die einstige Zusicherung der NATO, dass die NATO keine Truppen in Osteuropa stationieren werde. Er zitierte als Beweis Manfred Wörner, den Generalsekretär der NATO. Wörner soll am 17. Mai 1990 in Brüssel gesagt haben: „Schon der Fakt, dass wir bereit sind, die NATO-Streitkräfte nicht hinter den Grenzen der BRD zu stationieren, gibt der Sowjetunion feste Sicherheitsgarantien“"(Deutscher Bundestag 2016b: 10).

${ }^{360}$ Der russische Generalstabschef Waleri Gerassimow erklärte im Februar 2013, die Farbenrevolutionen dienen der Schwächung RUs (in: Klein 2018: 11-12). Deren Ziel sei der Regimewechsel in den moskaufreundlichen Ländern zu Gunsten des Westens. Die neuen westlichen Regime sollen laut Gerassimow anti-russisch sein. Andererseits soll in anti-russischen Ländern „eine Zone des Chaos“ um RU herum geschaffen werden, um schließlich einen Regimewechsel in RU selbst herbeizuführen (Gerassimow in Klein: ebd.). Der Libyen-Einsatz des Westens 2011, der „humanitär“ begründet wurde, führte zugleich aber zum Regimewechsel und zur Tötung Gaddafis. Laut Klein (ebd..) verhärtete dieser Einsatz die russische Haltung in dieser Frage nachhaltig. Dem Westen wirft RU in dieser aktuellen „Sicherheitsstrategie von 2015“ den Regierungswechsel der legitim gewählten Regierungen z. B. durch die sogenannten Farbenrevolutionen und die Unterstützung der innenpolitischen Instabilität und der Konflikte im postsowjetischen Raum vor (President Of The Russian Federation 2015, Artikel 18).
} 
russischer Beschwerden erweitert ${ }^{361}$ und Raketenabwehrsysteme aufgebaut werden, fühlt sich RU in seinen sicherheitspolitischen Befürchtungen um seine territoriale Integrität und Souveränität bestätigt. 2016 wurde in Rumänien ein Raketenabwehrsystem aufgebaut. Die USA erklärten nach dem milliardenschweren Waffendeal mit Polen im November 2017, dass die Raketenabwehrsysteme in Polen gegen mögliche russische Aggression gebaut werden (O. V. 2017: US-Regierung genehmigt ...). Diese Ereignisse und die Erklärung RUs, Chinas, Irans und Nord-Korea durch die USA in ihren aktuellen amerikanischen „Nationalen Verteidigungsstrategie 2018“ (National Defense Strategy) als sicherheitspolitische Gefahren sind für RU die Bestätigung seiner sicherheitspolitischen Sorgen.

In seinen aktuellen nationalen Dokumenten (Militärdoktrin von 2014, Sicherheitsstrategie der Russischen Föderation von 2015 und Außenpolitikkonzeption von 2016) benennt RU die USA/NATO und den Islamismus als größte sicherheitspolitische Gefahren für seine territoriale Integrität und Souveränität. RU bezeichnet in seiner aktuellen „Militärdoktrin von 2014“ (Präsident der Russischen Föderation 2014: 13-15) die NATO-Aktivitäten und Erweiterung, die Verstärkung der ausländischen militärischen Kontingente auf Territorien der Staaten, die an die Russische Föderation und an mit ihr verbündete Staaten angrenzen oder in anliegenden Gewässern, Raketenabwehrsysteme, die territorialen Ansprüche gegenüber der Russischen Föderation und ihren Verbündeten, die Einmischung in die inneren Angelegenheiten, Verletzung der internationalen Vereinbarungen und Verträge, Terrorismus, Radikalismus, die völkerrechtswidrige Nutzung der Informations- und Kommunikationstechnologien zu militärischen Zwecken, die Tätigkeiten der ausländischen Geheimdienste gegen RU als außenpolitische Gefahren.

In seiner aktuellen „Sicherheitsstrategie der Russischen Föderation von 2015“ definiert RU die NATO-Erweiterung und ihre Einsätze als sicherheitspolitische Gefahr gegen seine nationale Sicherheit (President Of The Russian Federation 2015, Artikel 15, Artikel 106). Nach RU verschlechtert sich die regionale und globale Stabilität durch das Stürzen der legitim gewählten Regimes [durch z. B. sog. Farbenrevolutionen] und Provokation der innerstaatlichen Instabilität und Konflikte zusätzlich. Dadurch entstehen neue „Brennpunkte“, die die Entstehung des Extremismus fördern (ebd.: Artikel 18). Die Entstehung der Terrororganisation, die sich selbst Islamischen Staat (IS) nennt und die

\footnotetext{
${ }^{361}$ Gemeint ist der NATO-Beitritt Albaniens und Kroatien im Jahre 2009 und NATO-Beitrittsverhandlung mit Montenegro 2016.
} 
Stärkung ihres Einflusses definiert RU als Ergebnis der [westlichen] Politik infolge seiner Angriffe, bzw. Aktivitäten (wie z. B. in Irak und Syrien) vor (ebd.). Die USA und ihre Verbündeten handeln RU zufolge gegen die russischen innen- und außenpolitischen Interessen, wollen ihre Dominanz in der Weltpolitik erhalten und RU durch die politischen, wirtschaftlichen, militärischen Maßnahmen und Informationsdruck eindämmen (ebd.: Artikel 12).

Die NATO-Erweiterung Richtung russischer Grenzen und ihre Militäraktivitäten in den an RU angrenzende Regionen werden auch in der „Außenpolitikkonzeption von 2016“ als sicherheitspolitische Gefahren für RU und den GUS-Raum definiert (The Ministry of Foreign Affairs of the Russian Federation 2016, Artikel 70). Der internationale Terrorismus, Extremismus, Drogenhandel, illegale Migration usw. werden als regionale Gefahren gegen den GUS-Raum genannt (ebd., Artikel 55). Die Bekämpfung des internationalen Terrorismus, z. B. des Islamischen Staates, schreibt das Land als Priorität im Bereich der internationalen Sicherheit vor (ebd., Artikel 15, Artikel 33). Um ihn gemeinsam zu bekämpfen, ruft das Land die internationale Gemeinschaft auf, unter der Schirmherrschaft der UNO zu kooperieren (ebd., Artikel 31, Artikel 33, Artikel 97). Der Pantürkismus oder ähnliches wird in diesem Außenpolitikkonzept in keiner Weise erwähnt. Daraus kann geschlussfolgert werden, dass RU den türkischen Pantürkismus in ZA nicht als Gefahr ansieht; sondern eher ihre „möglichen islamistischen Aktivitäten“. Aufgrund der türkischen Diskurse und offenen Sympathie für den Islamismus, die während des ägyptischen Frühlings sowie während des Syrien-Kriegs deutlich zu sehen war/ist, würde RU eher die mögliche türkische Unterstützung der Islamisten gegen RU befürchten.

RU schreibt in der „Militärdoktrin“, dass sich seine Militärpolitik auf die Gewährleistung der Verteidigung und Sicherheit der Russischen Föderation und seine Verbündete ausgerichtet ist. Und fügt hinzu, dass RU im Falle eines bewaffneten Überfalls auf einen Mitgliedstaat der GUS (u. a. alle zentralasiatischen Staaten) oder eine andere beliebige Handlung unter Einsatz von militärischer Gewalt gegen sich als einen Akt der Aggression gegen den Unionsstaat betrachten und Antwortmaßahmen ergreifen wird (Präsident der Russischen Föderation 2014: 22). In der „Militärdoktrin“ (2014: 39) und „Außenpolitikkonzeption von 2016“ schreibt das Land, dass RU für die Sicherheit in der Region die sicherheitspolitische Arbeit mit den GUS-Mitgliedsstaaten, wie z. B. im Rahmen 
der OVKS, vertiefen wird. In den letzten Jahren gab es zahlreiche Anschläge der Islamisten in ZA. Alle Regionsstaaten sind der gleichen Meinung über den islamistischen Terror.

Laut den Sicherheitsstellen der Russischen Föderation (Tastekin 2015) kämpfen 1500 Kämpfer aus der Russischen Föderation, darunter die größte Gruppe mit 400 Kämpfern die Tschetschenen, auf der Seite des Islamischen Staates in Syrien. Die anderen sind die Tataren, Dagestenar und zum Islam konvertierte Russen usw. Aus zentralasiatischen Staaten kämpfen allein 3000 aus Usbekistan in Syrien. Putin zufolge beträgt die Zahl der Islamisten in den Reihen des IS aus GUS-Staaten insgesamt 7000 Menschen (O. V. 2015: Putin: 7.000 Dschihadisten ...). Sie machen 23,3 \% der ausländischen Kämpfer aus (O. V. 2015: Şok Rakam! Işid'in ...). Russisch ist laut Medienberichten in den von den IS-kontrollierten Gebieten Syriens und Iraks die zweit meist gesprochene Sprache nach dem Arabischen (Oguz 2016).

Die Rückkehr der Islamisten in ihre Herkunftsländer kann den religiösen Extremismus in ZA und in RU verstärken. Die Rolle der Religion nimmt in letzter Zeit in ZA stark zu (siehe Kap. 6.1). RU befürchtet Spill-Over-Effekte aus und via ZA in die Russische Föderation, weil in der Föderation etwa 30 Mio. Menschen muslimischen Glaubens leben. Die geographische Nachbarschaft ZAs einerseits zu Afghanistan andererseits zu RU macht die Region für RU strategisch sehr wichtig, denn die Instabilität in ZA betrifft unmittelbar die russische Sicherheit. In seiner aktuellen „Konzeption der Außenpolitik der Russischen Föderation von 2016“ definiert RU Afghanistan als sicherheitspolitisches Problem für sich und andere GUS-Staaten (besonders an Afghanistan angrenzende Staaten). In den letzten Jahren nahmen die islamistischen Anschläge von Afghanistan aus in ZA zu. Die Bekämpfung des Terrorismus und Drogenhandels kann nur durch die sicherheitspolitische Zusammenarbeit gelingen.

\subsection{OVKS, GUS und SOZ in Zentralasien}

RU stellt die USA/NATO, die Farbenrevolutionen, den islamistischen Terrorismus und den Drogenhandel in seinen nationalen Dokumenten als größte sicherheitspolitische Gefahren dar (siehe Kap. 6.6). Als zentrale sicherheitspolitische Aufgabe hebt das Land in seiner aktuellen „Außenpolitikkonzept von 2016“ die Bekämpfung des Terrorismus und Drogenhandels in der Region hervor und unterstrich die Relevanz der sicherheitspolitischen 
Zusammenarbeit der Organisationen für dieses Ziel (The Ministry of Foreign Affairs of the Russian Federation 2016, Artikel 97). Die zentralasiatischen Staaten teilen die russischen sicherheitspolitischen Sorgen, weil sie selbst durch sie betroffen sind. Sie arbeiten mit RU in den sicherheitspolitischen Organisationen GUS und OVKS zusammen. Des Weiteren arbeiten sie im Rahmen der SOZ mit China ${ }^{362}$ sicherheitspolitisch zusammen. ${ }^{363}$ Mit den sicherheitspolitischen Organisationen versucht RU, seinen sicherheitspolitischen Einfluss in den ehemaligen postsowjetischen Staaten zu erhalten und, wenn möglich, zu erweitern.

RU annullierte am 8.12.1991 den Unionsvertrag mit Weißrussland und der Ukraine und gründete die GUS. Die zentralasiatischen Staaten unterschrieben am 21.12.1991 die AlmatiDeklaration und traten der GUS bei (Hüseynov 2003: 394-395). Alle zentralasiatischen Staaten sind Mitglied der GUS. Turkmenistan ist seit 2005 ein beigeordnetes Mitglied. D. h. das Land hat mit Ausnahme der in der Satzung vorgesehenen Fälle nicht den Status eines ordentlichen stimmberechtigten Mitgliedes. Georgien trat nach dem August Krieg 2008 mit RU aus der GUS aus. Die Ukraine bezahlt seit dem Staatsreich 2014 keinen Mitgliedsbeitrag und nimmt nicht mehr an den Tätigkeiten der Organisation teil. Allerdings ist das Land offiziell Mitglied und nicht ausgetreten. Die ehemaligen sowjetischen Republiken Estland, Lettland und Litauen entschieden sich für die Westintegration und traten der GUS nicht bei.

RU nennt den GUS-Raum in allen seinen nationalen Dokumenten seit 1993 bis heute als Prioritätsraum (siehe hierzu Kap. 4.2.1). In seinem aktuellen „Außenpolitikkonzept“ betont das Land, dass die bi- und multilaterale Kooperation mit den GUS-Staaten vorangetrieben wird (The Ministry Of Foreign Affairs Of The Russian Federation 2016, Artikel 49). In

\footnotetext{
${ }^{362}$ Chinas sicherheitspolitisches Interesse an ZA ist in erster Linie aufgrund des autonomen westchinesischen Uighuren-Gebiets (Xinjiang) bestimmt. Das Land ist weiterhin wegen des zunehmenden Islamismus in der unmittelbaren Nachbarschaft besorgt. Daher kooperiert das Land mit den Regionstaaten und RU im Rahmen der sicherheitspolitischen Organisation SOZ und versucht, die sicherheitspolitische Zusammenarbeit mit den anderen Regionsstaaten, wie Afghanistan und Pakistan, zu vertiefen. Die Stabilität und der Status Quo in der Region ist für China sowohl sicherheitspolitisch als auch wegen seiner Seidenstraße-Initiative wirtschaftlich von großer Relevanz (siehe Kap. 5.5).

${ }^{363}$ RU arbeitet mit China sicherheitspolitisch auch bilateral zusammen. 1997 erklärten China und RU, dass sie gegen die US-Hegemonie und NATO-Erweiterung sind (O. V. 1997: Jiang in Moscow ...; Mammadov 2014: 29). 2001 unterschrieben sie einen Vertrag über ,gute Nachbarschaft, Freundschaft und Zusammenarbeit“ für die strategische Partnerschaft (Urbansky 2018). Seitdem versuchen beide Staaten ihre Zusammenarbeit zu vertiefen. Als Ständige Mitglieder des Sicherheitsrates der Vereinten Nationen arbeiten China und RU eng zusammen. Für die Stabilität in Afghanistan arbeiten sie im Rahmen der SOZ. RU und China führen seit 2012 gemeinsam Militärmanöver im Indischen Ozean und in den fernöstlichen Gewässern durch. Das erste Mal hielten sie im Mai 2015 ein gemeinsames Marine-Militärmanöver im Mittelmeer ab. Im August 2015 wiederholten sie das Marine-Militärmanöver mit mehr als 20 Kriegsschiffen im Japanischen Meer (Auswärtiges Amt 2015d). Im Juli 2017 hielten sie im Baltischen Meer ein großes Militärmanöver ab (Borchert 2018) usw. Sie wollen den USA/NATO zeigen, dass sie gegen sie sicherheitspolitisch zusammenhalten.
} 
Artikel 55 des Außenpolitikkonzepts (ebd.) fügt das Land hinzu, dass RU zu jedem GUSMitglied freundschaftliche Beziehungen auf Basis der Gleichberechtigung pflegen wird. Die Tatsache aber ist, dass sowohl die GUS als auch die OVKS von RU dominiert werden. Das Land ist die stärkste Militärmacht der Region und wird von den zentralasiatischen Staaten als „Ordnungs- bzw. Schutzmacht“ in der Region akzeptiert. Und RU verpflichtet sich, die GUS-Staaten im Falle eines Angriffes militärisch zu schützen, wie es in seiner aktuellen „Militärdoktrin 2014“ schreibt (Präsident Der Russischen Föderation 2014: 22). RU ist bis heute das einzige Land, das in ,seinem Nahen Ausland“ Hard-Power-Mittel einsetzen kann (Caman/Dagci 2013: 66), wie z. B. im Tadschikischen Bürgerkrieg (1992-1997), GeorgienKrieg (2008) und kürzlich auf der Krim (Eingliederung 2014) der Fall war. Gleichzeitig wird RU von zentralasiatischen Entscheidungsträgern als Garant ihrer Herrschaft angesehen, weil sich RU nicht in die inneren Angelegenheiten der zentralasiatischen Staaten einmischt.

Die OVKS ist die weitere sicherheitspolitische-militärische Organisation und ist aus dem 1992 unterzeichneten „Vertrag über Kollektive Sicherheit“ (VKS) hervorgegangen. Die Hauptaufgabe der OVKS wurde in der „Charter Of The Collective Security Treaty Organization“ (Collective Security Treaty Organization 2002, Artikel 3) folgendermaßen formuliert:

„The goals of the Organization shall be strengthening of peace, international and regional security and stability, protection of independence on a collective basis, territorial integrity and sovereignty of the Member States, in achievement of which the Member States prefer political means. "

Die Mitgliedstaaten der OVKS dürfen laut dem Vertrag von 1992 (geändert 2010) keinem militärischen Bündnis beitreten und sich nicht an den Aktionen bzw. Operationen gegen andere Mitgliedstaaten beteiligen (Collective Security Treaty O. J., Artikel 1). Falls ein OVKS-Mitgliedstaat angegriffen wird, wird dieser Angriff gegen alle Mitgliedstaaten gelten (Collective Security Treaty o. J., Artikel 1, Präsident der Russischen Föderation 2014: 22, Artikel 25). Laut Artikel 4 dieses Vertrages sind alle Vertragsmitglieder verpflichtet, im Falle einer Aggression (bewaffneter Angriff, der die Sicherheit, Stabilität, territoriale Integrität und Souveränität bedroht) gegen ein Vertragsmitglied, ihm, einschließlich militärisch, zu helfen (Collective Security Treaty o. J., Artikel 1, Collective Security Treaty Organization 2019). RU definiert die OVKS als eines der wichtigsten Elemente des modernen Sicherheitssystems im postsowjetischen Raum und plädiert für die Weiterentwicklung der OVKS sowie ihre Umwandlung in eine angesehene multifunktionale 
internationale Organisation (The Ministry Of Foreign Affairs Of The Russian Federation 2016, Artikel 52).

Aktuell sind neben RU, Weißrussland und Armenien drei zentralasiatische Staaten Mitglieder der OVKS: Kirgisistan, Kasachstan und Tadschikistan. Kirgisistan schloss in der Mitte 2014 die US-Luftwaffenstützpunkt Manas infolge der russischen Militärhilfen. Als das kirgisische Parlament 2013 die Schließung Manas verabschiedete, bekam das Land von RU ein 1 Mrd. Dollar Militärhilfspaket (Yousaf 2013). In Kirgisistan verfügt RU über einen Luftwaffenstützpunkt in Kant, ein Testgelände für Unterwasserwaffen in Karakol, ein seismisches Labor in Mailuu- Suu und ein Zentrum für Militärkommunikation. In Kasachstan unterhält RU den weltweit bekannten Weltraumbahnhof Baikonur, das Raketentestgelände Saryschagan, ein Luftwaffenkommando in Karaganda u. a. Dieses Land ist für RU sicherheitspolitisch das wichtigste zentralasiatische Land, da RU mit Kasachstan eine $7600 \mathrm{~km}$ lange Grenze teilt und Kasachstan zwischen ihm und den anderen zentralasiatischen Ländern als Pufferzone gilt. In Tadschikistan hat RU mit 7000 Soldaten seine größten Streitkräfte im Ausland. Dieses Land hat die längste Grenze $(1387 \mathrm{~km}) \mathrm{zu}$ Afghanistan und ist die Hauptroute des Drogen- und Terrorhandels von Afghanistan nach ZA. Die sozio-ökonomischen Probleme Tadschikistans, wie z. B. Armut und Korruption, führen dazu, dass die Kriminalität zunimmt (siehe hierzu Kap. 6.1).

Turkmenistan, das einen neutralen Status hat, ist kein Mitglied der OVKS. Usbekistan verlängerte den fünfjährigen Vertrag mit der OVKS im Jahre 1999 nicht und trat das erste Mal aus der Organisation aus. Nach dem Andijan-Aufstand 2005, hinter dem der ehemalige usbekische Präsident Karimow den Westen vermutete, trat das Land diesmal vom westlichen GUUAM aus und trat 2006 wieder in die OVKS ein. Allerdings trat das Land 2012 erneut vom OVKS aus. Sein Rücktritt wurde in russischen Medien als usbekische Suche nach den Möglichkeiten für die militärische Zusammenarbeit mit den USA interpretiert (O. V. 2012: Özbekistan ABD ile ...). Tatsächlich wurde nach den Verhandlungen mit dem Westen im Mai 2014 in der usbekischen Hauptstadt Taschkent ein NATO-Verbindungsbüro mit NATOVerbindungsoffizier (Rosaria Puglisi) eröffnet. Dieses Büro hatte das Ziel, die Zusammenarbeit nicht nur mit Usbekistan, sondern auch mit allen zentralasiatischen Ländern zu fördern. Sein Schwerpunkt lag auf Unterstützung von Militärreformen und Modernisierung der Armee (Länder-Analysen 2014: 16). Am 1. April 2017 wurde es aufgrund der Haushaltsrevision geschlossen (O. V. 2017: NATO-Büro in ...). Seit dem 
Amtsantritt des usbekischen Präsidenten Mirsijojew im Jahre 2016 nähert sich Usbekistan wieder RU an. Im Oktober 2017 hielt das Land mit RU seit 2005 erstmals wieder ein Militärmanöver ab (Aripov 2018).

Auch China teilt die sicherheitspolitischen Sorgen RUs und der zentralasiatischen Staaten. Im Rahmen der SOZ arbeitet das Land mit ihnen sicherheitspolitisch zusammen. SOZ ging 2001 aus den 1996 gegründeten „Shanghai 5“ hervor. Die SOZ-Mitglieder sind neben China und RU, Kasachstan, Kirgisistan, Tadschikistan und Usbekistan. Turkmenistan ist unter Berufung auf ,immerwährende Neutralität" nicht SOZ-Mitglied, nimmt aber hochrangig als Sondergast an den Gipfeln teil (Auswärtiges Amt 2015d). Die SOZ wurde ursprünglich für den Grenzschutz der Mitgliedsstaaten gegründet. Zwar gewinnen die Wirtschafts- und Handelsfragen an Relevanz, besonders im energiepolitischen Bereich. Der Schwerpunkt der SOZ die Gewährleistung der Sicherheit und Stabilität in der Region. Für dieses Ziel entschieden sich die Mitglieder 2004 auf dem SOZ-Gipfel in Taschkent für die Einrichtung einer regionalen Antiterrorzusammenarbeit (Regional Anti-Terrorism Structure) (ebd.). Nach den Andijan-Unruhen in Usbekistan tagte die SOZ im Juli 2005 und beschloss den Abzug der US-Militärbasis aus Usbekistan. Im November 2005 mussten die USA, die Usbekistan hinter dem Andijan-Aufstand vermutete, auf Anforderung Usbekistans ihre Militärbasis schließen. Deutschland war der letzte NATO-Staat, der bis zum 11. Dezember 2015 eine Basis in ZA, in Usbekistan (Termez), nutzte (Bundeswehr 2015: Termez ...). Neben den USA/NATO gilt für China der Islamismus - wie auch für RU und zentralasiatische Staaten - als große sicherheitspolitische Gefahr.

In den letzten Jahren nahmen die islamistischen Terroranschläge in ZA zu (siehe hierzu auch Kap. 6.1). Die zentralasiatischen Staaten erkannten, dass sie die sicherheitspolitischen Probleme nur gemeinsam bewältigen können. Sie kooperieren sowohl bilateral miteinander als auch im Rahmen der regionalen sicherheitspolitischen Organisationen GUS, OVKS und SOZ. Usbekistan und Kasachstan unterschrieben im Juni 2013 einen „Vertrag über die strategische Partnerschaft zwischen der Republik Usbekistan und der Republik Kasachstan“. Mit diesem Vertrag kündigten sie ihren Willen für die Zusammenarbeit in regionalen sicherheitspolitischen Fragen an, besonders nach dem amerikanischen Abzug aus Afghanistan 2014 (Die Botschaft der Republik Usbekistan in der Bundesrepublik Deutschland o. J.). Am 14. - 15. September 2015 trafen sich die Präsidenten der OVKSMitglieder und vereinbarten Maßnahmen, die von Informationsaustausch bis zur 
Grenzsicherung reichen. Kurz danach, am 7. Oktober 2015, trafen sich der turkmenische Präsident Berdimuhammedow und der ehemalige usbekische Präsident Karimow und vereinbarten eine sicherheitspolitische Zusammenarbeit zur Grenzsicherung (Aidarbek 2015). Am 16. September 2016 trafen sich alle GUS-Mitglieder und vereinbarten die Vertiefung der sicherheitspolitischen Zusammenarbeit hinsichtlich der Grenzsicherung (Ydyrys 2017). 2017 unterschrieben Usbekistan mit Kasachstan einen gemeinsamen Plan zur Militärkooperation, der Zusammenarbeit bei Training, Übungen und Ausbildung vorsieht (Klein 2018: 39). Im März 2018 trafen sich die zentralasiatischen Staats- und Regierungschefs in Astana und im November 2019 in Taschkent um Schritte zur gemeinsamen Bekämpfung des Islamismus und wegen der islamistischen Kriegsrückkehrer aus Syrien und Irak sowie wegen der von Afghanistan ausgehenden Probleme zu vereinbaren (Jiracek 2019) (siehe auch Kap. 6.1). Die OVKS führt seit 2003 regelmäßig DrogenOperationen unter dem Namen „Kanal“ zur Bekämpfung des Drogenhandels aus Afghanistan in bzw. via ZA nach RU durch. Des Weiteren führt die Organisation regelmäßige Operationen gegen illegale Migration (russ. Nelegal). Im Rahmen der „Proksi““Operationen versucht die OVKS die Cyber-Kriminalität im Bereich des Islamismus zu bekämpfen.

RU ist in ZA sicherheitspolitisch erfolgreich, weil seine sicherheitspolitischen Interessen mit den sicherheitspolitischen Interessen der zentralasiatischen Staaten weitgehend übereinstimmen. Sie sind alle mit den sicherheitspolitischen Gefahren aus Afghanistan und innerhalb der Region konfrontiert. Sie alle sehen hinter den Farbenrevolutionen und Konflikten, bzw. Kriegen in den postsowjetischen Staaten den Westen, gemeint sind die USA und die NATO. Dieses Ereignis näherte die zentralasiatischen Staaten an RU an. Die zentralasiatischen Staaten ziehen die Stabilität der Demokratie vor, wie RU (Wipperfürth 2011: 69, 84-85) ${ }^{364}$ und China auch. Für die zentralasiatischen Entscheidungsträger ist RU das einzige Land, das die Stabilität in der Region aufrechterhalten und im Falle eines Konfliktes eingreifen kann. Sie akzeptieren russische Hard-Power. Ihre sicherheitspolitischen Mitgliedschaften und die Zusammenarbeit in der von RU dominierten GUS und OVKS bestätigt diese These. Die militärische Stärke RUs ist für die

\footnotetext{
${ }^{364}$ Das wichtigste Anliegen der Russen ist politische und wirtschaftliche Stabilität, wie eine repräsentative Umfrage des „Levada-Zentrums“ herausgab. Etwa 53 \% der Befragten zeigten sich mit der Aussage „lieber Stabilität als Freiheit und Demokratie“ einverstanden (O. V. 2016: Umfrage: Russen wollen ...).
} 
zentralasiatischen Staaten Garant ihrer territorialen Integrität und Souveränität. Wiederum ist RU auf die Zusammenarbeit mit diesen Staaten angewiesen, weil die Instabilität in und aus der Region der russischen territorialen Integrität und seiner Souveränität schaden kann.

\subsection{Die sicherheitspolitische Rivalität zwischen der Türkei und Russland um postsowjetische Staaten am Beispiel des Berg- Karabach-Konfliktes und der Krimfrage: „Türkenwelt"، gegen das „Nahe Ausland“6}

ZA sieht die TR als Teil „ihrer Türkenwelt“ und RU „seines Nahen Auslandes“. Beide Staaten handeln in der Region kultur- und bildungspolitisch, wirtschaftlich und sicherheitspolitisch im Rahmen dieser Konzepte, welche gegensätzlich sind. Weil bis jetzt zwischen den beiden Staaten keine direkte sicherheitspolitische Auseinandersetzung in ZA gab, eignen sich der Karabach-Konflikt und die Krimfrage gut als Fallbeispiele um das mögliche sicherheitspolitische Verhalten beider Staaten im Falle eines ernsthaften Konfliktes in ZA aufzuzeigen. Im Karabach-Konflikt ist die TR auf der aserbaidschanischen Seite, weil Aserbaidschan ein Turkstaat ist. Das orthodoxe RU hingegen ist auf der Seite des orthodoxen Armeniens und ist seine Schutzmacht. In der Krimfrage ist die TR wegen der turkophonen Krim-Tataren auf der Seite der Ukraine gegen RU. Sie erkennt die Annexion der Krim durch RU nicht an, was aus russischer Sicht keine Annexion, sondern eine völkerrechtliche Eingliederung der Krim in die Russische Föderation darstellt. 


\subsubsection{Der Berg-Karabach-Konflikt}

Anfang April 2016 brachen die Gefechte zwischen Armenien und Aserbaidschan um die mehrheitlich von Armeniern besiedelte aserbaidschanische Enklave Berg-Karabach erneut aus.

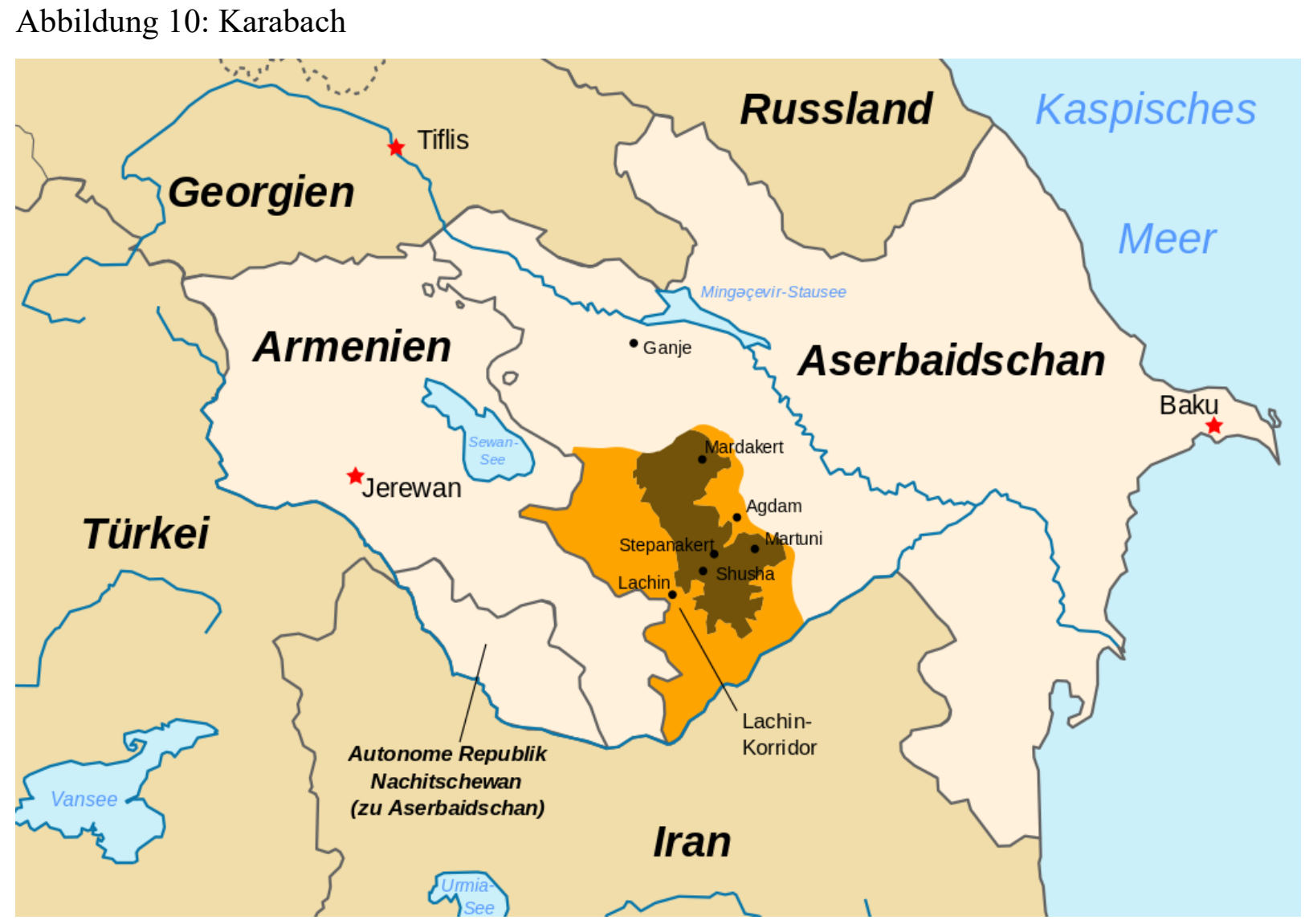

Quelle: Wikipedia o. J.

Die Konfliktparteien berufen sich auf unterschiedliche völkerrechtliche Prinzipien: Die Armenier reklamieren für sich das Recht auf Selbstbestimmung, Aserbaidschan hingegen das Recht auf die territoriale Integrität (Auswärtiges Amt 2010). ${ }^{365}$ In den Medien war von

365 Der Karabach-Konflikt verwandelte sich nach der Auflösung der Sowjetunion in einen Krieg. Bis zur Vereinbarung eines Waffenstillstandes am 24. Mai 1994 wurden insgesamt über $14.167 \mathrm{~km}^{2}$ (ca. 20\%) aserbaidschanischen Staatsterritoriums (Berg-Karabach plus umliegende 7 Provinzen Latschin, Kelbadschar, Agdam, Fisuli, Kubatli, Dschebrail und Sangelan, in denen überwiegend Aserbaidschaner wohnten) von armenischen Truppen besetzt. Insgesamt mussten mindestens 1,1 Mio. Menschen flüchten oder wurden vertrieben (Auch 2010: 113), davon 800.000 Aseris (Souleimanov 2004: 225). Schätzungen der Vertriebenen und Flüchtlinge wegen des Berg-Karabach-Krieges gehen bis auf eine Mio. Aseris, die durch Armenier vertrieben wurden. D.h. mit einem Viertel der Vertriebenen hat Aserbaidschan damit weltweit einen der höchsten Anteile an Vertriebenen und Flüchtlinge (Halbach 2010: 20). Die Zahl der Todesopfer beträgt zwischen 25.000 und 50.000 (davon 7000-15.000 Armenier bzw. 20.000-25.000 Aserbaidschaner) (Auch 2010: 114). 
einem „Stellvertreter Krieg“ im Südkaukasus die Rede. Die TR und RU wurden als Kriegsparteien, bzw. als Schutzmächte (die TR des Aserbaidschan und RU des Armenien) dargestellt (Willner 2016; Uhlemann 2016; Schrapel/Feyerabend 2016), deren Beziehungen zu jener Zeit wegen dem Abschuss des russischen Militärflugzeugs Su-24 durch die TR im November 2015 auf Eis lagen.

Der türkische Präsident Erdogan sicherte Aserbaidschan seine Unterstützung zu (O. V. 2016: Cumhurbaşkanı Erdoğan Azeri ...) und sagte in einem Interview mit dem aserbaidschanischen Fernsehsender ANS am 2. April 2016 folgendes:

\begin{abstract}
"Ich habe vorhin mit meinem Bruder Ilham Aliyev [aserbaidschnischer Präsident] gesprochen. Ich wollte mich bei ihm und bei unseren Streitkräften über den aktuellen Stand informieren. 12 aserische Brüder wurden Märtyrer, ich denke, dass 100 Armenier getötet wurden. Momentan gehen die Gefechte in Aserbaidschan weiter. Wir haben gebetet. Hoffentlich werden unsere aserischen Brüder im Krieg mit den kleinstmöglichen Verlusten die Oberhand gewinnen. Ich wünsche allen aserischen Brüdern Gottes Hilfe" 366367 (Übers. d. d. Verfasserin)
\end{abstract}

Am 4. April erklärte Erdogan, dass die TR weiterhin auf der aserbaidschanischen Seite stehe und Karabach eines Tages wieder Aserbaidschan gehören wird (O. V. 2016: Azerbaycan: Dağlık Karabağ'da ...). Der ehemalige Ministerpräsident der TR, Ahmet Davutoglu, hielt ähnliche Reden und sagte am 5. April 2016 folgendes (ebd.):

\begin{abstract}
„Wir, 78 Millionen Land [TR], werden bis alle besetzten Gebiete des geliebten Aserbaidschan befreit werden, auf der aserbaidschanischen Seite stehen. Jeder Märtyrer des geliebten Aserbaidschan ist unser. Die ganze Welt soll wissen, dass die TR gegen die armenischen Angriffe bis zum Weltende auf der Seite des geliebten Aserbaidschans stehen wird. "368 (Übers. d. d. Verfasserin)
\end{abstract}

\footnotetext{
${ }^{366}$ Erdoğan, "Az önce İlham Aliyev kardeşimle görüştüm. Kendisinden konuyla ilgili bilgileri aldım ve silahlı kuvvetlerimizden de son durumu öğreneyim istedim. 12 Azeri kardeşimiz şehit olmuş Ermenilerden de zannediyorum 100'ü aşkın öldürülen var. Şu anda çatışmalar Azerbaycan'da devam ediyor. Dualarımızı yaptık. İnşallah bu çatışmalarda Azeri kardeşlerimiz en az oranda kayıp vermek suretiyle bu işi başarırlar. Ben tüm Azeri kardeşlerime Allah'tan yardımlar niyaz ediyorum.”

${ }^{367}$ Die TR verfolgt, wie im Karabach-Fall zu sehen ist, einen offenen Pantürkismus in den Turkstaaten, während sie zugleich den Kurden in der TR ihre kulturellen Rechte verwehrt und sie zur Assimilation zwingt. Im Ausland bekämpft sie die Entstehung eines autonomen Kurdengebietes, bzw. Kurdistans, wie aktuell in Syrien oder in Irak der Fall ist. Es fehlt an wissenschaftlich vergleichenden Arbeiten über den „Türkischen Pantürkismus und ihre Anti-Kurden-Politik“.

368 Davutoglu: „Can Azerbaycan'ın işgal altındaki tüm toprakları kurtulana kadar biz de 78 milyon olarak Azerbaycan'ın yanında olacağız. Can Azerbaycan'ın kaybettiği her şehit bizimdir. Bütün dünya bilmelidir ki Türkiye, Ermenistan'ın saldırganlığı karşısında can Azerbaycan ile omuz omuza durmaya kıyamete kadar devam edecektir.“
} 
Die TR suchte für ihre Politik auch internationale Unterstützung. Auf dem 13. Gipfeltreffen der OIC forderte Davutoglu die muslimischen Länder auf, zur Befreiung Karabachs, Palästinas, und der Krim und zur Lösung der Probleme der muslimischen Minderheiten beizutragen (AKP 2016: Başbakan Davutoğlu ...).

RU hingegen gilt als armenische Schutzmacht und bezeichnet Armenien als ,unser Israel im Kaukasus“, wie es der russische Politiker Konstantin Satulin formulierte (Wehner 2008: 151). RU unterhält in Armenien weiterhin Truppenstützpunkte, ${ }^{369}$ kooperiert mit ihm im Rahmen der OVKS und EAWU, dominiert es wirtschaftlich und energiepolitisch und rüstet es auf. Gleichzeitig verkauft RU Aserbaidschan schwere Waffen, wie das Stockholmer internationale Friedensforschungsinstitut (SIPRI) feststellte:

„In den letzten Jahren hat das ölreiche Aserbaidschan seine Armee kräftig aufgerüstet. Laut dem letzten Bericht des Stockholmer internationalen Friedensforschungsinstituts (SIPRI) sind die aserbaidschanischen Waffenimporte zwischen 2010 und 2015 um 217 Prozent gestiegen. Den Großteil der Waffen-unter anderem moderne Panzer vom Typ T-90S, Luftabwehrsysteme und Mehrfachraketenwerfer sowie Kampfhubschrauber - kaufte Baku in Russland." (Smirnova 2016b).

Für RU kann der Karabach-Konflikt u. a. als Chance gesehen werden, seinen Einfluss in der Region zu erhalten, solange er eine „,kontrollierte Instabilität“ bleibt. RU kann dadurch seine Militärpräsenz in Armenien halten und durch die Waffengeschäfte mit den beiden Staaten gleichzeitig wirtschaftlich profitieren.

Der Karabach-Konflikt beherbergt jedoch ein Kriegspotential zwischen der TR und RU. Er kann beide Staaten in den Krieg hineinziehen, wie das während des ersten Karabach-Krieges (1992-1994) beinahe der Fall war. RU drohte der TR mit einem 3. Weltkrieg, für den Fall, dass sie gegen Armenien interveniert (Fuller 1993: 78; Cornell 1999; Kolobov/Kornilov/Özbay 2006: 143). Während des Berg-Karabach-Krieges schloss die Türkei 1993 ihre Grenze zu Armenien. ${ }^{370}$ Armenien setzt die TR und Aserbaidschan das erste Mal auf dem armenischen Genozid-Gedenktag am 24. April 1988 in Jerewan

\footnotetext{
369 Die Verteidigungsminister beider Staaten, Anatoli Serdjukow und Seiran Oganjan, haben in der armenischen Hauptstadt die Verlängerung des aus dem Jahr 1995 stammenden Vertrages vereinbart, der ursprünglich eine Laufzeit von 25 Jahren hatte. Moskaus Truppen bleiben mindestens bis 2044 in Armenien (Quiring 2010).

${ }^{370}$ Daher gewann das südkaukasische Georgien für die Türkei und die USA als Transitland für das Erdöl und Erdgas des Kaspischen Meeres und als „Brücke“ zu den „Turkrepubliken“ Aserbaidschan und ZA an Bedeutung.
} 
nachweislich in aller Öffentlichkeit gleich (Souleimanov 2004: 222). Tatsächlich sehen sich die TR und Aserbaidschan gegenseitig als ethnisch-sprachlich einheitliches Volk an, als „Bir Millet, Iki Devlet"“ (Ein Volk, Zwei Staaten). ${ }^{371}$

Armenien hat sowohl gegenüber Aserbaidschan Gebietsansprüche (Karabach) als auch gegenüber der TR. Der TR wirft das Land den Völkermord an Armenier vor, den die TR strikt ablehnt. In der vom armenischen Parlament verabschiedeten Unabhängigkeitserklärung am 23. August 1990 definiert Armenien östliche Gebiete der TR als „Westarmenien“ und definiert als Aufgabe der Republik, die internationale Anerkennung des Völkermordes an den Armeniern (The Government of the Republik of Armenia 1990). D. h. nach dieser Unabhängigkeitserklärung erkennt Armenien den Frieden von Kars vom 13. Oktober 1921 nicht an, der die Grenze zwischen beiden Staaten festlegt. Im armenischen Staatswappen wird der in der Osttürkei liegende Berg Ararat als Nationalsymbol abgebildet. Darin sieht die TR eine sicherheitspolitische Gefahr für ihre territoriale Integrität. Deshalb versucht die TR mögliche armenische Vorteile zu verhindern, ganz im Sinne eines NullSummen-Spiels.

Die internationalen Organisationen UNO und OSZE sind zur Lösung des Berg-KarabachKonflikts in Aserbaidschan und Armenien diplomatisch aktiv, allerdings bis heute ohne Erfolg. Seitens der UNO wurden allein 1993 vier Resolutionen (Nr. 822, 853, 874, 884) verabschiedet, die eine Wiederherstellung der territorialen Integrität Aserbaidschans fordern. ${ }^{372}$ Seit 1992 bemüht sich die „Minsker Gruppe“ der OSZE unter dem Vorsitz der USA, RU und Frankreich um eine Annäherung der verfeindeten Parteien (Auch 2010: 122). Mitte 2007 schlug die Minsker Gruppe vor, dass Armenien seine Soldaten aus den besetzen Territorien abzieht und die vertriebenen Aseris in ihre Heimatorte zurückkehren. Laut der Minsker Gruppe sollte eine Friedenstruppe in der Region für Sicherheit sorgen und das Land mit Wirtschaftshilfe wiederaufgebaut werden. Schließlich sollten die Einwohner in einem Referendum über den Status der Region entscheiden. Umgesetzt wurde bislang keiner dieser Vorschläge (O. V. 2008: Minsker Gruppe der ...). Die gegensätzlichen Interessen der Großmächte (USA und RU) im Südkaukasus erschweren die Konfliktlösung. Unter russischer Vermittlung vereinbarten Armenien und Aserbaidschan am 5. April 2016 in

\footnotetext{
${ }^{371}$ Die Bezeichnung „ein Volk, zwei Staaten“ wird fast bei jedem Treffen beider Staaten betont (siehe hierzu: O. V. 2016: Erdoğan ve Aliyev'den ...).

${ }^{372}$ Die TR versuchte mit Aserbaidschan zusammen die armenische Aggression gegen Aserbaidschan auf dem Türkengipfeltreffen von 1994 zu verurteilen (Caman 2005: 289). Dieser Vorschlag wurde von Kasachstan abgelehnt (ebd.).
} 
Moskau eine Feuerpause. Somit bleibt der etwa 100 Jahre alter Karabach-Konflikt als „eingefrorener Konflikt“" (frozen Conflict) weiterbestehen.

\subsubsection{Die Krimfrage}

Die türkische Ukraine-Politik ist durch ihre kultur- und sicherheitspolitischen Interessen geprägt und konzentriert sich nur auf die turksprachigen Krim-Tataren, welche als Teil der „Türkenwelt" angesehen werden. Aus diesem Grund sieht sich die TR als Schutzmacht der Tataren. Für RU hat die Krim hingegen in erster Linie eine strategische Bedeutung. Hier auf der Halbinsel, in Sewastopol (siehe Abbildung 11) befindet sich die russische Schwarzmeerflotte seit zaristischer Zeit.

Abbildung 11: Schwarzmeerflotte auf der Krim

\section{Russische Militäranlagen in Staaten der ehemaligen Sowjetunion}

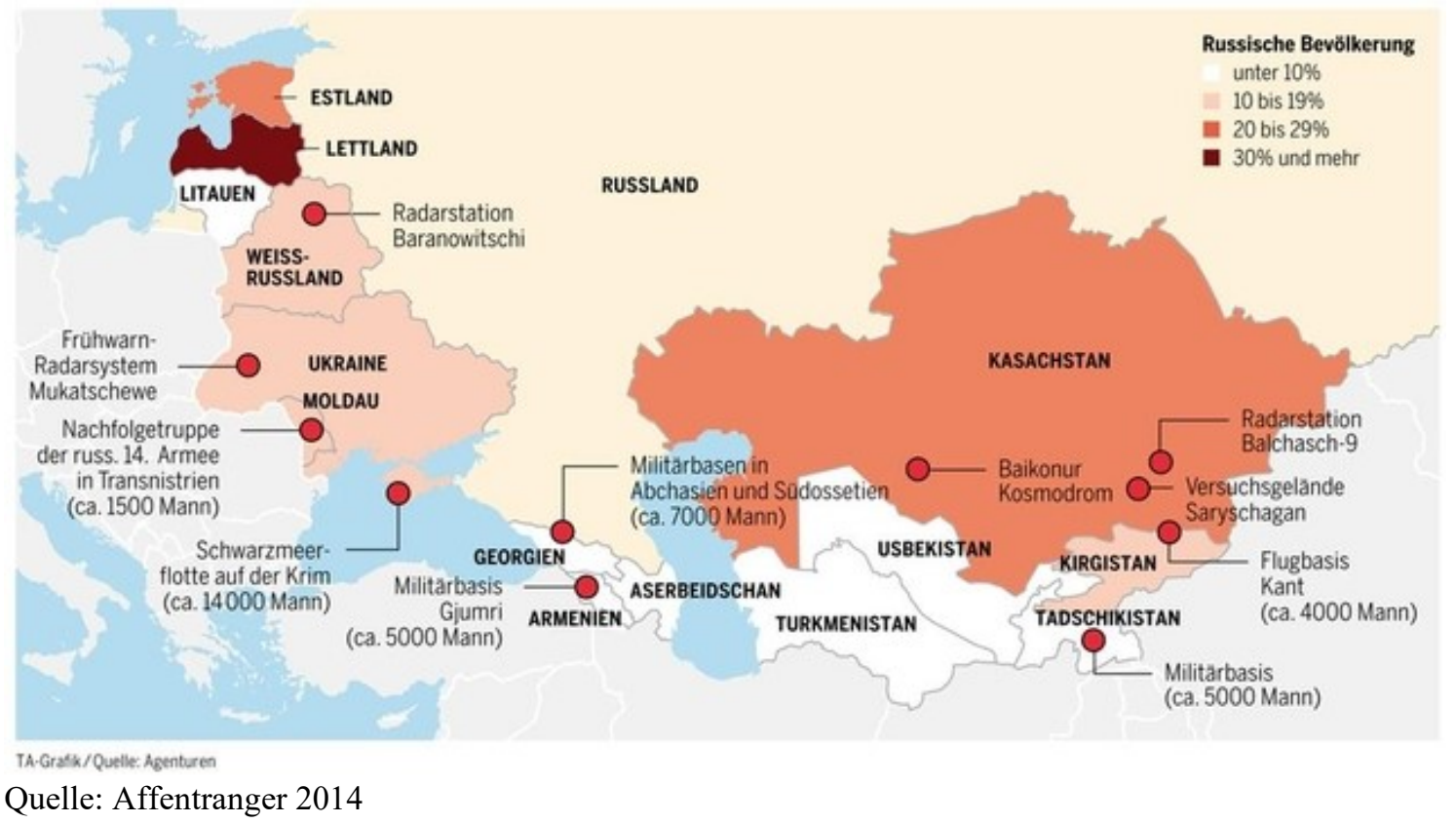

Im Jahre 2010 verlängerte RU mit dem russlandfreundlichen ukrainischen Präsidenten Wiktor Janukowitsch das Bleiberecht bis 2047. Als Gegenleistung erhielt die Ukraine von RU 30 \% Erdgasermäßigung (Köseoglu 2014). Nach der Eingliederung der Krim in die Föderation hat RU nun die strategisch wichtige Halbinsel am nördlichen Schwarzmeer unter seiner Herrschaft. Mit der Krim (und sowie von RU nach dem August-Krieg 2008 als unabhängig anerkannten Abchasien) erweiterte RU sein Macht- und Einflussgebiet am nördlichen Schwarzmeer. Andererseits hat die Krim eine „historische Bedeutung“ für RU, 
denn hier siegten die Russen gegen die europäischen Mächte England, Frankreich, Deutschland usw. (Seewald 2014). Des Weiteren sieht sich RU als Schutzmacht der Russen auf der Krim.

Infolge der Maidaner-Aufstände in Kiew und der anti-russischen Ereignisse in der Ukraine seit Ende 2013 entschied die Halbinsel Krim, sich von der Ukraine zu trennen. Infolge des Referandums am 16. März 2014 mit 95,6 \% der Wählerstimmen trat sie der Russischen Föderation bei (Sinelschtschikowa 2016). Sowohl die Ukraine als auch 100 Mitgliedsstaaten der Vereinten Nationen (darunter die EU und NATO-Staaten) erkennen die Legitimität des Referendums nicht an und sehen im Beitritt der Krim in die Russische Föderation eine völkerrechtswidrige Annexion. Daher verhängten die USA und die EUSanktionen gegen RU, die bis heute weiterbestehen. RU hingegen verwies auf den Fall Kosovo, das gegen die russische Zustimmung vom Westen als unabhängiger Staat anerkannt wurde. Und die Folge des Krim-Referendums sieht RU nicht als Annexion, sondern als Recht auf Selbstbestimmung der Krimer, als freiwilligen Beitritt, bzw. Eingliederung zur Russischen Föderation (ebd.).

Die Krim-Tataren (rund 232000 Personen, etwa $11 \%$ der Bevölkerung der Krim) waren überwiegend für die territoriale Integrität der Ukraine und boykottierten das KrimReferendum. Der Grund dafür ist, nach Äußerungen der Staatsanwältin der Krim, Natalia Poklonskaja, der Extremismus des Medschlis (Nationalversammlung der Krim-Tataren) und seine anti-russische Haltung. Sie sieht in den Anführern Refat Tschubarow und Mustafa Dschemilew (auf Türkisch wird er auch Mustafa Abdülcemil Kırımoğlu genannt) ${ }^{373}$ „Marionetten in den Händen großer westlicher Drahtzieher“ (O. V. 2016: Russland stuft Krimtataren ...). RU wirf Dschemilew vor, ein Geheimagent der TR zu sein (O. V. 2016: Porosenko „Mit Ajani“ ...). Laut der Staatsanwältin werden die Krimtataren für fremde Interessen instrumentalisiert. Sie fügt hinzu (ebd.), dass die Führung der Krimtataren mit den Terrorgruppierungen wie „Graue Wölfe“ (pantürkisch) und „Hizbut-Tahrir“ (islamistisch) zusammenarbeitet.

373 Er war bis 2013 der Vorsitzende der Nationalversammlung der Krim-Tataren (Medschlis des Krimtatarischen Volkes) und danach Abgeordneter im ukrainischen Parlament. Dschemilew wurde vom ukrainischen Präsidenten zu seinem Berater für „Angelegenheiten des krimtatarischen Volkes“ ernannt. Der aktuelle Vorsitzende des krimtatarischen Medschlis ist Refat Tschubarow. Die beiden Politiker dürfen seit 2014 nicht in die Russische Föderation reisen. 
Hizbut Tahrir ist eine in ZA aktive usbekische islamistische Organisation. Laut einem Bericht der „Welt“ gab es im Jahr 2014 Schätzungen zufolge 2000 bis 15.000 Krimtataren in der islamistischten Gruppe Hizbut-Tahrir ${ }^{374}$ auf der Krim (O. V. 2014: Mustafa Dschemilew ...). Der bekannte Krim-Tatare und ukrainische Abgeodnete Dschemilew verleugnet die Zusammenarbeit des tatarischen Medschlis mit Hizb ut-Tahrir (Interview mit Eichhofer 2015). Ihm zufolge verließen viele Radikale die Krim, da die Gruppe in RU verboten ist. Einige davon, laut Deschmilew, haben sich sogar ukrainischen Bataillonen angeschlossen und kämpfen für die Ukraine.

Das NATO-Land TR ist für die territoriale Integrität der Ukraine und verurteilte die „Annexion“ der Krim. Sie schloss sich aber nicht den westlichen Sanktionen gegen RU an. Der Sprecher des türkischen Staatspräsidiums, Ibrahim Kalin, nannte die Folgen des KrimReferendums als „Annexion und ethnische Säuberung der Krim-Tataren“ (O. V. 2016: Sözcü Kalın: Davutoğlu ...). Während der Eiszeit zwischen der TR und RU wegen des Abschlusses des russischen Militärflugzeugs durch die TR in Syrien im November 2015 bis zur Versöhnung im Juni 2016 näherten sich die TR und die Ukraine einander an. Mitte Februar 2016 besuchte der ehemalige türkische Ministerpräsident Davutoglu Kiew und kritisierte das russische Vorgehen in Syrien und auf der Krim, bzw. die Annexion der Krim (O. V. 2016: Başbakan Davutoğlu'ndan önemli ...). Diesem Besuch folgte ein Gegenbesuch des ukrainischen Präsidenten Petro Poroschenko. Anlässlich des Besuches in Ankara betonte Erdogan seine pro-ukrainische Haltung und kritisierte die russische Annexion der Krim als rechtswidrig. Beide Präsidenten äußerten auch ihren Willen um die Vertiefung ihrer politischen und wirtschaftlichen Beziehungen (Türkiye Cumhuriyeti Cumhurbaskanligi (2016): Türkiye Kırım'ın Gayrimeşru ...). Bei diesem Besuch wurde Poroschenko von Dschemilew sowie zahlreichen anderen Krim-Tataren begleitet (O. V. 2016: Erdoğan Poroşenko’yu resmi ...). Im Juli 2016 erklärte Poroschenko, dass es eine Pflicht für ihn sei, den Krim-Tataren eine Autonomie innerhalb der souveränen Ukraine zu gewähren (O. V. 2016: Autonomie für Krimtataren ...). Für RU ist allerdings die Krimfrage durch die Eingliederung der Krim in die Russische Föderation gelöst. Von den zentralasiatischen Staaten erkannten Kasachstan und Kirgisistan (beide OVKS-Mitglied) das KrimReferendum an.

\footnotetext{
${ }^{374}$ Hizbut Tahrir zielt auf die Gründung eines islamistischen Staates in ZA, kooperiert mit den anderen islamistischen Gruppierungen wie Taliban und IS.
} 
Wie die Beispiele Karabach- und Krimfrage zeigen, rivalisieren die TR und RU um den postsowjetischen Raum sicherheitspolitisch. Sie zeigen gleichzeitig, dass die TR im Falle einer sicherheitspolitischen Auseinandersetzung zwischen den Turkvölkern, bzw. Turkstaaten und RU unter heutigen Bedingungen die Turkvölker im Rahmen ihrer Möglichkeiten gegen RU unterstützen wird.

\subsection{Ist eine türkisch-russische strategische Sicherheitspolitik in Zentralasien möglich?}

Der Kalte Krieg ist zwar mit der Auflösung der Sowjetunion offiziell beendet. Die Auseinandersetzungen zwischen dem Westen und RU allerdings scheinen unter dem Namen „New Great Game“ weiterzubestehen. Die TR weicht allerdings in Teilfragen von den Zielen ihrer westlichen Verbündeten ab, wenn diese gegen ihre sicherheitspolitischen Interessen sind. Für die TR ist die Sicherheitspolitik ,high politics“ und steht über allen anderen Zielen des Staates. Im August-Krieg 2008 (zwischen RU und Georgien) versuchten zwei Kriegsschiffe der USA durch die türkischen Meerengen in das Schwarze Meer zu gelangen, um Georgien beizustehen. Die TR lehnte die Durchfahrt entsprechend des MontreuxMeerengen-Abkommens mit der Begründung ab, dass die Gesamttonnage der beiden USKriegsschiffe mit 140.000 Tonnen (O. V. 2008: Gürcistan'a insani yardımda ...) die nach dem Artikel 18/d des Abkommens erlaubte Gesamttonnage, nämlich 8.000 Tonnen (Baskent Üniversitesi o. J.: 6), weit übersteige. RU begrüßte das vertragsmäßige Verhalten der TR.

Die TR handelte während des August-Krieges rational, weil ein irrationales Handeln ihre territoriale Integrität und Souveränität in Gefahr hätte bringen können, wie es im 2. Weltkrieg der Fall war. Im 2. Weltkrieg unterstützte die TR, trotz ihrer Neutralität und Vereinbarungen mit RU, Deutschland. Als die Sowjetunion aus dem 2. Weltkrieg als Sieger hervorging, kündigte sie deshalb zunächst den „Freundschafts- und Nichtangriffsvertrag“ von 1925 mit der TR auf. Des Weiteren versuchte sie, den Moskau-Vertrag von 1921 und das Montreux-Meerengen-Abkommen von 1936 mit ihr aufzukündigen. Sie wollte von der TR die Städte Kars und Ardahan sowie die gemeinsame Kontrolle der türkischen Meerengen, wie im Kap. 3.6 detailliert erklärt wurde. Die sowjetischen Forderungen bedeuteten für die TR den Verlust ihrer Souveränität und territorialen Integrität. Wegen der russischen Gefahr suchte sie damals den westlichen Schutz und trat 1952 der NATO bei (Önder 1977: 242-245; Sandikli 2006: 8; Davutoglu 2011: 125; Steinbach 2007: 66) und blieb auch hauptsächlich aus diesem Grund in der NATO. Wenn sich die TR während des 
August-Krieges irrational verhalten hätte, wäre es vielleicht zu einem türkisch-russischen Krieg gekommen und RU hätte vermutlich versucht, die sicherheitspolitischen Vereinbarungen mit der TR, z. B. den Terrorabkommen, den Moskau-Vertrag und das Montreux-Meerengen-Abkommen, in Frage zu stellen. Das türkische Verhalten während des August-Krieges war somit in erster Linie sicherheitspolitisch motiviert. Die türkische Wissenschaft, Medien und Politik begründeten das allerdings in erster Linie im Zusammenhang der türkisch-russischen energiepolitischen Beziehungen.

Laut Kardas (2009), Davutoglu (in Bruno 2008) und Erdogan (Bila 2008) verringerte die energiepolitische Abhängigkeit der TR von RU ihre Autonomie und Handlungsoptionen während des August-Krieges. Kardas (2009) zufolge verfolgte die TR während des AugustKrieges aus diesem Grund eine „ergebungsvolle Politik“ (acquiescent policy) (Kardas 2009) gegenüber RU. Kurz nach dem August-Krieg, im September 2008, erklärte der damalige Chefberater des türkischen Ministerpräsidenten Erdogan, Davutoglu, in einem Interview, dass die TR aufgrund ihrer energiepolitischen Abhängigkeit von RU gegen die westliche Isolationspolitik RUs sei (Davutoglu in: Bruno 2008). ${ }^{375}$ Auch Erdogan äußerte sich ähnlich. Nach Erdogan zwangen „einige Kräfte“ die TR, sich für eine Seite zwischen dem Westen und RU zu entscheiden. Das ist aber ihm zufolge allein schon aufgrund der Energiebeziehungen und Handel mit RU nicht möglich (Bila 2008). Im Grunde genommen ging es der TR jedoch in erster Linie um ihre sicherheitspolitischen Interessen.

Für die TR ist RU eine große sicherheitspolitische Gefahr für ihre territoriale Integrität und Souveränität und gleichzeitig ein Hindernis für ihre Aktivitäten, wie z. B. in der „Türkenwelt“‘. Nach dem Kalten Krieg z. B., während des ersten Karabach-Krieges (1992-

\footnotetext{
375 Davutoglu sagte: „Turkey is a member of NATO. Turkey is a candidate for EU [membership]-part of Western bloc, there is no doubt about it. But you can't say that Turkish-Russian relations can be like DanishRussian relations, or Norwegian-Russian relations, or Canada-Russian relations. ... Any other European country can follow certain isolationist policies against Russia. Can Turkey do this? I ask you to understand the geographical conditions of Turkey. In principle, we are against isolation. We were against the isolation of Syria. We were against the isolation of Iraq, because isolation creates economic stagnation. Isolation creates a barrier. [...] If we, Turkey, isolate Syria and Iran at the same time, it means we will be closing our borders. With Syria, we have 800 kilometers, then we have Iraq-where there's a war-then if we are soon isolating Iran, then we were having problems with Armenia. The only opening border would be Georgia. ... If you isolate Russia, economically, can Turkey afford this? ... Unfortunately, we have to admit this fact. Turkey is almost 75-80 percent dependent on Russia [for energy]* We don't want to see a Russian-American or Russian-NATO confrontation. ... We don't want to pay the bill of strategic mistakes or miscalculation by Russia, or by Georgia." (Davutoglu in: Bruno 2008). Wenn Davutoglu tatsächlich aus wirtschaftlichen Gründen gegen die Isolation u. a. von Syrien wäre, wie im Zitat steht, hätte er als Außenminister den Bürgerkrieg in Syrien, bzw. die Islamisten gegen Assad nicht unterstützt. Selbst die Syrienpolitik ist in erster Linie von der Kurdenfrage der TR bestimmt, d. h. von ihren sicherheitspolitischen Interessen.
} 
1994) zwischen Aserbaidschan und Armenien, versuchte die TR, die Armenienfrage militärisch zu lösen. Da Aserbaidschan aus der türkischen Sicht ein „Türkenstaat“ ist und die TR sich als seine Schutzmacht versteht, versuchte sie, auf der aserbaidschanischen Seite in den Karabach-Krieg zu intervenieren. Dementsprechend wurde sie vom armenischen Schutzmacht RU im Falle einer Einmischung mit einem 3. Weltkrieg bedroht (Fuller 1993: 78; Cornell 1999; Kolobov/Kornilov/Özbay 2006: 143), wie im vorigen Unterkapitel erklärt wurde. RU ist militärisch der TR weit überlegen und die einzige Militär- und Atommacht der Welt, die den USA, bzw. der NATO die Stirn bieten kann. Des Weiteren kann das Land seine Waffen selbst herstellen und ist nicht wie die TR vom Waffenimport abhängig. Laut SIPRI-Studie ist RU weltweit der zweitgrößte Waffenlieferant. $21 \%$ aller Waffenexporte gingen 2018 von RU aus ${ }^{376}$ (Sarovic/Schneider 2019).

Armenien ist sicherheitspolitisch ganz auf RU angewiesen. Sollte RU seine Macht und seinen Einfluss verlieren, würde sich das Land, besonders im Falle eines erfolgreichen Pantürkismus der TR, in ernsthafter sicherheitspolitischer Gefahr befinden. Armenien ist geographisch durch die Turkvölker eingekreist: Im Westen durch die TR, im Süden durch die Aseris im Nord-Iran (etwa 15 bis 20 Mio. Aseris leben im Nord-Iran), im Osten durch Aserbaidschan, im Norden durch die in Georgien lebenden Turkvölker in Ahiska und Bordschali. Auf der anderen Seite des Kaspischen Meeres befinden sich die Turkstaaten, die die TR als „mögliche“ sicherheitspolitische Verstärkung sieht. Auch mögliche islamistische Bewegungen in diesem muslimisch geprägten Kreis um Armenien herum können für Armenien ein sicherheitspolitisches Problem werden. Gleichzeitig ist Armenien für die TR ein Hindernis vor der Vereinigung mit der „Türkenwelt“, weil das Land geographisch die TR von den turksprachigen Völkern trennt. Falls RU an Macht- und Einfluss verlieren würde, könnte die TR die Armenierfrage zu ihren Gunsten zu lösen versuchen.

Obwohl die türkisch-russische Geschichte, wie die 15 Kriege zwischen den beiden Staaten bestätigen, eine Geschichte der geopolitischen Rivalitäten und Kriege ist, gab es zwischen den beiden Staaten auch sicherheitspolitische Kooperationen. 1798 und 1805 kooperierten sie gegen Frankreich, 1833 gegen den osmanischen Vasallen Ägypten sicherheitspolitisch und in den Anfangsjahren der Republikgründung der TR unterstützte RU die TR

\footnotetext{
${ }^{376}$ Die USA sind der größte Waffenexporteur der Welt. $36 \%$ der weltweiten Exporte kommen aus den USA, $7 \%$ aus Frankreich, $6 \%$ aus Deutschland und $5 \%$ aus China (Schmiester 2019).
} 
sicherheitspolitisch, wirtschaftlich und militärisch (siehe hierzu Kap. 3.3). ${ }^{377}$ Sobald die sicherheitspolitische Gefahr verschwunden war, wurden die Bündnisse allerdings wieder, ganz im neorealistischen Sinne, aufgelöst. Nach dem Irak-Einsatz der USA/NATO 2003 kam es zwischen der TR und RU zur Annäherung. Nach Fiona Hill und Ömer Taspinar (2006: 81) näherten sich beide Staaten wegen der US-Irak-Invasion 2003 an, da sie diese als Destabilisierung ihrer südlichen Grenzen betrachteten. Laut Experten hat ihre Annäherung keinen strategischen Wert, sondern nur einen taktischen. Igor Torbakov (2007: 5) zufolge positionierten sich die TR und RU gegen die US-Irak-Invasion, weil die TR dadurch die Gründung eines Kurdistans im Nord-Irak (ebd.: 10) befürchtete, was für „,ihre Kurden“ ein schlechtes Beispiel hätte geben können. RU hingegen befürchtete die Machterweiterung des Westens in seiner unmittelbaren Nähe und den westlichen Zugriff auf die fossilen Brennstoffe des Kaspischen Meeres (ebd.: 10-11). Eugene Kogan (2009: 12) sieht auch als Hauptfaktor der türkisch-russischen Annäherung den Willen beider, den „Status Quo“ in der Region aufrecht zu erhalten. Laut ihm (ebd.) ist diese Partnerschaft situationsbedingt und nur durch die Ängste der TR entstanden. Sener Aktürk (2006: 359) hat eine ähnliche Einschätzung wie Kogan, Hill und Taspinar. Auch er sieht die türkisch-russische Annäherung als situationsbedingt und vorübergehend an. Genau aus der ähnlichen sicherheitspolitischen Motivation heraus handelten die TR und RU gemeinsam während des August-Krieges 2008, weil sie sich beide über den Status Quo am/um Schwarzen Meer einig waren. Gerade jetzt (2019) kooperieren die beiden Staaten aus ähnlichen sicherheitspolitischen Motiven heraus auch in Syrien. ${ }^{378}$

RU ist in Syrien für seine geopolitischen Interessen aktiv und verfügt hier über die Militärbasis Tartus am Mittelmeer. Der syrische Präsident Baschar al-Assad (2000 - im Amt) lud RU zur militärischen Unterstützung nach Syrien ein. Die TR ist auch in Syrien militärisch seit 2019 aktiv, wird allerdings von Assad und Syrien-Kurden*innen als Besatzungsmacht angesehen. Das türkische Ziel ist, im kurdisch geprägten Nord-Syrien die Entstehung eines autonomen Kurdengebiets zu verhindern und Assad zu stürzen. Die Kurdenfrage ist die größte sicherheitspolitische Frage der TR und hängt mit den möglichen

\footnotetext{
377 Des Weiteren kooperierten sie nach der türkischen Zypern-Invasion 1974 infolge der wirtschaftlichen Sanktionen des Westens gegen die TR, nach dem Kalten Krieg für die Gründung der „SchwarzmeerWirtschaftskooperation“ (SMWK) als Reaktion der TR auf die EU, im Rahmen der Terrorbekämpfung und aktuell in Syrien im Rahmen der Astana-Gespräche.

${ }^{378} \mathrm{Im}$ Dezember 2016 einigten sich die TR, RU und der Iran, in Syrien gemeinsam vorzugehen. Am 4. Mai 2017 unterschrieben die TR, der Iran und RU im kasachischen Astana ein Abkommen für die Gründung von 4 Schutzzonen in Syrien. Der Iran hat bezüglich der Kurdenfrage ähnliche Ziele wie die TR. Beide Staaten sind gegen die Entstehung eines autonomen kurdischen Gebiets in Nord-Syrien.
} 
Gebietsverlusten zusammen. Die PKK und „die Partei der demokratischen Union“ (Partiya Yekitiya Demokrat, PYD) der Syrien Kurdin*innen sind für die TR Terror-Organisationen und die TR ist für ihre Bekämpfung sowie Kontrolle des Nord-Syriens in Syrien einmarschiert. RU erkennt die PKK nicht als Terrororganisation an und erlaubte die Eröffnung des PYD-Verbindungsbüros in Moskau. RU ist zwar keine Schutzmacht der Kurden*innen in Syrien. Seine Existenz in Syrien allerdings begrenzt die türkischen Aktivitäten, wie in ihrer „Türkenweltpolitik“ im postsowjetischen Raum der Fall ist. Die TR würde auf ihre "Türkenweltpolitik" verzichten, wenn ihre territoriale Integrität und Souveränität in Gefahr gerieten. Ein gutes Beispiel dafür sind Erdogans Äußerungen über die turksprachigen Uighuren während seiner China-Reise im Juli 2019. Er sagte, dass die Menschen in (überwiegend Uighurengebiet) Xinjiang (China) im Wohlstand und glücklich leben (Bag 2019).

Die TR unterstützte bis ungefähr zu Beginn des Arabischen Frühlings 2011 in Syrien die Uighuren gegen China. Sie gewährte z. B. leitenden Funktionären der uighurischen Bewegung, Mehmet Emin Bugra und Isa Yusuf Alptekin Bleiberecht und unterstützte sie aktiv. Bugra und Alptekin setzten sich lebenslang für die Trennung des Uighuren-Gebietes von China ein. Am 28. Juli 1995 hatte der damalige Oberbürgermeister von Istanbul, Recep Tayyip Erdogan, einen Teil des Sultan-Ahmet-Parks (Blaue Moschee) in Istanbul nach Alptekin genannt und errichtete ein Denkmal für die uighurischen Märtyrer. Anlässlich der Eröffnungsrede dieses Denkmals sagte er folgendes (zit. nach: Clarke 2016):

"Eastern Turkestan is not only the home of the Turkic peoples but also the cradle of Turkic history, civilization and culture. To forget that would lead to the ignorance of our own history, civilization and culture. The martyrs of Eastern Turkestan are our martyrs."

China hingegen unterstrich zur selben Zeit seine Sorge um die Kurden*innen in der TR und forderte das Selbstbestimmungsrecht für die Kurden*innen in der TR ein (Clarke 2016). Der ehemalige Ministerpräsident Mesut Yilmaz erklärte aufgrund der chinesischen Erklärungen, die TR akzeptiere Xinjiang als Teil Chinas (ebd.). Trotzdem beharrte die TR auf ihre pantürkistisch-islamische Uighurenpolitik. 2009 sprach der damalige türkische Ministerpräsident Erdogan von einem ,uighurischen Genozid“ durch China (Cakir 2009). Seit dem Beginn des syrischen Bürgerkrieges thematisiert Erdogan die Uighurenfrage nicht mehr so intensiv wie früher. Die Kritik an China kommt nur noch von einigen Politiker*innen seiner Partei AKP. Und wie oben dargestellt wurde, lobte der türkische 
Präsident Erdogan 2019 die chinesische Uighurenpolitik. Hier spielten in erster Linie die sicherheitspolitischen Interessen der TR bezüglich der Kurdenfrage eine bestimmende Rolle. Während seiner China-Reise im Juli 2015 erklärte Erdogan, dass die TR die terroristischen Aktivitäten der „Islamischen Bewegung Ostturkestans“ gegen China nicht unterstütze und die chinesische „Ein-China-Politik“ akzeptiere (O. V. 2015: Erdoğan, Çin'de çark ...). Er fügte hinzu, dass die TR auch ein Terrorproblem habe und daher die Unterstützung der Internationalen Gemeinschaft brauche (ebd.). In dem Jahr dieser Rede war die TR im Syrienkrieg gegen die Syrien-Kurden und syrische Assad-Regierung mit Unterstützung der islamistischen „Rebellen“ (darunter sich auch die uighurischen Kämpfer befinden) involviert. Und seit 2019 ist die TR in Syrien militärisch aktiv, wie oben geschrieben wurde.

Die TR braucht in Syrien die chinesische und russische Unterstützung für ihre Syrienpolitik, da China und RU ständige Mitglieder des Sicherheitsrates der Vereinten Nationen und starke Wirtschafts- und Militärmächte sind. Andererseits sind die türkischen Beziehungen zu ihrem größten sicherheitspolitischen Partner USA seit den letzten Jahren belastet. ${ }^{379}$ Vor allem versucht die TR zu verhindern, dass China, RU und die USA in Syrien gegen ihre sicherheitspolitischen Interessen und im Interesse der Kurden*innen handeln. Das wäre eine Horrorszenario für die TR. ${ }^{380}$ Von ihrem NATO-Partner USA fühlt sich die TR in ihrer Syrienpolitik im Stich gelassen. ${ }^{381}$ In Syrien war das türkische Ziel in erster Linie die Erfolge der Syrien-Kurden*innen rückgängig zu machen. Deshalb forderte sie die Gründung einer Sicherheitszone unter ihrer Kontrolle, die ab ihrer südlichen Grenze $30 \mathrm{~km}$ tief in das syrische Gebiet und über $400 \mathrm{~km}$ lang bis zum irakischen kurdischen Teil reichen soll. D. h.

\footnotetext{
${ }^{379}$ Am 15. Juli 2016 gab es in der TR einen erfolglosen Militärputschversuch gegen die Erdogan-Regierung. Nach der Meinung Erdogans wurde der Putsch von den in den USA lebenden Prediger Fethullah Gülen geplant und von seinen Anhängern in der türkischen Armee durchgeführt. Indirekt beschuldigte er auch die USA als Unterstützer Gülens und forderte Gülens Auslieferung. Die USA lehnte das Auslieferungsgesuch ab. Dieser Putsch wurde, wie die türkischen Medien berichteten, dank russischer, geheimdienstlicher Informationen an den türkischen Geheimdient verhindert. Des Weiteren sind die US-Türkischen Beziehungen wegen des türkischen Kaufs des russischen Raketenabwehrsystem S-400 sowie Uneinigkeiten über die Syrien- bzw. Kurdenfrage belastet. Für die USA hingegen handelt die TR nicht im Interesse der NATO und kauft z B. von RU das Raketenabwehrsystem S-400 und plant, es in Betrieb zu nehmen. Das wollen die USA mit Sanktionen verhindern, weil RU dadurch an die Militärdaten der NATO-Militärsysteme eingreifen und diese vermutlich in ihrem Interesse gegen die NATO nutzen könnte.

${ }^{380}$ Eine mögliche westlich-russische strategische Partnerschaft könnte sich auf die türkische territoriale Integrität negativ auswirken, wenn sie sich über die demokratische Lösung der Kurden- und Armenierfrage einigen würden.

${ }^{381}$ Der türkische Minister für die Nationale Sicherheit, Hulusi Akar (2018 - im Amt), erklärte 2019 auf einem NATO-Treffen, die NATO ließe die TR in ihrem Kampf gegen die PKK und PYD in Syrien allein, obwohl die TR alle ihrer NATO-Pflichten erfülle (O. V. 2019: Son Dakika: Bakan ...).
} 
das gesamte kurdisch geprägte Nord-Syrien versucht die TR mit Hilfe RUs und Chinas sowie mit Druck auf die USA unter ihre Kontrolle $\mathrm{zu}$ bringen und hier einen Bevölkerungsaustausch durchzuführen. In die Sicherheitszone will sie die syrischen arabischen Flüchtlinge aus der TR ansiedeln und dadurch die geographisch-kulturelle Einheit „Kurdistans“ zerstören. Weil sie von den USA nicht die volle Zustimmung für ihre Pläne erhält, versucht sie ihre Pläne mit russischer und chinesischer Hilfe umzusetzen. Die derzeitige gemeinsame Zusammenarbeit der TR und RU hat allerdings einen taktischen Hintergrund und es ist zu erwarten, dass die TR die sicherheitspolitische Zusammenarbeit mit RU beenden wird, sobald sie ihre Ziele erreicht hat oder RU eine sicherheitspolitische Gefahr für sie darstellt. 


\subsection{Zusammenfassung}

ZA erweiterte seine energiepolitische Relevanz mit der Gründung der USA/NATOMilitärbasen für die Terrorbekämpfung in Afghanistan 2001 auf die geostrategische Relevanz. Allein die Existenz der Großmächte, USA, RU und China, durch die von ihnen dominierten Militärorganisationen (NATO, OVKS und SOZ) in ZA, unterstrich die geostrategische Relevanz der Region im New Great Game. Die TR handelt in ZA sicherheitspolitisch im Rahmen der NATO (Somuncuoglu 2011) und ihre sicherheitspolitischen Ziele für ZA stimmen mit denen der USA weitgehend überein: die Schwächung RUs und das Ersetzen seines Einflusses im Kaukasus und in ZA durch die TR. Unabhängig von der NATO versucht die TR noch, seit 2011 eine „Türkenarmee“ (TAKM) unter ihrer Leitung zu gründen. Sie ist zwar gegründet, ist aber nur eine sicherheitspolitische „Informationsstelle“ und von den zentralasiatischen Staaten ist nur Kirgisistan TAKMMitglied.

Die TR versuchte nach der Auflösung der Sowjetunion in der „Türkenwelt“ eine aktive Sicherheitspolitik zu verfolgen. Während des ersten Karabach-Krieges (1992-1994) wollte sie gegen Armenien in den Krieg eintreten. RU bedrohte die TR im Falle eines Angriffes mit einem 3. Weltkrieg (Fuller 1993: 78; Cornell 1999; Kolobov/Kornilov/Özbay 2006: 143), sodass sie den Angriff nicht wagen konnte. Dieser Fall zeigte der TR, dass RU im GUSRaum keinen anderen Hegemonen dulden möchte und werde. Den GUS-Raum definiert RU seit seinen ersten nationalen Dokumenten bis heute als „Prioritätsgebiet“ für die russische Außenpolitik, in erster Linie aus sicherheitspolitischen Interessen als „Sicherheitsgürtel“ gegen die sicherheitspolitischen Gefahren.

Die USA/NATO-Erweiterung und -Aktivitäten, Terrorismus, Drogenhandel und Farbenrevolution werden von RU in allen seinen nationalen Dokumenten als Hauptgefahren definiert. Dem Westen wirft RU in seiner aktuellen „Sicherheitsstrategie von 2015“ (President Of The Russian Federation 2015, Artikel 18) den Regierungswechsel der legitim gewählten Regierungen durch die sogenannten Farbenrevolutionen und die Unterstützung der innenpolitischen Instabilität und Konflikte im postsowjetischen Raum vor. Des Weiteren sieht das Land die Entstehung des Islamischen Staates (IS) als Ergebnis der westlichen Angriffe im Nahen Osten an (ebd.). RU warnte schon vor dem Irak-Einsatz vor Chaos und zunehmendem Terror (Wipperfürth 2011: 66). Putin erklärte am 16. Oktober 
2015, dass die Terroristen an Einfluss gewinnen und eines ihrer Ziele ZA sei (O. V. 2015: Putin: 7.000 Dschihadisten ...). Tatsächlich ist der IS seit einigen Jahren in Afghanistan tätig, kooperiert mit den anderen islamistischen Gruppierungen aus Afghanistan und ZA und verübt seit 2014 in ZA Anschläge. Ein weiteres Sicherheitsproblem für RU und ZA ist der Rückzug der Islamisten aus den Kriegsgebieten wie Syrien. Die Islamisten aus den GUSStaaten in Syrien machten im Jahre 2015 23,3 \% der ausländischen Kämpfer aus (O. V. 2015: Şok Rakam! Işid'in ...). Russisch ist laut Medienberichten in den von den ISkontrollierten Gebieten Syriens und Iraks die zweit meist gesprochene Sprache nach dem Arabischen (Oguz 2016).

ZA ist sunnitisch-muslimisch geprägt. Nach ihrer Unabhängigkeit nimmt die Religiosität in der Region zu. Neben sozio-ökonomischen Faktoren spielen dabei auch die Aktivitäten der muslimischen Länder, wie die TR und Saudi-Arabien, in ZA eine Rolle. Ein weiterer Faktor ist die Nachbarschaft zu Afghanistan. Das Land ist das Rückzugsgebiet der zentralasiatischen Islamisten. Afghanistan ist des Weiteren wegen des Drogenhandels ein großes sicherheitspolitisches Problem für die Region. RU teilt mit ZA gleiche sicherheitspolitischen Sorgen, befürchtet mögliche Spill-Over-Effekte aus Afghanistan und/oder via/aus ZA in die Russische Föderation. In der Russischen Föderation leben etwa 30 Mio. Muslime (21 \% der russischen Gesamtbevölkerung), deren mögliche Radikalisierung die territoriale Integrität der Föderation in Frage stellen kann.

Der Islamismus ist sowohl für die zentralasiatischen Staaten als auch alle seiner Nachbarstaaten (RU, China und Iran) eine sicherheitspolitische Gefahr. Ein möglicher Chaos-Zustand oder Krieg in ZA kann den Aufstieg des Islamismus in der Region beschleunigen und die gesamte Region einschließlich seiner Nachbarn in einen Brennpunkt verwandeln. Der Pantürkismus ist eine weitere sicherheitspolitische Gefahr für die Region und ihre Nachbarstaaten. In ZA leben überwiegend die Turkvölker und RU, China und Iran haben Turkvölker, die im Falle einer pantürkistischen Bewegung gegen sie aufstehen und von den anderen Turkvölkern Unterstützung bekommen können. Allerdings hat der Pantürkismus aktuell kein Potential, an Macht und Einfluss zu gewinnen, weil sich die zentralasiatischen Staaten vom türkischen Pantürkismus distanzieren. Die pantürkistischen Ziele der TR finden in ZA keine Akzeptanz in breiten Bevölkerungsschichten, weil der Pantürkismus die „eigenen historisch-kulturellen Eigenschaften“ der Turkstaaten nicht anerkennt und sie als „Türken“ vereinheitlichen möchte. Deshalb wird er von den 
zentralasiatischen Staaten weiterhin als Gefahr gegen ihre Landesgrenzen und eigene Identität angesehen. Usbekistan und Turkmenistan schlossen die türkischen Schulen wegen ihrer pantürkistischen und islamistischen Arbeit sowie der Zusammenarbeit mit der CIA. Die US-Militärbasis in Usbekistan schloss Usbekistan nach einem SOZ-Gipfel, weil das Land hinter den Andijan-Unruhen im Jahre 2005 die Unterstützung der USA vermutete. Für die zentralasiatischen Staaten ist RU die einzige Macht, die in der Region den Status Quo schützen kann, wie im Tadschikischen Bürgerkrieg (1992-1997), in den Andijan-Unruhen (2005) in Usbekistan und bei den Unruhen in Kirgisistan (2010) zu sehen war.

Die Ereignisse „Abschuss eines russischen Kampfflugzeuges Typ Su-24 an der syrischen Grenze am 24. November 2015 durch die TR“ und der OIC-Gipfel von 2016 zeigen die zentralasiatische Haltung gegenüber der TR und RU im Vergleich deutlich. Die zentralasiatischen Staaten nahmen kurz nach dem Abschuss des Kampfflugzeuges Su-24 eine klare Stellung auf der russischen Seite gegen die TR ein und forderten die TR auf dem GUS-Gipfeltreffen im Dezember 2015 auf, sich bei RU für diesen Fall zu entschuldigen (Dogan 2016). Der kirgisische Präsident Atambayew beschuldigte die TR am 24. Dezember 2015 öffentlich und forderte sie auf, bei RU um Entschuldigung zu bitten (O. V. 2016: Kırgızistan Cumhurbaşkanı Atambayev ...). Auf dem 13. Gipfeltreffen der OIC am 14. 15. April 2016 hingegen reagierten sie nicht auf die türkischen Anforderungen bezüglich der Karabach- und Krimfrage, genauso wie beim ersten Türkengipfel 1992, als die TR von ihnen Unterstützung für die Karabach-Frage und Zypern erwartete. Diese Ereignisse zeigen deutlich, dass die zentralasiatischen Staaten sicherheitspolitisch auf der russischen Seite sind. Die OVKS-Mitgliedschaft Kasachstans, Kirgisistans und Tadschikistan bestätigt diese Aussage. Usbekistan arbeitet seit 2017 mit RU sicherheitspolitisch eng zusammen. Nur Turkmenistan hielt sich aufgrund seiner Neutralität zurück. Im Falle einer ernsthaften sicherheitspolitischen Gefahr aber, wird sich auch Turkmenistan mit sehr großer Wahrscheinlichkeit sicherheitspolitisch an RU annähern. 


\section{FAZIT}

Die türkisch-russische Geschichte ist eine Geschichte der Rivalitäten. Sie wird wegen 15 Kriege zwischen den beiden Staaten als „konflikthaft“ bezeichnet. Ihren 1. Krieg führten die beiden Staaten wegen ZA, um das Khanat Astrachan (1568-1570). Die Zentralasiaten riefen den osmanischen Kalifen zur Hilfe, weil das Zarenreich die Pilgerwege nach der Eroberung des Khanats Astrachans 1554 geschlossen hatte (Inalcik 1999: 29-30). Der Zeitpunkt der Eroberung des Khanats Astrachans gilt als Anfang der türkisch-russischen Rivalität. Der Untersuchungszeitraum der Arbeit erstreckt sich vom Anfang der türkisch-russischen ZAP 1552-1554 bis zum Ende 2019. Die Analyse der türkisch-russischen ZAP ergab, dass die TR und RU in ZA in den kultur- und bildungspolitischen, wirtschaftlichen und sicherheitspolitischen Bereichen geopolitisch rivalisieren. Über diese Erkenntnis ist sich auch die Literatur einig. Meine 1. Hypothese ,Die Türkei und Russland rivalisieren in Zentralasien geopolitisch in kultur- und bildungspolitischen, wirtschaftlichen und sicherheitspolitischen Bereichen " kann damit als verifiziert gelten.

Mit meiner 1. Forschungsfrage „Warum rivalisieren die Türkei und Russland in Zentralasien geopolitisch? “ zielte ich auf die Erklärung ihrer Rivalitätsgründe in ZA, das Aufzeigen der Zusammenhänge und Schließung der Literaturlücken (siehe hierzu Kap. 1 und Kap. 1.2.3). Die kurze Antwort auf die 1. Forschungsfrage lautet: Die TR und RU rivalisieren in ZA geopolitisch deshalb, weil beide Staaten ZA als ihr „selbstverständliches Einflussgebiet“ ansehen und infolge dessen eine hegemoniale ZAP (die „Türkenweltpolitik“ gegen das „Nahe-Ausland-Politik") betreiben. Ihre kultur- und bildungspolitischen, wirtschaftlichen und sicherheitspolitischen Ziele in ZA sind gegensätzlich. Die pantürkistische ZAP der TR zielt auf die Vereinigung der Turkvölker unter ihrer Herrschaft ab. RU hingegen ist gegen die Entwicklung möglicher pantürkistischen Vereinigungen, wie es beim pantürkistischen Basmatschi-Aufstand (1918-1924) in ZA gegen die russische Herrschaft der Fall war. Aus taktischen Gründen unterstützt RU die Eigenständigkeit der zentralasiatischen Staaten, um ihre möglichen pantürkistischen und/oder islamistischen Vereinigungen zu verhindern.

Die türkisch-russische kultur- und bildungspolitische Rivalität in ZA lässt sich insbesondere an deren „Sprach- und Alphabetenpolitik“ verdeutlichen. Es geht der TR dabei um die Schaffung einer einheitlichen Sprache bzw. der Verbreitung des Türkischen unter den Turkvölkern, wofür die Schaffung eines einheitlichen Alphabets den ersten Schritt darstellt. Die wichtigsten türkischen Soft-Power-Instrumente in ZA waren die Gülen Schulen. RU 
hingegen wendet sich gegen dieses Ziel und versucht seinerseits, den Erhalt der russischen Sprache als Lingua Franca sowie den kulturpolitischen Einfluss in der Region zu gewährleisten. Die russische Sprache blieb bis heute die Lingua Franca in ZA. Allerdings versuchen die zentralasiatischen Staaten parallel zu diesen Hegemonialversuchen ihre Nationalsprachen aufzuwerten. Usbekistan und Turkmenistan ersetzten ihr kyrillisches Alphabet 1993 durch das lateinische Alphabet, das mit dem lateinischen Alphabet der TR nicht identisch ist und andere Buchstabencharaktere aufweist, die das Türkische nicht hat. Auch Kasachstan beschloss ab 2025 die Umstellung seines Alphabets auf das lateinische. Das Verhalten dieser Staaten zeigt, dass sie weder die türkische noch die russische kulturund bildungspolitische Hegemonie akzeptieren. Vielmehr wollen sie als „eigenständige Staaten mit eigener Kultur, Sprache, Ethnie und Nation“ wahrgenommen und anerkannt werden. Ein weiteres Beispiel zur Haltung der zentralasiatischen Turkstaaten ist, dass sich diese von den pantürkistischen Organisationen der TR möglichst fernhalten und mit ihr nur in den „kulturpolitischen“ Organisationen, wie TURKSOY, TÜRKPA und TDIK, zusammenarbeiten. Mit der TR wollen sie ausschließlich ihre „Sprachfamilie“ (Turksprachen) betonen.

Die türkisch-russische wirtschaftliche Rivalität in ZA ließ sich an den Pipelines Projekten für die Ausbeutung der kaspischen fossilen Rohstoffe beobachten. Die Literatur bezeichnet dieses Null-Summen-Spiel zwischen der von den USA geführten westlichen Achse - wozu auch die TR gehört - und RU als „New Great Game“. Es geht dabei um die Kontrolle und Ausbeutung der kaspischen fossilen Brennstoffe unter Umgehung RUs und Irans. Die hohen Investitionen der US-Firmen in die kasachische Erdölbranche und die Zuordnung der zentralasiatischen Staaten 1999 zum Zuständigkeitsgebiet der US-militärischen Einheit CENTCOM unterstreichen die energiepolitische Relevanz des kaspischen und der umliegenden Gebiete (Strategischen Ellipse) für die westliche Achse. Die USA und die TR konnten im Rahmen des New Great Games die kaspischen Erdölpipeline BTC, die Erdgaspipelines BTE und TANAP unter Umgehung RUs nach Westen verwirklichen. In die BTC wird auch aus Kasachstan verschifftes Erdöl eingespeist. Ein großes Erdgasprojekt der EU für die Ausbeutung u. a. des turkmenischen Erdgases und Isolierung RUs (dessen Staatshaushalt von Rohstoffeinnahmen abhängig ist), NABUCCO, scheiterte. Wirtschaftlich gesehen hat RU mehr Erfolge in ZA als die TR. Schätzungen zufolge arbeiten in RU 5 bis 10 Mio. Zentralasiaten (Ibrahimov 2017), d. h. im Durchschnitt etwa $10 \%$ der zentralasiatischen Bevölkerung. Kasachstan und Kirgisistan sind EAWU-Mitglieder, 
Tadschikistan prüft den Beitritt. Usbekistan hat Beobachterstatus. Turkmenistan bewahrt seine Neutralität. Die türkischen pantürkistischen Vorschläge hingegen, wie die Gründung eines wirtschaftlichen „Türkenraums“ unter ihrer Kontrolle, fand in ZA keine Akzeptanz.

Sicherheitspolitisch gesehen agiert die TR in ZA im Rahmen der NATO und versucht zusätzlich eine „Türkenarmee“ (TAKM) zu gründen. Von zentralasiatischen Staaten ist bis jetzt nur Kirgisistan der TAKM beigetreten und die TAKM gilt bis heute nur als Informationsstelle. Die TR versuchte nach der Auflösung der Sowjetunion eine aktive

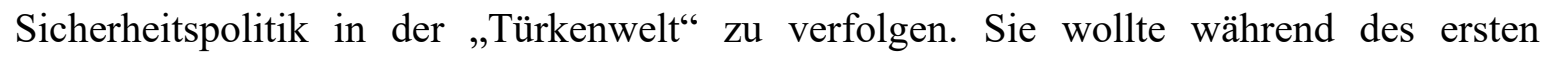
Karabach-Krieges (1992-1994) gegen Armenien in den Krieg eintreten. RU bedrohte die TR im Falle eines Angriffes mit einem 3. Weltkrieg (Fuller 1993: 78; Cornell 1999; Kolobov/Kornilov/Özbay 2006: 143), sodass sie den Angriff nicht wagen konnte. Dieser Fall zeigte deutlich, dass RU im GUS-Raum keinen anderen Hegemonen dulden werde.

Den GUS-Raum definiert RU seit seinen ersten nationalen Dokumenten bis heute als „Prioritätsgebiet“ für die russische Außenpolitik, in erster Linie aus sicherheitspolitischen Interessen als „Sicherheitsgürtel“ gegen die sicherheitspolitischen Gefahren. Die zentralasiatischen Staaten akzeptieren RU in der Region als „Schutzmacht“, die Hard-Power anwenden darf/kann, wie es im Tadschikischen Bürgerkrieg (1992-1997), den AndijanUnruhen (2005) in Usbekistan und Unruhen in Kirgisistan (2010) zu sehen war. Kasachstan, Kirgisistan und Tadschikistan arbeiten mit $\mathrm{RU}$ in der russisch dominierten sicherheitspolitischen Organisation OVKS zusammen. Usbekistan nähert sich seit der Amtszeit des usbekischen Präsidenten Mirsijojew (2016) RU an. Turkmenistan bewahrt seine Neutralität. Nach dem Abschuss eines russischen Kampfflugzeuges an der syrischen Grenze 2015 durch die TR forderten die zentralasiatischen Staaten die TR auf, sich bei RU für diesen Fall zu entschuldigen. Der Bitte der TR auf dem OIC-Gipfel von 2016, RU wegen der Krim und Armenien wegen Karabach zu kritisieren, kamen sie nicht nach.

Die zentralasiatischen Staaten teilen die gleichen sicherheitspolitischen Sorgen mit RU. Sie alle sehen die USA/NATO, den Islamismus, die Farbenrevolutionen, den Drogenhandel und den Pantürkismus als sicherheitspolitische Gefahr für ihre territoriale Integrität und Souveränität an. Sie sind sicherheitspolitisch auf RU angewiesen. Die TR hingegen wird wegen ihrer pantürkistischen und in letzten Jahren zunehmend islamistischen Politik (wie 
während des arabischen Frühlings in Ägypten und Syrienkrieges zu sehen war) als sicherheitspolitische Gefahr gesehen.

Mit meiner 2. Hypothese „Eine türkisch-russische „strategische Partnerschaft " in Zentralasien ist unter den heutigen Umständen nicht möglich " positionierte ich mich gegen die literarische Strömung „strategische Position“. Diese hält eine türkisch-russische strategische Partnerschaft in ZA aufgrund der türkisch-russischen bilateralen ,strategischen Beziehungen“ in Zukunft für möglich. Als „Strategische Partnerschaft" sind meistens die bilateralen energiepolitischen Beziehungen zwischen der TR und RU gemeint. Meine 2. Forschungsfrage „Ist eine türkisch-russische ,, strategische Partnerschaft“ in Zentralasien möglich? “ zielt auf die Verifizierung der 2. Hypothese und Gewinnung neuer Erkenntnisse. Die kurze Antwort auf diese Frage lautet: Nein, eine türkisch-russische strategische Partnerschaft ist in ZA unter heutigen Umständen nicht möglich, weil die TR dafür auf ihre pantürkistische ZAP ganz verzichten und ZA als russisches Hegemoniegebiet bzw. als russisches „Nahes Ausland“ anerkennen muss. In der türkischen Außenpolitik hingegen nehmen seit 2014 die pantürkistischen und islamistischen Äußerungen und Symbole zu.

Für RU sind Pantürkismus und Islamismus im Zusammenhang seiner turksprachig (14 \% der Gesamtbevölkerung RUs) und/oder muslimischen $(21 \%$ der russischen Gesamtbevölkerung) Minderheiten sowie wegen möglicher Spill-Over-Effekte aus Afghanistan oder ZA die größten sicherheitspolitischen Gefahren gegen seine territoriale Integrität und Souveränität. Die TR birgt für RU mit ihrer NATO-Partnerschaft und den pantürkistisch-islamistischen Zielen sicherheitspolitische Gefahren in sich. RU sieht die TR als verlängerten Arm der USA im postsowjetischen Raum an. Im Januar 2018 erklärte Erdogan selbst das Ziel des türkischen Einsatzes Syrien-Einsatzes (Afrin) mit dem pantürkistischen Ausdruck „Roten Apfel“(O. V. 2018: Erdoğan: Afrin'den geri ...). Des Weiteren zeigte die TR seine offene Sympathie für den Islamismus während des arabischen Frühlings. Sie solidarisierte sich mit den Muslimbrüdern in Ägypten und unterstützte die islamistischen Gruppierungen in Syrien gegen Assad.

Aktuell handelt die TR mit RU in Syrien sicherheitspolitisch. Eine „sicherheitspolitische strategische Partnerschaft" der TR mit RU ist aufgrund der türkischen NATOMitgliedschaft, den asymmetrischen Machtverhältnissen zwischen den beiden Staaten und ihrer gegensätzlichen sicherheitspolitischen Interessen unter heutigen Umständen nicht zu 
erwarten. Beide Staaten arbeiteten zwar in ihrer Geschichte sicherheitspolitisch oft zusammen. Ihre sicherheitspolitische Zusammenarbeit hatte bis jetzt allerdings keinen strategischen Charakter. Die sicherheitspolitischen Kooperationen kamen aus ihren sicherheitspolitischen und machtpolitischen Interessen zu Stande und waren kurzfristig und situationsbedingt. 1798 und 1805 kooperierten sie gegen Napoleon, 1833 gegen die osmanische Kolonie Ägypten, nach dem 1. Weltkrieg gegen den Westen, nach der türkischen Zypern-Invasion 1974 infolge der wirtschaftlichen Sanktionen des Westens gegen die TR, nach dem Kalten Krieg für die Gründung der „Schwarzmeer-Wirtschaftskooperation“ als Reaktion der TR auf ihre Diskriminierung durch die EU, gegen die von ihnen als Terroristen bezeichneten Gruppen (gemeint PKK für die TR und Tschetschenen für RU), während des Irak-Krieges 2003 und August-Krieges 2008 und aktuell in Syrien im Rahmen der AstanaGespräche. Ihre Geschichte zeigt, dass sie ihre sicherheitspolitischen Bündnisse auflösten bzw. ihre sicherheitspolitische Zusammenarbeit beendeten, sobald die sicherheitspolitische Gefahr überwunden war. D. h. sie kooperierten bis jetzt sicherheitspolitisch ganz im neorealistischen Sinne.

Die TR muss im Falle der strategischen sicherheitspolitischen Zusammenarbeit mit RU aus der NATO austreten. Das ist aktuell nicht zu erwarten, weil wie die TR für RU, birgt auch RU für die TR sicherheitspolitische Gefahren in sich. Die TR ist wegen RU 1952 der NATO beigetreten, weil RU mit der TR aufgrund ihres Verhaltens während des 2. Weltkrieges die sicherheitspolitischen Verträge und Abkommen aufkündigen wollte. Außerdem ist RU die Schutzmacht Armeniens und stuft die kurdischen Organisationen PKK und PYD nicht als Terrororganisationen ein. D. h. die drei größten sicherheitspolitischen Gefahren der TR, RU, Kurden und Armenien, würden eine mögliche türkisch-russische strategische Partnerschaft verhindern. Falls die TR der OVKS beitreten würde, ist sie verpflichtet, mit Armenien zusammenzuarbeiten. Wie alle OVKS-Mitglieder müsste auch sie in so einem Fall die russische militärische Überlegenheit akzeptieren. Die türkisch-russischen Beziehungen würden nicht auf gleicher Augenhöhe sein, was eine strategische Partnerschaft voraussetzt.

Wirtschaftlich versuchte RU, die TR durch die lukrativen Angebote, wie Entwicklungshilfen, auf seine Seite $\mathrm{zu}$ ziehen. Laut Neorealismus dient die Entwicklungshilfe für den Geberstaat zur Aufrechterhaltung und Verbesserung seiner Machtposition im anarchischen System (Waltz 1979: 111). In den Gründungsjahren der TR half die Sowjetunion der TR wirtschaftlich und technisch. Im Kalten Krieg näherte sich die 
TR nach dem Johnson-Brief des US-amerikanischen Präsidenten im Juni 1964 an die Sowjetunion an. 1967 unterschrieben beide Staaten ein wirtschaftliches Abkommen, das zwischen den beiden Staaten den Warenaustausch vorsah und die Sowjetunion der TR die Gründung von Fabriken versprach (Ulcenko 2003: 184-185). In den 70er Jahren gründete RU für die TR die bis heute wichtigsten Fabriken. Auch nach der türkischen ZypernInvasion 1974 wegen der wirtschaftlichen Sanktionen des Westens gegen die TR kooperierte RU mit ihr (Kazgan 2003: 149-152). Energiepolitisch decken die West-Pipeline seit 1987 und die Blue-Stream seit 2003 etwa 55-65 \% des gesamten Erdgasbedarfes der TR ab. Ende 2019 wurde die TurkStream Pipeline in Betrieb genommen, was die Importmenge erhöhen wird. Des Weiteren importiert die TR etwa $23 \%$ ihres Erdölbedarfes aus RU. Wie diese Ereignisse zeigen, nutzte RU jede Gelegenheit, die TR auf seine Seite zu ziehen, wenn sie mit ihren westlichen Partnern Probleme hatte. Der russische Präsident Putin lud die TR im November 2011 ein, anstelle der EU der EAWU beizutreten. Mit einem möglichen EAWUBeitritt müsste die TR allerdings auf ihr Zollabkommen mit der EU verzichten. Ihr Hauptwirtschaftspartner ist die EU. Des Weiteren muss sie ihre Grenzen zu Armenien öffnen und mit ihm wirtschaftlich zusammenarbeiten. Weiterhin würden sich ihre Beziehungen zu den USA verschlechtern, weil die USA gegen die EAWU sind. Somit lässt sich sagen, dass die türkisch-russischen ZAP unter heutigen Umständen weiterhin durch die geopolitische Rivalität geprägt wird.

Das Ziel dieser Arbeit, die Verifizierung der Hypothesen, Beantwortung der Forschungsfragen und Füllung der Forschungslücken, konnte mit Hilfe der methodischen Vorgehensweise erreicht werden. Die größte Schwierigkeit beim Verfassen dieser Arbeit entstand wegen seines langen Untersuchungszeitraums (1552-2019). Den Überblick zu behalten, die Zusammenhänge richtig zu erkennen und zuzuordnen, dabei auch die Interessen der für das Thema relevanten Akteure, wie der USA, der EU, China, mitberücksichtigen, erwies sich als anstrengend. Des Weiteren war die Arbeit mühsamer, weil viele der bestehenden Literaturquellen über das Thema politisiert und lückenhaft sind und es daher an wissenschaftlichen Arbeiten über das Thema mangelt. Aus diesem Grund versuchte ich das Wissen möglichst aus der Primärliteratur zu gewinnen. Wenn das nicht möglich war, prüfte ich alles im Rahmen der Möglichkeiten nach. In einigen Fällen war das nicht möglich, weil z. B. die türkischen Staatsarchive, Cankaya Köskü Arsivi (Archiv vom Cankaya) ungeöffnet sind und somit die Recherchen der türkischen ZAP in der Atatürk-Ära (1920-1938) fast unmöglich sind. Des Weiteren verhindert bzw. begrenzt ein Gesetz von 
1951 „Gesetz über strafbare Handlungen gegen Atatürk, Gesetznummer 5816“ die unabhängigen Recherchen über seine Zeit und Person.

Trotz allem bedarf diese Arbeit eine Langzeituntersuchung, weil die aktuellen ZAPerzeptionen der TR und RU sehr wesentlich durch die historischen Ereignisse bestimmt sind. Z. B. übernimmt das türkische Heer das Datum der Thronbesteigung des Oghus Khans des zentralasiatischen Hunnenreichs im Jahre 209 v. Chr. als Gründungsjahr des türkischen Heeres (Kara Kuvvetleri Komutanligi 2020). Dieses Beispiel zeigt deutlich, dass die TR sich mit ZA tief verbunden fühlt und die heutige ZAP der TR ohne Darstellung der Geschichte nicht zu verstehen ist. Ein weiteres Beispiel ist der Görsch der Standarte des türkischen Präsidenten, in der selbst das mongolische Timuridenreich (Türkiye Cumhuriyeti Cumhurbaskanligi o. J.) und die mongolische Goldene Horde als „Türkenstaat“ aufgezählt werden. Die turksprachigen Länder werden von der TR als „Türken“ gesehen. Auf der Homepage des türkischen Außenministeriums steht im Jahre 2019 für die Turkstaaten die Bezeichnung Türk Dünyasi („Türkenwelt“) und für die Turksprachen „Türk Dili““ („Türksprachen, türkische Sprachen oder Türkensprachen“) (Türkiye Cumhuriyeti Disisleri Bakanligi o. J. a). Die TR betrachtet die Bevölkerung der zentralasiatischen Turkstaaten also offiziell als „türkischsprachige Türken“. Der türkische pantürkische Anspruch auf die Leitung der turksprachigen Völker geht auf das 15. Jahrhundert zurück. Diese Tatsache macht gründliche historische Recherchen für das Thema unabdingbar. RU hingegen sieht das postsowjetische ZA als einen Teil seines „Nahen Auslands“ (russisch: blizhneye zarubezhye), als sein „,selbstverständliches Hegemoniegebiet“ und teilt mit der Region eine etwa 250-jährige Geschichte. Ohne die historischen Vorkenntnisse können die aktuelle ZAP der TR und RU nicht verstanden bzw. erklärt werden.

Die zeitintensive Langzeituntersuchung ermöglicht andererseits, die möglichen Gesetzmäßigkeiten zu erkennen oder verallgemeinerbare Aussagen zu treffen. Ich habe festgestellt, dass in ZA eine positive Korrelation zwischen der sicherheitspolitischen Zusammenarbeit und kultur- und bildungspolitischen Zusammenarbeit zu beobachten ist. D. h. die sicherheitspolitische Zusammenarbeit und -Interessen bestimmen die Grenzen der kultur- und bildungspolitischen Zusammenarbeit. Mit anderen Worten, je tiefer die sicherheitspolitische Zusammenarbeit und Ziele zwischen den Akteuren, desto tiefer ist ihre kultur- und bildungspolitische Zusammenarbeit. Der russische kultur- und bildungspolitische Einfluss ist am stärksten in den Mitgliedsstaaten der 
sicherheitspolitischen OVKS zu beobachten. Als z. B. Usbekistan nach 2015 der OVKS beitrat, öffnete das Land die Türen für den russischen kultur- und bildungspolitischen Einfluss weit auf (siehe hierzu Kap. 4.2.2). Zu der TR hingegen unterbrach Usbekistan seine Beziehungen nach dem Attentat an den usbekischen Präsidenten Karimow (siehe Kap. 4.1.2.2). Eine weitere Erkenntnis ist, dass die TR mit ihrer „Türkenweltpolitik“ auf die Schwächung RUs abzielt, weil ein schwaches RU für die TR keine Gefahr (wegen RU selbst, wegen Armenier- und Kurdenfrage) mehr für die türkischen Interessen ist (siehe hierzu Kap. $6.9)$.

Eine Langzeituntersuchung war des Weiteren wegen der möglichen neuen Erkenntnisgewinne von Vorteil. Während der Recherchen merkte ich z. B., was die rote Farbe der türkischen Flagge symbolisieren könnte. Seit der Ära des osmanischen Sultans Murad I. (1359-1389) benutzte das Osmanische Reich als Flagge zunächst ein rotes Tuch. Es ist bis heute ein Rätsel, wie diese Flagge entstand bzw. welche Bedeutung sie hat. Meiner Meinung nach ist ein plausibler Erklärungsansatz dafür, dass die TR die rote Flagge vom Umayyadenreich übernahm, welches zwischen den Jahren 660-750 im heutigen Damaskus (Syrien) das Kalifat (Oberhaupt der sunnitischen Muslime) eingerichtet hatte. D. h. das rote Tuch symbolisiert mit sehr großer Wahrscheinlichkeit das Kalifat des Umayyadenreichs (siehe Kap. 3.5).

Des Weiteren können das Geschichtsbuch „Oguzname“ (1436-1437), die Eroberung des Khanats Krim und die Astrachan-Expedition meiner Meinung nach als Anfang der pantürkistischen Theorie im Osmanischen Reich gelten und nicht wie bisher angenommen wird, die pantürkistischen Entwicklungen im 19. Jahrhundert (siehe Kap. 3.2). Im Oguzname erhebt das Land den Anspruch auf die Leitung der altaischen Völker, unter denen sich auch die Turkvölker befinden. Das Osmanische Reich wollte im 15. Jahrhundert durch die Eroberung des Khanats Krim, ein Nachfolgekhanat der zerfallenen tatarischmongolischen Goldenen Horde wie das Khanat Astrachans, am Erbe der Goldenen Horde teilhaben, schreiben die Quellen der Zeit (T.C. Basbakanlik Devlet Arsivleri Genel Müdürlügü 1992: XXXIX). (siehe Kap. 3.2). D. h. er sah schon damals die Goldene Horde als ,Verwandte“.

Die Aufenthalte aller leitenden zaristischen Pantürkisten (wie Gaspirali, Fitrat, Cobanzade) im Osmanischen Reich und ihre Tätigkeiten, die Ähnlichkeit der Zeitungsnamen von 
Gaspirali (Tercüman-i Ahval-i Zaman) und von Jung-Osmanen (Tercüman-i Ahval), die Ähnlichkeit der zentralasiatischen Flaggen mit der türkischen Flagge während des Basmatschi-Aufstandes (1918-1924) gegen das Zarenreich und die Leitung dieses Aufstandes durch die türkischen pantürkistischen Offiziere (Enver Pascha und nach seinem Tod Hadschi Sami Pascha) sind für mich Belege für die türkische Leitung der pantürkistischen Aktivitäten in ZA (Kap. 3.5 und Kap 3.6).

Die Langzeituntersuchung bietet auch die Möglichkeit, die möglichen Kontinuitäten oder Wandel der türkisch-russischen ZAP zu untersuchen. Die türkisch-russische ZAP war z. B. von ihren Anfängen bis heute durch die geopolitische Rivalität geprägt. D. h. hier ist eine Kontinuität festzustellen.

Zwischen Gülen und seiner Gülen-Bewegung und Ismail Gaspirali (Vater des Pantürkismus) und seiner Dschedid-Bewegung sind Parallelen zu finden. Sowohl Gülen als auch Gaspirali sind pantürkistisch geprägt, beide versuchten durch ihre kultur- und bildungspolitische Arbeit (d. h. durch die Soft-Power-Mitteln) die „Türkvölker“ zu vereinigen bzw. eine „Türkenwelt“ zu gründen. Dafür setzten beide sowohl Bildung (Schulen) als auch Medien ein. Selbst der Name der auflagestärksten Zeitung „Zaman“ der Gülen-Bewegung wurde meiner Meinung nach mit sehr großer Wahrscheinlichkeit aus dem Zeitungsnamen von Gaspirali „Tercüman-i Ahval-i Zaman“ abgeleitet. Gaspiralis Zeitungsname wiederum stammte vermutlich vom Zeitungsnamen „Tercüman-i Ahval““ ab, die seit 1860 von den türkischen Nationalisten im Osmanischen Reich herausgegeben wurde (siehe hierzu Kap. 3.5). Gülen kann meiner Meinung nach als Nachfolger von Gaspirali bzw. Jung-Osmanen angesehen werden, aus der die pantürkistische Gruppe „Ittihat ve Terakki“ hervorgegangen ist (siehe Kap. 4.1.2.2). 


\section{Erklärung}

Hiermit erkläre ich, dass ich die Dissertation selbständig verfasst und alle in Anspruch genommenen Hilfsmittel in der Dissertation angegeben habe, dass ich nicht die Hilfe einer kommerziellen Promotionsvermittlung in Anspruch genommen habe, dass meine Arbeit noch in keinem Prüfungsverfahren vorgelegen hat, dass ich nicht schon einmal einen Antrag auf Eröffnung eines Promotionsverfahrens gestellt habe und noch in keinem früheren Promotionsverfahren erfolglos geblieben bin, dass mir die Promotionsordnung bekannt ist und dass die Arbeit weder ganz noch in Auszügen veröffentlicht wurde.

Groß-Zimmern, 10. September 2020 


\section{LITERATURVERZEICHNIS}

ABAY, Emre Gürkan (2018): Rusya'nın Orta Asya Türk Cumhuriyetleri üzerindeki ekonomik etkisi [Wirtschaftlicher Einfluss Russlands auf die türkischen Republiken Zentralasiens]. In: AA, 19.10.2018, Moskova, https://www.aa.com.tr/tr/analiz-haber/rusya-nin-orta-asya-turkcumhuriyetleri-uzerindeki-ekonomik-etkisi/1286359 (Letzter Zugriff: 12.01.2019)

ACIK, Fatma (2002): Özbek Türk Şairi, Yazari, Dil Bilimcisi ve Düşünürü Abdulrauf Fitrat [Abdulrauf Fitrat, usbekischer Dichter, Schriftsteller, Linguist und Denker]. In: KÖK Journal of Social and Strategical Researches, Vol. IV, Num. 1, (Spring 2002), http://turkoloji.cu.edu.tr/CAGDAS\%20TURK\%20LEHCELERI/fatma acik ozbek dusunuru abd urauf fitrat.pdf (Letzter Zugriff: 04.9.2017)

AFFENTRANGER, Zita (2014): Die Angst der Nachbarn vor Moskaus «Hilfe». In: Basler Zeitung, 18.03.2014, 06:29 Uhr, https://bazonline.ch/ausland/europa/Die-Angst-der-Nachbarn-vorMoskaus-Hilfe/story/27496584 (Letzter Zugriff: 13.04.2015)

AIDARBEK, Amirbek (2015): Afganistan ve Orta Asya: Günümüzdeki Durumun Bölgesel Güvenlik Açısından Değerlendirilmesi [Afghanistan und Zentralasien: Bewertung der aktuellen Situation unter dem Gesichtspunkt der regionalen Sicherheit]. In: Avrasya Arastirma Enstitüsü, 25.10.2015, http://eurasian-research.org/tr/research/comments/security/afganistan-ve-orta-asya$\mathrm{g} \% \mathrm{C} 3 \% \mathrm{BCn} \% \mathrm{C} 3 \% \mathrm{BCm} \% \mathrm{C} 3 \% \mathrm{BCzdeki}$-durumun-b\%C3\%B6lgesel-g\%C3\%BCvenlika $\% \mathrm{C} 3 \% \mathrm{~A} 7 \% \mathrm{C} 4 \% \mathrm{~B} 1 \mathrm{~s} \% \mathrm{C} 4 \% \mathrm{~B} 1$ ndan $\quad$ (Letzter Zugriff: 22.07.2018)

AKINER, Shirin (1994): Post - Soviet Central Asia: past is prologue. In: Ferdinand, Peter (Hrsg.): The New Staates of Central Asia and Their Neighbors. New York: Council on Foreign Relations Press, (The Royal Institute of International Affairs), S. S. 4-35.

AKP (2016): Başbakan Davutoğlu, İslam İşbirliği Teşkilatı 13. Zirvesi’nde konuştu [Ministerpräsident Davutoglu sprach auf dem 13. Gipfel der Organisation der Islamischen Zusammenarbeit]. Nisan 14, 2016, 2:50:00, http://www.akparti.org.tr/site/haberler/basbakandavutoglu-islam-isbirligi-teskilati-13.-zirvesinde-konustu/83530\#1 (Letzter Zugriff: 02.02.2017)

AKSAY, Hakan (2016): ‘Tayyip Abi’ mazi oldu: Eski Sovyet coğrafyasında Gülen gerilimi [,Tayyip Abi' ist Vergangenheit: Spannungen in den Gebieten der ehemaligen Sowjetunion wegen Gülen]. In: T24, 05 Ağustos 2016, 00:00, http://t24.com.tr/yazarlar/hakan-aksay/tayyip-abi-mazioldu-eski-sovyet-cografyasinda-gulen-gerilimi,15191 (Letzter Zugriff: 04.08.2018)

AKSAY, Hasan (2009): Harp Akademileri Komutani Orgeneral Hasan Aksay'in Açiliş Konuşmasi [Eröffnungsrede von General und Kommandeur der Militärakademien Hasan Aksay]. In: Stratejik Arastirmalar Enstitüsü (Hrsg.): Enerji Güvenliğine Ortak Çözüm Arayışları: Uluslararası Sempozyum, 28-29 Nisan 2009. Ceviren Ve Yayına Hazırlayan: Dr.Öğ.Alb. Semih Sert Ve Ing.Müt. Dilek Çetinkaya, Istanbul: Türkiye Cumhuriyeti, Genelkurmay Başkanlığı, Harp Akademileri Komutanlığı, Stratejik Araştırmalar Enstitüsü, S.5-14.

AKTÜRK, Şener (2006): Turkish-Russian Relations after the Cold War (1992-2002). In: Turkish Studies, Vol. 7, No. 3, September 2006, S. 337-364. 
ALEXANDROVA, Olga (1995): Rußland und sein 'nahes Ausland': Integrationsvorstellungen und Ansätze der russischen Integrationspolitik (Berichte / BIOst, 20-1994). Köln: Bundesinstitut für ostwissenschaftliche und internationale Studien.

https://www.ssoar.info/ssoar/bitstream/handle/document/4179/ssoar-1995-alexandrovaruland und sein nahes ausland.pdf?sequence=1 (Letzter Zugriff: 29.01.2014)

ALTAN, Ahmet (2011a): Tarih ve Yalanlar [Geschichte und Lügen]. In: T24, 25.11.2011, http://t24.com.tr/haber/ataturk-diktatorluk-kurdu,183706 (Letzter Zugriff: 09.07.2015)

ALTAN, Ahmet (2011b): Atatürk bir Diktatördü! [Atatürk war ein Diktator!]. In: Analiz Merkezi, 20.09.2011, 18:16, http://www.analizmerkezi.com/ahmet-altan-ataturk-bir-diktatordu-25383h.htm (Letzter Zugriff: 09.07.2015)

ANDICAN, A. Ahat (2003): Cedidizm'den Bağımsızlığa Hariçte Türkistan Mücadelesi [Kampf für Türkistan vom Dschedidismus ohne Unabhängigkeit]. İstanbul: Emre Yayınları.

ANDICAN, A. Ahat (2009): Osmanli' dan günümüze Türkiye ve Orta Asya [Türkei und Zentralasien vom osmanischen Reich bis heute]. Istanbul: Dogan Kitap.

ARAS, Bülent (2009a) Turkey And The Russian Federation: An Emerging Multidimensional Partnership. August 2009, Brief No: 35, In: SETA, Policy Brief, letzter Zugriff: 1. April 2010, http://arsiv.setav.org/Ups/dosya/7776.pdf (Letzter Zugriff: 01.08.2010)

ARAS, Bülent (2009b): Türkiye ve Rusya Federasyonu: Cok boyutlu Ortaklik [Die Türkei und Russische Föderation: Multidimensionale Kooperation]. In: SETA-Analiz, SETA (Siyaset, Ekonomi ve Toplum Arastirmalari Vakfi), http://www.setav.org/ups/dosya/6743.pdf (Letzter Zugriff: 04.04.2010)

ARIPOV, Eldor (2018): Die neue Außenpolitik Usbekistans: Offen, proaktiv und pragmatisch. In: Botschaft der Republik Usbekistan in der Bundesrepublik Deutschland. 23.02.2018, aus dem Russischen von Brigitte Heuer, https:/www.uzbekistan.de/de/nachrichten/nachrichten-aktuell/dieneue-au\% $\% 3 \%$ Fenpolitik-usbekistans-offen-proaktiv-und-pragmatisch (Letzter Zugriff: $22.09 .2018)$

ARMAGAN, Mustafa (2015): Tarihi Gercekler [Historische Fakten]. Pergel, in: Cicek, Nevzat (2015): Tarihi Gercekler. Pergel, in: Ülke, 23 Ocak 2013, veröffentlicht am 24.1.2015, https://www.youtube.com/watch?v=NU4B5eGCiy0 （Letzter Zugriff: 09.07.2015)

ARYKBAJEW, Eldijar/TOKTOGULOWA, Sajkal (2017): Wer fördert Öl in Kirgistan? In: Novastan.org, 03.02.2017, aus dem Russischen übersetzt von Florian Coppenrath, https://www.novastan.org/de/kirgistan/wer-fordert-ol-in-kirgistan/ (Letzter Zugriff: 14.06.2017)

ASKER, Ali (2009): Bir kurumsallasma örnegi: Türk (Dili Konusan) Ülkeler Parlamenter Asamblesi [Ein Beispiel für Institutionalisierung: Parlamentarische Versammlung der türksprachigen Länder]. In: 21. Yüzyil Türkiye Enstitüsü, 03 Ekim 2009, Cumartesi, http://www.21yyte.org/tr/arastirma/orta-asya-arastirmalari-merkezi/2009/10/03/3034/birkurumsallasma-ornegi-turk-dili-konusan-ulkeler-parlamenter-asamblesi (Letzter Zugriff: 10.05.2011) 
ATMACA, Nurettin (2006): Kazakistan resmen BTC'ye bağlandı [Kasachstan schloss sich offiziell der BTC an]. In: Hürriyet, BAKÜ, (DHA), Haber Giriş: 16.06.2006 - 15:07, Son Güncelleme: 16.06.2006 - 15:45, https://www.hurriyet.com.tr/ekonomi/kazakistan-resmen-btc-ye-baglandi4594769 (Letzter Zugriff: 14.06.2017)

AUCH, Eva-Maria (2010): Berg-Karabach - Krieg um den „Schwarzen Garten“. In: Gumppenberg, Marie-Carin von/Steinbach, Udo (Hg.): Der Kaukasus. Geschichte- Kultur-Politik. 2., neubearbeitete Auflage, München: CH. Beck, S.113-124.

AUSSENMINISTERIUM DER RUSSISCHEN FÖDERATION (2000): Konzeption der Nationalen Sicherheit der Russischen Föderation. 10. Januar 2000, 16:11, Bestätigt durch den Erlass des Präsidenten der Russischen Föderation Nr. 24 vom 10. Januar, http://www.mid.ru/de/foreign policy/official documents//asset publisher/CptICkB6BZ29/content/id/589768 (Letzter Zugriff: 14.06.2017)

AUSWÄRTIGES AMT (2010): Der Konflikt um Nagorny-Karabach: In: Auswärtiges Amt, http://www.auswaertigesamt.de/diplo/de/Laenderinformationen/Armenien/ArmenienLinks/080306 KarabachKonflikt,navCtx=25922.html (Letzter Zugriff: 29.05.2011)

AUSWÄRTIGES AMT (2015a): Tadschikistan: Wirtschaft. März 2015, http://www.auswaertigesamt.de/DE/Aussenpolitik/Laender/Laenderinfos/Tadschikistan/Wirtschaft_node.htm (Letzter Zugriff: 14.02.2016)

AUSWÄRTIGES AMT (2015b): OSZE, Stand: 15.01.2015, http://www.auswaertigesamt.de/DE/Aussenpolitik/Friedenspolitik/OSZE/Uebersicht node.html (Letzter Zugriff: 17.03.2018)

AUSWÄRTIGES AMT (2015c): Kasachstan. Stand: März 2015, http://www.auswaertigesamt.de/DE/Aussenpolitik/Laender/Laenderinfos/01-

Nodes_Uebersichtsseiten/Kasachstan_node.html (Letzter Zugriff: 14.02.2016)

AUSWÄRTIGES AMT (2015d): Regionale Zusammenarbeit in Asien und Pazifik, Stand 07.07.2015, http://www.auswaertigesamt.de/DE/Aussenpolitik/RegionaleSchwerpunkte/Asien/Regionalorganisationen-Text node.html (Letzter Zugriff: 17.02.2016)

AUSWÄRTIGES AMT (2016): China: Außenpolitik. Stand: März 2016, http://www.auswaertigesamt.de/DE/Aussenpolitik/Laender/Laenderinfos/China/Aussenpolitik nod e.html (Letzter Zugriff: 19.09.2018)

AUSWÄRTIGES AMT (2017): Usbekistan. Stand: März 2017, http://www.auswaertigesamt.de/DE/Aussenpolitik/Laender/Laenderinfos/01-

Nodes_Uebersichtsseiten/Usbekistan_node.html (Letzter Zugriff: 19.09.2018)

AUSWÄRTIGES AMT (2018a): Kasachstan., https://www.auswaertigesamt.de/de/aussenpolitik/laender/kasachstan-node/kasachstan/206340 (Letzter Zugriff: 03.09.2019) 
AUSWÄRTIGES AMT (2018b): Kirgisistan. Stand: März 2018, https://www.auswaertigesamt.de/de/aussenpolitik/laender/kirgisistan-node/kirgisistan/206736 (Letzter Zugriff: 03.09.2019)

AUSWÄRTIGES AMT (2018c): Usbekistan. Stand: März 2018, https://www.auswaertigesamt.de/de/aussenpolitik/laender/usbekistan-node/usbekistan/206788 (Letzter Zugriff: 03.09.2019)

AUSWÄRTIGES AMT (2018d): Turkmenistan. Stand: März 2018, https://www.auswaertigesamt.de/de/aussenpolitik/laender/turkmenistan-node/turkmenistan/206772 (Letzter Zugriff: 03.09.2019)

AUSWÄRTIGES AMT (2018e): Tadschikistan. Stand: März 2018, https://www.auswaertigesamt.de/de/aussenpolitik/laender/tadschikistan-node/tadschikistan/206754 (Letzter Zugriff: 03.09.2019)

AUSWÄRTIGES AMT (2018f): Wirtschaft. März 2018, https://www.auswaertigesamt.de/de/aussenpolitik/laender/turkmenistan-node/-/206776 (Letzter Zugriff: 23.12.2019)

AUSWÄRTIGES AMT (2018g): OSZE. Letzter Zugriff: 03. September 2018, https://www.auswaertiges-amt.de/de/aussenpolitik/internationale-organisationen/osze (Letzter Zugriff: 11.11.2019)

AUSWÄRTIGES AMT (2018h): Russische Föderation, Außenpolitik. Stand: Mai 2018, https://www.auswaertiges-amt.de/de/aussenpolitik/laender/russischefoederation-node/-/201708 (Letzter Zugriff: 03.09.2019)

AUSWÄRTIGES AMT (2020): Tadschikistan: Reise- und Sicherheitshinweise. Stand 18.08.2020, (Unverändert gültig seit: 24.06.2020), https://www.auswaertigesamt.de/de/aussenpolitik/laender/tadschikistan-node/tadschikistansicherheit/206756 (Letzter Zugriff: 23.07.2020)

AYATA, Ali/YÜCEL, Gökberk (2013): Türk Dış Politikasında Değişim [Wandel in der türkischen Außenpolitik]. In: TURAN, Yıldırım/YALÇINKAYA, Alâeddin/EFEGIL, Ertan (Hrsg.): Siyaset, Ekonomi Ve Toplum Üzerine 3. Uluslararasi Mavi Karadeniz Kongresi: Uyuşmazlik Çözümü, İşbirliği Ve Demokratikleşme. Istanbul: Gündogan Yayinlari, S. 75-85.

AYNURAL, Salih/KESICI, Kayyum (2005): Bati Türkistan Cumhuriyetleri Birliği’nin Gerekliliği [Die Notwendigkeit der Union des Westturkistans]. In: Sosyal Siyaset Konferansları Dergisi, Sayi: 50, Prof. Dr. Nevzat Yalçintaş'a Armağan Özel Sayisi, S. 1211-1230.

AZERNEWS (2018): Caspian Pipeline Consortium increases export of oil. 5 March 2018, 17:40 (UTC+04:00), https://www.azernews.az/oil and gas/128298.html (Letzter Zugriff: 27.10.2019)

BABEROWSKI, Jörg (2009): Afghanistan als Objekt britischer und russischer Fremdherrschaft im 19. Jahrhundert. In: CHIARI, Ferdinand (Hrsg.): Afghanistan. 3., durchges. und erw. Aufl., Paderborn, München, Wien: Ferdinand Schöningh, (Im Auftrag des Militärgeschichtlichen Forschungsamtes), S. 26-35. 
BAG, Mustafa (2019): Cumhurbaşkanı Erdoğan'ın 'Uygurlar mutlu' ifadesinin çeviri hatası olduğu iddias1 [Behauptung, dass der Satz vom Präsidenten Erdogan "Uiguren seien glücklich" ein Übersetzungsfehler sei]. In: euronews, Son güncelleme: 24/07/2019, https://tr.euronews.com/2019/07/24/cumhurbaskani-erdoganin-uygurlar-mutlu-ifadesinin-cevirihatasi-oldugu-iddiasi (Letzter Zugriff: 25.11.2019)

BAHADIROGLU, Yavuz (2015): Tarihi Gercekler [Historische Fakten]. Pergel, in: Cicek, Nevzat (2015): Tarihi Gercekler. Pergel, in: Ülke, 23 Ocak 2013, veröffentlicht am 24.1.2015, https://www.youtube.com/watch?v=NU4B5eGCiy0 （Letzter Zugriff: 09.07.2015)

BAKILER, Yavuz Bülent (2014): Atatürk Dönemi Tarih Ders Kitab1 [Geschichtsbuch in der Atatürk-Ära]. In: HaberTürk, Öteki Gündem, https://www.youtube.com/watch?v=HEotxuJiW U (Letzter Zugriff: 25.09.2015)

BALCI, Ali (2011): 1990'lar Basınında „Ermenistan Tehdidi'nin“ İnşası [Entwicklung der „Armenischen Bedrohung“ in der Presse der 1990er Jahre]: Milliyet Gazetesi Örneği. https://dergipark.org.tr/en/download/article-file/17784 (Letzter Zugriff: 11.08.2015)

BALCI, Bayram (2014): The Gülen Movement and Türkisch Soft Power. In: Carnegie Endowment for International Peace. 04. February 2014, http://carnegieendowment.org/2014/02/04/g-lenmovement-and-turkish-soft-power-pub-54430 ～(Letzter Zugriff: 09.07.2015)

BALLIN, Andre (2017): Russlands Türken sind Tadschiken. In: Handelsblatt, 28.08.2017, 14:33 Uhr, http://www.handelsblatt.com/politik/international/weltgeschichten/ballin/gastarbeiterrusslands-tuerken-sind-tadschiken/20245624.html (Letzter Zugriff: 04.04.2018)

BARDAKCI, Murat (2014): Bu bayrak maalesef bir tasarım şaheseridir [Diese Flagge ist leider ein Meisterwerk des Designs]. In: Habertürk, 18.06.2014 - 09:59 Güncelleme: 18.06.2014 - 10:44, https://www.haberturk.com/yazarlar/murat-bardakci/959177-bu-bayrak-maalesef-bir-tasarim$\underline{\text { saheseridir }}$ (Letzter Zugriff: 09.07.2017)

BASARAN, Ali (2013): Diş Siyasi, İktisadi İlişsiler Etkileşimi Çerçevesinde Yeltsin Dönemi Rusya-Türkiye İlişkileri [Russisch-Türkische Beziehungen in der Jelzin-Ära bezüglich ihrer außenpolitischen und wirtschaftlichen Interaktionen]. Ankara Üniversitesi, Diss., Ankara 2013.

BASKENT ÜNIVERSITESI (o. J.): Montreux Boğazlar Sözleşmesi (1936): 20 Temmuz 1936 [Montreux-Meerengen-Abkommen (1936)], http://sam.baskent.edu.tr/belge/Montro_TR.pdf (Letzter Zugriff: 01.03.2018)

BASSIN, Mark (2011): „Klasik“ ve „Yeni“ Avrasyac1lı: Geçmişten Gelen Devamlılık ["Klassischer "und" Neuer " Eurasismus: Kontinuität aus der Vergangenheit]. In: Bilge Strateji, Cilt 3, Say1 4, Bahar 2011, Cev.: Özgür Tüfekci, S. 123-142.

BAUMANN, Rainer (2007): Deutschland als Europas Zentralmacht. In: SCHMIDT, Siegmar/HELLMANN, Gunther/WOLF, Reinhard (Hrgs.): Handbuch zur deutschen Außenpolitik. Wiesbaden: VS Verlag für Sozialwissenschaften, S. 62-72. 
BAUMANN, Rainer/RITTBERGER, Volker/WAGNER, Wolfgang (1999): Macht und Machtpolitik. Neorealistische Außenpolitiktheorie und Prognosen über die deutsche Außenpolitik nach der Vereinigung, in: Zeitschrift für Internationale Beziehungen, 2/1999, 6. Jahrgang, Heft 2, Dezember 1999, S. 245-286.

BAYSAL, Ugur (2009): Atatürk'ün Avrasya Politikasi'nda Mazlum Milletlerin Yeri [die unterdrückten Nationen in der eurasischen Politik Atatürks]. Yüksek Lisans Tezi, Istanbul: Istanbul Üniversitesi, Atatürk Ilkeleri ve Inkilap Tarihi Enstitüsü, Atatürk Ilkeleri ve Inkilap Tarihi Anabilim Dali.

http://acikerisim.istanbul.edu.tr/bitstream/handle/123456789/792/45267.pdf? sequence=1\&isAllow ed=y $\quad$ (Letzter Zugriff: 08.09.2013)

BELGE, Murat (2011): Militarist Modernlesme [Militärische Modernisierung]. Almanya, Japonya ve Türkiye. Istanbul: Iletisim.

BELLERS, Jürgen (о. J.): Methoden zur Analyse internationaler Beziehungen. In: http://www.jbellers.de/bellers/images/dokumente/methoden.pdf (Letzter Zugriff: 11.05.2015)

BIDDER, Benjamin (2016): Russisch-türkische: Wirtschaftsbeziehungen Zwei Autokraten, ein Ziel. In: Spiegel Online, 08.08.2016, 18:38, http://www.spiegel.de/wirtschaft/wladimir-putin-undrecep-tayyip-erdogan-zwei-autokraten-ein-ziel-a-1106661.html (Letzter Zugriff: 07.10.2016)

BIERMANN, Werner/KLÖNNE, Arno (2003): The Big Stick. Imperiale Strategie und globaler Militarismus - Die USA als Megamacht? Köln: PapyRossa Verlags (Neue Kleine Bibliothek 85). http://gcc.unipaderborn.de/www/wi/wi2/wi2 lit.nsf/0/d80760c37c49e61ac1256cd700688654/\$FILE/WB-BigStick-pW3sv.pdf (Letzter Zugriff: 24.05.2015)

BILA, Fikret (2008): Erdoğan: Rusya'yı göz ardı edemeyiz [Erdogan: wir können Russland nicht ignorieren]. In: Milliyet, 02.09.2008, 01:13, http://www.milliyet.com.tr/-/fikretbila/siyaset/siyasetyazardetay/02.09.2008/985699/default.htm (Letzter Zugriff: 02.10.2008)

BILGIC, M. Sadi (2016): Rus Jeopolitiği: Avrasyacı Yaklaşım ve Türkiye'ye Etkileri [Russische Geopolitik: eurasischer Ansatz und seine Auswirkungen auf die Türkei]. In: BILGESAM Analiz, Rusya, No: 1317, 4 Mayis 2016, letzter Zugriff: 25. August 2018, http://www.bilgesam.org/Images/Dokumanlar/0-167-20160504561317.pdf ((Letzter Zugriff: 11.03.2017)

BILGIN, Ayhan (2011): Das Militär in der politischen Kultur der Türkei. Vom Osmanischen Reich bis heute, Diss., Gottfried Wilhelm Leibniz Universität Hannover, http://edok01.tib.unihannover.de/edoks/e01dh12/685358429.pdf (Letzter Zugriff: 13.02.2014)

BIMBOES, Detlef (2000): Konfliktregion Kaspisches Meer. Kaukasus und Mittelasien - zwischen Erdöl, Krieg und Kriesen. In: LUEDTKE, Ralph-M./STRUTYNSKI, Peter (Hg.): Nach dem Jahrhundert der Kriege. Alternativen der Friedensbewegung. Kassel: Jenior, S. 182-207 (Kasseler Schriften zur Friedenspolitik Bd. 5). 
BLOGSPOT (о. J.): The Caucasus and Central Asia. http://karteasien.blogspot.com/search/label/Zentralasien （Letzter Zugriff: 09.07.2012)

BOGATUROV, Aleksey (2010): Türkiye, Rusya'nın yeni stratejik ortağ1 [Die Türkei ist Russlands neuer strategischer Partner]. In: Zaman, 10 Mayıs 2010, Pazartesi 11:55, http://www.zaman.com.tr/dunya turkiye-rusyanin-yeni-stratejik-ortagi 982396.html (Letzter Zugriff: 15.02.2014)

BORCHERT, Thomas (2018): Russisch-chinesische Provokation im Baltikum. 26.07.2017, 06:53 Uhr, http://www.fr.de/politik/militaermanoever-russisch-chinesische-provokation-im-baltikum-a$\underline{1320086}$ (Letzter Zugriff: 21.10.2018)

BOZDAG, Ismet (1998): Atatürk'ün Avrasya Devleti [Atatürks eurasischer Staat]. Istanbul: Tekin Yayınları.

BRAUNS, Nick (2016): Erdogan baut Privatarmee auf. In: Junge Welt, Ausgabe vom 16.07.2016, Seite 6, Ausland, https://www.jungewelt.de/2016/07-16/028.php?sstr= (Letzter Zugriff: 17.09.2016)

BRÜGGMANN, Mathias (1996): Weitsicht regiert den nördlichsten Vorposten des Islam. In: Welt, Veröffentlicht am 11.01.1996, https://www.welt.de/print-welt/article651953/Weitsicht-regiert-dennoerdlichsten-Vorposten-des-Islam.html (Letzter Zugriff: 08.06.2013)

BRUNO, Greg (2008): Turkey's Top Foreign Policy Aide Worries about False Optimism in Iraq. In: Council on Foreign Relation. 19. September 2008, http://www.cfr.org/turkey/turkeys-topforeign-policy-aide-worries-false-optimism-iraq/p17291 (Letzter Zugriff: 19.11.2013)

BRZEZINSKI, Zbigniew (2000): Living with Russia. In: National Interest, Fall 2000, Essay, http://nationalinterest.org/print/article/living-with-russia-919 (Letzter Zugriff: 02.05.2015)

BRZEZINSKI, Zbigniew (2001): Die Einzige Weltmacht. Amerikas Strategie der Vorherrschaft, aus dem Amerikanischen von Angelika Beck, mit einem Vorwort von Hans- Dietrich Genscher, 4. Auflage: Oktober 2001, Die amerikanische Originalausgabe erschien 1997 unter dem Titel 'The Grand Chessboard. American Primary and Its Geostrategic Imperatives" bei Basic Books, New York, 1. deutsche Aufl. Mai 1997, Frankfurt am Main: Fischer Taschenbuch Verlag Mai 1999.

BUNDESAMT FÜR VERFASSUNGSSCHUTZ (о. J.): Was ist Islamismus? https://www.verfassungsschutz.de/de/arbeitsfelder/af-islamismus-und-islamistischerterrorismus/was-ist-islamismus (Letzter Zugriff: 21.05.2017)

BUNDESANSTALT FÜR GEOWISSENSCHAFTEN UND ROHSTOFFE (BGR) (2009): Energierohstoffe 2009. Reserven, Ressourcen, Verfügbarkeit. Erdöl, Erdgas, Kohle, Kernbrennstoffe, Geothermische Energie, Stand 10.11.2009, https:/www.bgr.bund.de/DE/Themen/Energie/Downloads/Energierohstoffe_2009_gesamt.pdf;jsess ionid $=622627 \mathrm{CC} 1 \mathrm{C} 97 \mathrm{AF} 60 \mathrm{BAC} 2 \mathrm{E} 1792 \mathrm{D} 8 \mathrm{D} 73 \mathrm{BD} .1$ cid292? blob=publicationFile $\& \mathrm{v}=2$

(Letzter Zugriff: 19.04.2016) 
BUNDESANSTALT FÜR GEOWISSENSCHAFTEN UND ROHSTOFFE (BGR) (2014):

Energiestudie 2014: Reserven, Ressourcen und Verfügbarkeit von Energierohstoffen. Hannover, Dezember 2015,

http://www.bgr.bund.de/DE/Themen/Energie/Downloads/Energiestudie 2014.pdf;jsessionid=EE9 C988ABE0B81A57DD82F01E956D6EF.1 cid321? blob=publicationFile\&v=7 (Letzter

Zugriff: 19.04.2016)

BUNDESANSTALT FÜR GEOWISSENSCHAFTEN UND ROHSTOFFE (BGR) (2015):

Energiestudie 2015: Reserven, Ressourcen und Verfügbarkeit von Energierohstoffen. Hannover, Dezember 2015,

http://www.bgr.bund.de/DE/Themen/Energie/Downloads/Energiestudie_2015.pdf?_ blob=publicat ionFile\&v=2 (Letzter Zugriff: 19.04.2016)

BUNDESMINISTERIUM DER VERTEIDIGUNG (o. J.): OSZE., https://www.bmvg.de/de/themen/verteidigung/multinationale-zusammenarbeit/osze (Letzter Zugriff: 04. September 2018)

BUNDESNACHRICHTENDIENST (o: J.): Islamische Bewegung Usbekistans.

http://www.bnd.bund.de/DE/Themen/Lagebeitraege/IslamistischerTerrorismus/Unterpunkte/Islami scheBewegungUsbekistan node.html (Letzter Zugriff: 21.05.2017)

BUNDESREGIERUNG (2010): Gipfelerklärung von Lissabon. Herausgegeben von den Staatsund Regierungschefs, die an der Tagung des Nordatlantikrats in Lissabon teilgenommen haben, 1.12.2010, https://www.bundesregierung.de/ContentArchiv/DE/Archiv17/ Anlagen/2010/2010-1130-gipfelerklaerung-von-lissabon.pdf? blob=publicationFile\&v=1 (Letzter Zugriff: 4.

September 2018)

BUNDESREGIERUNG (2015): Deutschland in der OSZE.

https://www.bundesregierung.de/Content/DE/StatischeSeiten/Breg/Sicherheitspolitik/Artikel/201509-10-osze-grundsatzartikel.html (Letzter Zugriff: 05. September 2018)

BUNDESREGIERUNG (O. J.): NATO: Fragen und Antworten.

https://www.bundesregierung.de/breg-de/themen/sicherheit-und-verteidigung/fragen-undantworten-206618 (Letzter Zugriff: 22.11.2018)

BUNDESWEHR (2015): Termez: Ehemaliges „Tor nach Afghanistan“ geschlossen. Termez, 21.12.2015, http://www.einsatz.bundeswehr.de/portal/a/einsatzbw/start/aktuelle einsaetze/!ut/p/z1/hVDdT4Mw EP9reO0VNgR8K0OXGTKJTDf6YjpaSxVb0nVojH-8JYs-

GBfv4ZK738d9AIUdUM1GJZITRrPe1w29eMzTclNGWRQVm3uCV1cxvq0XxWyJE3iA7X8U6 mF8JgiGmgtovEdy1mMZQg0UKBeoNVq4KTuhnfJZWuaMRYOxrp-

Qo7UeQYpDg8MiD5P596jwk8QZqao0S4pVfjcZPrORvf9oWTsdDU3HNO9FZVpyatwAlb3Zn75 B9H6WSqBWPAkrLDpa3-6cGw6XAQ6wX FNvahBcMWQsTLAf4k6c3Cw82F4fU6Xa j8aMU2y_S1S1b/dz/d5/L2dBISEvZ0FBIS9nQSEh/\#Z7 B8LTL2922DTUA0IE50OS CD3GG1 (Letzter Zugriff: 14.06.2017)

BUNDESZENTRALE FÜR POLITISCHE BILDUNG (o. J.): Statistiken: Russische Erdgasexporte: Umfang, Pipelines, Abnehmerländer. 
http://www.bpb.de/internationales/europa/russland/214483/statistiken-russische-erdgasexporteumfang-pipelines-abnehmerlaender (Letzter Zugriff: 23.08.2018)

BURSALI, Orhan (2016): RTE/AKP ittifaksiz ayakta duramaz [RTE/AKP kann ohne Kooperation und. Unterstützung nicht weiter bestehen]. In: Cumhuriyet, 22 Ağustos 2016, Pazartesi, http://www.cumhuriyet.com.tr/koseyazisi/588418/Tarihin en buyuk yalani_Bilmiyorduk .html\# (Letzter Zugriff: 15.02.2018)

BÜYÜKAKINCI, Erhan (2012): Türk-Rus İlişkilerinin Değerlendirilmesi: Güvenlik Sorunsalından Çok Boyutlu Derinliğe Geçiş [Bewertung der türkisch-russischen Beziehungen: Übergang von Sicherheitsproblemen in mehrdimensionale Tiefe]. In: http://www.erhanbuyukakinci.com/dosya/Turk-Rus-iliskilerinin-Degerlendirilmesi.pdf (Letzter Zugriff: 17.07.2015)

ÇAKIR, Esma (2009): Erdoğan: Sincan olayları adeta soykırım [Erdoğan: Die Vorfälle in Xinjiang sind Völkermord]. In: Milliyet, 10.07.2009 - 18:41, Son Güncellenme: 10.07.2009 - 18:41, L'AQUILA, (DHA), https://www.milliyet.com.tr/siyaset/erdogan-sincan-olaylari-adeta-soykirim$\underline{1116290}$ (Letzter Zugriff: 14.06.2018)

CAKIR, Rusen (2013): Gülen cemaati sürecin neresinde? [Wo befindet sich die Gülen-Bewegung im Prozess?] In: Rusen Cakir, erschienen in Vatan am 09.05.2013, http://www.rusencakir.com/Gulen-cemaati-surecin-neresinde/2010 (Letzter Zugriff: 26.12.2019)

CAKIR, Rusen (2016a): „Gülen cemaatini CIA mi kurdu?“ [Hat die CIA die Gülen-Gemeinde gegründet?]. In: Medyascope.tv, 13. Agustos 2016, http://medyascope.tv/2016/08/13/gulencemaatini-cia-mi-kurdu/ (Letzter Zugriff: 01.10.2019)

CAKIR, Rusen (2016b): Fethullah Gülen Nurcu mu? [Ist Fethullah Gülen ein Nurcu?] In: Medyascope.tv, 13. Agustos 2016, letzter Zugriff: 01.10.2019, http://medyascope.tv/2016/08/13/fethullah-gulen-nurcu-mu/ （Letzter Zugriff: 26.12.2019)

CAMAN, Efe (2013): Üçüncü On Yılında Türkiye'nin Orta Asya Bölgesel Politikası. Sübjektif Algılardan Gerçeklere [Die Zentralasienpolitik der Türkei im dritten Jahrzehnt nach dem Kalten Krieg. Von subjektiven Wahrnehmungen zur Realität]. In: academia.edu, S. 175-223, https://www.academia.edu/3309278/\%C3\%9C \%C3\%A7\%C3\%BCnc\%C3\%BC_On_Y\%C4\%B11 $\% \mathrm{C} 4 \% \mathrm{~B} 1 \mathrm{nda} \mathrm{T} \% \mathrm{C} 3 \% \mathrm{BCrkiyenin}$ Orta Asya B\%C3\%B6lgesel Politikas $\% \mathrm{C} 4 \% \mathrm{~B} 1 . \mathrm{S} \% \mathrm{C} 3 \% \mathrm{BC}$ bjektif_Alg\%C4\%B1lardan_Ger\%C3\%A7eklere in Demirtepe Turgut and G\%C3\%BCner $\% \mathrm{C} 3$ $\% 96 z k a n \_$Ed. Uluslararas $\% \mathrm{C} 4 \% \mathrm{~B} 1$ Sistemde_Orta_Asya. D $\% \mathrm{C} 4 \% \mathrm{~B} 1 \% \mathrm{C} 5 \% 9 \mathrm{~F}$ Politika ve_G $\% \mathrm{C} 3 \% \mathrm{BC}$ enlik USAK Yay $\% \mathrm{C} 4 \% \mathrm{~B} 1$ nlar\% $\mathrm{C} 4 \% \mathrm{~B} 1$ Ankara 2013 (Letzter Zugriff: 26.12.2019)

CAMAN, Efe/DAGCI, Kenan (2013): Rusya Federasyonu'nun Sovyet Ardili Bölgeleri Algilayişi: Avrasyacilik Stratejisi ve Rus Diş Politikasi [Die Wahrnehmung der postsowjetischen Gebiete durch die Russische Förderation: Eurasisenstrategie und russische Außenpolitik]. In: TURAN, Yıldırım/YALÇINKAYA, Alâeddin/EFEGIL, Ertan (Hrsg.): Siyaset, Ekonomi Ve Toplum Üzerine 3. Uluslararasi Mavi Karadeniz Kongresi: Uyuşmazlik Çözümü, İşbirliği Ve Demokratikleşme, Gündoğan Yayınları: Istanbul, S. 63-73. 
CAMAN, M. Efe (2005): Türkische Außenpolitik nach dem Ende des Ost-West-Konflikts. Außenpolitische Kontinuität und Neuorientierungen zwischen der EU-Integration und neuer Regionalpolitik, Diss., Universität Augsburg. Vorgelegt in 2004, Datum der Freischaltung in OPUS: 22.07.2005, https://opus.bibliothek.uniaugsburg.de/opus4/frontdoor/deliver/index/docId/72/file/Dissertation Efe CAMAN.pdf (Letzter Zugriff: 06.06.2011)

CAMAN, Mehmet Efe (2019): Türkler, Uygurlar ve Türkîler: kimlik inşası üzerine bir deneme [Türken, Uighuren und Turkvölker: Ein Essay über die Identitätsbildung]. In: Tr 724, 18 Kasım 2019, https://www.tr724.com/turkler-uygurlar-ve-turkiler-kimlik-insasi-uzerine-bir-deneme/ (Letzter Zugriff: 19.11.2019)

CANTÜRK, Safura (2015): Gülen`in Dünyadaki Okullari Birer Birer Kapatiliyor [Gülens Schulen auf der ganzen Welt werden eine nach der anderen geschlossen]. In: Sabah, Giriş Tarihi: 20.5.2015, http://www.sabah.com.tr/gundem/2015/05/20/gulenin-dunyadaki-okullari-birer-birer-kapatiliyor (Letzter Zugriff: 27.01.2016)

CARLEY, Patricia M. (1995): Turkey and Central Asia. Reality Comes Calling, In: In: RUBINSTEIN, Alvin Z./SMOLANSKY, Oles M. (Hrsg.): Regional Power Rivalries in the New Eurasia. Russia, Turkey, and Iran, Armonk, New York, London: M. E. Sharpe, S. 169-197.

CARRÈRE D`ENCAUSE, Hélène (1988 [1966]): Islam and the Russian Empire: Reform and Revolution in Central Asia. Preface by Maxime Rodinson, translated by Quintin Hoare, London: Tauris, 1988.

CASPIAN PIPELINE CONSORTIUM (O. J. a): General Information. http://www.cpc.ru/EN/about/Pages/general.aspx （Letzter Zugriff: 26.12.2019)

CASPIAN PIPELINE CONSORTIUM (O. J. b): Shareholders. http://www.cpc.ru/EN/about/Pages/shareholders.aspx （Letzter Zugriff: 26.12.2019)

CEMAL, Hasan (2012): Atatürk diktatör değilse nedir? Demokrasinin yolu, ,tutsak akıl'ları özgürleştirmekten geçer! [Was, wenn Atatürk kein Diktator ist?.Der Weg der Demokratie ist es, ,die gefangenen Köpfe‘ zu befreien!]. In: Milliyet, 12.04.2012, 02:30, http://www.milliyet.com.tr/ataturk-diktator-degilse-nedir/siyaset/siyasetyazardetay/12.04.2012/1527128/default.htm （Letzter Zugriff: 21.03.2014)

CENTRUM FÜR DIE ANGEWANDTE POLITIKFORSCHUNG AN DER LMU MÜNCHEN (2007): Türkei in die EU? Themendossier. Stand: Dezember 2007, http://www.caplmu.de/themen/tuerkei/aussenpolitik/russland.php (Letzter Zugriff: 12.04.2012)

CICA (2015): Conference on Interaction and Confidence Building Measures in Asia (CICA) Türkish Chairmanship. http://www.cicaistanbul.org/about.en.mfa （Letzter Zugriff: 23.04.2017)

CICA (2017): About CICA. Stand: 03. September 2018, http://www.scica.org/page.php?page id=7\&lang=1 (Letzter Zugriff: 03.09.2018) 
CLARKE, Michael (2016): Uyghur Militants in Syria: The Turkish Connection. In: Jamestown Foundation, Publication: Terrorism Monitor, Volume: 14, Issue: 3, February 4, 2016, 10:06 PM Age: 4 years, https://jamestown.org/program/uyghur-militants-in-syria-the-turkish-connection/ (Letzter Zugriff: 05.04.2018)

CLOVER, Charles (2012): Clinton vows to thwart new Soviet Union. In: Financial Times, December 7 2012, Moscow, https://www.ft.com/content/a5b15b14-3fcf-11e2-9f71-00144feabdc0 (Letzter Zugriff: 23.04.2017)

CNPC (o. J.): Central Asia - China Gas Pipeline operational.

http://www.cnpc.com.cn/en/FlowofnaturalgasfromCentralAsia/FlowofnaturalgasfromCentralAsia2. shtml (Letzter Zugriff: 28.12.2019)

COLLECTIVE SECURITY TREATY ORGANIZATION (2002): CHARTER OF THE COLLECTIVE SECURITY TREATY ORGANIZATION, 7. Oktober 2002, https://en.odkbcsto.org/documents/documents/ustav_organizatsii_dogovora_o_kollektivnoy_bezopasnosti_ (Letzter Zugriff: 13.06.2016)

COLLECTIVE SECURITY TREATY ORGANIZATION (2019): From the Treaty to the Organization. https://en.odkb-csto.org/25years/ (Letzter Zugriff: 08.05.2020)

COLLECTIVE SECURITY TREATY ORGANIZATION (o. J.): COLLECTIVE SECURITY TREATY. Dated May 15, 1992, as amended by the Protocol on amendments to the Collective Security Treaty of May 15, 1992, signed on December 10, 2010, https://en.odkbcsto.org/documents/documents/dogovor_o kollektivnoy bezopasnosti/ (Letzter Zugriff: 13.06.2016)

CONSULATE GENERAL OF THE UNITED STATES (2015): U.S. Consulate General Almaty. In: http://almaty.usconsulate.gov/history.html (Letzter Zugriff: 11.11.2016)

CORNELL, Svante E. (1999): Geopolitics and Strategic Alignments in the Caucasus and Central Asia. In: Perceptions, June - August 1999 Volume IV - Number 2, http://sam.gov.tr/wpcontent/uploads/2012/01/SVANTE-E.-CORNELL.pdf (Letzter Zugriff: 03.10.2012)

CRISS, Nur Bilge (2010): Komsularla Sifir Sorun cok güzel bir söylem, ancak gercekci degil [Das Null-Problem mit Nachbarn ist rhetorisch sehr schön, aber nicht realistisch]. In: ÖZDAL, Habibe/DINCER, Osman Bahadir/YEGIN, Mehmet (Hrsg.): Mülakatlarla Türk Dis Politikasi. Cilt 3, Ankara: USAK, S. 131-146.

CURTIN, Edward (2016): Review of Paul Craig Roberts' Book - The Neoconservative Threat To World Order: Washington's Perilous War For Hegemony. In: IPE (Institute for Political Economy), Paul Craig Roberts, Global Research, 28 February 2016, http://www.paulcraigroberts.org/2016/02/29/review-of-paul-craig-roberts-book-theneoconservative-threat-to-world-order-washingtons-perilous-war-for-hegemony/ (Letzter Zugriff: 16.07.2018)

CUTLER, Robert M. (2012): Erdogan, Orta Asya da Özal' in Izinde [Erdogan auf den Spuren von Özal in Zentralasien]. In: Timetürk, 31.05.2012, 11:53, 
http://www.timeturk.com/tr/2012/05/31/erdogan-orta-asya-da-ozal-in-izinde.html (Letzter

Zugriff: 18.06.2014)

DAVLETOV, Timur (2003): Etnisite Isiginda Rusya Federasyonu [Russische Föderation im Lichte der Ethnizität]. In: Stradigma.com, Aylik strateji ve analiz e-Dergisi, Augustos 2003, Sayi: 7, S.122, http://www.stradigma.com/turkce/agustos2003/08_2003 09.pdf (Letzter Zugriff: 04.04.2010)

DAVUTOGLU, Ahmet (1996): Cecen direnisi bir terör hareketi midir? [Ist der Cecen-Widerstand ein Terrorakt?]. In: Yeni Safak, 20 Ocak 1996, Cumartesi,

https://www.yenisafak.com/yazarlar/ahmetdavutoglu/cecen-direnii-bir-teror-hareketi-midir-

2027462 (Letzter Zugriff: 07.03.2013)

DAVUTOGLU, Ahmet (2011): Stratejik Derinlik. Türkiye`nin Uluslararasi Konumu [Strategische Tiefe. Die Internationale Lage der Türkei], 61. Aufl., 1. Aufl. 2001, Istanbul: Küre Yayinlari.

DAVUTOĞLU, Ahmet (2013): Turkic Republics Since Independence. Towards a Common Future, Center for Strategic Research (SAM), Vision Papers, Say1: 5.

DEMBINSKI, Matthias (2006): Die Transformation der NATO. Amerikanische Vorstellungen und Risiken für Europa, HSFK-Report 11/2006, Hessische Stiftung Friedens- und Konfliktforschung (HSFK), https://www.hsfk.de/fileadmin/HSFK/hsfk_downloads/report1106.pdf (Letzter Zugriff 30.07.2018)

DEMIR, Yusuf/ERDEM, Nuri Sefa (2002): Türkiye, Rusya ve İran'la ittifak arayışında olmalı [Türkei soll Bündnis mit Russland und Iran suchen]. In: Sabah, 08.03.2002, http://arsiv.sabah.com.tr/2002/03/08/p01.html (Letzter Zugriff: 15.11.2014)

DEUTSCHER BUNDESTAG (o. J.): Erklärung der Parlamentarischen Versammlung der NATO über die Transformation der NATO. Verabschiedet auf ihrer Plenartagung am 21. November 2002 in Istanbul, C:ITEMP\Istanbul02_Schlußplenarerklärung .doc.txt, https://www.bundestag.de/resource/blob/189206/c13576a00e2e26d0d160123060131cd9/erk1 istan -data.pdf (Letzter Zugriff: 12.06.2019)

DEUTSCHER BUNDESTAG (2016a): Die Militärdoktrinen der Sowjetunion und der Russischen Föderation seit den 1970er Jahren Bedrohungsszenarien und Sprache im Vergleich. Wissenschaftliche Dienste, Ausarbeitung, WD 2 - 3000 - 052/15. Abschluss der Arbeit: 26. März 2015, https://www.bundestag.de/blob/412840/2d4ad1e108ccf499692bad325c8c6d48/wd-2-052-15pdf-data.pdf (Letzter Zugriff: 29.07.2017)

DEUTSCHER BUNDESTAG (2016b): Entwicklung der russischen Sicherheitspolitik seit der Amtseinführung Wladimir Putins als Präsident der Russischen Föderation im Jahr 2000. Wissenschaftliche Dienste, Ausarbeitung, Aktenzeichen: WD 2-3000-078/14, Abschluss der Arbeit: 21. Mai 2014, Fachbereich: WD 2: Auswärtiges, Völkerrecht, wirtschaftliche Zusammenarbeit und Entwicklung, Verteidigung, Menschenrechte und humanitäre Hilfe, https://www.bundestag.de/resource/blob/414776/0bab96642a9626ff21 caa1fd344cd5b1/WD-2-07814-pdf-data.pdf (Letzter Zugriff: 09.05.2017) 
DEVLET, Nadir (2016): İslam Kerimov ve Orta Asya'daki değişimler: Prof. Nadir Devlet ile söyleşi [Islam Kerimov und Veränderungen in Zentralasien: Interview mit Prof. Nadir Devlet]. In: Medyascope.tv, Interwiew mit Burak Tatari und Gökçe Çiçek Kösedağ1, .1 Eylül 2016, http://medyascope.tv/2016/09/01/islam-kerimov-orta-asyadaki-degisimler-prof-nadir-devlet-ilesoylesi// (Letzter Zugriff: 21.05.2017)

DEVRISEVA, Halide (2007): ISGAL DÖNEMINDEN (18.YY.) GÜNÜMÜZE KADAR RUSLARIN KAZAKLARA KARSI YÜRÜTTÜGÜ POLiTiKALAR [Russische Politik gegenüber den Kasachen von 18. Jahrhundert bis jetzt]. Ankara: Universität Ankara, Fachbereich Geschichte, http://acikarsiv.ankara.edu.tr/browse/3523/ (Letzter Zugriff: 15.12.2013)

DIE BOTSCHAFT DER REPUBLIK USBEKISTAN IN DER BUNDESREPUBLIK DEUTSCHLAND (o. J.): Auf dem Weg zum weiteren Ausbau der strategischen Partnerschaft. UzA, http://www.uzbekistan.de/de/nachrichten/auf-dem-weg-zum-weiteren-ausbau-der$\underline{\text { strategischen-partnerschaft }}$ (Letzter Zugriff: 18.03.2019)

DITTMER, Diana (2014): Machtspiele am Ölmarkt: Komplott gegen Russland? In: ntv, wirtschaft, Dienstag, 25. November 2014, https:/www.n-tv.de/wirtschaft/USA-und-Riad-gegen-RusslandKalter-Krieg-am-Olmarkt-article14027741.html (Letzter Zugriff: 29.04.2015)

DOGAN, Zülfikar (2016): Turkey Pulse: First the Middle East, now Central Asia slipping away from Turkey. In: Al-Monitor, January 6, 2016, Read more: http://www.almonitor.com/pulse/originals/2016/01/turkey-losing-its-standing-in-central-asia-after-middleeast.html\#ixzz4wGsvKkti (Letzter Zugriff: 14.07.2016)

DOLL, Nikolaus (2016): Bahnverbindung Deutschland-China ist eine Erfolgsgeschichte. In: Welt, Veröffentlicht am 29.12.2016, https://www.welt.de/wirtschaft/article160672317/BahnverbindungDeutschland-China-ist-eine-Erfolgsgeschichte.html (Letzter Zugriff: 15.11.2017)

DOMÍNGUEZ, Gabriel (2014): Central Asia's intensifying water dispute. Interview mit Deirdre Tynan (International Crisis Group), In: DW, 12.09.2014, http://www.dw.de/central-asiasintensifying-water-dispute/a-17917965 (Letzter Zugriff: 23.02.2015)

DONNELLY, Alton S. (1975): Peter the Great and Central Asia. In: Canadian Slavonic Papers, vol. XVII, No.2\&3 (Summer and Fall 1975), S. 202-217.

DSCHAFAROW, Rauf (2009): Die Politik der Groß- und Regionalmächte im Südkaukasus und in Zentralasien. Frankfurt am Main: Lang.

DSS (DRESDENER STUDIENGEMEINSCHAFT SICHERHEITSPOLITIK E. V.) (Hrsg.) (1994): Grundlagen der Militärdoktrin der Russischen Föderation. DSS Arbeitspapiere, Heft 11.1 - 1994: Dresden, Quelle: Krasnaja zvezda, Moskva, 19.11.1993, Ins Deutsche übertragen von Harald Kießlich-Köcher und Erich Hocke, http://www.sicherheitspolitik-dss.de/ap/ap011100.pdf (Letzter Zugriff: 21.08.2017)

DÜGEN, Turgay (2013): Avrasya Birligi'nde Türkiye Olsun mu Olmasin mi? [Soll die Türkei der Eurasischen Wirtschaftsunion beitreten oder nicht?] In: 21. Yüzyil Türkiye Entstitüsü, 12. Kasim 2013, Sali, http://www.21yyte.org/tr/arastirma/orta-asya-arastirmalari- 
merkezi/2013/11/12/7293/avrasya-birliginde-turkiye-olsun-mu-olmasin-mi]_(Letzter Zugriff: 10.11.2015)

DUGIN, Aleksandr (2007): Moskova-Ankara Ekseni [Moskau-Ankara-Achse]. Avrasya Hareketi“nin Temel Görüsleri, Istanbul: Analiz Basim Yayin.

DÜNDAR, Can (2010): Eski Istanbul Mit bölge baskani Gündes fena bombaladi [Ehemaliger Istanbuler Mit-Regionalpräsident Gundes bombardierte stark mit Informationen]. In: Milliyet, 20.12.2010, 23:11, http://www.milliyet.com.tr/agca-yi-kaciracak-olan-subayin-adini-bildirdik/candundar/guncel/gundemyazardetay/21.12.2010/1328823/default.htm （Letzter Zugriff: 26.11.2018)

DUSANBE TICARET MÜSAVIRLIGI (2015): Tacikistan Ülke Raporu 2015. http://www.ekonomi.gov.tr/portal/content/conn/UCM/path/Contribution $\% 20$ Folders/web/D $\% \mathrm{C} 4 \%$ B1\%C5\%9F\%20\%C4\%B0li\%C5\%9Fkiler/\%C3\%9Clkeler/Tacikistan/Ticaret $\% 20$ Temsilcili\%C4 \%9Fimiz/M\%C3\%BC\%C5\%9Favirlik\%20Raporlar\%C4\%B1/TAC $\% \mathrm{C} 4 \% \mathrm{~B} 0 \mathrm{~K} \% \mathrm{C} 4 \% \mathrm{~B} 0 \mathrm{STAN} \% 2$ 0\%C3\%9CLKE\%20RAPORU\%202015.pdf;jsessionid=biDEoiLxxczvv28DHIphvt2uesD8JGFA2c

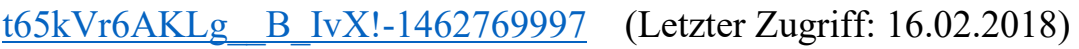

DWORSCHAK, Andre (2008): Die russische Außenpolitik der Ära Jelzin. Energiepolitische Implikation im kaspischen Raum. Saarbrücken: VDM Verlag.

EBBIGHAUSEN, Rodion (2019): Interview mit Susanne SCHRÖTER: Keine Kritik aus islamischen Ländern an China. In: dw, 04.12.2019, https://www.dw.com/de/keine-kritik-ausislamischen-1\%C3\%A4ndern-an-china/a-51525185 ～(Letzter Zugriff: 04.12.2019)

ECO (o. J.): Eco: Brief Introduction. In: ECO, http://www.ecosecretariat.org/detail_info/about eco_d.htm (Letzter Zugriff: 09.12.2018)

EICHHOFER, André (2015): Die Krim ist für uns wie ein zweites Nordkorea. In: Welt, 15.03.2015, http://www.welt.de/politik/ausland/article138440477/Die-Krim-ist-fuer-uns-wie-einzweites-Nordkorea.html (Letzter Zugriff: 22.04.2016)

ENGDAHL, F. William (2016): Das Gülen-Netzwerk: Eine CIA-Kreation zur besseren Kontrolle der islamischen Welt. In: Kopp Online, 24.07.2016, http://info.kopp-

verlag.de/hintergruende/geostrategie/f-william-engdahl/das-guelen-netzwerk-eine-cia-kreation-zurbesseren-kontrolle-der-islamischen-welt.html\#sdendnote1sym (Letzter Zugriff: 10.05.2016)

EPKENHANS, Tim (2006): Das Dilemma der OSZE in Zentralasien. In: Institut für Friedensforschung und Sicherheitspolitik an der Universität Hamburg/IFSH (Hrsg.), OSZEJahrbuch 2006, Baden-Baden 2007, S. 233-245.

EREM, Onur (2016): Beş soruda Şanghay İşbirliği Örgütü [Shanghai Cooperation Organization in fünf Fragen]. In: BBC, 21 Kasım 2016, https://www.bbc.com/turkce/haberler-dunya-38051013 (Letzter Zugriff: 18.12.2016)

ERGÜN, Mustafa/ÇIFTÇI Barış (2006): Türk Dünyasinin İlk Ortak Eğitim Reformu:Usul-ü Cedid Hareketi [Die erste gemeinsame Bildungsreform der türkischen Welt:Usul-ü Cedid Bewegung]. I. Uluslararası Türk Dünyası Kültür Kurultayı, Ege Üniversitesi Türk Dünyası Araştırmaları 
Enstitüsü, 9-15 Nisan 2006, Çeşme -İzmir,

https://leventeraslan.files.wordpress.com/2016/05/usulu-cedid.pdf （Letzter Zugriff: 06.06.2017)

ERHAN, Cagri (2003): Abd'nin Orta Asya politikasi ve 11 eylül sonrasi yeni açilimlari [USZentralasienpolitik und neue Strategien nach dem 11. September]. In: Stradigma.com, Aylik strateji ve analiz e-Dergisi, Ekim 2003, Sayi 9, S.1-21.

ERKIN, Feridun Cemal (1968): Türk-Sovyet iliskileri ve bogazlar meselesi [Türkisch-sowjetische Beziehungen und die Meerengen-Frage]. Ankara.

EROL, Mehmet Seyfettin (2012): Türkiye'nin Orta Asya Politikasina Rusya Federasyonu Ve Bölge Ülkelerinden Genel Bir Bakis [Die allgemeine Betrachtung der türkischen Zentralasienpolitik durch Russland und die Regionalstaaten]. In: Türk Dünyası Incelemeleri Dergisi, XII/1 (Yaz 2012), S.1-20.

EROL, Mehmet Seyfettin (2013): Yeni Büyük Oyun'da "bati'nin iki ötekisi" olarak Türkiye ve Rusya'nin Avrasya'da İşbirliği arayişlari [Die Kooperationsversuche zwischen der Türkei und Russland im New Great Game als zwei „nicht westliche Länder"]. In: Turan, Yıldırım/ Yalçinkaya, Alâeddin/ Efegil, Ertan (Hrsg.): Siyaset, Ekonomi Ve Toplum Üzerine 3. Uluslararasi Mavi Karadeniz Kongresi: Uyuşmazlik Çözümü, İşbirliği Ve Demokratikleşme, Gündoğan Yayınları: Istanbul, S. 49-62.

ERSANLI-BEHAR, Büsra (1994): Azerbaycan Özbekistan ve Türkmenistan'da Egitim ve Kültür Politikalar1 [Bildungs-und Kulturpolitik in Aserbaidschan, Usbekistan und Turkmenistan]. In: T.C. Kültür Bakanlıgi (Hg.): Bagimsizligin ilk yillari. Azerbaycan, Kazakistan, Kirgizistan, Özbekistan, Türkmenistan, Ankara, S. 143-220.

EUR-LEX (2010): Partnerschafts- und Kooperationsabkommen (PKA): Russland, Osteuropa, Südkaukasus und Zentralasien. Letzte Änderung: 29.09.2010, http://eurlex.europa.eu/legalcontent/DE/TXT/?uri=URISERV\%3Ar17002 (Letzter Zugriff: 13.07.2017)

EUROPÄISCHER RAT (2015): Neuer EU-Sonderbeauftragter für Zentralasien ernannt. Pressmitteilung, 177/15, 12:00, 15/04/2015, Auswärtige Angelegenheiten und internationale Beziehungen, http://www.consilium.europa.eu/de/press/press-releases/2015/04/15-new-eu-specialrepresentative-for-central-asia/ (Letzter Zugriff: 05.11.2015)

EUROPÄISCHES PARLAMENT (2016): Entschließung des Europäischen Parlaments vom 13. April 2016 über die Umsetzung und Überarbeitung der Zentralasienstrategie der EU (2015/2220(INI). Letzte Aktualisierung: 25. April 2016, http://www.europarl.europa.eu/sides/getDoc.do?type=TA\&reference=P8-TA-20160121\&language $=\mathrm{DE} \&$ ring $=\mathrm{A} 8-2016-0051 \quad$ (Letzter Zugriff: 18.01.2017)

EUROPEAN COMMISSION (2015): Central Asia - Border management. Last update: 14/06/2016, https://ec.europa.eu/europeaid/regions/central-asia/eu-support-border-management-central-asia en (Letzter Zugriff: 24.05.2017) 
European Commission (2017): Trade: Export Helpdesk, Statistics.

http://exporthelp.europa.eu/thdapp/display.htm;jsessionid=39E6A0065EF084F67FB92BDDF0EFB

B5E?page $=$ st $\% 2$ fst Statistics.html\&docType $=$ main\&languageId=en $\quad$ (Letzter Zugriff:

28.11.2018)

EUROSTAT (2018): EU imports of energy products - recent developments. Data extracted in April 2018, Planned article update: October 2018, https://ec.europa.eu/eurostat/statistics-

explained/index.php/EU imports of energy products -

recent developments\#Main_suppliers of natural gas and petroleum oils to the EU (Letzter

Zugriff: 28.11.2018)

FAYOS, Fernando Garcés de los (2016): Russland und Zentralasien. Europäisches Parlament Service, 09/2016,

http://www.europarl.europa.eu/atyourservice/de/displayFtu.html?ftuId=FTU 6.6.3.html (Letzter

Zugriff: 14.07.2017)

FLAGGENLEXIKON (o. J.): Aktuelle und historische Flaggen und Fahnen.

https://www.flaggenlexikon.de (Letzter Zugriff: 13.11.2019)

FREDOOM HOUSE (2018): Freedom in the World 2018. Table of Country Scores. https://freedomhouse.org/report/freedom-world-2018-table-country-scores (Letzter Zugriff:29.12.2018)

FULLER, Graham E. (1992): Turkey faces East: new orientations toward the Middle East and the old Soviet Union. Santa Monica: RAND, (R-4232-AF/ A).

FULLER, Graham E. (1993): Turkey`s New Eastern Orientation. In: FULLER, Graham E./LESSER, Ian O./HENZE, Paul u.a. (1993): Turkey`s new geopolitics: from the Balkans to Western China. Boulder; San Francisco; Oxford: Westview Press, S. 37-97.

FULLER, Graham E. (2008): Yeni Türkiye Cumhuriyeti [Neue Republik Türkei]. Istanbul: Timas.

FULLER, Graham E./LESSER, Ian O./HENZE, Paul u.a. (1993): Turkey`s new geopolitics: from the Balkans to Western China. Boulder; San Francisco; Oxford: Westview Press

GABOWITSCH, Mischa (2005): „Türkei und Russland- eurasische Rivalen“. In: Le Monde diplomatique, Dezember, http://www.monde-

diplomatique.de/pm/.dossier/tuerkei_artikel.id,20051209a0008 (Letzter Zugriff: 12.09.2012)

GANSER, Daniele (2015 [2012]): Europa im Erdölrausch. Die Folgen einer gefährlichen Abhängigkeit. Zürich: Orell Füssli Verlag, 6. Auflage.

GANSER, Daniele (2016a): Dr. Daniele Ganser über die NATO-Osterweiterung. In: KENFM, 9. März 2016, https://kenfm.de/kenfm-spotlight-dr-daniele-ganser-ueber-die-nato-osterweiterung/ (Letzter Zugriff: 28.11.2016)

GANSER, Daniele (2016b): Der Syrienkrieg einfach erklärt (Dr. phil. Daniele Ganser). In: Kla.tv, 15.06.2016, https://www.youtube.com/watch?v=rJOUfncDTt8 (Letzter Zugriff: 22.11.2016) 
GEINITZ, Christian/HÖFINGHOFF, Tim/KULS, Norbert (2012): Iran akzeptiert Renminbi für Öllieferungen an China. In: FAZ, 08.05.2012, http://www.faz.net/aktuell/wirtschaft/oelhandel-iranakzeptiert-renminbi-fuer-oellieferungen-an-china-11744184.html （Letzter Zugriff: 08.05.2012)

GENC, Savas (2006): Das neue „Great Game“ in Zentralasien um das Erdöl. Eine Region im Fadenkreuz der internationalen Interessen, Diss., Ruprecht-Karl-Universität, Heidelberg.

GERNER, Deborah J. (1995): The Evolution of the Study of Foreign Policy. In: NEACK, Laura/HEY, Jeanne A.K./HANEY, Patrick J. (Hrsg.): Foreign Policy Analysis: Continuity and Change in Its Second Generation. Englewood Cliffs/New Jersey: Prentice Hall, S. 17-32.

GHEMENT, Robert (2015): Türkei: Neue Hymne preist Erdogan als "unseren Anführer". In: Die Presse, 13.04.2015, 10:46, https://diepresse.com/home/politik/aussenpolitik/4707009/Tuerkei_Neue-Hymne-preist-Erdoganals-unseren-Anfuehrer- (Letzter Zugriff:18.12.2015)

GIUCCI, Ricardo/MDINARADZE, Anne (2017): Die Eurasische Wirtschaftsunion -Analyse aus einer handelspolitischen Perspektive - In: Berlin Economics, Berlin, 11. April 2017, https://berlineconomics.com/wp-content/uploads/EAWU-11-April-2017.pdf (Letzter Zugriff: 11.04.2017)

GKS (Federal State Statistic Service) [STATISTISCHES AMT DER RUSSISCHEN FÖDERATION] (2016): Commodity Structure Of Exports Of The Russian Federation (At Actual Prices). http://www.gks.ru/wps/wcm/connect/rosstat_main/rosstat/en/figures/activities/ (Letzter Zugriff: 14.12.2018)

GKS (Federal State Statistic Service) [STATISTISCHES AMT DER RUSSISCHEN FÖDERATION] (o. J.): Commodity Structure Of Exports Of The Russian Federation. http://www.gks.ru/bgd/regl/b15 12/IssWWW.exe/stg/d02/27-08.htm (Letzter Zugriff: 14.12.2018)

GODEHARDT, Nadine (2014): Chinas „neue“ Seidenstraßeninitiative: Regionale Nachbarschaft als Kern der chinesischen Außenpolitik unter Xi Jinping. In: SWP (Stiftung Wissenschaft und Politik), Juni 2014, Berlin, http://swp-

berlin.org/fileadmin/contents/products/studien/2014 S09 gdh.pdf (Letzter Zugriff: 12.04.2015)

GÖKDEMIR, Nurcan (2016): Diyanet in Dini Imani Para! [Für das Amt der Religionsangelegenheiten steht Geld über alles]. In: Birgün, 05.03.2016, 07:53, http://www.birgun.net/haber-detay/diyanet-in-dini-imani-para-105498.html (Letzter Zugriff: 05.03.2016)

GOLD.DE (2018): Ölpreis. Stand: 01.08.2018, letzter Zugriff: 09.09.2018, https://www.gold.de/oelpreis/ (Letzter Zugriff: 16.11.2018)

GOLUNOV, SERGEY (2004): The Role of Russia in Central Asia: Realities and Stereotypes. In: SEIDELMANN, Reimund/GIESE, Ernst (Hrsg.): Cooperation and Conflict Management in Central Asia. Frankfurt am Main, Berlin, Bern: Peter Lang (Studien zur Internationalen Entwicklungs- und Unweltforschung, hrgs. vom Zentrum für internationale Entwicklungs- und Unweltforschung der Justus-Liebig-Universität Gießen, Band 10), S. 189-201. 
GOVTRACKS.US (O. J.): Text of the Silk Road Strategy Act of 1999. 106th CONGRESS, 1st Session, H. R. 1152, https://www.govtrack.us/congress/bills/106/hr1152/text/ih ～(Letzter Zugriff: 21.03.2016)

GREWLICH, Klaus W. (2011): Geopolitik und Governance. Energie, Wasser, Herrschaft des Rechts in Zentralasien und Afghanistan, Baden-Baden: Nomos.

GRUSKA, Ulrike (2010): Abchasien - Kämpfe um den schönsten Teil der Schwarzmeerküste. In: STEINBACH, Udo/GUMPPENBERG, Marie-Carin von (Hrsg.) (2010): Der Kaukasus. Geschichte-Kultur-Politik, 2. neubearbeitete Auflage, München: C.H. Beck, S.103-112.

GÜL, Abdullah (2003): Türkiye Büyük Millet Meclisi Baskanligina [An die Große Nationalversammlung der türkischen Präsidentschaft]. In: T.C. Disisleri Bakanligi, Siyaset Planlama Genel Müdür Yardimciligi, Sayi: 026.21/2003/SPGY/239371, 11.06.2003, http://www2.tbmm.gov.tr/d22/7/7-0660c.pdf （Letzter Zugriff: 13.11.2012)

GUMPPENBERG, Marie-Carin von/GUMPPENBERG, Markus Brach-von (2006): Zur Rolle der OSZE in Zentralasien. In: bpb, Bundeszentrale für Politische Bildung, 19.1.2016, http://www.bpb.de/apuz/29960/zur-rolle-der-osze-in-zentralasien?p=all (Letzter Zugriff:17.11.2016)

GUMPPENBERG, Marie-Carin von/GUMPPENBERG, Markus Brach von (2010): Aserbaidschan - Machtpoker um Petroldollars. In: STEINBACH, Udo/GUMPPENBERG, Marie-Carin von (Hrsg.) (2010): Der Kaukasus. Geschichte-Kultur-Politik, 2.neubearbeitete Auflage, München: C.H. Beck, S. 49-63.

GUMPPENBERG, Markus Brach von (2010): Energie und Sicherheit -die neue Seidenstraße der Energie. In: STEINBACH, Udo/GUMPPENBERG, Marie-Carin von (Hrsg.) (2010): Der Kaukasus. Geschichte-Kultur-Politik, 2. neubearbeitete Auflage, München: C.H. Beck, S.164-180.

GÜNDOGDU, Abdullah (1997): Türkiye İle Türk Dünyası Arasındaki Münasebetlerin Tarihi Arka Plânı [Historischer Hintergrund der Beziehungen zwischen der Türkei und der türkischen Welt]. Yeni Türkiye Dergisi Türk Dünyası Özel Sayı 15, S. 295-300.

GÜRSEL, Haluk F. (1968): Tarih boyunca Türk-Rus Iliskileri [Türkisch-russische Beziehungen im Laufe der Geschichte]. Bir siyasi tarih incelemesi, Istanbul: Baha Matbaasi, Ak Yayinlari, Nr. 8.

HAFTENDORN, Helga (1990): Zur Theorie außenpolitischer Entscheidungsprozesse. In: RITTBERGER, Volker (Hrsg.): Theorien der Internationalen Beziehungen. Bestandaufnahme und Forschungsperspektiven, Politische Vierteljahresschrift-Sonderheft 21, Opladen: Westdeutscher Verlag, S. 401-423.

HALBACH, Uwe (1995): Ethno-territoriale Konflikte in der GUS. In: Friedrich-Ebert-Stiftung, Januar 1995, http://library.fes.de/pdf-files/netzquelle/c95-00117.pdf （Letzter Zugriff: 18.05.2014)

HALBACH, Uwe (2006): „Neue Seidenstraße“ und „New Great Game“ - Zentralasien nach dem Zerfall der Sowjetunion. In: 
http://www.unihamburg.de/onTEAM/grafik/1176796137/ring halbach.pdf (Letzter Zugriff: 14.12.2013)

HALBACH, Uwe (2013): Muslime in der Russischen Föderation. In: SWP-Aktuell 24, April 2013, Stiftung Wissenschaft und Politik Deutsches Institut für Internationale Politik und Sicherheit, https://www.swp-berlin.org/fileadmin/contents/products/aktuell/2013A24 hlb.pdf (Letzter Zugriff: 09.06.2018)

HALBACH, Uwe (2016): Der Konflikt zwischen Russland und der Türkei - Ende offen. In: SWPAktuell 32, April 2016, https://www.swp-

berlin.org/fileadmin/contents/products/aktuell/2016A32 hlb.pdf (Letzter Zugriff: 21.09.2017)

HALBACH, Uwe (2018): Der „Islamische Staat“ in Zentralasien. In: HEIDUK, Felix (Hg.) Das kommende Kalifat? "Islamischer Staat in Asien: Erscheinungsformen, Reaktionen und Sicherheitsrisiken". In: SWP-Studie, 9. Juni 201, (Stiftung Wissenschaft und Politik, Deutsches Institut fürInternationale Politik und Sicherheit) S.13-22, https://www.swpberlin.org/fileadmin/contents/products/studien/2018S09 hdk.pdf\#page=15 (Letzter Zugriff: 09.06.2018)

HALBACH, Uwe (o. J.): Der Kaspische Raum - Zwischen „Great Game“ und „Seidenstraße“. http://www.blz.bayern.de/blz/web/old_100111/halbach.htm (Letzter Zugriff: 20.04.2014)

HAMBLY, Gavin (Hrsg.) (1966): Zentralasien. Frankfurt am Main: Fischer Weltgeschichte, Band 16.

HAMEL, Christine (1998): Von der Wolga bis zur Newa: Moskau und Goldener Ring, St. Petersburg und Karelien, Nowgorod, Pskow und Kasan. Dumont Kunst Reiseführer, http://books.google.de/books?id=B7iMzlH5a8IC\&pg=PA424\&dq=christine+hammel+russland\&hl $=$ de\&sa $=$ X\&ei $=8 \mathrm{R} 5 \mathrm{WUZX}$ tOamn4gTuyoGYDw\&ved=0CDMQ6AEwAA $\quad$ (Letzter Zugriff: 24.12.2012)

HANEMANN, Thilo/HUOTARI, Mikko (2016): A New Record Year for Chinese Outbound Investment in Europa. In: MERICS, Mercator Institute for China Studies, Februar 2016, http://www.merics.org/merics-analysen/merics-studien/a-new-record-year-for-chinese-outboundinvestment-in-europe.html\#c11128 (Letzter Zugriff: 16.03.2016)

HARRIS, George (1995): The Russian Federation and Turkey. In: RUBINSTEIN, Alvin Z./SMOLANSKY, Oles M. (Hrsg.): Regional Power Rivalries in the New Eurasia. Russia, Turkey, and Iran, Armonk, New York, London: M. E. Sharpe, S. 3-25.

HASENCLEVER, Andreas (2001): Die Macht der Moral in der internationalen Politik. Militärische Interventionen westlicher Staaten in Somalia, Ruanda und Bosnien-Herzegowina, Frankfurt/Main, New York: Campus Verlag.

HAUNER, Milan (1990): What is Asia to us? Russia`s Asian Heartland Yesterday and Today, Boston, London, Sydney: Unwin Hyman. 
HAYIT, Baymirza (1956): Turkestan im XX. Jahrhundert. Darmstadt: C.W. Leske, (Forschungen zur neuen Geschichte der Völker Osteuropas und Asiens, Hrsg. von Gerhard von Mende, Band 1).

HAYIT, Baymirza (1980): Turkestan im Herzen Euroasiens. Köln: Studienverlag (Schriftenreihe des Instituts für Turkestan-Forschung).

HAYIT, Baymirza (1988): Türkistan Terimi Üzerine [Über den Begriff Turkestan], Türk Dünyas1 Araştırmaları Dergisi, Say1.53, 1988, S.23-34.

HEIN, Christoph (2018): Chinas langer Weg nach Westen. In: 25.05.2018, http://www.faz.net/aktuell/wirtschaft/der-handelsstreit/seidenstrasse-chinas-langer-weg-nachwesten-15605201.html (Letzter Zugriff: 26.05.2018)

HERMANN, Rainer (2016): Wie die Türkei mit der Religion ringt. In: Faz, 15.05.2016, http://www.faz.net/aktuell/politik/ausland/europa/tuerkei/islam-und-demokratie-wie-die-tuerkeimit-der-religion-ringt-14225714.html (Letzter Zugriff: 15.05.2016)

HILL, Fiona/TASPINAR, Ömer (2006): Turkey and Russia: Axis of Excluded? In: Survival, Spring 2006, Volume 48, No 1, S. 81-92.

HIPPLER, Jochen (2007): Intervention, Demokratie, Kontrolle - Die US-Politik im Mittleren Osten. http://www.jochenhippler.de/html/us-politik_im_mittleren_osten.html (Letzter Zugriff: 24.10.2014)

HOPKIRK, Peter (2001): The Great Game. On Secret Service in High Asia, Oxford: University Press.

HORAK, Slavomír (2016): Afghanistan aus der Sicht Turkmenistans. Schwieriger Nachbar oder Sicherheitsrisiko? In: ZENTRALASIEN-ANALYSEN, NR. 98, 26.02.2016, S. 2-5.

HUMBOLDT, Alexander von (2009 [1844]): Zentral-Asien. Untersuchungen zu den Gebirgsketten und zur vergleichenden Klimatologie. Neu bearbeitet und herausgegeben von Oliver Lubrich nach der Übersetzung Wilhelm Mahlmanns aus dem Jahr 1844, Frankfurt am Main: Bücherhilde Gutenberg.

HÜR, Ayse (2014): Din eğitiminin 94 y1llık serencamı [94 Jahre Religionsunterricht]. In: Radikal, 31/08/2014, http://www.radikal.com.tr/yazarlar/ayse-hur/din-egitiminin-94-yillik-serencami$\underline{1209991 /}$ (Letzter Zugriff: 31.08.2014)

HÜSEYNOV, Fuad (2003): Bağımsız Devletler Topluluğu'nun Oluşumunun Hukuki Boyutları [Rechtliche Dimensionen der Bildung der Gemeinschaft Unabhängiger Staaten]. In: Ankara Üniversitesi Hukuk Fakültesi Dergisi, Cilt 52, Sayı 4, S. 387-401.

IBRAHIMOV, Rafael (2017): Russia, Iran, and Turkey in Central Asia: A Nexus of Minor Tensions. In: Tony Blair Institute for Global Chance, 17th May 2017, https://institute.global/insight/co-existence/russia-iran-and-turkey-central-asia-nexus-minortensions (Letzter Zugriff: 20.07.2017) 
INALCIK, Halil (1999): OSMANLI-RUS ILISKILERI 1492-1700 [Osmanisch-Russische Beziehungen 1492-1700]. In: Türk-Rus iliskilerinde 500 yil 1491-1992, Ankara: Türk Tarih Kurumu, S. 25-36.

INOGATE (o. J.): In Brief, http://www.inogate.org/pages/1?lang=en

ISMAYILOV, Elnur/BUDAK, Türkan (2015): Bağımsızlık Sonrası Kazakistan'ın Enerji Politikası [Kasachische Energiepolitik nach der Unabhängigkeit]. In: BILGESAM ANALIZ/Enerji, No: 1189, 13. Subat 2015, http://www.bilgesam.org/Images/Dokumanlar/0-41120150216401189 2.pdf (Letzter Zugriff: 10.08.2018)

ISYAR, Ömer Göksal (2008): Avrasya da devletlerin sekillenis, yükselik ve düsüs sürecleri: Türk ve Rus Örnekleri [Der Prozess der Gründung, des Aufstieg und des Niederganges von Staaten in Eurasien: türkisches und russisches Beispiel]. In: OAKA, Cilt:3, Say1: 6, S. 104-136.

ISYAR, Ömer Göksel (2005): An analysis of turkish-american relations from 1945 to 2004: Initiatives and reactions in turkish foreign policy. In: ALTERNATIVES, Turkish Journal of International Relations, Vol.4, No.3, Fall 2005, S. 21-52.

JELZIN, Boris (1994): Auf des Messers Schneide. Tagebuch des Präsidenten, Berlin: Siedler Verlag.

JEPPESEN, Helle (2019): SIPRI: Militärausgaben steigen weiter. In: DW, 28.04.2019, https://www.dw.com/de/sipri-milit\%C3\%A4rausgaben-steigen-weiter/a-48501719 (Letzter Zugriff: 30.04 .2019 )

JIRACEK, Michal (2019): Zentralasien. In: Europäisches Parlament, Kurzdarstellungen zur Europäischen Union, 12-2019, https://www.europarl.europa.eu/factsheets/de/sheet/178/zentralasien (Letzter Zugriff: 02.01.2020)

JUSTUS-LIEBIG-UNIVERSITÄT-GIESSEN (2019): Aktuelles. http://www.unigiessen.de/fbz/fb04/institute/turkologie （Letzter Zugriff: 21.05.2017)

JUSTUS-LIEBIG-UNIVERSITÄT-GIESSEN (2019): Kirchner, Mark, Prof. Dr. http://www.unigiessen.de/fbz/fb04/institute/turkologie/personen/kirchner-mark （Letzter Zugriff: 21.05.2017)

KAFALI, Mustafa (o.J.): İsmail Gaspıralı'nın Yayımcılığı ve Gazeteciliği [Die Verlags- und Journalismustätigkeit Gaspiralis]. http://www.ismailgaspirali.org/yazilar/mkafali.htm (Letzter Zugriff: 18.09.2016)

KALIMULLIN, Robert (2012): Kasachstan plant bis 2050. In: Deutsche Allgemeine Zeitung, Freitag, 21. Dezember 2012, http://deutsche-allgemeine-zeitung.de/de/content/view/2616/68/ (Letzter Zugriff: 21.12.2012)

KALNOKY, Boris (2016): Wie die einstigen Weggefährten zu Erzfeinden wurden. In: Welt, 19.07.16, http://www.welt.de/politik/ausland/article157114663/Wie-die-einstigen-Weggefaehrtenzu-Erzfeinden-wurden.html (Letzter Zugriff: 19.07.2016) 
KALSIN, Berrin (2014). İsmail Gaspıralı ve Tercüman Gazetesi [İsmail Gaspıralı und Tercüman Zeitung], UHIVE, Uluslararası Hakemli İletişim ve Edebiyat Araştırmaları Dergisi; Ocak /Şubat /Mart -Kış Dönemi; Cilt: 2, Sayı: 2, Yı1:2014.

KAMALOV, Ilyas (2010): Komsuluktan Stratejik Isbirligine: Türk-Rus Iliskileri [Von der Nachbarschaft zur strategischen Zusammenarbeit: Türkisch-russische Beziehungen]. In: ORSAM, Rapor No: 18, The Black Sea International Rapor No: 3, Mayis 2010, http://www.orsam.org.tr/tr/trUploads/Yazilar/Dosyalar/201258 3raportum.pdf (Letzter Zugriff: 03.05.2010)

KAMALOV, Ilyas (2011): Rusya 'nin Orta Asya Politikalari [Russlands Zentralasienpolitik]. Rapor, Ankara: Hoca Ahmet Yesevi Uluslararası Türk-Kazak Üniversitesi, Haziran 2011 http://www.ayu.edu.tr/static/kitaplar/rusya ortaasya raporu.pdf (Letzter Zugriff: 02.10.2019)

KANTARCI, Hakan (2006): Kiskactaki Bölge Kafkasya [Region in der Zange, Kaukasus]. Istanbul: IQ Kültür Sanat Yayincilik.

KARA KUVVETLERI KOMUTANLIGI (2020): Türk Kara Kuvvetleri Tarihçesi [Geschichte der türkischen Landstreitkräfte]. Cumhuriyet Dönemi Öncesi Türk Kara Kuvvetleri, http://www.kkk.tsk.tr/KKKHakkinda/KKKtarihce.aspx ～(Letzter Zugriff: 20.04.2020)

KARDAS, Saban (2009): Turkey and Russia Developing a New Economic and Strategic Partnership. In: Eurasia Daily Monitor Volume: 6 Issue: 31, February 17, 2009 02:49 PM, http://www.jamestown.org/single/?no cache $=1 \&$ tx ttnews[tt news] $=34515$ (Letzter Zugriff: 23.08.2013)

KARPAT, Kemal H. (2008): Osmanli dan Cumhuriyete Kimlik Arayisi 5. Dil ve „Türklesme“ [Osmanische Identitätssuche Für Die Republik 5. Sprache und „Turklesme“]. In: Taraf, 09.03.2008, http://www.taraf.com.tr/prof-dr-kemal-h-karpat/makale-osmanlidan-cumhuriyetekimlik-arayisi-5.htm (Letzter Zugriff: 17.11.2013)

KASAPOĞLU, Çağıl (2016): Bazı ülkeler Gülen okullarını kapatmaya neden direniyor? [Warum widersetzen sich einige Länder der Schließung von Gülen-Schulen?] In: BBC Türkce, 2 Ağustos 2016, http://www.bbc.com/turkce/haberler-turkiye-36950705 (Letzter Zugriff: 02.08.2016)

KAZGAN, Gülten (2003): Bati ile iliskilerin Gölgesinde Türkiye-Rusya Iliskileri [Türkei-Russland Beziehungen im Schatten der Beziehungen zum Westen]. In: ULCENKO, Natalya Y./KAZGAN, Gülten (Hrsg.): Dünden Bugüne Türkiye Rusya: Politik, Ekonomik ve Kültürel Iliskiler. Kasim 2003, Istanbul: Istanbul Bilgi Üniversitesi Yayinlari 45, S. 145-181.

KAZTRANSOIL (2018): General information about KazTransOil. http://www.kaztransoil.kz/en/about the_company/ (Letzter Zugriff: 14.02.2019)

KELLER, Shoshana (2001): To Moscow, not Mecca: The Soviet Campaign Against Islam in Central Asia, 1917-1941. Praeger Publishers: Westport.

KHALILY, Reza (2018): Yasa Ve Moğol Döneminde Iran'in Hukuk Düzeni Üzerindeki Etkisi [Das Gesetz und sein Einfluss auf die Rechtsordnung des Iran während der mongolischen Zeit]. 
Übersetzung des Textes von Mercan NIGEHI (2006), erschienen in: CIHANNÜMA, Tarih ve Coğrafya Araştırmaları Dergisi, Sayı IV/1-Temmuz 2018,195-209.

KINDERMANN, Gottfried-Karl (1986): Zum Selbstverständnis des neorealistischen Ansatzes Einleitung zur dritten Auflage. In: KINDERMANN, Gottfried Karl (Hrsg.): Grundelemente der Weltpolitik. Eine Einführung Gleitwort Hans J. Morgenthau, 3., erweiterte Neuauflage, München, Zürich: Piper (Serie Piper, Band 553), Erste Aufgabe 1977, S. 11-47.

KIREYEV, Nikolay (2003): Avrasya Konzeptleri Isiginda Rusya-Türkiye Iliskileri [RusslandTürkei-Beziehungen im Lichte eurasischer Konzepte].. In: Ulcenko, Natalya Y./ Kazgan, Gülten (Hrsg.): Dünden Bugüne Türkiye Rusya: Politik, Ekonomik ve Kültürel Iliskiler. Kasim 2003, Istanbul: Istanbul Bilgi Üniversitesi Yayinlari 45, S. 199-215.

KİREYEV, Nikolay (2008): Rusya'da Avrasya Tezinin Bicimlenisi [Entwicklung der eurasischen These in Russland]. In: KAZGAN, Gülten (Hrsg.): Türkiye-Rusya Iliskilerinde Ihtilafli Konular ve Cözümleri. Istanbul: Istanbul Bilgi Üniversitesi Yayinlari 213, (Sempozyum-Panel 2), S. 11-27.

KISACIK, Sina (2012): Rusya'nin Enerji Politikalari Bağlaminda Orta Asya Ülkeleriyle İlişkileri [Russlands Beziehungen zu zentralasiatischen Ländern im Kontext der Energiepolitik]. In: Uluslararasi Politika Akademisi, 23 Aralik 2012, http://politikaakademisi.org/2012/12/23/rusyaninenerji-politikalari-baglaminda-orta-asya-ulkeleriyle-iliskileri/ （Letzter Zugriff: 05.12.2014)

KİSACIK, Sina (2014): 21. Yüzyılda Avrasya Jeopolitiği Bakımından Türkiye-Rusya Federasyonu İlişkileri [Die türkisch-russischen Beziehungen aus der eurasischen Geopolitikperspektive im 21. Jahrhundert]. In: Uluslararasi Politika Akademisi, 5 Aralik 2014, http://politikaakademisi.org/21yuzyilda-avrasya-jeopolitigi-bakimindan-turkiye-rusya-federasyonu-iliskileri/ (Letzter Zugriff: $05.12 .2014)$

KIVANC, Ümit (2015): Davutoglu aslinda hicbirsey söylemiyor. Interwiev mit Murat Sevki Coban [Davutoglu sagt eigentlich nichts. Interview mit Murat Sevki Coban]. In: T24, 04 Şubat 2015, 00:16, http://t24.com.tr/k24/yazi/davutoglu-aslinda-hicbir-sey-soylemiyor,30 (Letzter Zugriff: $04.02 .2015)$

KLEIN, Margarete (2018): Russlands Militärpolitik im postsowjetischen Raum. Ziele, Instrumente und Perspektiven, In: SWP, Stiftung Wissenschaft und Politik, Deutsches Institut für Internationale Politik und Sicherheit, SWP-Studie, 19. September 2018, https://www.swpberlin.org/fileadmin/contents/products/studien/2018S19 kle.pdf (Letzter Zugriff: 22.05.2019)

KLEIN, Margarete /WESTPHAL, Kirsten (2015): Russlands Wende nach China. In: SWP-Aktuell 78, September 2015, Stiftung Wissenschaft und Politik Deutsches Institut für Internationale Politik und Sicherheit, http://www.swpberlin.org/fileadmin/contents/products/aktuell/2015A78 kle wep.pdf (Letzter Zugriff: $07.10 .2015)$

KOCAASLAN, Nur Banu (2016): Ruşen Çakır: Cemaat'in kartları kolay kolay bitmez, şapkasından çok tavşan çıkarabilir [Rusen Cakir: Gülens Karten enden nicht leicht, er kann noch viele Kaninchen aus seinem Hut zaubern].. In: Diken, 03.08.2016, 23:18, http://www.diken.com.tr/rusen-cakir-cemaatin-kartlari-kolay-kolay-bitmez-sapkasindan-coktavsan-cikarabilir// (Letzter Zugriff: 03.08.2016) 
KOGAN, Eugene (2009): Turkish-American Strategic Partnership versus Turkish-Russian Partnership without Strategy. Oktober 2009, In: Internationales Institut Liberale Politik Wien (Sozialwissenschaftliche Schriftenreihe) http://www.iilp.at/publikationen/reihe studien/turkish american_strategic partnership versus turk ish russian partnership without strategy--363.html (Letzter Zugriff: 18.11.2013)

KOHEN, Sami (1997): Bir „Stratejik Ortaklik“ daha ... [Eine weitere "strategische Partnerschaft" ...]. In: MILLIYET, http://www.milliyet.com.tr/1997/12/17/t/yazar/kohen.html (Letzter Zugriff: 20.12.2012)

KOHEN, Sami (2000): Rusya ile „Ortaklik“ [„Partnerschaft“ mit Russland]. In: Milliyet, 26 Ekim 2000, http://www.milliyet.com.tr/2000/10/26/yazar/kohen.html （Letzter Zugriff: 12.07.2011）

KOHN, Hans (1955): The Mind of Modern Russia. Historical and Political Thought of Russia's Great Age, New Brunswick, New Jersey: Rutgers University Press.

KOHN, Hans (1957): Basic History of Modern Russia. Political, Cultural, and Social Trends, Princeton, Toronto, New York: D. Van Nostrand Company.

KOLDAS, Serhat (2014): TC'nin Sahte Laikliği ve Diyanet İşleri Başkanlığı [Gefälschter Säkularismus und das türkische Präsidium für Religionsangelegenheiten]. In: Marksist Tutum, Nisan 2014, no:109, http://marksisttutum.org/tcnin_sahte_laikligi_ve_diyanet_isleri_baskanligi.htm (Letzter Zugriff: 22.11.2015)

KOLOBOV, Oleg A./KORNILOV, Aleksandr A./ÖZBAY, Fatih (2006): Cagdas Türk-Rus Iliskileri. Sorunlar ve Isbirligi Alanlari (1992-2005) [Aktuelle Türkisch-Russische Beziehungen. Probleme und Bereiche der Zusammenarbeit (1992-2005)]. Istanbul: Tasam Yayinlari (Uluslararasi Iliskiler Serisi: 10).

KONCAK, İbrahim (2013): Ceditçilik Hareketi Ve Türkistan-Osmanli Devleti İlişskileri [Dschedidismus und Beziehungen zwischen Turkestan und dem Osmanischen Reich]. Çankırı Karatekin Üniversitesi Uluslararas1 Avrasya Strateji Dergisi 2(1): S. 105-114.

KÖNIG, Marietta S. (2010): Der ungelöste Streit um Süd-Ossetien. In: STEINBACH, Udo/GUMPPENBERG, Marie-Carin von (Hrsg.) (2010): Der Kaukasus. Geschichte-KulturPolitik, 2.neubearbeitete Auflage, München: C.H. Beck, S. 125-136.

KÖSEOGLU, Beril (2014): 9 Soruda Kırım hakkında bilmeniz gereken her şey [Alles, was Sie über die Krim in 9 Fragen wissen müssen]. 16.03.2014, 11:00 Uhr, http://www.diken.com.tr/9soruda-kirim-rusya-isgale-girisir-mi// (Letzter Zugriff: 04.04.2014)

KRAMER, Heinz (1996): Will Central Asia become Turkey's sphere of influence. In: SAM, Center for Strategic Research, Perceptions, March-May 1996, http://sam.gov.tr/wpcontent/uploads/2012/01/8.-WILL-CENTRAL-ASIA-BECOME-TURKEYS-SPHERE-OFINFLUENCE.pdf (Letzter Zugriff: 09.12.2013) 
KRAMER, Heinz (2010a): Die neue Außenpolitik-Konzeption der Türkei. In: SWP-Aktuell 25, März 2010, https://www.files.ethz.ch/isn/117484/2010_Turkey_FP.pdf (Letzter Zugriff:

03.06.2010)

KRAMER, Heinz (2010b): Die Türkei als Energiedrehscheibe. Wunschtraum und Wirklichkeit, April 2010, Berlin: SWPStudie (Stiftung Wissenschaft und Politik, Deutsches Institut für Internationale Politik und Wissenschaft), http://www.swp-

berlin.org/common/get document.php?asset id $=6997$ (Letzter Zugriff: 24.05.2010)

KRAMER, Heinz/REINKOWSKI, Maurus (2008): Die Türkei und Europa: eine wechselhafte Beziehungsgeschichte. Stuttgart: Kohlhammer.

KRELL, Gerd (2009): Weltbilder und Weltordnung. Einführung in die Theorien der Internationalen Beziehungen, 4., überarbeitete und aktualisierte Aufl., Baden-Baden: Nomos (Der „Studienkurs Politikwissenschaft“ wird herausgegeben von Prof. Dr. Winand Gellner, Universität Passau).

KÜCÜK, Evren/BEKAR, Nurgül (2019): Türk Diplomatlarin Bakiş Açisiyla Türk-Sovyet İlişkileri (1917-1925) [Türkisch-Sowjetische Beziehungen aus der Sichtweise der türkischen Diplomaten (1917-1925)]. In: Ankara Üniversitesi Sbf Dergisi, Cilt 74, No. 1, 2019, S. 163-192, https://dergipark.org.tr/en/download/article-file/643097 (Letzter Zugriff: 20.04.2020)

KURAN, Ahmet Bedevi (1948): Inkilap Tarihimiz ve Ittihat ve Terakki [Unsere Revolutionsgeschichte und Ittihat ve Terakki]. Istanbul: Tan Matbaasi.

KURAT, Akdes Nimet (1966): Türkiye ve İdil Boyu: 1569 Astarhan seferi, Ten-İdil kanalı ve XVI-XVII. yüzyıl Osmanl1-Rus münasebetleri, Band 1, Ankara: Ankara Üniv. Yayinlari.

KUT, Gün: Yeni Türk Cumhuriyetleri ve Uluslararası Ortam [Neue türkische Republik und internationales Umfeld]. In: T.C. Kültür Bakanlıgı (1994): Bagımsızlıgın llk Yılları: Azerbaycan, Kazakistan, Kırgızistan, Özbekistan, Türkmenistan, T.C. Kültür Bakanligi Yayinlari/1723, Halk Kültürleri Arastirma ve Gelistirme Genel Müdürlügü/221, Türk Cumhuriyetleri Dizisi: 2, S. 9-24.

LÄNDER-ANALYSEN (2014): Chronik: Usbekistan im Jahr 2014. http://www.laenderanalysen.de/zentralasien/chroniken/Chronik_us_2014_dru.pdf (Letzter Zugriff: 09.09.2015)

LANG, Kai-Olaf (2004): Pragmatische Kooperation statt strategische Partnerschaft: Zu Stand und Perspektiven der deutsch-polnischen Beziehungen. In: SWP-Aktuell 48, Oktober 2004, Stiftung Wissenschaft und Politik, Deutsches Institut für Internationale Politik und Sicherheit, https://www.swp-berlin.org/fileadmin/contents/products/aktuell/aktuell2004_48_lng_ks.pdf (Letzter Zugriff: 09.07.2013)

LENDON, Brad (2017): Qatar hosts largest US military base in Mideast. In: CNN, Updated 0600 GMT (1400 HKT), June 6, 2017, https://edition.cnn.com/2017/06/05/middleeast/qatar-us-largestbase-in-mideast/index.html (Letzter Zugriff: 28.11.2017)

LINSKA, Marion/HANDL, Andrea/RASULY-PALECZEK, Gabriele (2003): Einführung in die Ethnologie Zentralasien. Wien Jänner, 
http://www.univie.ac.at/Voelkerkunde/html/inh/stud/studmate files/Zentralasien_WS10/Skriptum \%20Z-Asien.pdf (Letzter Zugriff: 06.09.2012)

LIST, Dörte (2004): Regionale Kooperation in Zentralasien. Hindernisse und Möglichkeiten, Diss., Justus-Liebig-Universität Giessen. http://geb.uni-

giessen.de/geb/volltexte/2005/2206/pdf/ListDoerthe-2004-11-11.pdf （Letzter Zugriff: 14.06.2014)

LO, Bobo (2008): Axis of Convenience. Moscow, Beijing, and the New Geopolitics, London/New York.

LÜDERS, Michael (2003): Macht und Glauben in Zentralasien. In: Aus Politik und Zeitgeschichte, B 37/2003: Der Islam, 5.09.2003, http://www.bpb.de/apuz/27433/macht-und-glauben-inzentralasien?p=all (Letzter Zugriff:25.01.2017)

LÜDERS, Michael (2015): Wer den Wind sät. Was westliche Politik im Orient anrichtet, 8. Aufl., München: C. H. Beck,

LUDWIG, Michael (2013): Heroin aus Afghanistan: Tödliche Ware vom Hindukusch. In:

Frankfurter Allgemeine, 16.06.2013, Moskau, http://www.faz.net/aktuell/politik/ausland/asien/heroin-aus-afghanistan-toedliche-ware-vomhindukusch-12217059.html (Letzter Zugriff: 08.09.2017)

MAAS, Utz (2018): Trubetzkoy, Nikolaj Sergejevic. In: Verfolgung und Auswanderung deutschsprachiger Sprachforscher 1933-1945. Zuletzt aktualisiert: 04. Mai 2018, https://zflprojekte.de/sprachforscher-im-exil/index.php/katalog-m-z/t/469-trubetzkoy-nikolajsergejevic\#_edn1 (Letzter Zugriff: 04. Mai 2018)

MALEK, Martin (1994): Sprachenpolitik in der Gemeinschaft Unabhängiger Staaten (GUS). In: Osteuropa, 8/1994, S. 743-759.

MALEK, Martin (2002): Aktuelle Aspekte der Außenpolitik Russlands. In: Bundesheer, Oktober 2002, http://www.bmlv.gv.at/wissen-forschung/publikationen/beitrag.php?id=1396 (Letzter Zugriff: 07.09.2013)

MALEK, Martin (2003): Die NATO und Russland zwischen Kooperation und Konfrontation. Studien und Berichte zur Sicherheitspolitik 3/2003, in: Bundesheer,. Juli 2003, http://www.bmlv.gv.at/wissen-forschung/publikationen/beitrag.php?id=44 (Letzter Zugriff: 19.04.2014)

MAMAJONOV, Nuriddin (2012): Ein kurzer Blick über Usbekistan. In: Beiträge zur Entwicklung in Usbekistan und China, hrsg. von Grabau Stiftung, Anthology, Grin Verlag, S. 5-16, http://books.google.de/books?id=Ex 4IJBGDGEC\&printsec=frontcover\&dq=Beitr\%C $3 \% \mathrm{~A} 4 \mathrm{ge}+\mathrm{zu}$ $\mathrm{r}+$ Entwicklung $+\mathrm{in}+$ Usbekistan + und + China $\& \mathrm{hl}=\mathrm{de} \& \mathrm{sa}=\mathrm{X} \& \mathrm{ei}=8 \mathrm{UWuUsbaMoiytAbNlIC4Cw \& ved}$ =0CEMQ6AEwAA\#v=onepage \&q=Beitr $\% \mathrm{C} 3 \% \mathrm{~A} 4 \mathrm{ge} \% 20 \mathrm{zur} \% 20$ Entwicklung $\% 20$ in $\% 20$ Usbekist an\%20und $\% 20$ China\&f=false $\quad$ (Letzter Zugriff: 27.07.2015)

MAMMADOV, Halit (2014): Rus Dış Politikasında Stratejik- Zihinsel Süreklilik ve Putin'in Dış Politika Doktrini [Strategisch-mentale Kontinuität in der russischen Außenpolitik und Putins 
außenpolitische Doktrin]. Rapor, Ankara: Hoca Ahmet Yesevi Uluslararası Türk-Kazak

Üniversitesi inceleme-araştırma dizisi ; yayın no: 16,

http://www.ayu.edu.tr//yayinlar/rus dis_politika_rapor.pdf (Letzter Zugriff: 15.06.2015)

MANGOLD, Ijoma (2018): Heucheln, um zu herrschen. In: Zeitonline, 14. November 2018, 16:44 Uhr, editiert am 20. November 2018, 14:53 Uhr, Nr. 47/2018, 15. November 2018, https://www.zeit.de/2018/47/hegemonie-perry-anderson-macht-buch （Letzter Zugriff:

$30.08 .2019)$

MARDIN, Serif (2008): Türk Modernlesmesi [Türkische Modernisierung]. Istanbul: Iletisim Yayinlari.

MASALA, Carlo (2005): Kenneth N. Waltz. Einführung in seine Theorie und Auseinandersetzung mit seinen Kritikern, mit einem Vorwort von John J. Mearsheimer und einem Nachwort von Kenneth N. Waltz, Baden-Baden: Nomos.

MATUNINA, L. (2008): Rus Dis Politikasinda Türkiye'nin Önemi [Bedeutung der Türkei in der Russischen Außenpolitik]. In: Kazgan, Gülten (Hrsg.): Türkiye-Rusya Iliskilerinde Ihtilafli Konular ve Cözümleri. Istanbul: Istanbul Bilgi Üniversitesi Yayinlari 213, (Sempozyum-Panel 2), S. 79-93.

MAYRING, Philipp (2010): Qualitative Inhaltsanalyse. Grundlagen und Techniken. 11. aktualisierte und überarbeitete Auflage, Weinheim, Basel: Beltz.

MCBRIDE, James (2015): New Geopolitics of China, India, and Pakistan: Building the New Silk Road. In: Council on Foreign Relations, May 22, 2015, https://www.cfr.org/backgrounder/building-new-silk-road （Letzter Zugriff: 30.05.2015)

MEACHER, Michael (2003): This war on terrorism is bogus. In: the Guardian, Saturday 6 September 2003 12.15 BST, http://www.theguardian.com/politics/2003/sep/06/september11.iraq (Letzter Zugriff: 05.03.2014)

MEARSHEIMER, John J. (2001): The Future of the American Pacifier, In: Foreign Affairs, Vol. 80, No. 5 (September/October, 2001), S. 46-61.

MENZEL, Ulrich (2001): Zwischen Idealismus und Realismus. Die Lehre von den internationalen Beziehungen, Frankfurt am Main: Suhrkamp.

MENZEL, Ulrich (2008): Imperium oder Hegemonie? Folge 7: Das Osmanische Reich (14531571): Weltreich zwischen Europa und Asien oder Hegemonialmacht im Orient? Februar 2008, Nr. 86, http://www.ulrichmenzel.de/forschungsberichte/BlaueReihe86.pdf (Letzter Zugriff: 10.09.2016)

MICIJEVIC, Anis /SCHNEIDER, Stefan /HUA, Sha (2018): China reagiert auf Trump und verkündet seinerseits neue Strafzölle auf US-Importe. In: Handelsblatt, 18.09.2018, Update: 18.09.2018, 16:34 Uhr, https://www.handelsblatt.com/politik/international/handelsstreit-zwischenusa-und-china-china-reagiert-auf-trump-und-verkuendet-seinerseits-neue-strafzoelle-auf-us- 
importe/23081736.html?ticket=ST-1656168-NS6USIYmDEzYBGrPj3y3-ap1 (Letzter Zugriff: 18.09.2018)

MOMINKULOV, Canat/TUMBAYEVA, Rabiga /KALIOLLAKIZI, Ardak (2012): Avrasya Birligi yle ilgili Kazaklarin Milli Cikarlari [Nationale Interessen der Kasachen im Zusammenhang mit der Eurasischen Union]. Kültür Evreni, Bahar, Sayi 12, 22 Haziran 2012, Ankara: Kültür Ajans, S. 157-164, http://www.kulturevreni.com/12-157.pdf (Letzter Zugriff: 08.06.2014)

MORAVCSIK, Andrew (1997): Taking Preferences Seriously. A Liberal Theory of International Politics, in: International Organization, 51, 4/Autumm1997, S.513-553, http://www.princeton.edu/ amoravcs/library/preferences.pdf （Letzter Zugriff: 21.05.2017)

MORGENTHAU, Hans J. (1963): Macht und Frieden. Grundlegung einer Theorie der internationalen Politik, Gütersloh: C. Bertelsmann Verlag.

NATIONAL ENERGY POLICY DEVELOPMENT GROUP (2001): Report of the National Energy Policy Development Group. Reliable, Affordable, and Environmentally Sound Energy for America's Future, Mai 2001, http://www.wtrg.com/EnergyReport/National-Energy-Policy.pdf (Letzter Zugriff: 20.08.2013)

NATO (1994): NATO-Gipfelkonferenz in Brüssel. Tagung der Staats- und Regierungschefs des Nordatlantikpakts am 10. und 11. Januar 1994 in Brüssel, Erklärung der Staats- und Regierungschefs. http://www.nato.diplo.de/contentblob/1940824/Daten/189408/199401 Brssel DownlDat.pdf (Letzter Zugriff: 25.02.2015)

NATO (2016a): Partnership for Peace. 07 Apr. 2016, 16:25, http://www.nato.int/cps/en/natolive/topics 50349.htm (Letzter Zugriff: 03.12.2016)

NATO (2016b): NATO's relations with Central Asia. 22 Feb. 2016, 16: 58, http://www.nato.int/cps/en/natolive/topics_107957.htm (Letzter Zugriff: 03.12.2016)

NEKRASOV, M. (1999): XVI. Yüzyılda Rus-Osmanlı Ekonomik İlişkileri [Russisch-Osmanische Beziehungen im 16. Jahrhundert]. In: Türk Rus İlişkilerinde 500 Y1l 1491-1992, Ankara: Türk Tarih Kurumu, S. 91-96.

NESTLER, Franz (2015): Russland wird Chinas wichtigster Öllieferant. In: Faz, 01.07.2015, http://www.faz.net/aktuell/finanzen/devisen-rohstoffe/russland-wird-chinas-wichtigsteroellieferant-13677926.html (Letzter Zugriff: 03.01.2016)

NIGEHI, Mercan (2006): Yasa ve Eser-i An ber Nizâm-i Huqûqi-i İran der ‘Asr-i Moğol”, Rüşd Amûziş-i Târix, 7. dönem, Sayı: 3, Bahar 1385 (2006), S. 48-54

NOGAYEVA, Ainur (2012): ABD, Rusya Ve Çin'in Nüfuz Mücadelesinde Orta Asya: Araçlar ve Süreçler [Zentralasien im Machtkampf zwischen den Vereinigten Staaten, Russland und China: Mittel und Prozesse]. In: Billig, Yaz 2012, Sayi 62, S. 183-204. 
NURBEKOV, Altair (2014): Eurasian Economic Integration 'Will Continue,' Nazarbayev Says. In: The Astana Times, zunächst veröffentlicht in: Eurasia \& Word, 2. April 2014, http://astanatimes.com/2014/04/eurasian-economic-integration-will-continue-nazarbayev-says/ (Letzter Zugriff: 11.09.2015)

NYE, Joseph S., Jr. (1990): Bound to Lead: The Chancing Nature of American Power, New York: Basic Books.

NYE, Joseph S. Jr. (2004): Soft Power: The Means to Success in World Politics, New York: PublicAffairs.

NYE, Joseph S. (2011): Macht im 21. Jahrhundert. Politische Strategien für ein Neues Zeitalter, München: Siedler.

O. V. (1997): Jiang in Moscow for summit with Yeltsin. Joint declaration expected, in: CNN Interactive, World News, Story Page, April 22, 1997, Web posted at: 12:12 p.m. EDT (1612 GMT), http://edition.cnn.com/WORLD/9704/22/russia.china/index.html (Lezter Zugriff: 26. Juli 2018)

O. V. (2000): Putin`den Ortaklik Teklifi [Putins Angebot für die Partnerschaft]. In: Milliyet, 27 Mayis 2000, http://www.milliyet.com.tr/2000/05/27/dunya/dun01.html (Letzter Zugriff: 27 Mayis 2000)

O. V. (2000): Russian Minister of Foreign Affairs Igor Ivanov Confers with Turkish Foreign Minister Ismail Cem, in: Rusya Federasyonu’nun Türkiye Büyükelciligi, 20.09.2000, Daily News Bulletin, http://www.turkey.mid.ru/hron/34.html (Letzter Zugriff: 16.02.2015)

O. V. (2001): Bush vor dem Kongress: „Entweder sind Sie mit uns oder mit den Terroristen“. In: Der Tagesspiegel, 21.09.2001, 00:00 Uhr, http://www.tagesspiegel.de/politik/bush-vor-demkongress-entweder-sind-sie-mit-uns-oder-mit-den-terroristen/257864.html (Letzter Zugriff: 10.10.2013)

O. V. (2002): Bush reiht Iran in die „Achse des Bösen“ ein. In: Die Welt, Veröffentlicht am 31.01.2002, https://www.welt.de/print-welt/article371345/Bush-reiht-Iran-in-die-Achse-desBoesen-ein.html (Letzter Zugriff: 10.10.2013)

O. V. (2006): BTC boru hattı yarın açılıyor [BTC Pipeline wird morgen eingeweiht]. In: Hürriyet, Haber Giriş: 12.07.2006 - 11:21, Son Güncelleme:12.07.2006 - 11:21, https://www.hurriyet.com.tr/gundem/btc-boru-hatti-yarin-aciliyor-4738691 (Letzter Zugriff: 22.08.2014)

O. V. (2007): Brüchige Unabhängigkeit in den 1990er Jahren. In: Tagesschau, Stand: 29.08.2007, 00:33 Uhr, https://www.tagesschau.de/ausland/meldung320794.html (Letzter Zugriff: 16.11.2013)

O. V. (2008): Gürcistan'a insani yardımda Montrö krizi [Montreux-Krise in der humanitären Hilfe für Georgien]. In: CNN Türk.Com, 16.08.2008 - 22:36, Son Güncelleme: 16.08.2008, 23:23, https://www.cnnturk.com/2008/dunya/08/16/gurcistana.insani.yardimda.montro.krizi/490695.0/ind ex.html (Letzter Zugriff: 21.12.2012) 
O. V. (2008): Minsker Gruppe der OSZE. In: Tageschau, 17.10.2008, 16:43, http://www.tagesschau.de/ausland/minskergruppe100.html (Letzter Zugriff: 17.05.2010)

O. V. (2009): Kayi Soyu Teorisi Siyasi Bir Iddia [Kayi-Abstammungstheorie ist ein politischer Anspruch], 23.08.2009. In:

http://www.sabah.com.tr/Gundem/2009/08/23/kayi soyu teorisi_siyasi bir_iddia (Letzter Zugriff: 21.05.2017)

O. V. (2009): Rusya ile Türkiye 20 anlasma imzaladi, hedef 100 milyar dolar [Russland und die Türkei unterzeichnen 20 Abkommen, Ziel \$ 100 Milliarden]. In: Haberus, 07.08.2009, 09:15, http://www.haberrus.com/gundem/360-rusya-ve-tuerkiye-20-anlama-imzalad-hedef-100-milyardolar.html (Letzter Zugriff: 07.08.2009).

O. V. (2010): Gewalt in Kirgistan eskaliert. In: Frankfurter Rundschau, 12.06.2010, 08:06 Uhr, http://www.fr.de/politik/ethnische-unruhen-gewalt-in-kirgistan-eskaliert-a-1028078 (Letzter Zugriff: 11.05.2013)

O. V. (2010): Yılmaz: Mavi Akım'dan vazgeçmedim, siyasi bedelini ödedim [Yilmaz: ich habe den Blue Stream nicht aufgegeben, ich habe dafür den politischen Preis bezahlt]. In: Radikal, 05/03/2010, 02:00, http://www.radikal.com.tr/ekonomi/yilmaz-mavi-akimdan-vazgecmedimsiyasi-bedelini-odedim-983801/ (Letzter Zugriff: 13.09.2016)

O. V. (2011): Kozinoğlu'yla birlikte gömülmeyen sırlar-(TAMAMI) [Geheimnisse, die nicht mit Kozinoğlu- begraben sind (Alle)]. In: Aydinlik, 15 Kasım 2011 Salı 22:05, http://www.aydinlikgazete.com/mansetler/kozinogluyla-birlikte-gomulmeyen-sirlar-tamamih5461.html (Letzter Zugriff: 03.12.2016)

O. V. (2012): İlk Türk Okulu'nun bu hikayesini biliyor muydunuz? [Kennen Sie die Geschichte der ersten türkischen Schule?] In: Samanyoluhaber, 12 Haziran 2012, 11:18, http://www.samanyoluhaber.com/dunyao/Ilk-Turk-Okulunun-bu-hikayesini-biliyormuydunuz/775330/ (Letzter Zugriff: 20.09.2016)

O. V. (2012): Bizi de Şangay Beşlisi'ne alın! [Bringt uns zum Shanghai Five!] In: Milliyet, 26.07.2012 - 02:30, Son Güncellenme: 26.07.2012 - 02:30, ANKARA, https://www.milliyet.com.tr/siyaset/bizi-de-sangay-beslisi-ne-alin-1571936 (Letzter Zugriff: 26.07.2012)

O. V. (2012): Özbekistan ABD ile anlasmak istiyor [Usbekistan will sich mit den USA einigen]. In: T24, 30.06.2012, http://t24.com.tr/haber/ozbekistan-abd-ile-anlasmak-istiyor,207427 (Letzter Zugriff: 30.01.2015)

O. V. (2012): USA wollen Großteil der Marine in den Pazifik verlegen. In: Zeitonline, von AFP, dpa und Reuters, 2. Juni 2012, 12:39 Uhr, https://www.zeit.de/politik/ausland/2012-06/usa-pazifikaufruestung (Letzter Zugriff: 10.04.2015)

O. V. (2013): Erdogan Birlige Girmek Istiyor [Erdogan will der Union beitreten]. In: SABAH, Giriş Tarihi: 24.10.2013, 21:04, Güncelleme Tarihi: 24.10.2013, 21:08, 
https://www.sabah.com.tr/aktuel/2013/10/24/erdogan-o-birlige-girmek-istiyor (Letzter Zugriff: 24.10.2013)

O. V. (2013): Rusya'nın Yeni Dış Politika Anlayışı: Temel Hükümler [Russlands neues Verständnis der Außenpolitik: Grundlegende Bestimmungen]. In: Newstimes.az. 12.03.2013, http://newtimes.az/tr/politics/1465 (Letzter Zugriff: 12.03.2013)

O. V. (2014): Avrasya Birliği kuruldu, Türkiye bekleniyor... Nazarbayev: Türkiye Avrasya Ekonomik Birliği'ne üye olmalı [Die Eurasische Union wurde gegründet, die Türkei wird erwartet... Nazarbajew: Türkei soll Mitglied der eurasischen Wirtschaftsunion werden]. In: YENICAG, 22.06.2014, 01:10, https://www.yenicaggazetesi.com.tr/avrasya-birligi-kurulduturkiye-bekleniyor-98969h.htm (Letzter Zugriff: 22.06.2014)

O. V. (2014): Azerbaycan Gülen okullarını kapattı [Aserbaidschan schloss die Gülen-Schulen]. In: Aljazeera Turk, 19 Haz 2014, Güncelleme 11:37, http://www.aljazeera.com.tr/haber/azerbaycangulen-okullarini-kapatti (Letzter Zugriff: 21.06.2014)

O. V. (2014): Mustafa Dschemilew: Tatarenführer bis 2019 von der Krim verbannt. In: Welt, 22.04.2014, http:/www.welt.de/politik/ausland/article127177373/Tatarenfuehrer-bis-2019-vonder-Krim-verbannt.html (Letzter Zugriff: 22.04.2014)

O. V. (2014): Nazarbayev: Türkiye, Avrasya Ekonomik Birliği’ne üye olmalı [Nazarbajew: die Türkei sollte Mitglied der eurasischen Wirtschaftsunion werden]. In: GÜNDEMAVRASYA, 05.06.2014, 17:12, http://www.gundemavrasya.com/nazarbayev-turkiye-avrasya-ekonomikbirligine-uye-olmali-3042h.htm (Letzter Zugriff: 05.06.2014)

O. V. (2014): Türkmenistan Avrasya Birliği'ne katılmayacak [Turkmenistan wird der eurasischen Union nicht beitreten]. In: Dünya Bülteni, 14:43, 15 Temmuz 2014, Sal1, http://www.dunyabulteni.net/haber/303986/turkmenistan-avrasya-birligine-katilmayacak (Letzter Zugriff: 13.02.2016)

O. V. (2014): Währungen: China und Russland handeln in Yuan. In: Die Presse, 21.12.2014, 18:29 Uhr, http://diepresse.com/home/wirtschaft/international/4624600/Waehrungen China-und$\underline{\text { Russland-handeln-in-Yuan (Letzter Zugriff: 22.04.2016) }}$

O. V. (2015): „Strategische Energiepartnerschaft“ - China baut Mega-Pipeline nach Russland. In: RT Deutsch, 01.07.2015, 11:45 Uhr, https:/deutsch.rt.com/24485/wirtschaft/strategischeenergiepartnerschaft-china-baut-mega-pipeline-nach-russland// (Letzter Zugriff: 01.07.2015)

O. V. (2015): „Yeni Türkiye bizim ,kızıl elma“ mız“ [„,Die neue Türkei ist unser 'Roter Apfel'“]. In: MILLIYET, 10.04.2015, 13:32, Son Güncellenme: 10.04.2015 - 14:28, İHA, https://www.milliyet.com.tr/siyaset/yeni-turkiye-bizim-kizil-elma-miz-2042010 (Letzter Zugriff: 10.04.2015)

O. V. (2015): Elmas' ruhlu öğretmenin Kırım'dan Kenya'ya uzanan vefa hikâyesi [Die Loyalitätsgeschichte einer hochgeistigen Lehrerin von der Krim bis nach Kenia]. In: Zaman, Yayınlanma Tarihi: 30 Ocak 2015, 13:58, http://video.zaman.com.tr/-elmas-ruhlu-ogretmeninkirim-dan-kenya-ya-uzanan-vefa-hikayesi_ozZ96va4.html (Letzter Zugriff: 20.04.2016) 
O. V. (2015): Erdoğan und Putin schließen Bündnis gegen Gülen-Bewegung. In: Deutsch Türkische Nachrichten, 22.04.15, 14:54, http://www.deutsch-tuerkischenachrichten.de/2015/04/511233/erdogan-und-putin-schliessen-buendnis-gegen-guelen-bewegung2/ (Letzter Zugriff: 22.04.2015)

O. V. (2015): Erdoğan, Çin'de çark etti: „Doğu Türkistan İslami Hareketi'nin terörünü kınıyoruz“ [,Wir verurteilen den Terror der Osttürkischen Islamischen Bewegung“, sagte Erdogan in China]. In: marksist.org, 30.07.2015, 12:15, https://marksist.org/icerik/Yazar/2498/mobileRedirect (Letzter Zugriff: 30.07.2015)

O. V. (2015): Gülen cemaatinin Tacikistan'daki okulları kapatıllyor [Die Gülen-Schulen in Tadschikistan werden geschlossen]. In: Dünya Bülteni, 14:57, 05 Ocak 2015 Pazartesi, http://www.dunyabulteni.net/haber/318801/gulen-cemaatinin-tacikistandaki-okullari-kapatiliyor (Letzter Zugriff: 05.05.2015)

O. V. (2015): Kerimov'a suikastın taşeronu Pensilvanya [Der Subunternehmer des KerimowAttentats ist Pennsylvania]. In: SABAH, Giriş Tarihi: 7.4.2015, 02:15 Güncelleme Tarihi: 7.4.2015 12:51, http://www.sabah.com.tr/gundem/2015/04/07/kerimova-suikastin-taseronu-pensilvanya (Letzter Zugriff: 12.11.2017)

O. V. (2015): Nuh Mete Yüksel'e kumpas kuran kadın tespit edildi [Die Frau, die Nuh Mete Yüksel in Schwierigkeit gebracht hatte, wurde identifiziert]. In: Star, 21.02.2015, 10:37, Güncelleme: 21.02.2015, 16:24, http://haber.star.com.tr/guncel/nuh-mete-yuksele-kumpas-kuran-kadin-tespitedildi/haber-1002543 (Letzter Zugriff: 22.09.2015)

O. V. (2015): Özbekistan'a AIDS'le mücadele için 13,8 milyon dolar [13,8 Millionen Dollar für den Kampf gegen AIDS in Usbekistan]. In: Timetürk, 02.12.2015, 18:57:57, https://www.timeturk.com/ozbekistan-a-aids-le-mucadele-icin-13-8-milyon-dolar/haber-99043 (Letzter Zugriff: 02.02.2017)

O. V. (2015): Putin: 7.000 Dschihadisten aus GUS-Staaten kämpfen in Reihen des IS, deren nächstes Expansionsziel ist Zentralasien. In: RT Deutsch, 16.10.2015, 16:27 Uhr, https://deutsch.rt.com/34543/international/putin-7-000-dschihadisten-aus-gus-staaten-kaempfen-in$\underline{\text { reihen-des-is-deren-naechstes-expansionsziel-ist-zentralasien/ }}$ (Letzter Zugriff: 16.10.2015)

O. V. (2015): Reuters: IŞiD Rusya'ya cihat ilan etti [Reuters: IS hat gegen Russland den Dschihad erklärt]. In: T24, 14 Ekim 2015, 02:19, https://t24.com.tr/haber/reuters-isid-rusyaya-cihat-ilanetti,312897 (Letzter Zugriff: 14.10.2015)

O. V. (2015): Şok Rakam! Işid'in Kaç Bin Militani Var? [Schock-Zahl! Wie viele Militanten hat der IS?]. In: Haber 3, 10.11.2015, 22:39 Uhr, http://www.haber3.com/sok-rakam-isidin-kac-binmilitani-var-3661508h.htm (Letzter Zugriff: 10.11.2015)

O. V. (2015): Tacikistan 'da paralel okullar kapatiliyor [Die Gülen-Schulen in Tadschikistan werden geschlossen]. In: Sabah, 07.01.2015, http://www.sabah.com.tr/gundem/2016/10/10/aliyevunutmadi-o-gece-etrafinda-birlestiniz-ve (Letzter Zugriff: 07.01.2015) 
O. V. (2016): Aşkabat'taki „Gülen'cilerin yuvası“ kapatıld1 [„Gulens nest“ in Aschgabat wurde geschlossen]. In: Dünya Bülteni, 11 Ağustos 2016 Perşembe, 14:24,

http://www.dunyabulteni.net/orta-asya/373721/askabattaki-gulencilerin-yuvasi-kapatildi (Letzter Zugriff: 11.08.2016)

O. V. (2016): „Die Amerikaner stehen auf unserer Seite“: Al-Nusra erhält Waffen von den USA. In: Focus Online, Montag, 26.09.2016, 01:24, https://www.focus.de/politik/deutschland/syrienkonflikt-die-amerikaner-stehen-auf-unserer-seite-al-kaida-erhaelt-waffen-von-denusa id 5987030.html (Letzter Zugriff: 26.09.2016)

O. V. (2016): 2015 Ekim Döneminde Petrol ve Doğalgaz İthal Ettiğimiz Ülkeler [Länder, von denen wir Ö1 und Erdgas im Oktober 2015 importiert haben]. In: Enerji Atlasi, 07.01.2016, http://www.enerjiatlasi.com/haber/2015-ekim-doneminde-petrol-ve-dogalgaz-ithal-ettigimizulkeler (Letzter Zugriff: 30.01.2016)

O. V. (2016): Autonomie für Krimtataren: Ukrainischer Staatspräsident verspricht Krimtataren Selbstverwaltung. In: TRT Deutsch, 13.07.2016 - 15.07.2016, http://www.trt.net.tr/deutsch/welt/2016/07/13/autonomie-fur-krimtataren-528154 (Letzter Zugriff: 20.07.2016)

O. V. (2016): Azerbaycan: Dağl1k Karabağ'da son iki günde 16 askerimiz öldü [Aserbaidschan: In den letzten zwei Tagen starben 16 Soldaten in Berg-Karabach]. In: BBC-Türkce, 5 Nisan 2016, http://www.bbc.com/turkce/haberler/2016/04/160405 daglik karabag (Letzter Zugriff: 05.04.2016)

O. V. (2016): Başbakan Davutoğlu'ndan önemli açıklamalar [Wichtige Aussagen von Ministerpräsident Davutoglu]. In: Hürriyet, 15 Şubat 2016, 12:06 (Son Güncelleme: 15 Şubat 2016, 14:33), Kiev, http://www.hurriyet.com.tr/basbakan-davutoglundan-onemli-aciklamalar-40054761 (Letzter Zugriff: 15.02.2016)

O. V. (2016): Bekir Bozdağ: Başarsalardı Gülen Humeyni gibi gelecekti, rejim değişecekti [Bekir Bozdag: wenn Sie Erfolg gehabt hätten, wäre Gülen wie Khomeini gekommen, das Regime hätte sich verändert]. In: HaberTürk, 28.07.2016 - 10:56, Güncelleme: 28.07.2016 - 19:14, https://www.haberturk.com/gundem/haber/1273191-bekir-bozdag-basarsalardi-gulen-humeynigibi-gelecekti-rejim-degisecekti (Letzter Zugriff: 28.07.2016)

O. V. (2016): Cumhurbaşkanı Erdoğan Azeri Televizyonuna Konuştu [Präsident Erdogan sprach dem Aserbaidschanischen Fernsehsender]. In: haberler.com, 02. April 2016, Cumartesi, 19:50 Uhr, http://www.haberler.com/cumhurbaskani-erdogan-azeri-televizyonuna-konustu-8319549-haberi/

(Letzter Zugriff: 02.04.2016)

O. V. (2016): Cumhurbașkanı Erdoğan: Fethullah Gülen hakkında yanılgıya düșmüșüz. Allah bizi affetsin [Präsident Erdogan: wir haben uns bzgl. Fethullah Gülen geirrt. Möge Allah uns vergeben]. In: T24, Bagimsiz Internet Gazetesi, 30 Temmuz 2016, 21: 45, http://t24.com.tr/haber/cumhurbaskani-erdogan-10-bin-137-tutuklu-18-bin-699-gozalti-var,352681 (Letzter Zugriff: 30.07.2016) 
O. V. (2016): Dynastien kommen und gehen. In: Geschichte ist alles, 21. Februar 2016, In: http://geschichte.verenalang.at/wp-content/uploads/2016/02/Karte_Russland.jpg (Letzter Zugriff: 11.12.2017)

O. V. (2016): Erdoğan Poroşenko'yu resmi törenle karşıladı [Erdogan begrüßt Poroschenko bei offizieller Zeremonie]. In: Milliyet, 09.03.2016, 18:15,| Son Güncelleme: 09.03.2016, 18:40, http://www.milliyet.com.tr/erdogan-porosenko-yu-resmi-torenle/siyaset/detay/2206967/default.htm (Letzter Zugriff: 09.03.2016)

O. V. (2016): Erdoğan ve Aliyev'den „Tek millet, iki devlet“ vurgusu [„Eine Nation, zwei Staaten“ von Erdogan und Aliyev]. 25.04.2016, 23:27, http://www.turkiyegazetesi.com.tr/gundem/364613.aspx （Letzter Zugriff: 25.04.2016)

O. V. (2016): Erdoğan, „Türkiye Maarif Vakfı Kanunu“ onayladı „Erdogan genehmigte das „Gesetz der Maarif-Stiftung der Türkei“]. In: Evrensel, 28 Haziran 2016, 08:01, https://www.evrensel.net/haber/283749/erdogan-turkiye-maarif-vakfi-kanunu-onayladi (Letzter Zugriff: 29.06.2016)

O. V. (2016): Gülen, Erdoğan'la ilişkisini anlattı: Hep seçimlerden önce görüştük [Gülen beschrieb sein Verhältnis zu Erdogan: „wir haben uns immer vor den Wahlen getroffen“]. In: Diken, 09.09.2016, 09:48, http://www.diken.com.tr/gulen-erdoganla-iliskisini-anlatti-hep-secimlerdenonce-gorustuk/ (Letzter Zugriff: 09.09.2016)

O. V. (2016): Gülen'in 1999'da yayınlanan olay videosu: „Sivrilirsek sonumuz Cezayir gibi olur“ [Gülens 1999 veröffentlichtes Video: „Wenn wir auffallen, werden wir wie Algerien enden“]. In: Medyascope.tv, 18 Ağustos 2016, http://medyascope.tv/2016/08/18/gulenin-1999da-yayinlananolay-videosu-sivrilirsek-sonumuz-cezayir-gibi-olur/ (Letzter Zugriff: 18.08.2016)

O. V. (2016): İran yıllar sonra Avrupa'ya ilk petrol sevkiyatını yaptı [Der Iran machte nach Jahren den ersten Erdölexport nach Europa]. In: Hürriyet, 16.02.2016, http://enerjigundemi.com/2016/02/16/iran-yillar-sonra-avrupaya-ilk-petrol-sevkiyatini-yapti/ (Letzter Zugriff: .9.11.2016)

O. V. (2016): Kasachstan: Eurasische Wirtschaftsunion mit Russland ist keine Sowjetunion 2.0. In: Eurasianews, 5. April 2016, http://eurasianews.de/blog/kasachstan-eurasische-wirtschaftsunionmit-russland-ist-keine-sowjetunion-2-0/ (Letzter Zugriff: 10.04.2016)

O. V. (2016): Kasachstans Außenminister: IS an Anschlag in Aktobe beteiligt. In: Sputnik, 15:38, 20.06.2016 aktualisiert 15:41 20.06.2016, https://de.sputniknews.com/panorama/20160620310747466-is-anschlag-aktobe/ (Letzter Zugriff: 20.06.2016)

O. V. (2016): Kazakistan'daki Gülen okulları için flaş gelişme [Flash-Entwicklung für GülenSchulen in Kasachstan]. In: Hürriyet, 05 Ağustos 2016, 16:39, Son Güncelleme: 05 Ağustos 2016, 17:24, http://www.hurriyet.com.tr/kazakistandaki-gulen-okullari-icin-flas-gelisme-40182723 (Letzter Zugriff: 09.09.2018) 
O. V. (2016): Kırgızistan Cumhurbaşkanı Atambayev: Türkiye Rusya'dan özür dilemeli [Kirgisischer Präsident Atambayev: Die Türkei muss sich bei Russland entschuldigen]. 24 Aralik 2015 Güncelleme 13:19 TSİ, In: Aljazeera-Turk, http://www.aljazeera.com.tr/haber/kirgizistancumhurbaskani-atambayev-turkiye-rusyadan-ozur-dilemeli (Letzter Zugriff: 24.09.2017)

O. V. (2016): Moscow to Host Russia-China-Pakistan Strategic Talks on Afghanistan in December: Kabulov. In: The Nation, 11. November 2016, http://nation.com.pk/international/21-Nov2016/moscow-to-host-russia-china-pakistan-strategic-talks-on-afghanistan-in-december-kabulov (Letzter Zugriff: 11.11.2016)

O. V. (2016): Opium für die Taliban. In: Frankfurter Allgemeine, Aktualisiert am 23.10.2016, 09:22 Uhr, http://www.faz.net/aktuell/politik/ausland/afghanistan-opium-fuer-die-taliban14494094.html (Letzter Zugriff: 28.10.2016)

O. V. (2016): Porosenko „Mit Ajani“ Cemilev ile neden yakinlasti? [Warum näherte sich Poroschenko an den Agent des türkischen Geheimdienstes (Mit) Dschemilew? an] In: Sputnik, 14:42, 12.04.2016 (Güncellendi 15:50, 12.04.2016), http://tr.sputniknews.com/columnists/20160412/1022103468/ukrayna-porosenko-cemilev-mit.html (Letzter Zugriff: 20.04.2016)

O. V. (2016): Putin und Erdoğan besiegeln Gaspipeline-Deal. In: Zeit Online, 11. Oktober 2016, 2:44 Uhr, http://www.zeit.de/politik/ausland/2016-10/russland-tuerkei-pipeline-recep-tayyiperdogan-wladimir-putin (Letzter Zugriff: 18.01.2017)

O. V. (2016): Russland stuft Krimtataren-Vertretung als Extremisten-Gruppierung ein. In: Sputnik, 16:48, 26.04.2016 (aktualisiert 17:24, 26.04.2016), http://de.sputniknews.com/politik/20160426/309480951/russland-verbietet-medschlis-deskrimtatarischen-volks.html (Letzter Zugriff: 26.04.2016)

O. V. (2016): Rusya'dan flaş Fethullah Gülen iddiası [Blitznachricht: Behauptung aus Russland über Fethullah Gülen]. In: CUMHURIYET, 25 Temmuz 2016, Pazartesi, 21:15, http://www.cumhuriyet.com.tr/haber/dunya/574121/Rusya_dan_flas_Fethullah_Gulen_iddiasi.html \# (Letzter Zugriff: 09.09.2018)

O. V. (2016): Sözcü Kalın: Davutoğlu yarın Cumhurbaşkanı Erdoğan'a veda ziyaretinde bulunacak [Sprecher Kalin: Davutoglu wird morgen Präsident Erdogan einen Abschiedsbesuch abstatten]. In: DHA, 18.05.2016, 14:21, http://www.dha.com.tr/sozcu-kalin-davutoglu-yarin-cumhurbaskanierdogana-veda-ziyaretinde-bulunacak_1230395.html (Letzter Zugriff: 18.05.2016)

O. V. (2016): Tadschikische Regierung prüft Beitritt zur Eurasischen Wirtschaftsunion. In: AHK, Delegation der Deutschen Wirtschaft für Zentralasien, 21.07.2016, http://zentralasien.ahk.de/news/nachrichten-tadschikistan/ahk-zentralasien-news-austadschikistan/artikel/tadschikische-regierung-prueft-beitritt-zur-eurasischenwirtschaftsunion/?cHash=663cbc3c97db0e15df069a6cfc0f8824 (Letzter Zugriff: 20.11.2017)

O. V. (2016): Umfrage: Russen wollen lieber Stabilität als Freiheit und Demokratie. In: Eurasisches Magazin, 18.01.2016, https://www.eurasischesmagazin.de/ticker/Russen-istStabilitaet-wichtiger-als-Freiheit/322 (Letzter Zugriff: 09.05.2016) 
O. V. (2016): Waffenstilstand erneut verletzt. In: Daily Karabakh, 01 April 2016, 11:43, http://www.dailykarabakh.com/news.php?id=3500\&lang=de （Letzter Zugriff: 01.04.2016)

O. V. (2017): A new route for transportation of Kashagan oil opened. In: Global Oil \& Gas Atyrau. 21 February 2017, https://www.oil-gas.kz/en/press-centre/news/385-21-02-2017kzt (Letzter Zugriff: 18.09.2018)

O. V. (2017): Alternatif Avrasya Gümrük Birligi. In: Yenisafak, 19 Ağustos 2017, 04:00, https://www.yenisafak.com/ekonomi/alternatifavrasya-gumruk-birligi-2781777 (Letzter Zugriff: 19.08.2017)

O. V. (2017): Milliardengeschäft der Taliban: Afghanistan verdoppelt Drogenernte. In: NTV, Mittwoch, 15. November 2017, https://www.n-tv.de/politik/Afghanistan-verdoppelt-Drogenerntearticle20134053.html (Letzter Zugriff: 15.11.2017)

O. V. (2017): NATO-Büro in Zentralasien geschlossen. In: RT-Deutsch, 6.04.2017, 17:46 Uhr, https://deutsch.rt.com/newsticker/48816-nato-buro-in-zentralasien-geschlossen/_(Letzter Zugriff: 06.04.2017)

O. V. (2017): Ortak Türk ordusu kuruluyor [Gemeinsame türkische Armee wird gegründet]. 13 Aralık 2017, 10:59, Son Güncelleme: 13 Aralık 2017, 11:05, https://www.yenisafak.com/gundem/ortak-turk-ordusu-kuruluyor-2916692 (Letzter Zugriff: 22.12.2017)

O. V. (2017): Özbekistan ve Rusya arasındaki askeri tatbikat sona erdi [Die Militärübung zwischen Usbekistan und Russland ist beendet]. In: Özbekistan Haber, 08 Ekim 2017, 12:55, https://ozbekistanhaber.com/112/YAAM/zbekistan ve Rusya arasndaki askeri tatbikat sona erd i.html (Letzter Zugriff: 05.07.2017)

O. V. (2017): Russland ist jetzt Chinas wichtigster Öl-Lieferant. In: Frankfurter Allgemeine, 23.01.2017, http://www.faz.net/aktuel1/wirtschaft/wirtschaftspolitik/russland-liefert-mehr-oel-nachchina-als-saudi-arabien-14734201.html （Letzter Zugriff: 28.01.2017)

O. V. (2017): Rusya ve Özbekistan'dan Ortak Askeri Tatbikat [Gemeinsame Militärübung von Russland und Usbekistan]. In: Haberler.com, 3 Temmuz 2017, Pazartesi, 14:11, https://www.haberler.com/rusya-ve-ozbekistan-dan-ortak-askeri-tatbikat-9789966-haberi/ (Letzter Zugriff: 05.07.2017)

O. V. (2017): Rusya'da yabancı işçi profili [Ausländische Arbeitnehmer Profil in Russland]. In: Türkrus, 10.10.2017, http://turkrus.com/473905-rusyada-yabanci-isci-profili--xh.aspx （Letzter Zugriff: 10.10.2017)

O. V. (2017): US-Regierung genehmigt Milliardendeal mit Polen. In: Zeit Online, 18. November 2017, 3:57 Uhr, Quelle: ZEIT ONLINE, dpa, AFP, ces, https:/www.zeit.de/politik/ausland/2017-

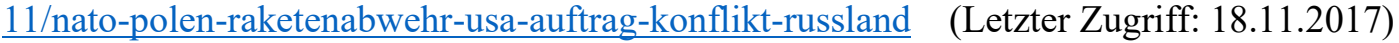


O. V. (2018): China rechtfertigt „Umerziehungslager“ für Uiguren. In: Zeit Online, 13. November 2018, 10:11 Uhr, https://www.zeit.de/politik/ausland/2018-11/china-xinjiang-uigurenumerziehungslager-kritik-verteidigung （Letzter Zugriff: 17.11.2018)

O. V. (2018): EAWU kurz vor Abschluss eines Freihandelsabkommens mit Indien. In: OWC. Außenwirtschaft, 10. Oktober 2018, https:/owc.de/2018/10/10/eawu-kurz-vor-abschluss-einesfreihandelsabkommens-mit-indien/ (Letzter Zugriff: 10.10.2018)

O. V. (2018): EAWU weitetet Kooperationen mit China und Iran aus. In: OWC. Außenwirtschaft, 18. Mai 2018, https://owc.de/2018/05/18/eawu-weitetet-kooperationen-mit-china-und-iran-aus/ (Letzter Zugriff: 30.05.2018)

O. V. (2018): Erdoğan: Afrin'den geri adım atmak yok; hedefimiz Kızılelma [Erdogan: Kein Zurück aus Afrin; unser Ziel ist der Rote Apfel]. In: T24, 22 Ocak 2018, 14:31, http://t24.com.tr/haber/erdogan-afrinden-geri-adim-atmak-yok,541806 (Letzter Zugriff: 22.01.2018)

O. V. (2018): Rusya'da Müslüman nüfus problemi [Muslimisches Bevölkerungsproblem in Russland]. In: Dünya Bülteni, 06 Temmuz 2018, Cuma 09:30, https://www.dunyabulteni.net/arsiv/rusyada-musluman-nufus-problemi-h6590.html (Letzter Zugriff: 06.07.2018)

O. V. (2018): Trump in Zentralasien: USA locken Kasachstan mit milliardenschwerer Energiekooperation. In: RTDeutsch, 19.01.2018, 18:27 Uhr, https://deutsch.rt.com/asien/63872trump-in-zentralasien-usa-locken-kasachstan// (Letzter Zugriff: 19.01.2018)

O. V. (2018): USA verhängt Sanktionen gegen China wegen Kaufs russischer Waffen. In: Handelsblatt, 21.09.2018, 11:30 Uhr, https://www.handelsblatt.com/politik/international/sanktionen-usa-verhaengt-sanktionen-gegenchina-wegen-kaufs-russischer-waffen/23097718.html?ticket=ST-1694424cMYhAngYC1hmgzWHikzc-ap1 (Letzter Zugriff: 21.09.2018)

O. V. (2018): Weltweit wird mehr für Rüstung ausgegeben - am meisten in den USA. In: Welt, 02.05.2018, https://www.welt.de/politik/ausland/article175987998/Sipri-Weltweit-wird-mehr-fuerRuestung-ausgegeben-am-meisten-in-den-USA.html (Letzter Zugriff: 03.05.2018)

O. V. (2019): Son dakika: Bakan Akar'dan NATO'ya çağrı [Blitznachricht: Minister Akar lädt die NATO ein]. In: HÜRRIYET, Haber Giriş: 30.11.2019 - 13:30, Son Güncelleme: 30.11.201913:34, https://www.hurriyet.com.tr/gundem/son-dakika-bakan-akardan-natoya-cagri-41386375 (Letzter Zugriff: 30.11.2019)

O. V. (2020): Özbekistan Senatosundan Avrasya Ekonomik Birliğinde gözlemci statüsüne onay [Genehmigung des Beobachterstatus in der Eurasischen Wirtschaftsunion durch den Senat von Usbekistan]. In: TRTAVAZ, 11 Mayis 2020, 15:56, https://www.trtavaz.com.tr/haber/tur/avrasyadan/ozbekistan-senatosundan-avrasya-ekonomikbirliginde-gozlemci-statusune-onay/5eb94b8a01a30a1ad0d9b88c $\quad$ (Letzter Zugriff:11.05.2020) 
O. V. (o. J.): Rusya'dan Gülen okullarına yasak [Russland verbot Gülen-Schulen]. In: MILLIYET, http://www.milliyet.com.tr/Guncel/HaberDetay.aspx?aType=HaberDetayArsiv\&KategoriID $=24 \&$ $\underline{\text { ArticleID }=255638 \& \mathrm{PAGE}=1} \quad$ (Letzter Zugriff: 24.07.2017)

OBA, Ali Engin (1995): Türk Milliyetçilinin Dogusu [Die Geburt des türkischen Nationalismus]. Ankara: İmge Kitabevi.

OFFICE OF THE HISTORIAN (1945 a): Record by the United Kingdom Delegation of a Meeting at the Moscow Conference of Foreign Ministers. In: Foreign Relations of the United States:

Diplomatic Papers, 1945, General: Political and Economic Matters, Volume II, Office of the Historian, 740.00119 Council/12-2645, Moscow, December 19, 1945, https:/history.state.gov/historicaldocuments/frus1945v02/d239 (Letzter Zugriff: 22.09.2018)

OFFICE OF THE HISTORIAN (1945b): The Ambassador in the Soviet Union (Harriman) to the Secretary of State. Foreign Relations of the United States: Diplomatic Papers, 1945, The Near East and Africa, Volume VIII, 761.6711/3-2145: Telegram, Moscow, March 21, 1945, [Received March 21-6:10 p.m.], https://history.state.gov/historicaldocuments/frus1945v08/d1183 (Letzter Zugriff: 19.09.2018)

OFFICE OF THE HISTORIAN (1945c): Memorandum by the Acting Secretary of State. Foreign Relations of the United States: Diplomatic Papers, The Conference of Berlin (The Potsdam Conference), 1945, Volume I, Office of the Historian, Washington, June 18, 1945, 761.6711/61845, No. 683, https://history.state.gov/historicaldocuments/frus1945Berlinv01/d683 (Letzter Zugriff: 19.09.2018)

OFFICE OF THE HISTORIAN (1945 d): The Ambassador in Turkey (Wilson) to the Secretary of State. In: Foreign Relations of the United States: Diplomatic Papers, The Conference of Berlin (The Potsdam Conference), 1945, Volume I, Office of the Historian, 761.6711/7-345: Telegram, No. 695, Ankara, July 3, 1945-noon, https:/history.state.gov/historicaldocuments/frus1945Berlinv01/d695 (Letzter Zugriff: 19.09.2018)

OGUZ, Esedullah (2016): Kafkasya ve Orta Asya cumhuriyetlerinde IŞiD tehlikesi [IS-Gefahr im Kaukasus und in den zentralasiatischen Republiken]. In: Habertürk, 07 Temmuz 2016 Perşembe, 02:12:58, Güncelleme: 02:31:47, http://www.haberturk.com/dunya/haber/1263555-kafkasya-veorta-asya-cumhuriyetlerinde-isid-tehlikesi (Letzter Zugriff: 07.07.2016)

OKUR, Hülya (2010): Interview mit Hüseyin Hatemi: Alevilikte de Sünnilikte de Hastalik Belirtileri Var. In: haberx, 27.09.2010, 10:25, http://www.haberx.com/alevilikte_de_sunnilikte_de_hastalik_belirtileri_var(17,n,10458627,381).as px (Letzter Zugriff: 11.09.2012)

OKUR, Mehmet Akif (2011): Yeni Çağın Eşiğinden „Avrasya'nın Kalbi“ne Bakmak: Tarihten Geleceğe Orta Asya'nın Jeopolitiği Üzerine Değerlendirmeler [Blick vom Rand des neuen Zeitalters ins "Herz Eurasiens": Bewertungen der Geopolitik Zentralasiens von der Geschichte in die Zukunft]. İnceleme-Araştırma dizisi, Yayin Nr.: 05, Ankara: Hoca Ahmet Yesevi Uluslararası Türk-Kazak Üniversitesi. 
ÖNDER, Zehra (1977): Die türkische Außenpolitik im Zweiten Weltkrieg. München: R.

Oldenbourg Verlag (Südosteuropäische Arbeiten 73, herausgegeben von Mathias Bernath).

ORGANISATION OF ISLAMIC COOPERATION (2016): History. http://www.oicoci.org/oicv3/page/?p id=52\&p ref=26\&lan=en (Letzter Zugriff: 10.09.2017)

ORTAYLI, Ilber (2005): Ilber Ortayli ile Tarihin Sinirlarina Yolculuk [Reise an die Grenzen der Geschichte mit Ilber Ortayli]. Istanbul: Ufuk Kitaplari.

ORTAYLI, Ilber (2010): Osmanli Imparatorlugu nda Alman nüfuzu [Deutscher Einfluss im osmanischen Reich]. Istanbul: Timas yayinlari.

ORTAYLI, Ilber (2013): Das Osmanische Reich. Episoden seiner Geschichte. Frankfurt am Main: Literaturca Verlag.

OSCE (o. J.): Who we are. Participating State. http://www.osce.org/states

OULTCHENKO, Natalia (2003): Turkey's Strategic Future: A Russian View. Mai 2003, Center for European Policy Studies (CEPS), International Institute for Strategic Studies (IISS), http://www.isn.ethz.ch/Digital-Library/Publications/Detail/?ots591=0c54e3b3-1e9c-be1e-2c24a6a8c7060233\&lng=en\&id=22401 (Letzter Zugriff: 13.12.2014)

ÖZAL, Turgut (1991): Die Reden von türkischen Präsidenten Turgut Özal über „21. Jahrhundert wird das Jahrhundert der Türkei und Türken sein“ [Cumhurbaskani Turgut Özal’in „21. Asir Türkiye 'nin ve Türklerin Asri Olacak" konulu konusmalari]. 22 Mayis 1991, Bursa Celik Palas, Ankara: Basbakanlik Basimevi. Siehe auch T. B. M. M. Tutanak Dergisi, D. 18, Yasama yili: 5, Cilt: 63, 1. Birlesim: 1.9.1991 Pazar, https://www.tbmm.gov.tr/tutanaklar/TUTANAK/TBMM/d18/c063/tbmm18063001.pdf (Letzter Zugriff: 29.04.2014)

ÖZBAY, Fatih (2011): Soguk Savas Sonrasi Türkiye-Rusya Iliskileri: 1992-2010 [TürkischRussische Beziehungen nach dem Kalten Krieg: 1992-2010]. In: Bilge Strateji, Cilt 2, Say1 4 , Bahar 2011, S. 35-77.

ÖZDAL, Habibe (2010): Medvedev`in Türkiye Ziyareti ve Gündemdeki Konular [Medwedews Türkei-Besuch und Fragen auf der Tagesordnung]. In: USAK, 10 Mayis 2010, http://www.usakgundem.com/yazar/1580/medvedev\%E2\%80\%99in-t\%C3\%BCrkiye-ziyareti-veg\%C3\%BCndemdeki-konular.html (Letzter Zugriff: 02.07.2014)

ÖZDAMAR, Ramazan (2010): Türkiye'nin Orta Asya Politikası Eksiklikler ve Öneriler [Die türkische ZentralasienPolitik: Mängel und Vorschläge]. In: TUIC Akademi, 22 Nisan 2010, 09:14, http://www.tuicakademi.org/index.php/128-uncategorised/142-turkiyenin-orta-asya-politikasieksiklikler-ve-oneriler （Letzter Zugriff: 15.09.2013)

ÖZGAN, Osman (2016): Gerilimi artıralım Hz. Mehdi gelsin [Erhöhen wir die Spannung, damit der Mahdi kommt]. In: Yeni Safak, 13 Temmuz 2016, 04:00, http://www.yenisafak.com/gundem/gerilimi-artiralim-hz-mehdi-gelsin-2493243 (Letzter Zugriff: 12.08.2016) 
ÖZKARTAL, Mirac Zeynep (2011): Osmanlı, Oğuz soyundan değil mi? [Stammen die Osmanen nicht von Ogusen?]. In: haber7com, 15.02.2011, 10:49, GÜNCELLEME 15.02.2011 10:49, http://www.haber7.com/kitap/haber/710137-osmanli-oguz-soyundan-degil-mi (Letzter Zugriff: 07.09.2015)

ÖZLEM, Kader (2013): Kerimov Yönetiminde Özbekistan'ın İç ve Dış Politikasının Analizi (1991-2012) [Analyse der innen - und Außenpolitik Usbekistans unter Kerimov (1991-2012)]. In: Die Elektronische Zeitschrift für politikwissenschaftliche Studien. Juni 2013 Vol:4 Nr.:2, S. 29-51, http://www.academia.edu/4778722/Kerimov Y\%C3\%B6netiminde \%C3\%96zbekistan \%C4\%Bln \%C 4\%B0\% C3\%A7 ve D\%C4\%B1\%C5\%9F Politikas\%C4\%B1n\%C4\%B1n Analizi 1991-2012 (Letzter Zugriff: 15.06.2014)

ÖZLÜ, Hüsnü (2012): „Türk-Afgan Dostluk Ve İşbirliği Anlaşması““ Kapsamında Atatürk Dönemi Türkiye- Afganistan İlişkilerine Bakış [Ein Überblick über die Türkei-Afghanistan-Beziehungen während der Atatürk-Ära im Rahmen des „Türkisch - Afghanischen Freundschafts-Und Kooperationsabkommens"]. In: Uluslararası Avrasya Sosyal Bilimler Dergisi, Cilt:3, Say1:8 ss: $(31-46)$,

http://www.ijoess.com/Makaleler/1852504037 \%c3\%96zl\%c3\%bc, \%20h\%c3\%bcsn\%c3\%bc\%20 AR\%c5\%9e\%c4\%b0V\%20BELGELER\%c4\%b0\%20I\%c5\%9eI\%c4\%9eINDA.pdf (Letzter Zugriff: 13.03.2017)

PABST, Volker (2015): Pakistans Krieg: Mit zweischneidigem Schwert. In: Neue Zürchner Zeitung, 15.06.2015, 09:00 Uhr, http://www.nzz.ch/international/naher-osten-und-nordafrika/mitzweischneidigem-schwert-1.18562141 (Letzter Zugriff: 04.03.2017)

PAKSOY, H. [Hasan] B. [Bülent] (1997): Türk Tarihi [Türkische Geschichte], Toplumlarin Mayasi, Uygarlik. Izmir: Mazhar Soylu Holding.

PALMER, Robert Roswell (1978): A History of the Modern World. Fifth Edition, New York, Alfred A Knopf, S. 504-506.

PAPST, Volker (2019): Erdogan lässt die Uiguren fallen. In: Neue Zürcher Zeitung, 02.02.2019, 05.30 Uhr, https://www.nzz.ch/international/erdogan-china-wird-zum-neuen-freund-uigurenhaben-das-nachsehen-ld.1454181 (Letzter Zugriff: 12.02.2019)

PARKER, W. H. (1960): Europe: How Far? The Geographical Journal, Vol. 126, No. 3, September 1960, S. 278-297.

PASTUKHOVA, Maria/ WESTPHAL, Kirsten (2016): Ein gemeinsamer Energiemarkt in der Eurasischen Wirtschaftsunion. In: SWP-Aktuell 6, Februar 2016 (Stiftung Wissenschaft und Politik), https://www.swpberlin.org/fileadmin/contents/products/aktuel1/2016A06_Pastukhova_wep.pdf (Letzter Zugriff: $02.10 .2019)$

PAUL, Jürgen (2012): Zentralasien. Neue Fischer Weltgeschichte, Band 10, Frankfurt am Main: S. Fischer. 
PRADETTO, August (2012): Zentralasien und die Weltmächte, oder: Great Game Boys auf Reisen. Frankfurt am Main: Peter Lang (Strategische Kultur Europas, Herausgegeben von August Pradetto, Band 9).

PRÄSIDENT DER RUSSISCHEN FÖDERATION (2000): Militärdoktrin der Russischen Föderation. Bestätigt durch Erlaß des Präsidenten der Russischen Föderation, Nr. 705 vom 21. April 2000, Deutsche Übersetzung:

Dresdner Studiengemeinschaft Sicherheitspolitik (DSS), http://www.bits.de/EURA/DEURAT/Russland2de.htm (Letzter Zugriff: 14.07.2017)

PRÄSIDENT DER RUSSISCHEN FÖDERATION (2013): Konzeption der Außenpolitik der Russischen Föderation. Gebilligt vom Präsidenten der Russischen Föderation, Wladimir Putin, am 12. Februar 2013: In: Russisches Außenministerium. 303-18-02-2013, https://www.mid.ru/en/foreign_policy/official_documents//asset publisher/CptICkB6BZ29/content/id/122186?p p id=101 INSTANCE CptICkB6BZ29\& 101_INSTANCE_CptICkB6BZ29_languageId=de_DE (Letzter Zugriff: 21.05.2017)

PRÄSIDENT DER RUSSISCHEN FÖDERATION (2014): Militärdoktrin der Russischen Föderation. Sicherheitspolitik und Streitkräfte der Russischen Föderation, hrsg. von: Dresdner Studiengemeinschaft Sicherheitspolitik, DSS-Arbeitspapiere Präzisiserte Redaktion 12/2014, Heft 113 - 2015, Übersetzung aus dem Russischen: Dr. Rainer Böhme, Dresden, http://www.sicherheitspolitik-dss.de/ap/ap113000.pdf (Letzter Zugriff 10.05.2016)

PRESIDENT OF THE RUSSIAN FEDERATION (1993): Conception Of The Foreign Policy Of The Russian Federation, No: 284, 23. April 1993, https://www.dcaf.ch/.../bm_arbatov_05_concept foreignpolicy.pdf (Letzter Zugriff: 12.08.2017)

PRESIDENT OF THE RUSSIAN FEDERATION (2000): The Foreign Policy Concept Of The Russian Federation. Approved by the President V.Putin, June 28, 2000, http://www.bits.de/EURA/russia052800.pdf (Letzter Zugriff: 09.05.2016)

PRESIDENT OF THE RUSSIAN FEDERATION (2015): Russian National Security Strategy. December 2015, Fulltext Translation, [Signed] Russian Federation President V. Putin, Moscow, the Kremlin, 31 December 2015, No. 683, http://www.iee.es/Galerias/fichero/OtrasPublicaciones/Internacional/2016/Russian-NationalSecurity-Strategy-31Dec2015.pdf (letzter Zugriff: 22.05.2016)

PUTZ, Catherine (2018): Paul Stronski on Central Asia's Big Questions. In: The Diplomat, 20. November 2018, https://thediplomat.com/2018/11/paul-stronski-on-central-asias-big-questions/ (Letzter Zugriff: 20.05.2019)

QUIRING, Manfred (2009): Pulverfass Kaukasus. Konflikte am Rande des russischen Imperiums, Berlin: Ch. Links Verlag.

RAHMANOV, Akhmed (2016): Zentralasien und die Russisch-Türkische Krise. In: Novastan.org, 1. April 2016, https://www.novastan.org/de/kirgistan/zentralasien-und-die-russisch-turkische-krise/ (Letzter Zugriff: 14.07.2016) 
RAIMONDO, Justin (2016): Bekam Aserbaidschan grünes Licht von den USA für den Angriff auf Bergkarabach? In: HayPress, Armenische Nachrichten, 5. April 2016,

https:/haypressnews.wordpress.com/2016/04/05/bekam-aserbaidschan-gruenes-licht-von-den-usafuer-den-angriff-auf-bergkarabach// (Letzter Zugriff: 21.12.2016)

RASHID, Ahmed (1994): The Resurgence of Central Asia. Islam or Nationalism? Karachi: Oxford University Press und London \& New Jersey: Zed Books.

REFAH AJANS (2014): Erbakan İran konuşması: „Amerika Ne İstediyse Tersini Yaptım“ [Erbakans Iran Rede: ,ich habe genau das Gegenteil getan, was Amerika wollte"]. In: Youtube, Veröffentlicht am 14.04.2012, https://www.youtube.com/watch? $\mathrm{v}=$ GS-X19rAOIw _(Letzter Zugriff: 04.06.2016)

REINKOWSKI, Maurus (2008): Das Osmanische Reich und Europa. In: KRAMER, Heinz/REINKOWSKI, Maurus: Die Türkei und Europa. Eine wechselhafte Beziehungsgeschichte. Stuttgart: W. Kohlhammer, S. 11-102.

REPUBLIC OF TURKEY, MINISTIRY OF FOREIGN AFFAIRS (2011): Turkey's Political Relations With Russian Federation. Stand: 2011, http://www.mfa.gov.tr/turkey_s-politicalrelations-with-russian-federation.en.mfa (Letzter Zugriff: 08. August 2018)

ROBINS, Philip (1993): Between sentiment and self-interest: Turkey`s policy toward Azerbaijan and the Central Asian States. In: Middle East Journal, vol. 47, No: 4, S. 593-610.

ROTH, Klara (2015): Zentralasien und der IS: Debatten um Ursachen und Umgang mit zentralasiatischen Kämpfern. In: Zentralasienanalysen, NR. 87, 01.04.2015, S. 2-5, http://www.laender-analysen.de/zentralasien/pdf/ZentralasienAnalysen87.pdf (Letzter Zugriff: 21.08.2015)

RÖTZER, Florian (2017): "Keinen Inch weiter nach Osten": Was den Russen zur Wiedervereinigung über die Nato versprochen wurde. In: Telepolis, 15. Dezember 2017, https://www.heise.de/tp/features/Keinen-Inch-weiter-nach-Osten-Was-den-Russen-zurWiedervereinigung-ueber-die-Nato-versprochen-wurde-3918651.html? seite=all (Letzter Zugriff: 04.12.2017)

ROY, Olivier (2007): The New Central Asia. Geopolitics and the Birth of Nations. New York: I. B. Tauris.

RUDOLF, Moritz (2015): One Belt, One Road: Die Seidenstraßeninitiative. In: Merics, Mercator Institute for China Studies, Dezember 2015, http://www.merics.org/mericsanalysen/infografikchina-mapping/seidenstrassen-initiative.html (Letzter Zugriff: 18.09.2017)

RUSSKIJ MIR (2015): Ziele und Aufgaben.

http://www.russkiymir.ru/languages/germany/Tseli.htm （Letzter Zugriff: 21.04.2017)

RUSYA FEDERASYONU'NUN TÜRKIYE BÜYÜKELCILIGI (2001): Transcript of Minister of Foreign Affairs of The Russian Federation Igor Ivanov's Remarks at Press Conference Following Signing of a Russian-Turkish Document (New York, November 16, 2001), In: Rusya 
Federasyonu`nun Türkiye Büyükelciligi, 2125-17-11-2001, http://www.turkey.mid.ru/hron/31.html (Stand: 19.03.2014) (Letzter Zugriff: 08.10.2011)

SADYRBEK, Mahabat (2014): Die EU: Ein neuer Spieler auf dem „Schachbrett“ Zentralasien? In: Novastan.org, 23.05.2014, http://www.novastan.org/articles/die-eu-ein-neuer-spieler-auf-demschachbrett-zentralasien (Letzter Zugriff: 27.06.2016)

SAGORSKIJ, Andrej (2014): Zwischen Ökonomie und Geopolitik. In: HETT, Felix/SZKOLA, Susanne (Hg.): Die Eurasische Wirtschaftsunion: Analysen und Perspektiven aus Belarus, Kasachstan und Russland. In: FES Perspektive, Dezember 2014, S. 3-6, http://library.fes.de/pdffiles/id-moe/11131.pdf (Letzter Zugriff: 03.05.2016)

SAHIN, Erdal (2013): Türk Dünyasinda Yazi Birligi: Latin Alfabesi Temelinde Yeni Türk Alfabesi [Schriftliche Einheit in der türkischen Welt: Das neue türkische Alphabet auf der Basis des lateinischen Alphabets]. In: Yeni Türkiye, Sayı 53, S. 449-457.

SALZEN, Claudia von (2015): Deutschland und der Afghanistan-Einsatz. Neuer Geheimvertrag mit Usbekistan. In: Der Tagesspiegel, 05.01.2015, http://www.tagesspiegel.de/politik/deutschlandund-der-afghanistan-einsatz-neuer-geheimvertrag-mit-usbekistan/11183182.html (Letzter Zugriff: 27.07.2015)

SANCAKTAR, Caner (2010): Balkanlar Türkiye İçin Neden Önemli? [Warum ist der Balkan für die Türkei wichtig?]. In: TASAM, Türkiye Stratejik Arastirmalar Merkezi, 27 May 2010, https://tasam.org/tr-TR/Icerik/71/balkanlar turkiye icin neden onemli (Letzter Zugriff: 14.01.2014)

SANDER, Oral (2000): Siyasi Tarih: İlkçağlardan 1918'e [Politische Geschichte: von den Anfängen bis 1918]. 8. baski, Ankara: İmge.

SANDIKLI, Atilla (2006): Önsöz [Vorwort]. In: KOLOBOV, Oleg A./KORNILOV, Aleksandr A./ÖZBAY, Fatih: Cagdas Türk-Rus Iliskileri. Sorunlar ve Isbirligi Alanlari (1992-2005), Istanbul: Tasam Yayinlari (Uluslararasi Iliskiler Serisi: 10).

SAPMAZ, Ahmet (2008): Rusya'nın Transkafkasya Politikası ve Türkiye’ye Etkileri [Transkaukasische Politik Russlands und ihre Auswirkungen auf die Türkei]. İstanbul: Ötüken Yayınları.

SAROVIC, Alexander/SCHNEIDER, Anna-Sophie (2019): Sipri-Studie: Das sind die größten Waffenlieferanten der Welt. In: Spiegel Online, Montag, 11.03.2019, 12:57 Uhr, http://www.spiegel.de/politik/ausland/sipri-studie-das-sind-die-groessten-waffenlieferantenweltweit-a-1256580.html (Letzter Zugriff: 21.05.2019)

SATKE, Ryskeldi/MICHEL, Casey/KORKMAZ, Sertaç (2014): Turkey in Central Asia: Turkic Togetherness? In: The Diplomat, 28 November 2014, http://thediplomat.com/2014/11/turkey-incentral-asia-turkic-togetherness/ (Letzter Zugriff: 21.12.2014) 
SATPAJEW, Dossym (2014): Die Eurasische Wirtschaftsunion als geopolitisches Instrument und Wirtschaftsraum. Eine Analyse aus Kasachstan, In: Friedrich-Ebert-Stiftung, Perspektive, Juli 2014, http://library.fes.de/pdf-files/id-moe/10810.pdf （Letzter Zugriff: 17.03.2015)

SATRA, Daniel (2019): Chinas Plan für 2049. In: Tagesschau.de, Stand: 26.03.2019, 16:17 Uhr, https://www.tagesschau.de/ausland/neue-seidenstrasse-101.html (Letzter Zugriff: 18.04.2019)

SCHIEK, Sebastian (2016): Zentralasien und die Eurasische Wirtschaftsunion: Zustimmung trotz Krise. Warum die Bevölkerung noch hinter dem Integrationsprojekt steht. In: SWP-Aktuell, 31, April 2016.

SCHIMMELFENNING, Frank (2009): Internationale Polititik. Gegenstand, Probleme, Fragestellungen, in: LAUTH, Hans-Joachim/WAGNER, Christian/ (Hrsg.) (2009):

Politikwissenschaft: Eine Einführung. 6.überarb. und veränd. Auflage, Schöningh: Paderborn, München, Wien, S. 135-162.

SCHIRRMACHER, Christine (2009): Schiiten und Sunniten-Unterschiede der islamischen „Konfessionen“, http://www.islaminstitut.de/uploads/media/Schiiten.pdf (Letzter Zugriff: 21.05.2019)

SCHMIESTER, Carsten (2019): SIPRI-Bericht: USA bleiben größter Waffenexporteur der Welt. In: tagesschau.de, Stand: 11.03.2019, 00:34 Uhr, https://www.tagesschau.de/ausland/sipriwaffenexporte-101.html (Letzter Zugriff: 21.05.2019)

SCHMOLLER, Jesko (2018): Zentralasiatische Region: Einfluss und Rolle des Islamismus und dschihadistischen Terrorismus. In: bpb, Bundeszentrale für politische Bildung, 20.3.2018, http://www.bpb.de/internationales/weltweit/innerstaatliche-konflikte/266547/einfluss-und-rolledes-islamismus\#footnode2-2 (Letzter Zugriff: 10.03.2019)

SCHOLVIN, Sören (2009): Ein neues Great Game um Zentralasien? In: GIGA Focus, Nr. 2, https://www.giga-hamburg.de/de/system/files/publications/gf global 0902.pdf (Letzter Zugriff:03.12.2011)

SCHÖRNIG, Niklas (2006): Neorealismus. In: Schieder, Siegfried/Spindler, Manuela (Hrsg.): Theorien der Internationalen Beziehungen. 2. Überarb. Aufl., Opladen, Farmington Hills: Verlag Barbara Budrich, S.65-92.

SCHRAPEL, Thomas/FEYERABEND, Florian Constantin (2016): Konflikt um Berg-Karabach: Droht ein neuer Krieg im Südkaukasus? In: KAS, Tbilisi, 5. Apr. 2016, http://www.kas.de/wf/de/33.44750/ (Letzter Zugriff: 05.04.2016)

SCHUBERT, Klaus/KLEIN, Martina (2016): Das Politiklexikon. 6., aktual. u. erw. Aufl. Bonn: Dietz 2016. Lizenzausgabe Bonn: Bundeszentrale für politische Bildung. http://www.bpb.de/nachschlagen/lexika/politiklexikon/17607/hegemonie （Letzter Zugriff: 28.11.2018) 
SCHÜTZ, Birger (2019): Der Abstieg zum Rohstoff-Lieferer. In: Moskauer Deutsche Zeitung, 11.03.2019, https://mdz-moskau.eu/der-abstieg-zum-rohstoff-lieferer/ (Letzter

Zugriff:19.03.2019)

SEEBAß,Gottfried (2006): Geschichte des Christentum III. Spätmittelalter - Reformation Konfessionalisierung, Stuttgart: Kohlhammer.

SEEWALD, Berthold (2014): Darum hängen die Russen an der ukrainischen Krim. In: Die Welt, 27.02.14, http://www.welt.de/geschichte/article125245826/Darum-haengen-die-Russen-an-derukrainischen-Krim.html (Letzter Zugriff: 27.02.2014)

SEIDEL, Eberhard/DANTSCHKE, Claudia/YILDIRIM, Ali (2001): Politik im Namen Allahs. Der Islamismus - eine Herausforderung für Europa. Hrsg. von Ozan CEYHUN, Stand 30. September 2001, http://www.thegreatdebate.eu/pdf/Muslims\%20in\%20Germany/politik_im_namen_allahs.pdf (Letzter Zugriff: 21.12.2012)

SEIFERT, Arne C. (2012): Der politische Islam in Zentralasien - Gegner oder demokratischer Partner? Hamburg, November 2012: CORE Working Paper 25, http://ifsh.de/fileCORE/documents/CORE\%20WP25.pdf (Letzter Zugriff: 04.08.2015)

SEMIZ, Yasar (2014): İttihat ve Terakki Cemiyeti ve Türkçülük Politikası [Komitee der Vereinigung und Fortschritt und pantürkistische Politik], Konya: Selçuk Üniversitesi Türkiyat Araştırmaları Dergisi, S. 217-244.

SEN, Faruk (2001): Kaukasus und Mittelasien: neue gemeinsame Interessenssphären für die Länder der Europäischen Union und der Türkei. In: SEN, Faruk/HILL, Bernhard (Hrsg.): Kaukasus, Mittelasien, Nahost - Gemeinsame Interessen von EU und Türkei, München: Hans Seidel Stiftung. S. 64-72.

SEUFERT, Günter (2002): Offener Streit um EU-Option in der Türkei. In: Berliner Zeitung, 19.03.2002, http://www.berliner-zeitung.de/archiv/reformforderungen-bruessels-wurden-nur-zumteil-erfuellt-offener-streit-um-eu-option-in-der-tuerkei,10810590,9983080.html (Letzter Zugriff: 26.05.2014)

SEZER, Mustafa (2013): Schengen olmazsa Şanghay [Wenn nicht Schengen, dann Shanghai]. In: Türkiye, 28.01.2013 - 01:00, Son Güncelleme: 28.01.2013 - 01:00, http://www.turkiyegazetesi.com.tr/Genel/a563034.aspx ～(Letzter Zugriff: 29.01.2013)

SHTALTOVNA, Anastasiya/HORNIDGE, Anna-Katharina (2005): Zwischen staatlicher Kontrolle und Liberalisierung. Baumwollanbau in Usbekistan und kasachstan im Vergleich. In: ZENTRALASIEN-ANALYSEN NR. 86, 06.03.2015, S. 2-8, https://www.laenderanalysen.de/zentralasien/pdf/ZentralasienAnalysen86.pdf (Letzter Zugriff: 06.03.2015)

SIDIKOV, Bahodir (2004): Endecker. In: STEINBACH, Udo/GUMPPENBERG, Marie-Carin von (Hrsg.): Zentralasien. Geschichte, Politik, Wirtschaft, Ein Lexikon, München: C.H. Beck, S. 67-72. 
SIEDSCHLAG, Alexander (2004): Neorealismus in der Theorie internationaler Politik. In: Innsbruck Forum on International Relations, IFIR Tutorial, Dezember2004, http://www.ifir.at/pdf/Tutorial/Siedschlag Neorealismus.pdf (Letzter Zugriff: 10.11.2009).

ŞIK, Ahmet (o. J.): Imamin Ordusu [Armee des Imams]. https://imaminordusuindir.wordpress.com/2011/04/03/ataturkcu-evren\%E2\%80\%99den-inciler/ (Letzter Zugriff: 29.02.2015)

SIMON, Gerhard (1991): Die Desintegration der Sowjetunion durch die Nationen und Republiken, in: Berichte des Bundesinstituts für ostwissenschaftliche und internationale Studien, Nr. 25/1991.

SIMSIRGIL, Ahmet (2016): Asrin Ihanetinin Analizi [Analyse des Verrats des Jahrhunderts]. In: ahmetsimsirgil.com, 28 Tem 2016, 16:59, http://ahmetsimsirgil.com/asrin-ihanetinin-analizi/ (Letzter Zugriff: 28.07.2016)

SINELSCHTSCHIKOWA, Jekaterina (2016): Halbinsel Krim: Sieben Fragen und Antworten. In: Russia Beyond The Headlines, 15. März 2016, http://de.rbth.com/gesellschaft/2016/03/15/halbinsel-krim-sieben-fragen-und-antworten_576001 (Letzter Zugriff: 11.03.2016)

SMIRNOVA, Julia (2015): Putin will Erdogan auf den Knien sehen. In: Welt, 01.12.2015, https://www.welt.de/politik/ausland/article149492882/Putin-will-Erdogan-auf-den-Kniensehen.html (Letzter Zugriff: 19.01.2016)

SMIRNOVA, Julia (2016a): Aus Ignoranz wurde Russland zur HIV-Hochburg. In: Welt, Veröffentlicht am 01.12.2016, https://www.welt.de/gesundheit/article159872331/Aus-Ignoranzwurde-Russland-zur-HIV-Hochburg.html (Letzter Zugriff: 21.01.2017)

SMIRNOVA, Julia (2016b): In Bergkarabach prallt Putins Ego auf Erdogans. In: Die Welt, 03.04.2016, http://www.welt.de/politik/article153953260/In-Bergkarabach-prallt-Putins-Ego-aufErdogans.html (Letzter Zugriff: 03.04.2016)

SOFUOGLU, Ebubekir (2009): Osmanli Sultani Halifenin Orta Asya ve Hindistan Müslümanlari Üzerindeki Etkinligi [Der Einfluss des osmanischen Sultans und Kalifs auf die Muslime Zentralasiens und Indiens]. In: COMAK, Ihsan (Hrsg.): Rusya Calismalari. Stratejik Arastirmalar 2, Istanbul: Tasam Yayinlari (Uluslararasi Iliskiler Serisi: 19), S. 225-243.

SOMUNCUOGLU, Anar (2011): Rusya-Orta Asya Iliskilerinde Kollektif Güvenlik [Kollektive Sicherheit in den Beziehungen zwischen Russland und Zentralasien]. In: 21. Yüzyil Türkiye Entsitüsü, Bilim, Birlik, Baris. 05 Ocak 2011, Carsamba, http://www.21yyte.org/tr/arastirma/ortaasya-arastirmalari-merkezi/2011/01/05/6053/rusya-orta-asya-iliskilerinde-kolektif-guvenlik (Letzter Zugriff: 05.01.2011)

SOMUNCUOĞLU, Tümen (2008): 19. Asir Sonu 20. Asir Başlarinda İdil boyu Tatarlarinin Türkistan'daki Faaliyetleri [Aktivitäten der Idil-Tataren in Turkistan am Ende des 19. und Anfang des 20. Jahrhunderts]. In: Türk Dünyası İncelemeleri Dergisi / Journal of Turkish World Studies, Cilt: VIII, Say1 2, Sayfa: 87-101, İZMIR 2008. 
SONN, Tamara (2005 [2004]): A Brief History of Islam. Malden, Oxford, Carlton: Blackwell Publishing.

SOUCEK, Svat (2003): A History of Inner Asia. Cambridge, New York, Melbourne: Cambridge University Press.

SOULEIMANOV, Emil (2004): Der Konflikt um Berg-Karabach. In: OSZE - Jahrbuch 2004, S.217-236, http://www.core-hamburg.de/documents/jahrbuch/04/Suleimanow-dt.pdf) (Lezter Zugriff: 10.04.2010)

SPINDLER, Manuela (2006): Interdependenz. In: Schieder, Siegfried/Spindler, Manuela (Hrsg.): Theorien der Internationalen Beziehungen. 2. Überarb. Aufl., Opladen, Farmington Hills: Verlag Barbara Budrich, S. 93-120.

STADELBAUER, Jörg (2003): Mittelasien - Zentralasien: Raumbegriffe zwischen wissenschaftlicher Strukturierung und politischer Konstruktion. In: Petermanns Geographische Mitteilungen 147 (5): S. 58-63.

STADELBAUER, Jörg (2004a): Archäologie und Frühgeschichte. In: STEINBACH, Udo/GUMPPENBERG, Marie-Carin von: Zentralasien. Geschichte, Politik, Wirtschaft. München: C.H. Beck, S. 26-32.

STADELBAUER, Jörg (2004b): Zentralasien als Begriff. In: STEINBACH, Udo/GUMPPENBERG, Marie-Carin von (Hrsg.): Zentralasien. Geschichte, Politik, Wirtschaft, Ein Lexikon, München: C.H. Beck, S. 318-326.

STALIN, J. [Josef] W. [Wissarionowitsch] (1951): Werke, 4. November 1917-1920, herausgegeben auf Beschluss des Zentralkomitee der Kommunistischen Partei der Sowjetunion (Bolschewiki), die deutsche Ausgabe erscheint auf Beschluss des Zetralkomitees der Sozialistischen Einheitspartei Deutschlands, Berlin: Dietz Verlag, http://www.kpdml.org/doc/partei/stalin-band04.pdf (Letzter Zugriff: 12.11.2016)

STATISTA (2020a): Russland: Wichtigste Importländer im Jahr 2017. https://de.statista.com/statistik/daten/studie/171409/umfrage/wichtigste-importlaender-fuerrussland// (Letzter Zugriff: 07.07.2020)

STATISTA (2020b): Russland: Wichtigste Exportländer im Jahr 2018. https://de.statista.com/statistik/daten/studie/171398/umfrage/wichtigste-exportlaender-fuerrussland// (Letzter Zugriff: 07.07.2020)

STATISTISCHES BUNDESAMT (2017): Bruttoinlandsprodukt (BIP) je Einwohner, jeweilige Preise. Letzte Aktualisierung: 13.12.2017, https://www.destatis.de/DE/ZahlenFakten/LaenderRegionen/Internationales/Thema/Tabellen/Basist abelle_BIPproKopf.html (Letzter Zugriff: 22.05.2018)

STEIN, Claudia (2004): Raumstruktuelle Wirkungen von Transformation. Mittelasien und das Fergana-Tal, Frankfurt am Main: Peter Lang (Europäische Hochschulschriften, Reihe IV, Geographie und Heimatkunde, Bd./Vol. 25). 
STEINBACH, Udo (2007 [2000]): Geschichte der Türkei. München: C.H. Beck. 4., durchgesehene und aktualisierte Auflage.

STEINBACH, Udo (2010): Türkei - Politik in historischem Hinterland. In: STEINBACH, Udo/GUMPPENBERG, Marie-Carin von (Hrsg.): Der Kaukasus. Geschichte - Kultur - Politik, 2., neubearbeitete Auflage, München: C.H. Beck, S. 92-102.

STEINER, Eduard (2010): Blutige Unruhen: Russland verwehrt Kirgisistan Hilfe. In: Die Presse, 12.06.2010, 17:04, https://diepresse.com/home/politik/aussenpolitik/573200/Blutige-

Unruhen_Russland-verwehrt-Kirgisistan-Hilfe (Letzter Zugriff: 14.06.2010)

STEINER, Eduard (2016): Die ausweglose Öl-Misere des Wladimir Putin. In: Die Welt, 11.02.16, http://www.welt.de/wirtschaft/article152060829/Die-ausweglose-Oel-Misere-des-Wladimir-

Putin.html (Letzter Zugriff: 11.02.2016)

STRITTMATTER, Kai (2018): Peking will Muslime in Lagern umerziehen. In: Süddeutsche Zeitung, 19. Juni 2018, 20:21 Uhr, https://www.sueddeutsche.de/politik/volksrepublik-chinapeking-will-muslime-in-lagernumerziehen-1.4019185 (Letzter Zugriff: 19.07.2018)

SULTANOW, Bulat (2016): Stabilität in Zentralasien - Ein pessimistischer Blick aus Kasachstan. In: ZENTRALASIEN-ANALYSEN NR. 97, 29.01.201, S. 2-8.

T. C. BASBAKANLIK DEVLET ARSIVLERI GENEL MÜDÜRLÜGÜ (1996): Balkan ülkelerinin tarihi kaynaklari bakimindan Basbakanlik Osmanli Arsivi`nin Önemi [Die Bedeutung des osmanischen Archivs des Premierminister in Bezug auf die historischen Ressourcen der Balkanländer]. Ismet Inark, Devlet Arsivleri Genel Müdürü, Yayin Nu: 6, Ankara 1996, https://www.devletarsivleri.gov.tr/varliklar/dosyalar/eskisiteden/yayinlar/genel-mudurlukyayinlar/balkan \%C3\%BClkelerinin tarihi kaynaklari bakimindan basbakanlik osmanli arsivini n \%C3\%B6nemi.pdf (Letzter Zugriff: 13.11.2012)

\section{T. C. BASBAKANLIK, TIKA (TÜRK ISBIRLIGI VE KOORDINASYON AJANSLIGI} BASKANLIGI) (2015): Hakkimizda. http://www.tika.gov.tr/tr/sayfa/hakkimizda-14649 (Letzter Zugriff: 04.04.2016)

T.C. BASBAKANLİK DEVLET ARSIVLERİ GENEL MÜDÜRLÜGÜ (Hrsg.) (1992): Osmanli Devleti ile Kafkasya, Türkistan ve Kirim hanliklari arasindaki münasebetlere dair arsiv belgeleri (1687-1908) [Archivdokumente über die Beziehungen zwischen dem Osmanischen Reich und dem Kaukasus, Turkestan und den Khanaten Kirim (1687-1908)]. Osmanli Arsivi Daire Baskanligi, Yayin Nu: 3, Ankara- Haziran 1992.

T.C. BASBAKANLIK KAMU DIPLOMASISI KOORDINATÖRLÜGÜ (o. J.): Türkiye'nin 2014 yılı yardımları \% 47,3'lük artışla 6,4 milyar dolara çıktı [Türkeis Hilfe stieg 2014 um 47,3\% auf 6,4 Milliarden Dollar]. http://kdk.gov.tr/haber/turkiyenin-2014-yili-yardimlari-473luk-artisla-64milyar-dolara-cikti/590 (Letzter Zugriff: 28.07.2016)

TANAP (2016): Hakkimizda [Über uns]. http://www.tanap.com/kurumsal/hakkimizda/ (Letzter Zugriff: 03.03.2017) 
TAPPEINER, Julia (2018): Highway to Heroin - vom Drogenhandel und Neuen Konsum in Zentralasien. In: Novastan, 06.01.2018, https://www.novastan.org/de/kirgistan/highway-to-heroinvom-drogenhandel-und-neuen-konsum-in-zentralasien/ (Letzter Zugriff: 08.01.2018)

TARASSOW, Stanislaw (2014): Zusammenarbeit Russlands mit der Türkei. In: http://german.ruvr.ru/2014 04 18/Zusammenarbeit-Russlands-mit-der-Turkei-0235/ (Letzter Zugriff: 13.03.2015)

TARIHI BILGI (o. J.): Ayastefanos ve Berlin Antlaşmalarının Kısaca Maddeleri ve Aralarındaki Farklar. In: TarihiBilgi.org, https://tarihibilgi.org/ayastefanos-ve-berlin// (Letzter Zugriff: 28.04.2017)

TARIHI OLAYLAR (o. J.): Sadabad Pakti. In: Tarihi Olaylar, https://www.tarihiolaylar.com/tarihi-olaylar/sadabat-pakti-1369 (Letzter Zugriff: 21.11.2017)

TASHAN, Seyfi (2009): The Caucasus and Central Asia: Strategic Implications. Diş Politika Foreign Policy, Issue: 1/2009, pages: 344-367, https://www.ceeol.com/search/articledetail?id=154734 (Letzter Zugriff: 12.10.2016)

TASTEKIN, Fehim (2015): IŞiD Kafkasya'ya da bela oluyor [IS sorgt auch im Kaukasus für Ärger]. In: Radikal, 23.06.2015, http://www.radikal.com.tr/yazarlar/fehim-tastekin/isidkafkasyaya-da-bela-oluyor-1383829/ (Letzter Zugriff:23.06.2015)

TECSON (2018): Entwicklung der Erdölpreise (1970-2017): Die Ölpreisentwicklung im Rückblick. https://www.tecson.de/historische-oelpreise.html (Letzter Zugriff:04.01.2019)

TELLAL, Erel (2012): Rusya ve Türkiye'nin Avrasya'daki işbirliği,ilişkilerin önünü açacaktır [Die türkisch-russische Zusammenarbeit in Eurasien wird den Weg für ihre bilateralen Beziehungen öffnen]. In: The Voice of Russia, 27 Aralik 2012, 11:54, http://tr.sputniknews.com/turkish.ruvr.ru/2012_12_27/Rusya-Turkiye-Avrasya/ (Letzter Zugriff:31.12.2012)

TEMENA, Özlem (2017): Ergenokon'dan Erdoğan'a: Kızıl Elma! [Von Ergenokon bis Erdogan: Roter Apfel]. In: Gazete Duvar, 23 Eki 2017, (Son Güncelleme 22:24), https://www.gazeteduvar.com.tr/politika/2017/10/23/ergenokondan-erdogana-kizil-elma/ (Letzter Zugriff:23.10.2017)

THE GOVERNMENT OF THE REPUBLIK OF ARMENIA (1990): Armenian Declaration of Independence. Yerevan, August 23, 1990, http://www.gov.am/en/independence/ (Letzter Zugriff:23.03.2011)

THE MINISTRY OF FOREIGN AFFAIRS OF THE RUSSIAN FEDERATION (2016): Konzeption der Außenpolitik der Russischen Föderation (gebilligt von Präsident der Russischen Föderation, Wladimir Putin, am 30. November 2016), 2232-01-12-2016, http://www.mid.ru/en/foreign policy/official documents/lasset publisher/CptICkB6BZ29/content/id/2542248?p p id=101_INSTANCE CptICkB6BZ29\& 101 INSTANCE CptICkB6BZ29 languageId=de DE (Letzter Zugriff: 12.12.2016) 
THIMM, Johannes (2018): Nato: Die ungleiche Lastenteilung ist die Kehrseite amerikanischer Vorherrschaft. In: SWP, Stiftung Wissenschaft und Politik, Deutsches Institut für Internationale Politik und Sicherheit, 30.08.2018, https://www.swp-berlin.org/kurz-gesagt/2018/nato-dieungleiche-lastenteilung-ist-die-kehrseite-amerikanischer-vorherrschaft/ (Letzter Zugriff: 21.12.2018)

TIEZZI, Shannon (2015): The China-Pakistan Alliance: The Key to Afghan Stability? In: The Diplomat, 11. February 2015, http://thediplomat.com/2015/02/the-china-pakistan-alliance-the-keyto-afghan-stability/ (Letzter Zugriff: 15.02.2015)

TIMTSCHENKO, Viktor (2015): Back to the USSR? In: mdr, Mitteldeutscher Rundfunk, Veröffentlicht: Februar 2015, https://www.mdr.de/heute-imosten/eurasische wirtschaftsunion100 cpage-4 page-2 zc-6380e5e1.html (Letzter Zugriff:14.04.2016)

TINC, Ferai (2000): Türkiye, Orta Asya`dan Siliniyor [Türkiye, Orta Asya'dan Siliniyor]. In: Hürriyet, 30 Nisan 2000, http://hurarsiv.hurriyet.com.tr/goster/haber.aspx?id=-150959 (Letzter Zugriff:02.05.2017)

TOKER, Mustafa (2004): İsmail Gaspirali ve "Dilde Birlik" fikri üzerine [Ismail Gaspirali und über die Idee der „Einheit in der Sprache“]. In: Dergipark, S. 31-45, https://dergipark.org.tr/download/article-file/258101_(Letzter Zugriff: 16.05.2017)

TOPAL, Coşkun (2018): „Türk-Rus İlişkileri ve Moskova Anlaşması“ [Türkisch-russische Beziehungen und Moskauer Abkommen]. Karadeniz Araştırmaları Enstitüsü Dergisi, 4/6, S.313330, http://www.ktu.edu.tr/dosyalar/karendergi 624d1.pdf (Letzter Zugriff: 25.01.2019)

TORBAKOV, Igor (2007): Making Sense of the Current Phase of Turkish-Russian Relations. In: The Jamestwon Foundation, Occasional Paper, October 2007, S. 1-19.

TRACECA (o. J.): TRACECA Member Countries, Last updated: 02 February 2012, http://www.traceca-org.org/en/countries/ (Letzter Zugriff: 12.09.2018)

TRADE MAP (2017): Trade statistics for international business development, Monthly, quarterly and yearly trade data. Import \& export values, volumes, growth rates, market shares, etc., https://www.trademap.org/

TRADE MAP (2017): Bilateral trade between Kazakhstan and China. Product: TOTAL All products. http://www.trademap.org/Bilateral_TS.aspx?nvpm=1|398||156||TOTAL|||2|1|1|2|2|1|1|1|1 (Letzter Zugriff: 22.10.2018)

TRADE MAP (2017): Bilateral trade between Kazakhstan and Germany. Product: TOTAL All products, http://www.trademap.org/Bilateral_TS.aspx?nvpm=1|398||276||TOTAL|||2|1|1|1|2|1|1|1|1 (Letzter Zugriff: 22.10.2018)

TRADE MAP (2017): Bilateral trade between Kazakhstan and Germany. Product: TOTAL All products, http://www.trademap.org/Bilateral TS.aspx?nvpm=1|398||276||TOTAL|||2|1|1|1|2|1|1|1|1 (Letzter Zugriff: 22.10.2018) 
TRADE MAP (2017): Bilateral trade between Kazakhstan and Italy. Product: TOTAL All products, http://www.trademap.org/Bilateral_TS.aspx?nvpm=1|398||381||TOTAL|||2|1|1|2|2|1|1|1|1 (Letzter Zugriff: 22.10.2018)

TRADE MAP (2017): Bilateral trade between Kazakhstan and Russian Federation. Product: TOTAL All products, http://www.trademap.org/Bilateral TS.aspx?nvpm=1|398||643||TOTAL||2|1|1|2|2|1|1|1|1 (Letzter Zugriff: 22.10.2018)

TRADE MAP (2017): Bilateral trade between Kazakhstan and Russian Federation. Product: TOTAL All products, http://www.trademap.org/Bilateral TS.aspx?nvpm=1|398||643||TOTAL|||2|1|1|1|2|1|1|1|1 (Letzter Zugriff: 22.10.2018)

TRADE MAP (2017): Bilateral trade between Kazakhstan and Turkey. Product: TOTAL All products, http://www.trademap.org/Bilateral_TS.aspx?nvpm=1|398||792||TOTAL||2|1|1|2|2|1|1|1|1 (Letzter Zugriff: 22.10.2018)

TRADE MAP (2017): Bilateral trade between Kazakhstan and Turkey. Product: TOTAL All products, http://www.trademap.org/Bilateral_TS.aspx?nvpm=1|398||792||TOTAL|||2|1|1|1|2|1|1|1|1 (Letzter Zugriff: 22.10.2018)

TRADE MAP (2017): Bilateral trade between Kyrgyzstan and China. Product: TOTAL All products, http://www.trademap.org/Bilateral_TS.aspx?nvpm=1|417||156||TOTAL|||2|1|1|1|2|1|1|1|1 (Letzter Zugriff: 22.10.2018)

TRADE MAP (2017): Bilateral trade between Kyrgyzstan and Kazakhstan. Product: TOTAL All products, http://www.trademap.org/Bilateral TS.aspx?nvpm=1|417||398||TOTAL|||2|1|1|2|2|1|1|1|1 (Letzter Zugriff: 22.10.2018)

TRADE MAP (2017): Bilateral trade between Kyrgyzstan and Russian Federation. Product: 99 Commodities not elsewhere specified. https://www.trademap.org/Bilateral TS.aspx?nvpm=1|417||643||99||4|1|1|2|2|1|1|1|1 (Letzter Zugriff: 22.10.2018)

TRADE MAP (2017): Bilateral trade between Kyrgyzstan and Russian Federation. Product: TOTAL All products, http://www.trademap.org/Bilateral TS.aspx?nvpm=1|417||643||TOTAL|||2|1|1|2|2|1|1|1|1 (Letzter Zugriff: 22.10.2018)

TRADE MAP (2017): Bilateral trade between Kyrgyzstan and Switzerland. Product: TOTAL All products, http://www.trademap.org/Bilateral_TS.aspx?nvpm=1|417||757||TOTAL||2|1|1|2|2|1|1|1|1 (Letzter Zugriff: 22.10.2018)

TRADE MAP (2017): Bilateral trade between Kyrgyzstan and Turkey. Product: TOTAL All products, http://www.trademap.org/Bilateral_TS.aspx?nvpm=1|417||792||TOTAL|||2|1|1|2|2|1|1|1|1 (Letzter Zugriff: 22.10.2018) 
TRADE MAP (2017): Bilateral trade between Tajikistan and China. Product: TOTAL All products, https://www.trademap.org/Bilateral_TS.aspx?nvpm=1|762||156||TOTAL||2|1|1|1|2|1|1|1|1 (Letzter Zugriff: 22.10 .2018 )

TRADE MAP (2017): Bilateral trade between Tajikistan and Kazakhstan. Product: TOTAL All products, http://www.trademap.org/Bilateral_TS.aspx?nvpm=1|762||398||TOTAL|||2|1|2|2|2|1|1|1|1 (Letzter Zugriff: 22.10.2018)

TRADE MAP (2017): Bilateral trade between Tajikistan and Russian Federation. Product: TOTAL All products.

https://www.trademap.org/Bilateral TS.aspx?nvpm=1|762||643||TOTAL|||2|1|1|1|2|1|1|1|1 (Letzter Zugriff: 22.10 .2018 )

TRADE MAP (2017): Bilateral trade between Tajikistan and Switzerland. Product: TOTAL All products. https://www.trademap.org/Bilateral_TS.aspx?nvpm=1|762||757||TOTAL|||2|1|1|2|2|1|1|1|1 (Letzter Zugriff: 22.10.2018)

TRADE MAP (2017): Bilateral trade between Tajikistan and Turkey. Product: TOTAL All products.. https://www.trademap.org/Bilateral_TS.aspx?nvpm=1|762||792||TOTAL||2|1|1|1|2|1|1|1|1 (Letzter Zugriff: 22.10.2018)

TRADE MAP (2017): Bilateral trade between Turkey and Turkmenistan. Product: TOTAL All products, http://www.trademap.org/Bilateral_TS.aspx?nvpm=1|792||795||TOTAL|||2|1|1|2|2|1|1|1|1 (Letzter Zugriff: 22.10.2018)

TRADE MAP (2017): Bilateral trade between Turkmenistan and China. Product: TOTAL All products, https://www.trademap.org/Bilateral_TS.aspx?nvpm=1|795||156|TOTAL||2|1|2|2|2|1|1|1|1 (Letzter Zugriff: 22.10.2018)

TRADE MAP (2017): Bilateral trade between Turkmenistan and Germany. Product: TOTAL All products, http://www.trademap.org/Bilateral TS.aspx?nvpm=1|795||276||TOTAL|||2|1|2|1|2|1|1|1|1 (Letzter Zugriff: 22.10.2018)

TRADE MAP (2017): Bilateral trade between Turkmenistan and Italy. Product: TOTAL All products, http://www.trademap.org/Bilateral_TS.aspx?nvpm=1|795||381||TOTAL||2|1|2|2|2|1|1|1|1 (Letzter Zugriff: 22.10.2018)

TRADE MAP (2017): Bilateral trade between Turkmenistan and Russian Federation. Product: TOTAL All products, https://www.trademap.org/Bilateral_TS.aspx?nvpm=1|795||643||TOTAL||2|1|2|1|2|1|1|1|1 (Letzter Zugriff: 22.10 .2018 )

TRADE MAP (2017): Bilateral trade between Uzbekistan and China. Product: TOTAL All products, http://www.trademap.org/Bilateral_TS.aspx?nvpm $=1|860||156| \mid$ TOTAL|||2|1|2|1|2|1|1|1|1 (Letzter Zugriff: 22.10.2018)

TRADE MAP (2017): Bilateral trade between Uzbekistan and Korea, Republic of. Product: TOTAL All products, 
http://www.trademap.org/Bilateral TS.aspx?nvpm=1|860||410||TOTAL||2|1|2|1|2|1|1|1|1 (Letzter Zugriff: 22.10.2018)

TRADE MAP (2017): Bilateral trade between Uzbekistan and Russian Federation. Product: TOTAL All products, http://www.trademap.org/Bilateral TS.aspx?nvpm=1|860||643||TOTAL|||2|1|2|1|2|1|1|1|1 (Letzter Zugriff: 22.10.2018)

TRADE MAP (2017): Bilateral trade between Uzbekistan and Switzerland. Product: TOTAL All products, http://www.trademap.org/Bilateral TS.aspx?nvpm=1 |860||757||TOTAL|||2|1|2|2|2|1|1|1|1 (Letzter Zugriff: 22.10.2018)

TRADE MAP (2017): Bilateral trade between Uzbekistan and Turkey. Product: TOTAL All products, http://www.trademap.org/Bilateral TS.aspx?nvpm=1 |860||792||TOTAL|||2|1|2|2|2|1|1|1|1 (Letzter Zugriff: 22.10.2018)

TRADE MAP (2017): List of products exported by Kazakhstan http://www.trademap.org/Product_SelCountry_TS.aspx?nvpm=1|398||||TOTAL|||2|1|1|2|2|1|1|1|1 (Letzter Zugriff: 22.10.2018)

TRADE MAP (2017): List of importing markets for a product exported by Kazakhstan. https://www.trademap.org/Country SelProductCountry TS.aspx?nvpm=1|398|||TOTAL|| 2|1|1|2|2|1|2|1 (Letzter Zugriff: 22.10.2018)

TRADE MAP (2017): List of importing markets for a product exported by Turkmenistan. Product: TOTAL All products.

http://www.trademap.org/Country SelProductCountry TS.aspx?nvpm=1|795||||TOTAL|||2|1|2|2|2|1 2|1|1 (Letzter Zugriff: 22.10.2018)

TRADE MAP (2017): List of importing markets for a product exported by Uzbekistan (Mirror). Product: TOTAL All products, http://www.trademap.org/Country SelProductCountry TS.aspx?nvpm=1|860||||TOTAL|||2|1|2|2|2|1 2|1|1 (Letzter Zugriff: 22.10.2018)

TRADE MAP (2017): List of importing markets for a product exported by Kyrgyzstan. Product: TOTAL All products, http://www.trademap.org/Country SelProductCountry TS.aspx?nvpm=1|417||||TOTAL||2|1|1|2|2|1 2|1|1 (Letzter Zugriff: 22.10.2018)

TRADE MAP (2017): List of importing markets for a product exported by Tajikistan (Mirror). Product: TOTAL All products, http://www.trademap.org/Country_SelProductCountry_TS.aspx?nvpm=1|762||||TOTAL|||2|1|2|2|2|1 $|2| 1 \mid 1$ (Letzter Zugriff: 22.10.2018)

TRADE MAP (2017): List of products imported by Kazakhstan. http://www.trademap.org/Product SelCountry TS.aspx?nvpm=1|398||||TOTAL|||2|1|1|1|2|1|1|1|1 (Letzter Zugriff: 22.10.2018) 
TRADE MAP (2017): List of products imported by Tajikistan.

https://www.trademap.org/Product_SelCountry_TS.aspx?nvpm=1|762||||TOTAL|||2|1|1|1|2|1|1|1|1

(Letzter Zugriff: 22.10.2018)

TRADE MAP (2017): List of supplying markets for a product imported by Turkmenistan (Mirror). Product: TOTAL All products, http://www.trademap.org/Country SelProductCountry TS.aspx?nvpm=1|795||||TOTAL|||2|1|2|1|2|1 2|1|1 (Letzter Zugriff: 22.10.2018)

TRADE MAP (2017): List of supplying markets for a product imported by Uzbekistan (Mirror). Product: TOTAL All products, http://www.trademap.org/Country SelProductCountry TS.aspx?nvpm=1|860||||TOTAL|||2|1|2|1|2|1 2|1|1 (Letzter Zugriff: 22.10.2018)

TRADE MAP (2017): List of supplying markets for a product imported by Kyrgyzstan. Product: TOTAL All products, http://www.trademap.org/Country_SelProductCountry_TS.aspx?nvpm=1|417||||TOTAL||2|1|1|1|2|1 2|1|1 (Letzter Zugriff: 22.10.2018)

TRADE MAP (2018): Bilateral trade between Turkey and Russian Federation, Armenia, Kazakhstan, Kyrgyzstan, Belarus. Exports, https://www.trademap.org/ (Letzter Zugriff: 21.04.2019)

TRADE MAP (2018): Bilateral trade between Turkey and Russian Federation. https://www.trademap.org/(X(1)S(wi0ytsi2pitvuiezpffo5jep))/Bilateral TS.aspx?nvpm=1\%7c792 \%7c\%7c051\%7c\%7cTOTAL $\% 7 \mathrm{c} \% 7 \mathrm{c} \% 7 \mathrm{c} 2 \% 7 \mathrm{c} 1 \% 7 \mathrm{c} 1 \% 7 \mathrm{c} 2 \% 7 \mathrm{c} 2 \% 7 \mathrm{c} 1 \% 7 \mathrm{c} 1 \% 7 \mathrm{c} 1 \% 7 \mathrm{c} 1$ (Letzer Zugriff: 21.04.2019)

TRANSPARENCY INTERNATIONAL (2018): Corruption Perceptions Index 2016, Surveys 25. January 2017, https://www.transparency.org/news/feature/corruption_perceptions index 2016 (Letzter Zugriff: 19.02.2018)

TRENIN, Dmitri (1997): Russia and Turkey: A Cure for Schizophrenia. In: SAM, Center for Strategic Research, Perceptions, June-August 1997, http://sam.gov.tr/tr/wpcontent/uploads/2012/01/DMITRI-TRENIN.pdf (Letzter Zugriff: 25.06.2012).

TUİÇ (2014): Bağımsız Devletler Topluluğu-BDT (Commonwealth Of Independent States-CIS): In., 12 Agustos 2014, http://www.tuicakademi.org/index.php/temel-kavramlar/4633-bagimsizdevletler-toplulugu-bdt-commonwealth-of-independent-states-cis （Letzter Zugriff: 19.08.2018)

TUIK (2016): Ülke guruplarina göre yillik ihracaat [Jährliche Exporte nach Ländergruppen]. http://www.tuik.gov.tr/UstMenu.do?metod=temelist （Letzter Zugriff: 09.12.2018)

TURAN, Ilter (2008): Türkiye`nin Dis Politikasinda Orta Asya Ülkelerinin Rolü ve Önemi [Die Rolle und Bedeutung zentralasiatischer Länder in der türkischen Außenpolitik]. In: KAZGAN, Gülten (Hrsg.): Türkiye-Rusya Iliskilerinde Ihtilafli Konular ve Cözümleri. Istanbul: Istanbul Bilgi Üniversitesi Yayinlari 213, (Sempozyum-Panel 2), S. 95-107. 
TURAN, Sibel (2014): Değişen Dengeler Işı̆̆ında Orta Asya daki Küresel ve Bölgesel Güç Odakları Üzerine Bir İnceleme [Eine Studie über globale und regionale Machtzentren in Zentralasien im Lichte sich ändernder Umständen]. In: Bilgesam, 14. August 2014, http://www.bilgesam.org/incele/1739/-degisen-dengeler-isiginda-orta-asya'daki-kuresel-vebolgesel-guc-odaklari-uzerine-bir-inceleme (Letzter Zugriff: 22.01.2016)

TÜRK DIL KURUMU (o. J.): Tarihce [Geschichte]. http://tdk.gov.tr/tdk/kurumsal/tarihce-2/ (Letzter Zugriff: 30.09.2018)

TÜRK DILI KONUŞAN ÜLKELER İŞBIRLIĞI KONSEYI (o. J.): Genel Bilgi [Allgemeines]. http://www.turkkon.org/tr-TR/genel_bilgi/1/10 (Letzter Zugriff: 21.03.2018)

TÜRK, Fahri (2014): Türkische Schulen in Zentralasien - ein Instrument auswärtiger Kulturpolitik? In: ZENTRALASIEN-ANALYSEN, NR. 73, 31.01.2014, S. $2-7$.

TÜRKIYE CUMHURIYETI CUMHURBASKANLIGI (2016): Türkiye Kırım'ın Gayrimeşru İlhakını Tanımamıştır, Tanımayacaktır [Die Türkei hat die Annexion der Krim nicht anerkannt und wird sie nicht anerkennen]. 09.03.2016, http://www.tccb.gov.tr/haberler/410/40098/turkiyekirimin-gayrimesru-ilhakini-tanimamistir-tanimayacaktir.html (Letzter Zugriff: 07.07.2018)

TÜRKIYE CUMHURIYETI CUMHURBASKANLIGI (o. J.): Fors. https://www.tccb.gov.tr/cumhurbaskanligi/resmi-simgeler/fors/ (Letzter Zugriff: 27.05.2020)

TÜRKIYE CUMHURIYETI DISISLERI BAKANLIGI (o. J. a): Orta Asya Ülkeleri ile Iliskiler [Beziehungen mit den zentralasiatischen Staaten]. http://www.mfa.gov.tr/turkiye-orta-asyaulkeleri-iliskileri.tr.mfa (Letzter Zugriff: 12.08.2018)

TÜRKIYE CUMHURIYETI DISISLERI BAKANLIGI (o. J. b): Türkiye 'nin Enerji Profili ve Stratejisi [Energieprofil und Strategie der Türkei]. http://www.mfa.gov.tr/turkiye nin-enerjistratejisi.tr.mfa (Letzter Zugriff: 21.11.2019)

TÜRKIYE CUMHURIYETI DISISLERI BAKANLIGI (o. J. c): Türkiye-Kazakistan siyasi iliskileri [Politische Beziehungen zwischen der Türkei und Kasachstan]. http://www.mfa.gov.tr/turkiye-kazakistan-siyasi-iliskileri_tr.mfa (Letzter Zugriff: 16.08.2018)

TÜRKIYE CUMHURIYETI MOSKOVA BÜYÜKELCILIGI (o. J.): Türkiye-Rusya Diplomatik İlişkilerin Kuruluş Tarihi [Das Datum der Aufnahme diplomatischer Beziehungen zwischen der Türkei und Russland]. http://moskova.be.mfa.gov.tr/Mission/About (Letzter Zugriff: 16.08.2018)

TÜRKSOY (o. J. a): Türksoy Hakkinda [Über Türksoy]. http://www.turksoy.org/tr/turksoy/about (Letzter Zugriff: 04.10.2019)

TÜRKSOY (o. J. b): Üyeler [Mitglieder]. http://www.turksoy.org/ (Letzter Zugriff: 04.10.2019)

TÜYSÜZOGLU, Göktürk (2013): Avrasya Birliği: Ekonomik Bütünleşme Gölgesinde İnşa Edilen Rusya Hegemonyas1 [Eurasische Union: Russische Hegemonie im Schatten der wirtschaftlichen Integration]. In: Uluslararasi Politika Akademisi, 29 Aralik2013, 
http://politikaakademisi.org/avrasya-birligi-ekonomik-butunlesme-golgesinde-insa-edilen-rusyahegemonyasi// (Letzter Zugriff: 21.08.2014)

U. S. DEPARTMENT OF STATE (2016): U.S.-Central Asia (C5+1) Joint Projects. Diplomacy in Action. Fact Sheet Office of the Spokesperson, Washington, DC, August 3, 2016, http://www.state.gov/r/pa/prs/ps/2016/08/260805.htm （Letzter Zugriff: 23.11.2019)

U. S. DEPARTMENT OF STATE (2017): C5+1 Fact Sheet. Washington, DC, September 22, 2017. https://www.state.gov/r/pa/prs/ps/2017/09/274386.htm （Letzter Zugriff: 21.11.2019)

U. S. DEPARTMENT OF STATE (o. J.): U.S. Support for the New Silk Road. https://www.state.gov/p/sca/ci/af/st/newsilkroad/index.htm （Letzter Zugriff: 21.11.2019)

U. S. EMBASSY \& CONSULATE IN KAZAKSTAN (2018): History. https://kz.usembassy.gov/embassy-consulates/almaty/history/ (Letzter Zugriff: 16. August 2018)

UCAROL Rifat (2000): Siyasi Tarih [Politische Geschichte] (1789-1999). Beşinci Bask1, İstanbul: Filiz Kitabevi.

UHLEMANN, Godehard (2016): Konflikt um Berg-Karabach: Stellvertreterkrieg im Kaukasus. In: RP Online, 4. April 2016, $18.37 \mathrm{Uhr}$, http://www.rp-online.de/politik/ausland/armenien-undaserbaidschan-krieg-um-berg-karabach-aid-1.5878003 (Letzter Zugriff: 24. November 2018)

ULCENKO, Natalya Y. (2003): Rusya ve Türkiye`nin Stratejik Güvenliginin Saglanmasinda Enerji Hammaddeleri Ihracaat ve Ithalatinin Rolü [Rolle der Exporte und Importe von Energierohstoffen bei der Gewährleistung der strategischen Sicherheit Russlands und der Türkei]. In: ULCENKO, Natalya Y./KAZGAN, Gülten (Hrsg.): Dünden Bugüne Türkiye Rusya: Politik, Ekonomik ve Kültürel Iliskiler. Kasim 2003, Istanbul: Istanbul Bilgi Üniversitesi Yayinlari 45, S. 183-197.

UNAIDS (2018): Countries. http://www.unaids.org/en/regionscountries/countries (Letzter Zugriff: 09.01.2019)

UNAIDS (2018a): Kazakhstan. http://www.unaids.org/en/regionscountries/countries/kazakhstan (Letzter Zugriff: 09.01.2019)

UNAIDS (2018b): Kyrgyzstan. http://www.unaids.org/en/regionscountries/countries/kyrgyzstan (Letzter Zugriff: 09.01.2019)

UNAIDS (2018c): Tajikistan. http://www.unaids.org/en/regionscountries/countries/tajikistan (Letzter Zugriff: 09.01.2019)

ÜNAL, Yenal (2017): Türk Dünyasi ve Atatürk-2. [Türkenwelt und Atatürk-2] In: Bartin Halk Gazetesi, 19.07.2017, 10:00, http://www.bartinhalkgazetesi.com.tr/turk-dunyasi-ve-ataturk-26624m.htm (Letzter Zugriff: 20.07.2017)

UNITED NATIONS, DEPARTMENT OF ECONOMIC AND SOCIAL AFFAIRS, POPULATION DIVISION (2019): World Population Prospects 2019, Data Query, Total 
Population by sex (thousands), https://population.un.org/wpp/DataQuery/ (Letzter Zugriff: 30.04.2020)

UNITED STATES DEPARTMENT OF DEFENSE (2018): Defense Budget Overview, Office of the Under Secretary of Defense (Comptroller) Chef Financial Officer, February 2018, Fiscal Year 2019, Budget Request Revised February 13, 2018, https://comptroller.defense.gov/Portals/45/Documents/defbudget/fy2019/FY2019 Budget Request Overview Book.pdf (Letzter Zugriff: 19.04.2018)

UNODC (UNITED NATIONS OFFICE ON DRUGS AND CRIME) (2010): World Drug Report 2010. United Nations: New York, 2010, https://www.unodc.org/documents/wdr/WDR_2010/World_Drug_Report 2010 lo-res.pdf (Letzter Zugriff: 14.2.2017)

UNODC (UNITED NATIONS OFFICE ON DRUGS AND CRIME) (2014): World Drug Report 2014. United Nations: New York.

http://www.unodc.org/documents/wdr2014/World_Drug_Report_2014_web.pdf (Letzter Zugriff: 14.2.2017)

URBANSKY, Sören (2018): Unheimliche Freunde: China und Russland. In: Zeitgeschichte Online, Veröffentlicht am 17. März 2018, https://zeitgeschichte-online.de/thema/unheimlichefreunde-china-und-russland (Letzter Zugriff: 10. April 2018)

ÜSTEL, Aziz (2016): Türk-Islam Sentezini Konusalim mi? In: Star, 07.03.2016, Pazartesi, http://www.star.com.tr/yazar/turkislam-sentezini-konusalim-mi-yazi-1093906/ (Letzter Zugriff: 09.03.2016)

UTZ, Raphael (2008): Russlands unbrauchbare Vergangenheit. Nationalismus und Außenpolitik im Zarenreich. Wiesbaden: Harrassowitz Verlag (Forschungen zur osteuropäischen Geschichte, Band 73).

VARLI, Fatma (2016): Die Türkisch-Russische Syrienpolitik. In: Links-Netz, Februar 2016, http://www.links-netz.de/K texte/K varli syrien.html (Letzter Zugriff: 29. August 2020)

VIRNICH, Birgit (2016): Russland: Kampf gegen Drogensucht. In: Das Erste, Weltspiegel, Stand: 17.04.2016, 20:41 Uhr, http://www.daserste.de/information/politikweltgeschehen/weltspiegel/russland-208.html （Letzter Zugriff: 21.05.2016)

WAGNER, Christian (2018): Der „Islamische Staat“ in Südasien. In: HEIDUK, Felix (Hg.) Das kommende Kalifat? „Islamischer Staat in Asien: Erscheinungsformen, Reaktionen und Sicherheitsrisiken“. In: SWP-Studie, 9. Juni 2018, (Stiftung Wissenschaft und Politik, Deutsches Institut fürInternationale Politik und Sicherheit) S.23-38, https://www.swpberlin.org/fileadmin/contents/products/studien/2018S09 hdk.pdf\#page=15 (Letzter Zugriff: 13.06.2018)

WALT, Stephen M. (1987): The Origins of Alliances. Ithaca, London: Cornell University Press. 
WALTZ, Kenneth N. (1959): Man, the State and War. A theoretical Analysis, New York: Columbia University Press.

WALTZ, Kenneth N. (1979): Theory of International Politics. Reading, Massachusetts, California: Addison-Wesley Publishing Company.

WALTZ, Kenneth N. (2000): Structural Realism After the Cold War. International Security, Volume 25, Summer 2000, No 1, S. 5-41.

WÄLZHOLZ, Gunnar (1997): Nationalismus in der Sowjetunion. Entstehungsbedingungen und Bedeutung nationaler Eliten, Osteuropa-Institut der Freien Universität Berlin, Arbeitspapiere des Bereichs Politik und Gesellschaft, hrsg. von: Klaus SEGBERS, Heft 8/1997, http://www.oei.fuberlin.de/politik/publikationen/AP08.pdf

WEBJAEN.ES (2010): En la provincia de Jaén hay censados 19.148 extranjeros, https:/webjaen.wordpress.com/2009/09/23/en-la-provincia-de-jaen-hay-censados-19-148extranjeros/ (Letzter Zugriff: 16.07.2019)

WEHNER, Markus (2008): Blick nach Süden: Die Russische Föderation und Transkaukasien. In: CHIARI, Bernhard (Hg.) (2008): Kaukasus. Wegweiser zur Geschichte. Paderborn, München, Wien: Ferdinand Schöningh (Herausgegeben vom Militärgeschichtlichen Forschungsamt), S.145153.

WELZEL, Christian (2012): Methoden und Arbeitsweisen. Wissenschaftstheoretische und methodische Grundlagen. In: Lauth, Hans-Joachim/ Wagner, Christian (Hrsg.):

Politikwissenschaft: Eine Einführung. 7. Überarbeitete Auflage, Ferdinand Schöning: Paderborn, S. 389-423.

WIKIPEDIA (2009): Turkestan um 1900. https://de.m.wikipedia.org/wiki/Datei:Turkestan_1900de.svg (Letzter Zugriff: 15.07.2019)

WIKIPEDIA (2018): Syrdarja. https://de.wikipedia.org/wiki/Syrdarja （Letzter Zugriff: 15.07.2019)

WIKIPEDIA (o. J.): Bergkarabach, zuletzt bearbeitet am 21. November 2018 um 19:56 Uhr, https://de.wikipedia.org/wiki/Bergkarabach （Letzter Zugriff: 23. November 2018)

WILHELM, Andreas (2006): Außenpolitik. Grundlagen, Strukturen und Prozesse. Verlag, München/Wien: R. Oldenbourg Wissenschaftsverlag.

WILHELMI, Wolfgang (2002): Die Politik der Russländischen Föderation gegenüber dem „Nahen Ausland" unter besonderer Berücksichtigung von Rolle und Einfluss des Militärs. Baden-Baden: Nomos.

WILLNER, Anja (2016): Stellvertreterkrieg zwischen Putin und Erdogan? In: Focus, Dienstag, 05.04.2016, 06:05, http://www.focus.de/politik/ausland/in-bergkarabach-eskaliert-die-gewaltwieder-stellvertreter-krieg-hier-prallen-putins-und-erdogans-interessenaufeinander id 5406707.html (Letzter Zugriff: 23. November 2018 ) 
WINROW, Gareth M. (1996): Turkey`s relations with the Transcaucasus and the Central Asian Republics. In: SAM, Center for Strategic Research, Perceptions, March May 1996, http://sam.gov.tr/wp-content/uploads/2012/01/11.-TURKEYS-RELATIONS-WITH-THETRANSCAUCASUS.pdf (Letzter Zugriff: 21.02.2012)

WIPPERFÜRTH, Christian (2011): Russlands Außenpolitik. Lehrbuch, Elemente der Politik. VS Verlag.

WORLD BANK (2017): World Development Indicators: Unemployment. http://wdi.worldbank.org/table/2.5 (Letzter Zugriff: 20. Mai 2019)

WORLD NUCLEAR ASSOCIATION (2015): Uranium and Nuclear Power in Kazakhstan. In: Juni 2015, http://www.world-nuclear.org/info/Country-Profiles/Countries-G-N/Kazakhstan/ (Letzter Zugriff: 03.08.2015)

YARKADAS, Baris (2013): Erdoğan cemaate neden rest çekti? In: Gercek Gündem, 15 Kasım 2013, http://www.gercekgundem.com/yazarlar/baris-yarkadas/1621/erdogan-cemaate-neden-restcekti (Letzter Zugriff: 23.11.2013)

YAVUZ, Hakan (1998): Değişen Türk Kimliği ve Dış Politika: Neo-Osmanlıcılığın Yükselişi [Veränderung der türkischen Identität und Außenpolitik: Der Aufstieg des Neo-Osmanismus]. In: Osmanische Forschungen, http://www.osar.com/modules.php?name=Encyclopedia\&op=content\&tid=501472 （Letzter Zugriff: 04.11.2011)

YAZICI, Nuri (1997): Tarihte Türkler ve Türk Devletleri [Türken in der Geschichte und deren Staaten], Konya, Damla Matbaas1, 1997

YDYRYS, Kanat (2017): IŞiD ve Orta Asya [IS und Zentralasien]. In: Ankasam, Ankara Kriz ve Siyaset Arastirmalari Merkezi, 11 Ocak 2017, https://ankasam.org/isid-ve-orta-asya/ (Letzter Zugriff: 15.01.2017)

YEGENOV, Shatlyk (2018): Orta Asya'da Artan Silahlanma Yarişi Ve Sebepleri [Das zunehmende Wettrüsten in Zentralasien und seine Ursachen]. In: Uluslararasi Afro-Avrasya Araştirmalari Dergisi, Ocak 2018, Sayi 5, S. 86-94, http://dergipark.gov.tr/download/article$\underline{\text { file/412578 }}$ (Letzter Zugriff: 24.03.2018)

YELKENCI, Ömer Faruk (2010): Türk Modernlesmesi ve II. Abdülhamid in Egitim Hamlesi [Türkische Modernisierung und II. Abdülhamids Bildungszug]. Istanbul: Kaktüs Yayinlari.

YESILYURT, Süleyman (2016): Als Gast bei Murat Gener beim Fehrnsehprogramm „Toplumsal Hafiza“ über Fethullah Gülen. In: A Haber, 21.08. 2016, Youtube, https://www.youtube.com/watch?v=wqTqu99Jm00_(Letzter Zugriff: 21.08, 2016)

YIGIT, Ali (o. J.): Rusya Federasyonun` da yasayan Türk Topluluklarinin Anadillerini Kullanma Oranlarindaki Bölgesel Farkliliklar [Regionale Unterschiede im Gebrauch der Muttersprache türkischer Gemeinschaften in der Russischen Föderation]. In: AYK, http://www.ayk.gov.tr/wpcontent/uploads/2015/01/Y\%C4\%B0\%C4\%9E\%C4\%B0T-Ali-RUSYA- 
FEDERASYONUN\%E2\%80\%99DA-YA\%C5\%9EAYAN-T\%C3\%9CRK-

TOPLULUKLARININ-ANAD\%C4\%B0LLER \%C4\%B0N\%C4\%B0-KULLANMA-

ORANLARINDAK\%C4\%B0-B\%C3\%96LGESEL-FARKLILIKLAR.pdf (Letzter Zugriff:

09.06.2016)

YOUSAF, Farooq (2013): Russia's Central Asia Power Play. In: The Diplomat, 2 September 2013, http://thediplomat.com/2013/09/russias-central-asia-power-play// (Letzter Zugriff: 10.07.2014)

YUNUS EMRE ENSTITÜSÜ (2015): Yunus Emre Enstitüsü. http://www.yee.org.tr/ (Letzter Zugriff: 01.12.2017)

YUNUS EMRE ENSTITÜSÜ (2016): Yunus Emre Enstitüsü.

http://www.yee.org.tr/tr/kurumsal/yunus-emre-enstitusu _(Letzter Zugriff: 01.12.2017)

ZALEZSKY (O. J.): Russian Subjugation of Central Asia. In: Deviant Art, https://zalezsky.deviantart.com/art/Russian-Subjugation-of-Central-Asia-498620454 (Letzter Zugriff: 07.01.2014)

ZIMMERMANN, Hubert (2011): EU-China: Eine strategische Partnerschaft? Europagespräche des Instituts für Geschichte, Stiftung Universität Hildesheim, 10.01.2011, Marburg, http://www.unihildesheim.de/en/fb1/institute/geschichte/oeffentliche-vortraege-int-konferenzen/europagespraeche/wintersemester-201011/eu-china-eine-strategischepartnerschaft/export.pdf?filename $=\mathrm{EU}$ -

China\%3A\%20Eine\%20strategische\%20Partnerschaft\%3F.pdf\&cHash=66776cf7198660329a7099 d75c743481 (Letzter Zugriff: 17.03.2015) 